2. To: (Receiving Organization)

Distribution

Solid Waste Disposal

8. Originator Remarks:

Requesting approval for SD

11. Receiver Remarks:

11A. Design Baseline Document?

[] res

$[X]$ No
5. Proj./Prog./Dept./Div.:
3. From: (Originating organization) Solid Waste Disposal

6. Design Authority/ Design Agent/Cog. Engr :

M. I. Wood

\section{Related EDT No.:}

$N / A$

7. Purchase Order No.:

$N / A$

9. Equip./Component No.:

$\mathrm{N} / \mathrm{A}$

10. System/Bldg./Facility:

$N / A$

12. Major Assm. Dwg. No.:

$N / A$

13. Permit/Permit Application No.: $N / A$

14. Required Response Date:

$08 / 15 / 96$

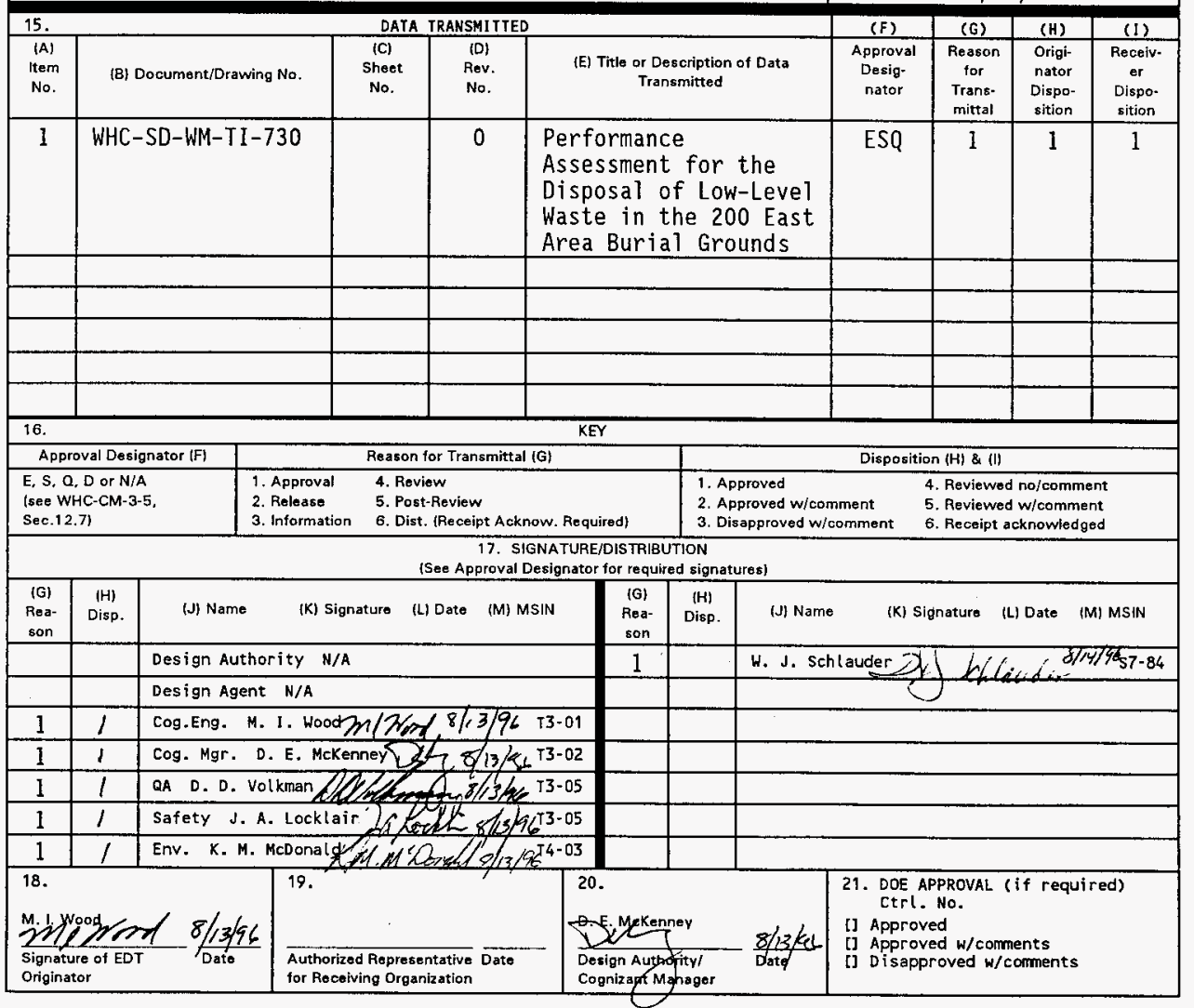




\title{
Performance Assessment for the Disposal of Low-Level Waste in the 200 East Area Burial Grounds
}

\author{
M. I. Wood
}

Westinghouse Hanford Company, Richland, WA 99352

U.S. Department of Energy Contract DE-ACO6-87RL10930

$\begin{array}{lll}\text { EDT/ECN: } & 615678 & \text { UC: } 900 \\ \text { Org Code: } & 87000 & \text { Charge Code: } \\ \text { B\&R Code: } & \text { EW3 } 3130020 & \text { Total Pages: } 521540<\mathrm{kms} \quad 6 / 15 / 46\end{array}$

Key Words: Performance Assessment, 200 East Area LLBG, DOE Order

Abstract:

A performance assessment analysis was completed for the 200 East Area Low-Level Burial Grounds (LLBG) to satisfy compliance requirements in DOE Order 5820.2A. In the anslysis, scensrios of radionuclide release from the 200 East Area lowlevel waste facilities were evaluated.

The analysis focused on two primary scenarios leading to exposure. The first was inadvertent intrusion. In this scensrio, it was assumed that institutional control of the site and knowledge of the of the disposal facility has been lost. Waste is subsequently exhumed and dose from exposure is received. The second scenario was groundwater contamination. In this scenario, radionuclides are leached from the waste by infiltrating precipitation and transported through the soil colunin to the underlying unconfined aquifer. The contaminated water is pumped from a well $100 \mathrm{~m}$ downstream and consumed, causing dose.

Estimates of potential contamination of the surrounding environment were developed and the associated doses to the naximum exposed individual were calculated. The doses were compared with performance objective dose limits, found primarily in the DOE Order 5820.2A. In the 200 East Area LLBG, it was shown that projected doses are estimated to be well below the limits because of the combination of environmental, waste inventory, and disposal facility characteristics of the 200 East Area LLBG. Waste acceptance criteria were also derived to ensure that disposal of future waste inventories in the 200 East Area LLBG will not cause an unacceptable increase in estimated dose.

TRADEMARK DISCLAIMER. Reference herein to any specific commercial product, process, or service by trade name, trademark, manufacturer, or otherwise, does not necessarily constitute or imply its endorsement, recommendation, or favoring by the United States Government or any agency thereof or its contractors or subeontractors.

Printed in the United states of America. To obtain copies of this document, contact: HHC/BCS Document Control Services, P.O. Box 1970, Mailstop H6-08, Richland WA 99352, Phone (509) 372-2420; Fax (509) 376-4989.
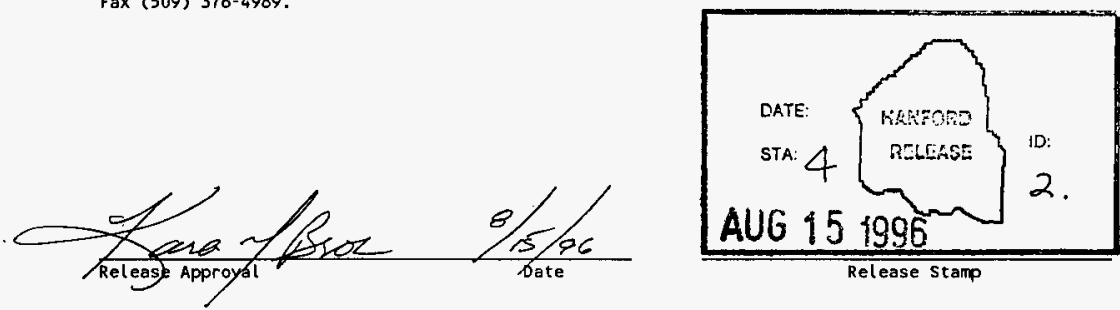

Approved for Public Release 
Rev. 0

\title{
Performance Assessment for the Disposal of Low-Level Waste in the 200 East Area Burial Grounds
}

\author{
Authors \\ M. I. Wood \\ R. Khaleel \\ P. D. Rittmann \\ S. H. Finfrock \\ T. H. DeLorenzo \\ D. Y. Garbrick
}

Prepared for the U.S. Department of Energy Office of Environmental Management

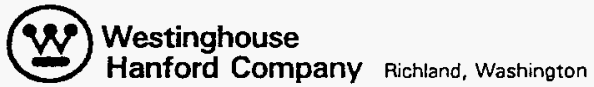

Hanford Operations and Engineering Contractor for the 


$$
\text { WHC-SD-WM-TI-730, REV } 0
$$

\section{EXECUTIVE SUMMARY}

This document reports the findings of a performance assessment (PA) analysis for the disposal of solid low-level radioactive (LLW) waste in the 200 East Area Low Level Burial Grounds (LLBG) of the Hanford Site. This PA analysis is required by the U.S. Department of Energy (DOE) Order 5820.2A (DOE 1988a) to demonstrate that a given disposal practice is in compliance with a set of performance objectives quantified in the order. These performance objectives apply to DOE-generated LLW disposed of at any DOE-operated site since the order was finalized on September 26, 1988.

The 200 East Area LLBGs are found in two locations. The active 218-E-10 burial ground and adjacent inactive burial grounds are in the northwest corner of the 200 East Area. The active $218-\mathrm{E}-12 \mathrm{~B}$ burial ground and adjacent inactive burial grounds are located in the northeast corner of the 200 East Area. Each burial ground area is considered separately in the analysis. All low-level waste (LLW) and the radioactive constituents of low-level mixed waste (LLMW) disposed of in active burial grounds are evaluated in this performance assessment. In the 218-E-12B burial ground, a separate analysis is also provided for the reactor compartment facility in Trench 94 because of differences in disposal facility configuration and waste stream characteristics. The potential effects of waste disposed of before September 26, 1988, in both the active and inactive burial grounds will be considered in a composite analysis due December 31, 1997, based on guidance developed by DOE (DOE 1996). The composite analysis will evaluate the potential dose effects of interacting radionuclide releases from all waste sites on the 200 Area Plateau.

The general type of disposal facility under consideration for the 200 East Area is a shallow unlined trench of variable width $(-3$ to $10 \mathrm{~m})$, length $(-50$ to $100 \mathrm{~m})$, and depth $(-5$ to $10 \mathrm{~m})$. Waste is typically packaged in containers (metal drums or boxes [box materials include cardboard, wood, metal, and concrete]) and placed in trenches up to $8 \mathrm{ft}$ from the surface. Once a trench is filled, a soil cover is placed over the waste. Except for the reactor compartment trench, trenches are typically arranged in parallel fashion with the long axis running due north and south. The reactor compartments are typically large cylindrical waste packages that could range from about $9 \mathrm{~m}$ to $13 \mathrm{~m}(30-42 \mathrm{ft})$ in diameter and $11 \mathrm{~m}$ to $17 \mathrm{~m}(37-55 \mathrm{ft})$ in length. Trench 94 is dedicated to the disposal of the reactor compartments. To accomodate these large packages, the trench is about $15 \mathrm{~m}$ (50 ft) deep, $490 \mathrm{~m}(1,600 \mathrm{ft})$ long and $120 \mathrm{~m}(400 \mathrm{ft})$ wide.

Types of waste include paper, plastics, wood, concrete rubble, activated metal, sludges, etc. Other than the reactor compartment waste generated by the U.S. Navy, the majority of waste received in the 200 East Area LLBG has been provided by Hanford Site generators in the 200 East Area. These include B Plant, PUREX, and tank farm operations. The radionuclide inventory in a waste package is typically reported as total beta/gamma activity, major fission product isotopes, and uranium where present. Some minor constituents in these inventories that are of concern in PA analyses are explicitly reported. However, in some cases only total beta/gamma activity inventory information was provided. It was, therefore, necessary to derive specific radionuclide inventories to estimate potential dose from inventory release 
into the environment. This was done by assuming that radionuclides are present in waste in proportion to their activities in the production reactor output. Using this approach, the greatest activity usually comes from ${ }^{90} \mathrm{Sr}$ and ${ }^{137} \mathrm{Cs}$. Activities of groundwater-mobile radionuclides $\left(\mathrm{e} . \mathrm{g} .,{ }^{14} \mathrm{C}\right.$, ${ }^{129} \mathrm{I}$, and $\left.{ }^{9} \mathrm{Tc}\right)$ were also estimated. The reactor compartment waste is activated metal that contains relatively large inventories of ${ }^{63} \mathrm{Ni},{ }^{59} \mathrm{Ni}$, and ${ }^{14} \mathrm{C}$. Lesser amounts of of ${ }^{99} \mathrm{Tc},{ }^{129} \mathrm{I}$, and ${ }^{34} \mathrm{Nb}$ are also present.

The two types of disposal-facility conditions defined for the Hanford site are considered in this analysis. The first condition, Category 1 waste, is assumed to have no functional barriers and is intended to contain very low concentrations and quantities of radionuclides in the inventory. The second condition, Category 3 waste, is assumed to have a cover that controls infiltration to the same degree as the natural soil and vegetation system. Waste form or waste material control of radionuclide release is also assumed for wastes containing high concentrations of long-lived mobile radionuclides (e.g., ${ }^{99} \mathrm{Tc},{ }^{14} \mathrm{C},{ }^{129} \mathrm{I}$, uranium). These isolation barriers allow disposal of higher concentrations or quantities of radionuclides in the inventory. Category 1 and 3 waste conditions are similar to Condition 5 assumed by the Nuclear Regulatory Commission (NRC) in 10 Code of Federal Regulation (CFR) 61 for the disposal of $C 1$ ass $A$ and $C$ waste, respectively. This approach evaluates different types of disposal facilities. The more frequently used approach evaulates a unique disposal facility design (well-defined barriers) and a unique radionuclide inventory. The reactor compartment trench is treated as a Category 3 facility.

Two disposal conditions are being evaluated for three reasons. First, uncertainties in future waste inventory are large because of the large number of generators providing waste for disposal, variability in the types of waste streams, and variability in the quality and completeness of the waste characterization data. Second, although the analysis shows that most of the waste already disposed of in the 200 East Area LLBG is Category 3 waste, numerous options are available for future waste disposal operations in the 200 East Area LLBG. Much of the waste to be disposed of at the Hanford Site contains very little activity. Thus, segregating those wastes that can be disposed of at minimal expense from those wastes that require enhanced isolation at greater cost may be a desirable waste management option. Currently, Categories 1 and 3 waste are frequently disposed of in the same trench. Third, the relative effectiveness of different kinds of barriers to satisfy performance objectives on the Hanford Site is clarified by evaluating facilities with different waste isolation capabilities.

For each type of facility, a set of calculations was completed to estimate the potential dose to humans resulting from the release of radionuclides from the facility into the surrounding environment (i.e., soil, water, and air). Dose estimates were determined for radionuclide-release scenarios that were relevant to the performance objectives stated in DOE Order 5820.2A. Dose estimates were then compared with performance objectives to determine the effectiveness of these facilities in meeting performance objectives. In this manner, compliance with DOE Order 5820.2A was established.

As a result of the conditions under which waste is received at the 200 East Area LLBG, dose-estimate calculations were applied in two ways to 
determine with reasonable assurance that compliance with the performance objectives would be satisfied. First, because the sources of waste are not restricted to a unique set of generators or a finite volume of waste, criteria were developed to ensure that waste accepted for disposal could not result in a potential dose in excess of the performance objectives. The primary waste acceptance criteria are radionuclide-specific concentration limits $\left(\mathrm{Ci} / \mathrm{m}^{3}\right)$ for isotopes with half-lives longer than 5 years and total activity limits (curies) for long-lived environmentally mobile radionuclides. Second, compliance with the performance objectives was evaluated by estimating potential dose resulting from the disposal of the projected final inventory of LLW in the 200 East Area LLBG. This evaluation was performed to demonstrate the adequacy of the disposal practices for the total quantity of waste expected to be disposed of in the facility over time.

The performance objectives are summarized in Table S-1. The primary source of these objectives is DOE Order 5820.2A, which specifically identifies the all-pathways and intruder-protection scenarios. The air emissions objectives are taken from the Clean Air Act (Title 40 Code of Federal Regulations (CFR) Part 61). Proposed 10 CFR 834 contains limits on air and water contamination, including the radon surface-flux limit. The drinking water objective is taken from the proposed EPA drinking water standard (40 CFR 141) and the proposed standard (56U38 FR 33050 1991).

Table S-1. Performance Objectives for the 200 East Area LLBG*.

\begin{tabular}{|c|c|c|}
\hline \multirow[b]{2}{*}{ Exposure pathway } & \multicolumn{2}{|c|}{ General public protection } \\
\hline & $\begin{array}{c}\text { Time period } \\
(y r)\end{array}$ & Performance objective \\
\hline Al1 pathways & $\leq 10,000$ & $25 \mathrm{mrem} / \mathrm{yr}$ \\
\hline Air emissions (excluding $\mathrm{Rn}$ ) & $\leq 10,000$ & $10 \mathrm{mrem} / \mathrm{yr}$ \\
\hline \multirow[t]{2}{*}{ Air emissions (Rn) } & $\leq 10,000$ & $20 \mathrm{pCi} / \mathrm{m}^{2} \mathrm{~s}$ \\
\hline & \multicolumn{2}{|c|}{ Intruder Protection } \\
\hline Continuous Exposure & 100 to 500 & $100 \mathrm{mrem} / \mathrm{yr}$ \\
\hline \multirow[t]{2}{*}{ Single Acute Exposure } & 100 to 500 & $500 \mathrm{mrem} / \mathrm{yr}$ \\
\hline & \multicolumn{2}{|c|}{ Groundwater Resource Protection } \\
\hline Drinking Water & $\leq 10,000$ & $4 \mathrm{mrem} / \mathrm{yr}$ \\
\hline
\end{tabular}

*Limits apply to the maximum exposed individual.

The times of compliance are not specified in the orders except for the minimum 100 years for inadvertent intrusion. In this analysis, compliance with the performance objectives is evaluated over a postclosure period of up to 10,000 years. The specific "time of compliance" varies depending on the performance objective, and usually corresponds to the calculated time at which 
WHC-SD-WM-TI-730, REV 0

peak dose occurs. For two cases, radon air emissions and intruder dose from uranium plus its ingrowing daughter products, the time of compliance was set before maximum flux and dose were predicted to occur. The peak time of radon flux is considered to be excessively long (>100,000 years). The intruder dose maximum for uranium plus daughters occurs we 11 beyond 10,000 years. Given the artificial nature of the intruder scenario and to be consistent with the approach of the Nuclear Regufatory Commission (NRC) in 10 CFR 61, a maximum time of intrusion was set at 500 years.

The performance objectives are interpreted to define two basic kinds of release scenarios: inadvertent intrusion by humans and release of radionuclides from the facility by natural causes, the primary mechanism being leaching of radionuclides into the soil column with migration to groundwater. Air contamination by vapor transport was also evaluated and determined to be inconsequential. Details of the intruder and groundwater contamination scenarios and the associated waste acceptance criteria are summarized in the following paragraphs.

To address the intruder objectives, three commonly occurring human activities were considered that could result in contact with buried radioactive waste: building a home with a basement, drilling a well for irrigation and drinking water, and farming (crop growth and 1ivestock). Irrigated farming is a major commercial activity in areas surrounding the Hanford Site and a common practice because of the semi-arid conditions at the Hanford Site and the plentiful supply of surface water and groundwater.

These three general activities were used to develop four intruder scenarios: two which consider acute exposure events and two which consider chronic exposure events. The acute exposure scenarios are excavation, during which waste is exhumed to construct a home basement, and drilling a water well. Pathways of exposure include external exposure to gamma-emitting isotopes and inhalation of contaminated dust. The chronic exposure scenarios are post excavation and post drilling, during which the exhumed waste is mixed with soil, spread around the site, and subsequently used to grow crops for consumption. In addition to external exposure and inhalation, dose is assumed to be received by ingesting contaminated crops grown in the waste/soil mixture.

Doses from inadvertent intrusion are linearly proportional to initial radionuclide concentrations in the disposal facility. Thus, waste acceptance criteria based on intrusion scenario limits are defined as concentration limits. Radionuclide-specific intruder concentration limits for each type of facility were determined using a three-step process. First, the set of scenarios appropriate for the facility characteristics was identified. Second, the scenario in the set that provided the largest ratio of potential dose to performance objective dose limit for the same initial radionuclide concentration was determined. Third, a unique set of site-specific parameter values was chosen to estimate radionuclide-specific doses for that scenario. These parameter values are referred to as base-case or best-estimate values. By taking the ratio of the performance objective to the dose calculated for each radionuclide, a corresponding concentration limit was derived. Concentration limits were not estimated for radionuclides with half-lives of 5 years or less because the minimum intrusion time is 100 years. These very 
WHC-SD-WM-TI-730, REV 0

short half-life radionuclides will have decayed to insignificant quantities after 100 years.

For the Category 1 facility, it was assumed that all of the intruder scenarios could occur because the waste could be disposed of in a shallow trench. The scenario that provided the maximum dose was the post-excavation scenario. It was assumed that intrusion occurred 100 years post-closure. For the Category 3 facility, an assumed depth of burial of $5 \mathrm{~m}$ or more excludes excavation and post-excavation as a means of intrusion. Consequently, the post-drilling scenario provides the maximum dose. It was assumed that intrusion occurred 500 years post-closure. Any or a combination of the following may be used to deter intruders: public records, markers, and cover materials (e.g., rip rap) to alert the intruder to an unusual circumstance. Both the reduced quantity of waste exhumed (drilling versus basement excavation) and the additional time to intrusion increased the allowable concentration limits relative to Category l limits. For some radionuclides (e.g., $\left.{ }^{60} \mathrm{Co}\right)$, the additional decay time was sufficient to allow such large concentrations that no limits were needed.

To address the groundwater contamination performance objectives, two groundwater scenarios were assumed to provide dose to humans. The alipathways scenario was defined as a two-step process in which radionuclides are first leached from the disposal facility caused by precipitation infiltrating the waste material and subsequently being transported down through the partially saturated or vadose zone into the unconfined aquifer. Subsequently, an individual drills a well into the aquifer and draws contaminated water for drinking, crop irrigation, and livestock consumption. Dose is received by direct exposure to gamma-producing radionuclides in the soil, inhalation of contaminated dust, and ingestion of contaminated crops, water, beef, and milk. The only source of dose in the drinking water scenario was ingestion of contaminated water from the unconfined aquifer.

Waste acceptance criteria for groundwater contamination were derived using the same process described above to determine intruder limits. Doses from groundwater contamination are proportional to total activity in the disposal facility, unless solubility or corrosion reactions (constant concentration controls) are assumed to control the release of a radionuclide. Thus, waste acceptance criteria for groundwater contamination are defined for most radionuclides as activity limits $(C i)$. Uranium was the only radionuclide for which solubility control was found sufficient to satisfy the dose limits. The corrosion controlled release mechanism is assumed for the activated metal waste in reactor compartments. If corrosion is the release controlling mechanism, doses are proportional to concentrations in the metal waste $\left(\mathrm{Ci} / \mathrm{m}^{3}\right)$. Of the two groundwater scenarios considered, the maximum dose relative to the performance objectives occurs for the drinking water scenario.

The dose calculations for groundwater contamination showed that the combination of environmental conditions and expected waste inventory limit the type of radionuclides that could provide a significant dose. These radionuclides are long-1 ived and non-sorbing (e.g., ${ }^{14} \mathrm{C},{ }^{129} \mathrm{I},{ }^{99} \mathrm{TC}$ and $\left.\mathrm{U}\right)$. Low infiltration rates and a thick vadose zone caused a sufficiently long travel time to the unconfined aquifer below the 200 East Area LLBG that shortlived poorly to moderately sorbing radionuclides decayed to insignificant levels before reaching the aquifer. Conversely, moderately and strongly 
sorbing long-lived radionuclides $(\mathrm{Kd} \geq 10 \mathrm{ml} / \mathrm{g})$ were estimated to have very long travel times to the unconfined aquifer (in excess of $10,000 \mathrm{yr}$ ).

Consequently, total activity limits are recommended only for the smal] set of long-lived, non-sorbing radionuclides. A 1 imit was also assigned to ${ }^{3} \mathrm{H}$ in a Category 1 facility. ${ }^{3} H$ has a relatively short half 1 ife, but must be considered because of the short travel time to the unconfined aquifer, given the assumed infiltration rate for this facility condition.

Waste acceptance criteria for groundwater protection were based on the potential dose received from peak groundwater concentrations that were predicted to occur at times less than 10,000 years. As with the intruder scenarios, a unique set of parameters was selected for each type of facility to estimate peak doses that were considered to be the best-estimate or basecase values. Some parameters were varied depending on the situation. These include:

- Different infiltration rates were chosen for Category 1 and 3 facilities ( $5 \mathrm{~cm} / \mathrm{yr}$ and $0.5 \mathrm{~cm} / \mathrm{yr}$, respectively)

- Different sets of hydrologic parameters were chosen for the $218-E-10$ and the $218-E-12 B$ areas

- Different waste release mechanisms for some Category 3 analyses including diffusional control and constant concentration control

- Different trench configuration for the trench containing the reactor compartments.

Larger activity limits were allowed for the Category 3 waste facility because of the assumption of lower infiltration rates. Also, within the Category 3 facility, the activity 1 imits could be increased if waste form control of release were assumed. For example, a decrease in the assumed diffusion coefficient of material leaching from the waste form reduces the rate of release and the peak groundwater concentration, thus permitting an increase in the activity limit. No groundwater-specific limits were required for reactor compartment waste because the Category 3 intruder limits turned out to be more restrictive.

The final step of the PA analysis was to estimate potential dose to humans assuming the entire projected inventory of LLW was ultimately disposed in the 200 East Area LLBG. To complete this evaluation, a total inventory was estimated. Burial ground inventory records for all waste disposed of after September 26, 1988, were coupled with 1 ife-cycle waste volume forecasts (Valero et a1. 1996) from the primary generators to project the entire inventory. It was assumed that the distribution of radionuclide concentrations and quantities per generator volumes would remain constant. Because the present waste stream includes significant volumes of Category 3 waste, doses calculated under these conditions were used. The doses are summarized in Table $\mathrm{S}-2$.

The comparison shows that all performance objectives are easily satisfied. In the projected inventory, the primary radionuclides contributing to projected dose for the intruders are ${ }^{137} \mathrm{Cs}$ and ${ }^{90} \mathrm{Sr}$. Although an intruder dose was calculated for drilling through the reactor compartment (about 
$11 \mathrm{mrem} / \mathrm{yr}$ ), this scenario is not viewed as credible because of the extreme hardness of the reactor vessel metal. A drill used for wells dug in sandy soil is unlikely to penetrate such material.

Table S-2. Comparison of Dose Estimates with Performance Objectives.

\begin{tabular}{|l|l|c|c|}
\hline \multirow{2}{*}{$\begin{array}{c}\text { Performance } \\
\text { objective }\end{array}$} & \multicolumn{1}{|c|}{ Exposure pathway } & \multicolumn{2}{c|}{ Estimated dose or flux* } \\
\cline { 3 - 4 } $25 \mathrm{mrem} / \mathrm{yr}$ & Groundwater, all pathways & $218-\mathrm{E}-10$ & $218-\mathrm{E}-12 \mathrm{~B}^{* *}$ \\
\hline $4 \mathrm{mrem} / \mathrm{yr}$ & Groundwater, drinking & 0.02 & 0.009 \\
\hline $100 \mathrm{mrem} / \mathrm{yr}$ & Post-drilling & 0.02 & 0.008 \\
\hline $20 \mathrm{pCi} / \mathrm{m}^{2} / \mathrm{s}$ & Radon flux & 0 & 0.00005 \\
\hline $10 \mathrm{mrem} / \mathrm{yr}$ & Air contamination & $n i l$ & 0.009 \\
\hline
\end{tabular}

*All units of measure are the same as the respective performance objective. **Contributions from both Hanford Site-generated waste and the reactor compartments are provided. Essentially no contribution to dose was provided by the reactor compartment waste.

The primary radionuclides contributing to projected dose from groundwater contamination were ${ }^{129} \mathrm{I}$, uranium, ${ }^{99} \mathrm{Tc}$, and ${ }^{79} \mathrm{Se}$. No reliance was placed on waste form performance in making these calculations because no wastes presently disposed of or projected for disposal were identified that required waste form performance. The projected radionucide release from the reactor compartments provided insignificant dose from groundwater because of yery low corrosion rates of the activated metal waste. With the exception of ${ }^{222} \mathrm{Rn}$, all doses are calculated from the peak groundwater concentrations that are predicted to occur less than 1,000 years after closure. The ${ }^{222} \mathrm{Rn}$ dose will increase over time until secular equilibrium with its parent, ${ }^{238} \mathrm{U}$, occurs at about 1 million years.

The results of these calculations combined with the development of waste acceptance criteria to administratively control waste accepted for disposal indicate that compliance with the performance objectives is being achieved in the 200 East Area LLBG. The potential for interaction between contaminant plumes released from the 200 East Area LLBG and contaminant plumes from other sources on the 200 Area Plateau has not been completed. Interactive effects will be evaluated in a future composite analysis in which dose will be evaluated at a site boundary. The initial boundary to be considered will encompass the 200 Area Plateau as defined by the Future Sites Working Group (FSWG 1992). The minimal potential dose estimates determined for the analysis suggest that relative contributions from the active 200 East Area LLBG will be insignificant. 
WHC-SD-WM-TI-730, REV 0

This page intentionally left blank. 
WHC-SD-WM-TI-730, REV 0

\section{CONTENTS}

1.0 INTRODUCTION . ........................ 1-1

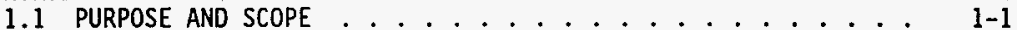

1.2 OTHER HANFORD SITE PERFORMANCE ASSESSMENTS ....... $1-2$

1.3 APPROACH TO PERFORMANCE ASSESSMENT FOR THE 200 EAST LLBG . . 1-3

1.3.1 Define Performance Objectives ......... 1-3

1.3.2 Select Radionuclide Release Scenarios and Scenario

1.3.3 Select Paramter Values . . . . . . . . . . . 1-5

1.3.4 Estimate Dose .............. 1-6

1.3.5 Demonstrate Compliance with Performance objectives : 1-7

1.4 REGULATIONS FOR THE DISPOSAL OF LOW-LEVEL WASTE $\ldots \ldots$

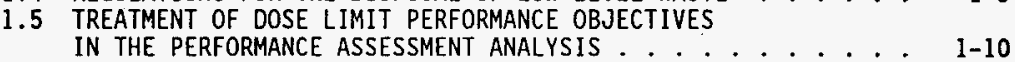

1.6 POINTS AND TIMES OF COMPLIANCE RELATED TO
DOSE LIMIT PERFORMANCE OBJECTIVES

2.0 DISPOSAL FACILITY DESCRIPTION . . . . . . . . . . . 2-1

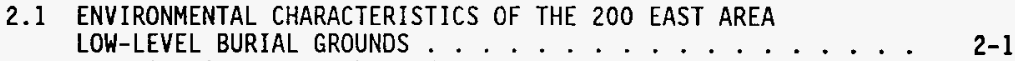

2.1.1 Site Geography and Demography ......... 2-1

2.1.2 Site Climatology and Meteorology........ 2-2

2.1 .3 Site Ecology . . . . . . . . . . . 2-2

2.1.4 Regional and Site-Specific Land Use ...... 2-2

2.1 .5 Seismology ................ 2-3

2.1.6 Radiation Background ............. 2-3

2.1 .7 Regional Hydrogeology ............. 2-4

2.1.8 Hydrogeology of the 200 East Area LLBG ..... 2-6

2.1.9 Geochemistry of the Soli Coiumn . . . . . . 2-8

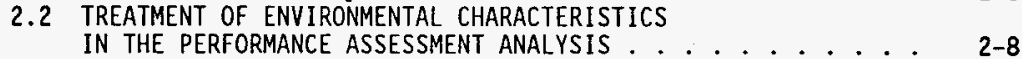

2.2.1 Meteorology and Climatology . . . . . . . . 2-8

2.2.2 Erosion Effects ........... 2-10

2.2 .3 Seismicity . . . . . . . . . . . 2-11

2.2.4 Geology and Hydrology . . . . . . . . . . . 2-11

2.2.5 Soil Column Geochemistry ........... 2-12

2.2.6 Other Disposal Facility and Environmental

Characteristics ......... 2-12

2.3 LOW-LEVEL WASTE CHARACTERISTICS ......... $2-13$

2.3.1 General' Waste Characteristics . . . . . . . . 2-13

2.3.2 Characteristics of Hanford Site-Generated Waste : 2-14

2.3.3 Characteristics of Reactor Compartment Wastes . . 2-16

2.4 TREATMENT OF WASTE CHARACTERISTICS IN THE PERFORMANCE

ASSESSMENT ANALYSIS . ........... 2-17

2.5 WASTE TREATMENT, CERTIFICATION, AND DISPOSAL $\cdots 2-18$

2.5.1 Waste Treatment and Certification . . . . . 2-18

2.5.2 Low-Level Waste Disposal Practices and Facility

Description ..............2-19 
CONTENTS (cont.)

2.5.3 Planned Modifications to Current Low-Level

Waste Disposal Practices .......... 2-20

2.6 TREATMENT OF DISPOSAL FACILITY FEATURES IN THE

PERFORMANCE ASSESSMENT ANALYSIS ........... 2-21

3.0 PERFORMANCE ASSESSMENT ANALYSIS METHODOLOGY . . . . . . . . 3-1

3.1 INTRUDER SCENARIO ANALYSIS . ........... 3-1

3.1.1 Conceptual Model of the Inadvertent Intruder

Scenarios .................. 3-1

3.1.2 Mathematical Simulation of Dose Estimates to the Inadvertent Intruder........... 3-3

3.1.3 Post-drilling Base Case Parameter Selection ... 3-5

3.2 GROUNDWATER CONTAMINATION ANALYSIS ........... 3-7

3.2.1 Overview of the Conceptual Model .......... 3-8

3.2.2 Overview of the Model ing Approach ....... 3-12

3.2.3 Source Term Analysis ........... 3-14

3.2.4 Contaminant Flux in the Vadose Zone and the Unconfined Aquifer ............ 3-20

3.2.5 Quality Control/Quality Assurance Practices for VAMBD-CG ................ 3-29

3.2.6 Groundwater Pathway Dose Calculations . . . . . 3-30

3.3 ADDITIONAL ANALYSES ................... 31

3.3.1 Vapor Diffusion Pathway Analysis ....... 3-31

3.3.2 Upward Diffusion................3-32

4.0 ANALYTICAL RESULTS ................... . . . . . . .

4.1 ANALYTICAL RESULTS FOR INADVERTENT INTRUDER SCENARIOS $\ldots$ 4-1

4.1.1 Dose Estimate Results . . . . . . . . . 4-1

4.1.2 Intruder Dose Sensitivity Analysis ........ 4-2

4.1.3 Intruder Scenario Uncertainty Analysis ...... 4-5

4.2 ANALYTICAL RESULTS FOR THE GROUNDWATER PATHWAYS SCENARIOS : 4-8

4.2.1 Peak Time and Concentration Results from the Release and Transport Analyses ........... 4-9 4-12

4.2.2 Sensitivity Analyses for the Groundwater Pathway . . 4-12

4.2.3 Determination of Inconsequential Radionuclides in the Groundwater Pathway ............ 4-16

4.2.4 Dose Estimates for Dose-Producing Radionucl ides in Groundwater ................ 4-16

4.2.5 Groundwater Concentration Uncertainty Analysis . . 4-17

4.3 ADDITIONAL ANALYSES ................ 4-23

4.3.1 Vapor Transport of Carbon-14 to the Intruder and Radon-222 Surface Flux .......... 4-23

4.3.2 Offsite Dose Estimates from Vapor Diffusion of Carbon-14 and Hydrogen-3 .......... 4-24

4.3.3 Upward Migration of Contaminants . . . . . . 4-25

4.4 INTEGRATION OF RESULTS

4.4.1 Determination of Inadvertent Intruder Concentration Limits ................ 4-28 
CONTENTS (cont.)

4.4.2 Determination of Groundwater Pathway Inventory Limits ............... 4-32

4.4.3 Implementation of PA-Generated Waste Acceptance Criteria ............... 4-35

4.4.4 Dose Estimates for the Total Projected Inventory and Comparison with Performance objectives ......

4.4.5 Summary of Significant Findings Affecting Compliance Evaluation ................. 4-39

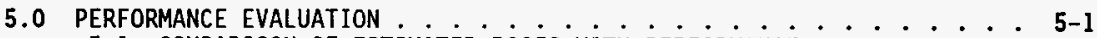

5.1 COMPARISON OF ESTIMATED DOSES WITH PERFORMANCE

OBJECTIVES . . . . . . . . . . . . . . .

5.2 DESIGN CHANGES REQUIRED TO MEET PERFORMANCE OBJECTIVES $\ldots . .5$

5.3 ADDITIONAL APPLICATIONS OF PERFORMANCE ASSESSMENT RESULTS IN WASTE MANAGEMENT ............ 5-2

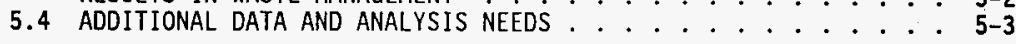

6.0 LIST OF PREPARERS ................... . . . . . . . . .

7.0 REFERENCES . . . . . . . . . . . . . . . $7-1$ APPENDICES

A STRATIGRAPHY, LOW-LEVEL BURIAL GROUND SOIL-COLUMN HYDROLOGIC PROPERTIES, 200 AREAS SOILS PROPERTIES, AND CONTAMINANT PLUMES

B - ADDITIONAL WASTE CHARACTERIZATION INFORMATION

C MODELING EQUATIONS, PARAMETER SELECTION, AND PARAMETER VALUES USED FOR THE EXPOSURE PATHWAY ANALYSIS

D COMPILATION OF VAM3D-CG BENCHMARKING, VERIFICATION, AND CALIBRATION DOCUMENTATION

E APPLICATION OF THE SITEWIDE MODEL TO 218-E-10 AND 218-E-12B SITES

$F$ SUMMARY OF RADIONUCLIDE, FIELD OBSERVATIONS AND ANALYSES

G RESPONSE TO PEER REVIEW PANEL COMMENTS 
WHC-SD-WM-TI-730, REV 0

LIST OF FIGURES

2-1 Map Showing Location of Hanford Site and the 200 East Area LLBG .

2-2 Topography of the Hanford Site

2-3 Historical Seismicity of the Columbia Plateau and

Surrounding Areas

2-4 Hydrologic Basins Designated for the Washington State Portion of the Columbia Plateau ....................

2-5 Generalized Stratigraphy of the Suprabasalt Sediments and Columbia River Basalt Group of the Hanford Site . . . . . . . . . F2-6

2-6 Geomorphic Features in the Vicinity of the Environmental Restoration Disposal Facility.............. F2-7

2-7 Water Table Map for the 200 Areas, 1993 . . . . . . . . . . . . . F2-8

2-8 Estimated Pre-Hanford Site Water Table Map . . . . . . . . . . F2-9

2-9 Cold Creek Watershed Floodplain from the

Probable Maximum Flood .. . . . . . . . . . . . . . . . F2-10

2-10 Low-Level Waste Burial Ground Locations in the 200 East Area . . F2-11

2-11 Schematic of a Typical Nuclear Vessel Reactor Compartment . . . . F2-12

2-12 Plan View Map of 218-E-10 . . . . . . . . . . . . . . . F2-13

2-13 Plan View Map of 218-E-12B . . . . . . . . . . . . . . . . . . F2-15

2-14 Plan View Map of Active Disposal Trenches in 218-E-10..... F2-17

2-15 Plan View of Active Trenches in 218-E-12B ........... F2-19

2-16 Conceptual Disposal Arrangement of 100 Reactor Compartments in the 218-E-12B Burial Ground . . . . . . . . . . . . . . . F2-21

2-17 Schematic Comparison of Analyzed Trench Section Used in Groundwater Analyses Versus Conceptual Waste Volume Area . . . F2-22

3-1 Finite Element Mesh for the Model Cross Section ......... . F3-1

4-1 Saturation Contours for 5-cm/yr Recharge ........... . F4-1

4-2 Velocity Plots for 5-cm/yr Recharge . . . . . . . . . . . . . . F4-3

4-3 Velocity Field for 5-cm/yr Recharge (Fuil Simulation Field) . . . F4-4

4-4 Release History for 5-cm/yr Recharge Advection Dominated . . . . F4-5

4-5 Differing Effects of Infiltration Rates on Leaching History . . . F4-6

4-6 Effect of Varying Diffusion Coefficients on Leaching History . . F4-7

4-7 Plume Cross Section for Case la as a Function of Time . . . . . . F4-9

4-8 Radionuclide Concentration at the 100-m Well, Assuming AdvectionControlled Release Under Category 1 Conditions . . . . . . . . . F4-11

4-9 Plume Cross Section for Cases la-cc at 100 Years . . . . . . . . F4-13

4-10 Radionuclide Concentrations at the 100-m Well, Assuming Solubility-Controlled Release for Category l Conditions ..... F4-15

4-11 Radionuclide Concentrations at the 100-m We11, Assuming Solubility-Controlled Release for Category 3 Conditions . . . . F4-16

4-12 Radionuclide Concentrations at the 100-m We11, Assuming Diffusion Release Under Category 1 Conditions . . . . . . . . F4-17

4-13 Radionuclide Concentrations at the 100-m Well, Assuming Diffusion Release Under Category 3 Conditions....... . . . F4-18

4-14 Radionuclide Concentrations at the 100-m We11, Assuming Advection-Controlled Release and a 40-m Trench

4-15 Radionuclide Concentration at the 100-m Well, Assuming Advection-Controlled Release Under Category 3 Conditions

4-16 Plume Cross Sections for Advection-Controlled Release for Different $\mathrm{Kd}$ Values at 100 Years 


\section{LIST OF FIGURES (cont.)}

4-17 Radionuclide Concentrations at the 100-m Well for Advection-

Controlled Release Under Category 1 Conditions

and Different Kd Values............... F4-23

4-18 Radionuclide Concentration at the 100-m Well for Advection-

Controlled Release Under Category 3 Conditions

and Different Kd Values ............... . F4-24

4-19 Radionuclide Concentrations 100 m Downstream of the $218-\mathrm{E}-10$

Burial Ground for Advection-Controlled Release Under

Category 1 Conditions .............. F4-25

4-20 Radionuclide Concentrations 100 m Downstream at the 218-E-10

Burial Ground for Advection-Controlled Release Under

Category 3 Conditions . . . . . . . . . . . . F4-26

4-21 Plume Cross Section for the Clastic Dike Case Under Advection-

Controlled and Category 1 Conditions .......... F4-27

4-22 Radionuclide Concentrations $100 \mathrm{~m}$ Downstream for Clastic Dike

Case and and Advection-Controlled Release Under

Category 1 Conditions . . . . . . . . . . . . . F4-29

4-23 Plume Cross Section for the Hot Spot Case Under Advective-Controlled and Category 1 Conditions . . . . . . . F4-31

4-24 Radionuclide Concentrations at the 100-m Well for Hot-Spot Inventory Distribution and Advection-Controlled Release Under Category 1 Conditions ........... F4-33

4-25 Radionuclide Concentrations at the 100-m Well Downstream from the Reactor Compartment Trench for Constant ConcentrationControlled Release ................. F4-34

4-26 Radionuclide Concentrations at $100-\mathrm{m}$ Well Downstream from the Reactor Compartment Trench for Constant ConcentrationControlled Release and an Extended Trench $(40 \mathrm{~m})$ Under Category 3 Conditions .............. F4-35

4-27 Unit Gradient Measurements and Corrected Tempe Celi Measurements for Sample 3-0571 .......... . F4-36

4-28 Unscaled Moisture Retention Data and Best Fit van Genuchten Curves for Two Soil Categories . . . . . . . . . F4-37

4-29 Probability Distribution Plot of Saturated Hydraulic Conductivity in the Unconfined Aquifer ......... F4-38 
WHC-SD-WM-TI-730, REV 0

\section{LIST OF TABLES}

2-1 Inventory Disposed of by Hanford Site Generators

in the 200 East Area LLBG Since September 26, $1988 \ldots \ldots$. . . . . T2-1

2-2 Summary of Current Hanford Site-Generated Inventory in the

200 East Area LLBG .................. T2-2

2-3 Range and Frequency of Beta/Gamma Concentrations per Waste

Package per Trench ............... T2-3

2-4 Projected and Final Hanford Site-Generated Inventory of Mobile

Radionuclides in the 200 East Area LLBG ......... T2-4

2-5 Current and Projected Inventory Estimates for Reactor

Compartments in Trench $94 \ldots . . . . . . .2$ T2-5

3-1 Calculation of the Inhalation Time for the Intruders $\ldots$ T3-1

3-2 Human Food Consumption Parameters ............. T3-1

3-3 Summary of Performance Assessment Methodology . . . . . . . T3-2

3-4 Hydraulic Property Input Data for the 218-E-12B Site ..... . T3-3

3-5 Hydraulic Property Input Data for the 218-E-10 Site . . . . . . T3-4

3-6 Radionuclide Sorption Coefficients in the Soil Column. . . . T T3-5

4-1 Radionuclides Considered in the Dose Analysis . . . . . . . . T4-1

4-2 Radioactive Decay Chains Used in the Spreadsheet ...... T4-4

4-3 Total Doses for the Post-Excavation Scenario Using

Kennedy and Strenge (1992) Concentration Ratios....... T4-5

4-4 Total Doses for the Post-Drilling Scenario Using

Kennedy and Strenge (1992) Concentration Ratios....... T4-6

4-5 Comparison of Dose to the Intruder by Exposure Pathway at 300 Years Post-Closure .............. T4-7

4-6 Comparison of Total Dose Ratios Under Leaching Conditions Using Two Databases ... . . . . . . . . . . . T4-9

4-7 Ratio of Total Doses: Nonleaching and Leaching. . . . . . . T4-10

4-8 Relative Contributions to Ingestion Dose by Food Type . . . . . T4-10

4-9 Ratios of GENII and EPA Internal Dose Factors to

DOE Internal Dose Factors . . . . . . . . . . . . T4-11

4-10 Ratio of Pathway Doses for Kennedy and Strenge (1992)

Versus Baes et al. (1984b) Parameters . . . . . . . . . . T4-12

4-11 Base-Case Conditions for 200 East Area LLBG Analyses . . . . . T4-14

4-12 Summary of Modeling Results for 200 East Area LLBG . . . . . . T4-15

4-13 Radionuclides that Decay to Insignificant Quantities Before Entry into the Unconfined Aquifer .............. T4-16

4-14 Radionuclide Dose Estimates for Groundwater Pathways . . . . T4-16

4-15 Descriptive Statistics for van Genuchten

Parameters $\theta_{s}, \theta_{1}, \alpha, n$, and Saturated Hydraul ic

Conductivity $\mathrm{K}_{\text {f }}$ for two Soil Categories ....... . . . T4-17

4-16 Van Genuchten Model Paramters Describing the Unscaled Mean

Hydraulic Curve . . . . . . . . . . . . . . T4-17

4-17 Computed Diffusive and Advective Fronts for

Low-Recharge Scenarios ........... . . T4-18

4-18 Category 1 and 3 Concentration Limits Based on ........ T4-19

4-19 Inventory Limits for Groundwater-Mobile Radionuclides in the 200 East Area Active LLBG ............ T4-20 
WHC-SD-WM-TI-730, REV 0

\section{LIST OF TABLES (cont)}

4-20 Groundwater Concentration Limits for Reactor Compartment Radionuclides ................. . T4-20

4-21 Mobile Radionuclide Trigger Values ............ T4-20

5-1 Comparison of Dose Estimates with

Performance objectives .............. . . T5-1 
WHC-SD-WM-TI-730, REV 0

\section{ACRONYMS}

CERCLA Comprehensive Environmental Response, Compensation, and Liability Act of 1980

CFR Code of Federal Regulations

DNFSB Defense Nuclear Facilities Safety Board

DOE

U.S. Department of Energy

DOE-HQ U.S. Department of Energy, Headquarters

EPA

ER

U.S. Environmental Protection Agency

ERC

Environmental Restoration (Program)

ERDF

environmental restoration contractor

ISSS

Environmental Restoration Disposal Facility

LLBG

International Soil Science Society

LLMW

LLW

low-level burial grounds

low-leve 1 mixed waste

NEPA

NRC

low-level waste

ORNL

PA

National Environmental Policy Act

PCG

Nuclear Regulatory Commission

Oak Ridge National Laboratory

performance assessmen

PNL

Preconditioned Conjugate Gradient

PRP

Pacific Northwest Laboratory

RL peer review panel

TRU

WAC

U.S. Department of Energy, Richland Operations Office transuranic waste acceptance criteria

WHC Westinghouse Hanford Company 
WHC-SD-WM-TI-730, REV 0

\subsection{INTRODUCTION}

\subsection{PURPOSE AND SCOPE}

A site-specific performance assessment (PA) analysis is required by U.S. Department of Energy (DOE) Order 5820.2A (Chapter III, Section 3.b. [1]) (DOE 1988a) to support disposal of low-level waste (LLW) after September 26, 1988, at DOE waste management sites such as the Hanford Site. The DOE order has also established a Peer Review Panel (PRP) to evaluate PA analyses for consistency and technical adequacy. To achieve compliance with DOE order 5820.2A, the PA analysis must be reviewed by the PRP and approved by DOE. This document provides an analysis that evaluates the disposal of lowlevel radioactive waste in the 200 East Area Low-Level Burial Grounds (LLBG) at the Hanford Site.

The primary purpose of this PA analysis is threefold:

- To estimate the potential dose to humans resulting from the disposal of the current and projected LLW inventory in the 200 East Area LLBG

- To compare the estimated doses with dose-limit performance objectives defined in the DOE order (Chapter III, Section 3.a. [2] and [3])

- To derive waste acceptance criteria that ensure that perofrmance objectives are met.

If the projected doses can, with reasonable assurance, be shown to fall below the dose limits, compliance is demonstrated. Consequences of releasing hazardous materials from the disposal facilities are not considered in this analysis. Consistent with the DOE order, only waste inventories disposed of after September 26, 1988, have been considered in this analysis. Waste disposed of in the 200 East Area LLBG before this date will be considered in a separate large-scale composite analysis that evaluates potential dose effects from all residual waste left in the near-surface soil column on the 200 Area Plateau.

The analysis evaluates the effects of site-specific characteristics of the Hanford Site and disposal facility features that influence radionuclide mobility. These features include the hydrogeologic and climatological characteristics, the physical characteristics of the disposal unit, and the physicochemical characteristics of the waste. The Hanford Site is located in south-central Washington State where the climate is semiarid. Disposal of LLW at the Hanford Site occurs primarily in two burial ground areas at the 200 East Area and 200 West Area, which are located on a plateau in the interior of the site. The 200 East LLBG consists of two burial ground areas, located in the northwest and northeast corners of the 200 East Area. Depth to the water table is about $200 \mathrm{ft}$ (about $75 \mathrm{~m}$ ). The PA analysis considers each burial ground area separately because they are separated geographically.

Two distinct types of waste are disposed of in the 200 East Area LLBG. The first is the normal assortment of LLW (e.g., clothing, metal, plastics, 
filters, debris) that are packaged in commonly used containers (e.g, 55-gal drums and wooden or steel boxes). The second waste type consists of defueled nuclear reactor compartments taken from U.S. Navy vessels. The waste inventory consists primarily of activated corrosion-resistant metals that are heavily shielded and enclosed by both the thick steel reactor vessel and the thick steel exterior structure of the reactor compartments. Different source term analyses are provided for each waste type because of differences in inventory and physical and chemical properties.

The standard method of disposal is placement of waste in shallow trenches approximately $7 \mathrm{~m}(20 \mathrm{ft})$ deep that are subsequently covered with several feet of soil. In the case of the naval reactor compartments, the trench floor is approximately $17 \mathrm{~m}(50 \mathrm{ft})$ below grade, which shortens the distance from the waste to the underlying unconfined aquifer. The conceptual model and mathematical representation account for this difference.

Additional LLW sites are active or potentially active in other areas on the Hanford Site. These are or will be the subjects of separate PA analyses or Comprehensive Environmental Response, Compensation, and Liability Act of 1980 (CERCLA) risk assessments. Other areas and facilities include the 200 West Area LLBG, the Environmental Restoration Disposal Facility (ERDF), a disposal facility for waste generated by CERCLA remediation activities, and a site for the disposal of LLW generated by the remediation of liquid and sludge waste stored in underground tanks on the Hanford Site.

\subsection{OTHER HANFORD SITE PERFORMANCE ASSESSMENTS}

Other PA analysis documents have been completed to evaluate the effects of radionuclide release from LLW disposal facilities at the Hanford Site.

A PA analysis was completed for the 200 West Area LLBG (Wood et al. 1995a). The review cycle with the PRP was completed and the document was forwarded to the U.S. Department of Energy, Headquarters (DOE-HQ) for approval with a recommendation of technical adequacy. Conditional approval of this PA has since been granted by DOE (Cowan 1996). The fundamental approach to the 200 West Area LLBG has been adopted for use in the 200 East LLBG because the performance objectives that must be satisfied to comply with DOE Order 5820.2A are identical for both analyses. Also, much of the background data used directly in this analysis or in support of modeling assumptions are identical or similar to those used in Wood et al. (1995a). This approach is driven by the proximity of the two sites, similarities in the waste being disposed of, and use of a similar disposal practice.

Areas of commonality between the two analyses include the following:

- A description of the general environmental characteristics of the site and the treatment of environmental charactistics as input to the radionuclide release scenario models

- A definition of inadvertent intruder scenarios and dose estimate methodology 
- A definition of groundwater contamination radionuclide release scenarios, conceptual model development, and selection of mathematical models for estimating radionuclide contamination of the unconfined aquifer beneath the facility. Waste release models and dose estimate methodology, including types of input parameters, are identical to those used in the 200 West Area PA analysis. Parameter values differ when site-specific information is available (e.g., the hydrologic properties of the underlying soil column).

- A definition of additional radionuclide-release scenarios such as gaseous release and transport and upward diffusion.

Where this PA and the 200 West Area PA are similar enough, much of the description in this analysis was taken directly from from Wood et a1. (1995a).

Kincaid et al. (1995) prepared a PA analysis for the disposal of lowlevel waste generated by remediation of liquid waste in underground doubleshell tanks at the Hanford Site. The disposal method considered was grouting of the waste and placement of the grouted waste form in underground concrete vaults. A preliminary PA analys is (Wood et al. (1995b) was also prepared for the Environmental Restoration Disposal Facility (ERDF) using the methodology followed in this document. Finally, an interim PA analys is is being prepared for double-shell tanks waste. That analysis assumes vitrification of the waste stream and disposal in a "low-activity waste (L.A.W.)" facility.

Estimates of dose are not expected to be identical for solid waste in the 200 East Area LLBG and double-shell tank or ERDF waste because of differences in radionuclide inventory and the proposed methods of disposal. However, because of the similar environmental conditions and the same performance objectives, the methods used to estimate dose and the selection of parameter values affecting dose should be consistent to the extent possible. Efforts have been made to ensure consistency in the selection of performance objectives, radionuclide release scenarios, and parameter values that characterize hydrogeologic properties, radionuclide mobility, and inadvertent intruder dose estimates.

\subsection{APPROACH TO PERFORMANCE ASSESSMENT FOR THE 200 EAST LLBG}

As described in Section 1.1, the primary tasks in the PA analysis are to estimate potential dose to humans, assuming a radionuclide release from the disposal facility occurs, and demonstrate compliance with the performance objectives in DOE Order $5820.2 \mathrm{~A}$ (see Section 1.4). The five-step process developed to complete these tasks and the critical underlying assumptions for each step are described in Sections 1.3.1 through 1.3.5.

\subsubsection{Define Performance Objectives}

Performance objectives are usually quantified as dose limits and some are provided in DOE Order 5820.2A. The performance objectives identify two primary methods by which dose could be received. The first is environmental contamination caused by the release of radionuclides from the disposal 


$$
\text { WHC-SO-WM-TI -730, REV } 0
$$

facility by natural causes. In this case, the primary performance objectives were the 25-mrem/yr all pathways limit and the drinking water 1 imit of $4 \mathrm{mrem} / \mathrm{yr}$. Of these, the 4-mrem/yr limit was more significant in terms of compliance. The second method is inadvertent intrusion by humans into the waste site if knowledge of the waste site's existence and location is lost. The primary performance objectives are the acute exposure dose limit of $500 \mathrm{mrem}$ and the chronic dose limits of $100 \mathrm{mrem} / \mathrm{yr}$. Of these, the chronic dose of $100 \mathrm{mrem} / \mathrm{yr}$ was more limiting in terms of compliance.

\subsubsection{Select Radionuclide Release Scenarios and Scenario Parameters}

The radionuclide release scenarios were defined by the type of performance objectives listed in DOE Order 5820.2A. Leaching of radionuclides from the disposal facility by infiltrating precipitation and subsequent contamination of the underlying unconfined aquifer was the most signifcant source of environmental contamination from natural causes. Consumption of contaminated water by the individual was assumed to cause the dose. Intrusion scenarios were restricted to common activities in the Hanford Site region (i.e., excavation and drilling) that could result in waste being exhumed. Dose occurred as a result of direct contact with the waste, mixing waste with garden soil, and consuming crops grown in contaminated soil.

Having established the general type of radionuclide release scenario, a conceptual model was developed for each scenario. The conceptial model is a simplified representation of the radionuclide release process in the real system. A simplified model was needed for both types of scenarios because the complexities of any real environment or human activity cannot be mathematically represented exactly in a temporal or spatial sense. Simplifying assumptions were considered acceptable as long as all primary environmental conditions, facility conditions, and release mechanisms affecting radionuclide transport into the accessible environment and subsequent dose were conservatively represented in the conceptual model.

For the release and transport scenario, the natural hydrogeologic system is extremely heterogeneous on a local scale, the final distribution of future waste volume and waste inventory in the disposal facility are uncertain, and the meteorologic conditions are variable. This system was simplified in two areas to make up the conceptual model. First, the environmental (physical properties and boundary conditions) and disposal-facility properties that control radionuclide release were averaged temporally and spatially. Significant averaged characteristics that affect dose estimates included an assumption of steady-state infiltration, a homogeneous distribution of waste in the facility, steady-state waste-release mechanisms, single moisturehydraulic-conductivity relationships for each geologic layer, constant sorption values, identical sorption values for groups of radionuclides, and steady-state hydrologic flow conditions. These characteristics control the mass of waste released from the total waste volume as a function of time and the amount of mixing water that dilutes the contaminant concentrations.

Second, two types of disposal facilities were considered: Category 1 and Category 3 . The Category 3 facility characteristics were designed to have lower radionuclide release rates. The two facility types were distinguished by the selection of different average infiltration rates (lower for the Category 
3 facility) and, for some analyses, waste-form performance. Each disposal facility was representated by a single two-dimensional sijce of waste oriented parallel to the primary direction of groundwater flow. This relationship combined with the type of release mechanism assumed allowed groundwater contamination results to be extrapolated to larger waste volumes.

For the inadvertent intruder scenarios, the most significant simplification was to assume that the radionuclide inventory is homogeneously distributed in the waste and subsequently in garden soil into which the waste is mixed. Numerous other parameters affecting the rate and intensity of exposure were assumed to be constant leading to a constant or steady-state rate of dose received. For example, the concentration of contaminated dust in the air was assumed to be constant during the time the individual was present and inhaling dust-filled air.

\subsubsection{Select Parameter Values}

The sources of parameter values vary depending on the scenario. Given the complexities of the systems being investigated, particularly the natural system, a range of values for a particular parameter is expected. Because averaged characteristics must be used, a base-case value was also identified that was used as input in the mathematical model when calculating dose. Selection of the base-case parameter values was one of the most critical aspects of the analysis because the analysis compared the dose estimates associated with these values to performance objectives to determine compliance. The base-case values were selected that were expected to provide a conservatively large dose estimate when used as input into the mathematical code.

For the radionuclide release and transport scenarios, parameter values for natural properties were collected from available site data. Vadose zone soil properties were measured in the laboratory from field samples collected near the 200 East Area LLBG. Unconfined aquifer properties were taken from field measurements and laboratory sample measurements. The base-case values were selected from data on the nearest soil samples and field-measurement locations. Average infiltration values were based on lysimeter data and modeling estimates. Hydraulic gradient values were estimated from data on pre-Hanford well heads and extrapolation to future conditions using the sitewide geohydrologic model. Solubility and sorption values for specific radionuclides were based on thermodynamic data and site-specific experimental measurements, respectively.

Parameter values used to calculate intruder scenario doses were selected from those used in similar analyses at Hanford and other sites. For the most part, parameter values are independent of site-specific characteristics because inadvertent intrusion is a hypothetical event and generic in nature. The ranges of parameter values were typically smaller than those observed for natural system parameters. One site-specific characteristic that was significant in the estimate of dose to the intruder at the Hanford Site was the assumption of irrigation rates. Also, for the Category 3 facility, the type of excavation was restricted to well drilling, thereby 1 imiting the amount of waste that could be exhumed. Dose conversion factors and transfer factors were taken from recommended sources. 
WHC-SD-WM-TI-730, REV 0

\subsubsection{Estimate Dose}

For each scenario, mathematical models were selected to simulate the radionuclide release conceptual model. These models were then applied to calculate dose estimates.

The radionuclide release and transport scenario was modeled using a numerical code, VAM3D-CG. The two-dimensional slice model was represented by an array of nodes (Figure 3-1). Base-case parameter values were input to the code to quantify the physical system and boundary conditions. In the basecase analysis, a unit concentration $\left(\mathrm{Ci} / \mathrm{m}^{3}\right)$ or quantity $(\mathrm{C} \mathrm{i}$ ) in the facility was assumed for a generic radionuclide (depending on the radionuclide release mechanism). In effect, the inventary was assumed to consist of one radionuclide. The code was then executed and the primary result of the analysis was a unique curve for groundwater radionuclide concentration versus time at a well $100 \mathrm{~m}$ downstream. Of particular interest was the calculated peak concentration. The peak concentration, and all other concentrations, are proportional to the initial concentration or quantity. Therefore, the ratio of the unit value to the peak value is the estimated minimum dilution factor imposed by the natural system during release and transport. A set of curves were generated for Category 1 and Category 3 disposal facility conditions and for three sorption conditions (e.g., Kd values of 0,1 , and $10 \mathrm{ml} / \mathrm{g}$ ).

To extrapolate the results from the generic radionuclide to a specific radionuclide, one of the three sorption values was assigned to the radionuclide and the appropriate curve was corrected for the effects of decay and the assumed starting inventory or concentration of that radionuclide. Peak concentrations for parents and daughters that were different elements were predicted to occur at different times because variable elemental sorption characteristics separate them during transport through the soil column.

The dose estimate for a particular radionuclide was calculated from the groundwater concentration of interest, the assumed use of groundwater, and the volume of water used. In this analysis, the dose estimate with the greatest implications for compliance evaluation was that resulting from an annual consumption of groundwater at peak radionuclide concentrations. For a given radionuclide, the dose is the annual total activity consumed multiplied by the radionuclide-specific dose conversion factor for ingestion.

For the inadvertent intruder analyses, doses were calculated using a series of algebraic equations that quantify dose as a function of inventory to which the individual is exposed. Separate equations were needed to estimate dose for each of the exposure pathways (ingestion, inhalation, and direct exposure). In addition, equations were al so used to determine the effective dilution of inventory as radionuclides moved from one medium to another in the cycle of crop growth and consumption. As with the release-and-transport scenario, a generic radionuclide at an initial unit concentration (and an equivalent available activity because the waste volume was fixed) was assumed and the fraction of the initial inventory. to which the individual was exposed was determined. A dose for each individual radionuclide was calculated by using the radionuclide-specific transfer and dose conversion factor. 
Extrapolation to other radionuclides and initial concentrations was done in the same manner as for the release-and-transport scenario except that sorption effects were ignored. Also, parent and daughter isotopes were considered together in the intruder-scenario analyses. The dose contribution of the daughter was counted with that of the parent. These assumptions were made because no mechanism for separating parent and daughter was likely in the intruder scenario. The dose estimates of greatest importance in this analysis were those resulting from chronic exposure received during gardening in contaminated soil.

\subsubsection{Demonstrate Compliance with Performance Objectives}

For both the radionuclide release scenario and the inadvertent intruder scenarios, final inventories in the active burial ground trenches were estimated on the basis of waste volume forecasts. Using the extrapolation process described earlier, estimates of dose for each radionuclide in the inventory were determined for the disposal facility condition. For the release and transport scenario, dose was assumed to occur when the radionuclide was at its peak concentration in groundwater drawn from the well $100 \mathrm{~m}$ downstream. The dose contribution from each radionuclide in the projected inventory was then summed for each scenario and compared to the relevant performance objectives $(4 \mathrm{mrem} / \mathrm{yr}$ and $100 \mathrm{mrem} / \mathrm{yr}$ for the radionuclide release and transport and inadvertent intruder scenarios, respectively) to determine if they would be satisfied. Only radionucilides predicted to peak at the same time (i.e., having the same assigned Kd value and release mechanism) are summed together. In practice, potential dose was only summed for radionuclides with an assigned $\mathrm{Kd}$ of $0 \mathrm{~mL} / \mathrm{g}$. All other radionuclides present in the waste inventory have $K d$ values of more than $10 \mathrm{~mL} / \mathrm{g}$ and cannot provide significant dose within the compliance period.

Waste acceptance criteria also were developed to limit the final inventory of waste that could be disposed of in the burial grounds. This application of the analytical results was developed because the future inventory projections (e.g., uncertain radionuclide inventories, concentrations and volumes of waste to be dispositioned) are uncertain. The waste acceptance criteria are being applied to relativeiy small fractions of the total waste volume (individual waste packages) to ensure that "hot spot" waste concentrations (i.e., concentrations that exceed the established limits) are not excessive. These wastes may be acceptable for disposal because the limits are average values that are compared with large fractions or the entire waste volume of a disposal facility when determining compliance with the performance objectives. Thus, if the larger waste volume contains enough packages with concentrations well below the limits, the average limits of the combined packages will be acceptable. The waste acceptance criteria provide a means of ensuring that dose limits are not exceeded as additional inventory is disposed of in the burial grounds.

The waste acceptance criteria consist of radionuclide-specific concentration or activity limits that correspond to the performance-objective dose limits (intrusion- and groundwater-contamination-induced doses, respectively). The limits were calculated by taking the product of the performance-objective dose 1 imit and the ratio of concentration or inventory to dose that was quantified in the relevant base case analyses. This is 
possible because the doses are linearly proportional.to concentration or inventory as long as all other input parameters are held constant. Because the base case analyses were constructed to yield a conservatively high dose estimate, the corresponding limits are conservatively low.

The waste acceptance process compares radionuclide-specific concentrations and inventories on a waste-package basis with the corresponding limits. The comparison yields a fraction of allowable dose for each radionuclide in a particular waste package. A total fraction of dose is then determined by summing the fractions of all radionuclides in the package that contribute to dose.

Waste acceptance criteria are being implemented in two ways. First, concentration limits to satisfy intruder-scenario performance objectives have been included in Chapter 3 of the waste acceptance criteria document (WHC 1993) that is used to determine the acceptability of waste for disposal. Reporting limits have also been identified for radionuclides that can contaminate groundwater within the assumed compliance period. The purpose of the reporting limits is to identify waste streams with potentially significant sources of the important radionuclides. The limits have been converted to conservative concentration values that will ensure that significant sources of mobile radionuclides will be identified. Once the sources are identified, the generator will be queried to identify the expected inventories of the relevant radionuclides.

Second, a tracking report has been implemented that queries the Solid Waste Information Tracking System (SWITS) and provides current inventories of groundwater-contaminating (e.g., mobile) radionuclides for each active trench or burial ground. All information on waste package inventories is recorded in SWITS. The current inventory is being routinely compared with inventory limits for the burial ground or trench (the entire burial ground in the case of $218-E-10$ and $218-E-12 B)$.

Major topics that require discussion in the PA analysis are defined in two guidance documents (Case et al. 1989 and Dodge et al. 1991). They include the following:

- A description of the performance objectives applied to the LLW disposal facilities (Chapter 1)

- A description of the site and its disposal facilities and waste characteristics (Chapter 2)

- A discussion of analytical methods and release pathways (Chapter 3)

- A discussion of the analytical results, sensitivity and uncertainty analyses, and an integration and interpretation of the results (Chapter 4)

- A summary evaluation of the adequacy of site performance and a description of future work required to finalize the $P A$ analys is and monitor performance of LLW disposal facitities (Chapter 5). 
WHC-SD-WM-TI-730, REV 0

\subsection{REGULATIONS FOR THE DISPOSAL OF LOW-LEVEL WASTE}

DOE and U.S. Environmental Protection Agency (EPA) regulations apply to LLW disposal. The primary DOE order that relates to LIW is DOE Order 5820.2A (DOE 1988a). The following performance objectives are stated in Chapter 3, Paragraph $3 a$ of that order:

"1. Protect public health and safety in accordance with standards specified in applicable EH Orders and other DOE Orders.

2. Assure that external exposure to the waste and concentrations of radioactive material which may be released into surface water, groundwater, soil, plants, and animals results in an effective dose equivalent that does not exceed $25 \mathrm{mrem} / \mathrm{yr}$ to any member of the public. Releases to the atmosphere shall meet the requirements of 40 CFR 61 . Reasonable effort should be made to maintain releases of radioactivity in effluents to the general environment as low as is reasonably achievable.

3. Assure that the committed effective dose equivalents received by individuals who inadvertently may intrude into the facility after the loss of active institutional control (100 years) will not exceed $100 \mathrm{mrem} / \mathrm{yr}$ for continuous exposure or $500 \mathrm{mrem}$ for a single acute exposure.

4. Protect groundwater resources, consistent with Federal, State, and local requirements."

At the Hanford Site, RLID 5820.2A (DOE-RL 1993) was generated. It provided additional or clarifying performance objectives, but was cancelled in March 1995. However, some of the performance objectives are being used as guidance to define performance objectives assumed in this PA analysis. These performance objectives were provided in Chapter 3, Paragraph 3a, as follows:

"1. General Public Protection. Disposal systems shall be designed to ensure that exposure to any member of the public that results from disposal of solid LLW shall not exceed $25 \mathrm{mrem} / \mathrm{yr}$ effective dose equivalent (EDE) through all exposure pathways for at least 1,000 years after disposal. The point of compliance shall be no further from the edge of the waste than the Hanford Site boundary during the period of active institutional control. After the active institutional control period (assumed to be not more than 100 years) the point of compliance shall be not more than 100 meters from the edge of the disposal site.

2. Groundwater Protection. Disposal systems shall be designed to ensure that disposal of LLW after September 26, I988, does not result in concentrations of radionuclides (above existing levels) in groundwater exceeding those corresponding to an EDE of $4 \mathrm{mrem} / \mathrm{yr}$ to any person who might drink 2 liters per day of water from a well drilled into the aquifer, for at least 1,000 years after disposal. The point of compliance shall be no further than 100 meters from the edge of the waste. 
WHC-SD-WM-TI-730, REV 0

3. ALARA (Long-Term Protection). Reasonable effort shall be made to design disposal systems in such a way that potential exposures are ALARA for all times up to the year of maximum exposure. If the predicted population exposure is less than 500 person-rem/yr in the year of maximum exposure, the ALARA requirement is defined to have been complied with.

4. Intruder Protection. Disposal closure systems shall be designed to ensure that exposure to individuals who inadvertently intrude the closed facility after the active institutional control period shall not exceed $100 \mathrm{mrem} / \mathrm{yr}$ for continuous exposure, or $500 \mathrm{mrem}$ for a single acute exposure. For wastes that may remain hazardous to inadvertent intruders beyond 100 years, passive controls (e.g., long-term government ownership and control, appropriate markers, and barrier systems) shall be incorporated to provide reasonable assurance that inadvertent intruders will be warned and deterred from disturbing the site for up to 500 years.

5. Mixed-Waste Regulations. Disposal systems shall be designed to meet the applicable requirements of 40 CFR 264 and 265, and WAC 173-303 for the disposal of LLW-MW."

DOE has also drafted a proposed rulemaking, Title 10 Code of Federal Regulations (CFR) Part 834, "Proposed Rule, Radiation Protection of the Public and the Environment." In the proposed rule, the only requirement that applies directly to LLW disposal is the all pathways limit of $25 \mathrm{mrem} / \mathrm{yr}$

(Section 834.109). However, protection of air and drinking water, both of which could be contaminated as a result of disposal, are also covered (Sections 834.102 and 834.103). Proposed limits that could apply to disposal facilities include airborne release limits of $10 \mathrm{mrem} / \mathrm{yr}$ for all radionuclides excluding ${ }^{222} \mathrm{Rn}$ and a ${ }^{222} \mathrm{Rn}$ flux $7 \mathrm{imit}$ of $20 \mathrm{pCi} / \mathrm{m}^{2} / \mathrm{s}$ through the surface of the facility. For DOE-managed drinking water systems, a 4-mrem/yr 1 imit resulting from water consumption is proposed. Separate activity limits are recommended for ${ }^{226} \mathrm{Ra}$ and ${ }^{228} \mathrm{Ra}$ combined $\left(5 \times 10^{-9} \mu \mathrm{Ci} / \mathrm{ml}\right)$ and gross alpha excluding radon and uranium $\left(5.6 \times 10^{-8} \mu \mathrm{Ci} / \mathrm{ml}\right)$. Finally, for private or public drinking water systems downstream of the DOE facility, the radiological limits provided in 40 CFR 141 are recommended.

At present, no Washington State or local laws are in place to regulate radionuclide release from LLW disposal facilities. In 40 CFR 141 , radiological limits are recommended for drinking water facilities. Limits include $4 \mathrm{mrem} / \mathrm{yr}$ on beta- and gamma-emitting radionuclides. Separate limits are provided for individua'l alpha-emitting nuclides and total alpha radiation.

\subsection{TREATMENT OF DOSE LIMIT PERFORMANCE OBJECTIVES IN THE PERFORMANCE ASSESSMENT ANALYSIS}

The discussion in Section 1.4 identified a mixture of clearly defined and proposed performance objectives. This analysis uses the following criteria:

- The PA analysis shall only consider potential doses that could occur following closure of the Hanford Site LLW disposal facility. 
Potential doses received while the Hanford Site LLBGs are operational have been considered in a safety analysis (WHC 1995a).

- An inadvertent intruder into the Hanford Site LLW disposal facilities shall not receive an effective dose equivalent of more than 500 mrem from a single acute exposure or $100 \mathrm{mrem} / \mathrm{yr}$ for continuous exposure. The PA analys is will compare estimated doses from plausible intruder scenarios with these dose limits and demonstrate with reasonable assurance that the disposal facility and site-specific conditions affecting radionuclide release are sufficient to satisfy these dose limits.

- Any nonintruder member of a critical group (e.g., the maximum exposed individual) shall not receive an effective dose equivalent of more than $25 \mathrm{mrem} / \mathrm{yr}$ from all exposure pathways resulting from radionuclide release from the 200 East Area LLBG. The PA analysis compare all-pathways release estimates with this dose limit and demonstrate with reasonable assurance that the disposal facility and site-specific conditions affecting radionuclide release are sufficient to satisfy these dose limits.

- To protect groundwater resources, predicted groundwater concentrations resulting from the leaching and transport of radionuclides from the Hanford Site LLW disposal facilities to the water table shall be compared to concentrations that result in a 4-mrem/yr effective dose equivalent.

- The effective dose equivalent to any individual resulting from airborne effluents released from the Hanford Site LLW disposal facilities will not exceed $10 \mathrm{mrem} / \mathrm{yr}$. The limit applies to all radionuclides except ${ }^{222} \mathrm{Rn}$. For ${ }^{222} \mathrm{Rn}$, the surface flux limit of $20 \mathrm{pCi} / \mathrm{m}^{2} / \mathrm{s}$ averaged over the enitire facility is selected.

In the 200 West Area PA, Wood et al. (1995a) provided an evaluation of population dose from contamination of the Columbia River and comparison with the limit of 500 person-rem/year. This performance objective is not considered in this PA analysis for two reasons. First, the objective was defined only in DOE-RL (1993), which has been cancelled. Second, previous analyses (Wood et al. 1995a and Kincaid et al. 1995) showed that the groundwater protection dose of $4 \mathrm{mrem} / \mathrm{yr}$ was more restrictive. Waste acceptance criteria that satisfy the groundwater protection dose limit easily satisfy the population dose limit objective.

\subsection{POINTS AND TIMES OF COMPLIANCE RELATED TO DOSE LIMIT PERFORMANCE OBJECTIVES}

Two important aspects of the treatment of performance objectives are the point and the time of compliance. For the point of compliance, the following conditions are selected:

- For intruder dose limits, the intruder contacts the waste directly. 
- For the drinking water pathway and all-pathways scenarios, the point of compliance is the place where the maximum dose can be received by an offsite individual. The minimum point of compliance is $100 \mathrm{~m}$ from the edge of the waste (DOE 1993a). A well is constructed at this distance from which contaminated groundwater can be drawn for drinking and agricultural purposes.

Quantitative requirements on the time of compliance for any of the dose limit criteria are not specified. The following conditions are selected:

- DOE Order 5820.2A specifies that inadvertent intrusion cannot occur until loss of institutional control, which is defined as 100 years post-closure. In addition, for facilities containing waste that remains hazardous for more than 100 years and incorporating passive controls to deter intruders, a time of compliance of 500 years is defined in DOE-RL (1993).

- For the drinking water pathway, a minimum time of compliance of 1,000 years post-closure has been specified in DOE-RL (1993). As a design goal, the time of compliance has been extended to 10,000 years for potential doses received from the drinking-water and all-pathways scenarios. The 10,000-year period is consistent with the compliance time specified in proposed EPA regulations for the disposal of high-level waste (58 FR 7924). The analyses generally show that peak doses occur at elapsed times of about 1,000 years or less. In cases where peak doses occur after 10,000 years, the results and their effects are discussed. 


\subsection{DISPOSAL FACILITY DESCRIPTION}

This chapter provides site/facility information to complete a sitespecific PA analysis for disposal of LLW in the 200 East Area LLBG on the Hanford Site. The following topics are pertinent to the completion of a PA analysis:

- The general environmental conditions of the disposal facility (Section 2.1)

- The use of these environmental conditions in this PA analysis (Section 2.2)

- Waste characteristics (Section 2.3)

- The treatment of waste characteristics in the PA analysis (Section 2.4)

- A description of LLBG designs (Section 2.5)

- The treatment of disposal facility features in the PA analysis (Section 2.6).

This section describes those aspects of the disposal practices and environmental conditions that control the release of radionuclides into the environment. In addition, those aspects of the environment not explicitiy included in the models used in this PA analysis will be discussed and justified.

\subsection{ENVIRONMENTAL CHARACTERISTICS OF THE 200 EAST AREA LOH-LEVEL BURIAL GROUNDS}

The environmental conditions that characterize the 200 East Area LLBG are summarized because these topics have been discussed at length in other publications. The Hanford Defense Waste Environmental Impact Statement (DOE 1987), the grout PA (Kincaid et al. 1995), the 200 West Area LLBG (Wood et al. 1995a) provide additional information. Some of the information in these documents has not been updated for several years but is considered valid for the purposes of this PA analysis. Environmental characteristics discussed include regional geography and demography, regional and sitespecific geology, regional and site-specific hydrology, climatology, meteorology, ecology, and natural radiation background. Much of the general discussion text in this chapter is taken verbatim from Wood et al. (1995a).

\subsubsection{Site Geography and Demography}

The 200 East Area LLBG are located on the Hanford Site in south-central Washington State (Figure 2-1). The Hanford Site is located in a structural and topographic depression of the Columbia Plateau called the Pasco Basin. 
The northern and eastern boundaries of the Site generally follow the Columbia River. The western boundary is generally bounded by the Rattlesnake Hills and the southern boundary by the Yakima River. The Hanford Site covers an area of about $1,500 \mathrm{~km}^{2}\left(579 \mathrm{mi}^{2}\right)$. With the exception of a few natural basalt hills (e.g., Gable Butte and Gable Mountain), the site is relatively flat (Figure 2-2) with a topographical low at the Columbia River (about 100 to $120 \mathrm{~m} \mathrm{[328} \mathrm{to} 394 \mathrm{ft}]$ ) above sea level and a gradual increase in elevation toward the north central part of the site]. The 200 East Area LLBG are located in this region, commonly referred to as the 200 Area Plateau, at about $225 \mathrm{~m}(738 \mathrm{ft})$ elevation.

The nearest population center consists of three small cities (Richland, Kennewick, and Pasco) situated to the southeast of the site on the Columbia River. The population living within $80 \mathrm{~km}(50 \mathrm{mi})$ of the 200 East Area LLBG is about 270,000 (Kincaid et al. 1995).

\subsubsection{Site Climatology and Meteorology}

Meteorological data have been collected at the Hanford Meteorology Station (HMS), located between the 200 East and West Areas, since 1945. Hoitink and Burk (1994) provide a recent summary. Temperature and precipitation data have been recorded for the region since 1912. Generally, the Hanford Site climate is classified as semiarid with an average rainfall of about $16 \mathrm{~cm} / \mathrm{yr}$ ( $6 \mathrm{in} . / \mathrm{yr}$ ), nearly half of which occurs from November through January.

The prevailing winds of the area are from the northwest and secondarily from the southeast. Average wind speeds are about 10 to $15 \mathrm{~km} / \mathrm{h}$ ( 6 to $9 \mathrm{mi} / \mathrm{h}$ ). The area is subjected to occasional high winds (a peak gust wind of $130 \mathrm{~km} / \mathrm{h}$ [ $80 \mathrm{mi} / \mathrm{h}]$ ) was recorded at the HMS in 1972]. Only 24 tornados have been reported in the vicinity of the Hanford Site.

\subsubsection{Site Ecology}

Site ecology is thoroughly summarized in the Hanford Defense WasteEnvironmental Impact Statement (HDW-EIS) (DOE 1987), the Environmental Restoration Disposal Facility (ERDF) Remedial Investigation/Feasibility Study (RI/FS) (DOE-RL 1994) and Cushing (1995). Dominant vegetation at the Hanford Site includes sagebrush, rabbit brush, and a variety of grasses, including cheatgrass and bunchgrass. Common mammals on the site include mule deer, elk, jack and cottontail rabbits, coyotes, badgers, raccoons, and a variety of rodents. Common birds include grouse, doves, falcons, hawks, owls, geese, and ducks. A wide variety of fish live in the Columbia River including salmon, trout, shad, bass, whitefish, sturgeon, and catfish.

\subsubsection{Regional and Site-Specific Land Use}

In the region surrounding the Hanford Site, commercial land use is typically agricultural and relies on irrigation to grow crops. The sources of irrigation are generally the Columbia and Yakima Rivers and confined aquifers (sediment layers between upper basalt flows). Nuclear facilities in operation 
WHC-SD-WM-TI-730, REV 0

on or adjacent to the Hanford Site include the Washington Nuclear Plant 2 (WNP-2), a commercial nuclear reactor operated by the. Washington Public Power Supply System, the Siemens Nuclear Power Corporation Fuel Fabrication Plant, and ATG, Inc., a commercial volume reduction and decontamination facility adjacent to Siemens. All are situated southeast of the 200 East Area. In addition, a commercial LLW disposal facility operated by Ecology is located adjacent to the 200 East Area.

On the Hanford Site, a large number of facilities, including reactors and processing plants, have been operated to produce nuclear materials. These facilities are permanently shut down. The 200 West LLBG and the Solid Waste Operations Complex are operating for management of LLW, TRU waste, and mixed waste. The complex consists of a number of active and inactive burial sites (shallow-land trenches), storage buildings primarily for $\mathrm{MW}$, and administrative buildings. The Waste Receiving and Processing (WRAP) Facility, also present in the complex, will be operated in this area to treat, package, and ship transuranic (TRU) waste and LLW for disposal. Also, two RCRAcompliant LLMW trenches have been constructed and will be operated in the 218-W-5 Burial Ground. South of the 200 East and West Areas, a large RCRAcompliant disposal pit, the Environmental Remediation Disposal Facility (ERDF) will receive CERCLA remediation waste. This waste is largely contaminated soils from the 100 and 300 Areas.

\subsubsection{Seismology}

The Hanford Site is in an area of low seismicity (Figure 2-3). Earthquakes typically occur at shallow depths (focal depth $<6 \mathrm{~km}$ [ $-4 \mathrm{mi}$ ] from Caggiano and Duncan 1983) as multiple events or swarms at magnitudes of less than 3.5 on the Richter scale. Two moderate-sized earthquakes have been recorded near the site, one in 1936 in the Milton-Freewater area (Modified Mercalli intensity VII) about $54 \mathrm{~km}(40 \mathrm{mi})$ southeast of the Hanford Site and another in Corfu in 1918 (Modified Mercalli intensity IV to VI) about $189 \mathrm{~km}$ (118 $\mathrm{mi})$ north of the site. The Corfu earthquake is estimated to have produced peak ground accelerations of 0.01 to $0.03 \mathrm{~g}$ on site. The epicenters of recorded earthquakes occur somewhat randomly and are not strongly associated with any geologic structural features. A more recent compilation of seismic events (Geomatrix Consultants, Inc. 1996) confirms these general trends.

\subsubsection{Radiation Background}

The natural environment of the Hanford Site is contaminated by radiation from two sources: Hanford Site nuclear production activities during the last 50 years and fallout from nuclear weapons testing in other parts of the world. Radiation has been measured in Columbia River water, groundwater (primarily the unconfined aquifer), local soil, and wildlife including mammals, birds, and fish. The HDW-EIS (DOE 1987 ) reports small quantities (<1 pCi/L) of ${ }^{90} \mathrm{Sr}$, ${ }^{60} \mathrm{Co},{ }^{95} \mathrm{Zr},{ }^{129} \mathrm{I},{ }^{131} \mathrm{I},{ }^{137} \mathrm{Cs},{ }^{144} \mathrm{Ce}$, uranium, and plutonjum in the Columbia River. In Hanford Site soil, average quantities of ${ }^{90} \mathrm{Sr}$, plutonium, and uranium of less than $1 \mathrm{pCi} / \mathrm{g}$ have been reported. Slightly higher concentrations of ${ }^{137} \mathrm{Cs}$ (about $2 \mathrm{pCi} / \mathrm{g}$ ) have been measured. Quantities of ${ }^{90} \mathrm{Sr},{ }^{137} \mathrm{Cs},{ }^{60} \mathrm{Co}$, plutonium, and uranium have also been reported in mammals, 
birds, fish, and vegetation generally at values 1 ess than $0.01 \mathrm{pCi} / \mathrm{g}$. Annual analyses and reports are generated (e.g., Dirkes et al. 1994) to monitor Hanford Site radiation background.

Several contaminant plumes are present in the unconfined aquifer beneath the 200 Area Plateau which resulted from the disposal of waste water from various processing facilities into ponds, cribs, and ditches. Waste water was also discharged into one reverse well (216-B-5). Groundwater chemistry data were gathered and reviewed in 1992 (Ford 1993) as part of the 200 Aggregate Area Management Study (AAMS). Ford (1993) defines 18 contaminants with groundwater concentrations that can be mapped as plumes (i.e., at least one plume with multiple-well exceedances that are semicontiguous). Al1 plumes identified by Ford (1993) emanated from facilities within the 200 Areas. Radionuclides present in plumes or recorded in groundwater samples beneath or adjacent to the 200 East Area LLBG include ${ }^{3} \mathrm{H},{ }^{99} \mathrm{TC},{ }^{129} \mathrm{I},{ }^{137} \mathrm{Cs},{ }^{90} \mathrm{Sr}$, ${ }^{60} \mathrm{Co}$, and $2397240 \mathrm{Pu}$. Maps of the plumes are shown in Appendix A.

\subsubsection{Regional Hydrogeology}

The Hanford Site is located on a geologic province referred to as the Columbia Plateau. The Columbia Plateau covers much of eastern Washington, eastern Oregon, and parts of Idaho. It was formed by a massive upweling of basalt magma over a period of about 10,000,000 years. Specifically, the site is located in the Pasco Basin, a structural depression of the Columbia Plateau. About $3,000 \mathrm{~m}(10,000 \mathrm{ft})$ of basalt underlie a series of vadose sediments of variable thickness across the Hanford Site. The major sedimentary units are the Ringold Formation and the Hanford formation. The Ringold Formation overlies the uppermost basalt flow and was deposited by various erosional processes. The Hanford formation overlies the Ringold Formation and was deposited catastrophically in a series of major floods associated with glacial melting.

The hydrology of the Pasco Basin is characterized by a number of surface sources and aquifers associated with both the basalts and the suprabasalt sediments. The basalt aquifers consist of the tholeiitic flood basalts of the Columbia River Basalt Group and relatively minor amounts of intercalated fluvial and volcaniclastic sediments. The uppermost aquifer system occurs within the fluvial, lacustrine, and glaciofluvial suprabasalt sediments. This aquifer is regionally unconfined and is contained largely within the Ringold Formation and the Hanford formation.

Surface drainage enters the Pasco Basin from several other basins (Figure 2-4), including the Yakima River Basin, Horse Heaven Basin, Walla Walla River Basin, Palouse/Snake Basin, and Big Bend Basin. Within the Pasco Basin, the Columbia River is joined by major tributaries including the Yakima, Snake, and Walla Walla Rivers. Two intermittent streams, Cold Creek and Dry Creek, cut through the Hanford Site. Water drains through these pathways during the wetter winter and spring months. No perennial streams originate within the Pasco Basin.

The total estimated precipitation over the Pasco Basin averages less than $16 \mathrm{~cm} / \mathrm{yr}$ ( $6.3 \mathrm{in.} / \mathrm{yr}$ ). Mean annual runoff is estimated to be less than $2.5 \times 10^{4}$ acre-ft/yr, or approximately 3 percent of the total precipitation. 
The remaining precipitation is assumed to be lost through evapotranspiration, with a small component (perhaps $<1 \%$ ) contributing to recharging of the groundwater system (DOE 1988b).

Primary surface-water features associated with the Hanford Site are the Columbia and Yakima Rivers and their major tributaries, the Snake and Walla Walla Rivers. West lake, about 4.0 hectares ( 10 acres) in area and less than $0.9 \mathrm{~m}(3 \mathrm{ft})$ deep, is the only natural lake within the Hanford Site. Waste water ponds, cribs, and ditches associated with nuclear fuel reprocessing and waste disposal activities are also present on the Hanford Site.

Groundwater occurs both within the upper unconfined aquifer system and within a system of deeper confined to semiconfined aquifers in the basalt flow tops, flow bottom zones, and sedimentary interbeds (DOE 1988b). These deeper aquifers are intercalated with aquitards, consisting of basalt flow interiors (colonnades and entablatures).

The general direction of groundwater flow is from the natural recharge areas west of the Hanford Site to discharge areas, primarily toward the Columbia River. Recharge of the confined basalt aquifers occurs through infiltration on the anticlinal ridges bounding the Pasco Basin and from westward flow in basalt aquifers beneath the Columbia Plateau. Sources of natural recharge to the uppermost (unconfined) aquifer system are infiltration and runoff of precipitation, primarily from the ridges bounding the Pasco Basin, infiltration from ephemeral streams, and from rivers along influent reaches of the Yakima and Columbia Rivers. The movement of precipitation through the vadose zone has been studied at several locations on the Hanford Site (Gee 1987, Routson and Johnson 1990, Rockhold et al. 1990, Fayer et al. 1991). General conclusions have been that very little, if any, infiltration occurs where the soils are relatively fine grained and deeprooted vegetation is present. Where soils are coarse and vegetation is shallow rooted or not present, infiltration can exceed 50 percent of the precipitation.

Principal sources of natural recharge to the unconfined aquifer, where precipitation and surface runoff infiltrate to the water table, occur west of the 200 West Area. Several small ephemeral streams, such as Cold Creek and Dry Creek that are located between the Rattlesnake Hills and Umtanum Ridge, drain the western slopes of the Pasco Basin, losing water to the subsurface as they spread across the lower valley plains. From here, groundwater moves through the sediments generally from west to east (DOE 1988b). Studies performed on the Hanford Site indicate that some recharge to the water table [0 to $10 \mathrm{~cm} / \mathrm{yr}(0-4 \mathrm{in.} / \mathrm{yr})]$ may occur locally depending on surface conditions, especially during the winter months (Gee 1987); most precipitation, however, is returned to the atmosphere through evapotranspiration.

Recharge to the unconfined aquifer from liquid-waste disposal operations occurs at the Hanford Site, mainly in the 200 Areas. Recharge from the 200 Areas waste water disposal facilities is estimated to have been as much as 10 times the natural recharge at the Hanford Site (Graham et al. 1981). More recently, Fayer and Walters (1995) estimate the total volume of natural recharge over the Hanford Site at $8.47 \times 10^{6} \mathrm{~m}^{3} / \mathrm{yr}$ in 1992 . This value is of 
the same order of magnitude as the artificial recharge to 200 Areas waste disposal facilities during 1992 and is about half the discharge volume in 1979. Liquid waste disposal is now regulated, decreasing significantly, and will eventually cease.

\subsubsection{Hydrogeology of the 200 East Area LLBG}

The sources of the data described in this section are a detailed summary of the geohydrology of the 200 East Area by Connelly et al. (1992) and a detailed characterization of the 200 East Area Burial Grounds by Lindsey et al. (1994). These reports represent the most recent synthesis of available data that have been used to characterize the primary features of the vadose zone and unconfined aquifer.

The principal source of geologic and hydrologic information in the 200 East Area is boreholes. A generalized view of the suprabasalt sediment facies of 200 East Area is provided in Figure 2-5. The 200 East Area lies on the Cold creek bar, a geomorphic remnant of the cataclysmic floods of the Pleistocene (Figure 2-6). As the flood water raced across the lowlands of the Pasco basin and Hanford Site, the flood waters lost energy and began leaving behind deposits of gravels. The entire 200 Area Plateau is one of the most prominent of such deposits. In the northern half of the 200 East Area the water table is situated within gravel- to sand-dominated facies of the Hanford formation. To the south and east, it more commonly can be found within gravels of Ringold units $A$ and $E$ and silts of the lower mud unit. Transmissivity and hydraulic conductivity data are summarized in Connelly et al. 1992. The vadose zone beneath the 200 East Area LLBG consists primarily of Hanford formation sediments.

\subsubsection{Description of the Soil Column Underlying the 218-E-12B Burial}

Ground. Suprabasalt sediments beneath this burial ground consist entirely of the Hanford Formation (see Appendix A, Figures $A-1, A-2, A-3$, and $A-4$ ). From the surface down, the Hanford units are: gravel of unit 1 , sand of unit 2 , and gravel of unit 3 . The interstratified sand and gravel found at the base of unit 2, referred to as unit 2 a, are locally well developed beneath the eastern to central part of the site. Although each unit is defined on the basis of a dominant lithology, significant subordinate lithologies are intercalated in each unit.

Unit 1 is variable in thickness and distribution. It ranges from 11 to $37 \mathrm{~m}$ ( 35 to $120 \mathrm{ft}$ ) thick, is dominated by the gravel facies, and contains significant interstratified horizons dominated by the sand facies. The unit is thinnest in the southwestern part of the site and thickens to the north and east. Outcrop observations show that silt-rich interbeds are present and are normally a few to tens of centimeters thick. Silty horizons as much as $1 \mathrm{~m}$ $(3 \mathrm{ft})$ thick and continuous up to distances of at least several hundred meters also are present in the unit. These horizons are capable of generating perched water conditions. The contact between unit 1 and underlying strata generally is very irregular. These irregularities are the result of the interfingering nature of these deposits, which results in the absence of a distinct bounding surface. 
The sands of unit 2 are thickest (up to $55 \mathrm{~m}$ [180 ft]) in the southwestern part of the site while pinching out toward the east and north. Silty beds and horizons in this unit have the potential to form perched water zones although the lateral continuity of these zones is questionable because of the presence of clastic dikes and pinchouts found in outcrops of analogous strata. Interbedded sand and gravel of unit 2a is locally well developed, especially to the east where unit 2 pinches out and interfingers with gravelly units (unit 1 and 3 ). Unit 2 a represents a transition zone between units 2 and 3 .

Unit 3, defined by the abundance of the gravel facies, thickens to the north and northeast, from 12 to $45 \mathrm{~m}$ ( 40 to $150 \mathrm{ft}$ ) thick. Like unit 1 , interbeds of the sand and silt facies are present throughout unit 3 . Also like unit 1, these silts have the potential to generate perched water conditions.

2.1.8.2 Description of the Soil Column Underlying the 218-E-10 Burial Ground. The same sequence of units that underlies the 218-E-12B Burial Ground underlies the 218-E-10 Burial Ground (see Figures $A-4, A-5, A-6$, and $A-7$ in Appendix). Hanford formation units $1,2,2 a$, and 3 are all present. Boreholes adjacent to the BX-BY tank farms encountered a thin sequence of Ringold-like deposits suggestive of the lower mud unit. However, Ringold Formation deposits are not present beneath the burial grounds (Figures A-4 through A-6 in Appendix A).

Unit 1 ranges from 12 to $33.5 \mathrm{~m}$ (40 to $110 \mathrm{ft}$ ) thick beneath the burial ground. While it is dominated by the gravel facies, numerous interbeds of the sand facies also are present. The unit is thickest to the northwest and thins to the east and south. However, even though it is thickest to the northeast it also contains more interbedded sands in that direction.

The sands of unit 2 range from 27 to $40 \mathrm{~m}$ (90 to $130 \mathrm{ft}$ ) thick, generally thickening to the south and west. Several gravel intervals 3 to $5 \mathrm{~m}$ (10 to 15 $\mathrm{ft}$ ) thick occur locally in the middle part of the unit in the northeastern part of the area. In addition, significant gravelly intervals exist in the lower part of the unit and are referred to as unit $2 \mathrm{a}$. Unit $2 \mathrm{a}$ is up to $15 \mathrm{~m}$ (50 ft) thick.

As much as $34 \mathrm{~m}(110 \mathrm{ft})$ of gravelly strata assigned to unit 3 occur beneath the site. Most of the boreholes drilled at this burial ground did not reach the top of the basalt. Consequently, thicknesses are difficult to estimate for this unit. As is the case throughout the 200 East Area, minor interbedded sequences dominated by the same facies occur in these gravels.

Data from the boreholes that reach the top of basalt beneath the burial ground indicate the strata dip to the west and south beneath the site. This is consistent with regional data.

\subsubsection{Uppermost Aquifer System Characteristics Underlying the 200 East}

LLBG. A water table contour map of the uppermost aquifer for the Hanford Site, based on 1993 data, is shown in Figure 2-7. The position of the water table in the western portion of the Hanford Site is generally within the Ringold Unit E gravels. The water table in the eastern portion of the Hanford Site is generally within the Hanford formation. The gradient across the 
WHC-SD-WM-TI-730, REV 0

burial grounds is very slight (Figure 2-7). The general direction of flow is currentiy east to west under the 200 East Area LLBG. The primary driving force is the groundwater mound underneath B Pond which occurs east of the LLBG.

Recharge to the uppermost aquifer occurs primarily from wastewater disposal practices at surface ponds, ditches, and various cribs in the 200 East and 200 West Areas. Three large recharge mounds have developed at the Hanford Site: $U$ pond in the 200 West Area, B pond east of the 200 East Area and Gable Mountain Pond north of the 200 East Area. Under $U$ pond, which was decommissioned in 1985, the water table had risen more than $26 \mathrm{~m}(85 \mathrm{ft}$ ) since the start of the disposal operations. The mound under $B$ Pond has risen more than $9 \mathrm{~m}(30 \mathrm{ft}$ ) (Graham et al. 1981). Underneath the 200 East Area LLBG, the depth to the water table is about $66 \mathrm{~m}(-215 \mathrm{ft})$. The projected post-Hanford depth is about $69 \mathrm{~m}(\sim 225 \mathrm{ft})$. As this groundwater mound dissipates, the direction of groundwater flow beneath the 200 East burial grounds will likely reverse, returning to the easterly regional groundwater flow direction estimated to exist before Hanford Site operations began (Figure 2-8).

\subsubsection{Geochemistry of the Soil Column}

The general geochemical characteristics of the soil column are consistent in the suprabasalt sediments across the Hanford Site. Rout inely occurring soil phases are predominantly feldspar and quartz with minor quantities of smectite $\mathrm{clay}$, hydrous oxides, and calcium carbonate. For example, measured quantities of soil phases from the 218-W-5 Burial Ground (Serne et al. 1993) were approximately 31 percent feldspar, 43 percent quartz, 3 percent smectite clay, 1 percent hydrous oxides, and 2 percent calcium carbonate. Many analyses of the unconfined aquifer groundwater have been completed at the Hanford Site. Again, the data are very consistent. The groundwater is characterized as moderately alkaline ( $\mathrm{pH} \sim 7.8$ to 8.4 ) and oxidizing (Eh $\sim 280$ to $380 \mathrm{mV}$ with moderate concentrations of aqueous species [ $\sim 5 \mathrm{meq} / \mathrm{L}])$. Analyses of moisture from vadose zone sediments (Serne et al. 1993) show essentially the same characteristics.

\subsection{TREATMENT OF ENVIRONMENTAL CHARACTERISTICS IN THE PERFORMANCE ASSESSMENT ANALYSIS}

of the environmental characteristics described previously, only some must be represented in the PA analysis. For those characteristics that are represented, the manner in which they are represented is defined in the following sections. For those conditions that are not represented, a rationale for nonrepresentation in the $P A$ analysis is given.

\subsubsection{Meteorology and Climatology}

At the Hanford Site, the meteorological conditions that require consideration are precipitation, flooding potential, high winds, and tornados. of these, the most important process relative to $P A$ analyses is the assumption of infiltration rates into the disposed facility resulting from precipitation. 
Direct measurements of infiltration arid sites are seldom possible, and water balance methods of estimating recharge are of 1 imited use because they calculate infiltration as the residual of two uncertain (and often nearly of the same magnitude) parameters, evapotranspiration and precipitation. Both processes occur sporadically with varying degrees of intensity. Also, soil and vegetation characteristics affect infiltration rates. Based on multiyear lysimeter experiments, Gee et al. (1992) summarized the roles played by the three major factors of climate, soil, and vegetation at the Hanford Site. Infiltration is greatest for coarse-textured soils, least for fine-textured soils. It is greatest for surfaces that are maintained free of vegetation, least for surfaces supporting both shallow- and deep-rooted vegetation. Gee et al. concluded that under normal vegetated conditions in fine solls, recharge may be near zero. Fayer and Walters (1995) provide recharge infiltration estimates likely to be representative of a broad range of conditions that may be encountered at numerous locations at the Hanford Site. The estimates provided by Fayer and Walters (1995) may not be representative of local burial ground areas in the 200 East Area because some retired burial grounds have been vegetated. Nevertheless, recharge has a direct impact on PA analyses. Because of this variability in actual infiltration rates, a range of averaged rates is considered in this analysis as a function of assumed conditions (Section 3.2.3.3).

One other phenomenon, climatological change, is worth noting in connection with potential variability in recharge rate. A detailed discussion of past and potential changes in climate is found in Appendix B of the PA analysis for the disposal of LLW resulting from double-shell tank remediation at the Hanford Site (Kincaid et al. 1995). The evidence of past precipitation has been inferred from pollen and tree ring studies, which indicate periods where precipitation was -30 percent more than currently. This inferred increase does not necessarily mean that recharge is proportionately increased because vegetation types and associated evapotranspiration rates will also respond to shifts in weather patterns caused by glaciation processes. Another glaciation event is predicted to occur in 50,000 to 100,000 years. Quantitative predictions of changes in recharge caused by glaciation are very uncertain and were not provided. However, there is no indication that drastic changes in recharge should occur until full glaciation occurs. It is concluded that the record over the past 10,000 years is sufficient to presume that the present range of assumed values is reasonable for long-term future calculations.

The processes of flooding, tornados, and high winds are not evaluated in the PA analysis. A potential consequence of these events (erosion of a disposal facility cover) is also not considered in this analysis. The closest likely source of flooding in the vicinity of the 200 East Area LLBG would occur in the Cold Creek area (Figure 2-9), which is normally an ephemeral stream. The projected maximum flood would not reach the 200 East Area LLBG because it is not in the Cold Creek drainage area. The other long-term source of flooding could be the reoccurrence of glaciation events. It is assumed that human activity will be sufficiently disrupted by associated climatic and geomorphic changes that dose by displacement and dispersal of waste caused by flooding is inconsequential relative to other potential health effects.

An evaluation of the historical occurrence of tornados (DOE 1987) suggests that the probability of a highly destructive event is very low 
$\left(-10^{-6}\right)$ and, therefore, does not need to be considered as a likely event. High-wind events can be expected to occur on occasion. However, it is assumed that the type of disposal facilities being considered here will be primarily underground and that soil covers can be designed to minimize the erosional effects of wind and the likelihood of airborne distribution of contamination.

\subsubsection{Erosion Effects}

The cover will be designed to limit erosion over the compliance period. Two sources of information indicate that a cover can be designed to prevent erosion over a long period of time. First, observation of the natural environment indicates that large areas of the 200 Area Plateau do not undergo long-term erosion. These areas are well vegetated with a mixture of shallow and deep-rooted plants typical of a shrub-steppe environment. They show no indications of consistent water or wind erosion. Second, an extensive research program (the Hanford Barrier Program) has been in place to develop covers for disposal facilities or waste sites that would survive over the long term. The covers contain multiple components, each with different functions (Wing 1993). The design life for a functioning cover is only 1,000 years. However, given the episodic nature of expected erosion events, the design features should be sufficient for 10,000 years as easily as 1,000 years. The primary functioning component is the top layer, which consists of a vegetated soil containing a large fine-grained component and a pea-gravel component. The vegetation consists of a mixture of naturally occurring plants. These features have been developed to combat the potential for wind and water erosion.

The general hypothesis is that under normal vegetated conditions, gradual deposition of soil is likely to occur as the vegetation traps wind-blown soil. However, periodic drought and wildfire events could temporarily kill vegetation, exposing the surface and making it more vulnerable to erosional processes. Thus, episodic erosional events could occur. A series of smallscale wind and water erosion experiments were conducted to measure erosion as a function of changes in soil and atmospheric parameters.

The wind erosion experiments are summarized in Ligotke (1993). Erosion data were derived from wind tunnel experiments. The various soil conditions studied were 100 percent soil, soil with about a 30-percent pea-gravel component, and crusted soil. Crusted soil was created by exposing the soil to cycies of moisture and drying before experimentation. The soils were subjected to winds at variable speeds for different lengths of time. Wind speeds were selected to include the occasional large-velocity gusts that have been measured at the Hanford Site. Saltation effects were also evaluated by suspending particulate matter in the wind. The primary observation was that the addition of pea gravel to soil was a very effective agent in reducing the erosion rates (by factors of -20 to 100). In addition, comparison of erosion from shorter versus longer term experiments shows that total erosion is essentially constant. This suggests that the pea gravel acts to armor the surface such that the erosion process is short-lived and finite. The formation of a soil crust was also shown to be effective in reducing erosion.

The water erosion experiments are summarized in Gilmore and Waters (1993). Erosion data were derived using rain simulators over field plots. 
Bare soil, soil/gravel mixtures, and vegetated soils were tested. The rain simulator was set up to provide high-intensity precipitation for fairly short periods (from 20 to $60 \mathrm{~min}$ ). These conditions compare with infrequent storms predicted to occur every 100 years for longer durations (up to 1 day). In all cases, runoff was created, although not before the soil was sufficiently moistened. The loss of soil was minimal. The collected sediment quantities were to be approximately translated into erosion depths, the maximum being less than $5 \mathrm{~mm}$ under bare-soil conditions with or without the gravel admixture. The presence of vegetation proved to be the most efficient means of minimizing water erosion. An interesting incidental observation is that the vegetation appeared on the test plots without any assistance from the experimenters. Because of intermittent funding, the plots were left untended for 18 months, and more than 80 percent of the area was covered by cheatgrass and other species when testing resumed.

In addition to these smaller scale tests, a prototype barrier was constructed in the 200 East Area. Instrumentation has been provided to measure the degree of erosion on a larger scale. These measurements are expected to provide additional data to support the contention that minimal erosion may occur episodically with a properly designed cover and that periods of deposition will counterbalance the erosional effects.

Interim erosion control measures are currently being implemented to keep waste covered and minimize the spread of surface contamination. These measures include placing $8 \mathrm{ft}$ of soil on top of the waste in the retired burial grounds. The soil is planted with shallow-rooted grasses. Selective herbicides are routinely applied to destroy tumbleweeds and other-deep rooted vegetation that might penetrate into the waste. Also, constructed trenches that are unused are routinely sprayed with a soil fixant.

\subsubsection{Seismicity}

The nature of seismic events at the Hanford Site and the type of disposal facility being considered indicate that the potential for enhanced release and transport is not likely. First, no evidence has been found that permanent displacement in the soil column has occurred in the 200 Areas nor is any expected because of the lack of structural rigidity in the soil column. The only evidence of displacement occurs in basalt. The normal low intensity of seismic activity makes seismic displacement unlikely, and the geologic record suggests that permanent displacement is even more unlikely. Second, no large rigid features, such as vaults or large waste monoliths, are planned for the LLW disposal facilities. These structures would be most susceptible to displacement. Relatively 'small stabilized waste materials such as grouted drums and boxes will be surrounded by loose soils, which are expected to absorb the displacement energy in the unlikely event of such an occurrence.

\subsubsection{Geology and Hydrology}

For any geohydrological site, the conditions are sufficiently complex that completion of a mass transport modeling analysis can only be accomplished by assuming simplified representations of the real system. In the analysis, the major stratigraphic units are assumed to be present underneath the 
disposal facility, each having its own distinct hydrologic properties. Preferential vertical pathways were not considered in the base-case analysis, but sensitivity analyses were completed to evaluate the possible effect of features occurring in the area that could be potential pathways. Further discussion of geohydrologic parameters is provided in Section 3.2.4.3.

\subsubsection{Soil Column Geochemistry}

Chemical properties of the soil column are not direct inputs into the computer modeling of the groundwater transport analysis. Rather, these characteristics are used to identify the appropriate sorption characteristics for radionuclides of interest. Selection of $\mathrm{Kd}$ values (the distribution of an isotope between soil and water in units of $\mathrm{ml} / \mathrm{g}$ ) are provided in Section 3.2.4.3. For numerous radionuclides, Kd measurements have been collected in Hanford site soil in the presence of typical groundwater. The average density and moisture content values are also used to define the appropriate retardation values that are inputs to the computer model. The retardation values used in the model quantify contaminant travel times in the soil column relative to groundwater travel times.

Solubility-limiting reactions involving radionuclides depend on the local geochemical environment and may occur in the waste material and the soil column. However, relatively few radionuclides are potentially present in sufficient quantity to leach from waste above solubility-limiting concentrations. Solubility effects on radionuclide flux and groundwater contamination should only be significant in the waste volume itself because large amounts of native soil will be present in the disposal facility. Consequently, geochemical conditions affecting solubility will be controlled by the same soil-groundwater reactions in the facility and the soil column.

Because radionuclide release and flux are initiated in the facility, additional precipitation reactions are not expected to occur in the soil column. Uranium is the only isotope that is expected to precipitate. For uranium, the one case where geochemical conditions other than those imposed by soil-water reactions are expected to control solubility, a Portland cementwater control system will be used to reduce uranium solubility relative to soil-water conditions. This measure will prevent soil-water solubility reactions from occurring in the soil column.

\subsubsection{Other Disposal Facility and Environmental Characteristics}

The existing radiation background results from past practices and worldwide nuclear testing events. Because DOE Order 5820.2A (DOE 1988a) is focused on the consequences of future waste disposal, it is not required explicitly that the existing radiation background be added to the predicted radiation exposure from a facility containing newly generated waste.

Evaluation of 1 and use around the disposal site in the PA analysis is considered in terms of the potential effect such use might have on the performance of the facility and the dose that might be received via exposure pathways from the disposal facility. Other facilities in the immediate vicinity of the 200 East Area LLBG are processing facilities; liquid waste 
tanks; cribs; B pond, a liquid discharge facility. These facilities will not be operational during the postclosure period and other waste disposal facilities will not influence the performance of the 200 East Area LLBG. The $B$ pond facility is currently operational and exerts a considerable influence on groundwater flow patterns underneath the 200 East Area LLBG. However, the facility will be shut down well before the postclosure period and its influence on groundwater movement will end. A Low Activity Waste (LAW) facility south of the 200 East Area LLBG is planned for disposing the low activity fraction of double-shell tank waste. Some residual wastes in the tanks (primarily B, BX, and BY tank farms) and cribs may be present adjacent to the LLBG after remediation. Potential contaminant plumes from these waste sites could interact with potential LLBG contaminant plumes to create a more highty contaminated aquifer. This potential for multiple source contamination will be considered in a composite analysis that considers potential dose effects at a future disposal site boundary. DOE has issued guidance (DOE 1996) for completing this analysis.

The prevalent use of well water in the areas surrounding the Hanford Site for drinking and irrigation requires that well drilling and water use be considered as a primary means of exposure. The assumption of well drilling is used in the development of inadvertent-intruder scenarios and al1-pathways scenarios. Large-scale commercial irrigation on site is not currently considered to be a realistic scenario (see Section 4.3 for additional discussion).

\subsection{LOW-LEVEL WASTE CHARACTERISTICS}

This section provides a brief general discussion of the waste disposed of over time in the 200 East Area LLBG and its characteristics. This discussion will place the characteristics of the current and projected waste inventory into perspective. A more detailed discussion of the waste discharged since September 26, 1988, follows. The total current inventory estimates, waste characteristics of primary generators, and projected inventory estimates also are discussed. Current and projected generators are divided into the Hanford Site generators and the U.S. Navy generators because the waste types are significantly different and the burial grounds are segregated (i.e., the reactor compartments are disposed of in a dedicated trench).

\subsubsection{Characteristics of Historical Waste}

LLW has been disposed of in the 200 East Area LLBG since nuclear materials production and processing at the Hanford Site began. Initial primary generators of waste disposed of in the 200 East Area LLBG were the 200 East Area processing facilities, PUREX, B Plant, and tank farm operations, with the exception of the U.S. Navy. Waste generated off site has not been disposed in the 200 East Area LLBG. Typical waste types included clothing, plastics, construction materials, filters, and failed equipment. An important feature of the burial grounds was easy access to these facilities to minimize the time required to transport and dispose of high-radiation-emitting waste, thereby limiting worker exposure to dose to the extent possible. 
WHC-SD-WM-TI-730, REV 0

In recent years, the amount of such waste and the radionuclide concentrations in the waste have decreased significantly, although these generators continue to be the primary Hanford Site generators for the 200 East Area LLBG. Less than 4 percent of the total waste volume currently in the 200 East Area LLBG and less than 0.05 percent of the total beta/gamma activity was disposed of after September 26, 1988. Only two of nine burial grounds remain active in the 200 East Area (218-E-10 and 218-E-12B). Within these burial grounds, only five trenches have been used to dispose of Hanford Sitegenerated waste, one in $218-E-10$ and four in 218-E-12B. The types of waste materials have not changed significantly. This trend is expected to continue for these generators in the future and relatively small waste volumes are projected for disposal.

The primary generator of waste in the 200 East Area LLBG is now the U.S. Navy. The waste stream consists of defueled nuclear reactor compartments removed from decommissioned nuclear-powered vessels. One large trench, Trench 94 in 218-E-12B, has been dedicated to the disposal of these compartments.

\subsubsection{Characteristics of Hanford Site-Generated Waste}

Radionuclide inventory information for these waste types consists of total mixed fission product (MFP) curie estimates based on external radiation readings of waste packages and smear sample analysis for high-energy beta/gamma emitters that make up the majority of the activity in the waste. These isotopes and the total beta/gamma activity in the Hanford Site-generated waste are summarized in Table 2-1. The data are taken from the Sol id Waste Information Tracking System (SWITS), which uses individual waste package burial records as inventory sources. Also, since September 26, 1988, one 55-gallon drum containing uranium scrap metal was received from a Pacific Northwest National Laboratory (PNNL) laboratory.

The inventories disposed of by each generator are provided in Table 2-2. The isotopic mixtures for each major generator vary because of the facility's function. The primary function of PUREX has been to dissolve fuel and separate plutonium. The waste isotopic mix reflects the relative concentrations of new fue? as shown by the high fractions of ${ }^{144} \mathrm{Ce}$ and ${ }^{106} \mathrm{Ru}$. This is expected because PUREX processed newly generated fuel from $N$ reactor from 1982 through 1989 . Calculating ${ }^{144} \mathrm{Ce}$ and ${ }^{106} \mathrm{Ru}$ ratios with total beta/gamma activities and comparing them with the generalized mixed fission product profile over time shown in Appendix $B$ indicates that the waste has the isotopic signature of two-. to three-year-old fuel.

At B Plant, cesium and strontium were separated from dissolved fuel and high-level waste received from PUREX and tank farms. The predominance of the ${ }^{137} \mathrm{Cs}$ and ${ }^{90} \mathrm{Sr}$ isotopes in the isotopic mixture reflects this process. Tank farms have received wastes from many sources over time and liquid wastes have frequently been mixed. Therefore, the isotopic signature varies. Similarly, the other sources of waste (cribs, ponds and ditches, and derivative burial ground waste from other sources) display a variety of reported isotopic mixtures. 
Inventories for an additional set of radionuclides are also provided in Table 2-2. These radionuclides are known to be mobile in the geohydrologic environment and potential contributors to groundwater contamination. Normal MFP ratios indicate that these radionuclides are a small fraction of the total beta/gamma activity. Many wastes contain these isotopes near or below detection limits and concentration/inventory estimates must rely on process knowledge.

To estimate their inventories in the disposed-of waste, the generalized fraction of each radionuclide to the total beta/gamma activity, as calculated from the fuel production estimates (Table B-1 in Appendix B), was considered. To be conservative, the highest estimated fractions were used. These fractional values occur in the most decayed fuels and level off to nearly constant values as the isotopes with short half lives decay to insignificant activity. Further conservatism in the inventory estimates is expected because of the waste generated by separation of ${ }^{137} \mathrm{Cs}$ and ${ }^{90} \mathrm{Sr}$ in B Plant. We expect that the relative fractions of the minor constituent isotopes are reduced in the separation process, but cannot determine the degree of reduction.

Small inventories of transuranic isotopes are expected to occur in these wastes as we11. Generator information for these radionuclides is limited, but based on internal correspondence with the waste acceptance group or published documentation, the primary isotope present is ${ }^{24} \mathrm{Pu}$ with lesser amounts of ${ }^{239} \mathrm{Pu},{ }^{240} \mathrm{Pu}$, and ${ }^{241} \mathrm{Am}$. The ${ }^{239} \mathrm{Pu} /{ }^{240} \mathrm{Pu}$ and ${ }^{241} \mathrm{Am}$ inventory are expected to be about $10 \%$ and $0.1 \%$ of the ${ }^{241} \mathrm{Pu}$ inventory.

B Plant generators estimate that the plutonium isotope concentrations do not exceed $1 \%$ of the Category 1 limits in Table 4-18. For example, the ${ }^{241} \mathrm{Pu}$ limit is $6.1 \times 10^{-2} \mathrm{Ci} / \mathrm{m}^{3}$. The product of $1 \%$ of this 1 imit and the disposed B Plant volume $\left(892 \mathrm{~m}^{3}\right)$ yields a maximum ${ }^{241} \mathrm{Pu}$ inventory estimate of $0,54 \mathrm{Ci}$ of ${ }^{241} \mathrm{Pu}$. PUREX generators (Ellis and LeBaron 1995) indicate a ${ }^{241} \mathrm{Pu}$ to ${ }^{137} \mathrm{Cs}$ ratio of about 0.4 and Tank Farm Operations identify a ${ }^{241} \mathrm{Pu}$ to ${ }^{137} \mathrm{Cs}$ ratio of about 1.7. The approximated inventories of ${ }^{241} \mathrm{Pu},{ }^{239} \mathrm{Pu} /{ }^{240} \mathrm{Pu}$ and ${ }^{241} \mathrm{Am}$ from al1 three sources is about $16,1.6$, and $0.016 \mathrm{Ci}$, respectively.

In addition to the inventories of waste, the concentrations of radionuclides in individual waste packages were evaluated. The majority of waste packages were 55 -gallon $\left(0.21-\mathrm{m}^{3}\right)$ drums or smaller packages. Table 2-3 shows the distribution of packages containing discrete concentrations of total beta/gamma activity. Because most other radionuclides known or estimated in the waste inventory are considered to be proportional to the total beta/gamma activity, the relative distribution shown is representative for these radionuclides as well. Of interest is the distribution of the higher concentration packages. B Plant waste is characterized by a small number of large $\left(>35 \mathrm{~m}^{3}\right)$ higher concentration waste packages that were disposed of in the 218-E10 Burial Ground and a large group of small waste packages (e.g., 55-gallon- $\left[0.21-\mathrm{m}^{3}\right]$-drum size or less) of lower concentration. Waste packages from other generators show an almost normal distrjbution with the average and median values in the range of 0.01 to $0.1 \mathrm{Ci} / \mathrm{m}^{3}$.

For purposes of dose calculations for a final projected inventory of Hanford Site-generated waste, the future waste inventory was assumed to maintain the same average radionuclide characteristics and concentration profile. This approach may or may not accurately forecast future waste and 
must be considered highly uncertain. However, at least a qualitative evaluation of potential dose effects can be made in this analysis. Annual updates of waste inventory in the active LLBG and the associated dose estimates per the methodology developed in this document will be provided as part of the PA maintenance program. In this way, compliance with the performance objectives can be routinely provided.

It is also assumed that no mixed waste other than reactor compartment waste will be disposed of in the 200 East Area LLBG. Reactor compartment waste is designated as mixed because of small amounts of PCBs present in the compartment and their disposal has been approved by Ecology. Two mixed waste facilities are available in the 200 West Area LLBG and will be exhausted before developing additional mixed waste facilities is considered. If mixed waste disposal in the 200 East Area LLBG becomes a realistic expectation, updates of the PA analyses will include an evaluation of such facilities and the associated waste streams.

To estimate total waste inventory in the 200 East Area LLBG, the current inventory (Table 2-1) and the projected inventory (Valero et al. 1996) were summed. To estimate the projected inventory, the product of the average beta/gamma activity to current volume ratio and the projected volume for each of the major generators were calculated (Table 2-4). The projected volumes over a life-cycle forecast period for B Plant, PUREX, and tank farm operations are 90,760 , and $9,640 \mathrm{~m}^{3}$, respectively. The average total beta/gamma activity ratios for the current inventory are $2.2,0.05$, and $0.1 \mathrm{Ci} / \mathrm{m}^{3}$ for $B$ Plant, PUREX, and tank farms, respectively.

\subsubsection{Characteristics of Reactor Compartment Wastes}

The primary generator of waste in the active 200 East Area LLBG is the U.S. Navy. Defueled reactor compartments are being generated as waste by a nuclear-powered vessel decommissioning program. Currently, 55 compartments out of a proposed waste stream of 220 compartments have been disposed of in Trench 94 in the 218-E-12B burial ground. The initial estimate of compartments to be buried was 120 . However, an additional 100 compartments are being proposed for disposal and are the subject of an environmental impact statement (EIS) (U.S. Department of the Navy 1996). Excerpts from the EIS that describe the physical and radionuclide characteristics of this waste stream are provided in Appendix B. The general waste description in the EIS applies to all reactor compartments and is summarized below.

A schematic of the reactor compartment is shown in Figure 2-11. Radioactivity within the reactor compartment is primarily in the form of corrosion-resistant activated metals that make up the internal structure of the reactor pressure vessel. These metals are therefore doubly contained by the reactor vessel walls and the thick steel exterior structure of the reactor compartments. The Navy estimates that more than 99.9 percent of the inventory is found in these metals. Because of the highly corrosion resistant nature of the activated metals, the quantity of corrosion products is minimal (conservatively estimated to be $<0.1$ percent of the contained waste). Therefore, $<0.1$ percent of the inventory is estimated to be present in these corrosion products. 
The reported and estimated radionuclide inventories for this waste stream are summarized in Table 2-5. To estimate the total waste inventory, the compartments were separated into two groups: the initial 120 compartments and the additional 100 compartments that are the subject of the EIS. Table 2-5 provides the current inventory from compartments already disposed of. The total inventory for the 120 compartments is extrapolated from the current inventory, assuming proportional increases in inventory. The second group inventory estimate for high activity and mobile radionuclides is taken from the EIS information reproduced in Appendix B. Finally, the total inventory is estimated by summing the two groups.

\subsection{TREATMENT OF WASTE CHARACTERISTICS IN THE PERFORMANCE ASSESSMENT ANALYSIS}

A standard approach in PA analys is is to develop a specific waste inventory where particular waste isotopes are assumed to be present in the disposal facility at specific concentrations or total quantities. The analysis is completed to estimate the potential dose from the entire inventory (i.e., the summation of doses from each isotope present in the disposal facility). The estimate is then compared with the performance dose objectives (i.e., intruder scenario and all-pathway scenario). If the estimated dose is less than the performance objective dose, the facility performance is considered adequate. If the inventory assumption is changed and all other parameters remain constant, a different potential dose will be calculated. The PA methodology used in this document has been developed to provide this comparison.

The actual inventory that will be disposed of in the 200 East Area LLBG is highly uncertain, with the possible exception of the reactor compartment waste stream. Currently, Hanford Site-generated waste is disposed of infrequently in the $218-\mathrm{E}-10$ and $218-\mathrm{E}-12 \mathrm{~B}$ burial grounds. This trend is expected to continue because efforts are being made to consolidate waste disposal in the 200 West Area LLBG. Also, the actual volumes of waste that will be disposed of in the 200 East Area LLBG depend on waste management decisions for burial ground use. To ensure that waste will be accepted that satisfies the performance objectives of DOE Order 5820.2A (D0E 1988a), the PA methodology was adapted to develop WAC to be applied to future wastes received and disposed of in the 200 East Area LLBG.

In the analyses discussed in Chapter 3.0, either unit concentrations or quantities of radionuclides were assumed, depending on the type of analysis. Groups of radionuclides were sorted by chemical property (e.g., a set of radionuclides will be assumed to have the same sorption coefficient value). The analyses were completed for a limited number of characteristic properties (e.g., three different Kd values). The predicted dose under these conditions was then determined and compared with the appropriate performance objective dose 1 imit. Depending on the type of radionuclide release scenario, the dose for any given radionuclide is proportional to the radionuclide concentration or inventory if all other parameter values are held constant. Given the estimated dose for unit concentration or quantity, the dose for any other concentration or quantity can be calculated by ratio. 
This approach has two advantages that are considered necessary for this analysis. First, inventory limits can be calculated for any set of radionuciides. Thus, for a waste stream containing a radionuclide that is infrequently encountered, an estimate of the acceptability of that waste stream for disposal can be determined by comparing the acceptable inventory with the actual inventory. Second, different sets of inventory limits can be calculated for various combinations of environmental and disposal conditions, some of which provide greater isolation capability than others. Thus, a means of disposing of a range of waste inventory concentrations and/or quantities is provided.

For most of the waste streams in this analysis, the radionuclide inventory is assumed to be spread homogeneously throughout the waste material. Also, based on the results of the 200 West Area LLBG PA (Wood et a1. 1995a), consideration of waste material properties or waste form performance appears to be appropriate for only two waste streams. The first is the activated metal in the naval reactor compartments. The metal properties provides a significant reduction in radionuclide release rates relative to other waste materials (e.g., cloth, rubber, wood). The second is uranium-bearing waste, which may require the chemical buffering of leaching water provided by an encapsulating Portland cement-based matrix.

Finally, the reactor compartment waste is also considered independently because the radionuclide activity is doubly contained by reactor pressure vessel walls and the exterior structure of the reactor compartment. Although no credit is taken for the reduction in dose that might be achieved as a result of the time needed to corrode through the encapsulating metal before waste leaching begins, we do assume that the delay time is sufficient to separate the potential groundwater contaminant plumes from the reactior compartment waste and the contiguous Hanford Site-generated waste. In the EIS (U.S. Department of the Navy 1996), the U.S. Navy estimates that at least 600 years must pass for corrosion to breach the exterior structure of the reactor compartment and that 10,000 years will elapse before corrosion breaks through the reactor vessel walls.

\subsection{WASTE TREATMENT, CERTIFICATION, AND DISPOSAL}

This section provides a brief review of waste management practices at the Hanford Site. Current practices and proposed modifications are discussed. The iterative interaction between PA analysis recommendations and disposal practice modifications are also provided.

\subsubsection{Waste Treatment and Certification}

Currently, the Hanford Site has no waste treatment facilities for solid LLW. An off site contract is in place with ATG, Inc. to provide volume reduction. The Waste Receiving and Processing (WRAP) Facility is not scheduled for operation until 1997. The facility is split into several modules and will provide treatment for some LLW streams in addition to handling TRU waste. The current plan is to provide a grouting or polymer cement encapsulation or solidification capability for appropriate wastes. need for further types of treatment depends partly on the decisions about 
necessary treatment based on PA analysis and the types of wastes that are ultimately accepted for disposal. For example, one alternative is in situ grouting at the disposal facility rather than treatment in a facility. The generator may also provide waste stabilization.

Radioactive waste certification at the Hanford Site is based primarily on two manuals: WHC-EP-0063, Hanford Site Solid Waste Acceptance Criteria (WHC 1993) and WHC-EP-0846-0, Waste Specification System (WHC 1995b). These manuals require all radioactive waste generators to prepare a Waste Certification Summary (e.g., descriptions of radionuclide inventories and chemical and physical properties) for each waste stream. These summaries document how the radionuclide inventory, and chemical and physical properties of waste are characterized, packaged, and documented. The summaries are reviewed by WHC staff to ensure that the waste is acceptable for receipt at the Hanford Site disposal facilities. Waste shipping papers are reviewed by WHC staff before the waste is shipped and the waste is verified to match the summaries and the shipping papers when it is received on site.

\subsubsection{Low-Level Waste Disposal Practices and Facility Description}

Shallow land disposal of solid waste has occurred at the Hanford Site since the late $1940^{\prime} \mathrm{s}$. Initially, numerous areas near processing facilities were chosen as disposal sites. Before 1970, no distinction was made between TRU and low-level waste. At that time, the Atomic Energy Commission (AEC) required that TRU waste be retrievable stored. Types of underground retrievable storage included shallow trenches, concrete 1 ined " $V$ " trenches and asphalt pads. The segregated LLW continues to be disposed.

In the early 1980's, low-level liquid organic waste was segregated from LLW and stored retrievable underground. Low-level waste was further categorized in 1987 when the concept of mixed waste was established with mixed waste being defined as waste containing both radioactive and hazardous chemicals as identified by the EPA. Mixed waste disposal in unl ined trenches has been discontinued except for the reactor compartments. Storage of nonremote-handled mixed waste in above-ground buildings in the Central Waste Complex is the current practice.

The 200 East Area LLBGs are shown in Figure 2-10. Disposal has occurred for several decades and as one burial ground became full other burial grounds were started. Several of the burial grounds are retired. These include $218-E-1,218-E-2,218-E-4,218-E-5,218-E-5 A, 218-E-8$, and 218-E-12A. Disposal of waste did not occur in 218-E-2A and $218-E-9$. The on ly remaining active burial grounds in the 200 East Area LLBG are 218-E-10 and 218-E-12B (Figures 2-12 and 2-13, respectively). Generally speaking, these burial grounds have been used sporadically since September 26, 1988. The burial grounds consist of multiple trenches that are, for the most part, oriented in parallel with the long axis in the north-south direction and the short axis in the east-west direction. One exception is Trench 94, which is oriented with the long axis east-west and the short axis north-south. Currently, only two trenches (Trenches 9 and 14) in 218-E-10 are constructed with available space. In 218-E-12B, only five besides Trench 94 are usable. These are Trenches 32 , $36,38,42,48$ and 53 . 
Only Trench 9 has been used in the 218-E-10 Burial Ground and only Trenches $32,38,42,48,53$ and 94 have been used in the 218-E-12B Burial Ground. These active trenches are shown in Figures 2-14, 2-15, and 2-16. of these, only Trench 94 is used routinely. Figures 2-12 and 2-13 show large areas of available space for waste disposal and plans have been developed for their eventual use.

The routine method of disposal for Hanford Site-generated $L L W$ in the 200 East Area LLBG is to place waste in an unlined trench about 6 to $7 \mathrm{~m}$ deep that vary in length to about $500 \mathrm{~m}$. The trenches are typically either flatbottomed (about $8 \mathrm{~m}$ wide) or $V$-shaped (about $3 \mathrm{~m}$ wide) and have side slopes of approximately $45^{\circ}$. Waste is usually packaged in carbon steel 55-gat drums or wooden boxes and placed in the trench. Packages may be stacked up to within about $2.5 \mathrm{~m}$ of the surface. Soil is then placed over the packages up to grade. Some retired trenches have been planted with cheatgrass to stabilize the soil cover. Active trench covers are kept free of vegetation through the use of herbicides to reduce the growth of radioactive vegetation, primarily tumbleweed.

Disposal of the reactor compartments is restricted to Trench 94 in 218-E12B. Because of the larger size of the reactor compartments (about 9 to $13 \mathrm{~m}$ [29.5 to $42.7 \mathrm{ft}$ ] in diameter and 11 to $17 \mathrm{~m}[36.1$ to $55.8 \mathrm{ft}$ ] 1ong), Trench 94 was excavated to a depth of about $15 \mathrm{~m}(50 \mathrm{ft})$. The compartments are placed on pedestals and left uncovered. Typically, three or four compartments are placed in the trench annually.

In response to ongoing $P A$ analytical results and precedents set by the Nuclear Regulatory Commission (NRC) in 10 CFR 61 for disposal of commercial LLW, a disposal practice has been established to dispose of stabilized Category 3 waste (Wood et a1. 1995a) either in high-integrity containers (HICS), which are generally concrete cylinders or stabilized waste forms. The higher inventory waste is labeled as Category 3 waste and has inventory limits established by the intruder scenario analyses completed in this document.

\subsubsection{Planned Modifications to Current Low-Level Waste Disposal Practices}

RCRA legislation and DOE Order 5820.2A both affect the current disposal practice for LLW. The 200 East Area LLBGs are part of the disposal area that will ultimately reach a state of closure that is consistent with RCRA regulations. Adding a protective cover over the burial trenches is the most likely change in disposal.practices that will be adopted to satisfy the regulations. Typically, a cover is a multilayer barrier that restricts the flow of precipitation through the waste volume. A secondary requirement may be to stabilize underlying waste in situ to prevent subsidence of the cover.

Additional modifications to disposal practices may be required to satisfy performance objectives found in DOE Order 5820.2A. Specific disposal methods are not provided in the order. Rather, it must be shown that whatever method is used to dispose of LLW, the performance objectives will be satisfied with reasonable assurance. Necessary changes in disposal practices are identified by the PA analysis, which is structured to examine the performance of a given facility design and determine the relative effectiveness of the chief 
components of the system. If the performance is predicted to be inadequate for a given facility, design changes are recommended and the new conditions are analyzed. This process is continued until a particular facility design is predicted to be adequate. The following section describes the initial basecase conditions for LLW disposal facilities that were evaluated in this analysis.

\subsection{TREATMENT OF DISPOSAL FACILITY FEATURES IN THE PERFORMANCE ASSESSMENT ANALYSIS}

The aspects of the disposal facility that need to be considered in the PA analysis include the physical dimensions of the facility and the characteristics of the facility that influence contaminant release and subsequent dose to humans. Treatment of these characteristics is discussed in Chapter 3.0. Relevant characteristics differ depending on the consideration of intruder versus groundwater-pathway scenarios. Parameter values for a given characteristic also may differ, depending on the type of facility being considered.

Figures 2-12 and 2-13 show several features that make exactly replicating the burial ground and waste configuration in the modeling simulations impractical. First, a variety of waste types are stored or disposed of in these facilities including TRU, mixed TRU, mixed LLW, and LLW. Similarly, LLW volumes disposed of before and after September 27, 1988, are commingled. The waste is not segregated spatially by type and intermittent open space is potentially available for use. Second, although one configuration for future trenches is indicated in the figures, others are possible.

Given these uncertainties, we adapted the simplified two-step approach used for the 200 West Area LLBG (Wood et al. 1995a) to model the 200 East Area LLBG. First, for each primary burial ground area $(218-\mathrm{E}-10$ and $218 \mathrm{E}-12 \mathrm{~B}$, respectively), the individual trenches are collectively considered as one large trench with waste occupying all of the trench volume. In other words, the model represents a region containing waste and oriented along the direction of flow, not a particular physical trench. Estimates of dose and the development of waste acceptance criteria can be adjusted to various sized facilities as long as the facility dimensions are known in the directions parallel and perpendicular to the primary direction of groundwater flow. The second step of the approach was to model a smaller, representative portion of the burial ground volume and extrapolate the results to the larger facility. This approach reduces the cost and time to complete the computations and at the same time provides a reasonably conservative estimate of radionuclide release and subsequent groundwater contamination. The technical justification for this approach is discussed in Section 3.2.1.

To define the overall facility, each burial ground area was assumed to be a rectangle rather than the actual irregular shape (Figure 2-14). The lengths and widths are the maximum dimensions of these burial grounds in the east-west and north-south directions. For the $218-E-10$ burial ground area, the northsouth and east-west dimensions are assumed to be $640 \mathrm{~m}(2,100 \mathrm{ft})$ and $990 \mathrm{~m}$ $(3,250 \mathrm{ft})$, respectively. For the $218-E-12 B$ burial ground area, the northsouth and east-west dimensions are assumed to be $640 \mathrm{~m}(2,100 \mathrm{ft})$ and $890 \mathrm{~m}$ $(2,900 \mathrm{ft})$, respectively. The contribution to dose from the reactor 
compartments is considered separately using the dimensions of Trench $94[120 \mathrm{~m}$ $(400 \mathrm{ft})$ in the north-south direction and $490 \mathrm{~m}(1,600 \mathrm{ft})$ in the east-west direction].

Having determined the dimensions of the large facilities, the numerical analysis is based on a representative cross section that is oriented parallel to the primary direction of groundwater flow (east-west). The conceptual representation is shown in Figure 2-17. For normal Hanford Site-generated waste, the trench is arbitrarily assumed to be $20 \mathrm{~m}(65.6 \mathrm{ft})$ long in the direction parallel to flow and $7 \mathrm{~m}(23 \mathrm{ft})$ deep, with the bottom squared off. The width of the trench perpendicular to flow can be any length. The waste inventory is assumed to be located in the bottom $4.5 \mathrm{~m}(14.8 \mathrm{ft})$ of the trench distributed over a width of $1 \mathrm{~m}(3.3 \mathrm{ft})$ in the north-south direction. For the reactor compartment waste, the same conceptual model is used, but the dimensions are different. In this case the trench was modeled as being $15 \mathrm{~m}$ $(49.2 \mathrm{ft})$ deep with the bottom $12.5 \mathrm{~m}(41 \mathrm{ft})$ containing waste and the rest clean fill. In each case a soil layer of $2.5 \mathrm{~m}(8.2 \mathrm{ft})$ is assumed to cover the waste.

Infiltration rates through the different layers of the proposed soil covers were not treated individually. Rather, a total infiltration rate was assumed for the maximum recharge that the cover would allow and this recharge was applied to the whole model where it provides the driving force for radionuclide release into the soil column. Two different recharge values were modeled: $0.5 \mathrm{~cm} / \mathrm{yr}(0.2 \mathrm{in.} / \mathrm{yr})$ and $5.0 \mathrm{~cm} / \mathrm{yr}(2.0 \mathrm{in} . / \mathrm{yr})$. A groundwater well is assumed to exist $100 \mathrm{~m}(328 \mathrm{ft})$ downstream from the nearest waste boundary. This well serves as the right-hand boundary of the model and the control point for determining maximum concentration limits.

Radionuclide release from this representative slice of the total facility is modeled and the results are extrapolated to any larger section of the facility of interest. For advection- and diffusion-controlled release rate assumptions, distributing the waste over a longer trench either does not affect the result or reduces the dose, so modeling the trenches as only $20 \mathrm{~m}$ long is conservative. For a concentration-limited release, the dose estimate increases with length, but the relationship is treated as proportional, which is a conservative assumption (see Section 3.2.1).

One significant difference between trench orientation in the 200 West Area LLBG and the 200 East Area LLBG is that the long axes of the trenches are oriented parallel to the general flow in the 200 West Area LLBG and perpendicular in the 200 East Area LLBG. This situation prevents estimates of total dose from groundwatẹr contamination and waste acceptance criteria (WAC) for individual trenches in the 200 East Area LLBG. Total dose estimates and WAC can only be considered for the total burial ground. The only exception is the reactor compartment waste, which is considered separately in terms of dose and WAC.

In this PA analysis, two types of facilities were evaluated. One contains very low-inventory waste and the other contains higher inventory wastes up to Class C limits as defined by the NRC in 10 CFR 61. The distinguishing features of the facilities as they relate to the analysis include the following: 
- The Category 1 waste facility is covered by a sand/gravel cover with no vegetation or sparse shallow-rooted vegetation such as cheatgrass, thereby allowing maximum infiltration through the waste. The Category 3 facility is covered by a soil that supports a natural vegetation ecosystem that includes a mixture of shallow- and deeprooted vegetation. Some fine soil additives may be required to support the vegetation. This cover is meant to be equivalent to natural conditions in limiting infiltration through the waste.

- Waste is covered by a minimal thickness of cover (about $3 \mathrm{~m}$ ) in the Category 1 facility, thus allowing the maximum exhumation of waste by the inadvertent intruder. The Category 3 facility contains a minimum $5 \mathrm{~m}$ of cover to limit the exhumation of waste to drilling.

- No waste form stabilization requirements are used for waste disposal in the Category 1 facility. For the Category 3 facility, stabilization is required to support the soil cover overburden.

- Radionuclide immobilization is not required of the waste form/waste material disposed of in the Category l facility. Radionuclide immobilization may be required for some wastes in the Category 3 facility depending on the concentration of long-lived radionuclides that are mobile in the soil column.

For Category 3 waste, a combination of physical indicators and societal records is expected to exist to deter the inadvertent intruder for up to 500 years after closure. The primary physical indication of the burial ground is the soil cover with associated visible markers, which may include signs and fences. The primary societal records include legal documents that describe the location and purpose of the facility. A strong technical basis cannot be provided for determining how long an inadvertent intruder can be assumed to be deterred from exhuming waste because of the unpredictability of human activities.

The 500-year period is based on the regulatory approach adopted by the NRC to develop the intruder protection classification system in 10 CFR 61 . This approach is described in 0ztunali et al. (1981). Three levels of intruder protection for disposal facilities were envisioned that provided increasing protection and corresponding increases in assumed deterrence time. The lowest level of protection was essentially no protection and intrusion occurred immediately after active institutional control was assumed to end. The intermediate level of protection assumed covering of waste with either lower inventory waste or soil cover to a depth of $5 \mathrm{~m}(1 \mathrm{ft})$. In this case, intrusion occurred 500 years after closure. The highest level of protection assumed solidification of waste by grouting or some other means and intrusion was assumed to occur 1,000 years after closure. The underlying assumption is that the disposal facility is recognizable to the inadvertent intruder during the assumed deterrence period either by providing a distinctive cover that maintains its shape through adequate stability of the waste volume or by a recognized stabilized waste form.

In this analysis, we equate the Category 3 configuration with the intermediate level of protection. Under these conditions, the waste volume must be stabilized to the extent that the cover will maintain its shape. This 
requires that erosion control be adequate and subsidence minimal.

Section 2.2.2 covers erosion control. It was determined that simulated natural vegetation conditions would prevent chronic erosion and that a cover would remain indefinitely unless disturbed by humans. The use of concrete HICs, including backfilling between HICs with soil, stabilized waste forms, and void-space limitations in waste packages, is assumed to provide subsidence control. If it is determined during closure activities that additional void filling is required, technically feasible methods exist to enhance subsidence control (e.g., grout injection).

An operational filling plan has been completed showing specific locations for Category 1 and 3 waste (Pratt et a1. 1995). In all likelihood, when the burial grounds are finally closed, the facility will more nearly resemble a Category 3 facility. However, consideration of the Category 1 facility allows the option of using some part of the facility in this fashion. The other advantage to this approach has been the use of Category 1 conditions as an aid to sensitivity analyses. 
Figure 2-1. Map Showing Location of Hanford Site and the 200 East Area LLBG (adapted from DOE-RL 1994a).

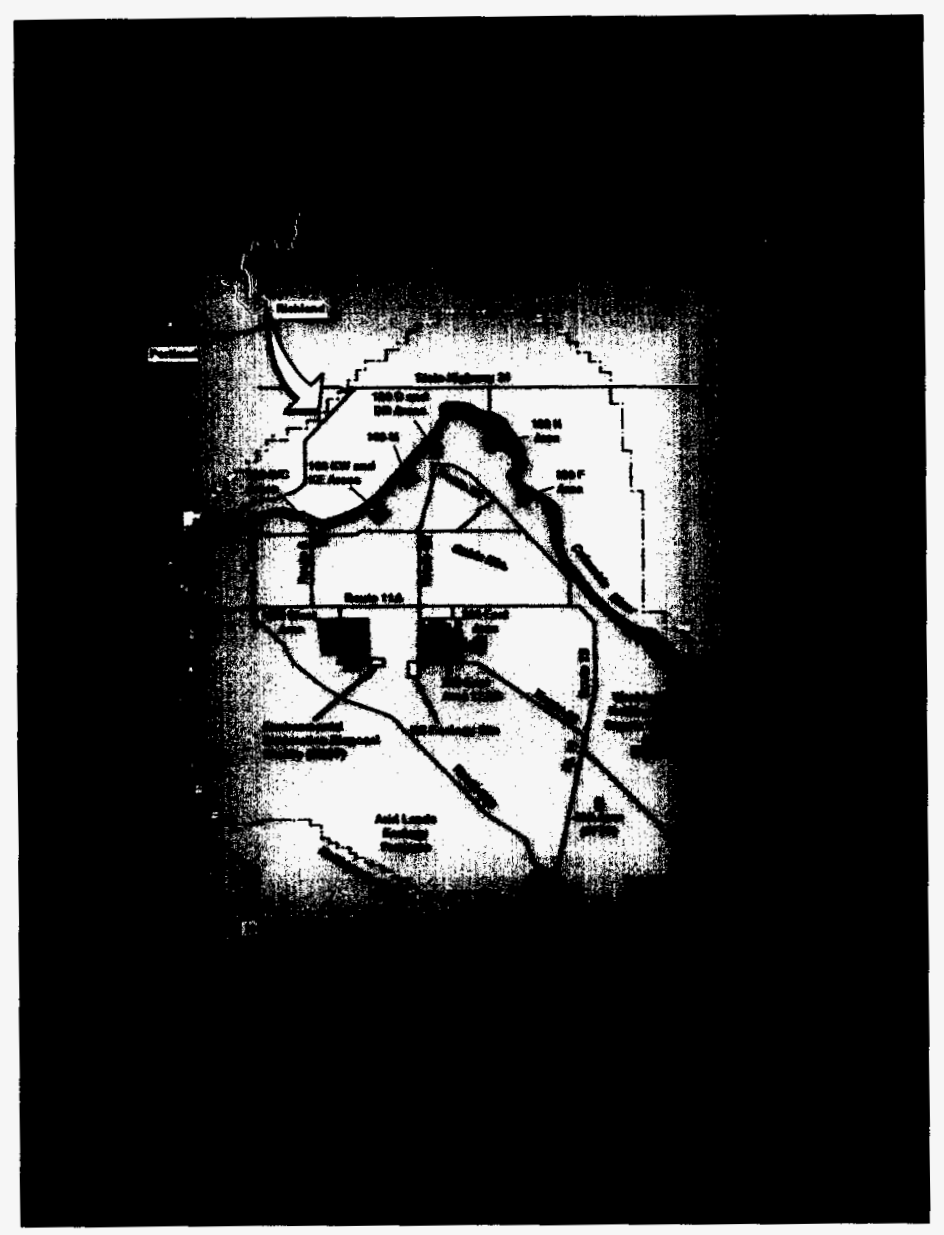


Figure 2-2. Topography of the Hanford Site (adapted from DOE 1994).

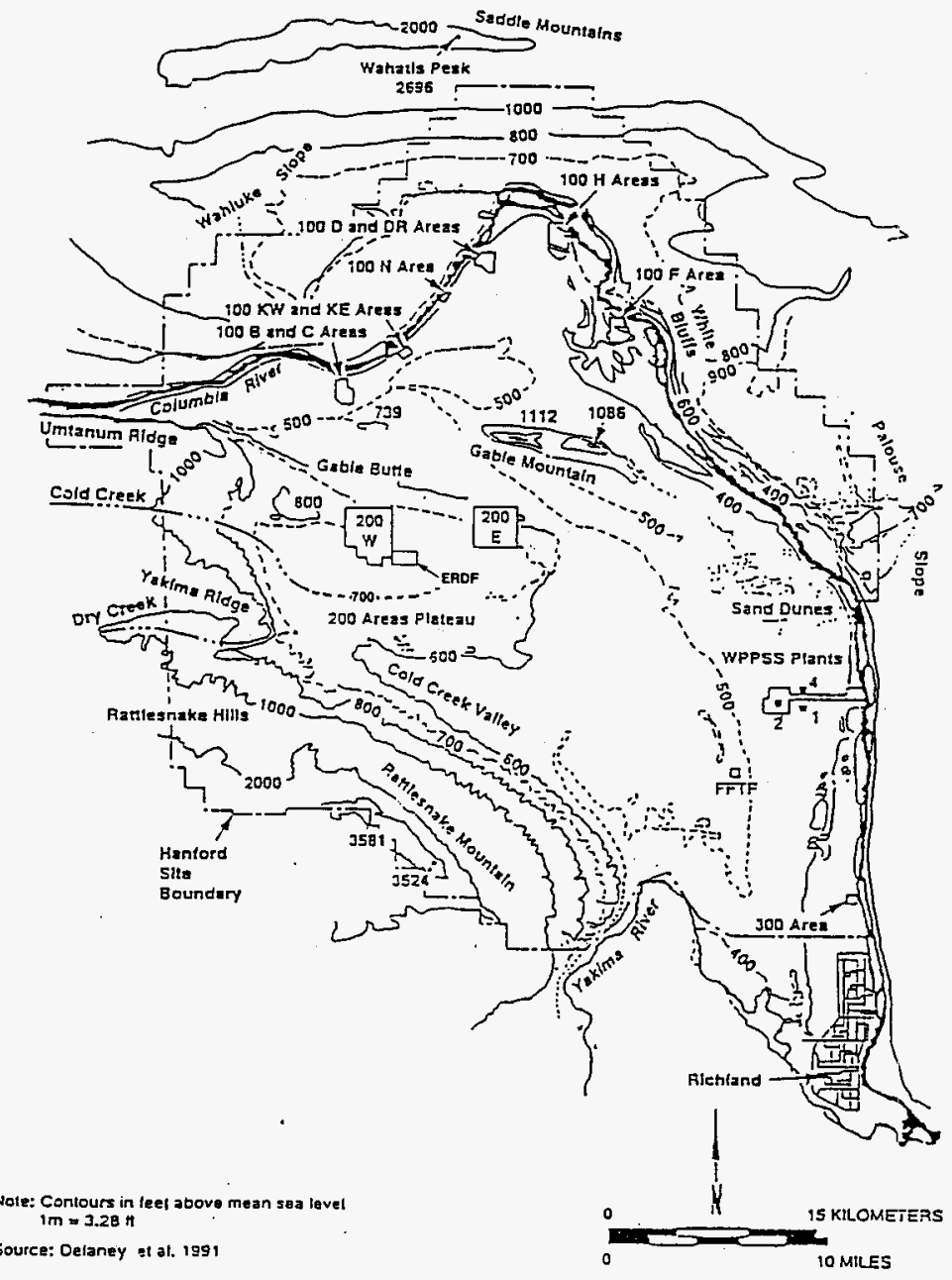


Figure 2-3. Historical Seismicity of the Columbia Plateau and Surrounding Areas (Geomatrix 1996).

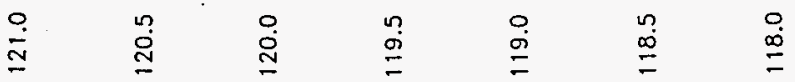

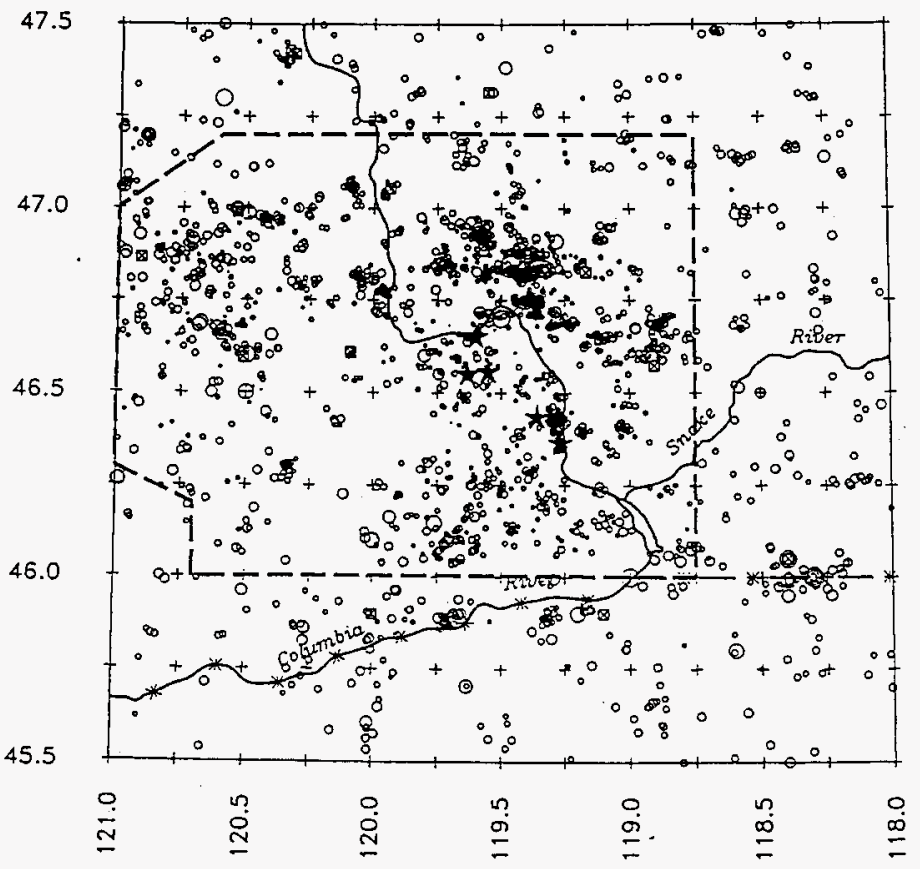

Magnitude

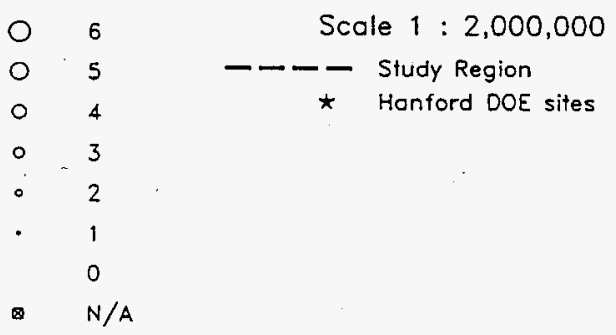


Figure 2-4. Hydrologic Basins Designated for the Washington State Portion of the Columbia Plateau (from Kincaid et al. 1993).

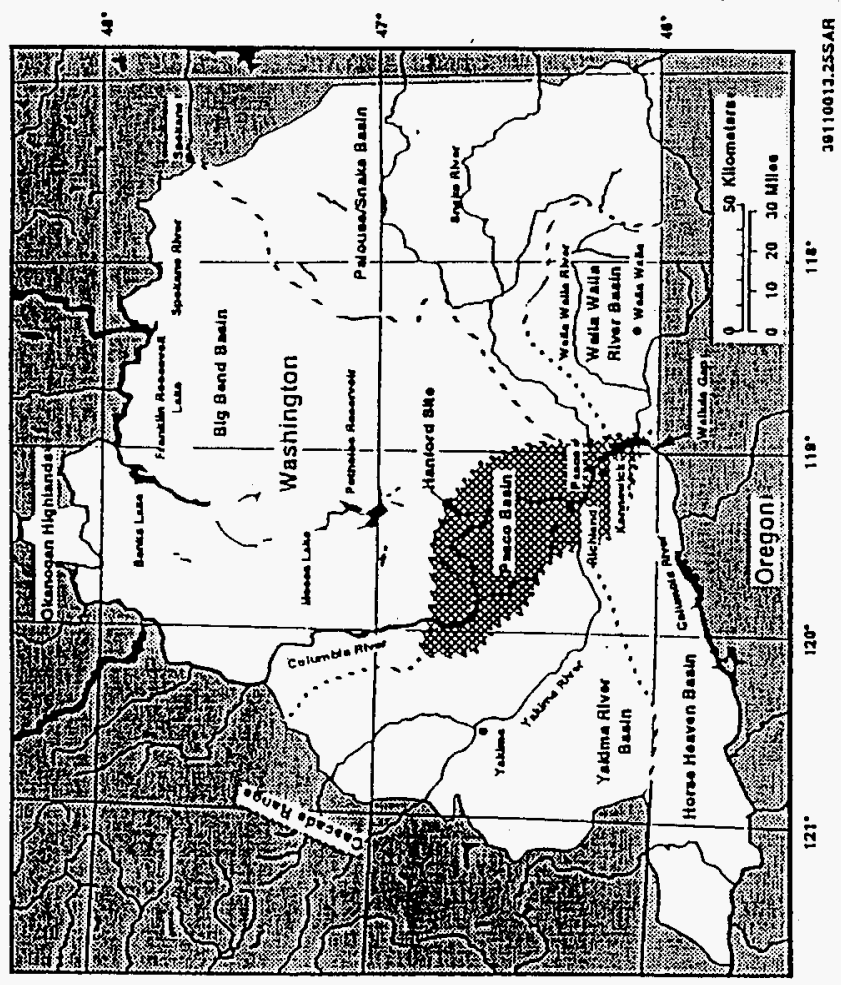


Figure 2-5. Generalized Stratigraphy of the Suprabasalt Sediments and Columbia River Basalt Group of the Hanford Site (Reidel et al. 1995).
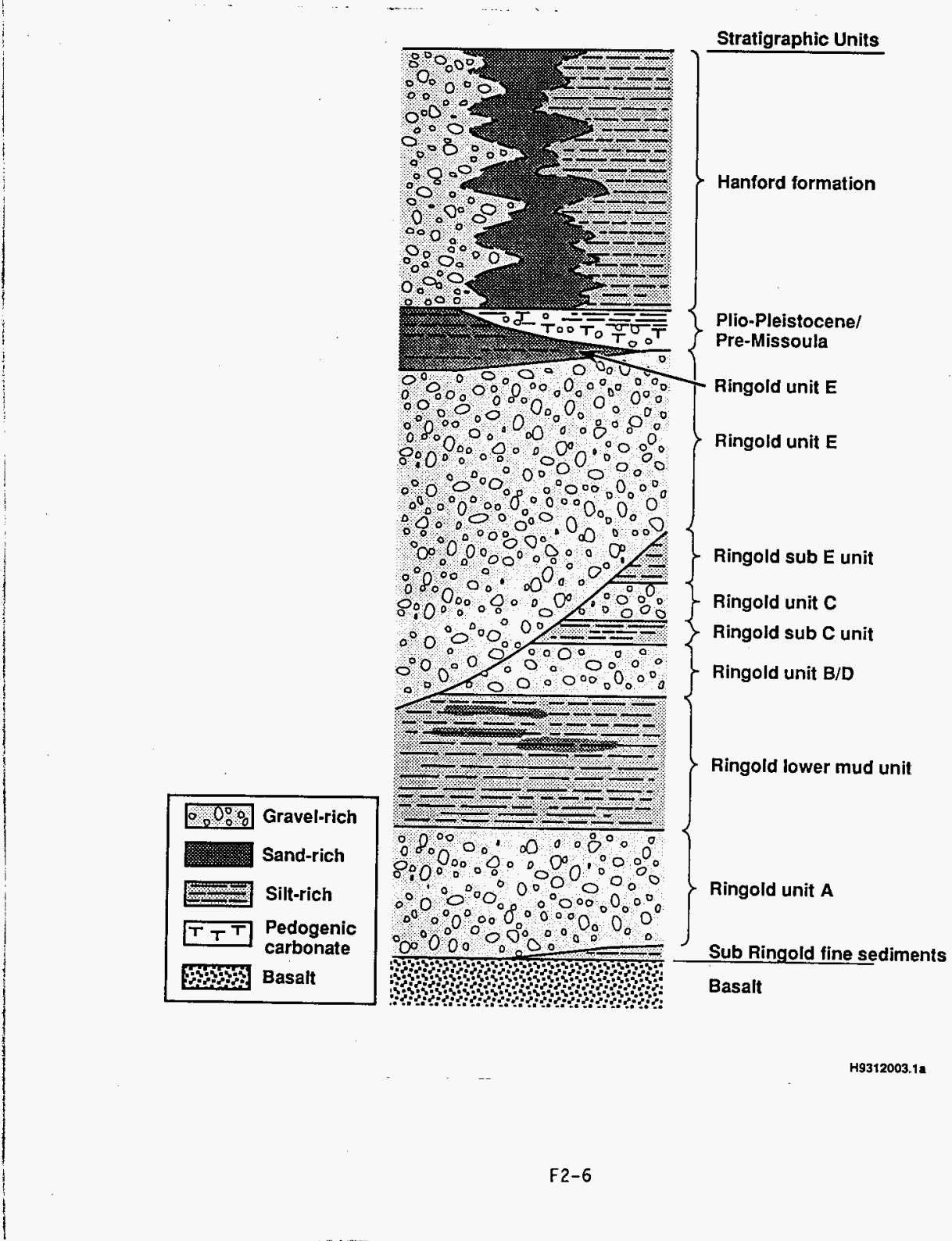


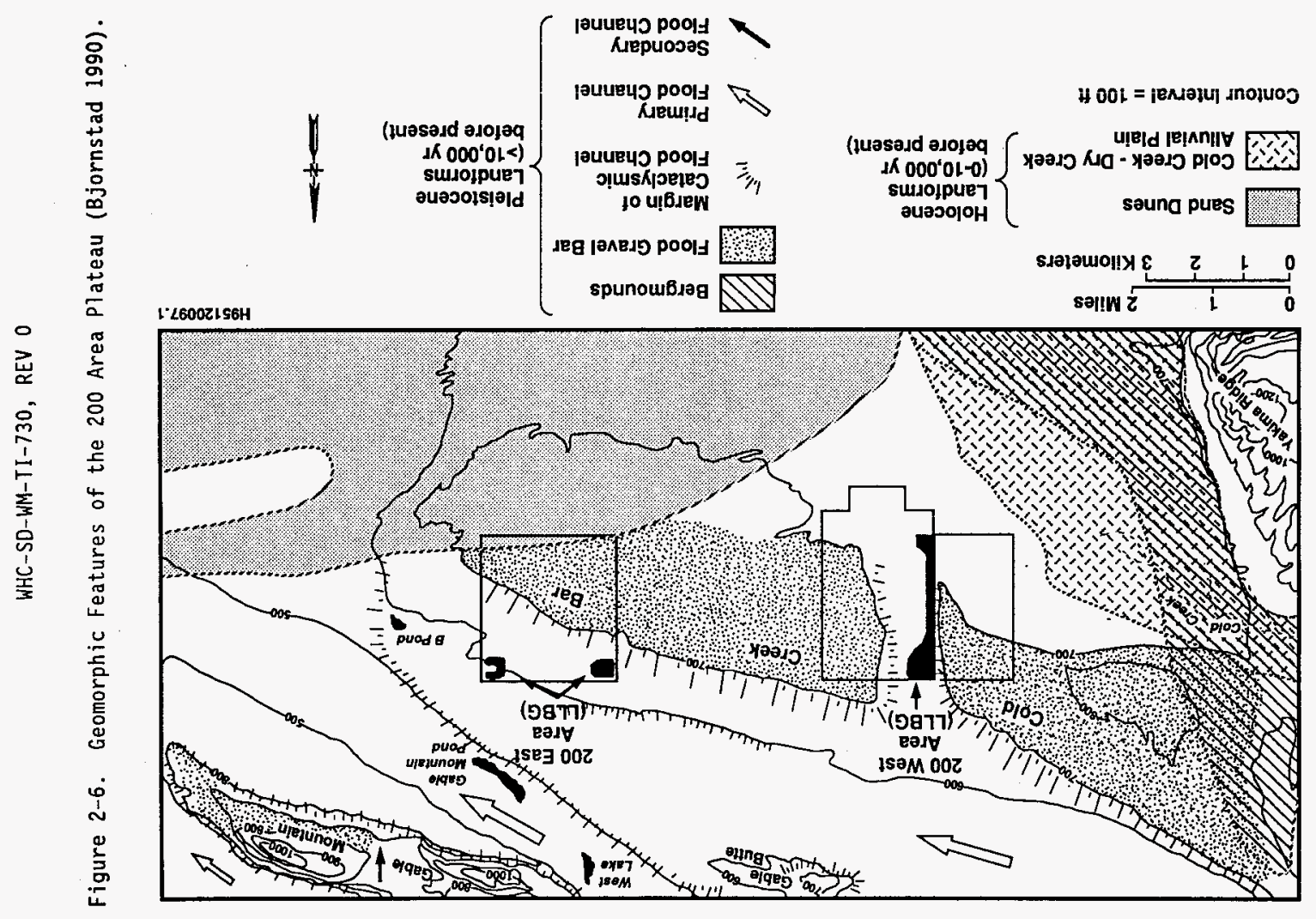


Figure 2-7. Water Table Map for the 200 Areas, 1993 (Reidel et al. 1995).

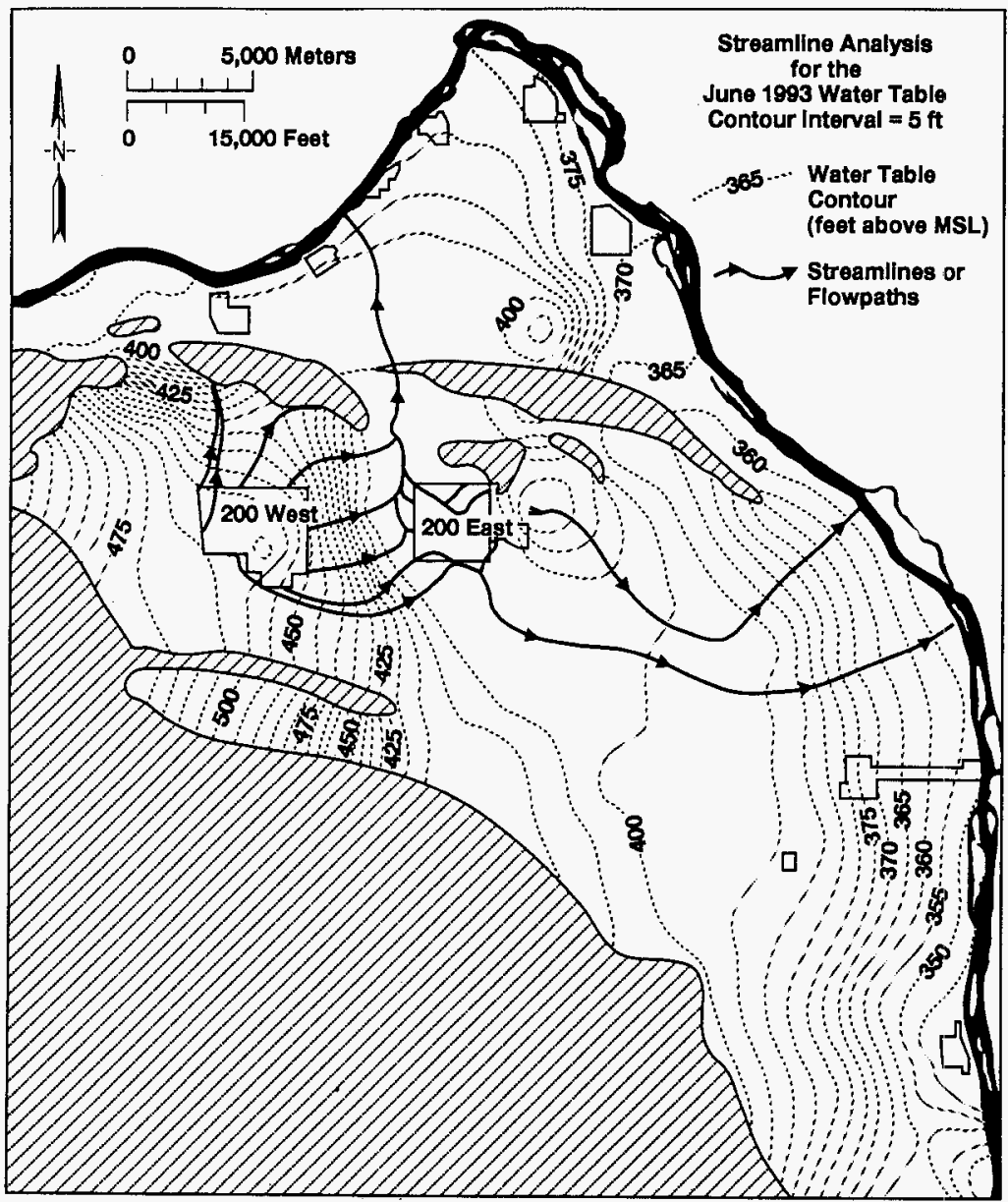

H\$503014.19 
Figure 2-8. Estimated Pre-Hanford Site Water Table Map.

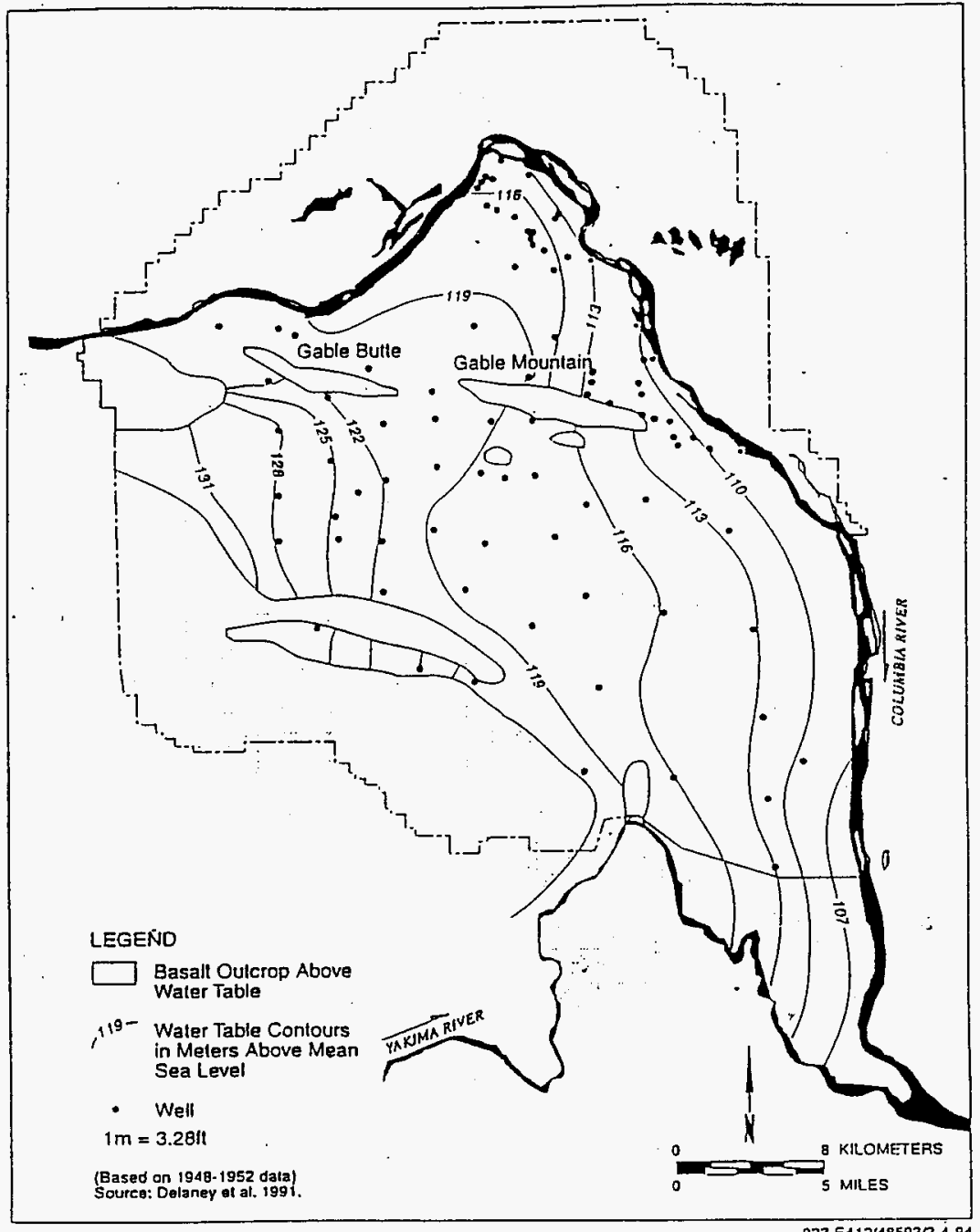

$923 \mathrm{E} 412 / 48593 / 3.4 .94$ 
Figure 2-9. Cold Creek Watershed Floodplain from the Probable Maximum Flood (DOE 1987).

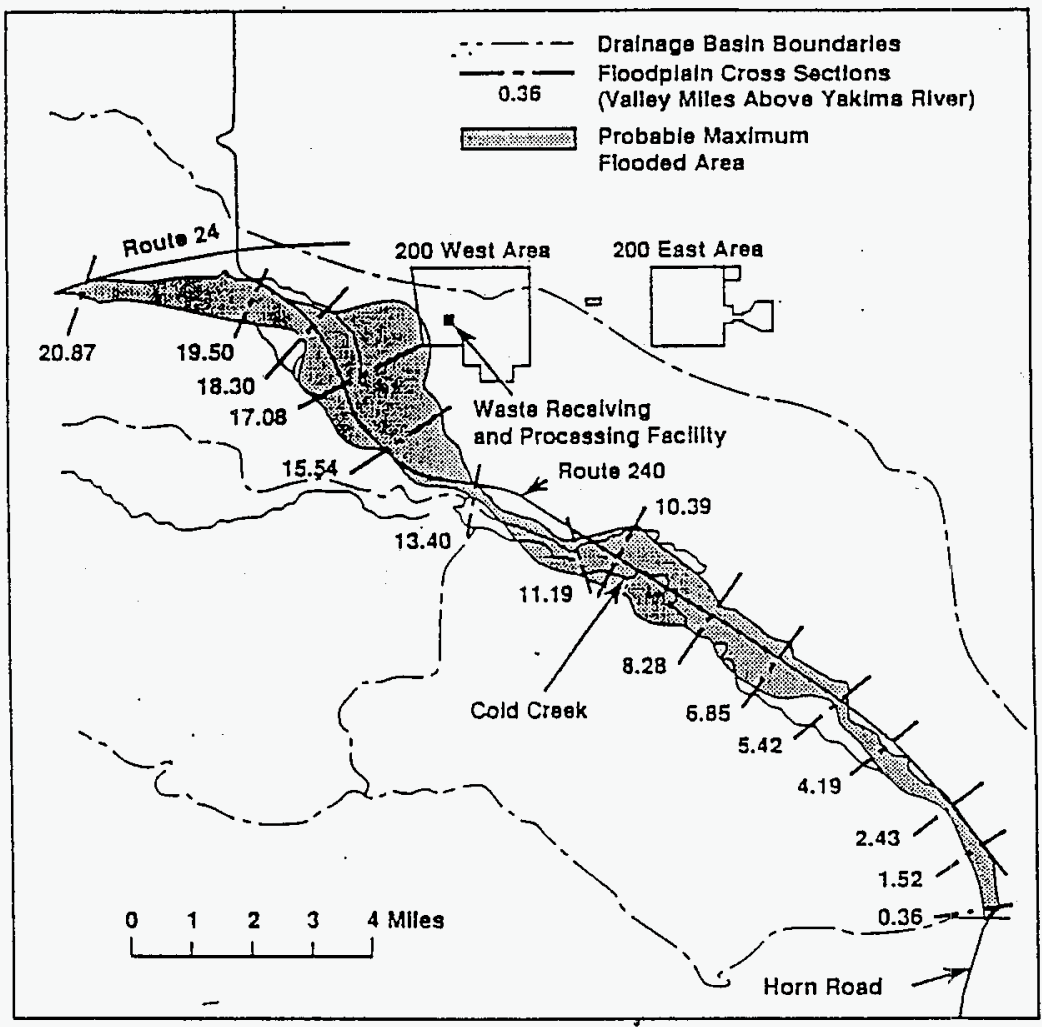

39103001.10 


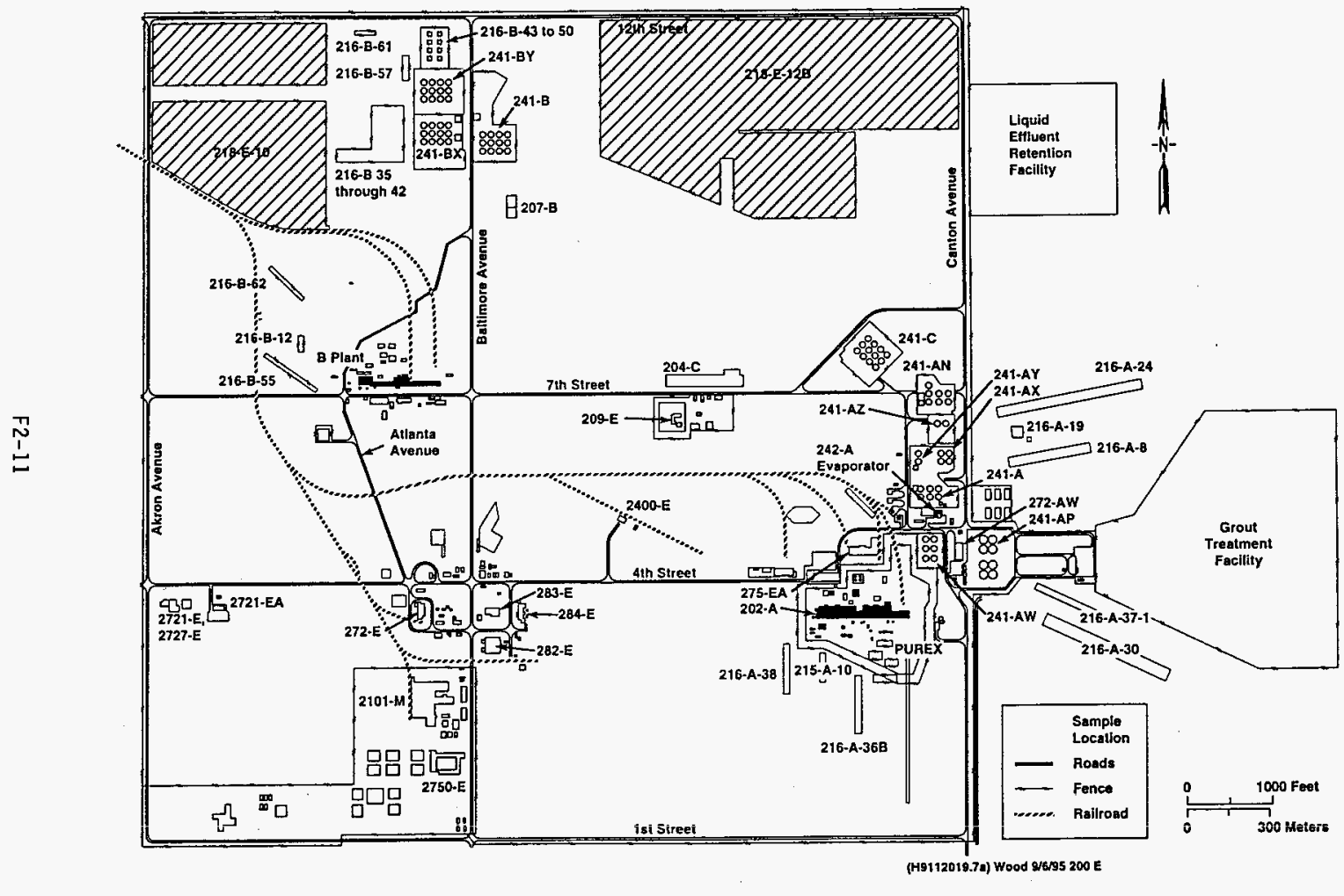

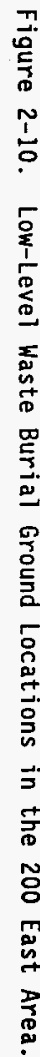

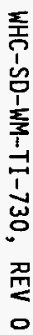


Figure 2-11. Schematic of a Typical Nuclear Vessel Reactor Compartment (U.S. Department of the Navy).

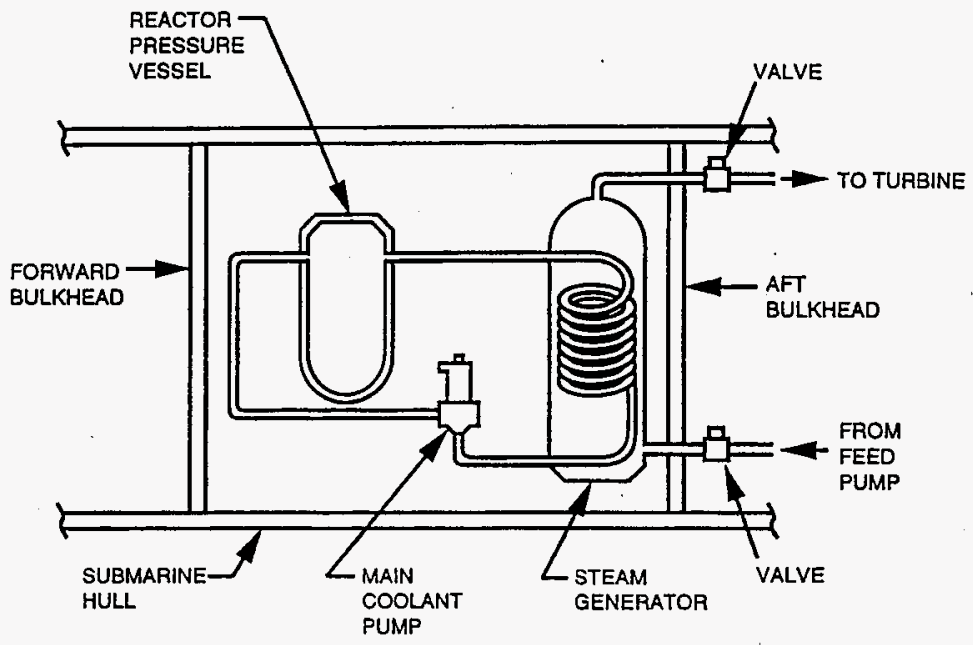




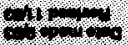

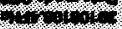

1.850

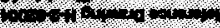

(m-m) $11:$ $4+210$

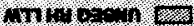

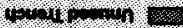

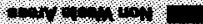

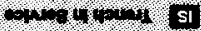

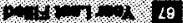
$0.1+1,10.0,1,(7)$ 4212.1010

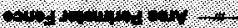
$+0,1,0+100$ $(-, 1,1,1 \%, 0,0$

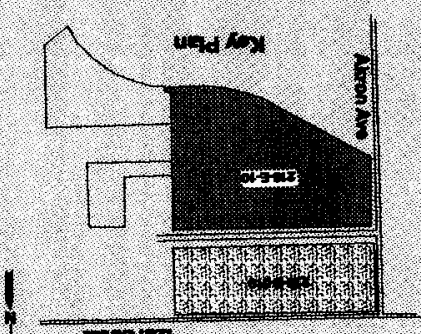

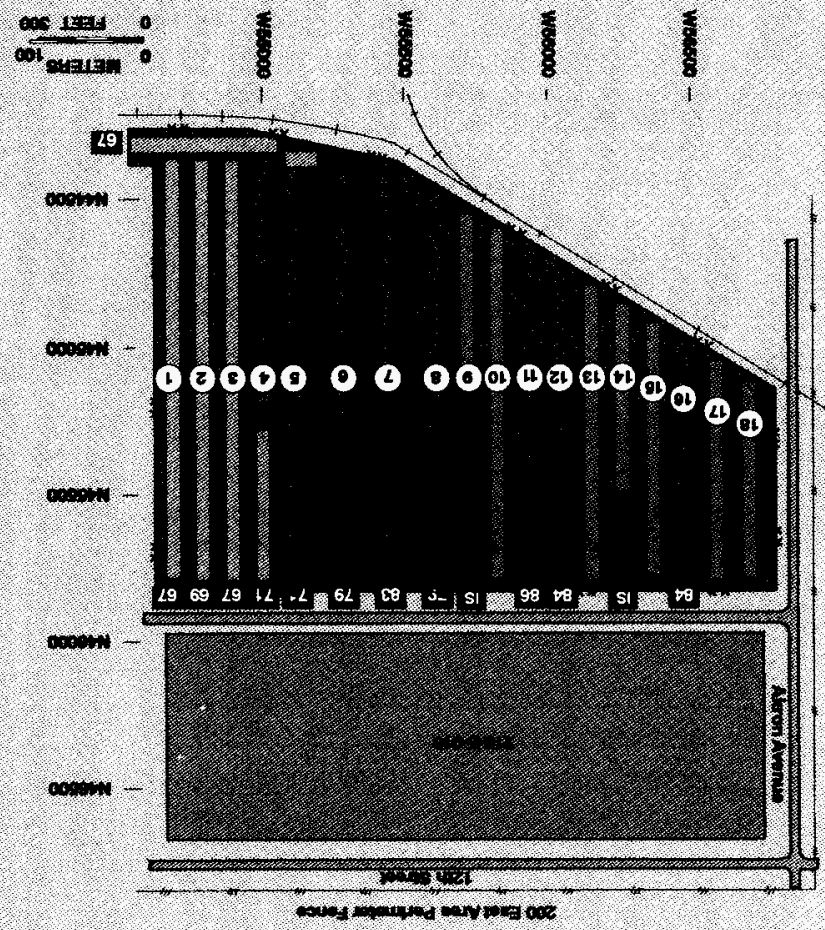


WHC-SD-WM-TI-730, REV 0

Figure 2-13. Plan View Map of 218-E-12B.

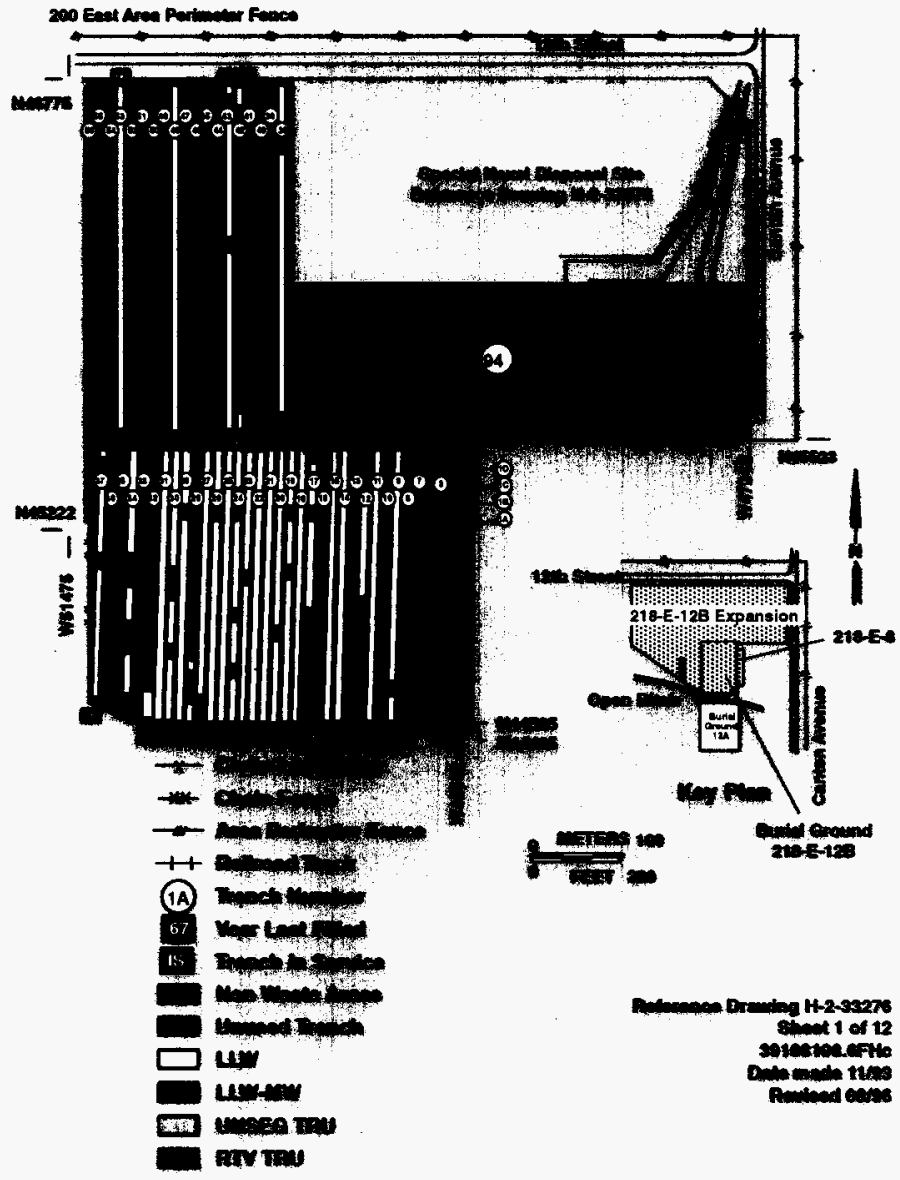


WHC-SD-WM-TI-730, REV 0

Figure 2-14. Plan View Map of Active Disposal Trenches in 218-E-10.
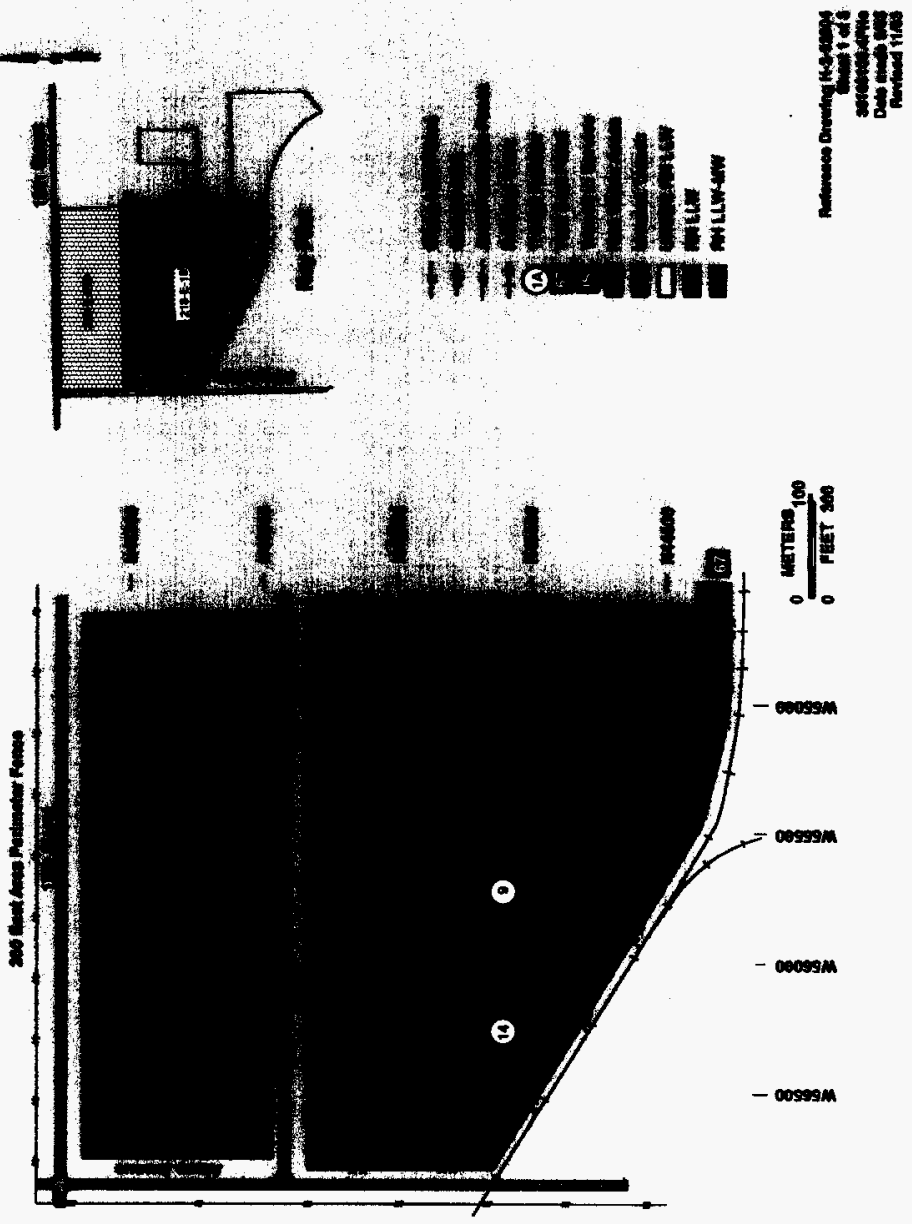
WHC-SD-WM-TI-730, REV 0

Figure 2-15. Plan View of Active Trenches in 218-E-12B.

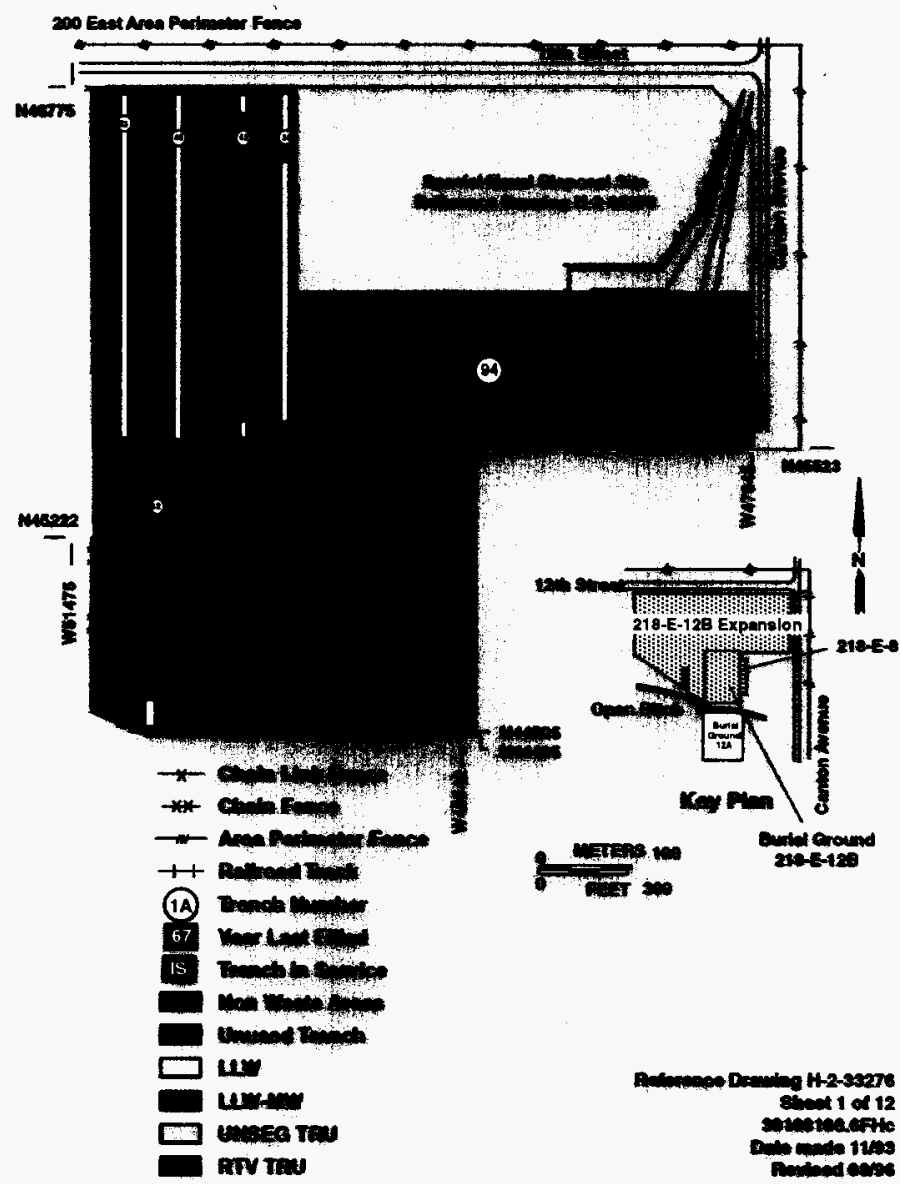


Figure 2-16. Conceptual Arrangement of 100 Reactor Compartments in Above-Ground Storage at 218-E-12B Burial Ground.

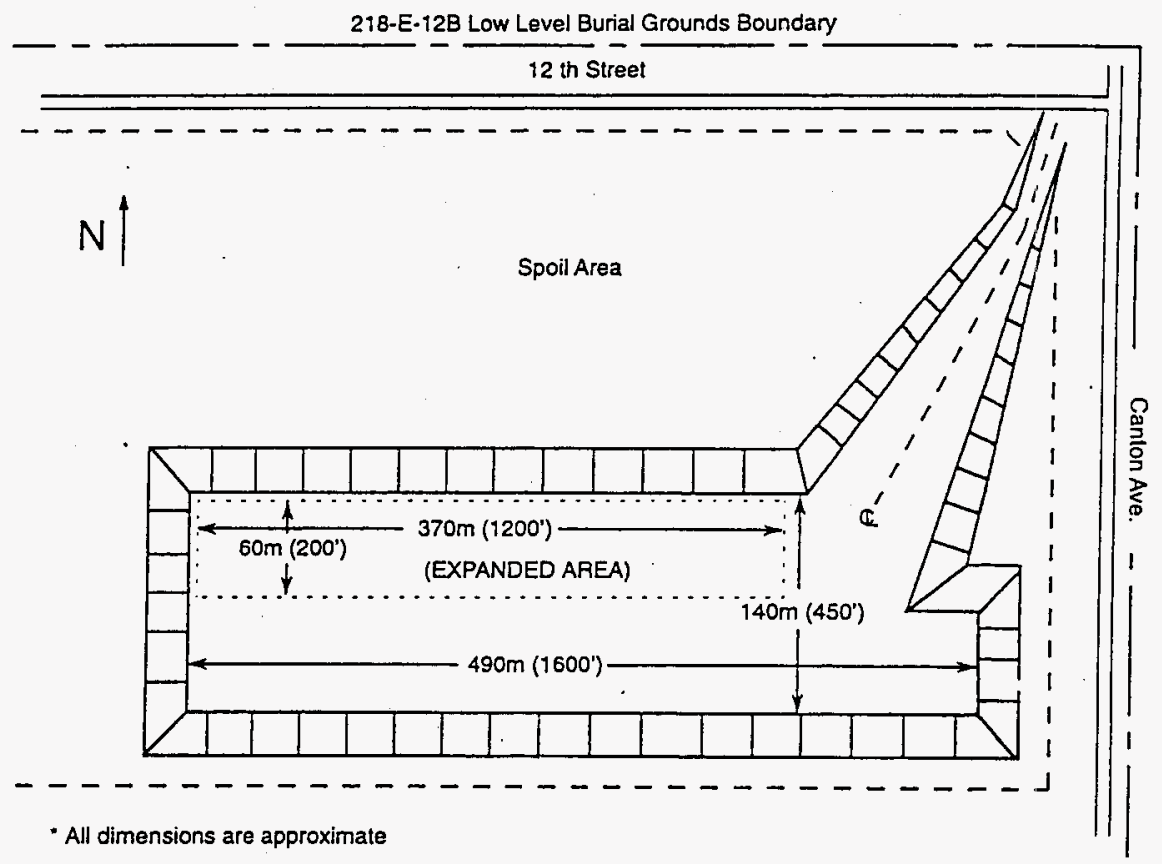


WHC-SD-WM-TI-730, REV 0

This page intentionally left blank. 


$$
\text { WHC-SD-WM-TI-730, REV } 0
$$

Figure 2-17. Schematic Comparison of Analyzed Trench Section Used in Groundwater Analys is Versus Conceptual Waste Volume Area.

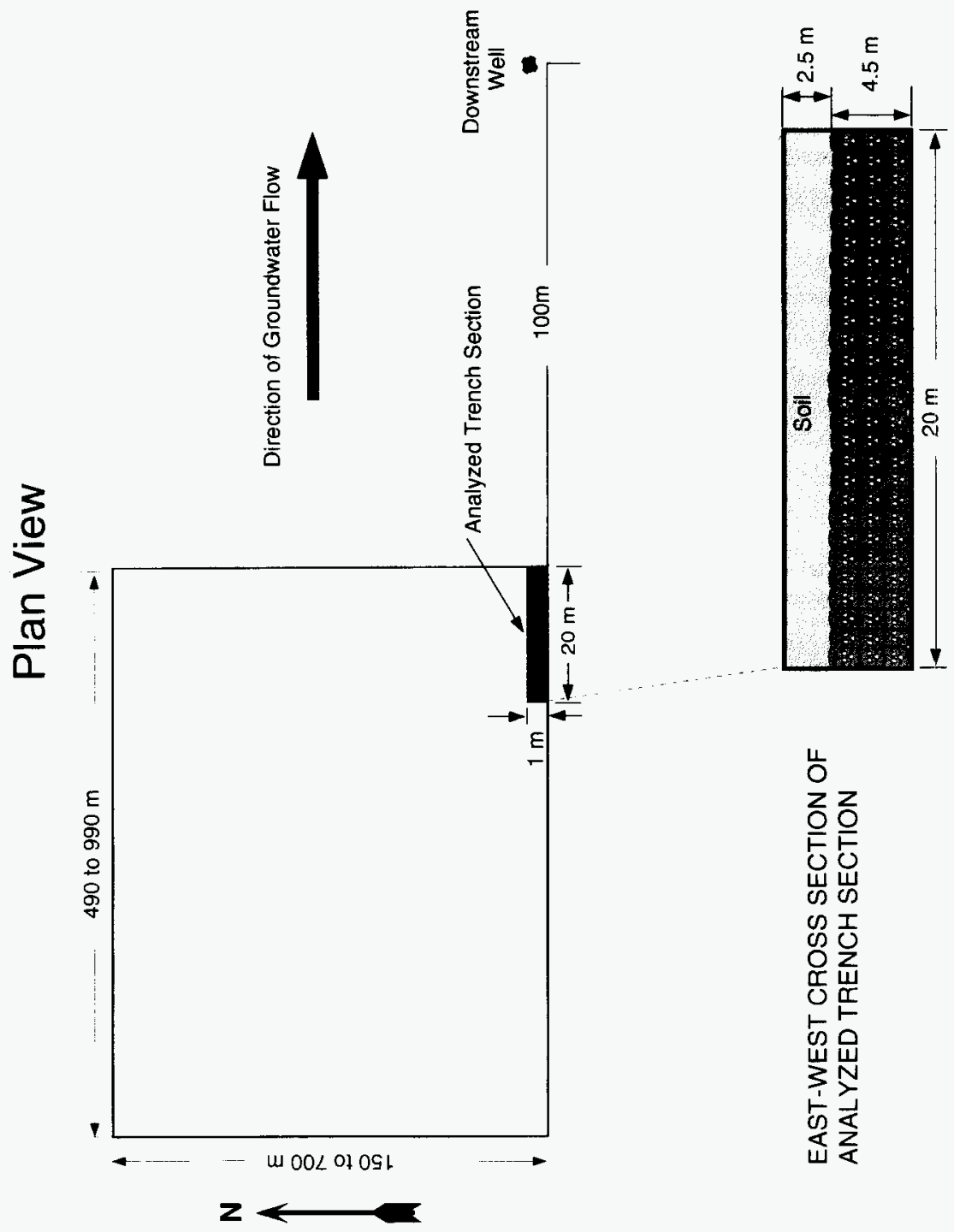


Table 2-1. Inventory Disposed of by Hanford Site Generators in the 200 East Area LLBG Since September 26, 1988.

\begin{tabular}{|l|c|c|c|}
\hline \multirow{2}{*}{ Radionuclide } & \multicolumn{3}{|c|}{ Radionuclide-Specific Inventory (Ci) } \\
\cline { 2 - 4 } & \multicolumn{2}{|c|}{ Burial Ground } & \multirow{2}{*}{ Tota1 } \\
\cline { 2 - 4 } & $218-\mathrm{E}-10$ & $218-\mathrm{E}-12 \mathrm{~B}$ & 2,110 \\
\hline Beta/Gamma & 2,017 & 93 & 411 \\
\hline${ }^{137} \mathrm{Cs}$ & 400 & 11 & 635 \\
\hline${ }^{90} \mathrm{Sr}$ & 618 & 17 & 6.4 \\
\hline${ }^{144} \mathrm{Ce}$ & & 6.4 & 1.1 \\
\hline${ }^{106} \mathrm{Ru}$ & & 1.1 & 0.4 \\
\hline${ }^{151} \mathrm{Sm}$ & & 0.4 & 3 \\
\hline${ }^{147} \mathrm{Pm}$ & & 3 & $3.5 \mathrm{E}-10$ \\
\hline${ }^{14} \mathrm{C}$ & & $3.5 \mathrm{E}-10$ & 6.3 \\
\hline${ }^{60} \mathrm{Co}$ & & 6.3 & 54,500 \\
\hline $\mathrm{U}^{*}$ & & 54,500 & \\
\hline
\end{tabular}

*The uranium inventory is measured in grams.

Inventory data are summarized from the Solid Waste Information Tracking System (SWITS) database. 
Table 2-2. Summary of Current Hanford-Site Generated Inventory in the 200 East Area LLBG.

\begin{tabular}{|c|c|c|c|c|c|c|c|}
\hline \multirow{3}{*}{ Facilities } & \multicolumn{7}{|c|}{ Radionucl ide-Specific Inventory $(C i)$ in Currently Disposed-of Uaste, $* *$} \\
\hline & \multicolumn{2}{|c|}{ B Plant } & \multicolumn{2}{|c|}{ PUREX } & \multirow{2}{*}{$\begin{array}{c}\text { Tank Farms } \\
\text { ETF }\end{array}$} & \multirow{2}{*}{ other } & \multirow{2}{*}{ Totsl } \\
\hline & 221B & 2258 & $202 \mathrm{~A}$ & $202 A L$ & & & \\
\hline Beta/Gamma & 1,856 & 112 & 15 & 10 & 59 & 58 & 2,110 \\
\hline${ }^{12} \mathrm{Cs}$ & 356 & 23 & 0.55 & 0.32 & 8.7 & 23 & 411 \\
\hline${ }^{\infty} \mathrm{sr}$ & 581 & 33 & 0.43 & 0.28 & 16.3 & 5.8 & 635 \\
\hline${ }^{204} \mathrm{ce}$ & & & 3.9 & 1.5 & 8.0 E-06 & & 6.4 \\
\hline${ }^{100} \mathrm{Ru}$ & & & 0.7 & 0.4 & 7.0 E-06 & & 1.1 \\
\hline${ }^{\text {s"ism }} \mathrm{Sm}$ & & & 0.2 & 0.2 & $9.0 \mathrm{E}-06$ & & 0.4 \\
\hline${ }^{107} \mathrm{Pm}$ & & & 1.8 & 1.6 & 0.0001 & & 3.4 \\
\hline${ }^{14} \mathrm{C}$ & & & $9.6 \mathrm{E}-11$ & $2.5 E-10$ & & & $3.5 E-10$ \\
\hline${ }^{\infty} \mathrm{Co}$ & & & & & 6.3 & 0.006 & 6.3 \\
\hline U* & & & & & & 54,500 & \\
\hline Volume $\left(\mathrm{m}^{3}\right)$ & 154 & 738 & 376 & 123 & 580 & 609 & 2,580 \\
\hline \multicolumn{8}{|c|}{ Est imated Inventory of Mobile Radionuclides (Ci) in Currently Disposed-of Waste } \\
\hline \multirow{2}{*}{ Facilities } & \multicolumn{2}{|c|}{ B Plant } & \multicolumn{2}{|c|}{ PUREX } & \multirow{2}{*}{$\begin{array}{c}\text { Tank Farms } \\
\text { ETF }\end{array}$} & \multirow{2}{*}{ other } & \multirow{2}{*}{ Total } \\
\hline & $225 \mathrm{~B}$ & $221 B$ & $202 \mathrm{~A}$ & 202AL & & & \\
\hline Radionuclide & \multirow{2}{*}{0.077} & \multirow{2}{*}{0.005} & \multirow{2}{*}{0.00063} & \multirow{2}{*}{0.00042} & \multirow{2}{*}{0.0024} & \multirow{2}{*}{0.0024} & \multirow{2}{*}{0.088} \\
\hline "TC & & & & & & & \\
\hline $129_{1}$ & 0.00011 & 6.9 E- 06 & 9.2 E- 07 & 6.2 E- 07 & $3.6 \mathrm{E}-06$ & 3.6 E-06 & 0.00013 \\
\hline${ }^{14} \mathrm{C}$ & $7.6 E-07$ & $4.6 E-08$ & 6.1 E-09 & $4.1 E-09$ & 2.4 E- 08 & 2.4 E- 08 & 8.5 E.07 \\
\hline "Se & 0.0013 & 8.1 E-05 & 1.1 E-05 & $7.3 \mathrm{E}-06$ & $4.3 \mathrm{E}-05$ & $4.2 \mathrm{E}-05$ & 0.0015 \\
\hline
\end{tabular}

*The uranium inventory is measured in grams.

* Current inventory data are sumarized from the Solid Waste Information Iracking System (SWITS) database. 
WHC-SD-WM-TI-730, REV 0

Table 2-3. Range and Frequency of Beta/Gamma Concentrations Per Waste Package Per Trench.

\begin{tabular}{|c|c|c|c|c|c|c|c|c|}
\hline \multirow{3}{*}{$\begin{array}{l}\text { Burial } \\
\text { ground/ } \\
\text { trench }\end{array}$} & \multirow{3}{*}{$\begin{array}{l}\text { Concentration } \\
(\log \mathrm{ci} / \mathrm{m} 3)\end{array}$} & \multicolumn{7}{|c|}{$\begin{array}{c}\text { Nuber of waste packages in the specified range of beta/game } \\
\text { concentration }\end{array}$} \\
\hline & & \multicolumn{6}{|c|}{ Generator } & \multirow{2}{*}{ Total } \\
\hline & & $\begin{array}{c}\text { E Tank } \\
\text { Farm }\end{array}$ & $\begin{array}{c}\text { 202A } \\
\text { (PUREX) }\end{array}$ & $\begin{array}{l}\text { 202AL } \\
\text { (PUREX) }\end{array}$ & $\begin{array}{l}2218 \\
\text { (B Plant) }\end{array}$ & $\begin{array}{l}225 B \\
\text { (B P(ant) }\end{array}$ & Misc & \\
\hline \multirow{3}{*}{ E10/T9 } & 1 to 2 & & & & 1 & & & 1 \\
\hline & 0 to 1 & & & & & 3 & & 3 \\
\hline & $(-1)$ to 0 & & & & 1 & & & 1 \\
\hline$E 128 / I 32$ & $(-5)$ to $(-4)$ & & & & & & 1 & 1 \\
\hline$E 128 / T 38$ & $(-4)$ to $(-3)$ & & & & & & & 0 \\
\hline \multirow{3}{*}{$\mathrm{E} 12 \mathrm{~B} / \mathrm{T} 42$} & $(-4)$ to $(-3)$ & & & & & & 1 & 1 \\
\hline & $(-5)$ to $(-4)$ & & & & & & 1 & 1 \\
\hline & $<(-7)$ & & & . & & & 3 & 3 \\
\hline \multirow{9}{*}{$E 12 B / T 48$} & 0 to 1 & 5 & & & & & & 5 \\
\hline & $(-1)$ to 0 & 20 & & & & 1 & & 21 \\
\hline & $(-2)$ to $(-1)$ & 139 & & & 1 & 1 & & 141 \\
\hline & $(-3)$ to $(-2)$ & 43 & & & & & & 43 \\
\hline & $(-4)$ to $(-3)$ & 3 & & & 136 & 19 & & 158 \\
\hline & $(-5)$ to $(-4)$ & 5 & & & 1 & & 2 & 8 \\
\hline & $(-6)$ to $(-5)$ & 1 & & & 1 & & 1 & 3 \\
\hline & $(-7)$ to $(-6)$ & & & & & & 1 & 1 \\
\hline & $<(-7)$ & & & & & & & 0 \\
\hline \multirow{10}{*}{ E12B/T53 } & 1 to 2 & 2 & & & & & & 2 \\
\hline & 0 to 1 & 30 & . & 2 & 1 & & & 33 \\
\hline & $(-1)$ to 0 & 24 & 4 & 29 & 50 & & & 07 \\
\hline & $(-2)$ to $(-1)$ & 637 & 315 & 1,357 & 73 & 44 & 9 & 2,435 \\
\hline & $(-3)$ to $(-2)$ & 399 & & 132 & 45 & 143 & 13 & 732 \\
\hline & $(-4)$ to $(-3)$ & 117 & 1 & & 45 & 178 & 22 & 363 \\
\hline & $(-5)$ to $(-4)$ & 214 & 36 & 4 & 218 & 1 & 6 & 479 \\
\hline & $(-6)$ to $(-5)$ & 18 & 54 & & 32 & & 18 & 122 \\
\hline & $(-7)$ to $(-6)$ & 1 & 320 & & 118 & & & 439 \\
\hline & $<(-7)$ & & 4 & 4 & 5 & & & 13 \\
\hline
\end{tabular}


Table 2-4. Projected and Final Hanford Site-Generated Inventory of Mobile Radionuclides in the 200 East Area LLBG.

\begin{tabular}{|c|c|c|c|c|c|}
\hline \multirow[t]{2}{*}{ Facility } & \multicolumn{5}{|c|}{ Projected Future Inventory $(\mathrm{C} i)^{* *}$} \\
\hline & B Plant & PUREX & Tank farms & Other & Total \\
\hline Radionuclide & \multirow[b]{2}{*}{198} & \multirow[b]{2}{*}{38} & \multirow[b]{2}{*}{964} & & \multirow[b]{2}{*}{1,200} \\
\hline Beta/Gamma & & & & & \\
\hline${ }^{9} \mathrm{Tc}$ & 0.004 & 0.002 & 0.04 & & 0.05 \\
\hline${ }^{129} \mathrm{I}$ & $1.2 \mathrm{E}-05$ & $2.3 \mathrm{E}-06$ & $5.9 E-05$ & & 0.0001 \\
\hline${ }^{14} \mathrm{C}$ & $3.7 E-08$ & $1.5 \mathrm{E}-08$ & $3.9 \mathrm{E}-07$ & & $4.4 E-07$ \\
\hline${ }^{79} \mathrm{Se}$ & 0.00014 & 0.000027 & 0.0007 & & 0.0009 \\
\hline \multirow[t]{2}{*}{ Facility } & \multicolumn{5}{|c|}{$\begin{array}{l}\text { Current plus projected future mobile radionuclide inventory } \\
\text { (Ci) }\end{array}$} \\
\hline & B Plant & PUREX & Tank farms & Other & Total \\
\hline Radionuclide & \multirow[b]{2}{*}{0.086} & \multirow[b]{2}{*}{0.003} & \multirow[b]{2}{*}{0.042} & \multirow[b]{2}{*}{0.002} & \multirow[b]{2}{*}{0.13} \\
\hline${ }^{99} \mathrm{Tc}$ & & & & & \\
\hline${ }^{129} \mathrm{I}$ & 0.0001 & $3.8 \mathrm{E}-06$ & $6.2 \quad E-05$ & $3.6 \mathrm{E}-06$ & 0.0002 \\
\hline${ }^{14} \mathrm{C}$ & $8.5 \mathrm{E}-07$ & $2.5 \mathrm{E}-08$ & $4.2 \quad E-07$ & $2.4 E-08$ & 1. $3 \mathrm{E}-06$ \\
\hline${ }^{79} \mathrm{Se}$ & 0.0014 & $4.5 \quad E-05$ & 0.0007 & $4.2 \mathrm{E}-05$ & 0.002 \\
\hline U* & & & & 54,500 & 54,500 \\
\hline
\end{tabular}

*The uranium inventory is measured in grams.

** Individual radionuclide inventories are based on fractional quantities relative to total beta/gamma curies (Appendix B). 
Table 2-5. Current and Projected Inventory Estimates for Reactor Compartments in Trench 94.

\begin{tabular}{|c|c|c|c|c|c|}
\hline \multirow{2}{*}{ Radionuclide } & \multicolumn{2}{|c|}{$\begin{array}{c}\text { Current Inventory/ } \\
\text { Concentration }\end{array}$} & \multicolumn{2}{|c|}{$\begin{array}{l}\text { Projected Inventory } \\
\text { (Ci) }\end{array}$} & \multirow{2}{*}{$\begin{array}{l}\text { Total } \\
\text { Inventory } \\
\text { (Ci) }\end{array}$} \\
\hline & (Ci) & $\left(\mathrm{Ci} / \mathrm{m}^{3}\right)$ & Group 1 & Group 2 & \\
\hline${ }^{241} \mathrm{Am}$ & $3.0 \mathrm{E}-01$ & $5.0 \mathrm{E}-04$ & $6.5 \mathrm{E}-01$ & & $6.5 \mathrm{E}-01$ \\
\hline${ }^{243} \mathrm{Am}$ & $2.2 \mathrm{E}-05$ & $3.6 \mathrm{E}-08$ & $4.8 E-05$ & & $4.8 \mathrm{E}-05$ \\
\hline${ }^{10} \mathrm{Be}$ & $1.3 \mathrm{E}-06$ & $2.1 E-09$ & $1.3 E-06$ & & $1.3 \mathrm{E}-06$ \\
\hline${ }^{14} \mathrm{C}$ & $1.2 \mathrm{E}+02$ & $2.0 \mathrm{E}-01$ & $2.6 \mathrm{E}+02$ & $3.8 \mathrm{E}+02$ & $6.4 E+02$ \\
\hline${ }^{36} \mathrm{Cl}$ & $6.0 \mathrm{E}-03$ & $9.9 \mathrm{E}-06$ & $6.0 \mathrm{E}-03$ & & $6.0 \mathrm{E}-03$ \\
\hline${ }^{262} \mathrm{Cm}$ & $8.9 \quad E-07$ & $1.5 \mathrm{E}-09$ & $1.9 \mathrm{E}-06$ & & $1.9 \mathrm{E}-06$ \\
\hline${ }^{243} \mathrm{Cm}$ & $9.9 \mathrm{E}-09$ & $1.6 \mathrm{E}-11$ & $2.2 \mathrm{E}-08$ & & $2.2 E-08$ \\
\hline${ }^{244} \mathrm{Cm}$ & $3.9 \mathrm{E}-06$ & $6.4 \mathrm{E}-09$ & $8.5 E-06$ & & $8.5 E-06$ \\
\hline${ }^{60} \mathrm{Co}$ & $9.1 E+05$ & $1.5 E+03$ & $2.0 E+06$ & $9.7 E+05$ & 3.1) E+06 \\
\hline${ }^{137} \mathrm{Cs}+{ }^{1374} \mathrm{Ba}$ & $6.0 E+00$ & $9.9 \mathrm{E}-03$ & $1.3 E+01$ & & $1.3 \mathrm{E}+01$ \\
\hline${ }^{3} \mathrm{H}$ & $1.1 \quad E+03$ & I. $9 E+00$ & $2.5 E+03$ & & $2.5 \mathrm{E}+03$ \\
\hline${ }^{129} \mathrm{I}$ & $2.9 \mathrm{E}-03$ & $4.8 \mathrm{E}-0.06$ & $6.3 \mathrm{E}-03$ & $2.0 \mathrm{E}-06$ & $6.3 E-03$ \\
\hline${ }^{93} \mathrm{Mo}_{0}$ & $6.9 \mathrm{E}-02$ & $1.1 \mathrm{E}-04$ & $1.5 \mathrm{E}-01$ & & $1.5 \mathrm{E}-01$ \\
\hline${ }^{93 \mu} \mathrm{Nb}$ & $5.6 \mathrm{E}-01$ & $9.3 \mathrm{E}-04$ & $1.2 \mathrm{E}+00$ & & $1.2 E+00$ \\
\hline${ }^{94} \mathrm{Nb}$ & $1.3 \mathrm{E}+01$ & $2.1 \mathrm{E}-02$ & $2.8 E+01$ & $7.1 \mathrm{E}+01$ & $9.9 \mathrm{E}+01$ \\
\hline${ }^{59} \mathrm{Ni}$ & $4.6 E+03$ & $7.6 E+00$ & $1.0 E+04$ & $1.9 E+04$ & $2.9 \mathrm{E}+04$ \\
\hline${ }^{63} \mathrm{Ni}$ & $8.0 E+05$ & $1.3 E+03$ & $1.7 \mathrm{E}+06$ & $2.1 E+06$ & $3.8 \mathrm{E}+06$ \\
\hline${ }^{237} \mathrm{~Np}$ & $2.2 \mathrm{E}-05$ & $3.6 E-08$ & $4.8 \mathrm{E}-05$ & & $4.8 E-05$ \\
\hline${ }^{238} \mathrm{Pu}$ & 6.0 E-01 & $9.8 \mathrm{E}-04$ & $1.3 \mathrm{E}+00$ & & $1.3 E+00$ \\
\hline${ }^{239} \mathrm{Pu}$ & $1.6 E-04$ & $2.6 E-07$ & $3.4 \quad E-04$ & & $3.4 \mathrm{E}-04$ \\
\hline${ }^{240} \mathrm{Pu}$ & $1.7 \mathrm{E}-04$ & $2.7 \mathrm{E}-07$ & 3.6 E-04 & & $3.6 \mathrm{E}-04$ \\
\hline${ }^{241} \mathrm{Pu}$ & $1.0 \mathrm{E}+01$ & $1.7 \mathrm{E}-02$ & $2.2 \mathrm{E}+0 \mathrm{l}$ & & $2.2 \mathrm{E}+01$ \\
\hline${ }^{242} \mathrm{Pu}$ & $3.9 \mathrm{E}-07$ & $6.4 \mathrm{E}-10$ & $8.5 E-07$ & & $8.5 \quad E-07$ \\
\hline${ }^{79} \mathrm{Se}$ & $2.3 \mathrm{E}-05$ & $3.8 \mathrm{E}-08$ & $5.0 \mathrm{E}-05$ & $2.9 \mathrm{E}-03$ & $3.0 \mathrm{E}-03$ \\
\hline${ }^{90} \mathrm{Sr}+{ }^{90} \mathrm{r}$ & $3.9 E+00$ & 6.4 E-03 & $8.5 E+00$ & & $8.5 E+00$ \\
\hline${ }^{99} \mathrm{Tc}$ & $8.1 \mathrm{E}-01$ & $1.3 \mathrm{E}-03$ & $1.8 E+00$ & $2.3 E+00$ & $4.1 E+00$ \\
\hline${ }^{93} \mathrm{Zr}$ & $5.6 \mathrm{E}-01$ & $9.3 E-04$ & $1.2 E+00$ & & $1.2 \mathrm{E}+00$ \\
\hline
\end{tabular}


WHC-SD-WM-TI-730, REV 0

This page intentionally left blank.

T2-6

r...... 
WHC-SD-WM-TI-730, REV 0

\subsection{PERFORMANCE ASSESSMENT ANALYSIS METHODOLOGY}

This chapter describes the methodology for estimating the potential dose to humans resulting from the release of radionuclides from the disposal facility. The chapter is organized by scenario type: inadvertent intruder, groundwater contamination, and additional scenarios. The inadvertent intruder analysis is based on the possibility that knowledge of the disposal facility could be lost and an intruder come in contact with the waste. Dose is received by exposure to the waste or by mixing waste with garden soit and consuming contaminated crops grown in the soil. The groundwater contamination analysis is based on the assumption that groundwater is contaminated by radionuclides leached from the disposal facility and transported through the soil column to the water table. Subsequent use of the groundwater, by drinking only or by drinking and irrigation (the all-pathways scenario), results in dose to the individual. Additional scenarios include radionuclide transport by vapor diffusion and liquid diffusion to the surface from an undisturbed facility. Much of this description is repeated from Wood et al. (1995a) and Wood et al. (1995b).

In each section, the discussion is initiated by describing the conceptual model of the pathways considered, followed by the mathematical approach used to represent the model. Finally, the primary parameters and parameter values used in the analysis to quantify dose estimates are described.

\subsection{INTRUDER SCENARIO ANALYSIS}

Intruder scenarios must be selected and quantified to estimate potential dose from a disposal facility and to compare dose estimates with dose limit performance objectives (Section 1.4). This section describes the process of scenario selection and the scenarios used in the analysis.

\subsubsection{Conceptual Model of the Inadvertent Intruder Scenarios}

Many scenarios can be considered as plausible means of inadvertent intrusion. To complete an analysis, the large number of possible scenarios must be reduced to a few that are representative and will provide a maximum projected dose relative to other potential scenarios for a similar set of initial conditions. Using these criteria, a disposal facility design can be proposed that reasonably can be expected to satisfy the performance objectives defined in DOE Order 5820.2A (DOE 1988a) to protect the inadvertent intruder.

In this analysis, inadvertent intrusion is defined as an activity that results in direct contact with the waste in the disposal facility. Three types of intrusion are considered.

- Excavating a basement for a dwelling

- Drilling a well for water to be consumed or used for irrigation

- Growing crops with roots that penetrate into waste material.

In each case, the waste must be extracted directly from the disposal facility. Exhumed waste is assumed to be indistinguishable from soil with the exception of activated metal. We have assumed (as has the Nuclear Regulatory 
Commission. (NRC) in 10 CFR 61) that radionuclides entrained in activated metals are less likely than other forms to be dispersed into the environment, even when exhumed and mixed with soil, thus reducing the potential dose from this source relative to other waste materials.

The excavating and drilling types have been further subdivided into the following scenarios:

1. Well Orilling. A $30-\mathrm{cm}-(12-$ in.-) diameter well is driven through the waste.

2. Post-drilling. Waste from the well hole is mixed with soil in which vegetables are grown. The vegetables are consumed. Soil is also consumed.

3. Excavation. $100 \mathrm{~m}^{3}\left(3,532 \mathrm{ft}^{3}\right)$ of waste is exhumed during construction of a house with a basement.

4. Post-excavation. Waste from the basement excavation is mixed with soil in which vegetables are grown. The vegetables are consumed. Soil is also consumed.

5. Residential Garden. Crop roots or other natural plant roots penetrate the waste zone, thereby contaminating crops that are consumed.

This list of scenarios was reduced to two, post-drilling and postexcavation, for further evaluation of the proposed disposal facilities based on the following process:

1. A set of applicable scenarios was determined for each type of disposal facility (Categories 1 and 3) as, a function of the facility features. For the Category 1 facility, waste is buried at a minimal depth $(-3 \mathrm{~m}[\sim 10 \mathrm{ft}])$ and accessible by excavation, drilling, or root penetration. Thus, all five scenarios apply. For the Category 3 facility, waste is buried at sufficient depth ( $5 \mathrm{~m}$ [16 ft] or more) to eliminate excavation and root penetration as a feasible means of exhuming waste. Thus, only drilling and postdrilling are applicable scenarios. It is also assumed that intrusion occurs at 100 and 500 years post-closure for Category 1 and 3 waste, respectively.

2. Given the set of applicable scenarios for each facility type, the scenario that results in the largest dose for a given inventory is the limit-defining scenario. Aaberg and Kennedy (1990) compared projected doses for these scenarios. Their work clearly shows that, assuming the same initial waste concentration, the maximum dose generally occurs when the post-excavation scenario is used. For some radionuclides, other residential garden scenarios provided a slightly higher dose (less than one order of magnitude difference). Given the uncertainties inherent in the scenario parameter assumptions, these differences in projected dose are not considered significant. For these reasons, considering only the postexcavation scenario was sufficient to define waste concentration limits for Category 1 waste disposal. Similarly, when comparing 
drilling and post-drilling scenarios, the maximum dose occurs consistently with the post-drilling scenario; therefore, it is the only scenario considered in this analysis for defining Category 3 waste disposal concentration limits.

The pathways by which the intruder may be exposed to radiation from the exhumed waste are as follows:

- Ingestion of vegetables grown in the contaminated soil

- Ingestion of soil

- Inhalation of radionuclides on dust suspended in the air by gardening activities and wind

- External exposure to contaminated soil while working in the garden or residing in a house built on top of the waste site.

Two methods of performing dose calculations were completed. The first and primary method was a set of hand calculations organized on a spreadsheet. The radionuclide concentration inventory limits described in Chapter 4.0 are derived from these calculations. The second method was to use the computer code GENII, Version 1.485 (Napier et al. 1988) for benchmarking. This code was developed at the Hanford Site. Using this code has the advantage of rapid calculation, particularly when considering the effects of daughter contributions to the calculated dose for the parent. By developing a spreadsheet and doing a comparison with the GENII code (Appendix C), several goals were accomplished. First, a spreadsheet was carefully constructed using GENII formulas to duplicate results accurately. The authors gained a detailed knowledge of the factors affecting dose calculations in GENII. These formulas are discussed in Appendix $C$. Second, the parameter value assumptions were evaluated. In some cases (see Section 3.1.2), different parameter values were chosen from the default values given in GENII. Third, a few radionuclides considered were not provided in the GENII database; these radionuclides were more easily considered using the spreadsheet.

The environmental dose estimation methods and assumptions used in the current document are identical to those used in Wood et al. (1995a) and very similar to those found in the grouted PA (Kincaid et al. 1995). The differences are almost entirely simplifications that will not materially affect the computed doses. For example, the grouted double-shell tank LLW PA used the EPA values for local food production of 25 percent for vegetables and 20 percent for fruit. In the current document, these were simplified to 25 percent for all garden produce.

\subsubsection{Mathematical Simulation of Dose Estimates to the Inadvertent Intruder}

In the post-drilling and post-excavation scenarios, the dose to the intruder is calculated as a function of the pathway and the individual radionuclide. The three pathways through which a dose is received are ingestion, inhalation, and external exposure. The relative importance of each pathway depends largely on the type of radiation emitted by the specific radionuclide. To estimate dose, algebraic equations are used in a spreadsheet 
format. This section summarizes the basic equations for each pathway. Additional details of the analysis are provided in Appendix $C$.

Dose by ingestion is calculated by the following basic equation:

$$
H=C \quad Q \quad D
$$

where:

$H=$ annual dose received (mrem/yr)

$\mathrm{C}=$ concentration in substance consumed $(\mathrm{Ci} / \mathrm{kg}, \mathrm{Ci} / \mathrm{L})$

$Q=$ quantity of substance consumed ( $\mathrm{kg} / \mathrm{yr}, \mathrm{L} / \mathrm{yr}$ )

$D=$ dose conversion factor (mrem/Ci) from DOE/EH-0071 (DOE 1988c).

The soil concentration is quantified as a function of initial inventory, the dilution factor assumed as a result of mixing waste with uncontaminated soil, and the decay factor. In these analyses, a unit concentration is assumed to exist in the initial inventory at time zero (closure of the 200 East Area (LBG).

Dose by inhalation is calculated by the following basic equation:

$$
H=W V T M D
$$

where:

$H=$ annual dose received (mrem/yr)

$W=$ concentration in the dirt suspended in air $(\mathrm{Ci} / \mathrm{kg})$

$V=$ breathing rate $\left(\mathrm{m}^{3} / \mathrm{h}\right)$

$T=$ time of inhalation $(h / y r)$

$M=$ concentration of dirt in the air $\left(\mathrm{kg} / \mathrm{m}^{3}\right)$

$D=$ dose conversion factor (mrem/Ci) from DOE/EH-0071 (DOE 1988c).

The soil concentration is equal to that defined in the ingestion pathway; therefore, it depends on the same factors. The time of inhalation depends on the assumptions of living conditions such as time spent indoors versus outdoors, time spent at the home versus away from home, and time spent awake versus asieep. equation:

Dose by external exposure is calculated from the following basic

$$
H=p d W T D
$$

where:

$$
\begin{aligned}
& H=\text { annual dose received (mrem/yr) } \\
& W=\text { concentration in surface } 1 \text { ayer of soil }(\mathrm{Ci} / \mathrm{kg}) \\
& p=\text { soil density }\left(1,500 \mathrm{~kg} / \mathrm{m}^{3}\left[-93.51 \mathrm{~b} / \mathrm{ft}^{3}\right]\right)
\end{aligned}
$$


$d=$ thickness of soil in which radionuclides are mixed $(0.15 \mathrm{~m}[\sim 0.5 \mathrm{ft}])$

$T=t$ ime of exposure $(h / y r)$

$D=$ dose conversion factor $\left(\mathrm{mrem} / \mathrm{h}\right.$ per $\left.\mathrm{Ci} / \mathrm{m}^{2}\right)$ for contaminated thickness $d$.

As described, the soil concentrations are the same as for the other pathways. The time of exposure is calculated somewhat differently from time for the inhalation pathway to account for shielding provided by the dwelling floors and walls.

\subsubsection{Post-drilling Base Case Parameter Selection}

As shown in the previous discussion, in addition to the inventory, the fundamental parameters governing intruder dose estimates are the soil dilution factors, the time of exposure to external radiation, the quantity of contaminated air that is inhaled, the quantity of contaminated food that is ingested, and the dose conversion factors. These are summarized in the following paragraphs.

The post-excavation and post-drilling scenarios assume that the intruder has exhumed some of the waste and has relocated it to a garden. The scenarios differ only in the assumed initial soil concentration in the garden. All doses are proportional to this concentration. GENII assumes that the added waste is uniformly distributed through the top $15 \mathrm{~cm}(6 \mathrm{in}$.$) of soil in the$ garden (the tilling depth). This contaminated surface soil becomes the basis for the dose estimates for the resident gardener.

In the excavating operation, $100 \mathrm{~m}^{3}\left[3,531 \mathrm{ft}^{3}\right]$ is exhumed and spread over the garden. The large area exhumed is assumed to have 25 percent clean soil interspersed with the waste. Thus the actual volume of waste exhumed is $75 \mathrm{~m}^{3}[2,649 \mathrm{ft}]$. The resulting redistribution factor is $\left(75 \mathrm{~m}^{3}[2,649 \mathrm{ft}]\right) /$ $\left(2,500 \mathrm{~m}^{2}[26,911 \mathrm{ft}]\right)=0.03 \mathrm{~m}(.10 \mathrm{ft})$. In effect, $3 \mathrm{~cm}$ (1 in.) of waste is added to the garden.

In the well-drilling operation, $0.35 \mathrm{~m}^{3}\left(12 \mathrm{ft}^{3}\right)$ of waste $(0.3 \mathrm{~m}[1 \mathrm{ft}]$ diameter wel] through $5 \mathrm{~m}$. [16 ft] of waste) is brought to the surface and spread over a $2,500-\mathrm{m}^{2}\left(26,911-\mathrm{ft}^{2}\right)$ garden. For input to GENII, the "manual redistribution factor" takes the value $\left(0.35 \mathrm{~m}^{3}\right)\left[12 \mathrm{ft}^{3}\right] /\left(2,500 \mathrm{~m}^{2}\right)$ $\left[26,911 \mathrm{ft}^{2}\right]=1.4 \times 10^{-4} \mathrm{~m}$. In effect, $0.14 \mathrm{~mm}$ (.01 in.) of waste is added to the garden.

The quantities of waste exhumed and the size of the garden were selected somewhat arbitrarily on the basis of common practice. The area of the garden $\left(2,500 \mathrm{~m}^{2}\left[26,911 \mathrm{ft}^{2}\right]\right)$ is a realistic size for supplying the residents' vegetable diet (Napier et al. 1984). The value has been used in numerous previous assessments (Kincaid et a1. 1995; Kennedy and Strenge 1992). The $0.3-\mathrm{m}(1-\mathrm{ft})$ diameter for the well is large and represents a well drilled to support irrigation rather than just drinking. The mixing depth of $15 \mathrm{~cm}$ ( 6 in.) is considered an average plowing depth for normal farming practices. An attempt has been made to be reasonably conservative in the selection of values such that dose estimates will be high. The reasonableness of these parameter value choices is best thought of in terms of the soil dilution factor (ratio of total activity to volume of mixing soil). For this scenario, the soi] dilution value is $9.3 \times 10^{-4}\left(0.35 \mathrm{~m}^{3}\left[12 \mathrm{ft}^{3}\right] / 2,500 \mathrm{~m}^{2}\left[26,911 \mathrm{ft}^{2}\right]\right.$ $\times 0.15 \mathrm{~m}[0.5 \mathrm{ft}])$ for post-drilling. In essence, dilution of radionuclide 
WHC-SD-WM-TI-730, REV 0

concentration by a factor of about three orders of magnitude is assumed as a result of waste being exhumed by drilling.

The inhalation and external exposures are based on the following exposure times. The gardener is assumed to spend $1,800 \mathrm{hr} / \mathrm{yr}$ outside in the garden and $4,380 \mathrm{hr} / \mathrm{yr}$ inside. The remaining $2,580 \mathrm{hr} / \mathrm{yr}$ is spent elsewhere.

For estimating external exposure from the soil contamination, the house is assumed to reduce the dose rate to one-third the direct dose rate (Kennedy and Strenge 1992). In effect, the average time exposed at the unshielded dose rate is

$$
(1,800 \mathrm{hr} / \mathrm{yr}) * 1+(4,380 \mathrm{hr} / \mathrm{yr}) *(1 / 3)=3,260 \mathrm{hr} / \mathrm{yr}
$$

For estimating inhalation exposure, the air concentrations shown in Table 3-1 are used to estimate the average time of exposure to an air concentration of $0.1 \mathrm{mg} / \mathrm{m}^{3}$ (EPA 1992). The $4,380-\mathrm{hr}$ period has been divided into two equal periods of activity and sleep. The breathing rates shown in Table 3-1 are from ICRP 23 (1975). The time spent at each activity is based on common practice.

For input to GENII, a daily average breathing rate of $0.95 \mathrm{~m}^{3} / \mathrm{hr}$ is used. Thus, an inhalation exposure time of $4,680 \mathrm{hr}$ is needed to inhale the projected $445 \mathrm{mg}$ at the average air concentration of $0.1 \mathrm{mg} / \mathrm{m}^{3}$. This differs slightiy from the previous Pacific National Northwest Laboratory (PNNL) calculations (Aaberg and Kennedy 1990) of 4,390 hr/yr because breathing rate changes are now included.

Human intakes of radioactivity from the ingestion of food grown in the garden uses transport models in GENII that were developed from NRC Regulatory Guide 1.109 (NRC 1977); however, the default consumption parameters in GENII were not used. In their place, values for the "West" region from a recent survey (Yang and Nelson 1986) were used. These are listed in Table 3-2. Because grain is typically dry land farmed and not grown in gardens, the grain that is consumed is not considered to be contaminated in this analysis. Meat and milk consumption values are also given on this table, but are only assumed as a source of dose in the al1-pathways scenario. The assumed intake is based on the individual obtaining 25 percent of vegetable diet and 50 percent of animal diet from the farm. In addition, it is assumed that the intruder unintentionally consumes $100 \mathrm{mg} / \mathrm{d}$ of contaminated soil (EPA 1989).

Internal dose conversion factors were compared from three sources, the GENII code, DOE (1988c), and EPA (1989). The values are shown in Appendix C and are very similar. In the dose calculations the DOE source was used. External dose conversion factors are taken from the GENII Version 1.485 software package. The values were recomputed using the EXTDF program that accompanies GENII. External dose factors are at $1 \mathrm{~m}(3 \mathrm{ft})$ above a 15-cm- (6-in.-) thick layer of contaminated soil.

Besides those described earlier, a large number of parameters are used in the dose estimates, particularly for the ingestion pathways where multiple transfers of radionuclides are assumed (e.g., soil to plant to animal to 
human). Appendix $C$ lists the significant parameters as part of the pathway formula discussion.

Two sets of transfer factors were considered in these analyses. Transfer factors define the distribution of a given radionuclide expected to occur along a food pathway, which can include transfer of the radionuclide from soil to plant to human, from plant to animal, and from animal to human. The first set was compiled by Kennedy and Strenge (1992); the second set (Baes et al. 1984b) was developed at Oak Ridge National Laboratory (ORNL) for dose calculations.

Data sets from the literature are used because very little site-specific data are available on transfer factors, and collection of such data would be time consuming and expensive. There is some potential that the generic values used in the surveys identified previously were selected from data derived under conditions unlike the dry and sandy conditions of the Hanford Site. However, the preparation of the soil for a garden changes the properties of the surface layer. The tilling, watering, and addition of fertilizers produces soil that resembles the generic garden soil assumed by Kennedy and. Strenge (1992), and Baes et a). (1984b). Therefore, it is assumed that the concentration ratios found in these documents are adequate to describe plant uptakes in possible future gardens on the Hanford Site.

\subsection{GROUNOWATER CONTAMINATION ANALYSIS}

The groundwater contamination analyses were developed to estimate the potential dose to man that may occur as a result of radionuclide leaching from the disposal facility by chemical interaction of waste material with infiltrating rainwater and subsequent transport through the soil column to the water table. A person receives dose by using the contaminated water.

Section 3.2.l provides an overview of the conceptual model. This discussion focuses on the simplified representation of the natural processes that contaminate the groundwater by leaching waste from the 200 East Area LLBG. Particular emphasis is placed on the flow field description, transport scenario, and geohydrologic parameters in the unconfined aquifer derived from the Hanford Sitewide Model (Section 3.2.1.1). Section 3.2.1.2 provides an overview of a simplified disposal facility cross section model. Emphasis is placed on using the conceptual model to extrapolate results determined for the representation section of 200 East Area LLBG to the total disposal facility.

Section 3.2 .2 gives a general description of the mathematical modeling approach. The primary mathematical code used in these analyses was VAM3D-CG (Huyakorn and Panday 1992), a finite-element numerical code. Sections 3.2.3 through 3.2.6 deal with the major components of the process in greater depth including source-term calculations, flow and transport calculations, QA and QC practices, and dose calculations, respectively. Each section covering analysis components includes the pertinent aspects of the conceptual model, the mathematical simulation of the model, and the description of base-case parameters. Calibration exercises for the disposal facility cross-section model are described in Appendix D. Application of the sitewide model to the $P A$ analysis is discussed in Appendix $E$. 
WHC-SD-WM-TI-730, REV 0

\subsubsection{Overview of the Conceptual Model}

Radionuclide release and transport through the soil column and into an underlying aquifer is a dilution process controlled by many physical and chemical processes and material properties. Exact simulation of mass transport in a natural system is not a realistic goal because real environments contain inherent spatial and temporal heterogeneities. A truly comprehensive database cannot be generated and mathematical simulation is too complex to execute efficiently.

To quantify these processes and, ultimately, the dilution effect, a simplifying conceptual model was developed that could be expressed mathematically. In this analysis, three-dimensional waste volumes were projected onto a representative cross section and the analyses were run in a two-dimensional mode. Also, many non-steady-state processes and heterogeneous properties were averaged. This approach is justified as long as the processes controlling dilution are recognized and adequately represented by a simplified model. Similarly, as long as the averaged parameter values that quantify the necessary processes and properties provide a conservative result (i.e., the selected values are biased to provide a higher than expected prediction of radionuclide concentration and dose estimate), the analysis results are expected to be sufficient to demonstrate compliance with the performance objectives.

The two general processes that fundamentally control the radionuclide concentration in the groundwater withdrawn from a downstream well are as follows:

- The integrated radionuclide flux from the facility. The integrated flux is the total radionuclide mass exiting the disposal facility per unit time. Flux is controlled by waste release mechanisms and disposal facility characteristics such as the influence of barriers and the disposal facility's orientation relative to the general direction of regional groundwater flow.

- The volume of groundwater that mixes with the radionuclide activity released from the facility, which is determined by regional flow characteristics, primarily the hydraulic gradient and the saturated hydraulic conductivity.

3.2.1.1 Regional and Local Hydrologic Aspects of the Conceptual Model. To develop confidence that the regional flow characteristics affecting the dose estimates are understood and the important regionally derived parameter values have been conservatively selected, several approaches were taken. First, preHanford site operations well head data were evaluated to estimate the hydraulic gradient and general direction of flow beneath the 200 East Area LLBG. This is significant because the present regional flow characteristics have been noticeably altered on the 200 Area Plateau by Hanford Site operations liquid waste discharges into the soil column. Radionuclide releases based on likely infiltration rates suggest that the effects of Hanford Site operations should have disappeared by the time contaminant plumes originating from the LLBG reach the unconfined aquifer. Consequently, the post-Hanford Site operations regional flow characteristics are expected to be similar to the pre-operations condition as long as regional natural recharge characteristics are similar. 
Second, a sitewide model was developed to quantify the regional flow regime at the Hanford Site. The model can be manipulated to evaluate different conditions. The initial application of the sitewide model was to try simulating current conditions and recreating the distribution of the current contaminant plumes, primarily tritium (Appendix E). By comparing model results with the relevant database, the model's reliability can be evaluated. A close match between the model and the database indicates that the sitewide model adequately represents the major environmental properties (e.g., aquifer soil conductivity) and processes (e.g., sources of recharge and discharge) controlling regional flow patterns. It also increases confidence that homogenizing physical properties and boundary conditions on a large scale can be done and accurately represent the appropriate averaging of small-scale heterogeneities that exist in the real system.

Third, the sitewide model was used to estimate steady-state post-Hanford Site conditions underlying the 200 East Area LLBG (Appendix E). Comparing these results with pre-Hanford data provides additional confidence that site flow patterns can be estimated. Also, matching the hydraulic property data and gradient assumptions in the sitewide model with the two-dimensional facility model shows consistency between the large-scale regional approach and the local two-dimensional facility approach. Some potential alternative regional flow conditions are also discussed in Appendix $E$ and compared to the conceptual model assumed.

3.2.1.2 Two-Dimensional Disposal Facility Cross Section. The active disposal facilities in the 200 East Area LLBG are irregular three-dimensional arrays of individual trenches grouped in two primary locations. The conceptual model was designed to represent the three-dimensional waste volume of either burial ground in terms of a smaller and geometrically simple portion of the total waste volume. The model was also designed to allow estimates of radionuclide release from the representative section to be extrapolated to the actual waste volume.

The representative waste volume was assumed to be a three-dimensional rectangular box projected onto a two dimensional plane oriented parallel to the general direction of groundwater flow. To establish the numerical analys is grid (Figure 3-1), it was necessary to choose a cross section length and waste thickness. The width of the waste volume perpendicular to the cross section could be any length. For purposes of estimating radionuclide release, the waste was assumed to occupy a portion of the projected volume and was calculated as the product of the cross section length, waste thickness and the assumed width perpendicular to the cross section.

The bottom surface forms a horizontal rectangular plane, a "footprint," where the waste volume and the soil column intersect. The contaminant plume is discharged into the soil column across this plane, travels downward and intersects the water table. The projection of the plume onto the water table surface forms another horizontal plane about the same size as the waste volume-soil column planar interface. These relationships exist because the model assumptions allow for very little dispersion in any direction. The axes of the waste volume and the horizontal planes are parallel and perpendicular to the generalized direction of flow. 
Given these characteristics of the representative waste volume and the selected release mechanisms that control radionuclide flux, the radionuclide release modeling results for the representative section can be extrapolated to different waste volumes. The following points are key aspects of the extrapolation process:

- The cross section oriented parallel to the direction of flow and the downstream receptor well are in the same plane. Given these constraints, all activity released from the facility (i.e., the integrated flux) reaches the water table and is captured by the volume of groundwater that passes beneath the facility and ultimately intersects the downstream well. Thus, the radionuclide concentrations in the water withdrawn from the well are proportional to both the integrated flux exiting across the entire trench floor and the volume of groundwater into which the contaminants are released.

- The integrated flux is dominated by the selected release mechanism. Three conditions were considered in different cases in this analysis. First, advective release was assumed in which the radionuclide inventory was disseminated throughout the waste volume and was released by the infiltrated water. The release processes incorporate the effects of dispersion in the trench (Section 3.2.3.1). The integrated flux is proportional to the radionuclide inventory and the infiltration rate, but is essentially insensitive to the waste area (and therefore waste volume) over which the contaminant is released. The release rate is constant until inventory depletion prevents continuation of the initial rate. Thereafter, the release rate decreases. Second, solubilitycontrolled release is assumed in which chemical conditions in the waste impose a constant radionuclide concentration in the contaminated water leaving the facility. The flux is not proportional to the inventory because solubility-controlled concentrations are insensitive to changes in inventory as long as the chemical conditions are maintained. The integrated flux is proportional to the radionuclide concentration, the infiltration rate, and the waste area over which release is occurring (i.e., the intersection of the waste volume with a horizontal plane). Finally, diffusion-controlled release was assumed. In this case, integrated flux is proportional to inventory, the area-to-volume ratio of the container, and the diffusion coefficient.

- The volume of groundwater that mixes with the fluxed radionuclides is proportional to the linear dimension of the waste volume "footprint" that is perpendicular to flow. This occurs because relatively little dispersion is allowed in the model and the area over which the groundwater and the contaminant plume intersect is essentially the same as that of the area underneath the waste volume. Similarly, the orientation of the areal footprint relative to groundwater flow remains constant. Thus, as the linear dimension of the footprint perpendicular to flow increases or decreases, the volume of mixing groundwater increases or decreases.

The radionuclide concentration estimates in groundwater derived from the representative section can be extrapolated to different waste volumes and 
different waste inventories as long as the relative changes in integrated flux and mixing volumes of groundwater between the comparative conditions are understood. The critical concepts described previously can also be used to describe how radionuclide concentrations in well water can be related to input parameters (e.g., radionuclide inventory, size of waste volume, orientation of waste volume). The method of extrapolation is based on the following set of conditions.

1. In the base-case analyses, if advection- or diffusion-controlled release was assumed, a unit inventory of radionuclide $x$ was assumed to be distributed across the representative volume. The volume of mixing groundwater is fixed by the assumption that the representative section is $1 \mathrm{~m}$ wide in the direction perpendicular to groundwater flow. The direction perpendicular to flow is referred to as the width of the waste volume in the remainder of the document and the direction parallel to flow is referred to as the length of the waste volume. From this analysis, a groundwater concentration over time was calculated at the downstream well. As long as advection- or diffusion-controlled release is selected, extrapolation from the base case results can be done in the following ways:

a. If the inventory and the width are held constant, the groundwater concentration estimates are independent of the length over which the inventory is distributed. This occurs because the integrated flux is independent of the volume over which the inventory is released. Variability in radionuclide concentration within the waste volume has no influence on the results.

b. If the inventory is changed and the width is held constant, the change in groundwater concentration estimates are directly proportional to the relative change in inventory. This occurs because the integrated flux is changed and the mixing volume is held constant.

c. If the width is changed and the inventory is held constant, the change in groundwater concentration estimates are inversely proportional to the relative change in width. This occurs because the integrated flux is held constant and the mixing volume is changed.

d. If both the radionuclide inventory and the width are changed, the change in groundwater concentration estimates are proportional to both relationships described in (b) and (c). For example, if the radionuclide inventory is increased by a factor of 10 and the width is increased by a factor of 10 , no change in the groundwater concentration relative to the basecase analysis will occur.

2. In the base-case analyses, if a constant-concentration release mechanism were assumed, a given concentration of radionuclide $x$ would be assumed to exist within the representative volume (in the base-case analyses, a unit concentration was arbitrarily selected). The volume of mixing groundwater is fixed by the assumption that the 
inventory is distributed over a $1 \mathrm{~m}$ wide section in the direction perpendicular to flow. From this analysis, a groundwater concentration over time was calculated at the downstream well. As long as constant-concentration release is selected, extrapolation from the base-case results can be done in the following ways:

a. If the constant-concentration value and the length are held constant, the groundwater concentration estimates are independent of the width over which the inventory is distributed. Unlike the advection-controlled release condition, the integrated flux is proportional to the volume (and therefore, the horizontal area covered by the waste volume) over which the constant-concentration-controlled release is occurring. Because the proportional increase in integrated flux caused by the expansion of the volume in the direction perpendicular to flow is matched by the increased mixing volume of groundwater, no change in groundwater concentration occurs.

b. If the constant-concentration value is held constant and the length is changed, the change in groundwater concentration estimates is directly proportional to the relative change in length. This occurs because the integrated flux is changed but the mixing volume is not.

c. If the constant-concentration value is changed and the length is held constant, the change in groundwater concentration estimates is directiy proportional to the change in constant concentrations. This occurs because the integrated flux depends on the constant-concentration value.

d. If both the constant-concentration value and the length are changed, the change in groundwater concentration estimates is proportional to both relationships described in (b) and (c). For example, if the constant-concentration value and the length are each increased by a factor of 10 , the groundwater concentrations will be increased by a factor of 100 .

\subsubsection{Overview of the Hodeling Approach}

Table 3-3 summarizes the major components of the modeling approach. The relationship between the conceptual model, the mathematical models used to simulate the conceptual model, and the primary input parameters and data output are listed. The first two steps in the process provide the radionuclide flux at the disposal facility soil column boundary. The third step in the process estimates flux through the soil column to the unconfined aquifer and is used to calculate flux at the water table or at any distance downstream in the unconfined aquifer. Groundwater concentrations are also calculated as a function of time. The fourth step is to calculate dose assuming use of groundwater by humans and the groundwater concentrations provided in Step 3 as the source of dose.

For source-term release, the mass transfer code VAM3D-CG is used to quantify the groundwater advective flux conditions and analytical solutions 
WHC-SD-WM-TI-730, REV 0

are used to calculate the radionuclide release from the waste material or waste form. The VAM3D-CG code uses a finite element numerical approach to simulate the flow and transport processes. In this part of the model approach, it is used to quantify steady-state flow conditions as determined by the input parameters that control groundwater movement, such as assumed infiltration rate and hydrologic properties of the soil column, both vadose zone and unconfined aquifer.

The second part of the source-term release analysis is calculating the radionuclide release rates from the waste or waste form. The mixing cell cascade model used in this analysis (Kozak et al. 1990) is an analytical approach that uses the flow field parameters, an assumed advection-controlled release mechanism, and a disposal facility configuration to produce a radionuclide flux history, which is then input back to VAM3D-CG as a boundary condition to calculate radionuclide transport through the soil column. If diffusion is the assumed release mechanism, a one-dimensional analytical model is used as the boundary condition input. For constant concentration or solubility-controlled release, a constant concentration is assumed in solution that, combined with flow field parameters and the disposal facility configuration, produces the necessary radionuclide flux history. For the advective- and diffusion-controlled releases, a finite inventory is assumed that is ultimately depleted. For constant concentration-controlled release, the inventory is undefined, but is sufficient to sustain the constant concentration indefinitely.

The third step of the process is calculating the radionuclide transport through the vadose zone to the water table. The conceptualization of the modeling approach is based on the hydrogeologic condition at the Hanford Site. Long term, the groundwater in the unconfined aquifer underneath the 200 East Area LLBG will flow dominantly from west to east. The primary sources of natural recharge to the unconfined aquifer are the areas of high relief to the west of the Hanford site. From the recharge area, the groundwater flows downgradient to the discharge areas in the east, primarily the Columbia River. The general flow pattern is interrupted localiy by groundwater mounds and basalt outcrops in the 200 West and East Areas. The mounds are dissipating and should have little effect on the flow pattern in the post-Hanford era. Therefore, the flow field can be characterized satisfactorily using a two-dimensional approach because the velocity in the vadose zone is dominantly vertical and the velocity in the unconfined aquifer will be dominantly from west to east.

The code VAM3D-CG is again used to quantify radionuclide flux using the source term flux history, infiltration rates, and the hydraulic gradient as boundary conditions. Additional primary inputs are the hydrautic conductivities of the geologic units in the vadose zone and the unconfined aquifer. An important consideration in the vadose zone is the variability of hydraulic conductivity as a function of moisture content. The primary output of the code is the groundwater concentration as a function of time, which can be quantified at the vadose zone-unconfined aquifer boundary (the water table) or any location downstream.

A mass balance check was used, where possible, to ensure that the modeling steps (first, second, and third) were well integrated. For instance, where finite initial inventories were assumed, the total mass leaving the simulation domain at the right boundary (i.e., entering the drinking wel1) was 
checked to be approximately equal to the total mass of inventory released from the bottom of the trench.

The VAM3D-CG code simulates the vadose zone and unconfined aquifer in a single run. The concentration versus time at the drinking well is a calculated average from the output at the node points corresponding to the well screen. For the vadose zone application, VAM3D-CG-simulated results were benchmarked with the results simulated by PORFLOW (see Appendix G2 in Wood et al. 1995a). The solutions showed very good overall agreement when plotted, even though VAM3D-CG and PORFLOW employ significantly different solution techniques.

The fourth step of the modeling process is the dose calculation, which takes the groundwater concentration in the unconfined aquifer calculated in the third step and calculates a dose to the offsite individual or individuals, depending on water use. Two scenarios are considered in response to the performance requirements assumed in this analysis. These include the a) 1-pathways scenario with a performance objective of $25 \mathrm{mrem} / \mathrm{yr}$ and the groundwater drinking scenario with a performance objective of $4 \mathrm{mrem} / \mathrm{yr}$.

In the all-pathways scenario, water is drawn from a well $100 \mathrm{~m}$ (328 ft) downstream from the edge of the facility and used for drinking, watering crops, and watering livestock. The regional hydrologic flow patterns (Figure 2-8) and the sitewide model results (Appendix E) support the assumption that groundwater radionuclide concentrations and, therefore, potential dose, will diminish as a function of distance downgradient of the disposal facility. The individual receives a dose from ingestion of contaminated water, crops, milk, and beef. Doses by inhalation and external exposure are also received. In the groundwater-drinking scenario, the individual is exposed only by drinking well water.

\subsubsection{Source Term Analysis}

Section 3.2.3.1 discusses the conceptual model of radionuclide release rates, emphasizing the simplifying assumptions needed to complete a calculation. Section 3.2.3.2 describes the mathematical treatment of the source term and Section 3.2.3.3 discusses base-case parameter values.

3.2.3.1 Conceptual Model of Source Term Release. The actual process of radionuclide release from LLW cannot be modeled precisely because of the variability of chemical and physical reactions that occur in the waste material. In the real system, radionuclides are distributed in a heterogeneous fashion among different waste materials, radionuclides are released into solution at different rates because of the variability in waste material and the presence or absence of containers, and variable types and quantities of radionuclides are dissolved into the infiltrating water over time, depending on which waste material contacts a particular volume of water. Therefore, averaging concepts are used in modeling that simplify the mathematical representation of the real system. These concepts must be justified as being a conservative representation of the real system. 
WHC-SD-WM-TI-730, REV 0

To introduce conservatism into the source-term release estimates, the following assumptions were made.

- For most waste materials disposed of directly without treatment, it was assumed that the radionuclide inventory was immediately available for release into the infiltrating solution. However, some waste materials will provide resistance to release and contribute to the reduction of the peak radionuclide flux. In this analysis, the immobilizing properties of activated metal and a grout waste are assumed for some waste streams.

- It is assumed that all infiltrating water receives the maximum amount of dissolved radionuclides prescribed by the release mechanism assumed in the modeling analysis. Because of the variability in water contact with waste, maximum possible concentrations will not occur in all the water passing through the facility. Consequently, some reduction in the peak flux is expected relative to the calculated value.

- For those waste materials that are incorporated into a waste form that controls radionuclide release by diffusion (i.e., grout), it is assumed in the models that the diffusion coefficient values remain constant over time. Secondary chemical reactions first occur at surfaces of the material undergoing leaching and effectively reduce the diffusive coefficient characteristic of that material. If the peak flux rate from the facility has not been reached before the reduction in diffusive flux occurs, a reduction in peak flux from the facility is expected relative to the calculated value. Given the relatively rapid nature of these secondary mineralization reactions in natural systems (frequently on the order of weeks) and the infrequency of actual advection of infiltrating water at the Hanford Site disposal facilities, it is likely that actual flux will be less than the calculated value.

The conceptual model assumes additional conditions to facilitate modeling. These include the following:

- Radionuclide inventories are assumed to be homogeneously distributed among the wastes.

- For each modeling run, one type of release mechanism is assumed. In addition to advection-controlled release, a constant concentration is assumed as a separate type of release to simulate solubility control or steady-state corrosion control of radionuclide release. Also, a diffusion-controlled release rate was assumed for some cases. Selecting the appropriate release mechanism in dose estimate calculations depends. on the radionuclide of interest and the assumed conditions at disposal (Section 4.4.2)

- Unit concentrations (for constant-concentration runs) or unit quantities (for advection-controlled release runs) of single radionuclides are assumed for the modeling runs. Because dose estimates are directly proportional to initial inventory, the modeling runs with unit concentrations or quantities can be ratioed to calculate dose for any initial inventory values. 
3.2.3.2 Mathematical Simulation of Radionuclide Release Mechanisms. The source term is defined as the release of radionuclides from the 200 East Area LLBG into the soil column. The source terms were estimated by an advectiondominated release model (a mixing-cell cascade model) (Kozak et al. 1990), a constant-concentration release model, and a diffusion-limited release model. The mathematical description and conditions under which the different mechanisms are assumed are provided in the following sections.

3.2.3.2.1 Advection-Dominated Release Model. The advection-dominated release model (mixing-cell cascade model) is used to simulate the processes of releases from unstabilized waste. For unstabilized waste, the radionuclides exit the facility at a rate determined by the flow of water and the amount of dispersion (mixing) in the disposal unit (i.e., by near-field transport processes). The mixing-cell cascade model (Kozak et a1. 1990) is based on the dispersion analysis of processing tanks and allows the analysis to incorporate the effects of dispersion in the trench in a simplified manner. In this model, the disposal unit is considered to be composed of a cascade of $\mathbf{N}$ equalsized, well-stirred cells in series. The total volume of the $\mathrm{N}$ cells is equal to the volume of the disposal unit.

The mixing-cell cascade model for $\mathrm{N}$ equal-sized cells is described by the following equation:

$$
Q(t)=\operatorname{vAC}_{0} e^{-\alpha N t} \sum_{n=1}^{N} \frac{(\alpha N t)^{n-1}}{(n-I) !}
$$

where:

$Q=$ release rate $(\mathrm{Ci} / \mathrm{yr})$

$v=$ vertical Darcy velocity $(\mathrm{m} / \mathrm{yr})$

$A=$ horizontal (planar) area of the disposal unit

$\alpha=\mathrm{v} / \theta \mathrm{LR}$

$\theta=$ moisture content in the trench

$L=$ vertical depth of the disposal unit (m)

$R=$ retardation factor in the disposal unit $(R=1)$.

The initial concentration of contaminant in the interstitial water can be determined from the following equation:

$$
\mathrm{C}_{0}=\frac{\mathrm{m}}{\theta \mathrm{VR}}
$$

where m equals total facility inventory of the radionuclides in the disposal unit and $V$ equals total waste volume $\left(\mathrm{m}^{3}\right)$.

The mixing-cell cascade model provides results equivalent to the onedimensional, convective-dispersion equation with varying values of the dispersion coefficient (Kozak et al. 1990). In the limit, as $N$ approaches infinity, the model represents flow through a system with zero dispersion, 
whereas for $N$ equal to one, the model represents flow with an infinite dispersion coefficient. In this analysis, $N=10$. This number represents moderate dispersion.

3.2.3.2.2 Constant-Concentration Release Model. Radionuclide release from the trench may be controlled by a solubility-limiting reaction imposed by the soil-water environment or a waste form or by a constant-corrosion-rate reaction where contaminant release is assumed to depend on the dissolution of the waste matrix. One way to model the constant-concentration release is by replacing $C_{0}$ in Equation 3.5 with the constant concentration. The other way is to use a constant boundary source model with $C / C_{0}=1$, where $C_{0}$ is the constant concentration. The latter approach was used.

3.2.3.2.3 Diffusion-Dominated Release Model. The diffusion-dominated release model is used to simulate the release of contaminants from stabilized wastes. In the absence of convection through the waste container, the release can be modeled as a diffusion-limited process. A simple result, a 1-D diffusion solution, was adopted (Crank 1975). The solution, for a semiinfinite medium with the concentration $c_{0}$ throughout, initially, and with zero surface concentration, is given by

$$
c=C_{0} \operatorname{erf} \frac{x}{2 \sqrt{\left(D_{\theta} t\right)}}
$$

where:

erf $=$ standard error function

$D_{e}=$ effective diffusion coefficient of the radionuclides in the waste form

$t^{e}=$ time

$x=a$ distance from the source to the zero concentration surface.

The rate of loss of diffusing substance per unit area from the semi-infinite medium when the surface concentration is zero, is given by:

$$
\left(D_{e} \frac{\partial C}{\partial x}\right)_{x=0}=C_{0} \sqrt{\frac{D_{e}}{\pi t}}
$$

Equation (3.8) has the form of diffusion mass transfer based on leaching theory. This simplified release model leads to the following form:

$$
q=A C_{0} \sqrt{\frac{D_{e}}{\pi t}}
$$


where:

$q=$ release rate from a single waste container ( $\mathrm{C} i / \mathrm{yr}$ ),

$A$ = effective surface area of a single container, and

$\mathrm{C}_{0}=$ concentration in the container.

Because the LLW is likely contained in various sizes of drums and boxes, the diffusive release rate, $Q$, from all containers in the facility can be determined by the following equation:

$$
\begin{aligned}
Q & =C_{0} \sqrt{\frac{D_{e}}{\pi t}} \sum_{i=1}^{n} A_{i} \\
& =C_{0} A_{t} \sqrt{\frac{D_{\theta}}{\pi t}}
\end{aligned}
$$

where $n$ is the number of containers, $A_{i}$ is the surface area of $i$-th container and $A_{t}$ is total surface area of all containers.

Equation (3.10) was obtained by assuming that the concentration in all containers is constant, i.e.,

$$
I=C_{0} \sum_{i=1}^{n} V_{i}=C_{0} V_{t}
$$

where $I$ is total inventory, $V_{i}$ is the volume of $i$-th container and $V_{t}$ is total volume of all containers.

Substituting equation (3.11) into equation (3.10), we obtain the following equation:

$$
Q=I \frac{A_{t}}{V_{t}} \sqrt{\frac{D_{e}}{\pi t}}
$$

Where all containers are same size and shape, the ratio $A_{t} / V_{t}$ can be replaced by a ratio of a surface area over volume of a single container. The ratio $A_{t} / N_{t}$ (or $A / V$ of a single container) used throughout the model calculation is $9.3 \mathrm{~m}^{-1}$ the $A / V$ ratio of a 55 -gai drum.

The model calculation is conservative in two aspects. First, the surface area of each container might not be completely exposed to a moving stream of water. Second, the radionuclides reaching the surface of the container are assumed to be released into the water stream and instantaneously reach the bottom of the trench for release. 
3.2.3.3 Base-Case Parameter Selection. The major parameters that determine the source-term release rate include those describing the release rate and the infiltration rate. With regard to the advection-controlled dissolution assumption, the concentration in solution is arbitrarily set because no assumption is made of waste-form-controlled release. As discussed in Section 3.2.3.1, the peak groundwater concentration that is calculated in the modeling run and, therefore, the dose estimate, is directly proportional to the initial inventory quantity in the disposal facility, allowing the calculation of dose for any initial inventory.

Similarly, when constant-concentration source terms are assumed, the peak concentration values are proportional to the constant-concentration value. In this analysis, the constant concentration is derived from a solubilitycontrolled reaction or a constant corrosion rate. When solubility limits are controlling, the solubility depends on the chemical behavior of a particular radioelement in a specific geochemical environment. The solubility value is based on a thermodynamic database and associated data. The use of the solubility argument turns out to be significant only for uranium isotopes. The solubility values selected for uranium are $10^{-4}$ and $10^{-6} \mathrm{~mol} / \mathrm{L}$ in a soildominated and Portiand cement-dominated environment, respectively (Appendix $E$ of Wood et al. 1995a).

Constant concentrations derived from corrosion processes are based on the assumption of constant corrosion of activated metal waste. In this case, the mass of metal dissolved in solution per unit time is constant. Radionuclide activation products are assumed to be homogeneously distributed in the metal such that a constant activity of each radionuclide is dissolved in solution per unit time. Because the mass of solution into which the radionuclide is dissolved is also constant per unit time (e.g., the infiltration rate is assumed to be constant), a constant radionuclide concentration is derived. In this analysis, the corrosion-based source-term approach is applied to the reactor compartment waste stream where activated metal is the waste material.

To determine the radionuclide activity dissolved in solution, a general corrosion rate and radionuclide concentration in the activated metal waste must be selected. General corrosion rates in Hanford Site soil have not been measured for the reactor compartment metals. However, by looking at corrosion-rate measurements for the appropriate metal type taken in soil similar to Hanford Site soil, (alkaline, low moisture content, and low chloride content), a conservative upper bounding corrosion rate can be selected. Jenkins (1993) recommends a value of 0.01 and $0.02 \mathrm{mg} / \mathrm{dm}^{2} \mathrm{yr}$ for the two types of corrosion-resistant steels (Inconel A1loy-600 and CRES 304) found in the reactor vessels. In these analyses, a corrosion value of $0.02 \mathrm{mg} / \mathrm{dm}^{2} \mathrm{yr}$ is assumed. Correspondence from the generator (Wrzeski 1996) indicates that over 90 percent of the radionuclide inventory is present in the more corrosion-resistent metal. Using the recommended corrosion rate of the less corrosion-resistant metal that contains $<10$ percent of the inventory further increases the conservatism of the analysis.

The other significant parameter affecting radionuclide flux in the source-term release analysis is the assumed infiltration rate. Lysimeter data from various experiments conducted at the Hanford Site indicate that the fraction of recharge resulting from precipitation is highly dependent on the 
soil and vegetation conditions. These data are summarized by Gee et al. (1992) and are most conveniently considered in terms of three levels of infiltration. First, maximum recharge occurs in unvegetated coarse-grained soils with values ranging from about 5 to $10 \mathrm{~cm} / \mathrm{yr}$. Second, minimum recharge (no measurable infiltration or $<0.1 \mathrm{~cm} / \mathrm{yr}$ ) occurs in bare silt-loam soil or silt-loam soil with shallow- and deep-rooted vegetation. A long-term deep lysimeter test (Routson and Johnson 1990) produced evidence that minimum recharge occurs in sandy soil with a mixture of shallow- and deep-rooted vegetation, a condition typical of undisturbed Hanford Site soils. Seasonal variability in the moisture content of the top $3 \mathrm{~m}$ of soil was measured, but no measurable recharge occurred over 13 years. Third, intermediate recharge (<0.1 to about $5 \mathrm{~cm} / \mathrm{yr}$ ) occurs in sandy soil with shallow-rooted vegetation (e.g., grasses).

Given this breakdown of plausible ranges of recharge rates, the boundary value between high and intermediate recharge rates $(5-\mathrm{cm} / \mathrm{yr})$ was chosen for the Category 1 facility, for which a minimal-thickness soil cover is provided. For the Category 3 facility, a recharge rate of $0.5 \mathrm{~cm} / \mathrm{yr}$ is assumed. In this case, it is assumed that care is taken to provide a thick cover that will support a typical suite of native vegetation for which infiltration rates are generally unmeasurable. The choice of $0.5 \mathrm{~cm} / \mathrm{yr}$ is considered a reasonably conservative value averaged over a long time period and is consistent with data presented in Fayer and Walters (1995).

\subsubsection{Contaminant Flux in the Vadose Zone and the Unconfined Aquifer}

Once radionuclides are released into the partially saturated vadose zone, transport down through the vadose zone is assumed, ultimately leading to contamination of the unconfined aquifer. In this section, the methodology used to model this process is described beginning with the conceptual model. The mathematical basis for the code VAM $3 D-C G$ and the primary input parameters also are described.

\subsubsection{Conceptual Model of Mass Transport in the Hydrogeologic Environment.} The primary factors controlling mass transport in the soil column are the infiltration rate of water through the soil column, the features of the disposal facility affecting infiltration rate (in this analysis, the cover permeability), the permeability of the soils, and the hydraulic gradient. Given the variability of these conditions or processes as a function of time and space, certain simplifications must be made to complete a mathematical calculation. This is done by assuming steady-state conditions that approximate natural variability. The following assumptions are made in the conceptual model:

- Recharge from water infiltrating the soil column occurs sporadically in nature. Recharge estimates are further complicated by the occurrence of other processes affecting actual infiltration. These include seasonal storage in the soil cover or surface soil and evapotranspiration. In this model an averaged steady-state annual infiltration rate is assumed for soil and the disposal facility cover. The approach is sound because total mass transport over a fixed boundary and any given time is additive. As long as the average equals or exceeds the sum of the separate recharge events 
over a given time, estimates of total mass or activity of nuclides that contaminate the unconfined aquifer will be equivalent or conservatively high. Similarly, as long as the averaged recharge rate equals or exceeds the net infiltration through soil or the cover, a sophisticated model of each individual process affecting recharge is not necessary. It is assumed that the available empirical database is sufficient to select a reasonably conservative parameter value.

- The spatial variability in soil properties, even within the same formation, indicates that variability in hydraulic properties occurs in three dimensions. To limit the number of modeling analyses, a unique set of hydraulic conductivity values were assigned to each major stratigraphic unit in the vadose zone and unconfined aquifer beneath the 200 East Area LLBG as a function of moisture content and depth. It is assumed that variability in the permeability-moisturecontent relationships is sufficiently bounded by the available database. It is also assumed that variability in these parameters has a minimal impact on the radionuclide concentration estimates in the unconfined aquifer and, therefore, the potential dose to an individual. The assumptions are supported by comparing results from the separate analyses completed for the $218-E-10$ and the $218-E-12 B$ LLGBS. Data on the site-specific moisture retention curve are very similar. Results for groundwater contamination agree within an order of magnitude.

- The major stratigraphic units underlying the 200 East Area LLBG vary in thickness spatially. The conceptual model assumes a layer-cake stratigraphy with constant thickness for each layer. This assumption is justified by the observation that the hydrologic properties of each layer in the vadose zone are similar and changes in travel time resulting from this variability are insignificant. Sensitivity analysis (Wood et a1. 1995a) shows that radionuclide groundwater concentrations are relatively insensitive to changes in hydrologic conductivity within the range of expected values for the existing soils.

- The infiltration rate for the area immediately surrounding the facility is modeled to be the same as the infiltration rate in the facility. Section 4.3.4 of Wood et al. (1995a) shows that increasing the infiltration rate outside the covered area has only a small impact on the peak concentration.

3.2.4.2 Mathematical Simuiation of Contaminant Flux. The finite-element computer code VAM3D-CG (Huyakorn and Panday 1992) is being used to estimate the transfer of radionuclides that are released from the disposal facility and transported through the vadose. zone into the unconfined aquifer and, eventually, into the biosphere. VAM3D-CG is a proprietary product of HydroGeologic, Inc., of Herndon, Virginia.

The code uses a finite-element numerical approach to simulate the flow and transport process. It assumes a porous medium that can be either partially or completely saturated. The code is three-dimensional but is used in a two-dimensional mode that considers a cross-sectional slice through the disposal facility (Figure 3-1). A geometric grid is set up that represents a 
segment of the 200 East Area LLBG (1 $\mathrm{m}$ [3 $\mathrm{ft}$ ] wide oriented north-south) at the upper boundary of the grid, the hydrogeologic units of the vadose zone, the unconfined aquifer, and a well $100 \mathrm{~m}(328 \mathrm{ft})$ downstream from the trench. The well is at the right boundary of the flow domain.

To perform a variably saturated flow analysis, the VAM3D-CG code uses the pressure head or hydraulic head as the dependent variable if a rectangular grid is used. For an orthogonal curvilinear grid, the dependent variable is the hydraulic head. The governing equation for water flow in a variably saturated soil is written as:

$$
\frac{\partial}{\partial x_{i}}\left[\rho_{w} K_{i j} k_{x w}\left(\frac{\partial \Psi}{\partial x_{j}}+e_{j}\right)\right]=\frac{\partial}{\partial t}\left(\rho_{w} \phi S_{w}\right)-\rho_{w} q
$$

where:

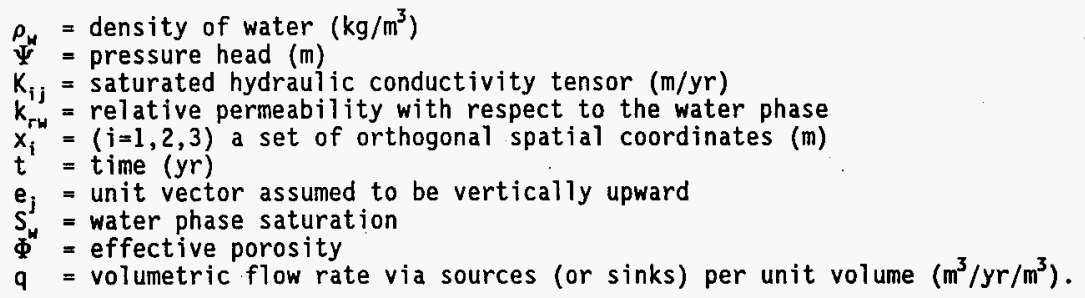

The pressure head, $\Psi$, and hydraulic head, $h$, are related by $h=\Psi+z$ where $z$ is in the vertical upward direction.

For a slightly compressible fluid, equation 3.13 can be written in the form:

$$
\frac{\partial}{\partial x_{1}}\left[K_{i j} k_{z w}\left(\frac{\partial \psi}{\partial x_{j}}+e_{j}\right)\right]=\left(S_{w} S_{s}+\phi \frac{d S_{w}}{d \psi}\right) \frac{\partial \psi}{\partial t}-q
$$

The specific storage coefficient, $S_{s}$, is defined as

$$
S_{s}=\rho_{w} g(\phi \beta+\alpha)
$$

where:

$\mathrm{g}$ is the gravitational constant $\left(\mathrm{m} / \mathrm{yr}^{2}\right)$ and $\alpha$ and $\beta$ are coefficients of compressibility of the porous medium and water, respectively $\left(\mathrm{m}^{2} / \mathrm{N}\right)$. 
To solve the variably saturated flow problem, two supplementary equations must be specified: the relationships of relative permeability versus water saturation and pressure head versus water saturation. Both Brooks-Corey and van Genuchten-Mualem models are incorporated in the VAM3D-CG code. These functions are given by Brooks and Corey (1966):

$$
k_{r w}=s_{e}^{n}
$$

and van Genuchten (1980) (derived from Mualem [1976]):

$$
k_{r w}=S_{\theta}^{1 / 2}\left[1-\left(1-S_{\theta}^{1 / \gamma}\right)^{\gamma}\right]^{2}
$$

where:

$n$ and $\gamma$ are empirical parameters and $S_{e}$ is the effective water saturation defined as $S_{e}=\left(S_{w}-S_{w r}\right) /\left(1-S_{w r}\right)$ with $S_{w r}$ as the residual water saturation.

The relationship of pressure head versus water saturation is described by the following function (van Genuchten 1980, Mualem 1976):

$$
\begin{aligned}
\frac{S_{w}-S_{w x}}{1-S_{w x}} & =\frac{1}{\left[1+\left(\alpha\left|\psi-\Psi_{a}\right|^{\beta}\right]^{\gamma}\right.} & & \text { for } \Psi<\Psi_{a} \\
& =1 & & \text { for } \Psi<\Psi_{a}
\end{aligned}
$$

where:

$\alpha=$ empirical parameter

$\beta=$ empirical parameter

$\Psi_{a}=$ the air entry pressure head (m).

The parameters $\beta$ and $\gamma$ are usually assumed to be related $\gamma=1-1 / \beta$. The BrooksCorey and van Genuchten functions for the moisture retention and relative permeability characteristics are derived from the laboratory measurements for a given soil. 
The governing equation for three-dimensional transport of a nonconservative component in a variably saturated soịl takes the form:

$$
\begin{gathered}
\frac{\partial}{\partial x_{1}}\left(D_{i j} \frac{\partial c}{\partial x_{j}}\right)-\frac{\partial}{\partial x_{i}}\left(v_{i} c\right)=\frac{\partial}{\partial t}\left[\phi S_{w} c+\rho_{s}(1-\phi) c_{s}\right]-q c * \\
+\lambda\left[\phi S_{w} c+\rho_{s}(1-\phi) c_{s}\right] \quad i, j=1,2,3
\end{gathered}
$$

where:

$D_{i j}=$ hydrodynamic dispersion tensor $\left(\mathrm{m}^{2} / \mathrm{yr}\right)$

$c=$ solute concentration in the fluid $\left(\mathrm{Ci} / \mathrm{m}^{3}\right)$

$v_{i}=$ Darcy velocity $(\mathrm{m} / \mathrm{yr})$

$\rho_{s}=$ density of solid grains $\left(\mathrm{g} / \mathrm{cm}^{3}\right)$

$\mathrm{c}_{\mathrm{s}}=$ adsorbed concentration $(\mu \mathrm{Ci} / \mathrm{g})$

$\lambda^{s}=$ first-order decay coefficient $(1 / y r)$

$c^{*}=$ solute concentration in the injected fluid $\left(\mathrm{Ci} / \mathrm{m}^{3}\right)$.

Assuming the relation between adsorbed and solution concentration is described by a linear equilibrium, equation 3.19 can be expressed as:

$$
\frac{\partial}{\partial x_{i}}\left(D_{i j} \frac{\partial c}{\partial x_{j}}\right)-\frac{\partial}{\partial x_{i}}\left(v_{i} c\right)=\frac{\partial}{\partial t}\left(\phi S_{w} R c\right)+\lambda \phi S_{w} R c-q c^{*}
$$

where $R$ is the retardation defined as:

$$
R=1+\frac{\rho_{s}(1-\phi) K d}{\phi S_{w}}=1+\frac{\rho_{B} K d}{\phi S_{w}}
$$

with the distribution coefficient Kd and the bulk density, $\rho_{\mathrm{B}}$, being defined as $\rho_{\mathrm{B}}=(1-\phi) \rho_{\mathrm{s}}$.

The hydrodynamic dispersion tensor components are computer derived using the following constitutive relations for homogeneous systems (Scheidegger 1961):

$$
D_{i j}=\alpha_{T}|V| \delta_{i j}+\left(\alpha_{L}-\alpha_{T}\right) \frac{v_{i} v_{j}}{|V|}+\tau D^{\circ} \delta_{i j}
$$


WHC-SD-WM-TI-730, REV 0

where:

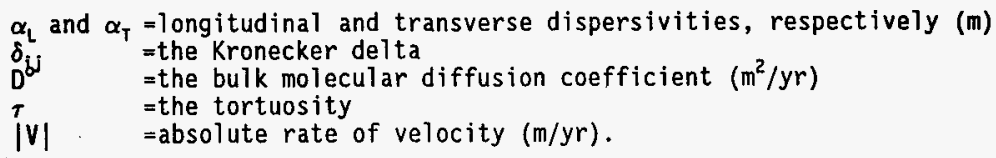

The Galerkin and upstream weighted residual procedures are employed for solving the flow and transport equations. Preconditioned Conjugate Gradient (PCG) and ORTHOMIN techniques are used to solve the large symmetric and asymmetric matrix equations. Element matrices are generated using influence coefficient formulas, thus avoiding costly numerical integration. The code can easily be adapted for one-, two-, or three-dimensional applications, including axisymmetric configurations. The detailed description of the numerical methods implemented in the code are given in the users' manual (Hayakorn and Pandan 1992).

3.2.4.3 Base-Case Parameter Selection. This section describes the basic input parameters to the flow and transport analysis. These include a description of stratigraphic parameters and hydrologic parameters used to control mass transport, geochemical parameters used to represent radionuclide sorption in the soil column, dimensions of the disposal trench used, additional boundary conditions, and the element grid used to simulate the disposal facility and hydrogeologic zones of the underlying soil column.

3.2.4.3.1 Representation of the Soil Column Stratigraphy. Construction of a geometric model to represent the vadose zone and unconfined aquifer zones beneath the 200 East Area LLBG is limited by the scale of geologic heterogeneity and the amount of geohydrologic data available to distinguish the stratigraphic units and subunits from each other. Separate soil column models were used for the 218-E-10 and 218-E-12B Burial Grounds because specific data bases are available for each site and are slightly different. The selected models use several hydrologically distinct units (see Section 3.2.4.3.2) that correspond to the major geologic units representing the vadose zone and the unconfined aquifer beneath the 200 East burial grounds. Unit thicknesses are based on a detailed study of the stratigraphy underlying the 200 East LLBG.

For modeling purposes, hydraulic properties assigned to each unit are based on data available from adjacent sites as described in the next section. It is recognized, however, that all the geologic units are variable perhaps to the extent of containing lenses with distinctly different particle size distributions, porosities, phase mineralogy volumes, and hydrologic characteristics. The use of layer-cake stratigraphy is justified by the observation that variations in thickness are not extreme for any of the units considered in the analysis. The aquifer thickness is projected to be no more than $5 \mathrm{~m}$. Thus, the entire aquifer is represented in the numerical geometry (Figure 3-1) and the downstream well screen is assumed to intercept the entire thickness of the unit.

Preferential vertical pathways are assumed to not be present in the soil column underneath the 200 East Area burial grounds and were not incorporated into the base-case analyses. Vertical to subvertical features referred to as clastic dikes occur sporadically in the Hanford formation. Although they have 
not been observed inside the 200 East Area LLBG, they may exist. The dikes vary greatly in the types of materials with which they are filled and their length. Typically the cross-sectional area perpendicular to the long axis of the dike is less than $1 \mathrm{~m}^{2}\left(11 \mathrm{ft}^{2}\right)$. No permeability information is available. Because of the small volume of these dikes and the low frequency of occurrence, they are expected to have little impact on the flux of contaminants.

For this analysis an additional case was examined in which a clastic dike was modeled as a $1.0-\mathrm{m}$ - $(3-\mathrm{ft})$-wide crack filled with fine-grained material (thus providing a preferential pathway through the coarser surrounding material). In addition to extending the crack from the bottom of the trench to the aquifer, the fine material was artificially distributed in a layer under the entire trench. The results of this model are discussed in chapter 4 (See Section 4.2.2.2.4).

\subsection{Moisture Retention and Unsaturated Hydraulic Conductivity}

Relations. A number of parameters are needed to model the vadose zone hydrology and transport from a solid-waste disposal site. The rate at which water can travel through the vadose zone is extremely sensitive to the moisture content of the sediment. Important parameters that characterize the vadose zone hydrology are the moisture-retention characteristics and unsaturated hydraulic conductivities of the soils and sediments within the vadose zone. These parameters, along with hydraulic properties of the unconfined aquifer, are needed to model the flow and transport from a solidwaste burial site.

Samples from Borehole 299-E34-1, located within the 218-E-12B LLEG, were analyzed in the laboratory to obtain the particle size distribution, bulk density, saturated hydraulic conductivity, moisture retention and unsaturated hydraulic conductivity data for the $218-E-12 B$ soils. Three moisture characteristic curves representing the three vadose zone units within the Hanford formation were selected for the simulations (the complete data set and their analysis are provided in Appendix A). The three vadose zone units are referred to in Table 3-4 as material types 1, 2, and 3 , respectively. The van Genuchten-Mualem parameters that were used for 218-E-12B simulations are noted in Table 3-4. As discussed in Appendix $A$, the parameters were obtained by a simultaneous fit of both laboratory-measured moisture retention and unsaturated conductivities.

Table 3-5 illustrates the hydraulic data characterizing the three vadose zone units for 218-E-10 simulations. Again, the van Genuchten-Mualem parameters were obtained by a simultaneous fit of both laboratory-measured moisture retention and unsaturated conductivities for samples from Borehole 299-E32-4 located within the 218-E-10 LLBG. Appendix A documents the available data on laboratory measurements for $218-E-10$ site soils.

3.2.4.3.3 Saturated Media and Transport Properties. The saturatted hydraulic conductivity and storativity are of primary interest for modeling of flow and transport within the unconfined aquifer. The input data on saturated hydraulic conductivity for each unconfined aquifer (i.e., for 218-E-1:B and 218-E-10) are those of Material Type 4 in Tables 3-4 and 3-5. VAM3D-CG requires an input estimate for the storage coefficient. A value of 0.0007 was used as the storage coefficient for aquifer material. The specific yields of unconfined aquifers are much higher than the storativities (i.e., storage 
WHC-SD-WM-TI-730, REV 0

coefficient times the saturated thickness) of confined aquifers. Specific yield is defined as the volume of water that an unconfined aquifer releases from storage per unit surface area of aquifer per unit decline in the water table (Freeze and Cherry 1979). Because VAM3D-CG is an integrated saturatedunsaturated model, the computations for volume of water released from storage caused by changes in moisture content in the vicinity of the water table and the associated specific-yield computations are directly incorporated into the mass balance equations being solved by the code.

A longitudinal dispersivity of $1.0 \mathrm{~m}(3 \mathrm{ft})$ and a transverse (1ateral) dispersivity of $0.1 \mathrm{~m}(0.3 \mathrm{ft})$ were used in the simulations for both saturated and unsaturated media. Within the saturated unconfined region of the flow domain, the initial pressure head values are assigned using a hydrostatic pressure head distribution. A concentration value of $\mathrm{C}=0$ is used as the initial concentration values for the radionuclides throughout the model.

3.2.4.3.4 Geochemical Parameters. Sorption and desorption reactions that control the distribution of radionuclides between water and solid can have a significant impact on release rates of the radionuclides from waste solids, on retardation of mass transport rates relative to groundwater transport rates, and on the peak concentrations in groundwater. Sorption process were assumed to occur only in the soil column. No credit was taken for desorption reactions in the waste dissolution process. Therefore, the parameter $R$ in source term equations (e.g. Equition 3.5) was assigned a value of unit that requires $\alpha \mathrm{K}^{\mathrm{d}}$ of $0 \mathrm{~mL} / \mathrm{g}$.

Typically, the distribution is quantified by a sorption coefficient or Kd $(\mathrm{mL} / \mathrm{g})$ whose value increases as the relative fraction of radionuclide increases on the solid phases. In these analyses, Kd values of $0,1,10$, and 100 have been selected to represent the set of radionuclides known to be part of a waste inventory (Table 3-5). The values represent radionuclides that are nonsorbing, slightly sorbing, moderately sorbing, and strongly sorbing. An overall summary of radionuclide sorption values is provided in Serne and Wood (1990). Additional information is provided in Kaplan and Serne (1995) and Kaplan et a1. (1995). Sorption data are also available for numerous radionuclides from batch experiments conducted under site-specific conditions. See Serne and Wood (1994) for a summary discussion. For those radionuclides for which data are not available, the similar chemical behavior of the element to an element for which data exist is used as a guide.

The four values considered in the analysis allow the selection of a reasonably conservative estimate of retardation for all radionuclides considered (Table 3-6). In this analysis, model runs were only completed for the three lower $\mathrm{Kd}$ values $(0,1$, and 10$)$. The model analyses provided the changes in peak groundwater concentrations as a function of Kd value. The modeling results from these analyses clearly show an inverse linear relationship between increases, in $\mathrm{Kd}$ values above $1 \mathrm{ml} / \mathrm{g}$ and decreases in peak groundwater concentration values. Thus, we have confidence that the peak concentration value at $\mathrm{Kd}=100 \mathrm{ml} / \mathrm{g}$ can be predicted to be a factor of 10 less than the peak value at $\mathrm{Kd}=10 \mathrm{ml} / \mathrm{g}$. Similarly, the groundwater concentration at the $100-\mathrm{m}(328-\mathrm{ft})$ downstream well versus time curve can be extrapolated.

In these analyses, the sorption process has only been used in the mass transport phase of the total groundwater contamination process. A Kd can also 
be used as a desorption mechanism in the waste release analysis. In this role, the Kd reduces predicted release rates for sorbing species. This: process was not used in this model, but should be mentioned in case future waste materials or waste forms warrant this application. For example, ${ }^{14} \mathrm{C}$ is highly sorptive in a Portland cement-based grout matrix. Empirical measurements of 600 to $10,000 \mathrm{ml} / \mathrm{g}$ have been reported (Bayliss et al. 1988). This value differs from that assumed in a soil matrix (Kd $=0 \mathrm{ml} / \mathrm{g}$ ) and would substantially reduce the estimated release rate from that currentiy assumed in nongrouted waste.

3.2.4.3.5 Disposal Facility Description. For this study, two representative sections of the 200 East Area LLBG were considered. The first section was applied to the standard burial ground trench that contains Hanford Site-generated waste. This trench was assumed to be $7 \mathrm{~m}(23 \mathrm{ft})$ deep, $20 \mathrm{~m}$ - $(66 \mathrm{ft})$ long in the direction of the aquifer flow, and $1 \mathrm{~m}(3 \mathrm{ft})$ wide. A cover layer is not represented specifically. Instead, an overall infiltration rate is assigned as a boundary condition. The second section was applied to Trench 94, which contains the submarine reactor compartments. In this case, the representative section was the same as the standard trench in orientation, trench length, and cover representation. However, the depth of the trench was assumed to be $15 \mathrm{~m}(49 \mathrm{ft})$, the approximate actual depth of Trench 94 .

3.2.4.3.6 Additional Model Parameters. As shown in Figure 3-1, a rectangular soil slab with an open trench on top was selected to simulate all cases. Boundary conditions were used to simulate the water infiltration (from precipitation) and the contaminant flux, as well as the gradient in the water table. Grid spacings used in the problem geometry are also shown in Figure 3-1. The vertical positions of the various material layers, as well as the aquifer, are marked on the side of Figure 3-1. Smaller grid spacings are used in the vicinity of material layer transitions, where rapid changes in material properties occur, and in the vicinity of the aquifer where the concentration gradients are expected to be steep. The two-dimensional network geometry consists of approximately 1,000 nodes and rectangular elements. The Tateral dimension of the domain is $200 \mathrm{~m}(656 \mathrm{ft})$ and the height is $75 \mathrm{~m}$ $(246 \mathrm{ft})$. The trench begins at $-20 \mathrm{~m}(-66 \mathrm{ft})$ and extends to $0 \mathrm{~m}(0 \mathrm{ft})$ in length. The trench is $7 \mathrm{~m}(23 \mathrm{ft})$ deep.

The near-field transport within the trench is performed by analytical models (discussed in Section 3.2.3) and incorporated into the finite element model as release boundary conditions. The right model boundary represents an intercepted well located $100 \mathrm{~m}(328 \mathrm{ft})$ from the trench. Several boundary conditions must be defined to complete the model. A prescribed recharge (infiltration) value is assigned across the top boundary nodes of a twodimensional, vertical-flow domain. (See Section 3.2.3.3 for a discussion of the values considered.) The left- and right-side boundary nodes within the vadose zone are assigned zero fluid and concentration fluxes. Based on the sitewide groundwater model (Law et al. 1996), a hydraulic gradient is established across the model flow domain from left to right. For the $218-E-10$ site, the gradient is $6.8 \times 15^{5}$ and for the $218-E-12 B$ site, the gradient is $1.08 \times 10^{-4}$. See Appendix $E$ for further discussion of gradient selection. A hydrostatic pressure head distribution is maintained for the lowermost nodes at the left boundary of the model (i.e., those within the unconfined aquifer). These nodes are al so assigned a zero concentration flux. Similarly, a hydrostatic pressure head distribution is maintained for the 
lowermost nodes at the right boundary. The bottom boundary nodes of the model are assigned zero fluid and concentration fluxes. The boundary nodes that define the trench are assigned a time-dependent contaminant flux (or, in some cases, a constant concentration) based on the initial trench inventory of radionuclides.

Initial conditions must also be defined for the model. VAM3D-CG requires input data on initial $(t=0)$ pressures and concentrations. The initial pressure heads within the unsaturated (vadose) zone are assigned using a unit gradient model. This, in turn, assigns the infiltration rate as being equal to unsaturated hydraulic conductivity. Using the moisture characteristic curves, the pressure head value for the given unsaturated hydraulic conductivity and, therefore, for the corresponding moisture content, is then obtained. Within the saturated unconfined region of the flow domain, the initial pressure head values are assigned using a hydrostatic pressure head distribution. A concentration value of $C=0$ is used as the initial concentration values for the radionuclides throughout the model.

\subsubsection{Quality Control/Quality Assurance Practices for VAM3D-CG}

VAM3D-CG was placed under configuration management in mid-1993. This process ensures that the source and executable codes are carefuliy controlled, and the results are traceable to the code that created them. Two versions of the code have been used in performance assessment work. The initial version $2.4 b$ of VAM 3D-CG was used to model radionuclide release and transport. processes in the 200 West Area LLBG PA (Wood et al. 1995a). Benchmarking and calibration studies were completed on Version 2.4b ( $\mathrm{Lu}$ and Langford 1994; Lu and Khaleel 1994). These studies are provided in Appendix D of this document. Version 3.1 was developed in 1994 to handle additional complexities associated with the modeling of radionuclide release and transport from ERDF (Wood et al. 1995b) and is al so used in this analysis. Version 3.1 was benchmarked against Version 2.4b ( $L u$ and Langford 1995) to determine the effects, if any, of the modifications, on the ability of the code to reproduce the original results.

Three sets of problems were repeated with Version 3.1 and compared to the results from Version $2.4 b$ :

1. Reproduction of the verification and benchmark testing problems published by the vendor (HydroGeologic, Inc.) in the user's manual.

2. Two benchmark-testing problems relevant to performance assessment applications at the Hanford Site. The first problem was a sensitivity case with a recharge rate of $10 \mathrm{~cm} / \mathrm{yr}$ and $\mathrm{crib}$ discharges that effectively resulted in conditions where ponding occurred. The second problem was a comparison of flow around a clay cap where the "stair stepping" is distinctly different than that used by the PORFLO-3 mode1. This comparison provided insight into the relative errors expected in the "stepped" region.

3. Verification of the VAM3D-CG source code as installed on the Silicon Graphics, Inc. (SGI) workstation. The selected tests were performed to show that the VAM $3 D-C G$ code on the SGI produces the same results 
as those previously on the Cray computer, which is no longer in service.

The test results showed excellent agreement with the first and third sets of problems. The values for both the maximum difference and the relative root mean square (RRMS) are negligible. The differences can be explained by rounding errors between the two computers.

For the second set of problems, the solutions showed very good overall agreement when plotted, even though VAM $3 D-C G$ and the benchmark code employ significantly different solution techniques. Although minor discrepancies exist, the two codes should perform equally well in performance assessment applications at the Hanford Site. The detailed results of verification and benchmarking are presented in Appendix $D$.

The overall comparison between Versions $2.4 \mathrm{~b}$ and 3.1 of VAM3D-CG is good. The comparison showed that features from Version $2.4 b$ needed to perform the analyses function correctly in Version 3.1 , and that new features that distinguish Version 3.1 from Version 2.4b also function correctly. The two versions can be expected to produce results that agree within one percent. Version 3.1 contains several enhancements that make it a more versatile modeling tool than earlier versions. Therefore, we conclude that VAMBD-CG Version 3.1 is acceptable and preferred over Version 2.4b for these analyses.

\subsubsection{Groundwater Pathway Dose Calculations}

Dose calculations for the groundwater pathway analysis are completed in the same fashion as those for intruder scenarios except that slightly different sources of dose occur depending on the scenario being considered. Also, radioactivity originates from the contaminated groundwater rather than the waste itself. Thus, the groundwater concentrations calculated from the flow and transport analyses are used to calculate dose. The pathways and parameter values for each of the scenarios (al1-pathways and groundwater drinking) are considered in this section.

3.2.6.1 All-Pathways Scenario. The farmer obtains contaminated groundwater from a well $100 \mathrm{~m}$ (328 ft) downgradient from the disposal facility and uses the water to drink, irrigate crops, and water livestock. The farmer receives dose by the following:

- Ingestion of water, crops, beef, and milk

- Inhalation of contaminated dust in the air

- External exposure to radiation.

The same parameters and parameter values were used in this analysis as in the intruder scenarios except that beef, milk, and water consumption were added as sources of dose. The maximum exposed individual consumes $730 \mathrm{~L} / \mathrm{yr}$ of water. The quantities of beef and milk consumption are shown in Table 3-2.

3.2.6.2 Groundwater-Drinking Scenario. The individual derives contaninated groundwater from a well $100 \mathrm{~m}(328 \mathrm{ft})$ downgradient from the disposal facility and uses the water only for drinking. Thus, dose is received only through the ingestion of water. It is assumed that the annual consumption of contaminated water is $730 \mathrm{~L} / \mathrm{yr}$. 
WHC-SD-WM-TI-730, REV 0

\subsection{ADDITIONAL ANALYSES}

To complete the discussion of potential exposure pathways, two other means of release must be considered: vapor release and upward diffusion. Vapor release is of concern only for ${ }^{14} \mathrm{C},{ }^{3} \mathrm{H}$, and ${ }^{222} \mathrm{Rn}$. Upward liquid diffusion from the waste facility is a possible means of transport for all radionuclides because of the expected low recharge rates.

\subsection{Vapor Diffusion Pathway Analysis}

Three radionuclides, ${ }^{14} \mathrm{C},{ }^{3} \mathrm{H}$, and ${ }^{222} \mathrm{Rn}$, have the potential to migrate upward into the atmosphere in gaseous form, thereby potentially exposing humans to radiation. The following situations were considered for each of these radionuclides:

1. The ${ }^{14} \mathrm{C}$ releases and concentration 7 imits are considered relative to potential dose to the intruder and the offsite individual.

2. The ${ }^{3} \mathrm{H}$ releases and concentration limits are considered relative to potential dose to the offsite individual. The potential for dose from ${ }^{3} \mathrm{H}$ is not considered reasonable for the 200 East Area LLBG because the time of intrusion is assumed to occur 500 years postclosure for Category 3 facilities. This is sufficient time to decay tritium activity of any low-level tritium waste stream to insignificant amounts. Even if the 100-year event is considered, the very small amounts of tritium in the 200 East Area LLBG waste streams (an average of $10^{-5} \mathrm{Ci} / \mathrm{m}^{3}$ ) cannot provide a significant dose (e.g., in Chapter 4.0, Section 4.3.1 of Wood et a]. [1995a], a yearly dose of about $10^{-2} \mathrm{mrem} / \mathrm{yr}$ was calculated for an initial tritium concentration of $1 \mathrm{Ci} / \mathrm{m}^{3}$ ). Despite this expectation, a concentration is calculated that corresponds to performance objective limits to the intruder at 500 years.

3. ${ }^{222} \mathrm{Rn}$ releases and concentration limits are considered relative to the performance objective of $20 \mathrm{pCi} / \mathrm{m}^{2}$ s surface flux for the undisturbed facility (Chapter 4.0).

The impact of a vapor diffusion pathway was considered in the 200 West Area LLBG PA analysis (Wood et al. 1995a) for the intruder. It was assumed that ${ }^{14} \mathrm{C}$ or ${ }^{3} \mathrm{H}$ could be inhaled if an intruder built a residence on an undisturbed waste site or on soil in which exhumed waste had been mixed. A one-dimensional analytical model was used to estimate radionuclide flux through the residence for these conditions. This same model was also used to calculate ${ }^{222} \mathrm{Rn}$ flux. This approach is used in this document to estimate the effects of ${ }^{14} \mathrm{C}$ and ${ }^{222} \mathrm{Rn}$ flux by the vapor pathway from the 200 East Area LLBG. The results of these analyses are discussed in Chapter 4.0 and are corisidered in the development of waste acceptance criteria (WAC) and in the calculation of ${ }^{222} \mathrm{Rn}$ flux and intruder dose from ${ }^{14} \mathrm{C}$.

The flux estimates are aiso used to evaluate dose from ${ }^{14} \mathrm{C}$ and ${ }^{3} \mathrm{H}$ to a maximally exposed offsite individual. An atmospheric dispersion mode1 (ISC2) from the EPA was used to estimate dose as a function of activity release from the disposal facility. Wind data taken from the HMS between 1983 and 1991 
were used as input to determine the direction and quantity of maximum exposure.

\subsubsection{Upward Diffusion}

The relatively low recharge expected at the Hanford Site gives rise to the possibility that mass transport upward from an undisturbed disposal

facility could bring radionuclides to the surface or into the plant root zone. A simple analytical model was developed (Hennig 1995) to compare the relative rates of upward movement driven by diffusion to downward movement driven by infiltration.

In addition, an analysis has been completed to evaluate the potential for upward movement by capillary action. These analyses are discussed in Section 4.3.3. For both types of phenomena, it was concluded that the potential for significant upward movement was essentially nil. 
WHC-SD-WM-TI-730, REV 0

Figure 3-1. Finite Element Mesh for the Model Cross Section.

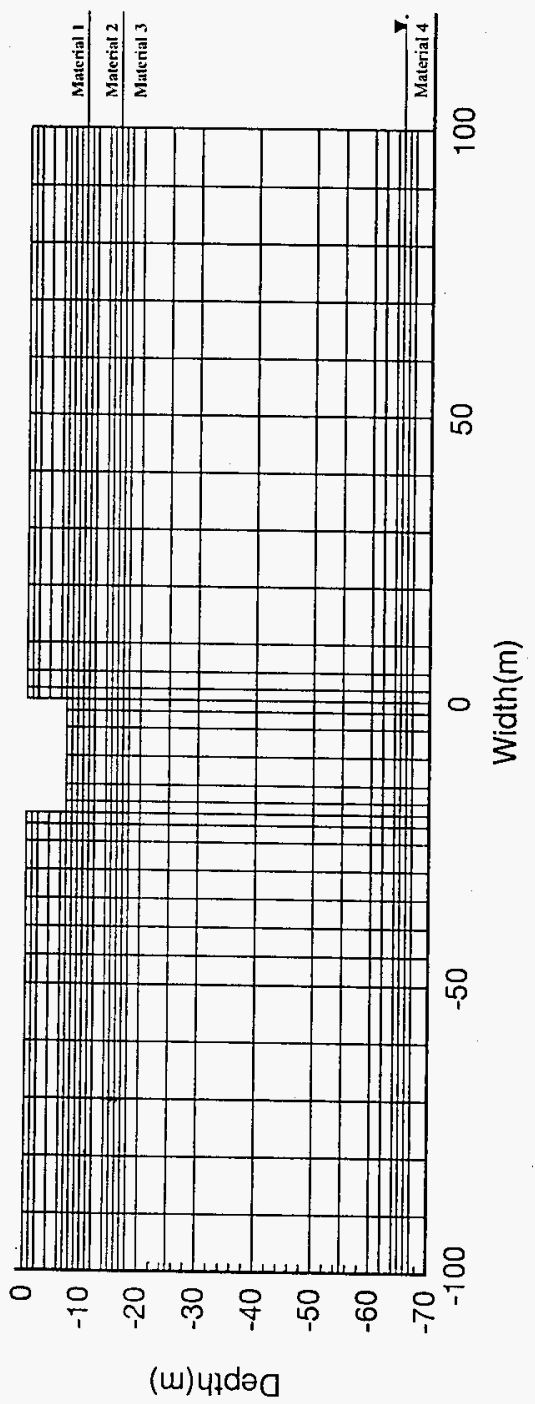


WHC-SD-WM-TI-730, REV 0

This page intentionally left blank.

F3-2 
Table 3-1. Calculation of the Inhalation Time for the Intruders.

\begin{tabular}{|l|c|c|c|c|}
\hline \multicolumn{1}{|c|}{ Activity } & $\begin{array}{c}\text { Air } \\
\text { concentration } \\
\left(\mathrm{mg} / \mathrm{m}^{3}\right)^{\mathrm{a}}\end{array}$ & $\begin{array}{c}\text { Exposure } \\
\text { time }(\mathrm{h})\end{array}$ & $\begin{array}{c}\text { Breathing } \\
\text { rate }\left(\mathrm{m}^{3} / \mathrm{h}\right)\end{array}$ & $\begin{array}{c}\text { Soil inhaled } \\
(\mathrm{mg} / \mathrm{yr})\end{array}$ \\
\hline Indoor (active) & 0.05 & 2,190 & 1.2 & 131.4 \\
\hline Indoor (asleep) & 0.05 & 2,190 & 0.45 & 49.3 \\
\hline Outdoor & 0.1 & 1,700 & 1.2 & 204 \\
\hline Gardening & 0.5 & 100 & 1.2 & 60 \\
\hline $\begin{array}{l}\text { Total Soi1 } \\
\text { Inhaled: } \\
445 \mathrm{mg} / \mathrm{yr}\end{array}$ & & & & \\
\hline
\end{tabular}

Representative averages are from Kennedy and Strenge (1992), Section 6.3.1.

Table 3-2. Human Food Consumption Parameters.

\begin{tabular}{|l|c|c|c|}
\hline \multicolumn{1}{|c|}{ Type of produce } & $\begin{array}{c}\text { Quantity } \\
(\mathrm{g} / \mathrm{d})\end{array}$ & $\begin{array}{c}\text { Calculated } \\
(\mathrm{kg} / \mathrm{yr})\end{array}$ & $\begin{array}{c}\text { Assumed intake } \\
(\mathrm{kg} / \mathrm{yr})\end{array}$ \\
\hline Leafy (leafy) & 45.3 & 16.53 & 4.1 \\
\hline Other (protected) & 152.5 & 55.66 & 13.9 \\
\hline $\begin{array}{l}\text { Fruit (exposed and } \\
\text { miscellaneous) }\end{array}$ & 105.3 & 38.43 & 9.4 \\
\hline Cereal (grain) $^{b}$ & 202.6 & 73.95 & 18.5 \\
\hline Meat (beef and pork) $^{c}$ & 115.0 & 41.98 & 21 \\
\hline Milk $^{c}$ & 283.5 & 103.48 & 51.7 \\
\hline
\end{tabular}

'Yang and Nelson (1986).

Grain is consumed but not assumed to be contaminated in either the intruder or all-pathways scenario.

cConsumption of meat and milk apply only to the al1-pathways scenario. 
Table 3-3. Summary of Performance Assessment Methodology.

\begin{tabular}{|c|c|c|c|}
\hline $\begin{array}{l}\text { Conceptual } \\
\text { models steps }\end{array}$ & Primary input parameters & $\begin{array}{c}\text { Mathematical } \\
\text { model }\end{array}$ & Output \\
\hline $\begin{array}{l}\text { 1. Establish } \\
\text { steady- } \\
\text { state } \\
\text { groundwater } \\
\text { flow field } \\
\end{array}$ & $\begin{array}{l}\text { - Infiltration rate } \\
\text { - Surrounding area } \\
\text { - Cover } \\
\text { - Hydrogeologic } \\
\text { properties } \\
\end{array}$ & $\begin{array}{l}\text { VAM3D-CG } \\
\text { RETC }\end{array}$ & $\begin{array}{l}\text { Steady-state } \\
\text { velocity } \\
\text { field }\end{array}$ \\
\hline $\begin{array}{l}\text { 2. Estimate } \\
\text { source term } \\
\text { release } \\
\text { rate }\end{array}$ & $\begin{array}{l}\text { - Infiltration rate } \\
\text { - Release mechanism } \\
\text { - Trench size } \\
\text { - Waste volume }\end{array}$ & $\begin{array}{l}\text { Mixing cell } \\
\text { cascade model } \\
\text { (Analytical) }\end{array}$ & $\begin{array}{l}\text { Radionuclide } \\
\text { flux history }\end{array}$ \\
\hline $\begin{array}{l}\text { 3. Quantify } \\
\text { soil column } \\
\text { and aquifer } \\
\text { transport }\end{array}$ & $\begin{array}{l}\text { Radionuclide flux } \\
\text { history } \\
\text { - Steady-state velocity } \\
\text { field } \\
\text { - Surrounding area } \\
\text { hydrogeologic } \\
\text { properties } \\
\text { Hell screen length } \\
\text { Representative trench } \\
\text { size and orientation } \\
\end{array}$ & $\begin{array}{l}\text { VAM3D-CG } \\
\text { RETC }\end{array}$ & $\begin{array}{l}\text { Well water } \\
\text { concentration } \\
\text { versus time } \\
\text { curves }\end{array}$ \\
\hline $\begin{array}{l}\text { 4. Calculate } \\
\text { dose }\end{array}$ & $\begin{array}{l}\text { - Peak concentration } \\
\text { - Peak time } \\
\text { - Dose parameter } \\
\text { - Edibles consumed } \\
\text { - Exposure time } \\
\text { - Air inhaled } \\
\text { - Transfer factors } \\
\text { - Dose conversion } \\
\text { factors } \\
\text { - Actual waste } \\
\text { inventory, volume, and } \\
\text { orientation }\end{array}$ & $\begin{array}{l}\text { Spreadsheet } \\
\text { (Analytical) } \\
\text { GENII* }\end{array}$ & $\begin{array}{l}\text { Radionuclide- } \\
\text { specific dose } \\
\text { estimates }\end{array}$ \\
\hline
\end{tabular}

*GENII was used to compare results from the spreadsheet analysis. 
Table 3-4. Hydraulic Property Input Data for the 218-E-12B Site.

\begin{tabular}{|c|c|c|c|c|c|c|c|c|c|c|}
\hline $\begin{array}{c}\text { Material } \\
\text { Number }\end{array}$ & $\begin{array}{l}\text { Sample } \\
\text { Number }\end{array}$ & $\begin{array}{c}\text { Formation } \\
\text { Type }\end{array}$ & $\begin{array}{l}\text { Soil } \\
\text { Type }\end{array}$ & $\begin{array}{l}\text { Depth } \\
\text { (m) }\end{array}$ & $\theta_{\mathrm{s}}$ & $\theta_{r}$ & $\begin{array}{c}\alpha \\
(\mathrm{L} / \mathrm{m})\end{array}$ & $\beta$ & $\underset{(m / y r)}{K_{s}}$ & $\begin{array}{c}P_{b^{3}} \\
\left(\mathrm{~g} / \mathrm{cm}^{3}\right)\end{array}$ \\
\hline 1 , unsat. & $5-0146$ & $\begin{array}{l}\text { Hanford } \\
\text { gravel }\end{array}$ & $\begin{array}{l}\text { Gravel } \\
\text { domin. }\end{array}$ & $0-10$ & 0.1450 & 0.0000 & 2.06 & 1.2779 & 3.78 & 2.25 \\
\hline 2, unsat. & $5-0147$ & $\begin{array}{c}\text { Hanford } \\
\text { sand }\end{array}$ & Sand & $10-16$ & 0.3526 & 0.0480 & 0.81 & 2.3787 & 684 & 1.71 \\
\hline 3, unsat. & $5-0148$ & $\begin{array}{c}\text { Hanford } \\
\text { gravel }\end{array}$ & $\begin{array}{l}\text { Gravel } \\
\text { domin. }\end{array}$ & $16-65$ & 0.1477 & 0.0130 & 2.05 & 1.5589 & 86 & 2.16 \\
\hline
\end{tabular}

Properties of the unconfined aquifer

\begin{tabular}{|c|c|c|c|c|c|c|}
\hline $\begin{array}{c}\text { Material } \\
\text { Number }\end{array}$ & $\begin{array}{c}\text { Formation } \\
\text { Type }\end{array}$ & $\begin{array}{c}\text { Soil } \\
\text { Type }\end{array}$ & $\begin{array}{c}\text { Depth } \\
(\mathrm{m})\end{array}$ & $n^{*}$ & $\begin{array}{c}\mathrm{K}_{\mathrm{s}}^{*} \\
(\mathrm{~m} / \mathrm{yr})\end{array}$ & $\begin{array}{c}P_{\mathrm{b}}{ }^{3} \\
\left(\mathrm{~g} / \mathrm{cm}^{3}\right)\end{array}$ \\
\hline 4 & $\begin{array}{c}\text { Hanford } \\
\text { gravel }\end{array}$ & $\begin{array}{c}\text { Grave } 1 \\
\text { domin. }\end{array}$ & $65-70$ & 0.2500 & $3.00 \times 10^{4}$ & 1.99 \\
\hline
\end{tabular}

*The properties $n$ and $K_{s}$ are from the Sitewide groundwater model (Law et al. 1996). 
Table 3-5. Hydraulic Property Input Data for the 218-E-10 Site.

\begin{tabular}{|c|c|c|c|c|c|c|c|c|c|c|}
\hline $\begin{array}{c}\text { Material } \\
\text { Number }\end{array}$ & $\begin{array}{l}\text { Sample } \\
\text { Number }\end{array}$ & $\begin{array}{c}\text { Formation } \\
\text { Type }\end{array}$ & $\begin{array}{l}\text { Soil } \\
\text { Type }\end{array}$ & $\begin{array}{l}\text { Depth } \\
\text { (m) }\end{array}$ & $\theta_{\mathrm{s}}$ & $\theta_{r}$ & $\begin{array}{c}\alpha \\
(\mathrm{L} / \mathrm{m})\end{array}$ & $\beta$ & $\underset{(m / y r)}{K_{s}}$ & $\underset{\left(\mathrm{g} / \mathrm{cm}^{3}\right)}{P_{\mathrm{b}}}$ \\
\hline 1 , unsat. & $5-0153$ & $\begin{array}{l}\text { Hanford } \\
\text { gravel }\end{array}$ & $\begin{array}{l}\text { Gravel } \\
\text { domin. }\end{array}$ & $0-10$ & 0.2157 & 0.0 & 1.23 & 1.3266 & 42.6 & $2.06^{\circ}$ \\
\hline 2 , unsat. & $5-0154$ & $\begin{array}{c}\text { Hanford } \\
\text { sand }\end{array}$ & Sand & $10-16$ & 0.3547 & 0.035 & 4.29 & 2.307 & $1.11 \times 10^{4}$ & 2.06 \\
\hline 3, unsat. & 5-0158 & $\begin{array}{c}\text { Hanford } \\
\text { gravel }\end{array}$ & $\begin{array}{l}\text { Gravel } \\
\text { domin. }\end{array}$ & $16-70$ & 0.2140 & 0.013 & 0.77 & 1.4226 & 43.5 & 2.15 \\
\hline
\end{tabular}

Properties of the unconfined aquifer

\begin{tabular}{|c|c|c|c|c|c|c|}
\hline $\begin{array}{c}\text { Material } \\
\text { Number }\end{array}$ & $\begin{array}{c}\text { Formation } \\
\text { Type }\end{array}$ & $\begin{array}{c}\text { So } j 1 \\
\text { Type }\end{array}$ & $\begin{array}{c}\text { Depth } \\
(\mathrm{m})\end{array}$ & $n^{*}$ & $\begin{array}{c}\mathrm{K}_{\mathrm{s}}^{*} \\
(\mathrm{~m} / \mathrm{yr})\end{array}$ & $\begin{array}{c}P_{\mathrm{b}} \\
\left(\mathrm{g} / \mathrm{cm}^{3}\right)\end{array}$ \\
\hline 4 & $\begin{array}{c}\text { Hanford } \\
\text { gravel }\end{array}$ & $\begin{array}{c}\text { Gravel } \\
\text { domin. }\end{array}$ & $70-75$ & 0.2500 & $8.99 \times 10^{4}$ & 1.99 \\
\hline
\end{tabular}

*The properties $n$ and $k_{s}$ are from the Sitewide groundwater model (Law et al. 1996). 
Table 3-6. Radionuclide Sorption Coefficients in the Soil Column.

\begin{tabular}{|c|l|}
\hline \multicolumn{1}{|c|}{$\mathrm{Kd}^{*}(\mathrm{~mL} / \mathrm{g})$} & \multicolumn{1}{|c|}{ Radioelement } \\
\hline 0 & $\mathrm{C}, \mathrm{Tc}, \mathrm{U}, \mathrm{H}, \mathrm{Se}, \mathrm{I}, \mathrm{Cl}, \mathrm{Re}$ \\
\hline 1 & $\mathrm{Co}$ \\
\hline 10 & $\mathrm{Eu}, \mathrm{K}, \mathrm{Ra}, \mathrm{Sr}, \mathrm{Np}$ \\
\hline 100 & $\mathrm{Am}, \mathrm{Ni}, \mathrm{Pu}, \mathrm{Th}, \mathrm{Cs}{ }^{* *}$ \\
\hline
\end{tabular}

*Kd values are reasonably conservative estimates based on many references including Serne and Wood (1990).

**A Kd value of 10 has also been assumed for ${ }^{137} \mathrm{Cs}$ in a screening analysis to eliminate this isotope as a potential groundwater contaminant. 
WHC-SD-WM-TI-730, REV 0

This page intentionally left blank. 
WHC-SD-WM-TI-730, REV 0

\subsection{ANALYTICAL RESULTS}

This chapter presents the results of the radionuclide release scenarios analyses. Sections 4.1 and 4.2 first present the base-case analytical results for the inadvertent intruder and groundwater contamination scenarios.

Section 4.3 covers the significance of other pathways and activities that may affect potential dose. These include the vapor pathway, upward liquid diffusion from an undisturbed facility, the effects of mixing contaminant plumes from the 200 East Area LLBG and other sources of waste on the Hanford Plateau, and the potential for enhanced dose resulting from increased recharge on the Hanford Plateau.

Section 4.4 integrates the total set of results to define the most significant influences on potential dose to humans for the Hanford Site conditions. Waste acceptance criteria for the disposal of LLW in the 200 East Area LLBG are provided on the basis of this integration effort. Finally, an estimate of potential dose from the filled and closed facility is made and compared with the performance objectives.

\subsection{ANALYTICAL RESULTS FOR INADVERTENT INTRUDER SCENARIOS}

\subsubsection{Dose Estimate Results}

Some uncertainties are involved in predicting which isotopes will be present in the LLW streams and in what quantities. Therefore, dose estimates have been provided for a large number of radionuclides. Table 4-1 lists those considered. Most, but not a11, radionuclides with half-lives of more than 5 years are included. Those omitted have not been reported in Hanford Site waste inventories. Radionuclides with half-lives of 5 years or less were not included because it is assumed that intrusion does not occur until 100 years after closure. For a radionuclide with a 5 -year half-life, this corresponds to 20 half-lives or a reduction in concentration by a factor of about $10^{6}$. A radionuclide in this category plausibly could not exist in any potential waste stream in concentrations sufficient to cause a significant dose after 100 years. The one radionuclide with a half life of less than 5 years that appears on the list is $242 \mathrm{Cm}$, which has a half-1ife of 163 days. This isotope is specifically identified in 10 CFR 61 and has been given a waste concentration limit for Class $C$ waste. Consequently, if a waste stream contains ${ }^{242} \mathrm{Cm}$, its concentration in that waste stream must be considered in the disposa1. of that waste because DOE Order $5820.2 \mathrm{~A}$ forbids the disposal of greater-than-Class $C$ waste without a specific evaluation and approval through the National Environmental Policy Act (NEPA) process.

The dose estimate from some radionuclides must include dose contributions from daughter products that are present with sufficient activity. Two conditions are considered. First, secular equilibrium may be already established between parent and daughter or expected to occur very quickly after waste disposal. Dose calculations are based on equal activities of parent and daughter(s). For the subset of radionuclides considered where secular equilibrium occurs, decay chains and important daughters included in 
the dose calculations are listed in Table 4-1. Second, some parent-daughter decay chain reactions do not achieve secular equilibrium, but the daughter activity build-up during exposure is sufficient for the daughter to make a significant contribution to dose during the assumed period of exposure. Parents and daughters from these types of decay chains for which dose is calculated are listed in Table 4-2. Some radionuclides have both types of daughters and are listed in each table.

Tables 4-3 and 4-4 1ist dose estimates resulting from the post-excavation and post-drilling. Unit concentrations $\left(1 \mathrm{Ci} / \mathrm{m}^{3}\right)$ of all radionuclides identified in Table 4-3 are assumed to be present in the waste stream initially. These results are easily adjusted for whatever initial concentration or quantity of radionuclide is of interest because of direct proportionality between initial conditions and final results. This process is used in Section 4.4 to calculate concentrations that result in dose estimates matching performance objectives (i.e., WAC). The dose numbers 1 isted in Tables 4-3 and 4-4 were calculated using the spreadsheet. For a given radionuclide, doses were calculated as a function of time, using the assumption of leaching or not leaching of radionuclides from the soil during crop growth. The soil-plant transfer coefficients for this table were taken from Kennedy and Strenge (1992). As part of the sensitivity analysis, an additional set of soil-plant transfer coefficients were al so considered (Baes et al. 1984b). For each radionuclide, the exposure pathway providing the greatest dose for a given radionuclide is also shown.

Doses estimates are provided for 100,300, and 500 years after emplacement in the disposal facility. This time frame was picked because of the assumptions that excavation occurs 100 years after disposal and postdrilling occurs 500 years after disposal. The comparative changes in dose are strictly related to half-life. For radionuclides with half-lives of 30 years or less, the dose for the same initial concentration decreases by more than 1 to more than 10 orders of magnitude. For radionuclides with half-iives of more than than 100 years, little or no decrease in dose is estimated because of decay. For a given radionuclide, the differences between dose estimates in the post-drilling and post-excavation scenarios are strictly related to the relative amounts of waste exhumed (basement excavation versus well drilling) and the subsequent soil dilution factor.

\subsubsection{Intruder Dose Sensitivity Analysis}

Each dose estimate value provided in Tables 4-3 and 4-4 assumes single values for each input parameter used to quantify the dose for a given exposure pathway. In most cases, only one value for a given parameter was considered, although, given the number of parameters involved, many different dose estimates can be calculated by assuming a range of plausible values. The potential effects that changes. in key parameter values have on dose estimates must be considered, particularly because of the direct correlation between dose estimates and waste classification concentration limits developed in Section 4.4 .

The sensitivity analysis is approached deterministically by evaluating the change in dose estimate as a function of systematic changes in parameter value. In the case of the intruder dose estimates, the dose response to a 
change in parameter value is easily understood because simple algebraic relationships are used to estimate dose. The following discussion is organized by major parameter types and exposure pathways (e.g., soil dilution, ingestion, and inhalation). In cases where multiple parameters contribute to uncertainty, overali uncertainty is estimated by taking the product of the uncertainty factors.

4.1.2.1 General Observations. Sensitivity of dose estimates to parametervalue variability is radionuclide specific. This observation, noted in Tables 4-3 and 4-4 where the influence of time of intrusion and effects on leaching radionuclide availability are estimated, is further quantified in Table 4-5 where the dose by pathway is provided for a unit quantity of radionuclide exhumed as a function of pathway. The column labeled "Root Up" refers to the ingestion of contaminated crops. The column labeled "Rain Sp" refers to the contribution of contaminated dirt deposited on the plant by rain splashing. The dose provided by the primary exposure pathway frequentiy exceeds the dose from the other pathways by a large factor. This is important when considering the sensitivity of dose estimates to specific parameters because many parameters are pathway specific. If the pathway is not a significant means of dose for a radionuclide, the parameter variability associated with that pathway is inconsequential. For example, the dose by ingestion of ${ }^{99} \mathrm{TC}$ in contaminated crops exceeds the dose from other pathways by more than two orders of magnitude. Thus, variability in a parameter that affects dose by inhalation or external exposure has no effect on the dose estimate for ${ }^{99} \mathrm{Tc}$.

The other general observation is that dose is rarely directly proportional to changes in the value of any given parameter because numerous parameters invariably contribute to dose in conjunction with other parameters. At the same time, contributing parameters are, in themselves, not usually interrelated. Thus, a potential increase in one parameter value does not cause an expected increase in another parameter, even though both contribute to dose from the same pathway. In most cases, if a parameter value is doubled (i.e., increased by 100 percent) and all other parameters remain constant, the dose increase is usually less than 50 percent. In the following sections, the parameters with the largest effect on dose relative to other parameters are discussed.

\subsubsection{Sensitivity Analysis of Parameters Affecting A11 Intruder Pathways.} The parameters considered in the analys is that affect all of the exposure pathways include the following:

- The initial concentration of radionuclides in the waste

- The soil dilution factor

- The leachability of radionuclides in the soil after mixing.

Al1 three parameters are related to the concentration of radionuclides in the soil that are available for contribution to dose.

Estimated doses are directly proportional to the initial radionuclide concentration in the waste and inversely proportional to the soil dilution factor (the ratio of material volume containing waste to the volume of soil in which the waste is mixed). Also, the potential for leaching of radionuclides from the soil after mixing can reduce the available inventory. Thus, if the 
initial concentration is doubled and all other parameters kept constant, the dose estimate will be doubled. For the soil dilution factor, the amount of waste exhumed is doubled and all other parameters are kept constant, the dose estimate doubles. If the amount of soil in which waste is mixed is doubled and 111 other parameters are kept constant, the dose estimate is halved.

Once radionuclides are mixed into the soil, they can be leached by precipitation or irrigation while crops are growing. The available concentration for plant uptake is reduced by leaching. The extent of reduction is assumed to depend on the reactivity of the isotope with the soil (i.e., the sorption coefficient or $\mathrm{Kd}$ ) and the flux of water through the soll column. The assumed values for these parameters are provided in Appendix $B$. Comparing Tables 4-6 and 4-7 shows that the difference between the doses for leaching and nonleaching is relatively insignificant. Table 4-6 demonstrates that the selection of leaching parameter values in the two databases considered in this report (Kennedy and Strenge 1992, Baes et al. 1984b) are similar. Table 4-7 shows that a decrease in dose up to a factor of 3 occurs for the nonsorbing radionuclides ${ }^{14} \mathrm{C},{ }^{36} \mathrm{Cl},{ }^{3} \mathrm{H}$, and ${ }^{99} \mathrm{TC}$ when leaching is assumed regardless of the database selected. For radionuclides that are moderately or strongly sorbing, the effect of the leaching process is nil.

4.1.2.3 Sensitivity Analys is of Ingestion Parameters. For the ingestion pathway, dose is directly proportional to the dose conversion factors and the quantity of radionuclides ingested. For the dose conversion factors, the sensitivity is straightforward because only the dose conversion factor parameter is used. However, the quantity of radionuclides consumed must be considered in terms of the secondary parameters that are used to calculate the total quantity. These parameters include types and quantities of food consumed (e.g., leafy vegetables, other vegetables, fruit, and grain), quantity of soil consumed, relative efficiency of radionuclide transfer from soil to plant (soil-to-plant transfer coefficients), and dry-to-wet ratios of different crops. Therefore, sensitivity depends on the relative values assumed for each food type and the behavior of each radionuclide in the biosphere.

To consider the sensitivity of the total ingestion dose to the soil ingestion pathway, differences in the soil-to-plant transfer coefficient can be ignored because plant consumption does not occur when soil is ingested directly. Also, as shown in Table 4-5, soil ingestion is not dominant: for any radionuclides except ${ }^{3} \mathrm{H},{ }^{79} \mathrm{Se},{ }^{210} \mathrm{~Pb}$, and ${ }^{209} \mathrm{Po}$. For ${ }^{3} \mathrm{H}$, the dose estimates are directly proportional to the quantity of dirt consumed. Soil ingestion is relatively important for ${ }^{79} \mathrm{Se}$ because of the inefficient transfer of ${ }^{7} \mathrm{Se}$ to crops, making the dirt ingestion pathway more prominent. For ${ }^{210} \mathrm{~Pb}$ and ${ }^{200} \mathrm{Po}$, the effect is not one for one because the contribution to dose from crop ingestion is nearly equivalent to soil ingestion. For these radionuclides, doubling the annual quantity of soil consumed results in approximately a 50-percent increase in dose. Relative to the projected 200 East Area LLBG inventory, none of these radionuclides occur in significant quantities.

The sensitivity of potential dose to ingested food can be evaluated by considering the relative contributions to dose provided by each food group consumed in the base case. It is also assumed that the relative value of each parameter used in the ingestion calculation remains the same. The relative contribution to dose is provided in Table 4-8 for each radionuclide whose 


$$
\text { WHC-SD-WM-TI-730, REV } 0
$$

primary pathway is ingestion. The initial concentration is assumed to be $1 \mathrm{Ci} / \mathrm{m}^{3}$ and the values are determined by the product of the quantity of each food group consumed (Table 3-2), the dry-to-wet ratio for each food type (Appendix B), and the soil-to-plant ratio for each food type (Appendix B).

Relative contributions from each food group vary somewhat depending on the radionuclide. Usually, the contributions from roots and grains are the largest. However, in no case does one factor completely dominate the total activity consumed. Doubling any of the parameter values that make up this calculation results in an increase of up to a factor of 1.6 in the calculated total activity.

4.1.2.4 Inhalation Parameter Sensitivity Analysis. For the inhalation pathway, estimated dose is directly proportional to the mass of contaminated dust inhaled, the soil concentrations of radionuclides, and the dose conversion factors. Dose estimates are directly proportional to radionuclide soil concentrations and dose conversion factor values (e.g., if either factor is doubled, the dose estimate will be doubled).

The sensitivity to mass of contaminated dust that is consumed is somewhat more complicated because several activities are included in the calculation. To evaluate sensitivity, changes in the parameters used to calculate the activity that provides the largest fraction of dose is considered, that being the time spent indoors and awake (Table 3-1). If any factor contributing to the calculated amount of inhaled dust from this activity is doubled (i.e., air concentration of dust, exposure time, or breathing rate), the total mass of dust consumed is increased by a factor of about 1.3. Doubling other parameters from the other activities will result in less increase in total dust consumed.

4.1.2.5 External Exposure Parameter Sensitivity Analysis. For the external exposure pathway, estimated dose is directly proportional to the effective time of exposure, radionuclide concentration in soil, and dose conversion factors. In calculating the effective time of exposure, provided by the floor and walls of the house must be considered for time spent indoors. Given the equation for calculating effective exposure time (Section 3.1.3) and the assumption that more time is spent indoors than outdoors, a maximum increase in dose would come from an assumed increase in the value of the shielding factor. If the base-case shielding factor (0.33) is doubled, the effective exposure time increases by a factor of about 1.5 .

\subsubsection{Intruder Scenario Uncertainty Analys is}

Uncertainty in dose estimates is evaluated deterministically by considering likely ranges of values for parameters used to calculate dose estimates for each exposure pathway. By examining lower and upper value estimates (bounding values), changes in dose can be determined relative to the stated base case. A range of parameter values can be considered for most parameters. The exception for the intruder scenarios is the dose conversion factors for external exposure for which one set of values is calculated from the GENII Version 1.485 software package using the EXTDF program, which uses ISOSHLD as the basis for calculating the dose conversion factor. 
4.1.3.1 Uncertainty Analys is of Parameters Affecting All Intruder Pathways. Uncertainty in the initial concentration of radionuclides in the waste is not a factor when considering the development of WAC. By defining WAC, concentration limits are set and disposal of waste is administratively controlled to ensure that limits are not violated. The concentration limits are meant to be averaged over some volume (the waste volume in an individual trench is assumed) and occasional waste volumes in excess of the limits could be permitted. When calculating a dose for waste that is actually disposed of, the dose will fall below the limit, but the range of potential dose below the limit is difficult to quantify because of uncertainty in the actual waste inventory.

In the excavation scenario, the waste volume is computed on the basis of an average size basement for a single dwelling $\left(100 \mathrm{~m}^{3}\left[3,531 \mathrm{ft}^{3}\right]\right)$, an average digging depth $(3 \mathrm{~m}[10 \mathrm{ft}])$, and a nominal depth of burial (2 in [7 ft]). It is also assumed that the waste volume is not completely waste. A reasonable waste fraction of 75 percent is assumed. These volume parameters are based on common practice and engineering judgment. To vary the waste volume we assume a variation in the size of a basement which corresponds to a range of common sizes for single family dwellings. Bounding values of $81 \mathrm{~m}^{3}$ and $144 \mathrm{~m}^{3}\left(2,860 \mathrm{ft}^{3}\right.$ and $\left.5,085 \mathrm{ft}^{3}\right)$ were chosen. The soil volume is based on the area of mixing and the depth of tilling. The base-case area is a little - over half an acre, which is considered to be a reasonable size lot. The basecase tilling depth is $15 \mathrm{~cm}(-6 \mathrm{in}$.). Both parameters were varied. Bounding values for the mixing area of 1,500 and $4,000 \mathrm{~m}^{2}$ (roughly 0.33 and 1 acre, respectively) were chosen. The tilling depth bounding values were estimated as \pm 30 percent. By adding the portion of the waste volume that was not waste to the soil volume, a total mixing volume was calculated. The lower bounding dilution factor was then calculated by dividing the low waste volume by the high mixing volume; the high bounding dilution factor was found by dividing the high waste volume by the low mixing volume. Relative to the base case, the bounding values increase or decrease the dilution factor by less than a factor of two. Thus, the change in dose caused by the variability in the dilution factor is estimated to change by the same factor.

For the post-drilling scenario, the same garden soil mixing volume is considered except that no appreciable contribution to the mixing volume from waste excavation occurs (e.g., the volume of well cuttings that is not waste is insignificant relative to the soil mixing volume). The waste volume is varied as a function of well radius and depth of waste. The well radius range is based on the approximate radii of a drinking-water we $11(0.075 \mathrm{~m}[0.25 \mathrm{ft}])$ and an irrigation well $(0.15 \mathrm{~m}[.49 \mathrm{ft}])$. Waste depth is varied from 5 to $10 \mathrm{~m}$ ( 6 to $33 \mathrm{ft}$ ). Using these values, the maximum and minimum dilution factors calculated are about 2 times higher and about 17 times lower, respectively, than the base-case value.

\subsubsection{Uncertainty Analys is of Ingestion Parameters. Uncertainty is} discussed in terms of the three major groups of parameters: dose conversion factors, soil dilution factors, and food consumption parameters. To evaluate uncertainty in dose conversion factors, three sources of factors were compared (see Table 4-9): the GENII database, DOE/EH-0071 (DOE 1988c), and the EPA Federal Guidance Report Number 11 (EPA 1989). Comparison of ingestion values shows a difference of no more than 40 percent for any radionuclide except ${ }^{99} \mathrm{TC}$ and ${ }^{187}$ Re where the GENII values are about 75 percent higher. A larger and 
unquantifiable uncertainty is associated with the limited database from which the dose conversion factors are estimated. A factor of 10 or more variability in factor values is possible. However, the numbers and associated variability used here represent expert consensus and the best available information.

In the base case, the average quantities consumed by the individual were taken from a survey conducted by Yang and Nelson (1986). Then, an average percentage of the diet that came from these food types grown in contaminated soil was assumed in the base case ( 25 percent). To estimate uncertainty, the percentage was varied with bounding values of 15 and 40 percent. The dry-to-wet ratio variability was taken as \pm 10 percent of the base case value. Using this approach, the maximum and minimum variability caused by these parameters is a factor of about two.

Uncertainty in the value of the soil-to-plant transfer factors is determined by comparing the variability of radionuclide values from two data sets (Kennedy and Strenge 1992 [NUREG/CR-5512] and Baes et al. 1984b [ORNL-5786]). Tables are provided in Appendix B. These databases are used because they are cohesive sets of data and because, for the most part, sitespecific data do not exist. The variability in these values between the two data sets is radionuclide specific. Table 4-10 compares the effects of variability in selected soil-to-plant transfer factors between the two data sets. With the exception of ${ }^{209} \mathrm{Po}$ and ${ }^{60} \mathrm{Co}$, the uncertainty in estimated dose caused by differences in soil-to-plant transfer parameter values is a factor of three or less. Because we are considering uncertainty to the base case where the NUREG/CR-5512 values are assumed, the maximum increase resulting from the $O R N L-5786$ values in the dose estimates is a factor of about two for $200 \mathrm{~Pb}$. A maximum decrease in dose estimate would be a factor of about 10 for ${ }^{209} \mathrm{Po}$.

The overall potential changes in dose resulting from parameter variability can be estimated by taking the product of the factors for each of the major parameters (soil dilution factor, dry-to-wet ratio, quantity of food consumed, soil-to-plant transfer value). Thus, depending on the radionuclide, a potential relative increase or decrease in dose in the post-excavation scenario is estimated to be up to a factor of 12 and 40 , respectively. Similarly, a potential relative increase in dose in the post-drilling scenario is calculated to be up to a factor of 12 or a potential relative decrease in dose by a factor of up to 340 .

4.1.3.3 Inhalation Parameter Uncertainty Analysis. The mass of consumed dust is calculated on the basis of time spent in the presence of dust, the concentrations of dust in, the air, and the breathing rate (see Section 3.1.3). The base-case calculation also assumes that the exposed individual is at the home site about 70 percent of the time. To make an estimate of bounding values, the individual is assumed to be at the site 60 percent and 80 percent of the time and that relative times at different activities, air concentrations, and breathing rates are the same in each case. It is assumed that the breathing rates vary by 10 percent and dust concentration in the air varies by a factor of 2 . Given these assumptions, the relative change in dust mass consumed is calculated to be a factor of about 2.6 increase or decrease relative to the base case. 
Dose conversion factors are assumed to be constant because of consensus on value selection among experts and the lack of data that quantifies true variability. The overall estimated potential change or uncertainty in dose from all factors combined (soil dilution factor and mass of dust consumed) is an increase by a factor of up to about five for the post-excavation scenario. For the post-drilling scenario, the overall calculated dose from all factors combined increases by a factor of up to about 5 ; the dose for the postdrilling scenario decreases by a factor of up to about 44 .

\subsubsection{External Exposure Parameter Uncertainty Analysis. As with the} inhalation pathway, it is assumed in the base case that the individual is exposed about 70 percent of the time with two-thirds of the time spent indoors and one-third of the time outdoors. A shielding factor is applied to time indoors because of the structural barriers to radiation provided by the dwelling.

To estimate bounding values, both percentage of time and the value of the shielding factor can be varied. For this pathway, no variability in the dose conversion factor is assumed. For exposure time, the individual is assumed to be exposed 60 or 80 percent of the time. A range of shielding values is referenced by Aaberg and Kennedy (1990) from 0.02 to 0.6 . A lower effective exposure time is, therefore, calculated by assuming the 60-percent exposure time at the same indoor/outdoor proportion as the base case and the lower shielding factor. The higher effective exposure time was calculated using the higher values. At the 60 - and 80 -percent exposure times, the relative change in dose resulting from the changes in effective exposure time is a factor of 2 decrease and a factor of 1.5 increase, relative to the base case. The overall estimated potential change in dose from all factors combined is an increase by a factor of about three or a decrease by a factor of about four for the post-excavation scenario. For the post-drilling scenario, the overall calculated change in dose from all factors combined is an increase by a factor of about 3 or a decrease by a factor of about 34 .

4.1.3.5 Summary of Uncertainty Analyses. The uncertainty factors are directly proportional to the dose calculations. Thus, the relative range of dose estimates around the base-case estimates can be quantified using the uncertainty factors. Overall, this analysis indicates that doses will not exceed the base-case assumptions by more than a factor of 20 and could be far less than the base-case estimate, possibly by a factor of about 300 , depending on the radionuclide and the dominant pathway.

\subsection{ANALYTICAL RESULTS FOR THE GROUNDWATER PATHWAYS SCENARIOS}

Section 4.2.1 describes the groundwater radionuclide concentration versus time relationships for the 200 East Area LLBG conditions. The results (radionuclide groundwater concentrations as a function of time) are presented at the key boundaries along the pathway from the disposal facility to the unconfined aquifer. Section 4.2.2 describes the results of sensitivity analyses used to determine the influence of various key parameters on groundwater concentrations. The results of the sensitivity analyses allow us to eliminate the majority of radionuclides as potential contributors to dose by the groundwater pathway. Therefore, Section 4.2.3 describes the screening process to eliminate radionuclides of concern and identifies the remaining 
radionuclides of concern. Section 4.2.4 presents dose estimates for the remainder of the radionuclides for the 200 East Area LLBG. Section 4.2.5 describes uncertainties associated with the groundwater concentration estimates for the remaining radionuclides.

Three burial ground conditions were differentiated in this analysis. First, separate evaluations were completed for each group of burial grounds, centered around $218-E-10$ and $218-E-12 B$, respectively. This was done because of their geographical separation and the somewhat different geohydrologic soil column characteristics of the two sites. Because these are the only real differences between the two disposal conditions, the majority of sensitivity cases were only run for one of the sites, 218-E-12B. The analysis of the 218-E-10 was limited to the consideration of the advection-controlled release mechanism for Category 1 and 3 infiltration rates.

The advection-controlled release cases were identified as base-case conditions because they can be used to develop waste acceptance criteria for their respective burial grounds. At the same time, comparing the resultis for these cases allowed the influence of differing soil column hydrologic properties on dose estimates to be evaluated. Thus, these cases are described in terms of sensitivity analyses below.

Second, within the 218-E-12B Burial Ground, standard Hanford Site trenches and the reactor compartment trench have been considered separately because the differences in trench depth creates a difference in the length of the flow path in the vadose zone. In addition, the reactor compartment waste stream is relatively homogeneous compared to normal waste. Thus, only one release mechanism was considered appropriate for describing radionuclide release from the waste material (i.e., the constant concentration mechanism through corrosion in runs $3 a-c c, 3 b-c c$, and $3 c-c c$ [Tables 4-11 and 4-12]). Again, these analyses are both base-case conditions that have been used to establish waste acceptance criteria and sensitivity cases to evaluate the sensitivity of dose estimates to depth of burial and release mechanism.

\subsubsection{Peak Time and Concentration Results from the Release and Transport Analyses}

In this section, the results of the radionuclide release and transport calculations are presented for the base-case conditions described for the 200 East Area LLBG (Section 3.2). The results are broken into the major aspects of release and transport, beginning with radionuclide flux from the disposal facility or source term (Section 4.2.1.1), followed by radionuclide flux to the unconfined aquifer and down to the $100-\mathrm{m}(328-\mathrm{ft})$ downstream well (Section 4.2.1.2). Once the radionuclides are released into the soil column, transport to the unconfined aquifer is modeled using the VAM3D-CG code.

Table 4-11 lists the cases that were evaluated and Table 4-12 summarizes the results.

The results of that modeling is represented here in two ways. First, cross sections of the contaminant plumes in the soil column underlying the trench are presented for the given conditions at one point in time subsequent to release from the trench. In the examples, the $218-E-12 B$ soil column properties are assumed. Times are picked where the radionuclide 
concentrations in the unconfined aquifer are near peak value. Second, radionuclide concentration versus time graphs are presented for groundwater that intercepts a well penetrating the unconfined aquifer $100 \mathrm{~m}$ downstream from the trench. The estimated peak concentration (averaged over a 5-m [16-ft] well screen) and times at which peak concentration occur are used to identify radionuclides that cannot provide significant dose and to quantify inventory limits for radionuclides that can provide significant dose.

Specific radionuclides are not considered in these sections. Instead, typical characteristics of radionuctide behavior to which individual radionuclides can be assigned are simulated. The relationship of the results to specific radionuclides is provided in Section 4.2 .3 where the potential contribution of individual radionuclides to dose by the groundwater pathway is evaluated.

4.2.1.1. Source Term Analys is for Base Case Conditions. To calculate radionuclide flux from the disposal facility, the flux of infiltrating water through the disposal facility and the mechanism of release from the waste material or the waste form must be considered. For the 200 East Area L.LBG, an average steady state flux of 5.0 or $0.5 \mathrm{~cm} / \mathrm{yr}$ is assumed; this establishes a steady-state flow field.

Figures 4-1 through 4-3 illustrate this steady-state condition for an infiltration rate of $5.0 \mathrm{~cm} / \mathrm{yr}$. Figure 4-1 shows the steady-state saturation levels (percent of the pores filled with water) in the vadose zone. Figure 4-2 shows the distribution of groundwater velocity vectors in the entire model. Figure 4-3 shows the velocity vectors just for the soil column that surrounds and underlies the disposal trench. These vector plots show the direction and magnitude of the water flow at every node in the model. The spacing of the arrows reflects the spacing of the mesh in the model and the magnitude is indicated by the size of the arrow (note the reference arrow at the top of each figure). In some cases the magnitude of the velocity is large enough that neighboring arrows overlap. There is no special significance to this.

In this analysis, three mechanisms of release were considered. In the first case, it was assumed that the entire inventory was immediateiy available for release with the initial inventory of $1.0 \mathrm{C} i$ of any given radionuclide evenly distributed in the disposal facility model. A simple mixing-cell calculation was then performed to establish a release rate from the waste to the underlying barrier. (See Section 3.2.3.2.1 for a discussion of this method.) Figure 4-4 shows the total release rate from the bottom of the trench. A value of $\mathrm{N}=10$ was used for all calculations and represents moderate dispersion or mixing in the trench. The release rate shown in Figure $4-4$ is expressed as both flux and concentration (flux is equal to the recharge rate times the concentration).

Neither sorption effects nor decay are factored into these calculations. These effects are included in the final dose calculation. The release curve shows a maximum flux of about $8.6 \times 10^{-2} \mathrm{Ci} / \mathrm{yr}$ at year 0.0 , followed by a decrease in flux as the inventory is depleted. The entire inventory has been released from the facility within 1,000 years. The peak flux and the time required to deplete the inventory completely depends on the rate of 
WHC-SD-WM-TI-730, REV 0

infiltration. Figure 4-5 shows how this varies with different recharge values.

The second release mechanism that was considered was a constant concentration release model that is used to simulate solubility or corrosion control. In this case, the concentration in solution is constant and controlied by the solubility or corrosion reaction. If solubility reactions are controlling, the release rate is independent of inventory. If corrosion is controlling, the release rate depends on the radionuclide concentration in the waste and the assumed corrosion rate. In this analysis, a constant. concentration of $1 \mathrm{Ci} / \mathrm{m}^{3}$ is assumed.

The third release mechanism that was used was a diffusion-dominated release in which the amount of contaminants available for release was controlled by the waste form. Release from the waste form was represented as a diffusion coefficient. Three different values, $1.0 \times 10^{-8} \mathrm{~cm}^{2} / \mathrm{s}, 1.0 \times$ $10^{-10} \mathrm{~cm}^{2} / \mathrm{s}$, and $1.0 \times 10^{-12} \mathrm{~cm}^{2} / \mathrm{s}$ were evaluated. This method is discussed in Section 3.2.3.2.3. Figure 4-6 shows the release rates resulting from the three different diffusion coefficients. The observed discontinuities in the release curves are believed to be numerical artifacts that can be resolved by refining the numerical approach. Because this part of the release curve does not affect the peak dose estimate at the downstream well, this additional modeling has not been completed.

4.2.1.2 Release and Transport Analys is for Advection-Dominated Release. The release and transport results for the base case are shown in Figures $4-7$ and 4-8. Figure 4-7 shows the change in the contaminant plume over time. Four different times were chosen to show a characteristic progression. Some significant aspects of the soil column hydrologic characteristics can also be seen in Figure 4-7. First, moderate dispersion is seen in the analysis as shown by the spreading of the plume in the vadose zone beyond the ends of the trench and the minimal vertical spreading of the plume in the aquifer. Second, the flat bottom of the plume clearly demonstrates the change in direction of flow from vertical to horizontal in the unconfined aquifer. Third, the concentration contour lines show a significant increase in dilution of radionuclide concentration brought about by mixing vadose-bearing water with fresh water in the unconfined aquifer. These characteristics are present for all sets of conditions considered in this analysis. In the remainder of the modeling runs discussed in this chapter, results will be presented in terms of well water concentrations versus time (e.g., Figure 4-8). In Figure 4-8, groundwater radionuclide concentrations rise to a peak of $7.3 \times 10^{-4} \mathrm{Ci} / \mathrm{m}^{3}$ at 86 years and then decrease to zero as the inventory plume passes the interception point with the well.

For this case, an intermediate concentration of about $0.01 \mathrm{Ci} / \mathrm{m}^{3}$ just above the water table was calculated. The concentration in water leaving the trench is about $0.083 \mathrm{Ci} / \mathrm{m}^{3}$. For this particular distribution of the inventory, the concentration is diluted by a factor 8 during transport through the vadose zone and an additional factor of about 15 determined by comparison with the peak concentration. The ratio of vadose zone to peak concentration indicates the effect of the plume mixing with the uncontaminated aquifer water. This dilution effect should be similar for all cases run in the analysis. The concentration ratio of trench to vadose zone will change 
WHC-SD-WM-TI-730, REV 0

depending on the assumed distribution of waste in the trench and the release mechanism.

4.2.1.3 Release and Transport Analysis for Constant Concentration Release. Figure 4-9 shows a typical contaminant plume for the constant-concentration release model. This is essentially identical to the plume from an advection release model at the time of peak concentration at the $100-m(328-\mathrm{ft})$ wel1. The primary effect of the constant-concentration assumption is that the concentration in the $100-\mathrm{m}(328-\mathrm{ft})$ well rises asymptotically to a peak value and does not reduce. This can be seen in Figure 4-10. The peak value for this case is $4.72 \times 10^{-2} \mathrm{Ci} / \mathrm{m}^{3}$. The peak concentration for the constantconcentration release cases increases rapidly at first, then approaches a maximum value asymptotically. As a result, the time at which the peak value is reached is not a meaningful parameter for these studies. The time at which the well concentration reaches 95 percent of maximum has been found to be a more appropriate way to compare the results of different models. In this case the 95-percent time was 115 years. The same calculations were performed for a reduced recharge of $0.5 \mathrm{~cm} / \mathrm{yr}$. This resulted in a peak value of $5.98 \mathrm{x}$ $10^{-3} \mathrm{Ci} / \mathrm{m}^{3}$. The complete curve is shown in Figure 4-11.

4.2.1.4 Release and Transport Analysis for Diffusion-Dominated Release. The diffusion-dominated model behaves similarly to the advection-dominated model except that it takes substantially longer for the entire inventory to be released. As a result, after the peak is reached, the drinking well concentration approached zero asymptotically. Figure 4-12 shows the drinkingwater-well concentration curves for the three different diffusion coefficients. The peak values for these cases are $2.73 \times 10^{-4}, 3.10 \times 10^{-5}$, and $3.11 \times 10^{-6} \mathrm{Ci} / \mathrm{m}^{3}$. The first case, corresponding to a diffusion coefficient of $1.0 \times 10^{-8} \mathrm{~cm}^{2} / \mathrm{s}$, has a peak approximately half the base case (advection dominated). The other two cases indicate that the peak concentration falls off approximately one order of magnitude for each twoorder reduction in the diffusion coefficient. The same cases were modeled using a reduced recharge of $0.5 \mathrm{~cm} / \mathrm{yr}$. The resulting drinking well concentrations were $1.07 \times 10^{-4}, 1.26 \times 10^{-5}$, and $1.25 \times 10^{-6} \mathrm{Ci} / \mathrm{m}^{3}$. The results are plotted in Figure 4-13.

\subsubsection{Sensitivity Analyses for the Groundwater Pathway}

The sensitivity analyses were developed for two purposes: to understand more clearly which parameters have the dominant effect on the contaminant transport for a given set of conditions and to understand the sensitivity of the results to parameter variability. The following discussion is organized according to those parameters affecting the source term, followed by those affecting the transport through the soil column. The sensitivity analyses are conducted exactly as the base-case calculations were except for changes in the parameter values of interest. Interpretation of sensitivity analysis results is based on a comparison of peak concentrations and occasionally the time at which peak concentrations occur. Of the various parameters discussed below, some of the more important ones were evaluated using the 200 East Area LLBG design and hydrogeologic input parameters.

4.2.2.1 Sensitivity Anatyses of Modeling Approximations. The large size of the 200 East Area LLBG makes it impractical to evaluate all scenarios using a 
WHC-SD-WM-TI-730, REV 0

fully explicit model. To reduce the complexity of the model a $20-m$ trench was used and 1 arger trench results were extrapolated from these results. To determine how the results depend on the trench length, two cases were run with longer trenches, one with a 40-m (131-ft) trench (Figure 4-14) and one with an 80-m (262-ft) trench. In both cases, doubling the length of the trench reduced the peak concentration by approximately 5 percent. This result may indicate additional dispersion because of the longer path, or it may be a result of numerical dispersion. Regardless, the effects of variable trench length on peak concentration estimates is minor.

This analysis assumed that the inventory was constant (independent of length), and that an advection-dominated release mechanism was in effect. If the inventory were increased proportionately with the length or a solubilitylimited (constant-concentration) release mechanism were used, the peak concentration would increase linearly.

\subsubsection{Sensitivity Analyses of Natural Parameters Affecting Radionuclide} Transport. In the base-case analysis, a simple geometric model was used to simulate the natural environment. In this section, sensitivity analyses are described to evaluate the effects of presumed variability in the hydrogeologic system or parameter values on radionuclide concentrations in groundwater.

4.2.2.2.1 Peak Concentration Response to Change in Infiltration Rate. To evaluate the impact of over-estimating the infiltration rate on the peak concentration, several cases were run with a reduced infiltration of $0.5 \mathrm{~cm} / \mathrm{yr}$. The radionuclide release from the facility curve used for these cases is shown in Figure 4-5. The first case, representing a factor-of-10 reduction in the recharge, resulted in a peak concentration of $1.20 \times 10^{-4} \mathrm{Ci} / \mathrm{m}^{3}$ (Figure 4-15), which constitutes a reduction factor of 5 from the base-case (Figure 4-8). Low recharge cases were also run for the constant concentration release, variable $\mathrm{Kd}$, diffusion, and alternative-site cases.

4.2.2.2.2 Peak Concentration Response to Changes in $\mathrm{Kd}$. The base-case analyses assumed a $\mathrm{Kd}$ value of $0 \mathrm{~mL} / \mathrm{g}$. However, different radionuclides have different $K d$ values. To quantify how this variation in $K d$ affects the peak concentration values, a parametric study was performed on the Kd value.

The $\mathrm{Kd}$ values considered were 0,1 , and $10 \mathrm{~mL} / \mathrm{g}$, representing radionuclides that are nonsorbing, weakly sorbing, and moderately or strongly sorbing, respectively. Figure 4-16 shows a typical contaminant plume for each case. Figure 4-17 shows the peak concentration versus time for each of the three cases. Peak values, for the three cases were $7.34 \times 10^{-4}, 2.46 \times 10^{-5}$, and $2.53 \times 10^{-6} \mathrm{Ci} / \mathrm{m}^{3}$. The same cases were run with a lower recharge of $0.5 \mathrm{~cm} / \mathrm{yr}^{-6}$ The peak values resulting from these cases were $1.20 \times 10^{-4}$, $3.19 \times 10^{-6}$, and $3.26 \times 10^{-7} \mathrm{Ci} / \mathrm{m}^{3}$ respectively. Complete curves are shown in Figure $4-18$.

Although the shapes of the concentration curves are nearly identical when scaled over time, as shown in Figures 4-17 and 4-18, for the three different Kd values, the time over which the plume occurs is longer and the peaks shift farther into the future with increasing $\mathrm{Kd}$ value. This reflects the increasing retardation of transport relative to groundwater flux with increasing reactivity between the radionuclide and the soil. Similarly, as 
the time of transport is increased and larger quantities of water interact with the radionuclide over time, a reduction in groundwater concentration occurs, as shown by the reduced peak concentration with increased $\mathrm{Kd}$. It is important to note that peak times are essentially proportional to the change in the retardation value, $R$ (Equation 3.21 ). Also, it appears that the peak concentration is inversely proportional to $\mathrm{Kd}$ values $\geq 1$.

\subsection{Radionuclide Groundwater Concentration Response to Soil}

Variations Across the Site. The 200 East Area LLBG site actualiy includes two separate burial ground areas with variation in soil stratigraphy (see Section 3.2.4.3.1). Two different site models were evaluated to compare how these differences affected the radionuclide groundwater concentration. The two sites of interest are the 218-E-10 and the 218-E-12B burial ground areas.

Two cases were run with the $218-E-10$ model, one with the nominal $5.0 \mathrm{~cm} / \mathrm{yr}$ recharge and one with the reduced $0.5 \mathrm{~cm} / \mathrm{yr}$ recharge. The first case (Figure 4-19) produced a peak drinking well concentration of $2.57 \mathrm{x}$ $10^{-4} \mathrm{Ci} / \mathrm{m}^{3}$ at 129 years. This is approximately a factor of 3 decrease from the 218-E-12B case and a 50-percent increase in the time to peak. The low recharge case (Figure 4-20) resulted in a peak concentration of $3.64 \mathrm{x}$ $10^{-5} \mathrm{Ci} / \mathrm{m}^{3}$ at 1,022 years, which represents a similar change from the 218-E-12B conditions.

\subsection{Radionuclide Groundwater Concentration Response to Naturaliy} 0ccurring Preferential Path Sites (Clastic Dike). Clastic dikes are naturally occurring phenomena where material from one geologic unit has intruded into another. In some circumstances, if the material properties of the affected units are sufficiently different, the dike may form a preferential flow path. In the vicinity of the 200 East Area LLBG, the three geologic units above the aquifer are sufficiently similar that that any clastic dikes that might be present are unlikely to significantly affect the peak well concentration. To quantify any possible effect, however, a very conservative and artificial case was constructed. In this case a column of fine material was inserted into the model running from the trench to the aquifer. Furthermore, the fine material was continued in a layer underneath the trench. This fine material, when placed in contact with the coarse material that makes up the geologic units under the 200 East Area LLBG, could provide a preferential flow path from the trench to the aquifer (Figure 4-21). However, the resulting peak well concentration of $1.78 \times 15^{6} \mathrm{Ci} / \mathrm{m}^{3}$ (Figure 4-22) is approximately a factor of 4 less than the base case. The peak occurs at 103.4 years, about 15 percent later than in the base case.

\subsubsection{Sensitivity Analyses of Manmade Parameters Affecting Radionuclide} Transport. Three processes relating to human activities that potentially affect radionuclide release and transport are discussed in this section:

- Disposal of heterogenous waste with variable inventory

- Deeper trench depths

- Pumping of groundwater for irrigation and drinking.

4.2.2.3.1 Radionuclide Groundwater Concentration Response to Presence of High-Concentration Waste Volumes. The base-case studies assume that waste inventories are homogeneously distributed throughout the disposal facility. Specific radionuclides are heterogeneously distributed because of the variety 
of waste streams with differing inventories that are being disposed of. Therefore, the potential for increased groundwater concentrations resulting from releases from high-concentration waste volumes, or hot spots, was evaluated.

For this study, the total quantity of radionuclides (assumed 1 Ci) was distributed over a $1-m(3-\mathrm{ft})$ section of the trench (located near the downstream end). Figure 4-23 shows a typical contaminant plume from this case; Figure 4-24 shows the peak concentration curve at the $100-\mathrm{m}(328-\mathrm{ft})$ we11. The hot-spot case produced a peak concentration of $7.24 \times 10^{-4} \mathrm{Ci} / \mathrm{m}^{3}$ occurring at 86 years. This is essentially identical to the base case (run la).

\subsection{Effects of Deeper Trenches (Reactor Compartment Disposal} Trench). Trench 94 in the 218-E-12B Burial Ground is used to dispose of reactor compartments. Because the compartments are large, this portion of the trench must be deeper $(-15 \mathrm{~m}[\sim 50 \mathrm{ft}])$. A deeper trench means a shorter distance to the aquifer and, presumably, a shorter travel time to the 1.00-m $(328-\mathrm{ft})$ well. To determine the actual impact of the deeper trench, several cases were run and compared to the normal trench models. Specifically, the trench was evaluated for three different values of $\mathrm{Kd}(0, \mathrm{l}$, and $10 \mathrm{mg} / \mathrm{L})$. In addition, a case was run with a longer trench. For all of these cases the release mechanism was modeled as constant concentration and the recharge was assumed to be $0.5 \mathrm{~cm} /$ year. The generic unit concentration for any radionuclide was assumed to be the inventory; the peak concentration identified in the following paragraphs are estimated for unit concentration. The estimated reactor compartment concentrations are much lower, as are the projected peak concentrations from reactor compartment waste.

For the $\mathrm{Kd}=0$ case, peak concentration was $5.99 \times 10^{-3} \mathrm{Ci} / \mathrm{m}^{3}$, essentially identical to the base case, and the 95-percent time was 930 years, a 14-percent reduction from the base case. The complete curve is shown in Figure 4-25.

The peak concentrations for the $K d=1$ and $K d=10$ cases were also $5.99 \times 10^{-3} \mathrm{Ci} / \mathrm{m}^{3}$, with the same shape curve except that the 95-percent times were 38,300 and 375,000 years, respectively. The $40-\mathrm{m}$ trench produced a peak concentration of $1.2 \times 10^{-2} \mathrm{Ci} / \mathrm{m}^{3}$, approximately twice that of the $20-\mathrm{m}$ (66-ft) trench (Figure 4-26). This indicates that the constant-concentration release model produces peak concentrations that are linearly proportional to the length of the trench.

\subsection{Radionuclide Groundwater Concentration Response to Pumping.} To receive a dose from contaminated groundwater, the groundwater must be pumped to the surface. In the base case, no pumping is assumed. The presence of a pump, however, will alter the velocity vectors and this might have an impact on the peak concentration. Preliminary estimates suggest that some reduction in peak concentration would result, but the effects are minimal. Pumping effects are not considered further in this analysis. 


\subsubsection{Determination of Inconsequential Radionuclides in the Groundwater Pathway}

The analytical results described in Section 4.2 for the base-case conditions and the sensitivity analyses are sufficient to eliminate a large number of radionuclides from further evaluation as potential sources of groundwater contamination and subsequent dose. The first group of radionuclides is short- and moderate-half-life radionuclides that either decay to inconsequential activities during transport to the unconfined aquifer or decay to a lesser extent and are present in such small initial quantities that inconsequential concentrations can reach the unconfined aquifer.

The radionuclides that are expected to decay to insignificant quantities during transport from the 200 East Area LLBG are listed in Table 4-13. A dilution factor and a activity reduction factor are provided to indicate the small quantities of these radionuclides that are predicted to reach the aquifer. To generate these numbers, the groundwater concentration-versus-time curves for the conditions of a conservative recharge rate of $5 \mathrm{~cm} / \mathrm{yr}$ and advective-controlled release were used. The dilution factor is the ratio of initial activity $(\mathrm{Ci})$ in the facility to the peak concentration $\left(\mathrm{C} / \mathrm{m}^{\mathrm{j}}\right)$ at the downstream well. For example, if $1 \mathrm{Ci}$ of ${ }^{60} \mathrm{Co}_{0}$ is initially present in the trench, the peak concentration at the downstream well is estimated to be $3.6 \times$ $10^{-23} \mathrm{Ci} / \mathrm{m}^{3}$. The activity reduction factor is the ratio of initial activity to the remaining activity at the estimated time of entry into the unconfined aquifer. The values indicate that unrealistically large initial activities would be required to produce a significant dose relative to the performance objectives.

\subsubsection{Dose Estimates for Dose-Producing Radionuclides in Groundwater}

In this section, dose estimates are provided for those radionuclides identified in the previous section that are predicted to reach the unconfined aquifer in significant quantities. In response to two different performance objectives, two scenarios are assumed to provide dose the the maximum exposed individual and one scenario provides dose to the surrounding population. These scenarios are the all-pathways irrigator scenario and the groundwaterdrinking scenario with annual dose limits of 25 and $4 \mathrm{mrem} / \mathrm{yr}$, respectively. For each scenario, contaminated water is drawn from a we $11100 \mathrm{~m}(328 \mathrm{ft})$ downstream from the waste disposal facility.

Radionuclide-specific dose estimates are provided in Table 4-14 for each of the scenarios. To generate these doses it is assumed that unit quantities of each radionuclide are present initially in the disposal facility, and Category I waste disposal facility conditions are used; the infiltration rate is $5 \mathrm{~cm} / \mathrm{yr}$ and there is no waste form performance. The doses are calculated by multiplying the peak concentration by the appropriate dose conversion factors. The drinking water dose also requires multiplication by the quantity of water consumed (730 L /yr). Similar calculations can be completed for any of the other conditions considered in this anaiys is (e.g., Category 3 conditions and waste form performance) by substituting the appropriate peak groundwater concentration into the dose calculation. 
A comparison of the all-pathways and groundwater-drinking dose estimates for every radionuclide except ${ }^{36} \mathrm{Cl}$ shows very 1 ittle difference in value because the primary source of dose in each case is consumption of groundwater. Some additional dose from other ingestion pathways, plus inhalation and external exposure contribute to the slightiy larger dose in the al1-pathways anaiysis.

This observation is significant when considering the quantification of waste acceptance criteria. A larger dose relative to the dose limit is provided by the groundwater-drinking scenario relative to the all-pathways scenario. If the relative ratios comparing the dose to the dose limit were identical, the all-pathways dose to drinking-water dose would be equal to the ratio of the limits $(6.25)$. The dose ratios are 2 to 5 times less than this value (Table 4-14) except for ${ }^{36} \mathrm{Cl}$. These comparisons show that only the groundwater-drinking scenario needs to be considered when developing waste acceptance criteria for all radionuclides of interest except ${ }^{36} \mathrm{C} 1$. The primary waste acceptance criteria are radionuclide-specific inventory limits that are calculated to provide the maximum allowable dose. Thus, if a radionuclide limit satisfies the groundwater-drinking dose, it automatically satisfies the al1-pathways limit. With regard to ${ }^{36} \mathrm{Cl}$, because of the absence or lack of significant quantities of this isotope in all waste streams known to be generators for the LLBG, we adopt the groundwater protection limit for consistency. If, in fact, some waste stream ${ }^{36} \mathrm{Cl}$ inventory does approach the limit, consideration of the appropriate limit will be revisited.

\subsubsection{Uncertainty in Computed Peak Radionuclide Concentrations}

In this section, the results of the sensitivity analyses and the screening process are used to identify the potential uncertainties in the radionuclide concentration estimates on critical isotopes and system parameters that can contribute to dose by the groundwater pathway. The discussion of uncertainty is organized to first consider radionuclide concentrations that do not depend on waste form performance.

Outside of the waste form performance, the system parameters identified that could influence radionuclide groundwater concentrations are the following:

- The infiltration rate, particularly that allowed by the disposal facility cover

- Hydraulic conductivity of saturated soils

- Moisture content-hydraulic conductivity relationships in vadose zone soils

- The presence of vertical, high-permeability zones (clastic dikes)

- The regional hydraulic gradient

- High radionuclide concentration zones in the disposal facility

- Sorption distribution coefficients (Kds). 
A detailed discussion of hydrologic property variability is provided Sections 4.2.5.1 and 4.2.5.2. The uncertainties introduced by other parameters affecting radionuclide transport and assumptions of waste form performance are addressed in Sections 4.2 .5 .3 and 4.2.5.4, respectively.

4.2.5.1 Vadose Zone Hydraulic Property Uncertainties. Uncertainty in moisture characteristic conductivity relationships in the vadose zone soils comes from two sources, extrapolation of laboratory measurements on core samples to in situ soils and inherent local heterogeneity in soil properties.

\subsection{Uncertainty in Extrapolation of Laboratory Results to Field}

conditions. The use of laboratory-measured moisture retention and unsaturated hydraulic conductivities, without correcting for field conditions, can introduce an indeterminate level of uncertainty in flow and transport calculations. The following describes the methods used to reduce the uncertainty from inappropriate use of laboratory measurements.

Laboratory measurements of the moisture retention data are typically made on the fine fraction ( $<2 \mathrm{~mm}[<.08 \mathrm{in}$.$] size) using the "Tempe" pressure cell$ method (Klute, 1986). Several samples analyzed for the 200 East burial grounds contain a high gravel fraction (>2 mm [>.08 in.]). Gravels can occupy appreciable volume in a soil sample without making a commensurate contribution to the moisture capacity of the soil. Mass-basis water content figures are lower than corresponding values for a soil on a rock-free basis because of the excessive contribution to the dry mass made by a rock that typically has a bulk density considerably larger than that of the finer fraction $(<2 \mathrm{~mm}$ [<.08 in.]). Determining moisture retention properties for the bulk sample (including gravels), therefore, requires special consideration (e.g., Gardner 1986; Bouwer and Rice 1984).

The Taboratory measurements were corrected for field conditions by accounting for the gravel fraction in the sample. In addition to obtaining Tempe cell measurements on $<2-\mathrm{mm}$ (<.08-in.) size fraction, independent measurements of moisture retention data were obtained in the laboratory on bulk field samples that included $>2-\mathrm{mm}$ ( $>.08$-in.) size fraction as well. The steady-state unit gradient method (Klute and Dirksen 1986) was used to obtain independent measurements of moisture retention data for the bulk samples (including $>2-m m$ size $[>.08-i n$.$] ).$

Figure 4-27 shows the moisture retention data, for a sandy gravel sample (Sample 3-0571) having 60 percent gravel, using the Tempe Cell (TC) and Unit Gradient (UG) methods. The raw (uncorrected) moisture retention data, based on TC measurements, clearl'y deviate significantly from those based on the UG method. However, the same TC measurements, corrected for the field bulk density and percent fines in the field sample, compare very favorably with the measurements based on the UG method.

This and other data, based on 23 samples containing gravel fractions ranging from about 10 to 66 percent, indicate that the moisture-retention data for gravelly soils can be predicted reasonably well by correcting the Tempe cell measurements by the field bulk density and the fraction of fines in the field samples (Khaleel and Relyea 1996). Uncorrected Tempe cell data do not represent the field conditions for gravelly soils that exist in 200 East 
burial grounds. However, for the coarse-textured, gravelly samples and the moisture regime being considered, the use of laboratory-measured moisture retention data, followed by gravel correction, results in an adequate characterization of retention properties under field conditions. Moisture retention data used in the PA were corrected for field conditions.

Another source of uncertainty is the use of inappropriate unsaturated conductivity estimates at the dry moisture regime for the recharge conditions at the Hanford Site. Unsaturated conductivities estimated by the van Genuchten-Mualem predictive mode1, using the fitted moisture retention curve and measured saturated hydraulic conductivity, $K_{s}$, were compared to those obtained by a scaled-predictive method that uses a single $K(\theta)$ measurement as a match point near the dry regime (Khaleel et al. 1995). In general, the measured $K^{\prime}$ 's and those predicted from van Genuchten-Mualem relationships showed considerable disagreement. Therefore, the use of laboratory-measured $K_{s}$ results in an inadequate characterization of $K(\theta)$ 's for the desired range of moisture content. Deviations between the measured and predicted $K$ 's were particularly severe at relatively low moisture contents; for some samples differences were in excess of two orders of magnitude at low $\theta$. However, use of the same moisture-retention curve-fitting parameters and a single steadystate head control-based $K(\theta)$ measurement near the dry regime resulted in considerable improvement. Results indicate that a $K(\theta)$ measurement near the dry regime must be used to obtain reliable estimates of unsaturated $K$ 's at low $\theta$ (Khaleel et al. 1995).

For this $P A$, as discussed in Appendix $A$, to avoid the uncertainty of extrapolating $K(\theta)$ curve, based on a $K_{s}$ measurement, $K(\theta)$ measurements were obtained for the samples analyzed. A simultaneous fit of both moisture retention and unsaturated conductivity measurements was then used to obtain the van Genuchten parameters. Such a procedure greatly reduces the uncertainty associated with estimation of $K(\theta)$ for the moisture regime of concern to this PA.

4.2.5.1.2 Uncertainty of Local Heterogeneity in Vadose Zone Soil Hydraulic Properties. The 200 Areas data on vadose zone soil moisture characteristics exhibit a high degree of variability. A separate study (Khaleel and Freeman 1995) was conducted to characterize the variability for 200 Areas soils. Results are summarized as follows, and relevance to the PA is discussed.

The first step in evaluating variability was to ascertain the usefulness of grouping various 200 Areas soil types into common categories with similar physical characteristics. The moisture retention data, followed by gravel correction, were sorted by texture based on sieve analys is and the International Soil Science Society (ISSS) classification scheme. Retention curves having similar textures were then plotted on a single graph to evaluate whether they indeed display common characteristics. Those displaying common characteristics were grouped so that an "average" curve could be defined. This led to a grouping of the moisture retention data for 176 samples by 6 categories:

- Sand mixed with finer fraction (SS, 48 samples)

- Sand (S, 76 samples) 
WHC-SD-WM-TI-730, REV 0

- Sand and gravel mixed with finer fraction (SSG, 6 samples)

- Gravelly sand (GS, 10 samples)

- Sandy gravel for which gravel content is approximately less than 60 percent of the sample weight (SG1, 25 samples)

- Sandy gravel for which gravel content is approximately greater than 60 percent by weight (SG2,; 11 samples).

The database comprising six soil categories for 200 Areas soils was used as the basis for characterizing the variability in van Genuchten model

parameters $\theta_{s}, \theta_{1}, \alpha, n$, and $K_{s}$ (Table A-1, Appendix A). Table A-1, Appendix A provides a compifation of the van Genuchten model parameters for 200 Areas soils. The soil types and their grouping by categories are indicated for each sample in Table A-1. Among the six categories, categories 2 (sand, S) and 5 (sandy grave1, SG1) are particularly relevant for this PA, because of their presence beneath the 200 East LLBG.

Descriptive statistics for soil categories $S$ and $S G 1$ are provided in Table 4-15. Among the five van Genuchten model parameters, the variability is highest for $K_{s}$ and least for parameter $n$; the coefficient of variation (CV) for $K_{s}$ can be as high as 194 percent (Table 4-15), whereas the $\mathrm{CV}$ for parameter $n$ varies from only 21 to about 39 percent. The high variability exhibited by $K_{s}$ is not unexpected given the highly heterogeneous nature of Hanford Site sediments and is consistent with values reported el sewhere (e.g., Carsel and Parrish 1988). The variability exhibited by $\theta_{s}$ was minimal; the $c v$ for $\theta_{s}$ was less than 25 percent for both soil categories. This is also consistent with data reported by other investigators (e.g., Carsel and Parrish

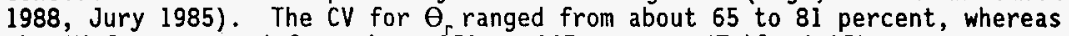
the $\mathrm{CV}$ for $\alpha$ ranged from about 151 to 247 percent (Table 4-15).

Figure 4-28 shows the moisture retention data for the two soil categories. For each category, the solid line represents the best fit van Genuchten curve through the unscaled data. Table 4-16 provides the fitted van Genuchten parameters. A clear progression of the moisture retention data and the best fit curves from fine (S) to coarse (SGI) categories are apparent from Figure 4-28.

On comparing Tables 4-15 and 4-16 with Tables 3-4 and 3-5, moisture retention data and saturated hydraulic conductivities used in the PA are clearly within the bounds of expected values for 200 Areas soils. The primary effect of variability in the unsaturated hydraulic properties is to increase or decrease the travel time by relatively small amounts. This changes the estimated time of peak concentration at the downstream well but has little effect on the peak concentration. For this parameter, significant changes in peak concentration only occur when radioactive decay reduces the inventory during transport. Because the only radionuclides of concern for groundwater contamination are long-lived, decay is not an important process affecting peak concentration estimates.

4.2.5.2 Uncertainty in Saturated Hydraulic Conductivity Estimates for the Unconfined Aquifer. Based on sitewide groundwater model (Law et al. 1996), saturated conductivity $\left(K_{s}\right)$ estimates of about $30,000 \mathrm{~m} / \mathrm{yr}(82 \mathrm{~m} / \mathrm{d})$ and 


$$
\text { WHC-SD-WM-TI-730, REV } 0
$$

$89,900 \mathrm{~m} / \mathrm{yr}(246 \mathrm{~m} / \mathrm{d})$ were used, respectively, for the uppermost aquifer beneath the 218-E-12B and 218-E-10 LLBGs. Saturated hydraulic conductivity estimates from in situ measurements for a limited number of wells in the uppermost aquifer in the 200 East Area are listed in Connelly et al. (1992). A probability distribution plot of these data is shown in Figure 4-29. A trend toward a lognormal distribution is suggested by Figure 4-29. Data distribution statistics are included on the right of the plot. Saturated conductivity estimates have been reported to be lognormally distributed for other sites (e.g., Freeze and Cherry 1979; Sudicky 1986; Hills and Wierenga 1991). For the 200 East Area, the unconfined aquifer saturated conductivity ranged from 8 to $7,600 \mathrm{~m} / \mathrm{d}$ (Connelly et al. 1992), with the estimates (untransformed data) for mean and standard deviation being about 3,296 and $23,962 \mathrm{~m} / \mathrm{d}$, respectively. Note that the mean estimate based on in situ measurement (e.g., pumping tests) is several orders of magnitude higher than the mean estimate based on laboratory methods (e.g., permeameters). This discrepancy is attributable to scale differences resulting from different sampling volumes for the laboratory versus field testing.

To evaluate the uncertainty associated with saturated conductivity estimates for the uppermost aquifer system, a run could be made with the highest measured value for $k_{s}$ (i.e., $7,600 \mathrm{~m} / \mathrm{d}$ ) in 200 East Area. This would, however, lead to a lower peak concentration and an earlier arrival of the peak concentration. For the local 218-E-12B LLBG area, measured $K_{s}$ values for the uppermost aquifer range from 430 to $3,500 \mathrm{~m} / \mathrm{d}$, whereas for the local $218-E-10$ LLBG area, measured $K_{s}$ values range from 300 to $1,700 \mathrm{~m} / \mathrm{d}$. The $K_{s}$ values used (i.e., $82 \mathrm{~m} / \mathrm{d}$ and $246 \mathrm{~m} / \mathrm{d}$ ) in the simulations are lower, but are within the range of values reported (Connelly et al. 1992) for the uppermost aquifer in the total 200 East Area. Although measurements are available on $K_{s}$ for the Hanford formation beneath the LLBG, these cannot be used after Hanford Site operations end because the water table will drop and be located within the Ringold Formation. The $K_{s}$ values being used reflect the Ringold Formation estimates and are identical to the values used in the sitewide groundwater model (Law et al. 1996).

The volume of mixing water and peak dose estimates are roughly proportional to the change in hydraulic conductivity value. If the base case values are compared to the local area measurements $(8-7,600 \mathrm{~m} / \mathrm{d})$, a relative decrease in peak value by a factor of 5 or more for the 218-E-12B LLBG and 1.5 or more for the 218-E-10 LLBG is predicted as a result of the base case hydraulic conductivity values selected.

4.2.5.3 Uncertainty in Other Parameter Values. The results of the sensitivity analyses show that for a disposal facility configuration identical to the base case, variability in other factors listed at the beginning of this section can change dose estimates and therefore contribute to uncertainty in dose estimates. However, most of these parameter variabilities are expected to have negligible effects on the base-case results.

The existence of clastic dikes (Section 4.2.2.2.3) and high-concentration (hot spot) packages (Section 4.2.2.2.4) appear to have 1 ittle effect on dose estimates relative to the base-case conditions, which assume homogeneous stratigraphy and evenly distributed inventory. Clastic dikes have little impact because of their small cross sectional area, lack of continuation through the vadoze zone, and rarity of occurrence in the LLBG. Concentration 
of inventory versus homogeneous distribution is insignificant as long as the total inventory is unchanged because the model assumes that all inventory released contributes to the final groundwater concentration. In addition, because we are only concerned about dose resulting from nonsorbing or slightly sorbing radionuclides, the variability in $\mathrm{Kd}$ values does not contribute to uncertainty.

The infiltration rates assumed for the Category 1 and Category 3 facilities are considered to be maximum average rates for the cover conditions assumed. For the purposes of estimating uncertainty in peak concentrations, a reduction in the base-case values ( 5 and $0.5 \mathrm{~cm} / \mathrm{yr}$ ) by a factor of 5 to 1 and $0.1 \mathrm{~cm} / \mathrm{yr}$ is considered a reasonable estimate of a lower bound based on the lysimeter study data summarized previously. The base-case data indicate that the peak concentration decreases by a factor of about 4 with a decrease in infiltration rate from 5 to $0.5 \mathrm{~cm} / \mathrm{yr}$ (a factor of 10). Thus, it is assumed that the relative potential decrease in peak concentration is a factor of two because of uncertainty in the average infiltration rate.

Finally, quantifying changes in hydraulic gradient values is difficult. However, sitewide model results (Appendix E) support the conclusion that the very small gradient used in the base-case analysis will satisfactorily reproduce pre-Hanford Site hydrologic flow conditions and that any changes in gradient are likely to be an increase caused by greatly enhanced irrigation on site or increased infiltration caused by climatologic change. In this case, the volume of unconfined aquifer water mixing with the potential contaminant plume increases and, therefore, decreases expected peak concentrations in a downstream wel1. Thus, no potential increases in peak concentration are expected to result from changes in the hydraulic gradient.

4.2.5.4 Uncertainty in Waste Form or Waste Material Performance Parameters. Uncertainties in dose estimates from waste form or waste material performance in this analysis are relevant to uranium-bearing waste and radionuclides entrained in activated metal. Uncertainty about solubility values is significant for those radionuclides with peak groundwater concentrations controlled by a precipitation reaction. In this analysis, this condition is relevant to uranium only.

The uncertainty in peak groundwater concentrations is directly proportional to the solubility. Uncertainty in solubility values depends on the accuracy of the thermodynamic database which, in turn, depends on the reliability of the database developed to quantify thermodynamic properties. The solubility estimates can al so be checked with empirical data to evaluate the accuracy of the estimates. Thermodynamic data for uranium indicate that solubility values could be double the value chosen under natural soil conditions. Conversely, empirical leaching tests of uranium contaminated soil (Serne et al. 1994) suggest that solubility values may be more than an order of magnitude less than the predicted thermodynamic value of about $60 \mathrm{mg} / \mathrm{L}$ (Serne et a1. 1993). In a grout-dominated environment, we estimate that solubility may be up to two orders of magnitude less than that assumed.

The other parameters affecting uranium peak concentrations are infiltration rate, the trench length parallel to flow, the vadose zone hydrologic properties, the hydraulic gradient, and the aquifer hydraulic conductivity. Combined with the other parameter uncertainty factors, the 
bounding changes in groundwater concentration for uranium are estimated to be an increase by a factor of about 2 and a decrease by a factor of about 30 . For grout-dominated solubility, the concentration could decrease by a factor of 3,000 relative to base-case conditions.

When the concentrations are based on metal corrosion, the other parameter adding to the uncertainty of dose calculations is the assumed corrosion rate. A conservative corrosion rate of $0.02 \mathrm{mg} / \mathrm{dm}^{2} / \mathrm{yr}$ was picked (U.S. Department of the Navy 1996). A larger corrosion rate was not projected and the lower range was not quantified. Thus, the bounding ranges in concentration for activated metal waste are no increase and some unquantified decrease.

\subsection{ADDITIONAL ANALYSES}

In this section, a number of additional radionuclide transport pathways and site conditions are evaluated for their potential impact on dose to humans. The additional pathways include vapor diffusion for those radionuclides that are known to partition into the vapor phase under ambient conditions and upward diffusion in liquid. Dose from transport by vapor is considered for the inadvertent intruder and the offsite individual.

Other site conditions that may affect the dose to humans include the potential for mixing of a contaminant plume from the 200 East Area LLBG with current contaminant plumes in the unconfined aquifer or potential plumes from other LLW disposal facilities and large-scale commercial agriculture irrigation that might occur on site in the future. The potential dose effects from mixing plumes from multiple waste sites will be evaluated in the composite analysis to be completed in 1997 following guidance developed by DOE (1996). The effects of agricultural land use in areas within the current Hanford site boundaries on hydrologic flow patterns will be considered. Agricultural land use in the burial grounds themselves is not considered to be a plausible scenario. No agricultural activities have ever occurred in the local burial ground areas. Further, documentation by concerned groups (HFSUWG 1992) strongly recommends that the 200 Areas be restricted to waste management activities for the foreseeable future.

\subsubsection{Vapor Transport of Carbon-14 to the Intruder and Radon-222 Surface Flux}

Wood et al. (1995a) evaluated the potential dose to the inadvertent intruder for both ${ }^{3} \mathrm{H}$ and ${ }^{14} \mathrm{C}$. Two cases were considered. The first was the exhumation of waste and distribution in surface soil accompanied by residence in a home. The second was the construction of a home on top of the undisturbed soil site. In each case, the calculation showed an increased dose for these radionuclides relative to the normal intruder scenario in which ${ }^{3} \mathrm{H}$ and ${ }^{14} \mathrm{C}$ are assumed to be attached to the contaminated soil. This result implied that dose estimates and WAC (i.e., concentration limits) should be driven by this pathway. However, other considerations suggested that dose by this means is unlikely to occur. The arguments are summarized in the following paragraphs. 
WHC-SD-WM-TI-730, REV 0

For ${ }^{14} \mathrm{C}$, the estimated dose cQuld only be calculated by assuming a very rapid release rate (e.g., a $1 \mathrm{Ci} / \mathrm{m}^{3}$ source would be depleted with in $10 \mathrm{yr}$ ). On the other hand, it was being assumed that the inadvertent intrusion event did not occur before 500 years post-closure. To receive the estimated dose, ${ }^{14} \mathrm{C}$ must be essentially immobilized in the waste volume until intrusion occurs and then be released very rapidly. This was viewed as an implausible set of events and the potential dose by this pathway was dismissed. A similar argument is applied to ${ }^{3} \mathrm{H}$. Further, in the case of ${ }^{3} \mathrm{H}$, the acceptable concentration is calculated to be about $2 \times 10^{12} \mathrm{Ci} / \mathrm{m}^{3}$. If a density of elemental hydrogen $\left(0.07 \mathrm{~g} / \mathrm{cm}^{3}\right)$ is assumed, this acceptable mass concentration is about $2.9 \times 10^{7} \mathrm{Ci} / \mathrm{g}$, which exceeds the specific activity of ${ }^{3} \mathrm{H}$ (about $10,000 \mathrm{Ci} / \mathrm{g})$.

To estimate ${ }^{222} \mathrm{Rn}$ flux to the atmosphere, a simple Fickian diffusion process is assumed to calculate flux and a steady-state condition is assumed. In this case, flux is described by the equation:

$$
J=C_{0} \exp (-x \sqrt{\lambda / D}) \sqrt{\lambda D}
$$

where:

$J=f l u x\left(C i / m^{2} / y r\right)$

$D=$ diffusion coefficient in soil, $31.5 \mathrm{~m}^{2} / \mathrm{yr}\left(1 \times 10^{-2} \mathrm{~cm}^{2} / \mathrm{s}\right)$

$\lambda=$ decay constant, $66.2 / \mathrm{yr}$

$\mathrm{C}_{0}=$ concentration in water vapor $\left(\mathrm{Ci} / \mathrm{m}^{3}\right)$

$x=$ soil thickness $(5 \mathrm{~m})$.

To calculate the flux, it is assumed that the initial ${ }^{222} \mathrm{Rn}$ concentration is $1 \mathrm{Ci} / \mathrm{m}^{3}$. The estimated flux under these conditions is $1,000 \mathrm{pCi} / \mathrm{m}^{2} \mathrm{~s}$. The effect of this result using projected waste inventories of the parent isotopes, ${ }^{238} \mathrm{U},{ }^{234} \mathrm{U}$, and ${ }^{226} \mathrm{Ra}$, for disposal in the 200 East Area LLBG is provided in Section 4.4.

\subsubsection{Offsite Dose Estimates from Vapor Diffusion of Carbon-14 and Hydrogen-3}

In Wood et a1. (1995a), the ISC2 program was used to estimate offsite flux using Hanford Site-specific wind data to estimate dose. Details are provided in Appendix $C$. To evaluate the flux to the offsite individual, the following equation was used to calculate dose:

$$
\text { Annual Inhalation Dose }=J * A *(X / Q) * B R * D C F
$$

where:

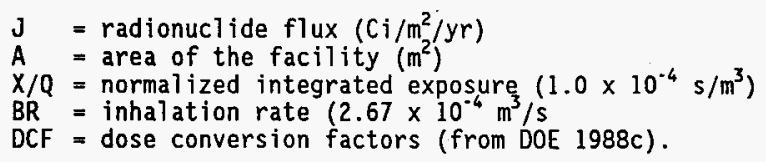


Using equation 4.1 to estimate the potential fluxes for ${ }^{14} \mathrm{C}$ and ${ }^{3} \mathrm{H}$, doses for an initial concentration of $1 \mathrm{ci} / \mathrm{m}^{3}$ were estimated at 670 and $1.4 \times 10^{-4} \mathrm{mrem} / \mathrm{yr}$ for ${ }^{14} \mathrm{C}$ and ${ }^{3} \mathrm{H}$, respectively. In Section 4.4 , potential offsite dose is estimated using the projected inventories for the 200 East Area LLBG.

\subsubsection{Upward Migration of Contaminants}

The anticipated low recharge for the 200 East Area LLBG site provides potential for upward migration of contaminants. Two potential mechanisms of upward migration of contaminants at the 200 East Area LLBG site are considered: upward diffusion and upward migration by capillary action.

4.3.3.1 Upward Diffusion. The potential for upward diffusion was investigated by comparing the computed upward diffusive front with the downward advective front of contaminants. Fick's second law is used to compute the concentration $(C)$ of a diffusive, nonreactive contaminant:

$$
D \frac{\partial^{2} C}{\partial^{2} z}=\frac{\partial C}{\partial t}
$$

where $Z$ is the distance, $t$ is time, and $D$ is the diffusion coefficient. The solution for concentration $C$ in equation (4.3) in the $z$ direction over time $t$ is given by:

$$
\frac{C}{C_{0}}=\operatorname{erfc}\left(\frac{z}{2 \sqrt{D t}}\right)
$$

where erfc is the complimentary error function and $C / C_{0}$ is the relative concentration. From (4.4), the mean penetration distance (L) by diffusion (i.e., for $C / C_{0}=0.5$ ) is given by:

$$
L=\sqrt{D E} .
$$

To determine the distance ( $L$ ) traveled by advection, a steady, one-dimensional (vertical), unit gradient model was used:

$$
L=V t=\left(\frac{q}{\theta}\right) t
$$

where $V=$ fluid velocity through the Hanford formation sediments under conditions of unit gradient, $t=$ travel time, $q=$ recharge rate, and $\theta=$ moisture content for Hanford formation sediments under unit gradient condition (derived from $\mathrm{K}(\theta)$ versus $\theta$ curve). 
Natural Hanford sediments below the near-surface zone affected by seasona 1, diurnal, and plant evapotranspiration cycles generally have a moisture content that is typically less than 10 percent by volume. Laboratory measurements (Serne et al. 1993) of diffusion coefficients for Hanford sediments indicate that for volumetric moisture contents of about 10 percent, the diffusion coefficients for a nonreacting tracer would be about $3 \times 10^{-7}$ $\mathrm{cm}^{2} / \mathrm{s}$. Using estimates of moisture content based on $\mathrm{K}(\theta)$ versus $\theta$ relationship for 200 East Area LLBG Hanford sediments (e.g., Sample 5-0153, Well 299-E32-4, Appendix A) and Serne et a1. (1993, Figure 8), Table 4-17 shows the diffusive distances traveled by upward migration and the advective distances traveled by downward migration for the anticipated low recharge of 0.005 and $0.05 \mathrm{~cm} / \mathrm{yr}$. These values are lower than base-case values and have been chosen to enhance the upward diffusion effect, a conservative assumption for this particular analysis.

Using a very low recharge estimate of $0.005 \mathrm{~cm} / \mathrm{yr}$, the advective travel distances expected for movement under unit gradient conditions in unsaturated Hanford sediments beneath 200 East Area LLBG are $0.083 \mathrm{~m}, 0.83 \mathrm{~m}$, and $1.67 \mathrm{~m}$ at $100,1,000$ and $2,000 \mathrm{yr}$, respectively. The computed diffusive distances are $0.178 \mathrm{~m}, 0.562 \mathrm{~m}$, and $0.794 \mathrm{~m}(.58 \mathrm{ft}, 1.8 \mathrm{ft}$, and $2.6 \mathrm{ft})$ at $100,1,000$, and 2,000 years, respectively. Therefore, under very low recharge (and therefore very dry conditions) around buried waste in the unsaturated sediments beneath the 200 East Area LLBG, the diffusive transport could be of equal or greater magnitude compared to the advective transport up to over 1,000 years. However, beyond 2,000 years, the advective transport exceeds the diffusive transport. For a recharge estimate of about $0.05 \mathrm{~cm} / \mathrm{yr}$, the diffusive and advective distances are of similar magnitude for up to about 10 years. At a time scale much earlier than $100 \mathrm{yr}$, the computed advective transport distances are greater than the diffusive transport distances. In either case, the maximum upward distance that can be traveled is computed to be less than $1 \mathrm{~m}(3 \mathrm{ft})$ for up to 1,000 years.

The fact that precipitation occurs episodically and at much higher rates than the assumed average, may effectively prevent any real upward movement by diffusion over a long period of time. Thus, with about $5 \mathrm{~m}$ (16 ft) of soil cover for disposed wastes, the upward radionuclide transport by diffusion does not appear to be significant for the conditions analyzed and is not considered a viable means of providing any significant dose.

4.3.3.2 Upward Migration by Capillary Action. The anticipated low recharge for the 200 East Area LLBG site also provides potential for upward migration of contaminants by capillary action. In particular, ground-surface evaporation may cause an upward capillary pressure gradient sufficient to overcome gravity and move infiltrated water back toward the surface by a process called capillary rise. The delivery of water to the surface by this mechanism is also referred to as exfiltration (as opposed to infiltration). The one-dimensional, transient. flow of water in an unsaturated medium can be written as:

$$
\frac{\partial \theta}{\partial t}=\frac{\partial}{\partial z}\left[D(\theta) \frac{\partial \theta}{\partial z}+K(\theta)\right]
$$


where $z$ is distance, $t$ is time, $\theta$ is volumetric moisture content, $K(\theta)$ is unsaturated hydraulic conductivity, and $D(\theta)$ is soil diffusivity:

$$
D(\theta)=K(\theta) \frac{\partial \psi}{\partial \theta}
$$

A considerable simplification of equation (4.7) is possible (resulting in its transformation into an ordinary differential equation) by omitting the explicit effect of gravity, $\partial K / \partial z$. This term is negligible whenever the effect of gravity is small compared to that of capiliarity (i.e., $\partial \psi / \partial z \gg 1)$. This can occur when the moisture content is relatively low. Omitting the gravitational term, equation (4.7) yields:

$$
\frac{\partial \theta}{\partial t}=\frac{\partial}{\partial z}\left[D(\theta) \frac{\partial \theta}{\partial z}\right]
$$

Using the assumption of constant diffusivity, equation (4.9) can be linearized as:

$$
\frac{\partial \theta}{\partial t}=D \frac{\partial^{2} \theta}{\partial^{2} z}
$$

The solution of equation (4.10), subject to an initial moisture content of $\theta_{i}$ and exfiltration with a constant surface moisture content of $\theta_{0}\left(\theta_{i}>\theta_{0}\right)$ is (Eagleson 1970):

$$
\frac{\theta-\theta_{0}}{\theta_{i}-\theta_{0}}=\operatorname{erf}\left[\frac{|z|}{2 \sqrt{D t}}\right]
$$

where erf is the error function.

Upward migration of contaminants by capillary rise is not considered to be significant as long as the "penetration depth" obeys (Eagleson 1970):

$$
4 \sqrt{(D t)}<Z
$$

Alternatively, for a soil cover thickness of $Z \mathrm{~m}$, the exfiltration duration, $T$, is given by:

$$
T \leq \frac{Z^{2}}{16 D}
$$

Again, as was discussed earlier, natural Hanford sediments below the near-surface zone affected by seasonal, diurnal, and plant evapotranspiration cycles generally have a moisture content that is typically well below 10 percent by volume. Assuming a minimum soil cover thickness of $Z=3 \mathrm{~m}$ and a computed diffusivity $D(\theta)$ (based on the moisture characteristic curves of Sample 5-0153 of $2 \times 10^{-7} \mathrm{~cm}^{2} / \mathrm{s}$ for an average volumetric moisture content of 
about 5 percent, the time $T$ is estimated to be in excess of 900 years. This suggests that, for any significant upward migration of contaminants to occur by capillary rise, the exfiltration period has to continue for more than 900 years. Such an extended dry period is considered highly unlikely. The fact that precipitation occurs episodically, at times at much higher rates than the assumed average rate, and the soil cover is subject to infiltrationredistribution cycles, upward radionuclide migration by capillary rise is not considered a viable means of providing any significant dose.

\subsection{INTEGRATION OF RESULTS}

In this section, the results from the base-case analyses, the sensitivity analyses and the uncertainty analyses are used to develop WAC and to estimate the peak doses in the compliance interval as a result of the disposal of LLW in the 200 East Area LLBG. The first two sections (Sections 4.4.1 and 4.4.2) deal with the development of intruder and groundwater scenario limits. Each section reviews the major parameters influencing dose estimates and, therefore, concentration and inventory limits. Sensitivities to parameter values and uncertainties in dose estimates are al so summarized from previous discussions. Limits are quantified and the conditions to which they apply are specified. In Section 4.4.3, the intruder and groundwater doses for the total projected inventory are compared with the performance objectives.

\subsubsection{Determination of Inadvertent Intruder Concentration Limits}

Section 4.4.1.1 describes the derivation of radionuclide-specific, base-case concentration limits. Section 4.4.1.2 covers special-case conditions that have influenced a few specific radionuclide concentrationlimit calculations.

\subsubsection{Summary of Parameters Affecting Dose Calculations and Quantification} of Concentration Limits. Concentration limits based on intruder scenarios are derived from the dose estimates described in Section 4.1 in which unit concentrations of specific radionuclides were assumed to exist in the disposal facility. Because dose estimates for a given radionuclide are directly proportional to the concentration at the time of intrusion, concentration limits for the radionuclide are calculated by taking the ratio of the initial concentration to the resultant dose estimate and multiplying by the performace objective ( $100 \mathrm{mrem} / \mathrm{yr}$ ). A base-case set of parameter values was selected to calculate the dose estimates. Realizing that the base-case dose estimates consisted of a unique set of parameter values and that other values could be selected, sensitivity analyses and uncertainty analyses were conducted to identify those parameters to which dose was most sensitive and to calculate bounding dose estimates as a function of expected parameter value ranges.

The following key observations were made.

1. Dose estimate changes were not directly proportional to changes in any parameter value except the radionuclide concentration at the time of intrusion. Typically, increasing any one parameter value by 100 percent results in dose changes of 10 to 60 percent. 
WHC-SD-WM-TI-730, REV 0

2. When computing potential uncertainties in dose estimates, cumulative factors were computed to combine the effects of all the parameters. Thus, the potential increase or decrease in dose estimates is larger than that of any one parameter and a bounding value could be calculated. Not unexpectedly, the calculated changes in dose by the ingestion pathway are relatively larger than either inhalation or external exposure because of the larger number of steps and parameters involved in the radionuclide transfer from soil to humans through the food chain.

3. Dose resulting from a given radionuclide tends to be dominated by one major pathway (e.g., ingestion versus inhalation or external exposure). Therefore, parameter variability affecting the other pathways usually has no impact on the dose estimate from that radionuclide.

4. Quantitative changes in dose relative to the base-case conditions were calculated as no greater than a factor of 10 and potentially lower by a factor of 100 or more.

These observations support the hypothesis that reasonably conservative doses are being estimated in the base-case analysis because the potential for decreased dose appears to be greater than the potential for increased dose. The calculations also show that the variability in parameter values and, therefore, the range of dose estimates is not extremely large, which improves confidence that an acceptable estimate of dose and, therefore, concentration limits can be generated.

The potential increased dose of up to a factor of 10 means that recommended concentration limits could be estimated at too high a value by the same factor. However, it is argued that such concern is unfounded. As described earlier, the selected base-case parameters quantify a conservatively high dose for the range of possible doses quantified. Also, additional conservatisms were not quantified because they are difficult to quantify or are created by the artificiality of the intruder concept. These conservatisms further reduce the estimated dose to some degree. For example, it is assumed implicitly that exhumed waste is indistinguishable from soil. This is clearly not going to be the case unless the waste were soil. Thus, if waste were exhumed it would probably be recognized and waste would be discarded rather than mixed with soil. Consequentiy, the intruder would only be chronically exposed to a fraction of the exhumed inventory and lower dose would result.

The purpose of the dose limits is to ensure that an averaged inventory does not allow excessive dose. Thus, an occasional high inventory waste volume that approaches the concentration limit or even exceeds it should not lead to an excessive dose overal1. We anticipate that low waste stream concentrations observed in the current inventory relative to the intrudergenerated limits will be similar in the future. This is supported by the generally decreasing trend in waste concentrations over the disposal period in the 200 East Area LLBG. The reactor compartment waste satisfies the Category 3 limits and is characterized by a well-defined inventory. Waste stream concentrations will be reviewed periodically in the PA maintenance phase to ensure that the expectation of low potential dose is credible. 
Concentration limits are quantified for the 200 East Area LLBG in Table 4-18. The following assumptions are associated with the formutation of the table for most of the radionuclides.

- Concentration limits for Category 1 waste have been calculated from the dose estimates of the post-excavating scenario occurring 100 years after disposal. It is assumed that disposal facility features allow all reasonable intrusion scenarios to occur.

- Concentration limits for Category 3 waste have been calculated from the dose estimates of the post-drilling scenario occurring 500 years after disposal. It is assumed that disposal facility features prevent excavation from being a likely event. At a minimum, a $\geq 5-m$ (16-ft) cover thickness is assumed. Also, a combination of disposal features and institutional memory are assumed to delay intrusion until 500 years post-closure.

- The selection of radionuclides on the list is not predicated on a particular waste stream or set of waste streams. The set of radionuclides includes all isotopes with half lives greater than 5 years. It is assumed that radionuclides with half lives of 5 years or less will have decayed to insignificant activities during the assumed minimum 100-year interval between disposal and intrusion.

- Doses taken from the nonleaching cases were used in calculating the concentration limits.

For transuranic (TRU) isotopes, the TRU limit $(100 \mathrm{nCi} / \mathrm{g})$ is likely to be more restrictive than the intruder concentration limit calculated in this analysis depending on the density of the waste assumed. If this is the case, the TRU limit takes precedence.

\subsubsection{Additional Considerations for Establishing Concentration Limits.} Some additional conditions require consideration for a few specific radionuclides to ensure that a reasonably conservative concentration limit is provided. These conditions or circumstances arise because they could increase the dose to humans and therefore necessitate the reduction of concentration limits.

For most radionuclides with daughter products in secular equilibrium at the times of intrusion, the contribution of the daughter is factored into the calculation of dose estimate and concentration limit. Also, maximum dose is calculated at the shortest assumed time of intrusion. The primary exception is ${ }^{238} \mathrm{U}$, which is assumed not to be in equilibrium with most of its daughter products (particularly ${ }^{226} \mathrm{Ra}$ ). The uranium waste that is disposed of is not natural uranium, but processed uranium that has been separated from its daughters. Extremely long periods relative to the 10,000-year performance objective period of compliance are required to achieve secular equilibrium or generate daughters that have a significant effect on dose.

To evaluate the relationship between ingrowth of daughters in the uranium decay chains for up to 10,000 years and potential dose increases, the intruder scenario calculations were extended to 10,000 years and total dose was 
determined. A factor of 10 increase for the ${ }^{233} \mathrm{U}$ dose and a factor of five increase in the ${ }^{234} U$ dose are calculated when the contribution to dose from the daughters are included at an intrusion time of 10,000 years post-closure. of these radionuclides, only ${ }^{234} \mathrm{U}$ is a commonly occurring radionuclide in waste. It is argued that this increase should not be considered sufficiently large to change the suggested concentration limits given the other uncertainties that are part of the intruder dose calculations. In addition, the maximum uranium concentrations expected in the 200 East Area LLBG waste are orders of magnitude below these limits. This conclusion will be evaluated periodically in the PA maintenance program.

A separate performance objective defining maximum allowable flux from a disposal facility $\left(20 \mathrm{pCi} / \mathrm{m}^{2} \mathrm{~s}\right)$ is applied to the ${ }^{222} \mathrm{Rn}$ inventory 1 imit. To evaluate the relative importance of ${ }^{222} \mathrm{Rn}$ in this context and to determine what effect, if any, the ${ }^{222} \mathrm{Rn}$ contribution to dose should have on the ${ }^{238} U$ and ${ }^{234} \mathrm{U}$ concentration limit, the potential flux of ${ }^{222} \mathrm{Rn}$ based on the ${ }^{238} \mathrm{U}$ and ${ }^{234} \mathrm{U}$ concentration limit was calculated using the results of the analysis in Section 4.3.1 that relate flux to concentration.

To evaluate ${ }^{222} \mathrm{Rn}$ release over time, its expected concentration must be estimated. The actual amounts of the isotope in the disposal facility depend on the quantities of the parents and the decay process. Parent isotopes that produce ${ }^{222} \mathrm{Rn}$ and are commonly found in waste are ${ }^{238} \mathrm{U}$ and ${ }^{234} \mathrm{U}$. ${ }^{230} \mathrm{Th}$ is also a significant contributor, but because it is part of the uranium decay chain and unlikely to be generated independently in waste, it is covered by the uranium calculation.

A grossiy conservative estimate of ${ }^{222} \mathrm{Rn}$ flux at 10,000 years can be calculated by considering the ${ }^{222} \mathrm{Rn}$ that can be generated from a burial ground that is completely filled with the either ${ }^{238} \mathrm{U}$ or ${ }^{234} \mathrm{U}$ at the intruder based Category 3 concentration 7 imits $\left(1.2\right.$ and $1.9 \mathrm{Ci} / \mathrm{m}^{3}$ for ${ }^{238} \mathrm{U}$ and ${ }^{234} \mathrm{U}$, respectively). Based on decay-chain estimates, these uranium concentrations correspond to ${ }^{222} \mathrm{Rn}$ concentrations of 0.06 and $8.3 \mathrm{Ci} / \mathrm{m}^{3}$, with ${ }^{234} \mathrm{U}$ being the large producer. Using the analysis in Section 4.3 .1 that relates ${ }^{222} \mathrm{Rn}$ flux to initial concentration, a peak flux of $8,300 \mathrm{pCi} / \mathrm{m}^{2} \mathrm{~s}$ is calculated.

To get a more reasonable evaluation of ${ }^{222} \mathrm{Rn}$ flux, it is necessary to recall that the ${ }^{222} \mathrm{Rn}$ flux limit is applied to the entire burial ground and to calculate a more realistic, yet conservative average ${ }^{234} U$ concentration. As an example, the uranium activity disposed of in 218-E-12B since

September 26,1988 , is about $0.4 \mathrm{Ci}$ disposed in one 55-gallon drum. The total volume of waste disposed was $2,580 \mathrm{~m}^{3}$. This is an average concentration of about $1.6 \times 10^{-4} \mathrm{Ci} / \mathrm{m}^{3}$. Further, the waste volume disposed is only a small fraction of the total burial ground volume. Thus, it is reasonable to expect that the actual average uranium concentration will be even smaller when the entire burial ground is considered. We conclude that the uitra-conservative estimate of $8,300 \mathrm{pCi} / \mathrm{m}^{2} \mathrm{~s}$ could be reduced by a factor of 1,000 (based on the ratio of the projected uranium concentration in waste $\left(116 \times 10^{-4} \mathrm{Ci} / \mathrm{m}^{3}\right)$ versus the hypothetical maximum concentration of $\left.1.9 \mathrm{ci} / \mathrm{m}^{3}\right)$, and still be considered conservative. Thus, it is not reasonable to alter the concentration limits for uranium isotopes because of radon flux limits.

For radionuclides present in activated metal it is assumed that the isotopes are more tightly bound to the waste matrix and, therefore, less 
WHC-SD-WM-TI-730, REV 0

available for providing dose. Thus, a factor of 10 increase in the concentration limit has been allowed for these isotopes. The same practice has been applied by the NRC in 10 CFR 61 . In a background document (0ztunali et a]. 1981), the NRC applies simple corrosion estimate arguments to compare mobility of radionuclides attached to the surface of trash waste to those imbedded in activated metal.

\subsubsection{Determination of Groundwater Pathway Inventory Limits}

This section describes the derivation of inventory limits for Hanfordgenerated waste in $218-E-10$ and $218-E-128$, and reactor compartment waste.

4.4.2.1 Summary of Parameters Affecting Dose Calculations and Quantification of Groundwater Pathway Inventory Limits. In Section 4.2.3, a screening process was developed to eliminate the majority of radionuclides under consideration as potential contributors to dose by the groundwater pathway. Many moderately to strongly sorbing radionuclides are predicted to have no significant capability to contaminate groundwater. A summary of field observations and analyses indicating the immobility of these radionuclides in the Hanford Site soil column is provided in Appendix F. The radionuclides that remained after the screening process were mostly long-lived radionuclides that traveled through the soil column unretarded by sorption processes. These were ${ }^{14} \mathrm{C},{ }^{36} \mathrm{Cl},{ }^{3} \mathrm{H},{ }^{129} \mathrm{I},{ }^{187} \mathrm{Re},{ }^{79} \mathrm{Se},{ }^{99} \mathrm{TC}$, and uranium.

The results of the sensitivity analyses showed that the most important parameters affecting maximum groundwater concentration are the infiltration rate through the waste and the waste form properties limiting the release of radionuclides. For the Category 1 waste facility where no waste form performance is assumed, the infiltration rate is the most important parameter. For the Category 3 waste facility, when diffusion is the release-controlling mechanism for non-sorbing radionuclides, the value of the diffusion coefficient is the overriding parameter. For uranium, when solubility is the release controlling mechanism, the solubility-controlled concentration and the infiltration rate dominate the maximum groundwater concentration estimates. For activated metals, the corrosion rate, the concentration of the radionuclide in the metal waste, and infiltration rate combine to control groundwater concentration estimates.

The results of the uncertainty analysis (Section 4.2.5) indicated that groundwater concentrations could exceed the base-case estimates by up to a factor of 2. This is relevant to the calculation of inventory limits because limits are inversely proportional to maximum concentrations. The factor-of-2 increase would occur if the uranium base-case solubility estimate were too low. Empirical evidence (Serne et al. 1994) suggests that the base-case value may be conservatively high. All other factors considered indicate that concentration estimates are likely to decrease relative to base-case assumptions. For example, it is most likely that the decrease in infiltration rate is a real expectation because of the database that supports the uncertainty evaluation. Thus, the potential for decreased groundwater concentration relative to the base case is considered more likely than for increased concentrations. In particular, it is expected for Category 3 waste facilities that the actual infiltration rate will be much less than the $0.5 \mathrm{~cm} / \mathrm{yr}$ assumed (i.e., 5 to 10 times lower). This factor would increase the Ci limits by a factor of about four to eight. It is concluded that the base- 
case peak concentration values are reasonably conservative and can be used to estimate inventory limits.

4.4.2.2 Groundwater Pathway Inventory Limits for Hanford-Generated Waste. Inventory limits for the groundwater pathway radionuclides are provided in Table 4-19 for 218-E-10 and 218-E-12B. Comparing dose from the same groundwater concentration for these radionuclides show that maximum dose relative to a performance objective occurred with the drinking water standard of $4 \mathrm{mrem} / \mathrm{yr}$. Consequently, inventory limits are determined that satisfy the drinking water standard.

The Timits are calculated in two steps. First, the ratio of the groundwater-limiting concentration that corresponds to the 4-mrem/yr dose over the maximum groundwater concentration estimated to result from the initial inventory of $1 \mathrm{Ci}$ in the representative $\mathrm{l} \mathrm{m}$ section for a given radionuclide is determined. This value is the allowable inventory in the representive section. Second, to determine the total facility limit, this value is multiplied by the north-south width of the burial ground. The inventory limits are quantified in Table 4-18 for the two burial ground areas. The north-south widths of the currently used sections of the 218-E-10 and 218-E-12B burial grounds are about 640 and $700 \mathrm{~m}$, respectively.

The limits listed for conditions of diffusional control assume a diffusion coeffficient for the waste form of $1 \times 10^{-10} \mathrm{~cm}^{2} / \mathrm{s}$. The limits will increase by a factor of the square root of 10 as the diffusion coefficent decreases by an order of magnitude. The limit is also sensitive to the assumed container area-to-volume ratio. As the ratio decreases, the limit increases. In this analysis an area to volume ratio of $9.3 \mathrm{~m}^{-1}$ was used. This is the area-to-volume ratio of a 55-gal drum $\left(9.3 \mathrm{~m}^{-1}\right)$.

An alternative limit based on solubility control is used for uranium under Category 3 conditions. In this case, the limit is a steady-state concentration in the water leached from the facility that results in a peak groundwater concentration that corresponds to the $4-\mathrm{mrem} / \mathrm{yr}$ imit if $730 \mathrm{~L}$ of groundwater are consumed by an individual. Also, the limit is proportional to the length of trench over which a constant concentration is assumed to be sustained. For a $20-\mathrm{m}$ trench in the 218-E-12B Burial Ground, the steady-state concentration yielding at dose of $4 \mathrm{mrem} / \mathrm{yr}$ is estimated to be $3.8 \times 10^{3} \mathrm{pCi} / \mathrm{L}$ $\left(3.8 \times 10^{-6} \mathrm{Ci} / \mathrm{m}^{3}\right)$.

4.4.2.3 Groundwater Pathway Inventory Limits for Reactor Compartment Waste. To determine limits for the inventory in the activated-metal waste that makes up the waste stream in the reactor compartments, the assumed mechanism controlling release is a steady-state corrosion rate. This corrosion rate is the basis for calculating a constant concentration that can then be used in conjunction with the steady-state peak concentration calculations to estimate dose and concentration limits. No credit is taken for the time required to breach the reactor compartment and the pressure vessel walls that contain the activated meta] waste.

To estimate a constant concentration, we assume the waste is a slab of metal covering the entire trench area. A fixed mass of metal (controlled by the corrosion rate) is dissolved into a fixed mass of infiltrating water (controlled by the infiltration rate) per unit of time. If the concentration 
of the radionuclide of interest in the metal is known, a constant concentration for that radionuclide in solution can be calculated. Conversely, a concentration limit for the radionuclide in the metal can be calculated that corresponds to the 4-mrem/yr groundwater protection limit.

To determine the limiting concentration for the reactor compartments, the constant concentration peaks for Trench 94 conditions are assumed (runs $3 a-c c$ and $3 d-c c)$. To determine the appropriate length of trench over which a constant concentration might be sustained and the appropriate peak concentration, it is assumed that 40 reactor compartments are disposed of parallel to the primary direction of groundwater flow (east-west). The radioactivity materials are essentialiy confined within the reactor pressure vessels, which are estimated to be about $2.5 \mathrm{~m}$ in diameter. Thus, $100 \mathrm{~m}$ of trench floor are estimated to be capable of sustaining the constant concentration of in-leaching water. To complete this calculation, we assume $100 \mathrm{~m}$ of trench. Assuming that the proportionality of change in peak concentration from the $20-\mathrm{m}$ estimate (run $3 \mathrm{a}-\mathrm{cc}$ ) to the $40-\mathrm{m}$ estimate (run $3 d-c c$ ), is maintained, a peak concentration for the $100-m$ case is estimated to be about $3.0 \times 10^{-2} \mathrm{Ci} / \mathrm{m}^{3}\left(3.0 \times 10^{7} \mathrm{pCi} / \mathrm{L}\right)$. This value corresponds to an initial concentration of $1 \mathrm{Ci} / \mathrm{m}^{3}$ in the leaching solution.

The calculated ratio of the initial solution concentration exiting the trench (the interface between the trench floor and the top of the soil column) to peak concentration at the downstream well (e.g., the dilution factor) can then be used to determine the initial solution concentration at the trench floor that would result in a potential drinking water dose of $4 \mathrm{mrem} / \mathrm{yr}$. This is done by taking the product of the dilution factor and the groundwater concentration that corresponds to a dose of $4 \mathrm{mrem} / \mathrm{yr}$. The groundwater concentration is radionuclide specific and is determined assuming consumption of $730 \mathrm{~L} / \mathrm{yr}$ and the radionuclide-specific dose conversion factor for ingestion (Table $\mathrm{C}-5$ ).

Having determined the acceptable initial solution concentration, an estimate of the radionuclide concentration in the waste that corresponds to that solution concentration is calculated. This is done by considering a square meter of waste surface area projected onto the trench bottom. The total annual allowable amount of radionuclide that can be dissolved is calculated by taking the product of the allowable concentration and the volume of water that interacts with the waste (the infiltration rate $[0.5 \mathrm{~cm} / \mathrm{yr}$ ] times the surface area $\left.\left[1 \times 10^{4} \mathrm{~cm}^{2}\right]\right)$. By assuming a corrosion rate for the projected surface area $\left(0.02 \mathrm{mg} / \mathrm{dm}^{2} / \mathrm{yr}\right)$, the total mass of metal that can be dissolved in a year is determined $(2 \mathrm{mg})$. The allowable concentration in the metal is the allowable curies divided by the mass of dissolved metal ( $\mathrm{Ci} / \mathrm{g})$. Conversion to a volumetric concentration is done by multiplying the masss concentration by the density. A typical steel metal density is $8 \mathrm{~g} / \mathrm{cm}^{3}$.

Comparing these 7 imits (Table 4-20) to the intruder limits (Table 4-18) for each radionuclide shows that Category 3 limits are more restrictive for all mobile radionuclides. Therefore, adherence to the intruder-based limits will also satisfy the groundwater-protection requirements and no specific groundwater 1 imits for this waste stream are required. 
WHC-SD-WM-TI-730, REV 0

\subsubsection{Implementation of PA Generated Waste Acceptance Criteria}

Implementation of PA requirements in LLW disposal practices at the Hanford Site is accomplished by documenting the requirements in the waste acceptance criteria document, Hanford Site Solid Waste Acceptance Criteria (WHC 1993) and in other procedures. Several organizations use this documentation to implement the PA requirements. Within the solid waste management organization, waste acceptance and burial ground operations groups are responsible for acceptance and receipt and disposal of LLW, respectively. The waste acceptance group is primarily responsible for ensuring the acceptability of waste to be disposed and the burial ground operations group is responsible for disposal of the waste. In addition, a data management group is responsible for maintaining burial ground records on a computer database system, SWITS (Solid Waste Information Tracking System). For example, the database information in Appendix $B$ of the 200 West Area Burial Ground PA document was taken from SWITS.

Two primary types of PA-generated requirements are being implemented: those based on the intruder scenarios and those based on groundwater contamination scenarios. In the following sections, the implementation process is described for each type of requirement.

4.4.3.1 Intruder Scenario Limit Implementation. The intruder limits are radionuclide concentration limits provided in Table 4-18. This table makes up a portion of the limits listed in Table 3-1 of the WAC (WHC 1993). Other limits are also provided in Table 3-1 that are derived from accident scenarios assumed to occur during burial ground operations (WHC 1995). The primary criteria are radionuclide-specific concentrations $\left(\mathrm{Ci} / \mathrm{m}^{3}\right)$ for two categories of waste, Category 1 and Category 3 . The generator is required to provide the radionuclide-specific activity and concentration for each container that is shipped to the LLBG. Using a sum of fractions procedure for waste containing multiple radionuclides, the waste classification can then be determined for each container.

The sum of fractions procedure consists of determining the ratio of each radionuclide in the waste container to its corresponding limit in Table 3-1 and summing the fractions. Either the Category 1 limits or the Category 3 limits must be used in one sum of fractions calculation. If the sum of fractions exceeds one, then the waste is classified in the higher limit category. For example, if a sum of fractions calculation is completed using the Category 1 limits, and the sum exceeds unity, the waste is Category 3 or, possibly, greater than Category 3.

If the waste in an individual waste container exceeds Category 3 1 imits, the waste could, with proper authorization, still be accepted by averaging the waste concentration over a larger volume, either the volume of a larger package or the volume of the trench. If the larger volume concept is invoked, a sum-of-fractions calculation must be done that includes the other wastes present in that larger volume. A record of that evaluation must be submitted to the GWAS and attached to the acceptance documentation. The option of considering a larger volume is based on the observation that the probability of exhuming a particular high-concentration package or packages is less than 100 percent. Permitting an averaging process over a larger volume, if necessary, is a reasonable compromise to the implicit and overly conservative 
assumption that the highest concentration waste package will be exhumed by the intrusion event.

The averaging concept cannot be extended to individual waste packages with radionuclide concentrations that are Greater than Class C (GTCC) as defined in 10 CFR 61. DOE Order 5820.2A does not permit disposal of this waste without a separate evaluation.

4.4.3.2 Groundwater Contamination Limit Implementation. To adequately address the PA requirements to protect groundwater and the offsite individual, those wastes that could potentially provide unacceptable dose must be identified. The results of the PA analysis show that a small number of radionuclides are capable of providing significant groundwater contamination. Examination of the waste disposed of since the finalization of DOE Order $5820.2 \mathrm{~A}$ and projected waste indicated that only a small number of waste streams contain the particular radionuclides of concern at high enough activity levels to be of concern. The radionuclides are long lived and mobile in the Hanford Site soil-water environment. Of these, uranium isotopes, ${ }^{99} \mathrm{Tc}$, ${ }^{14} \mathrm{C}$, and ${ }^{129} \mathrm{I}$ are the most commonly 1 isted.

Because the acceptance limits are not concentrations but total inventory or solubility values, the radionuclide concentration information currently provided by the generator must be augmented for the waste streams of concern to ensure that groundwater limits are not exceeded. The following actions have been taken to implement the PA groundwater protection requirements:

- Trigger values have been identified for the key radionuclides in the Tatest revision of the WAC (page change 5 in WHC 1993). These values (shown in Table 4-21) are concentrations that are a small fraction of the total allowed inventory assuming that a conservatively large number of containers may contain concentrations at the trigger value. Although these values are based on 200 West Area LLBG inventory limits, they are sufficient for the 200 East Area LLBG as well. The currently available trench space in 218-E-10 and $218-E-12 B$ is small and could be completely filled with waste at trigger value concentrations. The generator must inform the waste acceptance organization if the reporting limits have been exceeded. If more than one of the radionuclides of concern is present in the waste, a sum of fractions must be calculated to see if the combined total exceeds the trigger values.

- A tracking procedure has been developed to sum inventories of groundwater-mobile radionuclides using SWITS for a trench or a burial ground that can be scanned before emplacing further waste containing groundwater-mobile radionuclides. The tracking procedure also contains the most restrictive trench or burial ground limits for mobile radionuclides (e.g., no waste form performance) and can calculate the fraction of the limit that is currently disposed of. Thus, remaining capacity assuming no waste form performance can be calculated. The tracking procedure will be implemented in calendar year 1996.

Evaluation of wastes received in the recent past indicates that waste containing radionuclide concentrations above the reporting limits are rare. 
If the waste reported to the wasta acceptance organization contains radionuclide concentrations above the limit, the waste acceptance organization will then request the generator to provide an estimate of the total inventory from that waste stream for the radionuclides that exceed the limit. Through consultation with SWM, waste acceptance can be determined.

Several options are possible. First, the total inventory in the waste may be inconsequential and the waste can be disposed of. Second, if the waste inventory is substantial and cannot be disposed of in available trench space, waste might have to be stored temporarily until new trench space becomes available. Alternatively, waste treatment may be the selected option. Consultation with the generator and the PA preparer or equivalent will then proceed to determine the options for waste treatment. A report will be generated for the record that identifies the selected waste treatment and demonstrates that the PA requirements are satisfied. This justification will include an estimate of potential dose from the treated waste. Third, it is possible that the waste cannot be accepted or cannot be accepted without additional analyses.

\subsubsection{Dose Estimates for the Total Projected Inventory and Comparison with Performance objectives}

To evaluate compliance of a filled and closed 200 East Area LLBG with the performance objectives, a dose estimate was prepared for the entire LLBG using the available database. Both intruder and groundwater-protection dose projections are based on the summarized inventory and volume estimates in Tables 2-1, 2-2 and 2-4.

The general nature of the inventory data has limited the estimates of individual radionuclide inventories to assumptions of proportionality of relative activities with that estimated from production reactor histories. Given this basis, the only radionuclides present in sufficient abundance to provide a nontrivial intruder dose are ${ }^{137} \mathrm{Cs}$ and ${ }^{90} \mathrm{Sr}$. To estimate intruder dose for these radionuclides, it is assumed that the current average concentrations in the currently disposed of waste will remain the same. Both active burial grounds received waste with sufficiently high concentrations of ${ }^{137} \mathrm{Cs}$ and ${ }^{90} \mathrm{Sr}$ to be considered Category 3 wastes. The waste volumes disposed in $218-\mathrm{E}-10$ and $218-\mathrm{E}-12 \mathrm{~B}$ were 232 and $2,348 \mathrm{~m}^{3}$, respectively. Using the tota] activities listed in Table $2-1,{ }^{137} \mathrm{Cs}$ concentrations of 1.7 and 0.005 $\mathrm{C} \mathrm{i} / \mathrm{m}^{3}$ and ${ }^{90} \mathrm{Sr}$ concentrations of 2.7 and $.0145 \mathrm{Ci} / \mathrm{m}^{3}$ are present in $218-\mathrm{E}-10$ and $218-E-12 B$, respectively. Comparison with Category 3 limits yields an estimated total dose of 0.02 and $0.00005 \mathrm{mrem} / \mathrm{yr}$ intruder dose for $218-\mathrm{E}-10$ and $218-\mathrm{E}-12 \mathrm{~B}$, respectively.

An intruder dose can also be calculated for the reactor compartments based on the estimated concentrations shown in Table 2-4, the assumption that the waste is Category 3 waste, and the appropriate Category 3 limits are those designated for activated metal. The total dose estimate is about $0.7 \mathrm{mrem} / \mathrm{yr}$ with the primary contributor to the dose estimate being ${ }^{63} \mathrm{Ni}$. This dose is provided for information. Given the extreme hardness of the reactor vessel metals, it is most unlikely that the drilling scenario is plausible for the reactor compartment waste. Even if activated metal were drilled and exhumed, mixing with soil in a garden is unlikely. 
WHC-SD-WM-TI-730, REV 0

To determine a drinking water dose estimate for the $218-\mathrm{E}-10$ and 218-E-12B LLBG, the total inventory for each burial ground was estimated. For the 218-E-10 LLBG, it was assumed that the total inventory consists of currently disposed waste and the projected B Plant waste (Table 2-4). Assuming Category 3 conditions, the total dose was estimated for each radionuclide by multiplying the ratio of the projected inventory to allowed inventory (Table 4-19) by $4 \mathrm{mrem} / \mathrm{yr}$. The total dose was calculated by summing the contribution from each radionuclide. The combined dose estimate was 0.02 mrem with ${ }^{99}$ Tc being the major contributor. For the 218-E-12B LLBG, it was assumed that the total inventory consists of currently disposed of waste and the projected PUREX and tank farm operations waste. The uranium waste inventory was not included in this estimate for the reasons discussed in the following paragraphs. Using the same approach, a total dose of 0.008 mrem was estimated.

Two waste streams in 218-E12B, the reactor compartment waste in Trench 94 and the uranium metal waste, were estimated to provide no significant contribution to dose. Using an approach to model release from the RCs based on corrosion rate allows a dose calculation to be made by summing the radionuclide-specific ratios of actual mobile radionuclide concentrations (Table 2-5) to their respective limits (Table 4-20) and multiplying by $4 \mathrm{mrem} / \mathrm{yr}$. This calculation yields a potential dose of $0.0005 \mathrm{mrem} / \mathrm{yr}$. This calculation is still extremely conservative because immediate release of inventory is assumed. Realistically, the external structure of the reactor compartment is estimated to prevent release for at least 600 years and the thick steel of the reactor vessel will further contain, or at least substantially reduce, any release from the activated metals for over 10,000 years (U.S. Department of the Navy 1996). It is concluded that the potential contribution to dose from reactor compartment waste is inconsequential.

The projected dose for the one package of scrap uranium metal in 218-E-12B was calculated differently from other waste for several reasons. First, no additional uranium waste was assumed to be disposed of in this burial ground because of the availability of the 200 West Area LLBG and the minimal waste loading in the current waste stream. Also, of the three major generators, onTy PUREX could provide large amounts of uranium waste. Because of the very small volume of this waste and the correspondingly small volume of groundwater that could be contaminated by this waste, it is highly unlikely that a dose would actually be received by an offsite individual. Therefore, to estimate some nominal dose and provide some perspective, an artificial averaging condition has been devised.

For the purpose of this dose calculation, it is assumed that the waste is distributed homogeneousiy over the trench in a horizontal layer. The thickness of the layer is constrained by assuming that the ratio of its thickness to the total waste volume thickness is the same as the proportion of the uranium volume in the waste package, a 55-gallon drum. This spatial configuration effectively increases the size and extent of the contaminated water volume, thereby increasing the likelihood of interception with the groundwater we]1. At the same time, the projected dose will be reduced because the distributed length of uranium parallel to flow could be as much as the diameter of the drum. The volume of the uranium mass $(54,500 \mathrm{~g})$ is estimated to be about $0.0029 \mathrm{~m}^{3}$ assuming a density of pure uranium (about 
$\left.19 \mathrm{~g} / \mathrm{cm}^{3}\right)$. This is about 1 percent of the waste package volume. The trench is about $300 \mathrm{~m}$ wide in the direction perpendicular to flow. Assuming that the normal waste thickness in a trench is about $4 \mathrm{~m}$, the hypothetical uranium layer is $0.04 \mathrm{~m}$ thick. The makes the waste volume length $0.00024 \mathrm{~m}$.

The base-case estimate for solubility-controlled release in 218-E-12B yields a peak concentration of $5.98 \times 10^{-3} \mathrm{Ci} / \mathrm{m}^{3}$ for an initial solubility value of $1 \mathrm{Ci} / \mathrm{m}^{3}$ and a distribution of the contaminant over $20 \mathrm{~m}$ parallel to flow. To estimate a peak concentration for this case, the value is reduced proportionately according to the reduced length of uranium distribution and solubility value. A soil-water-dominated solubility of $2.7 \times 10^{-4} \mathrm{~mol} / \mathrm{L}$, which is approximately $4.5 \times 10^{5} \mathrm{pCi} / \mathrm{L}$ given the high specific activity (about $\left.7 \times 10^{-6} \mathrm{Ci} / \mathrm{g}\right)$ of this particular waste. The estimated peak concentration is $0.032 \mathrm{pCi} / \mathrm{L}$. The concentration corresponding to $4 \mathrm{mrem} / \mathrm{yr}$ is about $22 \mathrm{pCi} / \mathrm{L}$. Therefore, the estimated dose from this waste is $0.005 \mathrm{mrem} / \mathrm{yr}$.

If a similar type of waste containing high concentrations of uranium is disposed of in the 200 East Area LLBG in the future, the waste will be internally grouted or placed in a concrete HIC, thus effectively lowering the solubility constraint and the projected dose by more than an order of magnitude.

Other performance requirements include air contamination dose and radon flux. The two contributors to air contamination are tritium and ${ }^{14} \mathrm{C}$. Tritium is not reported in these wastes and the reported ${ }^{14} \mathrm{C}$ activities other than the submarine compartment waste are too low $\left(-10^{-10} \mathrm{Ci}\right)$ to provide significant dose. It is concluded that the air contamination dose will be nil from these wastes.

Radon flux depends on the presence and concentration of the parent isotopes, primarily ${ }^{234} \mathrm{U}$ and ${ }^{238} \mathrm{U}$. The impact of these parents on ${ }^{222} \mathrm{Rn}$ flux is variable depending on the decay characteristics. It is assumed that the majority of uranium received for disposal has been processed and no daughters are present in the waste beyond ${ }^{234} \mathrm{U}$ in the decay chain. Consequently, ingrowth of ${ }^{222} \mathrm{Rn}$ occurs over time leading to ever-increasing flux estimates until secular equilibrium is achieved. Of the two uranium parents present, the flux contribution from ${ }^{234} \mathrm{U}$ exceeds that from ${ }^{238} \mathrm{U}$ by about 2 orders of magnitude in the 10,000 - to 100,000-year period following disposal of wastes containing these radionuclides. Therefore, flux estimates assuming ${ }^{234} \mathrm{U}$ are provided here to represent the contribution to ${ }^{222} \mathrm{Rn}$ flux from uranium. The ${ }^{234} \mathrm{U}$ average concentration based on the currently disposed of waste is about $1.3 \times 10^{-4} \mathrm{Ci} / \mathrm{m}^{3}$. At 10,000 years, the estimated $\mathrm{flux}$ is $0.009 \mathrm{pCi} / \mathrm{m}^{2} / \mathrm{s}$ for Category 3 wastes. At 100,000 years, the estimated flux is $0.06 \mathrm{pCi} / \mathrm{m} 2 / \mathrm{s}$ for Category 3 wastes.

\subsubsection{Summary of Significant Findings Affecting Compliance Evaluation}

A series of radionuclide release scenarios were formulated that postulate natural and manufacturing processes causing radionuclide release from a LLW disposal facility, contamination of the surrounding environment, and exposure to humans. Conceptual models were designed that are simplified representations of these radionuclide release processes. The fundamental 
approach was to establish steady-state environmental conditions and steadystate release and transport functions to quantify the degree of contamination in groundwater, soil, and air. Then, parameter input values were selected to quantify contamination levels and associated dose received by humans. Finally, these dose estimates were compared with performance objectives to determine compliance. The previous discussion indicates that the performance objectives can be satisfied easily at the Hanford Site LLBG, given the combination of site-specific characteristics, waste disposal methods, and expected inventory of LLW.

Reasonable assurance of compliance was provided by justifying that the selected conceptual model and parameter input values provide a conservatively high estimate of environmental contamination and by estimating low doses relative to the performance objectives. Inadvertent intrusion and groundwater contamination were the two primary means of exposure considered.

Inadvertent intrusion scenarios are hypothetical events that are largely independent of site characteristics. Conservatism in dose estimates was achieved primarily by assuming that the event will occur and that exhumed waste will be indistinguishable from soil. These assumptions maximized the assumed level of environmental contamination. Otherwise, standard intrusion scenarios (excavation, drilling, and gardening) and parameter values were used (e.g., dose conversion factors, transfer factors, food consumption rates) that are generally used in these types of analyses. Sensitivity and uncertainty analyses showed that uncertainties in these types of parameters are not likely to increase dose estimates by more than one order of magnitude.

Groundwater contamination estimates depend primarily on site hydrogeologic conditions. This analysis demonstrated that the combination of a long soil column beneath the LLBG and low average infiltration eliminates the majority of radionuclides as potential contaminants. Either decay processes reduce activity to inconsequential levels during transport through the soil column or sorption reactions prevent entry into the underlying aquifer for times greatly in excess of the compliance period (up to 10,000 years). Infiltration rates can also be reduced by using covers designed to mimic natural conditions that minimize flow. Identifying which radionuclides are likely to reach the aquifer was supported by field observations of specific isotope contaminant plumes presently existing in the underlying aquifer and the conditions under which they occurred.

For those radionuclides that were predicted to reach the aquifer, conservatism in the estimate of peak contaminant concentrations was introduced by selecting average infiltration rates that are considered somewhat higher than expected and by assuming lower than expected sorption coefficients. As a rule, no sorption was assumed for these radionuclides, thus minizing travel time and maximizing concentrations. Also, little dispersion was allowed during transport to concentrate the contaminant plume. Conservatively small hydraulic gradients and hydraulic conductivity parameters were selected to reduce the estimate of mixing water in the aquifer and, therefore, the dilution factor. The selected flow regime for the local burial ground analysis was compared with projections from a calibrated sitewide model and estimates of hydrogeologic conditions that existed before Hanford Site operations to demonstrate that the projected conditions were consistent with fjeld observations. 
To increase confidence that compliance with the performance objectives would be maintained and monitored in the future, a set of waste acceptance criteria was developed to ensure that performance objectives will not be exceeded. To provide the most restrictive criteria for groundwater protection, dose limits were estimated from peak concentration estimates of the contaminant at the compliance point. Waste form characteristics were also developed from the analytical results. These characteristics can be used to enhance immobilization of radionuclides and effectively make disposing of larger inventories of groundwater-contaminating radionuclides possible.

A waste acceptance criteria document (WHC 1993) is in place that requires generators to identify their inventories and radionuclide concentrations on a radionuclide-specific basis. Generators must compare radionuclide concentrations in their waste with PA-derived concentration limits and trigger values. Waste with concentrations that exceed these limits is not acceptable without further justification or waste treatment. Finaliy, a tracking system has been developed to allow routine evalution of potential dose relative to the performance objectives. If necessary, waste disposal locations will be controlled or waste treatment will be mandated or waste will not be accepted. 
WHC-SD-WM-TI-730, REV 0

This page intentionally left blank. 
WHC-SD-WM-TI-730, REV 0

Figure 4-1. Saturation Contours for $5-\mathrm{cm} / \mathrm{yr}$ Recharge.

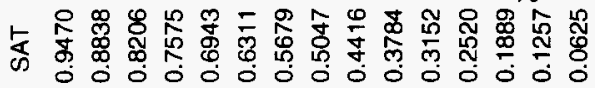

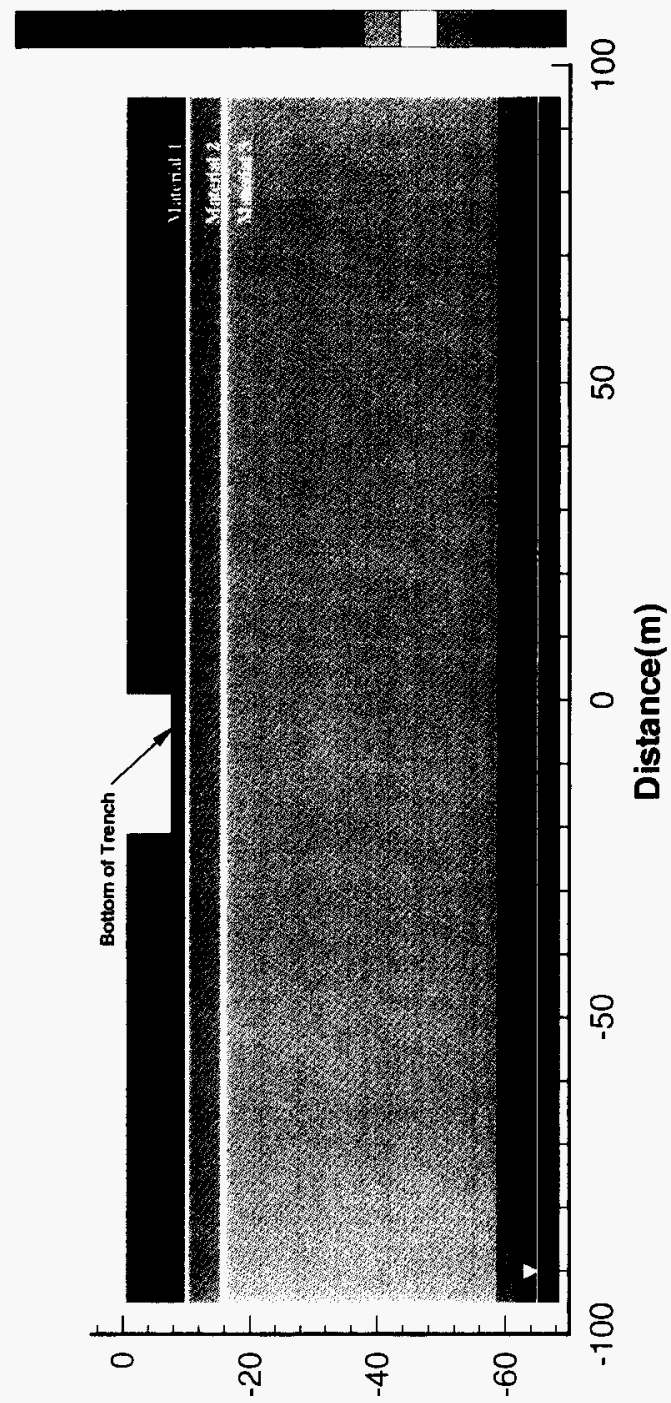

(w)yzdəa

F4-1/F4-2 
WHC-SD-WM-TI-730, REV 0

Figure 4-2. Velocity Plots for 5-cm/yr Recharge.

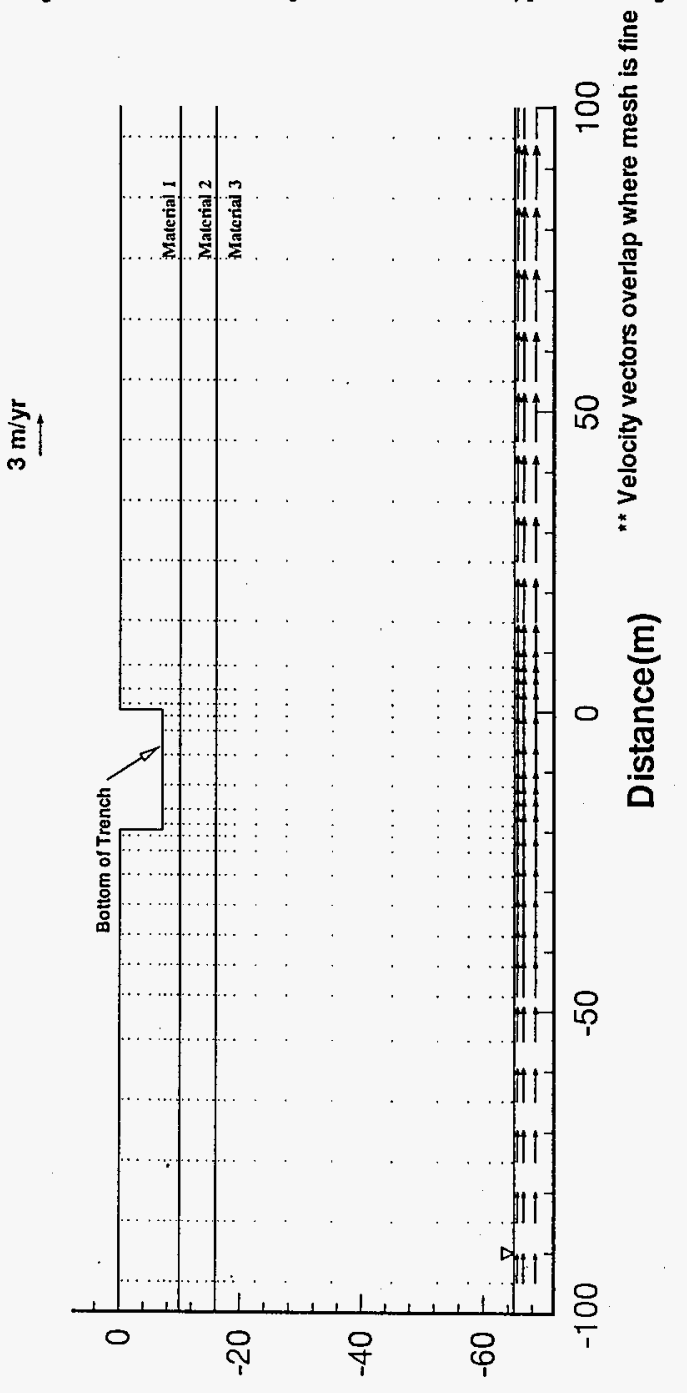

(u) प1dəa

F $4-3$ 


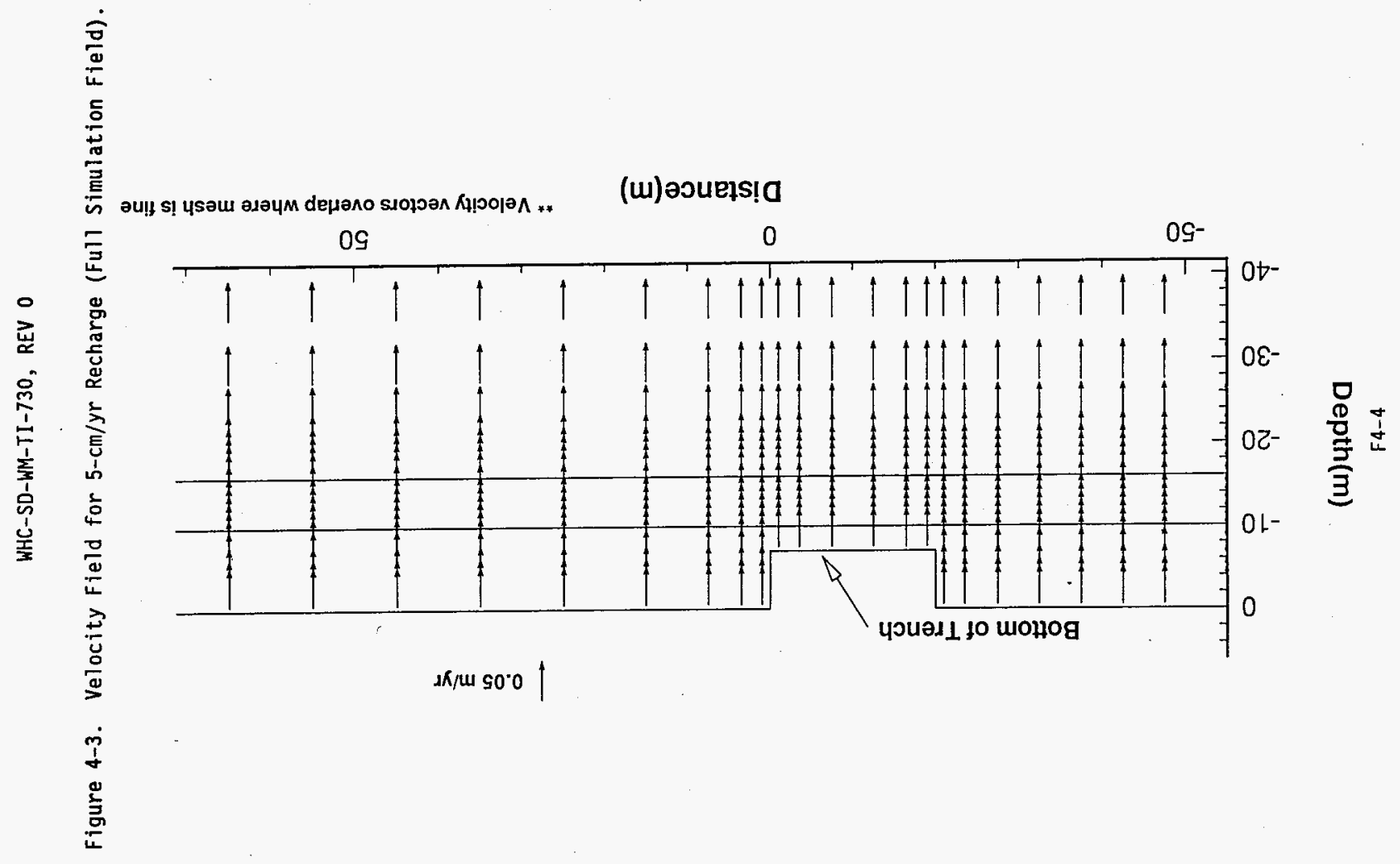




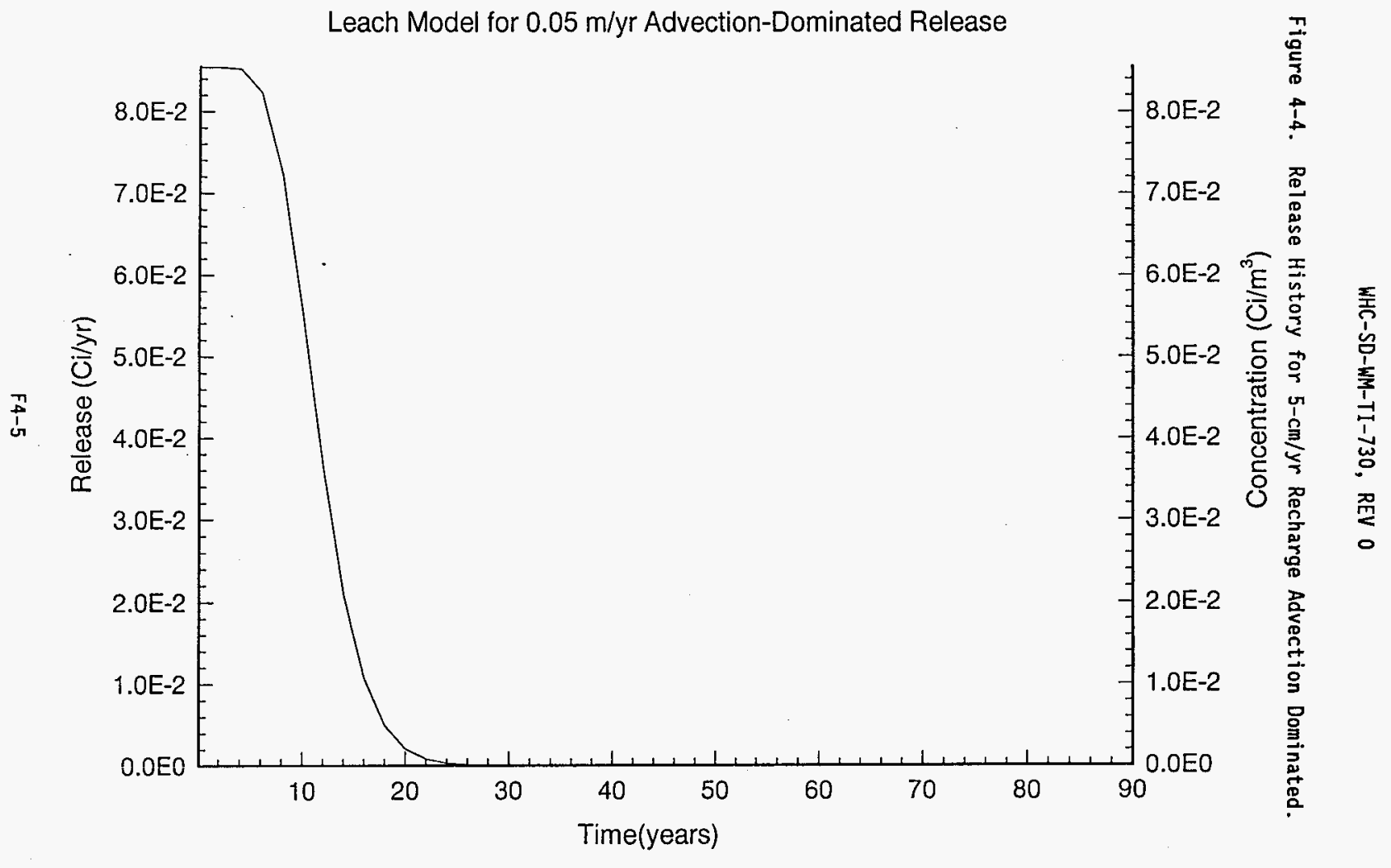


Figure 4-5. Differing Effects of Infiltration Rates on Leaching History.

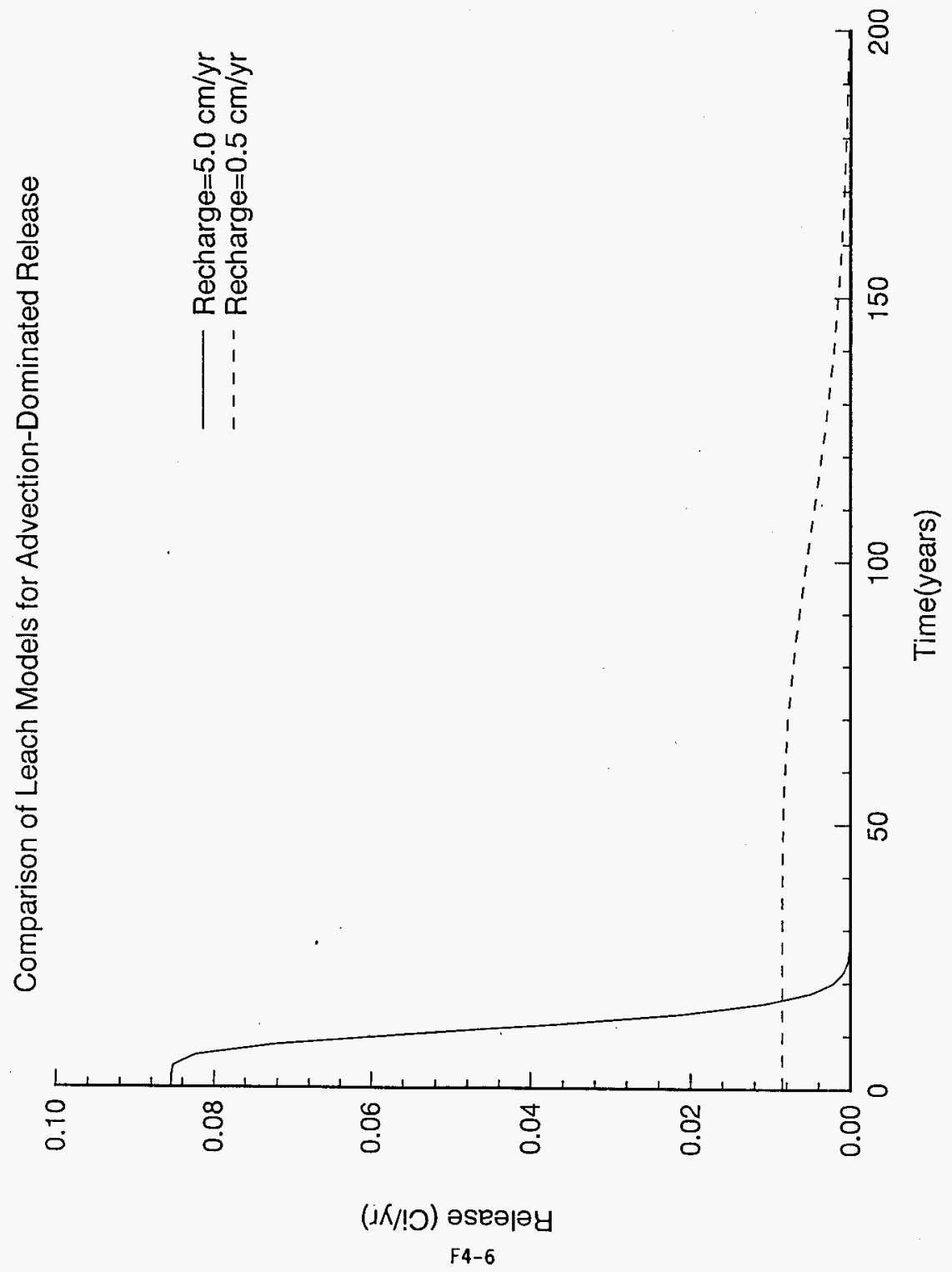


Figure 4-6. Effect of Varying Diffusion Coefficients on Leaching History. Leach Model for Diffusion, $5.0 \mathrm{~cm} / \mathrm{yr}$ Recharge
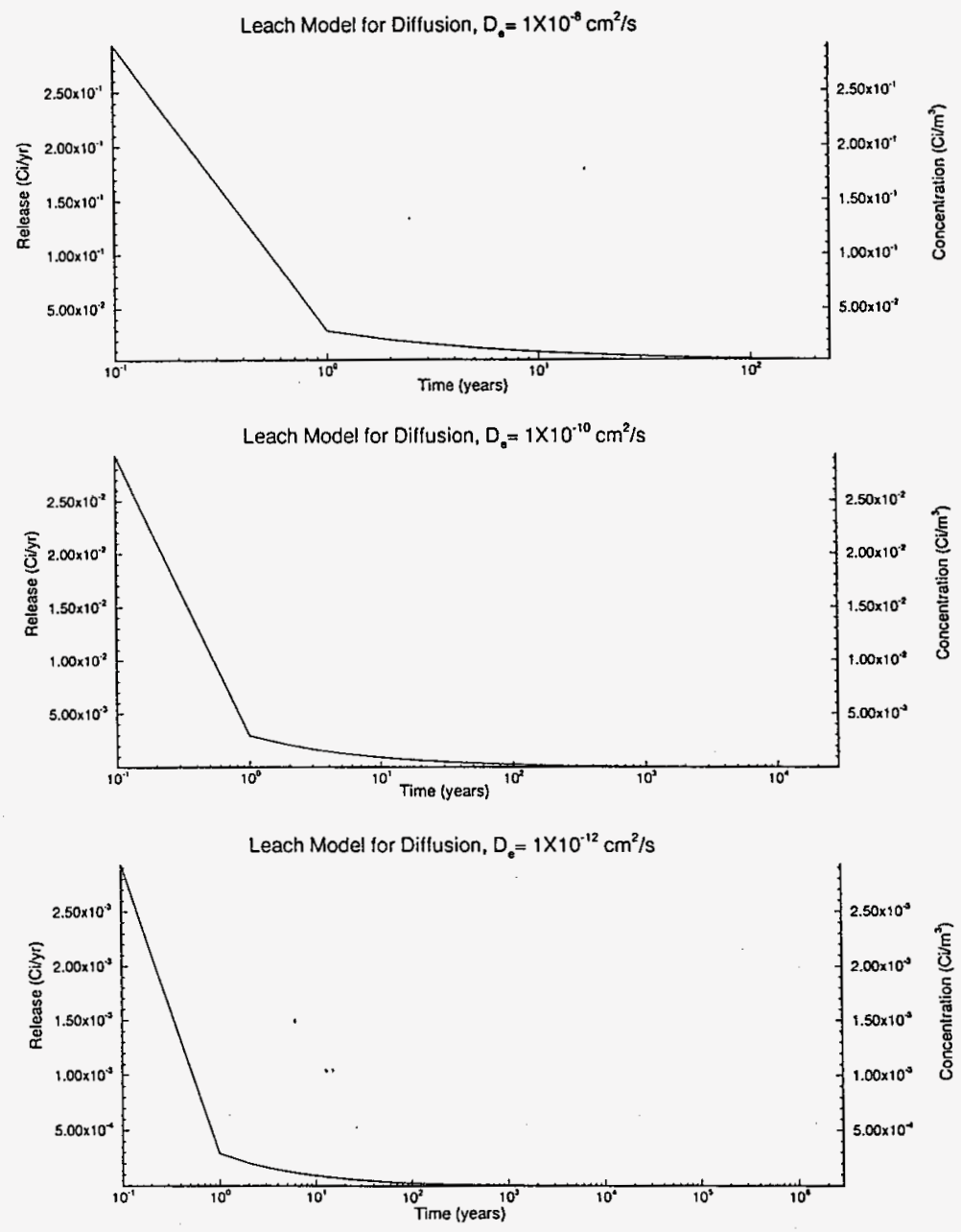
WHC-SD-WM-TI-730, REV 0

This page intentionally left blank.

F4-8 
WHC-SD-WM-TI-730, REV 0

Figure 4-7. Plume Cross Section for Case la as a Function of Time.
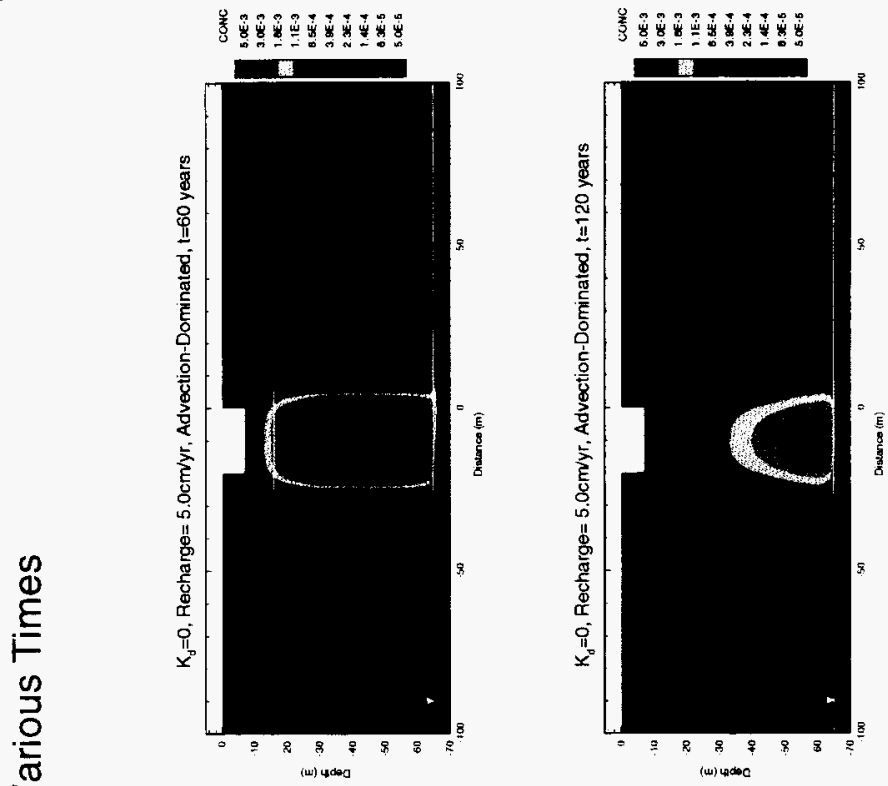

完
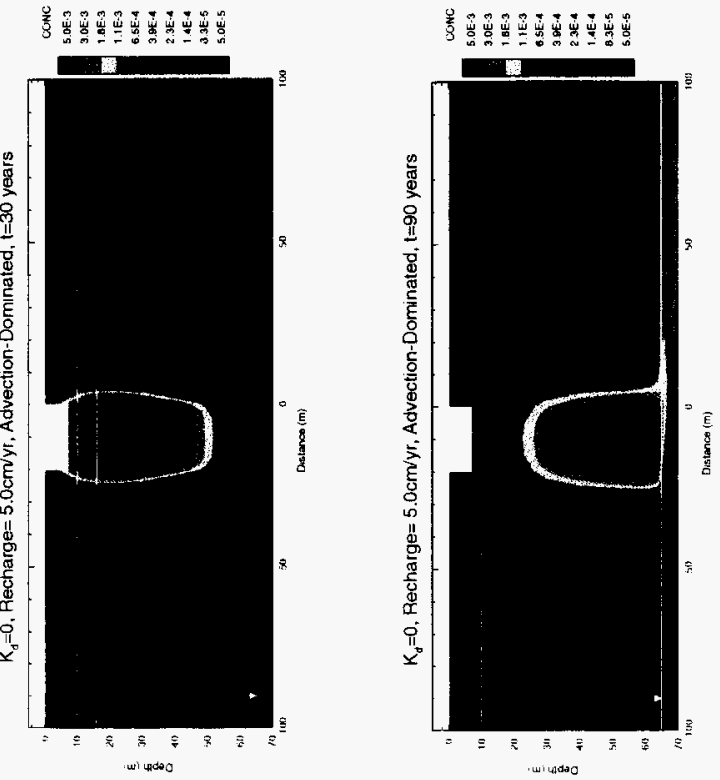

F4-9/F4- 10 
Figure 4-8. Radionuclide Concentration at the 100-m Well, Assuming AdvectionControlled Release Under Category 1 Conditions.

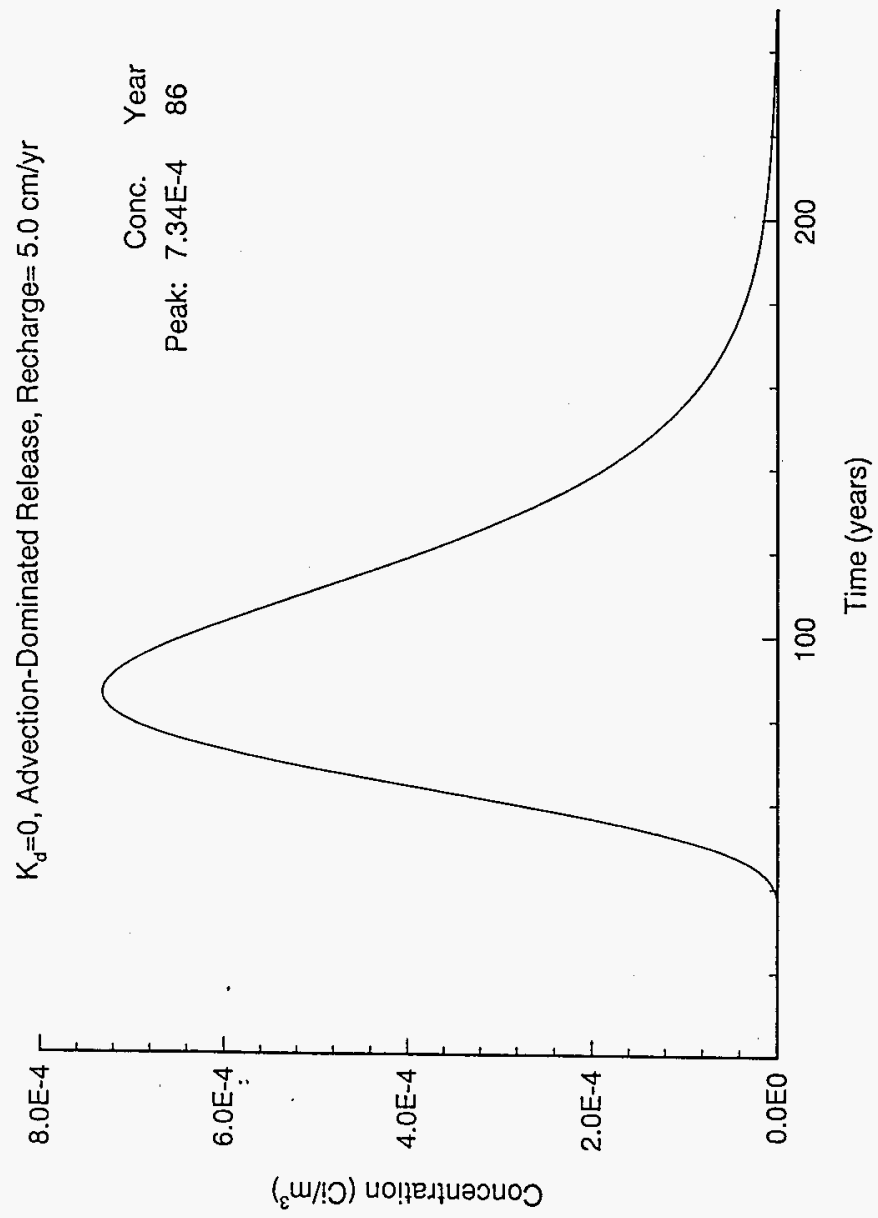


WHC-SD-WM-TI-730, REV 0

This page intentionally left blank.

F $4-12$ 


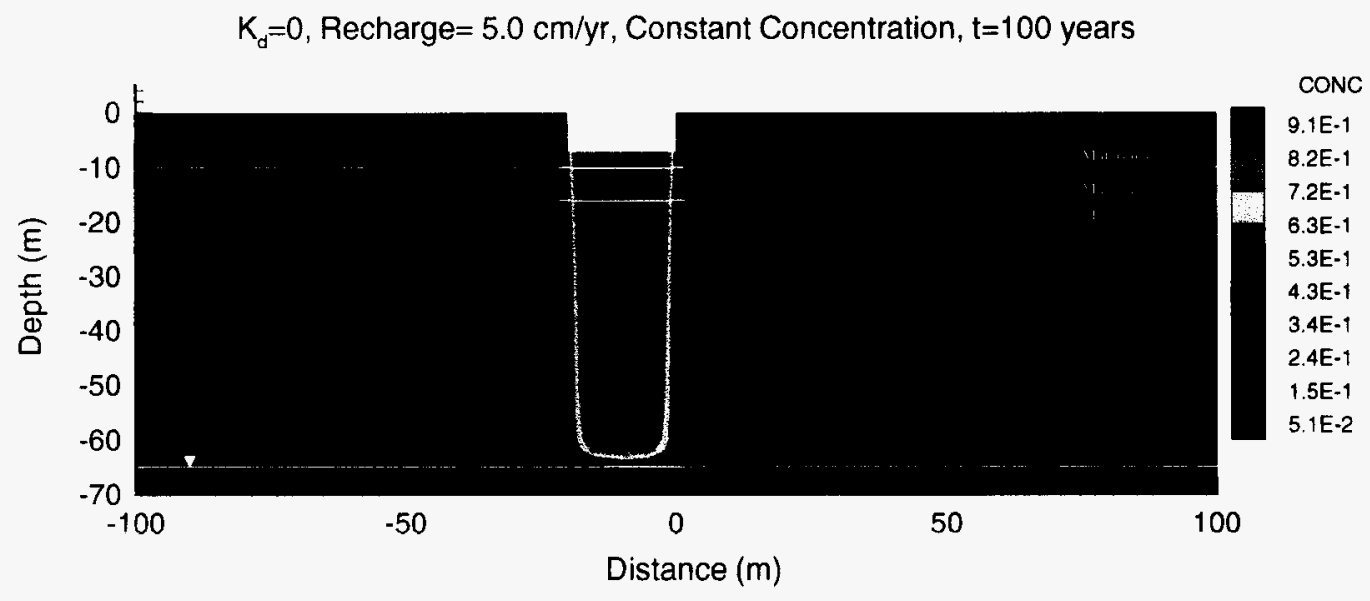


Figure 4-10. Radionuclide Concentration for 100-m Downstream Wel1, Assuming Solubility-Controlled Release for Category 1 Conditions.

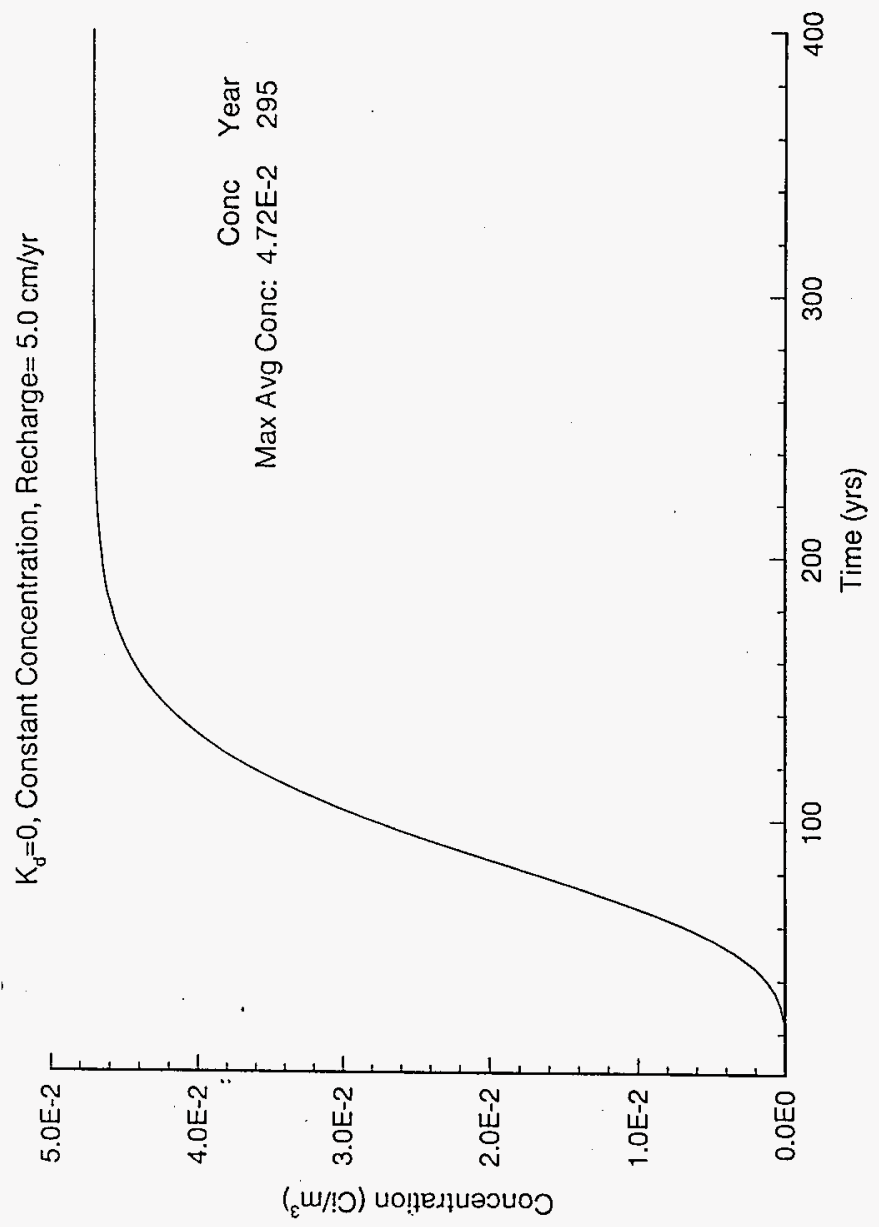


Figure 4-11. Radionuclide Concentrations at the 100-m We11, Assuming Solubility-Controlled Release for Category 3 Conditions.

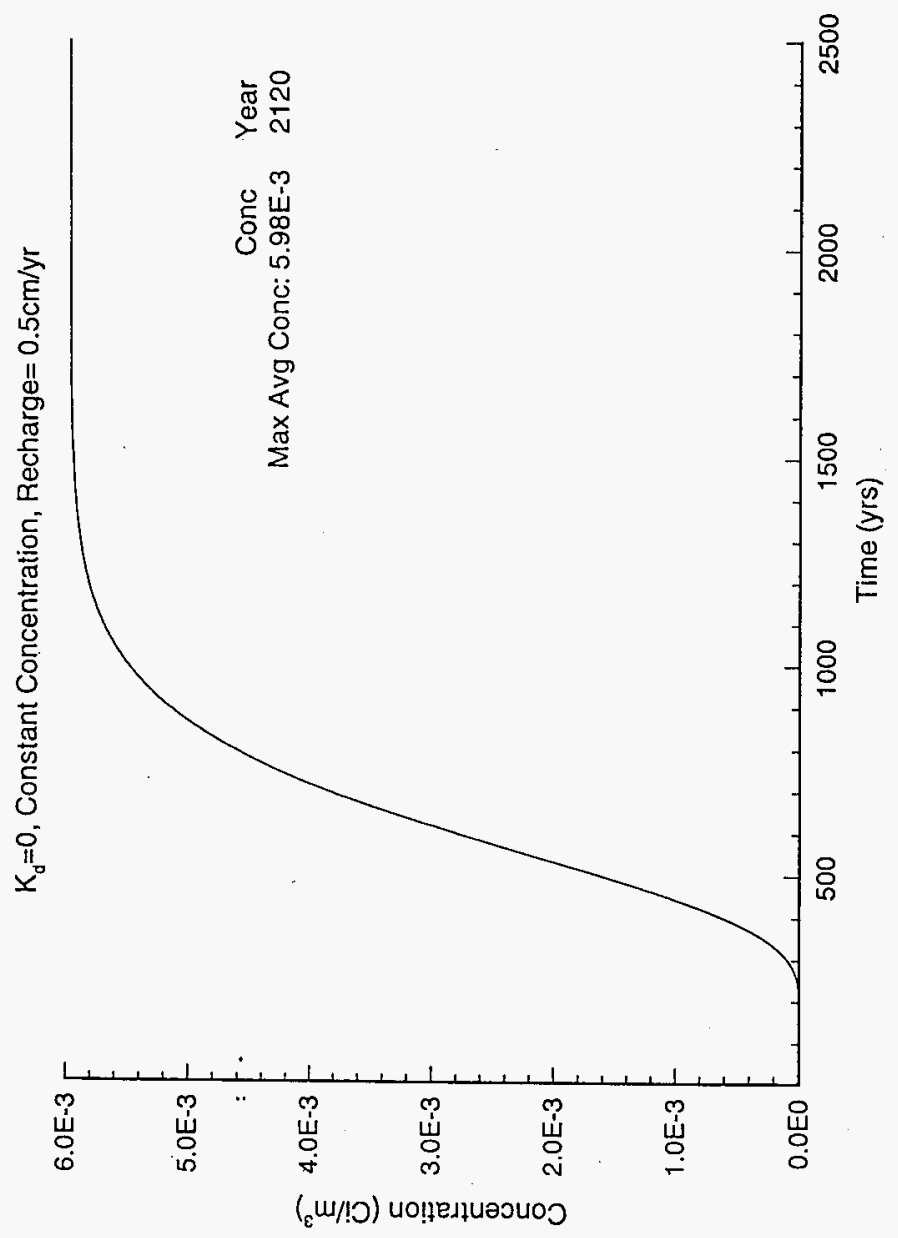


Figure 4-12. Radionuclide Concentrations at the 100-m We11, Assuming Diffusion Release Under Category 1 Conditions.
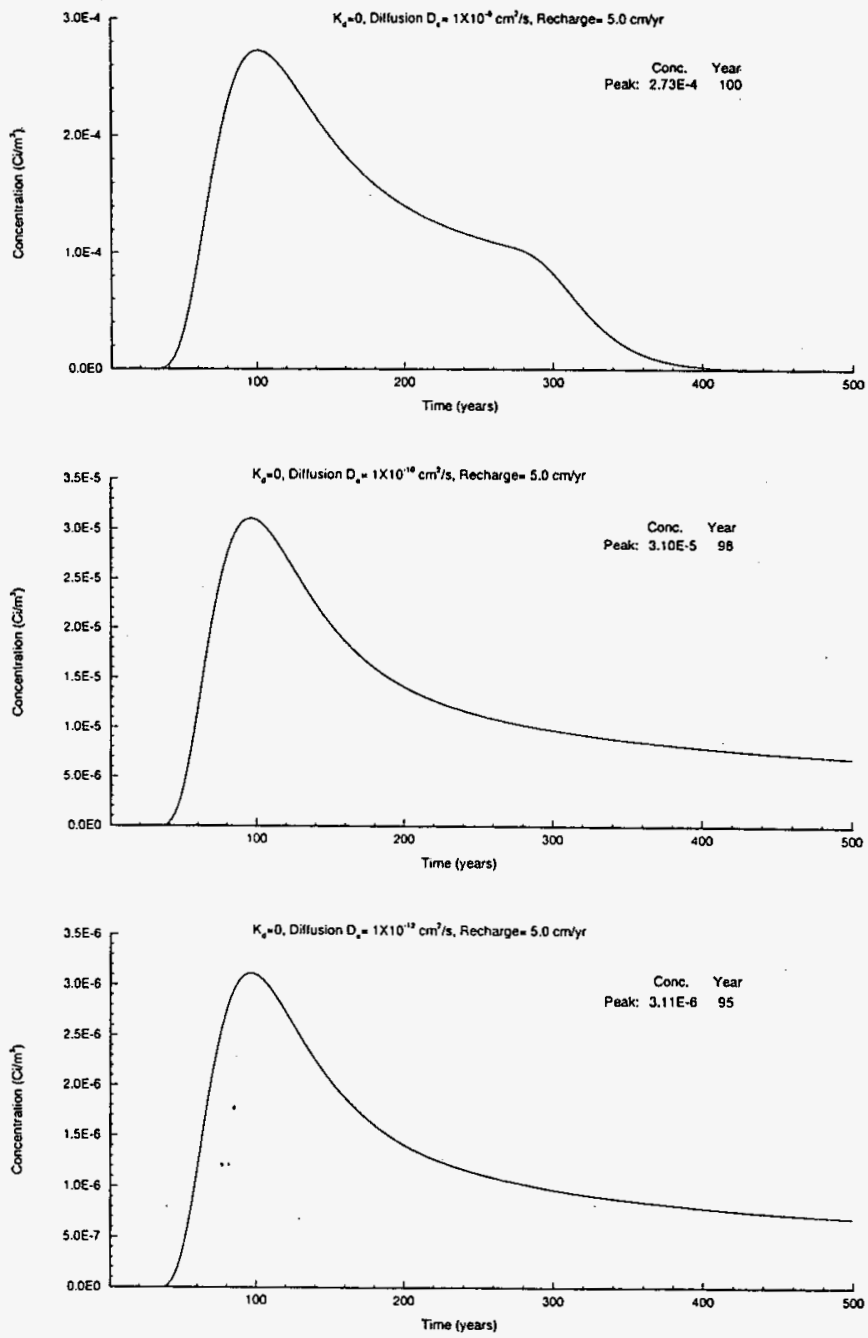
Figure 4-13. Radionuclide Concentrations at the 100-m Well, Assuming Diffusional Release Under Category 3 Conditions.
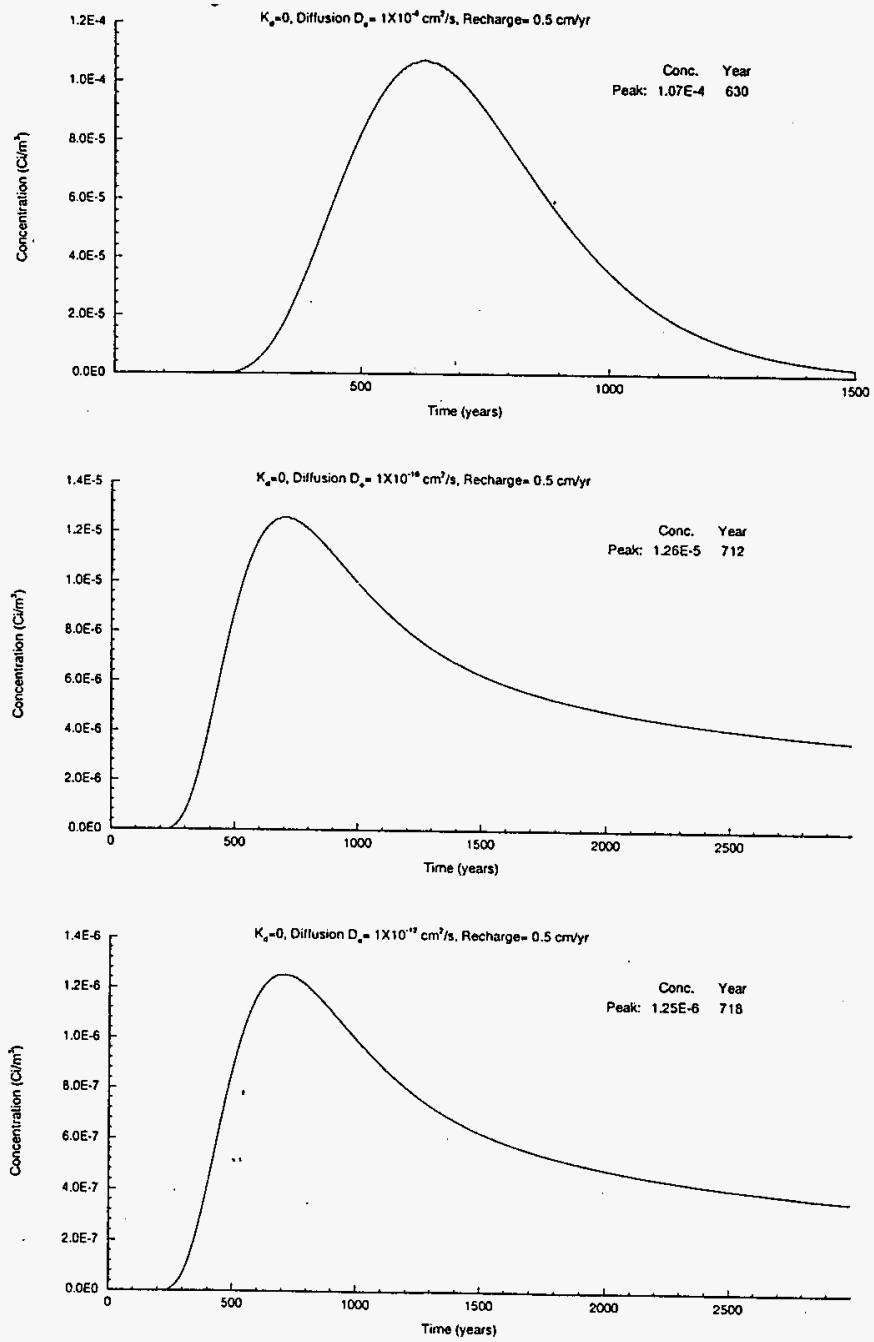
Figure 4-14. Radionuclide Concentrations at the 100-m Well, Assuming Aduction-Controlled Release and a 40-m Trench.

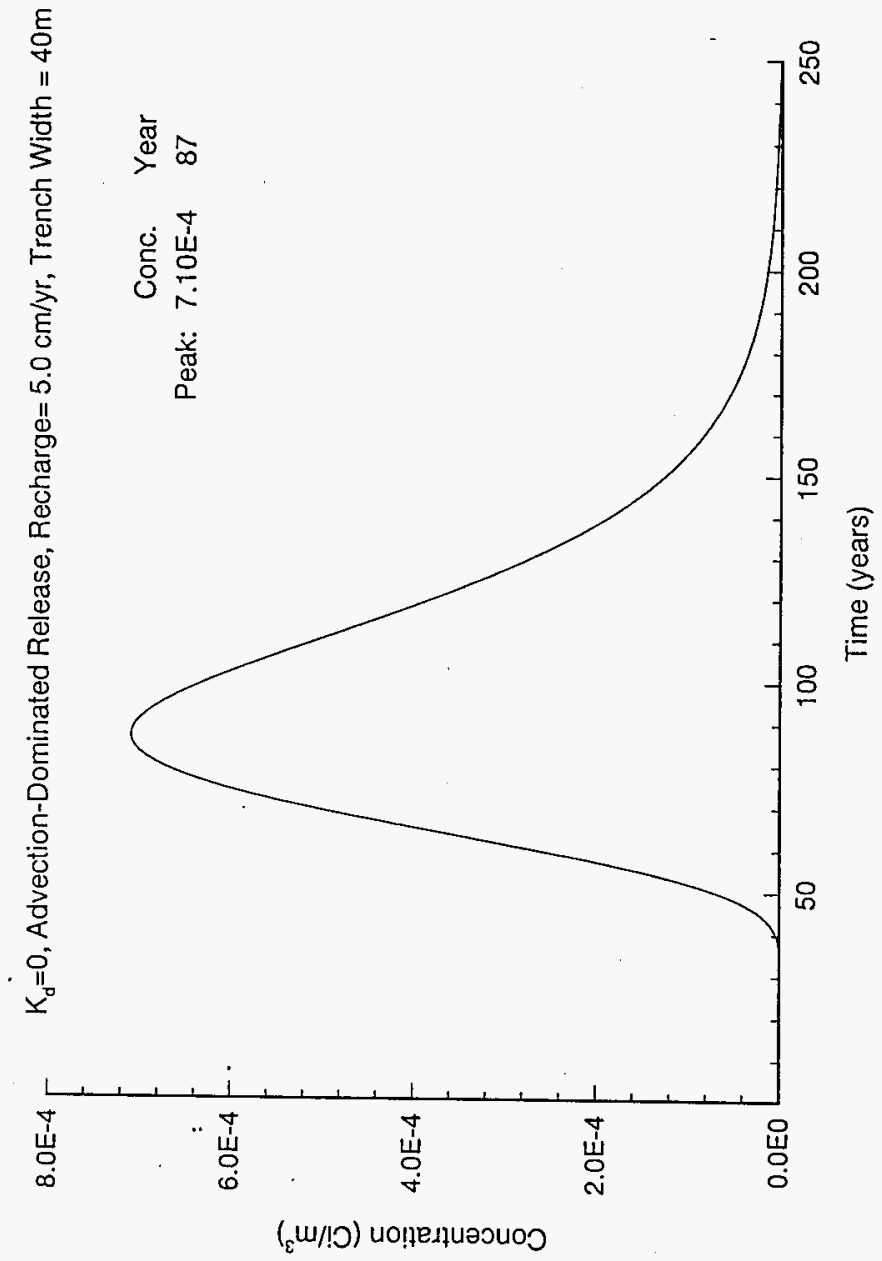


Figure 4-16. Plume Cross Sections for Advection-Controlled Release for Different $\mathrm{Kd}$ Values at 100 Years.

$K_{d}=0$, Recharge $=5.0 \mathrm{~cm} / \mathrm{yr}$, Advection-Dominated, $\mathrm{t}=100$ years

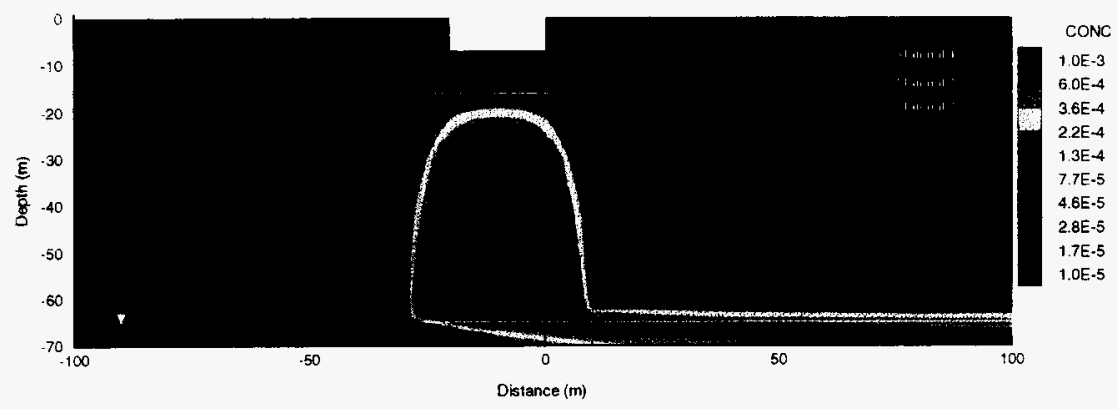

$K_{d}=1$, Recharge $=5.0 \mathrm{~cm} / \mathrm{yr}$, Advection-Dominated, $t=100$ years

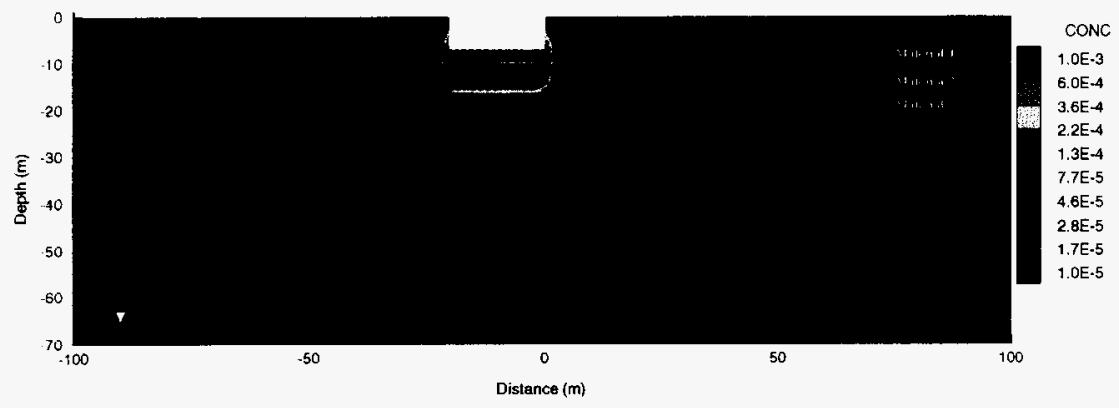

$K_{d}=10$, Recharge $=5.0 \mathrm{~cm} / \mathrm{yr}$, Advection-Dominated, $t=100$ years

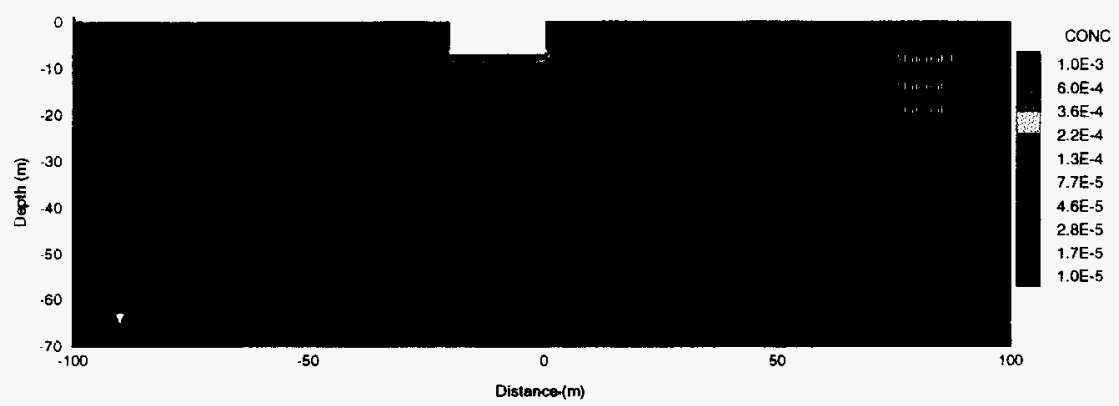

F4-21/F4-22 
Figure 4-17. Radionuclide Concentrations at the 100-m Well for AdvectionControlled Release Under Category 1 Conditions and Different Kd Values
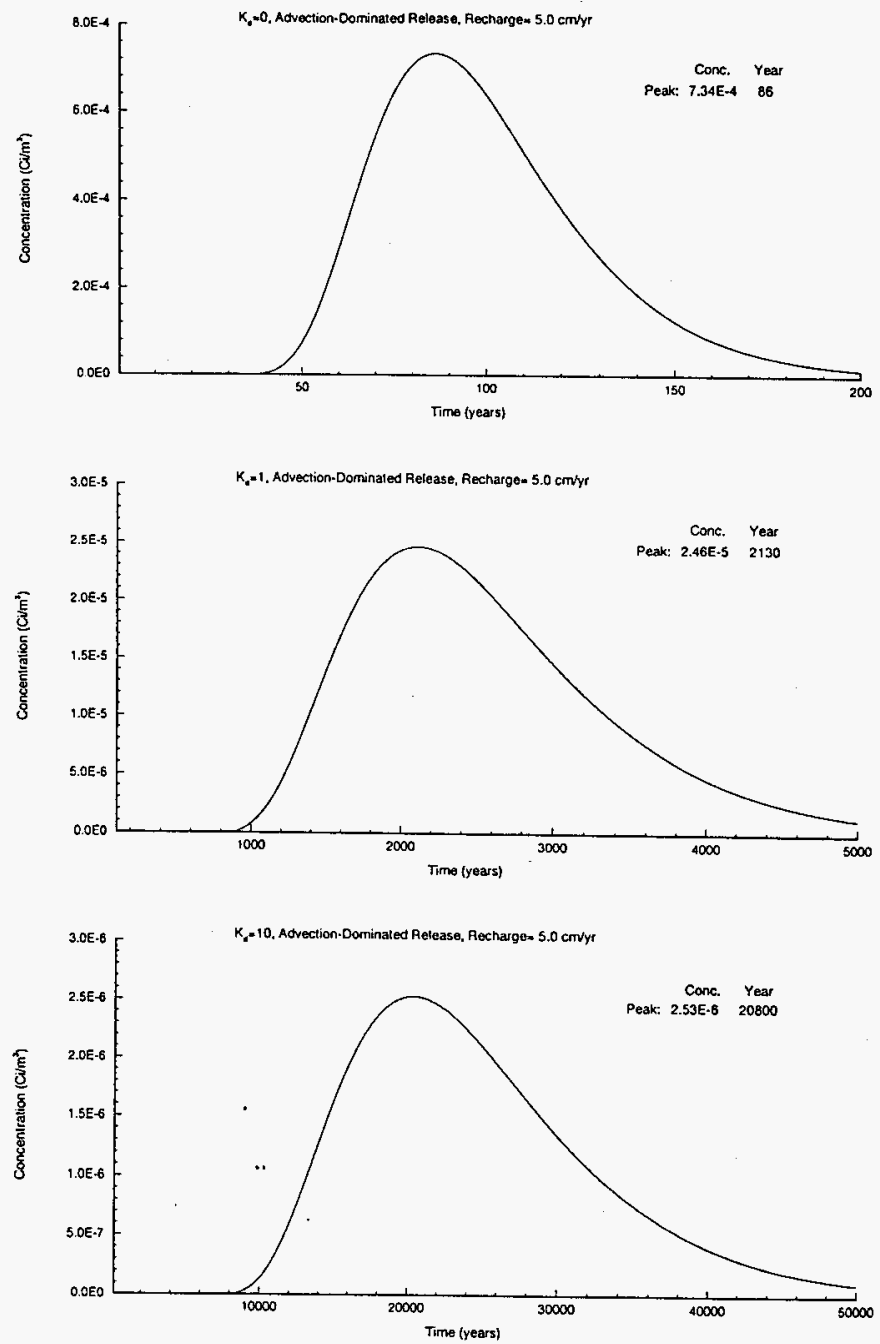
WHC-SD-WM-TI-730, REV 0

Figure 4-18. Radionuclide Concentration at the 100-m Well for AdvectionControlled Release Under Category 3 Conditions and Different Kd Values.
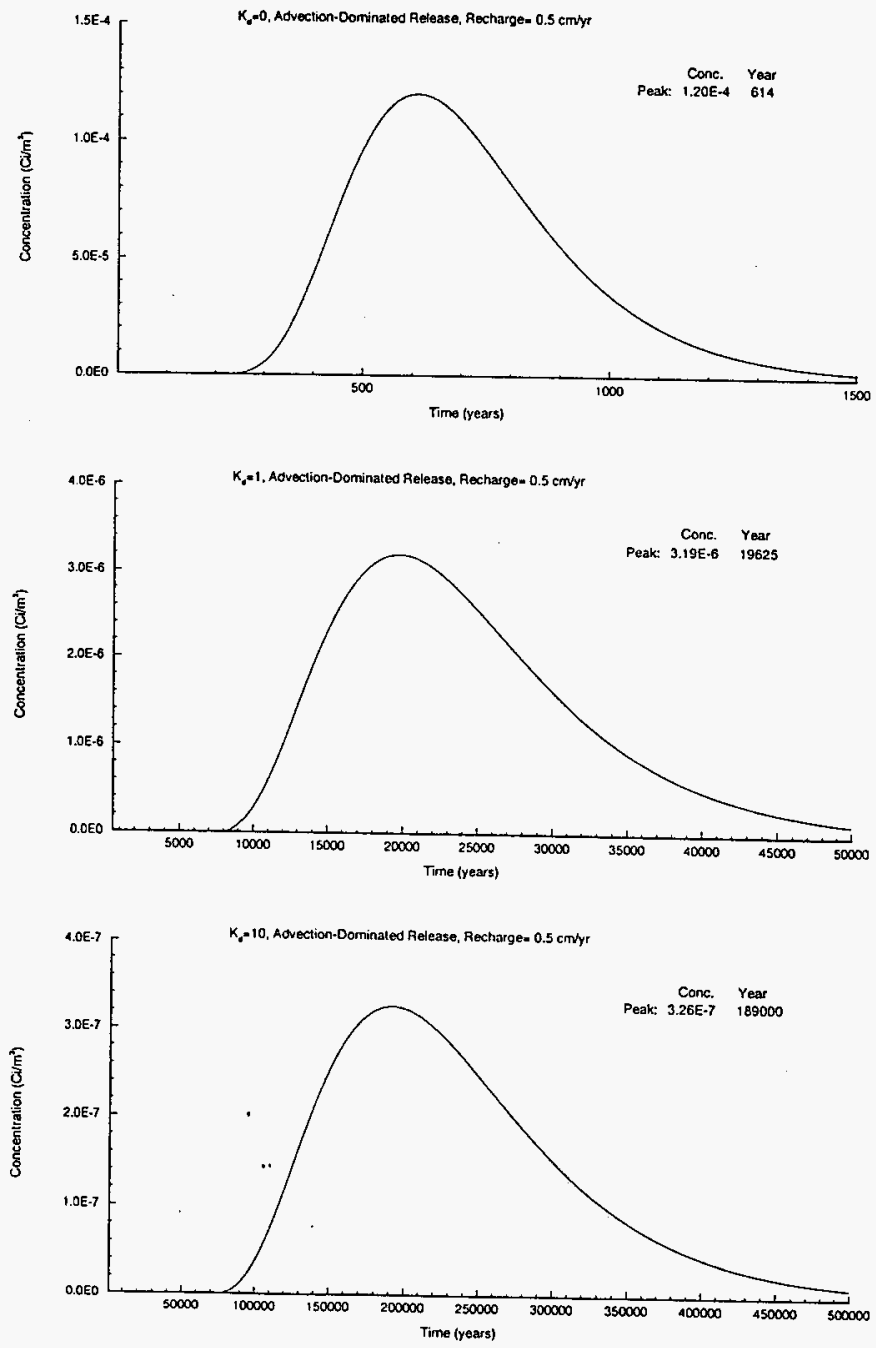
Figure 4-19. Radionucl ide Concentrations $100 \mathrm{~m}$ Downstream of the 218-E-10 Burial Ground for Advection-Controlled Release Under Category 1 Conditions.

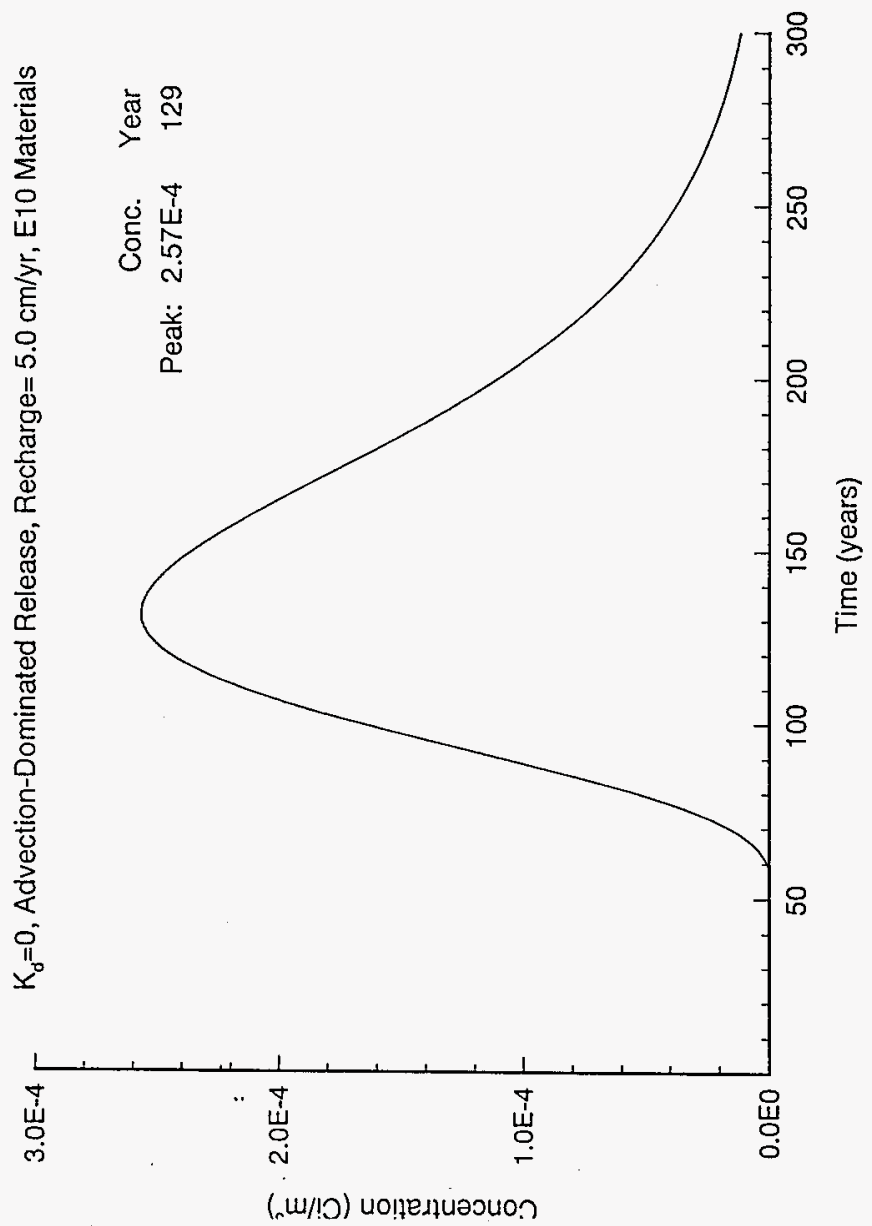


Figure 4-20. Radionuclide Concentrations $100 \mathrm{~m}$ Downstream at the 218-E-10 Burial Ground for Advection-Controlled Release Under Category 3 Conditions.

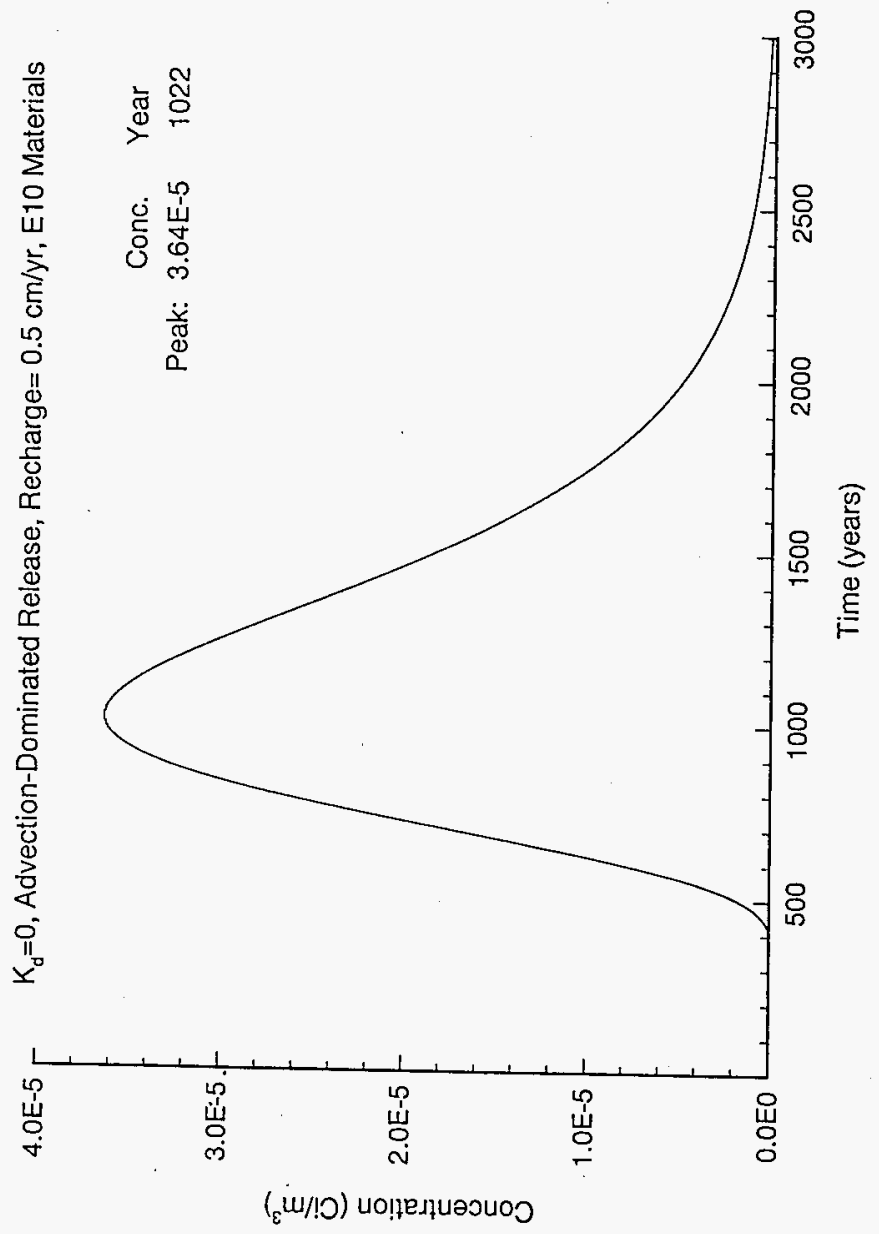


Figure 4-22. Radionuclide Concentration $100 \mathrm{~m}$ Downstream for $\mathrm{Clastic}$ Dike Case and Advective-Controlled Release Under Category 1 Conditions.

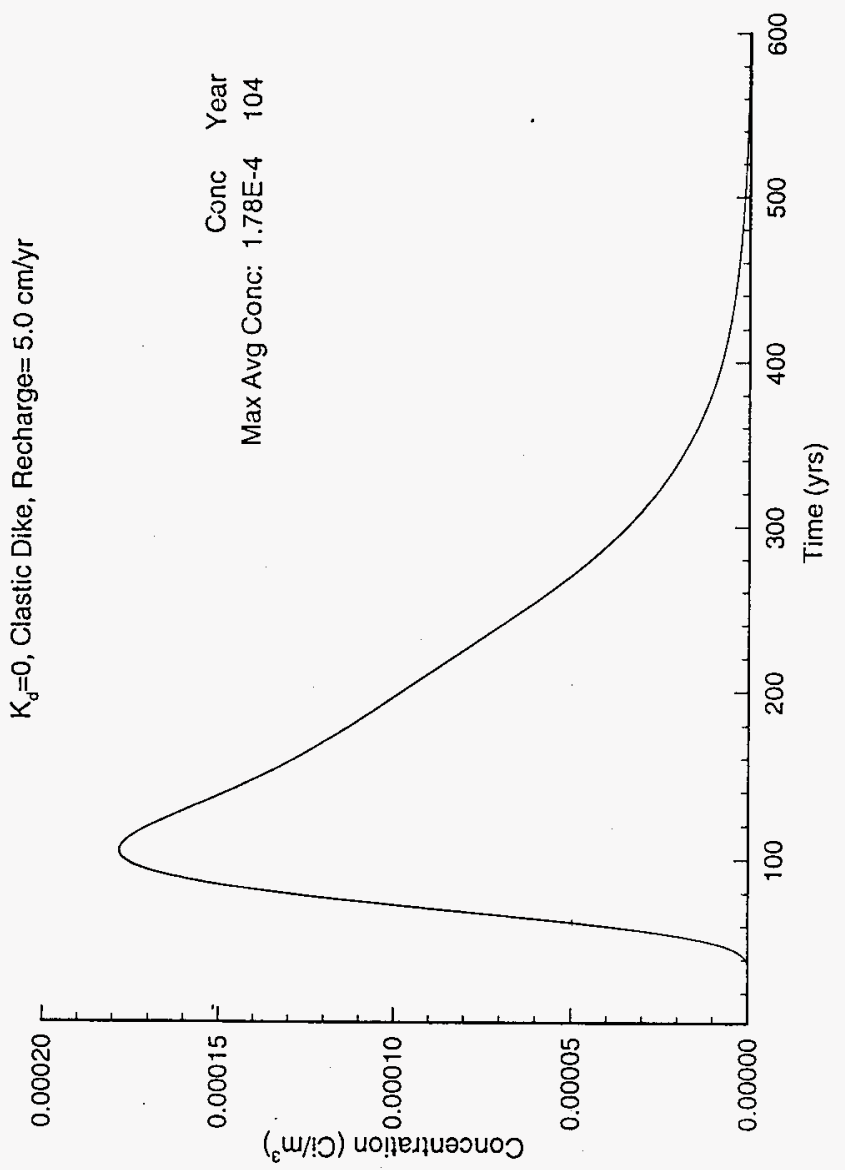


WHC-SD-WM-TI-730, REV 0

This page intentionally left blank. 
Figure 4-24. Radionuclide Concentrations at the 100-m Well for Hot-Spot Inventory Distribution and Advection-Controlled Release Under Category 1 Conditions.

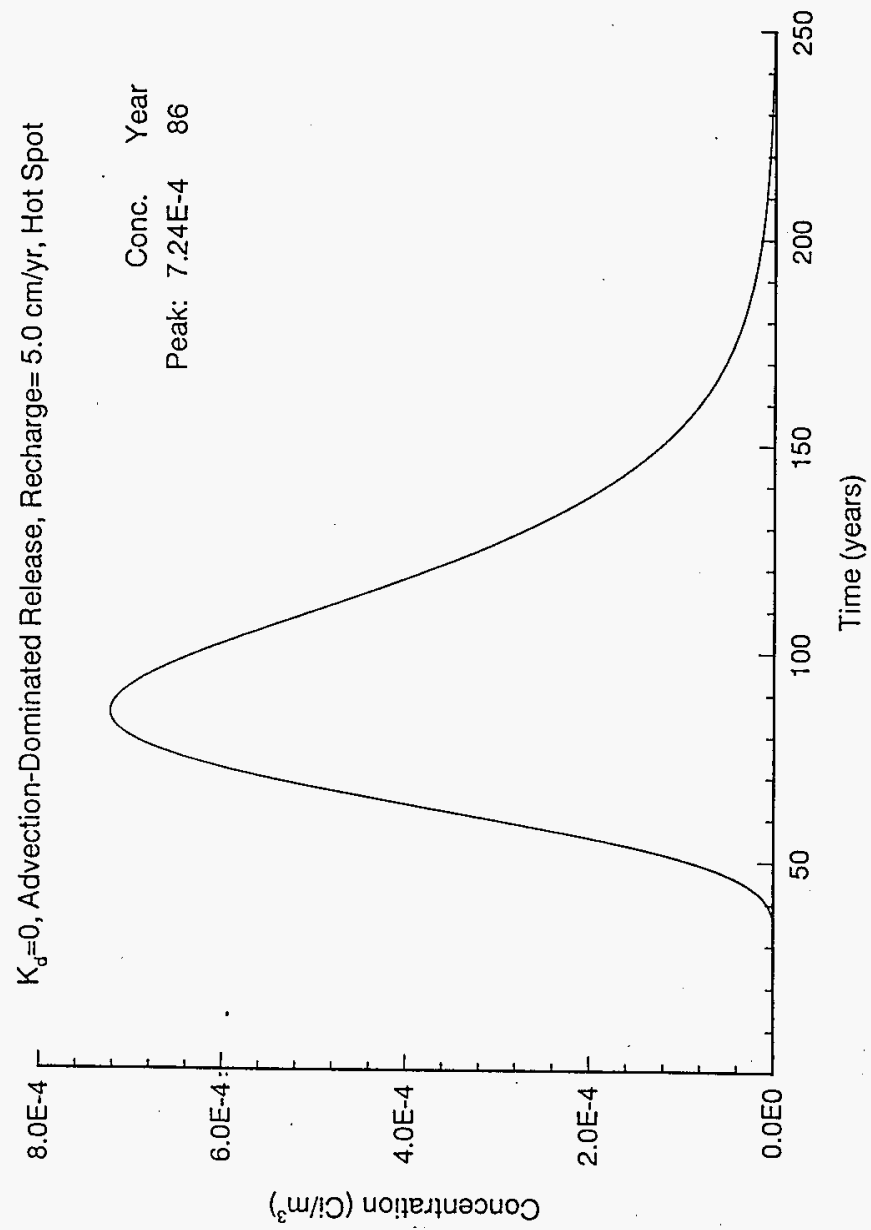


Figure 4-25. Radionuclide Concentrations at the 100-m Well Downstream from the Reactor Compartment Trench for Constant Concentration-Controlled Release and $\mathrm{Kd}=0$ Under Category 3 Conditions.

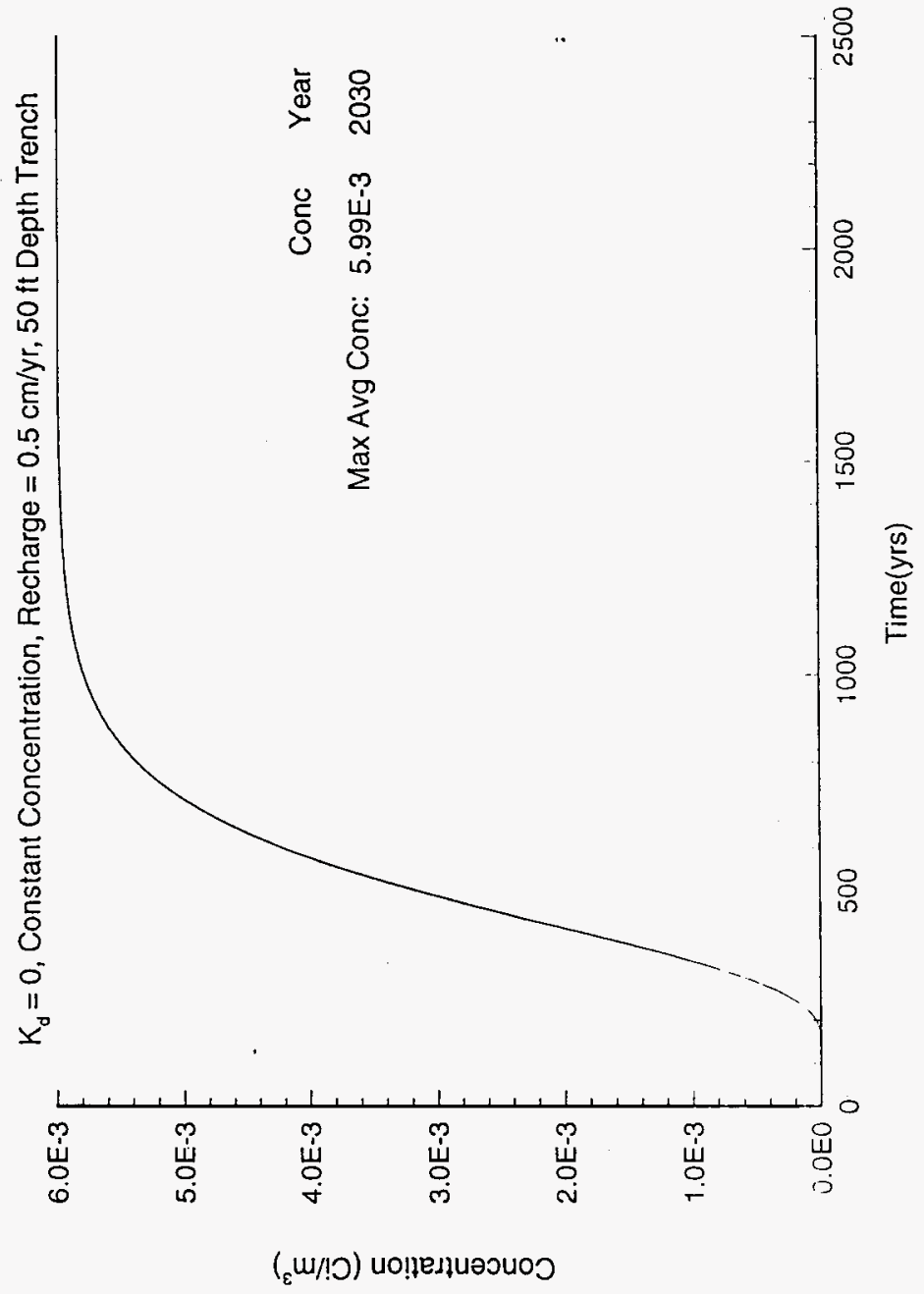


Figure 4-26. Radionuclide Concentrations at the 100-m Well Downstream from the Reactor Compartment Trench for Constant Concentration-Controlled Release and an Extended Trench $(40 \mathrm{~m})$ Under Category 3 Conditions.

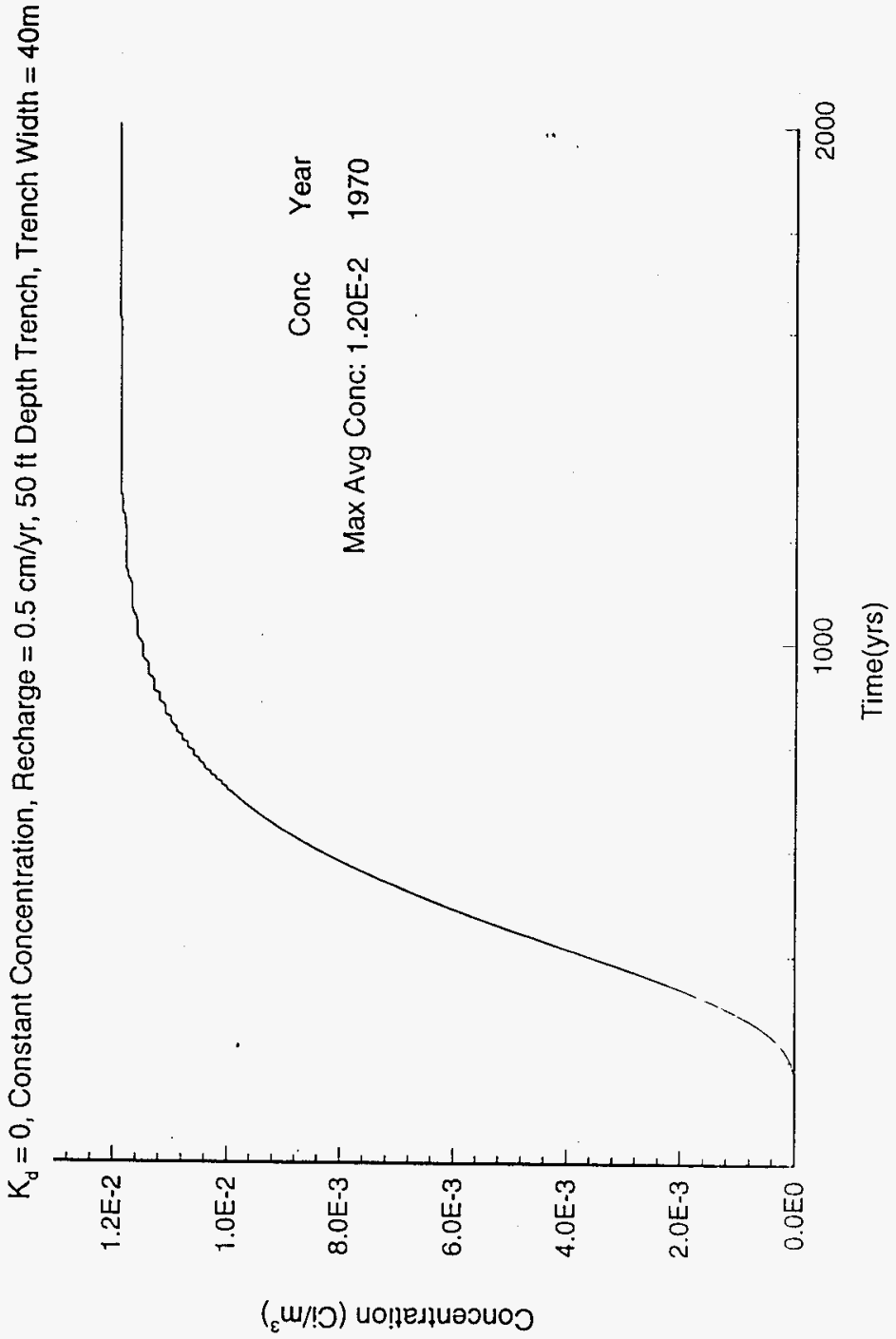


Figure 4-27. Unit Gradient Measurements and Corrected Tempe Cell Measurements for Sample 3-0571.

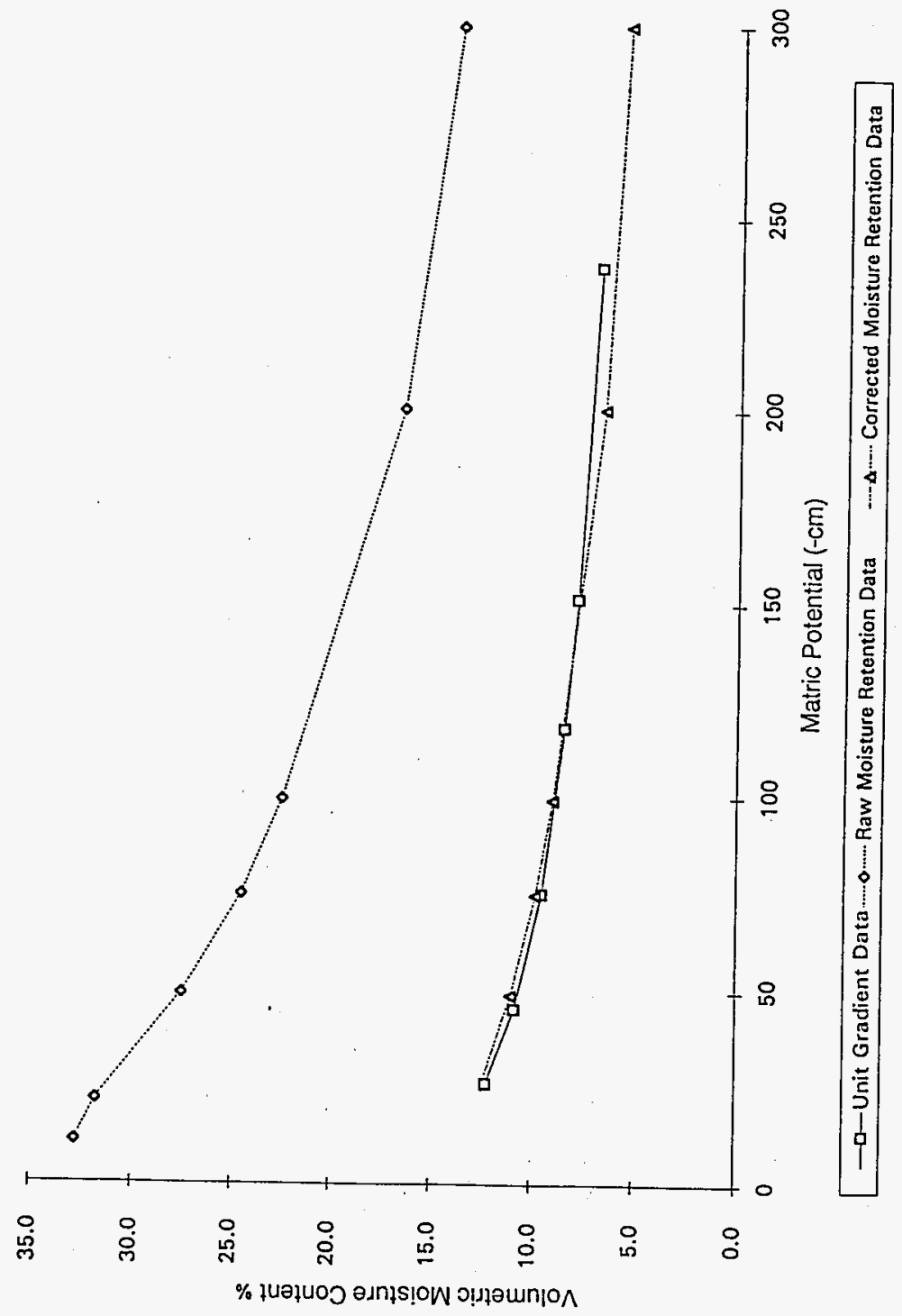

F4-36 
Figure 4-28. Unscaled Moisture Retention Data and Best Fit van Genuchten Curves for Two Soil Categories.
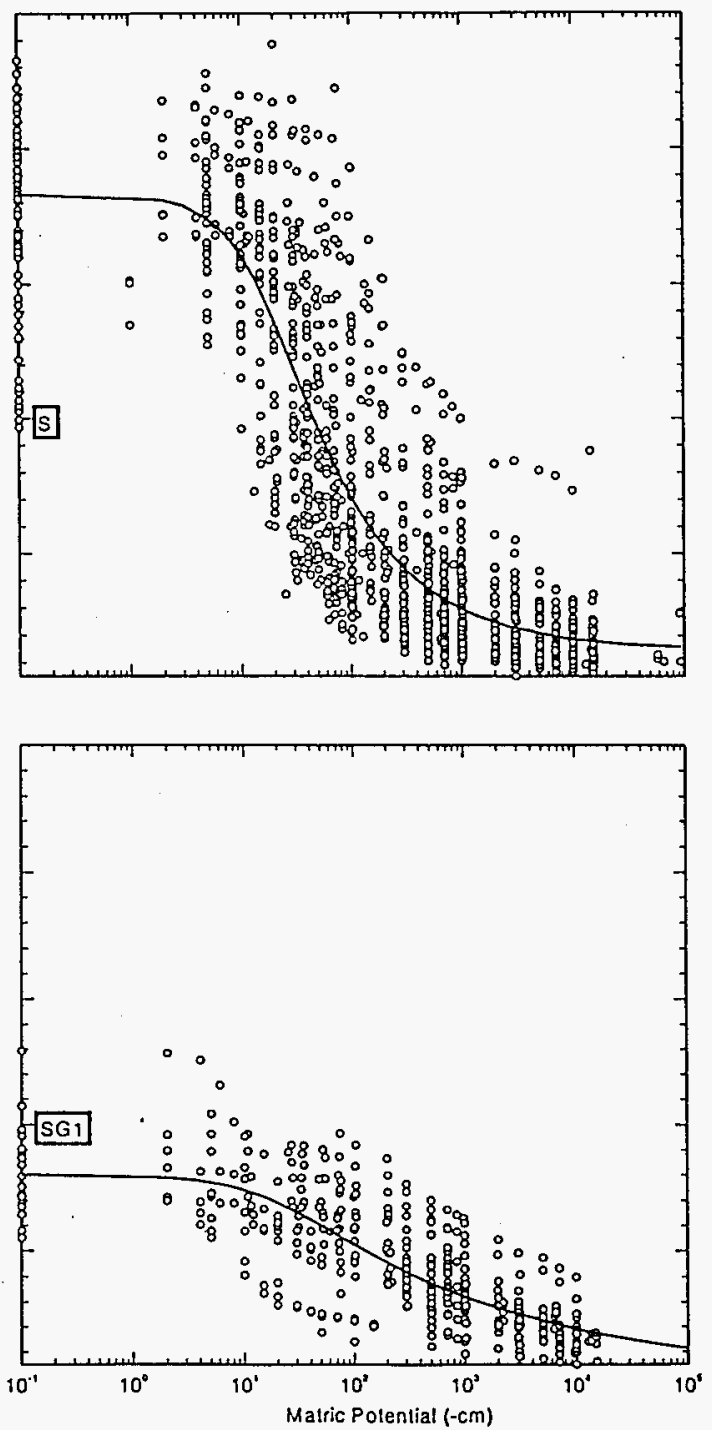
Figure 4-29. Probability Distribution Plot of Saturated Hydraulic Conductivity in the Unconfined Aquifer.

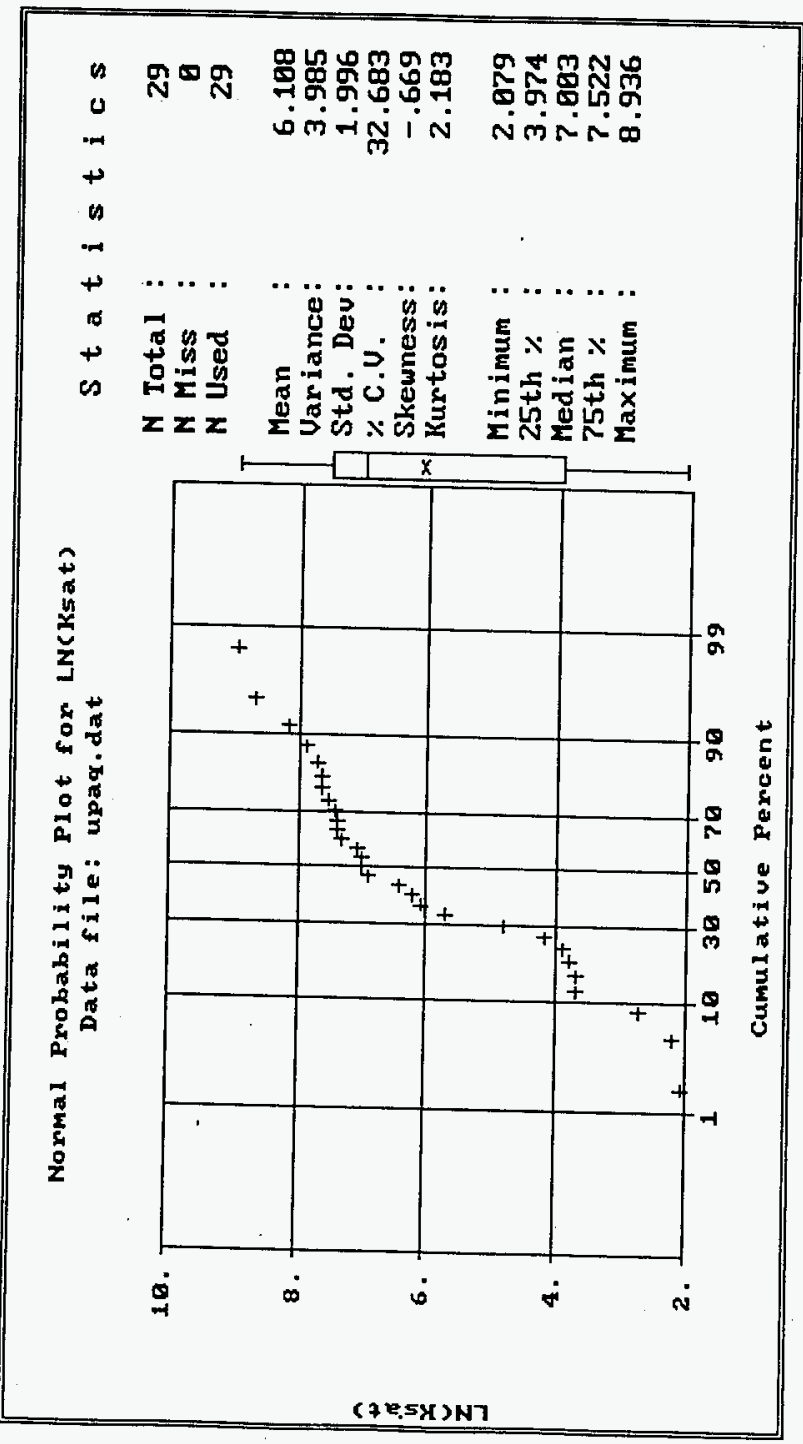

F4-38 
Table 4-1. Radionuclides Considered in the Dose Analysis. (3 sheets)

\begin{tabular}{|c|c|c|}
\hline Radionuclide & $\begin{array}{c}\text { Half--life } \\
\text { (yr) }\end{array}$ & Short-1ived progeny in equilibrium with parent ${ }^{b}$ \\
\hline${ }^{3} \mathrm{H}$ & 12.28 & \\
\hline${ }^{10} \mathrm{Be}$ & $1.60 E+06$ & \\
\hline${ }^{14} \mathrm{C}$ & 5,730 & \\
\hline${ }^{36} \mathrm{Cl}$ & 301,000 & \\
\hline${ }^{40} \mathrm{~K}$ & $1.277 \mathrm{E}+09$ & \\
\hline${ }^{60} \mathrm{Co}$ & 5.271 & \\
\hline${ }^{63} \mathrm{Ni}$ & 100.1 & \\
\hline${ }^{79} \mathrm{Se}$ & 65,000 & \\
\hline${ }^{90} \mathrm{Sr}$ & 28.6 & ${ }^{90}{ }_{Y}$ \\
\hline${ }^{93} \mathrm{Zr}$ & $1.53 E+06$ & \\
\hline $93 \mathrm{~m}_{\mathrm{Nb}}$ & 14.6 & \\
\hline${ }^{94} \mathrm{Nb}$ & 20,300 & \\
\hline${ }^{93} \mathrm{Mo}$ & 3,500 & \\
\hline${ }^{99} \mathrm{TC}$ & 213,000 & \\
\hline${ }^{107} \mathrm{Pd}$ & $6.50 E+06$ & \\
\hline${ }^{113 m} \mathrm{Cd}$ & 13.7 & \\
\hline${ }^{121 \mathrm{~m}} \mathrm{Sn}$ & 55 & ${ }^{121} \mathrm{Sn}(0.778)$ \\
\hline${ }^{126} \mathrm{Sn}$ & 100,000 & ${ }^{126 m} \mathrm{Sb},{ }^{126} \mathrm{Sb}(0.14)$ \\
\hline${ }^{129} \mathrm{I}$ & $1.57 \mathrm{E}+07$ & \\
\hline${ }^{135} \mathrm{Cs}$ & $2.30 \mathrm{E}+06$ & \\
\hline${ }^{137} \mathrm{Cs}$ & 30.17 & ${ }^{137 \mathrm{~m}} \mathrm{Ba}(0.946)$ \\
\hline${ }^{133} \mathrm{Ba}^{\mathrm{a}}$ & 10.5 & \\
\hline${ }^{147} \mathrm{Sm}$ & $1.06 \mathrm{E}+11$ & \\
\hline${ }^{151} \mathrm{Sm}$ & 90 & \\
\hline${ }^{150} \mathrm{Eu}^{\mathrm{a}}$ & 36 & \\
\hline${ }^{152} \mathrm{Eu}$ & 13.6 & . \\
\hline${ }^{154} \mathrm{Eu}$ & 8.8 & \\
\hline${ }^{152} \mathrm{Gd}^{\mathrm{B}}$ & $1.10 \mathrm{E}+14$ & \\
\hline${ }^{187} \mathrm{Re}$ & $4.7 E+10$ & \\
\hline${ }^{210} \mathrm{~Pb}$ & 22.26 & ${ }^{210} \mathrm{~B} \mathbf{i},{ }^{210} \mathrm{Po}$ \\
\hline
\end{tabular}


Table 4-1. Radionuclides Considered in the Dose Analysis. (3 sheets)

\begin{tabular}{|c|c|c|}
\hline Radionuclide & $\begin{array}{c}\text { Half } f-1 \text { ife } \\
(y r)\end{array}$ & Short-lived progeny in equilibrium with parent ${ }^{b}$ \\
\hline${ }^{209} \mathrm{Po}^{\mathrm{a}}$ & 102 & \\
\hline${ }^{226} \mathrm{Ra}$ & 1,600 & ${ }^{222} \mathrm{Rn},{ }^{218} \mathrm{Po},{ }^{214} \mathrm{Bi},{ }^{214} \mathrm{Po}$ \\
\hline${ }^{228} \mathrm{Ra}$ & 5.75 & ${ }^{228} \mathrm{AC}$ \\
\hline${ }^{227} \mathrm{AC}$ & 21.773 & 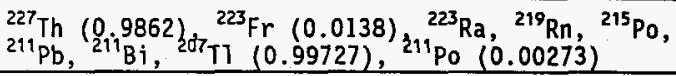 \\
\hline${ }^{228} \mathrm{Th}$ & 1.9132 & $\begin{array}{l}{ }^{224} \mathrm{Ra},{ }^{220} \mathrm{Rn},{ }^{216} \mathrm{Po},{ }^{212} \mathrm{Bi},{ }^{212} \mathrm{~Pb}(0.6507) \\
\mathrm{Tl}(0.3593)\end{array}$ \\
\hline${ }^{229} \mathrm{Th}$ & 7,340 & ${ }^{225} \mathrm{Ra},{ }^{225} \mathrm{Ac},{ }^{221} \mathrm{Fr},{ }^{217} \mathrm{At},{ }^{213} \mathrm{Bi},{ }^{213} \mathrm{Po},{ }^{208} \mathrm{Tl}$ \\
\hline${ }^{230} \mathrm{Th}$ & 77,000 & \\
\hline${ }^{232} \mathrm{Th}$ & $1.405 E+10$ & \\
\hline${ }^{131} \mathrm{~Pa}$ & 32,764 & \\
\hline $232 \mathrm{U}$ & 72 & \\
\hline${ }^{233} \mathrm{U}$ & 159,200 & \\
\hline${ }^{234} \mathrm{U}$ & 244,500 & \\
\hline $235 \mathrm{U}$ & $7.038 \mathrm{E}+08$ & ${ }^{231} \mathrm{Th}$ \\
\hline $236 \mathrm{U}$ & $2.34 E+07$ & \\
\hline $238 \mathrm{U}$ & $4.458 E+09$ & ${ }^{234} \mathrm{Th},{ }^{234 \mathrm{~m}} \mathrm{~Pa},{ }^{234} \mathrm{~Pa}(0.0016)$ \\
\hline${ }^{237} \mathrm{~Np}$ & $2.14 E+06$ & ${ }^{233} \mathrm{~Pa}$ \\
\hline${ }^{238} \mathrm{Pu}$ & 86.75 & \\
\hline${ }^{239} \mathrm{Pu}$ & 24,131 & \\
\hline${ }^{240} \mathrm{Pu}$ & 6,569 & \\
\hline${ }^{241} \mathrm{Pu}$ & 14.4 & ${ }^{237} U(2.45 \quad E-05)$ \\
\hline${ }^{242} \mathrm{Pu}$ & 375,800 & \\
\hline${ }^{266} \mathrm{Pu}$ & $8.26 \mathrm{E}+07$ & ${ }^{240} \mathrm{U}$ \\
\hline${ }^{241} \mathrm{Am}$ & 432.2 & \\
\hline${ }^{242 \pi} \mathrm{Am}$ & 152 & ${ }^{242} \mathrm{Am}(0.99524),{ }^{242} \mathrm{Cm}(0.827),{ }^{238} \mathrm{~Np}(0.00476)$ \\
\hline${ }^{243} \mathrm{Am}$ & 7,380 & ${ }^{239} \mathrm{~Np}$ \\
\hline${ }^{243} \mathrm{Cm}$ & 28.5 & \\
\hline${ }^{244} \mathrm{Cm}$ & 18.11 & \\
\hline${ }^{245} \mathrm{Cm}$ & 8,500 & \\
\hline${ }^{246} \mathrm{Cm}$ & 4.750 & \\
\hline
\end{tabular}


Table 4-1. Radionuclides Considered in the Dose Analysis. (3 sheets)

\begin{tabular}{|l|c|l|}
\hline Radionuclide & $\begin{array}{c}\text { Half-life } \\
(\mathrm{yr})\end{array}$ & Short-1ived progeny in equilibrium with parent \\
\hline${ }^{247} \mathrm{Cm}$ & $1.56 \mathrm{E}+07$ & ${ }^{243} \mathrm{Pu}$ \\
\hline${ }^{248} \mathrm{Cm}$ & 339,000 & \\
\hline
\end{tabular}

These are not present in the current GENII 1ibrary (Version 1.485).

NOTE: The numbers in parentheses are the branching ratios for the progeny radionuclide shown. The half-lives of all progeny radionuclides are less than 1 year.

The half lives of all progeny radionuclides are less than 1 year. These progeny are also called "implicit daughters" because all dose calculations for the parent nuclide include the effect of the computed progeny. The numbers in parentheses are the branching ratios for the progeny radionuclides shown. Half life and branching ratio values are taken from Kocher (1981). 
Table 4-2. Radioactive Decay Chains Used in the Spreadsheet.

\begin{tabular}{|l|l|}
\hline \multicolumn{1}{|c|}{ Parent radionuclide } & \multicolumn{1}{|c|}{ Progeny radionuclides } \\
\hline${ }^{93} \mathrm{Zr}$ & ${ }^{33 \mathrm{~m}} \mathrm{Nb}$ \\
\hline${ }^{93} \mathrm{Mo}$ & ${ }^{93 \mathrm{~m}} \mathrm{Nb}$ \\
\hline${ }^{226} \mathrm{Ra}$ & ${ }^{210} \mathrm{~Pb}$ \\
\hline${ }^{228} \mathrm{Ra}$ & ${ }^{228} \mathrm{Th}$ \\
\hline${ }^{230} \mathrm{Th}$ & ${ }^{226} \mathrm{Ra}$ and ${ }^{210} \mathrm{~Pb}$ \\
\hline${ }^{232} \mathrm{Th}$ & ${ }^{228} \mathrm{Ra}$ and ${ }^{228} \mathrm{Th}$ \\
\hline${ }^{232} \mathrm{U}$ & ${ }^{228} \mathrm{Th}$ \\
\hline${ }^{233} \mathrm{U}$ & ${ }^{229} \mathrm{Th}$ \\
\hline${ }^{261} \mathrm{Pu}$ & ${ }^{261} \mathrm{Am}$ and ${ }^{237} \mathrm{~Np}$ \\
\hline${ }^{244} \mathrm{Pu}$ & ${ }^{240} \mathrm{Pu}$ \\
\hline${ }^{241} \mathrm{Am}$ & ${ }^{237} \mathrm{~Np}$ \\
\hline${ }^{242 \mathrm{~m}} \mathrm{Am}$ & ${ }^{242} \mathrm{Pu}(0.173),{ }^{238} \mathrm{Pu}(0.827),{ }^{234} \mathrm{U}$ \\
\hline${ }^{243} \mathrm{Am}$ & ${ }^{239} \mathrm{Pu}$ \\
\hline${ }^{263} \mathrm{Cm}$ & ${ }^{239} \mathrm{Pu}(0.9976)$ and ${ }^{243} \mathrm{Am}(0.0024)$ \\
\hline${ }^{244} \mathrm{Cm}$ & ${ }^{240} \mathrm{Pu}$ \\
\hline${ }^{245} \mathrm{Cm}$ & ${ }^{241} \mathrm{Pu},{ }^{241} \mathrm{Am},{ }^{237} \mathrm{~Np}$ \\
\hline${ }^{247} \mathrm{Cm}$ & ${ }^{243} \mathrm{Am}$ \\
\hline
\end{tabular}

Note: The numbers in parentheses are the branching ratios for the longlived progeny radionuclides shown. The activity of the progeny is initially zero. The progeny nuclides accumulate with time caused by the decay of the parent. 
Table 4-3. Total Doses (mrem/yr per $\mathrm{Ci} / \mathrm{m}^{3}$ ) for the Post-Excavation Scenario Using (Kennedy and Strenge 1992) Concentration Ratios.

\begin{tabular}{|c|c|c|c|c|c|c|c|}
\hline \multirow{2}{*}{ Nucl ide } & \multicolumn{3}{|c|}{ With soil Leaching } & \multicolumn{3}{|c|}{ Without Soil Leachiog } & \multirow{2}{*}{ Poni-nent } \\
\hline & $100 \mathrm{yr}$ & 300 yr & 500 yr & $100 \mathrm{yr}$ & $300 \mathrm{yr}$ & $500 \mathrm{yr}$ & \\
\hline$H-3$ & $4.09=-04$ & $5.11 \mathrm{~F}-09$ & $6.39 E-14$ & $1.09 E-03$ & $1.37 \mathrm{~F}-0.8$ & $1.71 \mathrm{E}-13$ & Soil lng \\
\hline $\mathrm{B} e-10$ & Q.08 E+01 & Q.08E+01 & $208 E+01$ & $0.09+01$ & $200 \mathrm{E}+01$ & $9.09 \mathrm{~F}+01$ & Extern \\
\hline$c-14$ & $1.07 \mathrm{E}+03$ & $9.05 E+03$ & $1.02 E+03$ & $1.10 E+03$ & $1.07 \mathrm{E}+03$ & $1.05 E+03$ & Yeagie \\
\hline$C l-36$ & $1.43 \mathrm{E}+05$ & $1.43 \mathrm{E}+05$ & $1.43 \mathrm{~s}+05$ & $1.57 \mathrm{E}+05$ & $1.57 \mathrm{E}+05$ & $1.57 E+05$ & Veraje \\
\hline$x-40$ & $5.51 \mathrm{E}+04$ & $5.51 \mathrm{~F}+04$ & $551 \mathrm{E}+04$ & $5.60 \mathrm{E}+04$ & $5.60 \mathrm{E}+04$ & $5.60 F+04$ & Extern \\
\hline $\operatorname{co-60}$ & $1.33 \mathrm{E}+00$ & $5,05 E-12$ & $101=-23$ & $1.34 \mathrm{E}+0 \mathrm{OO}$ & $5.07 \mathrm{~F}-12$ & $192 F-23$ & Extern \\
\hline $\mathrm{Ni}=59$ & $2.54 E+02$ & $2.53 E+01$ & $2.53 E+01$ & $2.54 \mathrm{E}+01$ & $2.53 \mathrm{E}+01$ & $2.53 \mathrm{E}+01$ & Extern \\
\hline$M i-63$ & $1,68 E+01$ & $4.29 E+00$ & $1.05 E+00$ & $1.68 \mathrm{E}+01$ & $4.21 E+00$ & $1.05 E+00$ & Yeraie \\
\hline$s=-70$ & $1.27 \mathrm{E}+02$ & $127 \quad E+02$ & $1.96 \mathrm{E}+02$ & $1.98 E+02$ & $1.97 \quad E+02$ & $1.97 \mathrm{E}+02$ & Vequis \\
\hline$s r-90$ & $6.35 E+03$ & $4.92 E+01$ & $3.91=-01$ & $6,43 E+03$ & $5.05 \varepsilon+01$ & $3.96=-01$ & Veraie \\
\hline $2 r-93$ & $3.96 \mathrm{E}+01$ & $3.27 \mathrm{E}+01$ & $3.97 \mathrm{E}+01$ & $3.96 E+01$ & $3.97 \mathrm{E}+01$ & $3.97 E+01$ & Inhale \\
\hline $\mathrm{Nb}-923 \mathrm{~m}$ & $1.01 E-01$ & $7.58=-06$ & $5.70=-10$ & $1.01 \mathrm{E}-01$ & $7.50 \mathrm{E}-0.06$ & $5.71 E-10$ & Extern. \\
\hline $\mathrm{Nb}=94$ & $4.54 E+05$ & $4.50 E+05$ & $4.47 E+05$ & $4.54 E+05$ & $4.51 \quad E+05$ & $4.48 E+05$ & Extern \\
\hline Mo. 93 & $1.12 E+02$ & $1,09 . E+02$ & $1.04 E+02$ & $1.15 E+02$ & $1,10 E+02$ & $1.06=02+02$ & Venaie \\
\hline Ic- -99 & $2.60 \mathrm{E}+03$ & $2,60 E+03$ & $2.59 E+03$ & $4.28 E+03$ & $4.27 \mathrm{E}+03$ & $4.27 \mathrm{E}+03$ & Veroie \\
\hline Pd-107 & $6.49 E+00$ & $6.49 E+00$ & $6.49 E+00$ & $6.52 \mathrm{E}+00$ & $6.52 \mathrm{E}+00$ & $6.52 E+00$ & Yeorie \\
\hline$c d-113 m$ & $1.31 \mathrm{E}+02$ & $5.28=-03$ & $2.13 \mathrm{E}-07$ & $1.32 \mathrm{E}+02$ & $5.31[-03$ & 2.16 E-07 & Veooie \\
\hline$S n=121 m$ & $1.48 \mathrm{E}+02$ & $1.19 E+01$ & $2.58 \mathrm{E}-01$ & $1.48 \mathrm{E}+02$ & $1.19 \mathrm{E}+01$ & $9.60 \mathrm{E}-01$ & Extero \\
\hline $5 n-126$ & $6.40 E+05$ & $6.32 \mathrm{E}+05$ & $6.38 E+05$ & $6.43 E+0.5$ & $6.40 E+05$ & $6.40 E+05$ & Extern \\
\hline $1-129$ & $9.98 \mathrm{E}+03$ & $9.98 E+03$ & $298 \mathrm{E}+03$ & $1.17 E+04$ & $1.17 \mathrm{E}+04$ & $1.17 E+04$ & veroie \\
\hline Cs -135 & $6.09 \mathrm{~F}+02$ & $6.09 E+102$ & $6.09 E+02$ & $6.09 \quad E+02$ & $6.09 \mathrm{~F}+02$ & $6.09 \mathrm{E}+02$ & Verrie \\
\hline cs -137 & $1.81 E+04$ & $1.83 \mathrm{~F}+02$ & $1.85 \mathrm{E}+00$ & $181 \mathrm{E}+04$ & $1.83 E+02$ & $1.85 \mathrm{E}+00$ & Extern \\
\hline Ba-133 & $1.41 \mathrm{E}+02$ & 2.60 E- 04 & $4.79=-10$ & $1.42 E+02$ & $2.61 \quad F-04$ & $4.82 E-10$ & Extern \\
\hline $5 m-147$ & $5.73 E+03$ & $5.73 \mathrm{E}+03$ & $5.73 E+03$ & $5.74 E+03$ & $5.74 E+03$ & $5.74 \mathrm{E}+03$ & Inhale \\
\hline $5 m=151$ & $2.10 \quad E+00$ & $4.69 \mathrm{E}-04$ & $1,00 E=01$ & $2.19 \quad E+00$ & $4.69 \mathrm{E}-01$ & 1.01E-01 & inhale \\
\hline Eut-150 & $7,10 E+04$ & $1.51 E+03$ & $3.21 E+01$ & $7.11 E+04$ & $1.51 \mathrm{E}+03$ & $3.21 E+01$ & Extern \\
\hline$E_{11}-152$ & $2.09 \mathrm{E}+03$ & $7.82=-02$ & $2.93 \quad=-06$ & $2.09 E+03$ & $783=-02$ & $2.93 \mathrm{E}-0.6$ & Extern \\
\hline Ev-154 & $1.33 \mathrm{~F}+02$ & $192 \mathrm{E}-05$ & $2.76 \mathrm{E}=12$ & $1.33 \mathrm{E}+02$ & 1.92 E -05 & $2.76 \quad=-12$ & Extern \\
\hline $\operatorname{cd}-152$ & $1.56 \mathrm{E}+04$ & $156 \mathrm{E}+04$ & $1.56 E+04$ & $1,56 E+04$ & $1.56 \mathrm{E}+04$ & $1.56 E+04$ & Inhale \\
\hline $8=-187$ & $2.71 \mathrm{E}+00$ & $2.71 E+00$ & $2.71 E+00$ & $2.75 E+00$ & $2, \pi E+00$ & $2.75 E+0.0$ & veroie \\
\hline$P b-210$ & $2.68 \mathrm{E}+03$ & $5.29 \mathrm{E}+00$ & $1.05 \mathrm{E}-02$ & $2.69 E+03$ & $5.30 \mathrm{E}+00$ & $1.05 E-02$ & Soil Ino \\
\hline$B i-207$ & $5.98 \mathrm{~F}+04$ & $9.42 \mathrm{E}+02$ & $148 E+01$ & $5.92 \mathrm{E}+06$ & 264 E+02 & $1.49 \mathrm{E}+01$ & Extern \\
\hline$P 0=209$ & $102 \mathrm{E}+04$ & $2.62 \mathrm{E}+03$ & $6.73 E+02$ & $1.02 E+04$ & $2.62 \mathrm{E}+03$ & $6.74 E+02$ & Soil Ine \\
\hline Ra-226 & $5.94 \mathrm{E}+05$ & $5.47 \mathrm{E}+05$ & $5.02 E+05$ & $5.94 E+05$ & $5.48 E+05$ & $5.02 F+05$ & Extern \\
\hline Ra-228 & $5.84 E+00$ & $198 \mathrm{E}-10$ & $6.68 E-21$ & $5.84 E+00$ & $1.98=-10$ & $6.69 \mathrm{~F}-21$ & Extern \\
\hline$A C-227$ & $2.39 \mathrm{E}+04$ & $4.10 E+01$ & $7.04 \mathrm{E}-02$ & $2.39 E+04$ & $4.11 E+01$ & $7.05 \mathrm{E}-02$ & Inhale \\
\hline Th-228 & $7.77 \mathrm{E}-11$ & $2.64 F-42$ & $8.98 \mathrm{E}-74$ & $7.77 \mathrm{E}=11$ & $2.64=-42$ & $8.98 E-74$ & Extern \\
\hline Th-229 & $2.28 E+05$ & $2.24 \mathrm{E}+05$ & $2.19 \mathrm{E}+05$ & $2.28 \mathrm{E}+05$ & $2.24=+05$ & $2.19 E+05$ & Inhale \\
\hline Ih -230 & $4.7 \mathrm{E}+04$ & $9.71 E+04$ & $1.42 E+05$ & $4.78 \mathrm{E}+04$ & $2.71=+04$ & $1.42 \mathrm{E}+05$ & Extern \\
\hline Ih-232 & Q.22 E+05 & $9.22 \mathrm{E}+05$ & $9.22 \mathrm{E}+05$ & $9.22 \mathrm{E}+05$ & $2.22 E+05$ & $2.22 F+05$ & Extern \\
\hline PQ-231 & 7.05 $\mathrm{E}+05$ & $7.26 \mathrm{E}+05$ & $7.23 \mathrm{E}+05$ & $7.06 \mathrm{E}+05$ & $7.26 \varepsilon+05$ & $7.23 E+05$ & Inhala \\
\hline $11-232$ & $2.17 \mathrm{E}+05$ & $3.17 \mathrm{E}+04$ & $4.62 \mathrm{E}+03$ & $2,18 E+05$ & $3.18 E+04$ & $4.64 E+03$ & Extern \\
\hline $11-233$ & $1.345+04$ & $1.76 \mathrm{E}+04$ & $2.18 \mathrm{E}+04$ & $1.36 E+04$ & $1.78 E+04$ & $2.20 E+04$ & Inhale \\
\hline $11-234$ & $1.10 \mathrm{E}+04$ & $1,10 \mathrm{E}+04$ & 1.10 E+04 & $1.13 \mathrm{~F}+04$ & $1,12 E+04$ & $112 \mathrm{E}+04$ & Inhale \\
\hline $11-235$ & $3.56 \mathrm{~F}+04$ & $3.87 E+064$ & $4.17 \mathrm{E}+04$ & $3.63 \mathrm{~F}+04$ & $3.94 E+04$ & $4.25 E+04$ & Extern \\
\hline $11-236$ & $1.03 \mathrm{E}+04$ & $1.03 E+04$ & $1.03 E+04$ & $1.05 E+04$ & $1.05 E+04$ & $1.05 E+04$ & Inhale \\
\hline$\mu-238$ & $1.72 E+04$ & $1.72 \mathrm{E}+04$ & $1.72 \mathrm{E}+04$ & $1, \overline{T L} E+04$ & $1.75 E+04$ & $1 . \overline{2} E+04$ & Inthale \\
\hline $10-237$ & $1.32 E+05$ & $1.39 E+05$ & $1.39 E+05$ & $1,47 E+05$ & $1,47 E+05$ & $1.47 E+05$ & Extero \\
\hline$P u=238$ & $2.12 \mathrm{E}+04$ & $4.37 \mathrm{E}+03$ & $9.02 \mathrm{E}+02$ & $2.12 \mathrm{E}+04$ & $4.37 \mathrm{E}+03$ & $9.03 \mathrm{E}+02$ & Inhale \\
\hline$P u=239$ & $5.22 \mathrm{E}+04$ & $5.10 E+04$ & $5.96 E+04$ & $5.22 \mathrm{E}+04$ & $5.10 E+04$ & $5.16 \mathrm{E}+04$ & Inhala \\
\hline Pu-240 & $5.18 E+04$ & $5.07 \mathrm{E}+04$ & $4.97 E+04$ & $5.18 E+04$ & $5.08 E+04$ & $4.97 \mathrm{E}+04$ & Inhale \\
\hline$P u=241$ & $1.64 E+03$ & $1.10 \mathrm{E}+03$ & $8.67 \mathrm{E}+02$ & $1.64 E+03$ & $1,19 \mathrm{~F}+03$ & $8.67 \mathrm{E}+02$ & Inhale \\
\hline $\mathrm{Pu}=242$ & $4.95 \mathrm{E}+04$ & $4.95 \mathrm{~F}+04$ & $4.95 \mathrm{E}+04$ & $4.96 E+04$ & $4.96 E+04$ & $4.95 \mathrm{E}+04$ & Inhale \\
\hline$P_{1}=244$ & $1.64 \mathrm{E}+05$ & $1.65 \mathrm{E}+05$ & $1.66 \mathrm{E}+05$ & $1.64 E+05$ & $1.65 \mathrm{E}+05$ & $1.66 \mathrm{E}+05$ & Extern \\
\hline$A m=241$ & $4.77 \quad E+04$ & $3.47 \mathrm{E}+04$ & $2.52 \mathrm{E}+04$ & $4.78 E+04$ & $3.47 \mathrm{E}+04$ & $2.52 \quad E+04$ & Intale \\
\hline$A m=242 m$ & $5.32 \mathrm{E}+04$ & $2.95 E+04$ & $1.35 E+04$ & $5.32 \mathrm{E}+04$ & $2.95 \mathrm{E}+04$ & $1.35 E+04$ & Inhale \\
\hline$A \Pi=243$ & $9.79 \mathrm{E}+04$ & $9.63 \mathrm{E}+04$ & $9.48 E+04$ & $9.70 \mathrm{E}+04$ & $2.64 E+04$ & $9.49 \mathrm{E}+04$ & Extern \\
\hline$a_{n}=243$ & $5.62 \mathrm{E}+03$ & $1.05 \mathrm{E}+02$ & $6.22 \mathrm{E}+01$ & $5.62 \mathrm{E}+03$ & $1.05 \mathrm{E}+02$ & $6.23 \mathrm{E}+01$ & Extern: \\
\hline $\mathrm{c} m=244$ & $7.35 \mathrm{E}+02$ & $1.41 E+02$ & $1.37 \mathrm{E}+02$ & $7.36 \mathrm{E}+02$ & $1.41 \mathrm{E}+02$ & $1.37 \mathrm{E}+02$ & Iohale \\
\hline$c m-245$ & $7.53 \mathrm{E}+04$ & $8 . \overline{5} E+04$ & $2.59 \mathrm{E}+04$ & $7.53 \mathrm{E}+04$ & $B .75 \mathrm{E}+04$ & $9.59 \mathrm{E}+04$ & Inhale \\
\hline$c_{m-246}$ & $5.44 E+04$ & $5.29 \mathrm{E}+04$ & $5.13 \mathrm{E}+04$ & $5.44 \mathrm{E}+06$ & $5.29 \mathrm{E}+04$ & $5,13 E+04$ & inhole \\
\hline$c_{m}=247$ & $1.78 E+05$ & $1.79 \mathrm{E}+05$ & $1.80 E+05$ & $1.78 \mathrm{E}+05$ & $1,79 \mathrm{~F}+05$ & $1.80 \mathrm{E}+05$ & Extern \\
\hline$C_{i n}=248$ & $1.05 \mathrm{E}+05$ & $1.95 \mathrm{~F}+05$ & $1.95 \mathrm{E}+05$ & $195 \mathrm{E}+05$ & $1.95 \mathrm{~F}+05$ & $1.95 \mathrm{E}+05$ & Lohale \\
\hline
\end{tabular}


Table 4-4. Total Doses (mrem/yr/ger Ci/m $\mathrm{m}^{3}$ for the Post-Drill ing Scenario

\begin{tabular}{|c|c|c|c|c|c|c|c|}
\hline Nuel ide & Yith soil & & & Wi thout Soil & & & Dominant \\
\hline & $100 \mathrm{yr}$ & $300 \mathrm{yr}$ & $500 \mathrm{yr}$ & $100 \mathrm{yr}$ & $300 \mathrm{yr}$ & $500 \mathrm{yr}$ & \\
\hline $\mathrm{H}=3$ & $1.91 \mathrm{E}=06$ & $2.38 \ldots=11$ & $2.98 E-16$ & $5.11 E=06$ & $6.30 \mathrm{E}=11$ & $7.99 \mathrm{E}-16$ & soil Ing \\
\hline Be- 10 & $4.24 E-01$ & $4.24 E-01$ & $4.24 \mathrm{E}-01$ & $4.24 E-01$ & $4.24 \mathrm{E}-01$ & $4.24 E-01$ & \\
\hline$c-14$ & $5.00 \mathrm{~F}+00$ & $4.88 E+00$ & $6.76 \mathrm{~F}+00$ & $5.13 \mathrm{FtOn}$ & $501 E+00$ & $4.89 \mathrm{E}+0 \mathrm{O}$ & Veogie \\
\hline al-36 & $6.70 \mathrm{E}+02$ & $6.60 \mathrm{E}+02$ & $6.60 E+02$ & $7.351+02$ & $7.34 E+02$ & $7.34 E+102$ & Veroie \\
\hline$K-40$ & $2.57 \mathrm{E}+02$ & $2.57 \quad E+02$ & $2.57 \mathrm{E}+02$ & $2.61 E+02$ & $2.61 f+02$ & $2.61 \mathrm{E}+02$ & Extern \\
\hline$c 0-60$ & $6.22=-0.3$ & $2.35 \mathrm{E}-14$ & $8.91 F-26$ & $6.26 F-03$ & $237 \mathrm{~F}-14$ & $8.96=-26$ & Extern \\
\hline$M i-50$ & $1.18 E-01$ & $1.18 \mathrm{~F}-01$ & $118 \mathrm{~F}-01$ & $1.19 E-01$ & $1.18 E=01$ & $1818=01$ & Extern \\
\hline $\mathrm{Ni}=63$ & $7.85 E-02$ & $1.97 \mathrm{E}-02$ & $4.22 \mathrm{E}-03$ & $7.85 \mathrm{E}-02$ & $1.97 \quad E-02$ & $4.92=03$ & Vesole \\
\hline se-72 & $9.20 \mathrm{E}-01$ & $0.19 \mathrm{E}-01$ & $9.17 \mathrm{E}-01$ & $9.22 \mathrm{E}-01$ & $220 \mathrm{E}-01$ & 오18 E-01 & Veogie \\
\hline $\mathrm{Sr}-9 \mathrm{n}$ & $296 E+01$ & $233 F-01$ & $1.83 F-03$ & $3.00[E+01$ & $236 \mathrm{E}-01$ & $1.85=-03$ & Vegole \\
\hline $7 r-92$ & $1.85 E-01$ & $1.85 E-01$ & $1.85 E-01$ & $1.85 E-01$ & $1.85=-01$ & $1.85-E-01$ & Iobale \\
\hline$M b=93 m$ & $4.70=.04$ & $3.54 \quad F=08$ & $2.66 \mathrm{E}-12$ & $4.71 E-04$ & $3.54 \mathrm{E}-08$ & $2.66 \mathrm{E}-12$ & Extern \\
\hline$N b-24$ & $2.12 E+03$ & $2.10 \mathrm{E}+03$ & $2.09 \mathrm{~F}+03$ & $2.12 E+03$ & $2.11 E+03$ & 200 E+03 & Extern \\
\hline Mn-93 & $5.24 \mathrm{E}-0.1$ & $5.04 \mathrm{E}-01$ & $4.85 E-01$ & $5.35 E-01$ & $5.14 E-01$ & $4.95 \quad E-01$ & Veorie \\
\hline$I=-92$ & $1.21 E+01$ & $1.21 \mathrm{E}+01$ & $1.21 E+01$ & $2.00 E+01$ & $1.99 E+01$ & $1.99 E+04$ & Veacie \\
\hline $9 d-107$ & $3.03=-02$ & $3.03 \mathrm{E}-02$ & $3.03, E-02$ & $3.04 E-02$ & $3.04 \mathrm{~F}-02$ & $3.04 \quad F-02$ & Veacie \\
\hline $\mathrm{cot}-113 \mathrm{~m}$ & 6.12 E-01 & $2.47 \mathrm{~F}-0.5$ & 9.96_E-10 & $6.25 E-01$ & $2,48 E-05$ & $0.98=10$ & Vegcie \\
\hline $5 n=121 \mathrm{~m}$ & $6.91=-01$ & $5.56 E-02$ & $4.47 \mathrm{E}-03$ & $6.03 E=01$. & $5.57=-02$ & $4.48 E-03$ & Extern \\
\hline $5 n=126$ & $290 E+03$ & $2.98 E+03$ & $2.98 E+03$ & $2.99 E+03$ & $2.29 E+03$ & $298 E+03$ & Extern \\
\hline 1.129 & $4.66 E+01$ & $4.66 \mathrm{E}+01$ & $4.66 \mathrm{E}+01$ & $5.47 E+01$ & $5.47 \mathrm{~F}+01$ & $5.47 E+09$ & Veooie. \\
\hline cs-135 & $284 \mathrm{E}+00$ & $2.86 \mathrm{E}+00$ & $284 \mathrm{E}+00$ & $2.84 E+0.0$ & $2.84 E+00$ & $2.84=100$ & vesois \\
\hline$c_{s}=137$ & $8.44 E+01$ & $8.53 E-01$ & $8.62 E-0.3$ & $8.45 E+01$ & $8.54 \mathrm{E}-01$ & 8.63 E- -03 & \\
\hline$B=-133$ & $6.56 \mathrm{E}-0.1$ & $1.21 E-06$ & $2.24 \mathrm{E}-12$ & $6.60-E-01$ & $1.22=-06$ & $2.25 E-12$ & Extern \\
\hline $5 m-147$ & $2.68 F+01$ & $2.68 \mathrm{~F}+01$ & $268 \mathrm{E}+01$ & $2.68 E+01$ & $2.68 E+01$ & $2.68 E+01$ & Inhale \\
\hline$S m=151$ & $102 \mathrm{E}-02$ & $2.10 E-03$ & 4.69 E-04 & $1.02 \mathrm{E}-02$ & $2.12 \mathrm{E}=03$ & $4.69 \mathrm{E}-0 \mathrm{C}$ & Intale \\
\hline Eut $=150$ & $3.31 E+02$ & $7.05 E+00$ & $1,50 \mathrm{E}-01$ & $3.32 \mathrm{E}+02$ & $7.06 \mathrm{E}+00$ & $150-E-01$ & Extern \\
\hline E11-152 & $9.75+00$ & $3.65 \mathrm{E}=04$ & $1.37 F-08$ & $9.76 \mathrm{~F}+00$ & $3.65=-04$ & $1.37 E=08$ & Extern \\
\hline$E U=154$ & $6.21 E-01$ & 8.94 E- 08 & $1.29 \mathrm{E}-14$ & $6.22 E .01$ & $8.96 \quad E-08$ & $1.29 \mathrm{E}-14$ & Extern \\
\hline fad -152 & $7.27 \mathrm{E}+01$ & $7.27 \mathrm{E}+01$ & $7.27 \mathrm{E}+01$ & $7.28 \mathrm{E}+01$ & $7.28 \mathrm{~F}+01$ & $7.28 \mathrm{E}+01$ & Inhale \\
\hline Re-187 & $1.27 \mathrm{E} \cdot 02$ & $1.27 \mathrm{E}-02$ & $1.27 \mathrm{E}-02$ & $1.28 \mathrm{E}=02$ & $1.28 \mathrm{E}-02$ & 1,28 E-02 & Vecole \\
\hline$P b=210$ & $125 \mathrm{~F}+01$ & $2.47 \mathrm{E}-02$ & $4.88 \mathrm{E}-05$ & $1.25 E+01$ & $2.47 \mathrm{E}-02$ & $4.88 E-05$ & soil Ing \\
\hline $\mathrm{Bi}=207$ & $2.79 E+02$ & $4.39 \mathrm{E}+00$ & $6.92=0-02$ & $2.80 E+02$ & $4.41 E+00$ & $6,94 \mathrm{E}-02$ & Extern \\
\hline$P 0-200$ & $4.76 \mathrm{E}+01$ & $1.22 \mathrm{E}+01$ & $3.14 E+00$ & $4.71 E+01$ & $1.22 \mathrm{E}+01$ & $3.15 E+00$ & Sail Ina \\
\hline$R A=226$ & $2.7 \mathrm{~F}+03$ & $255 \mathrm{E}+03$ & $2.34 E+03$ & $2.77 \mathrm{E}+03$ & $2.5615+03$ & $2.34 \mathrm{E}+03$ & Extern \\
\hline$R a-228$ & $2.72 \mathrm{E}-02$ & $9.22 \mathrm{E}-13$ & $3.12 \mathrm{E}-23$ & $2.73=-02$ & $9.27 \mathrm{~F}-13$ & $3.12 \mathrm{E}-23$ & Extern \\
\hline$A c=227$ & $1.11 \mathrm{E}+02$ & $1.91 \mathrm{E}-01$ & 3.20 F-04 & $1.12 \mathrm{E}+02$ & $192 \mathrm{E}-01$ & $3.20 \mathrm{E}-04$ & ale \\
\hline$r_{h}-228$ & $3.63 F-13$ & $1.23 F-44$ & $4.19 E-76$ & $3.63 E-13$ & $1.23 \mathrm{E}-44$ & $4.49 \mathrm{E}-76$ & Extern. \\
\hline Th-229 & $1.06 \mathrm{E}+03$ & $1.04 \mathrm{E}+03$ & $1.02 E+03$ & $1.06 E+03$ & $1.04 \mathrm{E}+03$ & $1.02 \mathrm{E}+03$ & Intale \\
\hline$I h-230$ & $2.23 \mathrm{E}+02$ & $4.53 F+02$ & $6.64 E+02$ & $2.23 \mathrm{E}+02$ & $4.53 \mathrm{E}+02$ & $6.64 E+02$ & Extern \\
\hline Ih -232 & $430 \mathrm{E}+03$ & $4.30 \mathrm{E}+03$ & $4.30 E+03$ & $4.30 E+03$ & $4.30 \mathrm{E}+03$ & $4.30 \mathrm{E}+03$ & Extero \\
\hline Pa-231 & $3.29 E+03$ & $3.39 \mathrm{~F}+03$ & $3,37 \mathrm{E}+03$ & $3.20 E+03$ & $3.39 F+03$ & $3.38 \mathrm{~F}+\mathrm{n3}$ & Inhale \\
\hline $11-232$ & $1.01 \mathrm{E}+03$ & $1.48 \mathrm{~F}+02$ & $2.15 E+101$ & $102 E+03$ & $148 E+02$ & $2.16 \mathrm{E}+01$ & Extern \\
\hline $11-233$ & $6,24 \mathrm{E}+01$ & $8.22 \mathrm{E}+01$ & $1.02 \mathrm{E}+02$ & $6.345+01$ & $8.32 E+01$ & $1.03 \mathrm{E}+02$ & Inbale \\
\hline $11-234$ & $5.15 \mathrm{E}+01$ & $5.15 \mathrm{E}+01$ & $5.14 E+01$ & $5.25 \mathrm{E}+01$ & $5.25 \mathrm{E}+01$ & $5.25 \mathrm{E}+01$ & Inhale \\
\hline $11-235$ & $1.66 \mathrm{E}+02$ & $1.80 \mathrm{E}+02$ & $1.95 E+0 ?$ & $1,70 \mathrm{E}+02$ & $1.84 \mathrm{~F}+02$ & 1.98. $\mathrm{E}+\mathrm{OO2}$ & Extern \\
\hline $11-236$ & $4.81 E+01$ & $4.811 E+01$ & $4.81 E+01$ & $4.91 E+01$ & $4.91 E+01$ & $4.91 E+01$ & Inhale \\
\hline $11-238$ & $8.01 E+04$ & $8.01 \mathrm{E}+01$ & $8.01 E+01$ & $8.18 E+01$ & $8.18 E+01$ & 8. $18-F+01$ & bale \\
\hline$y p=237$ & $6.49 \mathrm{E}+02$ & $6.49 \mathrm{E}+02$ & $6.49 \mathrm{~F}+02$ & $6.87 \mathrm{~F}+02$ & $6.87 \mathrm{~F}+02$ & $6.87 E+02$ & Extern \\
\hline Pu-238 & $988 \mathrm{~F}+01$ & $2,04 \mathrm{E}+01$ & $4.21= \pm 00$ & $2.89 E+01$ & $2.04 E+01$ & $4.21 \mathrm{E}+00$ & Inbale \\
\hline P11-230 & $2.44 \mathrm{E}+02$ & $2.42 \mathrm{E}+02$ & $2,41 E+02$ & $2.44 E+02$ & $2,42 E+02$ & $261 \mathrm{E}+02$ & Inbale \\
\hline$P_{4-240}$ & $2.42 \mathrm{E}+02$ & $2.37 \mathrm{E}+02$ & $2.32 \mathrm{E}+02$ & $2,42 E+02$ & $2.37 \mathrm{E}+02$ & $232 \mathrm{E}+02$ & Inhale \\
\hline Pu-241 & $7.65 \mathrm{E}+00$ & $5.57 \mathrm{E}+00$ & $4.05=+00$ & $7.65 E+00$ & $5.57 \mathrm{E}+00$ & 4. $05 \mathrm{E}+00$ & Inbale \\
\hline $\mathrm{Pu}=242$ & $2.311 E+02$ & $2.31 E+02$ & $2.31 E+02$ & $2.31 E+02$ & $231 \mathrm{E}+02$ & $2,31 \mathrm{~F}+02$ & Inhale \\
\hline$P_{\omega-244}$ & $7.64 E+02$ & $7.69 \mathrm{E}+02$ & $7.73 \mathrm{~F}+02$ & $7.64 E+02$ & $7.69 \mathrm{E}+02$ & $7.74 \mathrm{E}+02$ & Extera \\
\hline$A m=241$ & $2.23 \mathrm{~F}+02$ & $1.62 \mathrm{E}+02$ & $1.17 \mathrm{E}+02$ & $2.23 E+02$ & $1.62 \mathrm{E}+02$ & $1.17 E+02$ & Inbale \\
\hline$A m-242 m$ & $2.48 \mathrm{E}+02$ & $138 E+02$ & $6.315+01$ & $2.48 E+02$ & $1.38 E+02$ & $6.315+01$ & Inhale \\
\hline$A m-243$ & $4.57 \mathrm{E}+02$ & $4.50 \mathrm{E}+02$ & $4.43 F+02$ & 4. $57, E+02$ & $450 E+02$ & $4.43 E+02$ & Extern \\
\hline $\mathrm{c}_{m}-263$ & $2.62 \mathrm{E}+01$ & $4.91 E-01$ & $2.90 \mathrm{E}-01$ & $2.62 E+01$ & $4.21=-01$ & $2.91 E-01$ & Externt \\
\hline $\mathrm{cm}_{\mathrm{m}}=244$ & $3,43, E+00$ & $6.56=-01$ & $6.41 E-01$ & $3.43 E+00$ & $6.56=-01$ & $6,41 E-01$ & Intale \\
\hline$c_{m}=245$ & $3.51 \mathrm{E}+02$ & $4.08 E+02$ & $4.47 E+02$ & $3.51 \mathrm{E}+02$ & $4.08 E+02$ & $4.47 \mathrm{E}+102$ & Inbale \\
\hline$C_{m}-246$ & $2.54 \mathrm{E}+02$ & $2.47 \mathrm{E}+02$ & $2,40 \mathrm{E}+02$ & $254 E+02$ & $2.478+02$ & $2.40 \mathrm{E}+02$ & Inhale \\
\hline $\mathrm{cm}-267$ & 8.31 $\mathrm{E}+\mathrm{O} 2$ & $8.37 \mathrm{E}+02$ & $8.42 E+02$ & $8.31 E+02$ & $8.37 \mathrm{E}+02$ & $8.42 \mathrm{~F}+02$ & Extern \\
\hline $\mathrm{Cm}_{\mathrm{m}}-24 \mathrm{~B}$ & $2.11 \mathrm{E}+02$ & $2,10-\mathrm{E}+02$ & $2.10 \mathrm{E}+02$ & $911 \mathrm{E}+02$ & Q.10 E+02 & $9.10 \mathrm{E}+02$ & \\
\hline
\end{tabular}

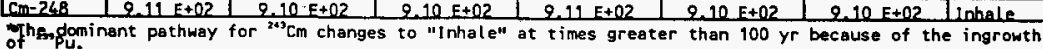


WHC-SD-WM-TI-730, REV 0

Table 4-5. Comparison of Dose to the Intruder by Exposure Pathway at 300-Years Post-Closure (mrem/Ci exhumed from the disposal facility).

(2 sheets)

\begin{tabular}{|c|c|c|c|c|c|c|c|}
\hline Nuclide & Inhale & Extern & Soil Ing & Root Up & Rain Sp & $\begin{array}{c}\text { Case } \\
\text { Totals } \\
\end{array}$ & $\begin{array}{l}\text { Maximum } \\
\text { Pathway }\end{array}$ \\
\hline $\mathrm{H}-3$ & $1.0 \mathrm{E}-17$ & $9.1 \mathrm{E}-21$ & $8.2 \mathrm{E}-16$ & $0.0 E+00$ & $2.0 \mathrm{E}-17$ & 8.47 E-16 & Soil Ing \\
\hline $\mathrm{Be}-10$ & $2.8 E-01$ & $5.7 \mathrm{E}-01$ & $2.7 \mathrm{E}-01$ & $8.9 \mathrm{E}-02$ & $5.1 E-03$ & $1.21 E+00$ & Extern \\
\hline$C-14$ & $1.5 \mathrm{E}-03$ & $8.8 E-03$ & $1.2 \mathrm{E}-01$ & $1.3 E+01$ & $2.3 \mathrm{E}-03$ & $1.36 \mathrm{E}+01$ & eggie \\
\hline$C 1-36$ & $1.4 \mathrm{E}-02$ & $9.5 \mathrm{E}-01$ & $1.7 \mathrm{E}-01$ & $1.9 E+03$ & $3.3 E-03$ & $1.91 \mathrm{E}+03$ & eggie \\
\hline$k-40$ & $9.4 E-03$ & $6.2 E+02$ & $1.2 E+00$ & $1.1 E+02$ & $.2 .3 E-02$ & $7.34 E+02$ & xtern \\
\hline $\mathrm{Co}-60$ & $3.1 \quad E-30$ & $2.5 \mathrm{E}-25$ & $4.4 \quad E-29$ & $2.3 E-28$ & $8.5 E-31$ & $2.55 \mathrm{E}-25$ & ixtern \\
\hline$i-59$ & $1.0 \mathrm{E}-03$ & $1.7 \mathrm{E}-01$ & $1.3 \mathrm{E}-02$ & $1.5 E-01$ & $2.4 E-04$ & $3.37 \mathrm{E}-01$ & tern \\
\hline$i-63$ & $7.5 \mathrm{E}-05$ & $7.8 \mathrm{E}-06$ & $1.1 E-03$ & $1.3 \mathrm{E}-02$ & $2.1 E-05$ & $1.41 \mathrm{E}-02$ & eggie \\
\hline Se-79 & $7.0 \mathrm{E}-03$ & $6.9 E-03$ & $5.3 E-01$ & $2.1 E+00$ & $1.0 \mathrm{E}-02$ & $2.62 \mathrm{E}+00$ & eggie \\
\hline$S r-90$ & $1.0 E-06$ & $1.4 E-04$ & $4.8 E-05$ & $5.0 \mathrm{E}-03$ & $9.1 \mathrm{E}-07$ & $5.22 \mathrm{E}-03$ & eggie \\
\hline $2 r-93$ & $2.8 \mathrm{E}-01$ & $6.9 E-02$ & $1.4 \mathrm{E}-01$ & $4.2 \quad E-02$ & $2.6 \mathrm{E}-03$ & $5.29 \mathrm{E}-01$ & Inhale \\
\hline $\mathrm{Nb}-93 \mathrm{~m}$ & $1.1 \mathrm{E}-12$ & $3.3 E-12$ & $1.6 \mathrm{E}-12$ & $1.6 \mathrm{E}-12$ & $3.1 E-14$ & $7.60 \mathrm{E}-12$ & tern \\
\hline $\mathrm{Nb}-94$ & $2.6 \mathrm{E}-01$ & $6.0 E+03$ & $3.2 \mathrm{E}-01$ & $3.1 \mathrm{E}-01$ & $6.1 E-03$ & $5.96 E+03$ & tern \\
\hline $0-93$ & $4.0 E-02$ & $3.5 \mathrm{E}-01$ & $1.1 E-01$ & $8.8 \mathrm{E}-01$ & $2.0 \mathrm{E}-03$ & $1.38 E+00$ & Veggie \\
\hline Tc-99 & $2.8 E-03$ & $3.0 \mathrm{E}-02$ & $3.9 E-02$ & $3.5 E+01$ & $9.6 \mathrm{E}-04$ & $3.46 \mathrm{E}+01$ & Veggie \\
\hline$P d-107$ & $1.0 E-02$ & $5.4 \mathrm{E}-06$ & $9.0 \mathrm{E}-03$ & $6.7 \mathrm{E}-02$ & $1.7 \mathrm{E}-04$ & $8.66 \mathrm{E}-02$ & ggie \\
\hline $\mathrm{Cd}-113 \mathrm{~m}$ & $1.1 E-11$ & $5.6 \mathrm{E}-12$ & $9.7 E-11$ & $2.7 \mathrm{E}-09$ & $1.8 E-12$ & $2.84 \mathrm{E}-09$ & \\
\hline $5 n-121 m$ & $1.3 \mathrm{E}-05$ & $1.2 \mathrm{E}-02$ & $2.3 E-04$ & $2.8 \mathrm{E}-04$ & $4.4 \mathrm{E}-06$ & $1.28 \mathrm{E}-02$ & Extern \\
\hline $5 n-126$ & $6.0 \mathrm{E}-02$ & $8.5 E+03$ & $1.2 E+00$ & $1.4 E+00$ & $2.2 \mathrm{E}-02$ & $8.51 \quad E+03$ & tern \\
\hline $\mathrm{I}-129$ & $1.1 E-01$ & $5.7 \mathrm{E}+00$ & $1.4 E+01$ & $1.1 E+02$ & $3.0 \mathrm{E}-01$ & $1.33 \mathrm{E}+02$ & \\
\hline Cs-135 & $3.6 \mathrm{E}-03$ & $1.9 \mathrm{E}-02$ & $4.6 \quad E-01$ & $7.6 E+00$ & $8.6 \mathrm{E}-03$ & $8.12 E+00$ & Veggie \\
\hline Cs-137 & $2.6 \quad E-07$ & $2.4 \mathrm{E}-02$ & $3.3 \mathrm{E}-05$ & $5.5 E-04$ & $6.2 \mathrm{E}-07$ & $2.46 \mathrm{E}-02$ & Extern \\
\hline $\mathrm{Ba}-133$ & $2.4 \mathrm{E}-17$ & $6.4 \mathrm{E}-12$ & $9.2 \mathrm{E}-16$ & $3.6 E-15$ & $1.8 \mathrm{E}-17$ & $6.39 \mathrm{E}-12$ & tern \\
\hline Sm-147 & $5.7 E+01$ & $0.0 E+00$ & $1.2 \mathrm{E}+01$ & $8.0 E+00$ & $2.2 \mathrm{E}-01$ & $7.64 \mathrm{E}+01$ & hale \\
\hline$S m-151$ & $4.9 E-04$ & $5.4 \mathrm{E}-05$ & $4.7 \mathrm{E}-04$ & $3.2 \mathrm{E}-04$ & $8.8 \mathrm{E}-06$ & $1.34 \mathrm{E}-03$ & Thale \\
\hline Eu-150 & $1.4 E-05$ & $4.3 \mathrm{E}-01$ & $2.6 \mathrm{E}-05$ & $1.8 E-05$ & $4.9 \mathrm{E}-07$ & $4.28 \mathrm{E}-01$ & Extern \\
\hline $\mathrm{Eu}-152$ & $1.5 \mathrm{E}-12$ & $3.9 E-08$ & $3.2 \mathrm{E}-12$ & $2.2 E-12$ & $6.2 E-14$ & $3.90 \mathrm{E}-08$ & xtern \\
\hline Eu-154 & $1.6 \mathrm{E}-18$ & $3.7 \mathrm{E}-14$ & $4.5 \quad E-18$ & $3.1 E-18$ & $8.5 E-20$ & $3.68 \quad E-14$ & tern \\
\hline Gd-152 & $1.9 E+02$ & $0.0 E+00$ & $9.7 E+00$ & $6.7 E+00$ & $1.8 \mathrm{E}-01$ & $2.08 E+02$ & Inhale \\
\hline $\mathrm{Re}-187$ & $3.8 E-05$ & $0.0 E+00$ & $5.3 \mathrm{E}-04$ & $3.6 \mathrm{E}-02$ & $1.0 \quad E-05$ & $3.62 \mathrm{E}-02$ & $\begin{array}{l}\text { Veggie } \\
\end{array}$ \\
\hline $\mathrm{Pb}-210$ & $2.9 E-06$ & $8.6 E-07$ & $7.4 \mathrm{E}-05$ & $6.0 \mathrm{E}-05$ & $1.4 \quad E-06$ & $1.39 \mathrm{E}-04$ & Soil Ing \\
\hline$B i-207$ & $3.4 \mathrm{E}-07$ & $2.0 \mathrm{E}-01$ & $9.8 \mathrm{E}-06$ & $1.1 E-05$ & $1.8 \mathrm{E}-07$ & $1.98 \mathrm{E}-01$ & Extern \\
\hline Po-209 & $2.7 \mathrm{E}-01$ & $3.9 E-01$ & $4.3 E+00$ & $3.9 \mathrm{E}+00$ & $8.1 E-02$ & $8.97 E+00$ & Soil Ing \\
\hline $\mathrm{Ra}-226$ & $1.9 \mathrm{E}+01$ & $5.9 E+03$ & $4.1 \quad E+02$ & $3.7 \mathrm{E}+02$ & $7.8 E+00$ & $6.69 E+03$ & xtern \\
\hline $\mathrm{Ra}-228$ & $2.4 E-24$ & $8.5 \mathrm{E}-23$ & $9.5 E-25$ & $7.7 E-25$ & $1.8 \mathrm{E}-26$ & $8.91 \quad E-23$ & Extern \\
\hline$A C-227$ & $6.4 \mathrm{E}-04$ & $1.7 \mathrm{E}-04$ & $1.1 E-04$ & $1.0 E-05$ & $2.2 \mathrm{E}-06$ & $9.39 \mathrm{E}-04$ & Inhale \\
\hline Th-228 & $4.5 \mathrm{E}-77$ & $1.1 \mathrm{E}-75$ & $8.7 \mathrm{E}-78$ & $8.5 E-79$ & $1.8 E-79$ & $1.20 \mathrm{E}-75$ & Extern \\
\hline Th-229 & 1. $5 \mathrm{E}+03$ & $1.1 E+03$ & $2.4 E+02$ & $2.2 E+01$ & $4.5 E+00$ & $2.92 E+03$ & Inhale \\
\hline Th-230 & $2.6 E+02$ & $1.4 E+03$ & $1.3 E+02$ & $8.7 E+01$ & $2.4 E+00$ & $1.90 E+03$ & Extern \\
\hline
\end{tabular}


Table 4-5. Comparison of Dose to the Intruder by Exposure Pathway at 300-Years Post-Closure (mrem/Ci exhumed from the disposal facility).

(2 sheets)

\begin{tabular}{|c|c|c|c|c|c|c|c|}
\hline ide & nhale & Extern & oil Ing & Root Up & Rain Sp & $\begin{array}{c}\text { Case } \\
\text { Totals }\end{array}$ & athway \\
\hline $1-232$ & $1.5 E+03$ & $1.0 E+04$ & $3.1 E+02$ & $1.3 E+02$ & $5.8 E+00$ & $1.23 E+04$ & \\
\hline & $6.3 E+03$ & $1.5 \mathrm{E}+03$ & $1.6 \mathrm{E}+03$ & $1.3 E+02$ & $3.1 \mathrm{E}+01$ & $9.64 \mathrm{E}+03$ & \\
\hline 232 & $.3 E+00$ & $.3 E+01$ & $1.1 E+00$ & 1.2 E+00 & $2.0 \mathrm{E}-02$ & $5.16 E+01$ & \\
\hline 233 & $1.8 E+02$ & $5.5 E+01$ & $2.9 E+01$ & $3.1 \mathrm{E}+01$ & $5.4 \mathrm{E}-01$ & $2.90 \mathrm{E}+02$ & \\
\hline 234 & $1.0 E+02$ & $2.4 E-01$ & $1.6 E+01$ & $2.9 E+01$ & $.1 \mathrm{E}-01$ & $1.47 \mathrm{E}+02$ & \\
\hline 235 & $1.6 E+02$ & $3.4 E+02$ & $3.3 \mathrm{E}+01$ & $2.9 E+01$ & $6.2 \mathrm{E}-01$ & $5.56 \mathrm{E}+02$ & \\
\hline-236 & $.4 E+01$ & $1.3 E-01$ & $1.6 E+01$ & $2.8 \mathrm{E}+01$ & $3.0 \mathrm{E}-01$ & $1.37 \mathrm{E}+02$ & $17 e$ \\
\hline-238 & $.4 E+01$ & $9.3 E+01$ & $1.5 E+01$ & $2.7 \mathrm{E}+01$ & $2.9 E-01$ & $2.29 E+02$ & \\
\hline $\mathrm{Np}-237$ & $3.7 E+02$ & $8.7 E+02$ & $2.4 E+02$ & $3.7 E+02$ & $4.6 E+00$ & $1.85 E+03$ & \\
\hline $\mathrm{Pu}-238$ & $7.1 E+00$ & $1.7 \mathrm{E}-03$ & $4.7 E+00$ & $1.3 \mathrm{E}-01$ & $8.9 \mathrm{E}-02$ & $1.20 E+01$ & \\
\hline $4-239$ & $4.0 E+02$ & $1.4 \mathrm{E}-01$ & $2.8 E+02$ & $7.0 \mathrm{E}+00$ & $5.2 E+00$ & $6.88 E+02$ & \\
\hline & $3.9 E+02$ & $9.0 \mathrm{E}-02$ & $2.6 \mathrm{E}+02$ & $6.8 E+00$ & $5.0 E+00$ & $6.62 E+02$ & \\
\hline Pu-241 & $6.4 \mathrm{E}+00$ & $2.9 \mathrm{E}-01$ & $4.5 \mathrm{E}+00$ & $2.6 \mathrm{E}-01$ & $8.5 \quad E-02$ & $1.16 \mathrm{E}+01$ & le \\
\hline $\mathrm{Pu}-242$ & $3.8 E+02$ & $6.8 \mathrm{E}-02$ & $2.7 \mathrm{E}+02$ & $6.8 E+00$ & $5.0 E+00$ & $6.60 \mathrm{E}+02$ & \\
\hline $1-244$ & $4.0 E+02$ & $1.5 E+03$ & $2.7 E+02$ & $7.0 E+00$ & $5.1 E+00$ & $2.21 \mathrm{E}+03$ & \\
\hline $\mathrm{Am}-241$ & $1.9 E+02$ & $8.5 E+00$ & ].3 E+02 & $7.6 \mathrm{E}+00$ & $2.5 E+00$ & $3.35 \mathrm{E}+02$ & le \\
\hline$A m-242 m$ & $1.0 \mathrm{E}+02$ & $4.9 E+00$ & $6.8 E+01$ & $2.7 E+00$ & $1.3 E+00$ & $1.80 \mathrm{E}+02$ & $1]$ \\
\hline$n-243$ & $4.0 E+02$ & $5.6 E+02$ & $2.8 E+02$ & $1.6 \mathrm{E}+01$ & $5.3 E+00$ & $1.26 \mathrm{E}+03$ & \\
\hline$m-243$ & $4.8 \mathrm{E}-01$ & $7.3 \mathrm{E}-03$ & $3.3 E-01$ & $8.5 E-03$ & $6.2 \mathrm{E}-03$ & $8.30 \mathrm{E}-01$ & le \\
\hline $\mathrm{Cm}_{\mathrm{m}-244}$ & $1.1 E+00$ & $2.5 \mathrm{E}-04$ & $7.3 \mathrm{E}-01$ & $1.9 \mathrm{E}-02$ & $1.4 E-02$ & $1.83 E+00$ & le \\
\hline $\mathrm{Cm}-245$ & $6.4 E+02$ & $1.8 E+02$ & $4.4 E+02$ & $1.7 \mathrm{E}+01$ & $8.2 E+00$ & $1.28 E+03$ & $7 \mathrm{e}$ \\
\hline $\mathrm{Cm}-246$ & $4.0 \mathrm{E}+02$ & $5.1 E-02$ & $2.7 E+02$ & $7.3 \mathrm{E}+00$ & $5.1 E+00$ & $6.85 \mathrm{E}+02$ & le \\
\hline $\mathrm{Cm}-247$ & $4.0 \mathrm{E}+02$ & $1.7 E+03$ & $2.7 E+02$ & $7.4 \mathrm{E}+00$ & $5.2 \mathrm{E}+00$ & $2.41 \mathrm{E}+03$ & ern \\
\hline $\mathrm{Cm}-248$ & $1.5 E+03$ & $5.0 E-02$ & $1.0 E+03$ & $2.8 \mathrm{E}+01$ & $1.9 E+01$ & $2.60 \mathrm{E}+03$ & Inhale \\
\hline
\end{tabular}

NOTE: The above values must be multiplied by the volume of waste exhumed. 
Table 4-6. Comparison of Total Dose Ratios Under Leaching Conditions Using Two Databases.

\begin{tabular}{|l|c|c|}
\hline \multirow{2}{*}{ Nuclide } & \multicolumn{2}{|c|}{$\begin{array}{c}\text { Kennedy and Strenge (1992)/ } \\
\text { Baes et al. (1984b) }\end{array}$} \\
\hline & Intruder & Al1 path \\
\hline $\mathrm{Cl-36}$ & 1.30 & 1.24 \\
\hline $\mathrm{Ni}-63$ & 1.24 & \\
\hline $\mathrm{Sr}-90$ & 1.57 & \\
\hline $\mathrm{Tc}-99$ & 1.41 & 1.28 \\
\hline $\mathrm{I}-129$ & 0.72 & \\
\hline $\mathrm{Cs}-135$ & 2.82 & \\
\hline $\mathrm{Pb}-210$ & 0.65 & \\
\hline $\mathrm{Po}-209$ & 1.65 & \\
\hline $\mathrm{U}-233$ & & \\
\hline $\mathrm{U}-234$ & 1.11 & \\
\hline $\mathrm{U}-236$ & 1.12 & \\
\hline $\mathrm{Np}-237$ & 0.84 & \\
\hline
\end{tabular}

NOTE: Doses for radionuclides with differences of less than $10 \%$ are not shown. 
WHC-SD-WM-TI-730, REV 0

Table 4-7. Ratio of Total Doses: NonLeaching and Leaching.

\begin{tabular}{|l|c|c|c|c|}
\hline \multirow{2}{*}{ Nuclide } & \multicolumn{2}{|c|}{$\begin{array}{c}\text { NUREG/CR-5512 } \\
\text { transfer factors }\end{array}$} & \multicolumn{2}{c|}{$\begin{array}{c}\text { ORNL-5786 transfer } \\
\text { factors }\end{array}$} \\
\cline { 2 - 5 } & Intruder & A11 pathways & Intruder & All pathways \\
\hline $\mathrm{H}-3$ & 2.68 & & 2.68 & \\
\hline $\mathrm{Cl}-36$ & & & 1.42 & 1.35 \\
\hline $\mathrm{TC}-99$ & 1.65 & 1.22 & & \\
\hline $\mathrm{I}-129$ & 1.17 & & & \\
\hline
\end{tabular}

NOTE: Doses for radionuclides with differences of less than $10 \%$ are not shown.

Table 4-8. Relative Contributions (\%) to Ingestion Dose by Food Type.

\begin{tabular}{|l|r|r|r|r|}
\hline \multicolumn{1}{|c|}{ Radionuclide } & Leafy & Root & Fruit & Grain \\
\hline $\mathrm{C}-14$ & 4.5 & 39.8 & 19.1 & 36.6 \\
\hline $\mathrm{Cl}-36$ & 32.0 & 28.0 & 13.7 & 26.4 \\
\hline $\mathrm{Ni}$ & 21.2 & 40.4 & 19.2 & 19.2 \\
\hline $\mathrm{Se}-79$ & 4.5 & 40.9 & 18.2 & 36.4 \\
\hline $\mathrm{Sr}-90$ & 15.4 & 67.3 & 7.0 & 10.3 \\
\hline Mo-93 & 16.4 & 34.4 & 16.4 & 32.8 \\
\hline $\mathrm{Tc}-99$ & 16.8 & 36.4 & 24.3 & 22.4 \\
\hline $\mathrm{Pd}-107$ & 15.0 & 35.0 & 17.5 & 32.5 \\
\hline $\mathrm{Cd}-113 \mathrm{~m}$ & 14.6 & 35.1 & 17.2 & 33.1 \\
\hline $\mathrm{I}-129$ & 0.2 & 40.8 & 20.4 & 38.5 \\
\hline $\mathrm{Cs}-135$ & 7.4 & 25.0 & 54.4 & 13.2 \\
\hline Re-187 & 16.7 & 33.3 & 16.7 & 33.3 \\
\hline $\mathrm{Pb}-210$ & 3.8 & 19.2 & 38.5 & 38.5 \\
\hline $\mathrm{Po}-209$ & 17.5 & 52.5 & 12.3 & 17.5 \\
\hline
\end{tabular}


WHC-SD-WM-TI-730, REV 0

Table 4-9. Ratios of GENII and EPA Internal Dose Factors to DOE. Internal Dose Factors

\begin{tabular}{|c|c|c|c|c|}
\hline \multirow{2}{*}{ Nuclide } & \multicolumn{2}{|c|}{ Inhalation } & \multicolumn{2}{|c|}{ Ingestion } \\
\hline & GENI I & EPA & GENII & EPA \\
\hline $\mathrm{Be}-10$ & & & 1.11 & 1.11 \\
\hline $\mathrm{Co}-60$ & 1.34 & 1.46 & & \\
\hline $\mathrm{Se}-79$ & & 1.11 & & \\
\hline $5 r-90$ & 0.89 & & & \\
\hline $\mathrm{Nb}-94$ & 1.18 & 1.26 & 1.42 & 1.40 \\
\hline Tc-99 & 1.20 & 1.11 & 1.72 & 1.12 \\
\hline $\mathrm{Sn}-121 \mathrm{~m}$ & 1.27 & 1.28 & 1.12 & 1.13 \\
\hline$S n-126$ & 1.33 & 1.34 & 1.15 & 1.15 \\
\hline I-129 & 0.84 & & 0.89 & \\
\hline $\mathrm{Ba}-133$ & & 1.13 & & \\
\hline Sm-151 & & & 1.14 & 1.14 \\
\hline $\operatorname{Re}-187$ & 1.20 & 1.11 & 1.75 & 1.15 \\
\hline $\mathrm{Pb}-210$ & 1.11 & & & \\
\hline $\mathrm{Bi}-207$ & 1.21 & 1.43 & & 1.12 \\
\hline $\mathrm{P} 0-209$ & 1.20 & 1.16 & 1.20 & 1.19 \\
\hline $\mathrm{Ra}-226$ & & & 0.87 & 1.20 \\
\hline $\mathrm{Ra}-228$ & & 1.13 & 0.70 & 1.20 \\
\hline Th-228 & 1.11 & & 0.77 & \\
\hline $\mathrm{U}-238$ & & & 1.12 & \\
\hline Np-237 & 1.30 & & 1.35 & 1.14 \\
\hline $\mathrm{Pu}-238$ & 0.85 & 0.85 & 0.84 & 0.84 \\
\hline $\mathrm{Pu}-239$ & 0.85 & 0.84 & 0.83 & 0.82 \\
\hline Pu-240 & 0.85 & 0.84 & 0.83 & 0.82 \\
\hline $\mathrm{Pu}-241$ & 0.82 & 0.83 & 0.79 & 0.80 \\
\hline $\mathrm{Pu}-242$ & 0.84 & 0.86 & 0.81 & 0.82 \\
\hline $\mathrm{Pu}-244$ & 0.84 & 0.84 & 0.83 & 0.83 \\
\hline$A m-241$ & 0.85 & 0.85 & 0.81 & 0.81 \\
\hline$A m-242 m$ & 0.81 & 0.82 & 0.83 & 0.84 \\
\hline Am-243 & 0.85 & 0.85 & 0.81 & 0.80 \\
\hline $\mathrm{Cm}-243$ & 0.88 & 0.88 & 0.87 & 0.87 \\
\hline $\mathrm{Cm}-244$ & & & 0.87 & 0.88 \\
\hline $\mathrm{Cm}-245$ & 0.84 & 0.84 & 0.82 & 0.83 \\
\hline $\mathrm{Cm}-246$ & 0.84 & 0.84 & 0.83 & 0.82 \\
\hline $\mathrm{Cm}-247$ & 0.86 & 0.85 & 0.84 & 0.83 \\
\hline $\mathrm{Cm}-248$ & 0.86 & 0.87 & 0.84 & 0.85 \\
\hline
\end{tabular}

NOTE: Differences less than $10 \%$ are not shown. 
Table 4-10. Ratio of Pathway Doses for Kennedy and Strenge (1992) Versus Baes et al. (1984b) Parameters.

\begin{tabular}{|c|c|c|c|c|}
\hline Nuclide & Soil Ing & Root Up & Rain Sp & Totals \\
\hline $\mathrm{C} 1-36$ & 1.51 & 1.30 & 1.30 & 1.30 \\
\hline $\mathrm{Co}-60$ & & 4.13 & & \\
\hline $\mathrm{Ni}-59$ & & 1.27 & & \\
\hline $\mathrm{Ni}-63$ & & 1.27 & & 1.24 \\
\hline $\mathrm{Sr}-90$ & & 1.60 & & 1.57 \\
\hline Tc-99 & 0.55 & 1.41 & 0.67 & 1.41 \\
\hline $\mathrm{I}-129$ & 0.78 & 0.71 & 0.87 & 0.72 \\
\hline Cs -135 & & 3.19 & & 2.82 \\
\hline Cs-137 & & 3.19 & & \\
\hline $\mathrm{Pb}-210$ & & 0.44 & & 0.65 \\
\hline Po-209 & & 10.59 & & 1.65 \\
\hline $\mathrm{Ra}-226$ & & 0.55 & & \\
\hline $\mathrm{Ra}-228$ & & 3.78 & & \\
\hline Th-228 & & 4.15 & & \\
\hline Th-229 & & 4.15 & & \\
\hline Th- 230 & & 0.60 & & \\
\hline$T h-232$ & & 3.82 & & \\
\hline$U-232$ & & 2.57 & & \\
\hline$U-233$ & & 2.56 & & \\
\hline$U-234$ & & 2.54 & & 1.11 \\
\hline$U-235$ & & 2.44 & & \\
\hline$U-236$ & & 2.54 & & 1.12 \\
\hline $\mathrm{U}-238$ & & 2.54 & & \\
\hline $\mathrm{Np}-237$ & & 0.58 & & 0.84 \\
\hline $\mathrm{Pu}-238$ & & 2.23 & & \\
\hline$P u-239$ & & 2.22 & & \\
\hline $\mathrm{Pu}-240$ & & 2.22 & & \\
\hline $\mathrm{Pu}-241$ & & 0.59 & & \\
\hline $\mathrm{Pu}-242$ & & 2.22 & & \\
\hline $\mathrm{Pu}-244$ & & 2.22 & & \\
\hline $\mathrm{Am}-241$ & & 0.59 & & \\
\hline$A m-242 m$ & & 0.77 & & \\
\hline$A m-243$ & & 0.59 & & \\
\hline $\mathrm{Cm}-243$ & & 2.17 & & \\
\hline $\mathrm{Cm}-244$ & & 2.22 & & \\
\hline $\mathrm{Cm}-246$ & & 2.30 & & \\
\hline $\mathrm{Cm}-247$ & & 2.30 & & \\
\hline $\mathrm{Cm}-248$ & & 2.30 & & \\
\hline
\end{tabular}


Table 4-10. Ratio of Pathway Doses for Kennedy and Strenge (1992) Versus Baes et a1. (1984b) Parameters.

\begin{tabular}{|l|l|l|l|l|} 
Nuclide & Soil Ing & Root Up & Rain Sp & Totals
\end{tabular}
NOTE: Values of less than $10 \%$ are not shown. Ratios are obtained by dividing Kennedy and Strenge (1992) doses by the Baes et al. (1984b) doses. Intruder Garden scenario doses at $300 \mathrm{yr}$ are used. Soil leaching is included. 
Tabie 4-11. Base-Case Conditions for 200 East Area LLBG Analyses.

\begin{tabular}{|c|c|c|c|c|}
\hline Run & $\begin{array}{c}\text { Recharge } \\
(\mathrm{cm} / \mathrm{yr})\end{array}$ & $K_{d}$ & Type of Release & Features \\
\hline $1 \mathrm{a}$ & 5 & 0 & Advection dominated & Base case 1 \\
\hline $1 \mathrm{~b}$ & 5 & 1 & Advection dominated & \\
\hline 1c & 5 & 10 & Advection dominated & \\
\hline $1 a-c c$ & 5 & 0 & Constant concentration & \\
\hline $2 a$ & 0.5 & 0 & Advection dominated & Base case 2 \\
\hline $2 b$ & 0.5 & 1 & Advection dominated & \\
\hline $2 c$ & 0.5 & 10 & Advection dominated & \\
\hline $2 a-c c$ & 0.5 & 0 & Constant concentration & \\
\hline ld & 5 & 0 & Advection dominated & Trench length $=40 \mathrm{~m}$ \\
\hline le & 5 & 0 & Advection dominated & Trench Tength $=80 \mathrm{~m}$ \\
\hline lg & 5 & 0 & Advection dominated & Hot spot \\
\hline li & 5 & 0 & Diffusion & $10^{-8} \mathrm{~cm}^{2} / \mathrm{s}$ \\
\hline $1 j$ & 5 & 0 & Diffusion & $10^{-10} \mathrm{~cm}^{2} / \mathrm{s}$ \\
\hline $1 \mathrm{k}$ & 5 & 0 & Diffusion & $10^{-12} \mathrm{~cm}^{2} / \mathrm{s}$ \\
\hline $2 i$ & 0.5 & 0 & Diffusion & $10^{-8} \mathrm{~cm}^{2} / \mathrm{s}$ \\
\hline $2 j$ & 0.5 & 0 & Diffusion & $10^{-10} \mathrm{~cm}^{2} / \mathrm{s}$ \\
\hline $2 k$ & 0.5 & 0 & Diffusion & $10^{-12} \mathrm{~cm}^{2} / \mathrm{s}$ \\
\hline $3 a-c c$ & 0.5 & 0 & Constant concentration & E12Bsub $50 \mathrm{ft}$ depth \\
\hline $3 b-c c$ & 0.5 & 1 & constant concentration & El2Bsub $50 \mathrm{ft}$ depth \\
\hline $3 c-c c$ & 0.5 & 10 & constant concentration & El2Bsub $50 \mathrm{ft}$ depth \\
\hline $3 d-c c$ & 0.5 & 0 & constant concentration & El2Bsub trench length $=40 \mathrm{~m}$ \\
\hline $4 a$ & 5 & 0 & Advection dominated & El0 base case 3 \\
\hline $4 a-c c$ & 5 & 0 & constant concentration & Elo materials \\
\hline $5 a$ & 0.5 & 0 & Advection dominated & E10 base case 4 \\
\hline $5 a-c c$ & 0.5 & 0 & constant concentration & El0 materials \\
\hline
\end{tabular}


WHC-SD-WM-TI-730, REV 0

Table 4-12. Summary of Modeling Results for 200 East Area LLBG.

\begin{tabular}{|c|c|c|c|c|}
\hline \multirow{2}{*}{ Run } & \multirow{2}{*}{ Site } & \multicolumn{2}{|c|}{ Year } & \multirow{2}{*}{$\begin{array}{l}\text { Peak Average } \\
\text { Concentration }\end{array}$} \\
\hline & & Peak & 95\% Peak & \\
\hline la & \multirow[t]{17}{*}{ E12B } & 86 & & $7.34 E-4$ \\
\hline $1 b$ & & 2,130 & & $2.46 \mathrm{E}-5$ \\
\hline lc & & 20,800 & & $2.53 \mathrm{E}-6$ \\
\hline $1 a-c c$ & & 295 & 162 & $4.72 E-2$ \\
\hline $2 a$ & & 614 & & $1.20 \mathrm{E}-4$ \\
\hline $2 \mathrm{~b}$ & & 19,625 & & $3.19 \mathrm{E}-6$ \\
\hline $2 c$ & & 189,000 & & $3.26 \mathrm{E}-7$ \\
\hline $2 a-c c$ & & 2,120 & 1,080 & $5.98 E-3$ \\
\hline Id & & 87 & & $7.10 \mathrm{E}-4$ \\
\hline le & & 89 & & $6.76 \mathrm{E}-4$ \\
\hline $1 \mathrm{~g}$ & & 86 & & $7.24 E-4$ \\
\hline $1 i$ & & 100 & & $2.73 \mathrm{E}-4$ \\
\hline $1 j$ & & 98 & & $3.10 E-5$ \\
\hline $1 \mathrm{k}$ & & 95 & & $3.11 E-6$ \\
\hline $2 i$ & & 630 & & $1.07 \mathrm{E}-4$ \\
\hline $2 j$ & & 712 & & $1.26 \mathrm{E}-5$ \\
\hline $2 k$ & & 718 & & $1.25 \mathrm{E}-6$ \\
\hline $3 a-c c$ & \multirow[t]{4}{*}{ E12BS } & 2,030 & 930 & $5.99 \mathrm{E}-3$ \\
\hline $3 b-c c$ & & 85,200 & 38,300 & $5.99 E-3$ \\
\hline $3 c-c c$ & & 834,000 & 375,000 & $5.99 \mathrm{E}-3$ \\
\hline $3 d-c c$ & & 1,970 & 940 & $1.20 \mathrm{E}-2$ \\
\hline $4 a$ & \multirow[t]{4}{*}{ E10 } & 129 & & $2.57 \mathrm{E}-4$ \\
\hline $4 a-c c$ & & 434 & 252 & $2.81 \mathrm{E}-2$ \\
\hline $5 a$ & & 1,022 & & $3.64 \mathrm{E}-5$ \\
\hline $5 a-c c$ & & 3,940 & 1,980 & $3.22 \mathrm{E}-3$ \\
\hline
\end{tabular}


Table 4-13. Radionuclides that Decay to Insignificant Quantities Before Entry into the Unconfined Aquifer.

\begin{tabular}{|c|c|c|c|c|c|}
\hline Radionuclide & $\mathrm{Kd}$ & $\begin{array}{l}\text { Time of } \\
\text { Peak (Yr) }\end{array}$ & $\begin{array}{c}\text { Half Life } \\
\left(Y_{r}\right)\end{array}$ & $\begin{array}{l}\text { Dilution } \\
\text { Factor }\end{array}$ & $\begin{array}{c}\text { Activity } \\
\text { Reductign } \\
\text { Factor }\end{array}$ \\
\hline $\begin{array}{l}\leq 5 \text {-yrhalf } \\
\text { life }\end{array}$ & 0 & $100^{a}$ & $\leq 5$ & $6.6 \times 10^{-12}$ & $1.1 \times 10^{6}$ \\
\hline${ }^{60}{ }^{62} \mathrm{O} \mathrm{Ra}^{154}{ }^{154} \mathrm{E}$, & $>1$ & $\sim 500$ & $\leq 10$ & $3.6 \times 10^{-23}$ & $1.1 \times 10^{35}$ \\
\hline${ }^{90} \mathrm{Sr},{ }^{137} \mathrm{Cs}$ & $>10$ & $\sim 4,000$ & -30 & $1.5 \times 10^{-49}$ & $1.35 \times 10^{40}$ \\
\hline${ }^{63} \mathrm{Ni} \mathrm{Pu}_{\mathrm{Pu}}{ }^{151} \mathrm{Sm}$, & $>10$ & $\sim 4,000$ & $\leq 100$ & $1.8 \times 10^{-21}$ & $1.1 \times 10^{12}$ \\
\hline${ }^{241} \mathrm{Am}^{\mathrm{b}}$ & $>100$ & $-40,000$ & 432 & $7.5 \times 10^{-37}$ & $7.4 \times 10^{27}$ \\
\hline
\end{tabular}

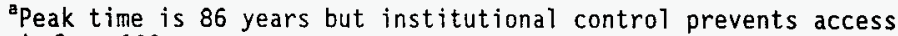
before 100 years

'These factors are estimated from the trend established by the $\mathrm{Kd}=1$ and $\mathrm{Kd}=10$ runs.

${ }^{c}$ The dilution factor is the ratio of the initial activity to the peak concentration.

dThe activity reduction factor is the ratio of the initial total activity to activity at the time of arrival at the water table.

Table 4-14. Radionuclide Dose Estimates for Groundwater Pathways.*

\begin{tabular}{|l|c|c|c|}
\hline Radionuclide & $\begin{array}{c}\text { Drinking Water Dose } \\
\text { (mrem/yr) }\end{array}$ & $\begin{array}{c}\text { All-Pathways } \\
\text { Dose (mrem/yr) }\end{array}$ & $\begin{array}{c}\text { Dose ratio } \\
\text { (Al1-Pathways/ } \\
\text { groundwater) }\end{array}$ \\
\hline${ }^{3} \mathrm{H}$ & 0.11 & 0.12 & 1.1 \\
\hline${ }^{14} \mathrm{C}$ & 1,100 & 2,400 & 2.2 \\
\hline${ }^{36} \mathrm{Cl}$ & 1,510 & 26,700 & 17 \\
\hline${ }^{79} \mathrm{Se}$ & 4,200 & 7,400 & 1.8 \\
\hline${ }^{99} \mathrm{TC}$ & 650 & 2,100 & 3.3 \\
\hline${ }^{129} \mathrm{I}$ & 141,000 & 292,000 & 1.8 \\
\hline${ }^{187} \mathrm{Re}$ & 4 & 6 & 1.5 \\
\hline${ }^{237} \mathrm{~Np}$ & $1,964,000$ & $2,216,000$ & 1.1 \\
\hline $\mathrm{U}$ & $1,209,000$ & $1,330,000$ & 1.1 \\
\hline
\end{tabular}

*These doses are from the base-case analys is assuming a $1-C i$ inventory per radionuclide and Category 1 infiltration conditions $(5 \mathrm{~cm} / \mathrm{yr})$. The values does not represent actual inventory projections and associated doses. 
Tab7e 4-15. Descriptive Statistics for van Genuchten Parameters $\theta_{s}, \theta_{r}, \alpha, n$, and Saturated Hydraulic Conductivity $K_{s}$ for Two Soil Categories.

\begin{tabular}{|c|c|c|c|c|c|c|c|}
\hline $\begin{array}{c}\text { Soil } \\
\text { Category }\end{array}$ & Parameter & $\begin{array}{l}\text { No. of } \\
\text { Samples }\end{array}$ & Low & High & Mean & $\begin{array}{l}\text { Standard } \\
\text { Deviation }\end{array}$ & $\begin{array}{c}\text { Coefficient } \\
\text { of } \\
\text { Variation } \\
(x)\end{array}$ \\
\hline \multirow[t]{5}{*}{$\mathbf{s}$} & $\theta_{3}$ & 76 & 0.197 & 0.519 & 0.346 & 0.073 & 21 \\
\hline & $\theta_{r}$ & 76 & 0 & 0.148 & 0.029 & 0.023 & 81 \\
\hline & $a(1 / \mathrm{cm})$ & 76 & 0.004 & 0.861 & 0.108 & 0.164 & 151 \\
\hline & $n$ & 76 & 1.193 & 4.914 & 2.111 & 0.817 & 39 \\
\hline & $K_{1}(\mathrm{~cm} / \mathrm{s})$ & 71 & $1.38 \mathrm{E}^{-6}$ & 0.058 & 0.006 & 0.011 & 190 \\
\hline \multirow[t]{5}{*}{ SG1 } & $\theta_{2}$ & 25 & 0.113 & 0.260 & 0.166 & 0.036 & 22 \\
\hline & $\theta_{r}$ & 25 & 0 & 0.062 & 0.023 & 0.015 & 65 \\
\hline & $a(1 / \mathrm{cm})$ & 25 & 0.002 & 0.919 & 0.083 & 0.204 & 247 \\
\hline & $n$ & 25 & 1.262 & 2.947 & 1.660 & 0.355 & 21 \\
\hline & $k_{1}(\mathrm{~cm} / \mathrm{s})$ & 24 & $1.9 \mathrm{E}^{-3}$ & 0.037 & 0.005 & 0.009 & 194 \\
\hline
\end{tabular}

Table 4-16. Van Genuchten Mode1 Parameters Describing the Unscaled Mean Hydraul ic Curve.

\begin{tabular}{|c|c|c|c|c|c|c|}
\hline $\begin{array}{c}\text { Soil } \\
\text { Category }\end{array}$ & $\alpha$ & $n$ & $\theta_{r}$ & $\theta_{s}$ & $r^{2}$ & $\begin{array}{c}\text { Sum of } \\
\text { Squares } \\
\text { (SS) }\end{array}$ \\
\hline S & 0.0626 & 1.5820 & 0.0295 & 0.3665 & 0.7381 & 5.4937 \\
\hline SG1 & 0.0594 & 1.2199 & 0.0000 & 0.1640 & 0.6343 & 0.4109 \\
\hline
\end{tabular}




\section{WHC-SD-WM-TI-730, REV 0}

Table 4-17. Computed Diffusive and Advective Fronts for Low-Recharge Scenarios.

\begin{tabular}{|c|c|c|c|c|}
\hline $\begin{array}{c}\text { Time, } \\
\text { yrs }\end{array}$ & $\begin{array}{c}\text { Advective } \\
\text { Distance } \\
\text { Traveled, } \\
\text { m for } \\
\begin{array}{c}q=0.005 \\
\mathrm{~cm} / \mathrm{yr}\end{array}\end{array}$ & $\begin{array}{c}\text { Diffusive } \\
\text { Distance, } \\
\text { m for } \\
\mathbf{q}=0.005 \\
\mathrm{~cm} / \mathrm{yr}\end{array}$ & $\begin{array}{c}\text { Advective } \\
\text { Distance } \\
\text { Traveled, } \\
\mathrm{m} \text { for } \\
\mathrm{q}=0.05 \\
\mathrm{~cm} / \mathrm{yr}\end{array}$ & $\begin{array}{c}\text { Diffusive } \\
\text { Distance, } \mathrm{m} \\
\text { for } \mathrm{q}=0.05 \\
\mathrm{~cm} / \mathrm{yr}\end{array}$ \\
\hline 1 & 0.00083 & 0.018 & 0.00625 & 0.025 \\
\hline 10 & 0.0083 & 0.056 & 0.0625 & 0.079 \\
\hline 100 & 0.083 & 0.178 & 0.625 & 0.251 \\
\hline 1,000 & 0.83 & 0.562 & 6.25 & 0.794 \\
\hline 2,000 & 1.67 & 0.794 & 12.5 & 1.123 \\
\hline
\end{tabular}


Table 4-18. Category 1 and 3 Concentration Limits Based on Intruder. Scenarios.

\begin{tabular}{|c|c|c|c|c|c|}
\hline \multirow{2}{*}{ Nucl ide } & \multicolumn{2}{|c|}{ Concentration Limits $\left(\mathrm{Ci} / \mathrm{m}^{3}\right)$} & \multirow{2}{*}{ Nuelide } & \multicolumn{2}{|c|}{ Concentration Limits $\left(\mathrm{Ci} / \mathrm{m}^{3}\right)$} \\
\hline & Category 1 & Category 3 & & Category 1 & Cotegory 3 \\
\hline $\mathrm{H}-3$ & $9.9 \mathrm{E}+04$ & NL & $\mathrm{Pa}-231$ & $1.4 \mathrm{E}-04$ & $3.0 \mathrm{E}-02$ \\
\hline Be-10 & $1.1 E+00$ & $2.4 E+02$ & $\mathrm{U}-232$ & $4.6 \mathrm{E}-04$ & $4.6 E+00$ \\
\hline$c-14$ & $9.1 \mathrm{E}-02$ & $2.1 \mathrm{E}+01$ & $\mathrm{U}-233^{\circ}$ & $7.4 E-03$ & 9.7 E-01 \\
\hline$c-14^{*}$ & $9.1 \mathrm{E}-01$ & $2.1 E+02$ & $U-234$ & $8.9 E-03$ & $1.9 E+00$ \\
\hline $\mathrm{cl}-36$ & $6.4 \mathrm{E}-0.05$ & 1.4 E-01 & $U-235$ & $2.8 \mathrm{E}-03$ & $5.0 \mathrm{E}-01$ \\
\hline$k-40$ & $1.8 E-03$ & $3.8 \mathrm{E}-01$ & $\mathrm{U}-236$ & $9.5 \mathrm{E}-03$ & $2.0 \mathrm{E}+00$ \\
\hline $\mathrm{CO}-60$ & $7.5 \mathrm{E}+01$ & NL & $U-238$ & $5.7 \mathrm{E}-03$ & $1.2 E+00$ \\
\hline $\mathrm{CO}-60^{\circ}$ & $7.5 E+02$ & NL & $\mathrm{Np}-237^{\circ}$ & $6.8 \mathrm{E}=04$ & $1.5 \mathrm{E}-01$ \\
\hline Ni-59 & $3.9 E+00$ & $8.5 E+02$ & Pu- $238^{\circ}$ & $4.7 \mathrm{E}-03$ & $2.4 E+01$ \\
\hline $\mathrm{Ni}-59^{\circ}$ & $3.9 \mathrm{E}+01$ & $8.5 E+03$ & Pu- $239^{\circ}$ & $1.9 \mathrm{E}-03$ & 4.2 E-01 \\
\hline $\mathrm{Hi}-63$ & $5.9 E+00$ & $2.0 \mathrm{E}+04$ & Pu-240 & $1.9 \mathrm{E}-03$ & $4.3 \mathrm{E}-01$ \\
\hline $\mathrm{Ni}-63^{2}$ & $5.9 \mathrm{E}+01$ & $2.0 E+05$ & $\mathrm{Pu}-241$ & 6.1 E-02 & $2.5 E+01$ \\
\hline $5 e-79$ & $5.1 \mathrm{E}-01$ & $1.1 E+02$ & Pu- $242^{\circ}$ & $2.0 \mathrm{E}-03$ & $4.3 \mathrm{E}-01$ \\
\hline $5 r-90$ & $1.6 \mathrm{E}-02$ & $5.4 \mathrm{E}+04$ & $P u=244^{\circ}$ & $6.1 \mathrm{E}-04$ & $1.3 \mathrm{E}-01$ \\
\hline $2 r-93$ & $2.5 \mathrm{E}+00$ & $5.4 E+02$ & Am- $241^{\circ}$ & $2.1 \mathrm{E}-03$ & $8.5 \mathrm{E}-01$ \\
\hline Hb- 94 & $2.2 E-04$ & $4.8 \mathrm{E}-02$ & $A m-242 m^{\circ}$ & $1.9 E-03$ & $1.6 \mathrm{E}+00$ \\
\hline $\mathrm{Nb}-94^{4}$ & 2.2 E-03 & $4.8 \mathrm{E}-01$ & $A m-243^{\circ}$ & $1.0 \mathrm{E}-03$ & 2.3 E-01 \\
\hline Mo. 93 & 8.7 E-01 & $2.0 \mathrm{E}+02$ & $\mathrm{Cm}-243^{\circ}$ & $1.8 \mathrm{E}-02$ & $3.4 \mathrm{E}+02$ \\
\hline Tc- 99 & $2.3 E-02$ & $5.0 \mathrm{E}+00$ & $\mathrm{Cm}-244^{\circ}$ & $1.4 \mathrm{E}-01$ & $1.6 E+02$ \\
\hline Pd- 107 & $1.5 E+01$ & $3.3 \varepsilon+03$ & $\mathrm{Cm}-245^{\circ}$ & $1.3 \mathrm{E}-03$ & $2.2 E-01$ \\
\hline $\mathrm{Cd}-113 \mathrm{~m}$ & 7.6 E-01 & NL. & $\mathrm{Cm}-246^{\circ}$ & $1.8 E-03$ & 4.2 E-01 \\
\hline $5 n-121 m$ & $6.7 \mathrm{E}-01$ & $2.2 \mathrm{E}+04$ & $\mathrm{Cm}-247^{\circ}$ & 5.6 E-04 & 1.2 E-01 \\
\hline $5 n-126$ & $1.6 E-04$ & $3.4 \mathrm{E}-02$ & $\mathrm{Cm}-248^{\circ}$ & 5.1 E-04 & $1.1 \mathrm{E}-01$ \\
\hline $1-129$ & 8.5 E-03 & $1.8 \mathrm{E}+00$ & \multirow{19}{*}{\multicolumn{3}{|c|}{$\begin{array}{l}\text { "Isotope is in activated metal. Category } 1 \text { and } 3 \\
\text { limits are } 10 \text { times those for isotopes not in } \\
\text { activated metal. } \\
\text { "Category } 3 \text { limit is the lower of this value and } \\
100 \mathrm{nCi} / \mathrm{g} \\
\mathrm{NL}=\text { no timit } \\
\text { Table edited April } 1994\end{array}$}} \\
\hline$B a-133$ & 7.1 E-01 & NL & & & \\
\hline $\mathrm{Cs}-135$ & $1.6 \mathrm{E}-01$ & $3.5 \mathrm{E}+01$ & & & \\
\hline cs- 137 & $5.5 \mathrm{E}-03$ & $1.2 \mathrm{E}+04$ & & & \\
\hline$\$ m-147$ & 1.7 E-02 & $3.7 \mathrm{E}+00$ & & & \\
\hline$S m-151$ & $4.6 E+01$ & $2.1 E+05$ & & & \\
\hline ELL- 150 & $1.4 E-03$ & $6.7 \mathrm{E}+02$ & & & \\
\hline Eu-152 & $4.8 E * 02$ & NL & & & \\
\hline Eu- 154 & 7.5 E-01 & $\mathrm{HL}$ & & & \\
\hline Gd-152 & 6.4 E- 03 & $1.4 E+00$ & & & \\
\hline Re-187 & $3.6 E+01$ & $7.8 \mathrm{E}+03$ & & & \\
\hline$P b-210$ & $3.7 \mathrm{E}-02$ & $2.1 E+06$ & & & \\
\hline Po-209 & $9.8 \mathrm{E}-03$ & $3.2 \mathrm{E}+01$ & & & \\
\hline $\mathrm{Re}-226$ & $1.7 \mathrm{E}-04$ & $4.3 E-02$ & & & \\
\hline $\mathrm{Ra}-228$ & $1.7 \mathrm{E}+01$ & $\mathrm{NL}$ & & & \\
\hline$A c-227$ & $4.2 \mathrm{E}-03$ & $3.0 \mathrm{E}+05$ & & & \\
\hline$I h-229$ & $4.4 \mathrm{E}-04$ & $9.8 \mathrm{E}-02$ & & & \\
\hline Th-230 & $2.1 \mathrm{E}-03$ & $1.5 \mathrm{E}-01$ & & & \\
\hline Th- 232 & 1.1 E-04 & $2.3 \mathrm{E}-02$ & & & \\
\hline
\end{tabular}


Table 4-19. Inventory Limits for Groundwater-Mobile Radionuclides by Burial Ground in the 200 East Area Active LLBG (Ci).

\begin{tabular}{|c|c|c|c|c|c|c|}
\hline \multirow{2}{*}{ Nucl ide } & \multicolumn{3}{|c|}{$218-E-12 B$} & \multicolumn{3}{|c|}{$218-E-10$} \\
\hline & Cat. 1* & Cat. 3* & Cat. 3** & Cat. 1* & Cat. 3* & Cat. $3^{* \star}$ \\
\hline${ }^{\prime} \mathrm{H}$ & 23,000 & NL & $\mathrm{NL}$ & 60,200 & NL & NL \\
\hline${ }^{34} \mathrm{C}$ & 2.5 & 15 & 145 & 6.5 & 46 & 130 \\
\hline${ }^{*} \mathrm{Cl}$ & 1.7 & 11 & 100 & 4.6 & 32 & 93 \\
\hline "se & 0.6 & 3.9 & 37 & 1.6 & 12 & 34 \\
\hline${ }^{n}{ }_{T C}$ & 4.0 & 25 & 230 & 10.5 & 74 & 210 \\
\hline${ }^{129} \mathrm{I}$ & 0.02 & 0.1 & 1.1 & 0.05 & 0.3 & 1.0 \\
\hline${ }^{107} R e$ & 630 & 3,900 & 36,700 & 1,600 & 16,400 & 34,000 \\
\hline u & 0.02 & 0.13 & 1.3 & 0.06 & 0.4 & 1.2 \\
\hline
\end{tabular}

* No waste form performance is assumed

** Diffusional control of release is assumed $\left(D=1 \times 10^{-10} \mathrm{~cm}^{2} / \mathrm{s}\right)$

Table 4-20. Groundwater Concentration Limits for Reactor Compartment Radionuclides.

\begin{tabular}{|l|c|c|}
\hline Radionuclide & $\begin{array}{c}\text { Solution Concentration } \\
\text { Limit } \\
\left(\mathrm{Ci} / \mathrm{m}^{3}\right)\end{array}$ & $\begin{array}{c}\text { Metal Concentration } \\
\text { Limit } \\
\left(\mathrm{Ci} / \mathrm{m}^{3}\right)\end{array}$ \\
\hline${ }^{14} \mathrm{C}$ & 0.00009 & 1,700 \\
\hline${ }^{36} \mathrm{Cl}$ & 0.00006 & 1,200 \\
\hline${ }^{79} \mathrm{Se}$ & 0.00002 & 440 \\
\hline${ }^{99} \mathrm{TC}$ & 0.0001 & 2,800 \\
\hline${ }^{129} \mathrm{I}$ & 0.0000006 & 13 \\
\hline
\end{tabular}

Table 4-21. Mobile Radionuclide Trigger Values for 200 West Area LLBG $\left(\mathrm{Ci} / \mathrm{m}^{3}\right)$ (WHC 1993, page change 5).

\begin{tabular}{|c|c|c|c|c|c|}
\hline Radi onucl ide & Category i & Category 3 & Radionuclide & Category 1 & Category 3 \\
\hline${ }^{14} \mathrm{C}$ & $3.3 E=05$ & $2.5 E-04$ & ${ }^{36} \mathrm{Cl}$ & $2.3 E-05$ & $1.8 E-04$ \\
\hline "se & $8.5 E-06$ & $6.3 E-05$ & "Tc & $5.3 E-05$ & $4.0 \mathrm{E}-02$ \\
\hline $12 ?_{1}$ & $2.3 E-07$ & $1.9 E-06$ & ${ }^{10 \%} \mathrm{Re}$ & 8.3E-03 & $6.3 E-02$ \\
\hline$U(a l t)$ & $2.8 E-07$ & $2.2 E-06$ & ${ }^{23 \prime} \mathrm{Np}$ & $2.8 E-06$ & $N / A$ \\
\hline 'H & $1.1 E+00$ & N/A & & & \\
\hline
\end{tabular}




$$
\text { WHC-SD-WM-TI-730, REV } 0
$$

\subsection{PERFORMANCE EVALUATION}

This PA analysis evaluated the radiological hazard posed by the disposal of low-level radioactive waste in the 200 East Area LLBG located in the 200 East Area on the Hanford Site. Potential dose has been estimated for a number of scenarios and disposal conditions and compared to dose limit performance objectives. In addition, waste acceptance criteria (primarily radionuclide-specific inventory limits), have been quantified to limit the potential dose from the disposal of future waste in the burial grounds.

\subsection{COMPARISON OF ESTIMATED DOSES WITH PERFORMANCE OBJECTIVES}

Table 5-1 summarizes the dose estimates, along with the performance objectives assumed as design goals in this analysis. The estimates are based on the projected inventories of the primary dose-producing radionuclides in the LLW inventory. Doses for the two burial ground areas that make up the 200 East Area LLBG (218-E-10 and 218-E-12B) are provided. Because most of the waste currently disposed of in these burial grounds is Category 3 waste, the doses are calculated using Category 3 conditions (primarily an infiltration rate of $0.5 \mathrm{~cm} / \mathrm{yr}$ and $5 \mathrm{~m}$ of cover). Also, no waste form performance is assumed.

Except for radon, all of the doses shown in Table 5-1 are predicted to occur before 10,000 years and are based on the peak groundwater concentration. The radon dose will increase beyond 10,000 years as it approaches secular equilibrium with ${ }^{238} \mathrm{U}$ and $234 \mathrm{U}$. Increases by a factor of about 30 and 100 in dose are predicted at 50,000 and 100,000 years. Based on the projected inventory, the performance objectives are satisfied by the proposed disposal methods in the 200 East Area LLBG.

As stated in the previous chapter, projecting a final LLW inventory in the 200 East Area LLBG and the range of radionuclide concentrations that could occur in the future is difficult. This uncertainty affects the dose estimates provided in Table 5-1. However, the conservatism used in developing inventory limit waste acceptance criteria, the ability to administratively control wastes that are accepted, and the options to use waste-form performance to immobilize wastes containing the groundwater-mobile radionuclides in larger quantities will prevent potential dose in excess of the performance objectives from occurring.

\subsection{DESIGN CHANGES REQUIRED TO MEET PERFORMANCE OBJECTIVES}

The current method of LLW disposal requires no significant change relative to current operations. At the time of burial-ground closure or partial burial-ground closure, however, for those parts of the burial ground containing Category 3 waste, a cover must be constructed that satisfies the infiltration rate control assumption of $0.5 \mathrm{~cm} / \mathrm{yr}$. Given the present state of knowledge, this is viewed as a design objective that can be easily accomplished with a simple one- or two-layer cover whose primary means of controlling infiltration is the use of a mixture of naturally occurring shallow- and deep-rooted vegetation. Other types of layers such as a capillary break layer (e.g., coarse gravel) may be used between the 
WHC-SD-WM-TI-730, REV 0

vegetation-covered surface layer and the waste to further inhibit water infiltration into the waste volume. The thickness of cover over the waste must also be $\geq 5 \mathrm{~m}$. This is also easily achievable because the current operational covers are between 2 and $3 \mathrm{~m}$. Erosion-control data (described in Section 2.2.2) suggest that long-term performance (in excess of 1,000 years) can be achieved by introducing pea gravel admix into the surface layer, covering the surface with native plants, and ensuring that cover slopes are gradual.

Given the uncertainty of radionuclide inventories of future waste, it is possible that waste form performance may be required for waste streams that contain large quantities of the groundwater mobile radionuclides. At present, none of the waste received has contained sufficiently large quantities of these radionuclides to require waste-form performance.

\subsection{ADDITIONAL APPLICATIONS OF PERFORMANCE ASSESSMENT RESULTS IN WASTE MANAGEMENT}

The PA function is part of the solid waste management organization at the Hanford Site. A routine interface is maintained with other aspects of the waste management organization to ensure that waste disposal is in compliance with the performance objectives. Some ongoing and planned activities are affected by the results of the PA analysis.

Currently, the primary interface occurs with the WAC document (WHC 1993). This document identifies waste packaging requirements and waste characterization information required of the generator before waste can be accepted for disposal. Requirements generated by the PA analyses are incorporated into the WAC. Stabilization requirements for Category 3 waste and Categories 1 and 3 radionuclide concentration limits are provided in this document on the basis of the 200 West Area PA analysis. These limits are the same for the 200 East Area LLBG. In addition, trigger concentrations have been added to the WAC to alert the waste operator to the potential for receipt of unacceptable quantities of groundwater-mobile radionuclides. A tracking system is being implemented to ensure that average concentration limits and total activity limits in the LLBG are not exceeded. The document accepts evolving requirements from the PA analysis and will be revised as needed.

An interface is maintained with generators who have characterization issues to resolve and with potential waste treatment facilities. Issues revolving around the level of effort required to characterize waste and decisions concerning the need to segregate and treat waste require $P A$ input on a regular basis. Another area expected to require PA input will be use of existing burial-ground space and the impact of adding contiguous disposal sites in the 200 East Area.

Numerous groundwater monitoring wells are in service around the burial grounds and will continue to be sampled as long as the burial grounds are operational and for some time post-closure. These analyses indicate that only negligible concentrations are anticipated in groundwater monitoring wells because of the very slow releases predicted for these disposal conditions. Even if a contaminant plume from a LLW disposal facility were to reach the unconfined aquifer, the models predict low levels of contamination that would be difficult to detect. 
The most effective form of monitoring is expected to be tracking the amount of precipitation that penetrates the disposal-facility cover. The PA analysis results indicate that recharge rates are one of the dominant drivers for the release of radionuclides that can be monitored in real time. The most likely method for monitoring recharge will probably be a combination of neutron probe measuring devices and lysimeters, placed either in the disposal facility cover or near the facility. If the lysimeter is placed near the facility, the cover materials can be duplicated in the lysimeter. Another possible monitoring area may be the vadose zone, although such techniques are currently limited in scope (e.g., indirect measurements of moisture content in soil and high energy gamma radionuclide inventories). Advances in monitoring techniques should be evaluated for potential value as they develop.

\subsection{ADDITIONAL DATA AND ANALYSIS NEEDS}

A commitment to complete a PA maintenance program during the operational life of the LLBG has been made by RL. The program is not yet clearly defined, but guidance is forthcoming and will be implemented. The main thrust of the program will be to routinely evaluate the relevance of the PA analysis (both assumptions and results) to current waste management practice and to develop a database that enhances confidence in the critical assumptions on which estimates of potential dose depend.

Additional waste release analyses may be required on a case-by-case basis for future waste streams if they contain large quantities of groundwatermobile radionuclides. The immobilization properties of the waste materials may be sufficient to dispose of a given waste, or waste-form development work may be required to dispose of this waste.

As closure covers are developed, it is expected that infiltration monitoring in the covers will be used to support the assumption that infiltration rates are below acceptable levels. Standard techniques exist for monitoring infiltration (e.g., Tysimeters and moisture-content sensors). As closure plans are developed and covers are placed over the facility, a program will be established to collect infiltration data in the cover. The exact methods used and the length of time over which data are collected have not been determined to date. As part of a PA maintenance program, these data should be collected and evaluated periodically to determine their effects on dose estimates. 
WHC-SD-WM-TI-730, REV 0

This page intentionally left blank.

5-4 
WHC-SD-WM-TI-730, REV 0

Table 5-1. Comparison of Dose Estimates with Performance Objectives.

\begin{tabular}{|l|l|c|c|}
\hline \multirow{2}{*}{ Performance objectives } & Exposure pathway & $\begin{array}{l}\text { Estimated } \\
\text { dose or flux* }\end{array}$ & \\
\cline { 3 - 4 } & & $218-\mathrm{E}-10$ & $218-\mathrm{E}-12 \mathrm{~B}$ \\
\hline $25 \mathrm{mrem} / \mathrm{yr}$ & $\begin{array}{l}\text { Groundwater, all } \\
\text { pathways }\end{array}$ & 0.02 & 0.009 \\
\hline $4 \mathrm{mrem} / \mathrm{yr}$ & $\begin{array}{l}\text { Groundwater, } \\
\text { drinking }\end{array}$ & 0.02 & 0.008 \\
\hline $100 \mathrm{mrem} / \mathrm{yr}(500 \mathrm{yr})$ & Post-drilling & 0.02 & 0.00005 \\
\hline $20 \mathrm{pCi} \mathrm{m} / \mathrm{s}$ at $10,000 \mathrm{yr}$ & Radon emission & 0 & 0.009 \\
\hline $10 \mathrm{mrem} / \mathrm{yr}$ & Air contamination & nil & nil \\
\hline
\end{tabular}

* The units of measure are the same as the performance objectives. 
WHC-SD-WM-TI-730, REV 0

This page intentionally left blank. 


\subsection{LIST OF PREPARERS}

Truc H. DeLorenzo, Scientist, formerly with Safety Analys is and Nuclear Engineering, Westinghouse Hanford Company.

B.S. Physical Science, Washington State University

Ms. DeLorenzo has 2 years of groundwater modeling experience with Westinghouse Hanford Company. She has been a key contributor in performing computer runs with VAM3D-CE for radionuclide release scenarios in the hydrogeologic system. She has provided graphic representations and tabular summaries of the results.

Scott H. Finfrock, Principal Scientist, Nuclear Analysis and Characterization, Westinghouse Hanford Company.

M.S. Nuclear Engineering, University of Washington

M.S. Computer Science, Washington State University

Mr. Finfrock has over 10 years of experience developing and applying finite difference computer codes. He has been a key contributor in performing computer runs with VAM3D-CG for radionuclide release scenarios in the hydrogeologic system. He has provided graphic representations of the results and written discussions on the results for the document.

Donna Y. Garbrick, Engineer, Environmental Science and Engineering, Inc.

B.S. Mechanical Engineering, Colorado State University 1992

Ms. Garbrick has 2 years of experience in groundwater modeling at the Hanford Site. She has been a key contributor in performing computer runs with VAM3D-CG for radionuclide release scenarios in the hydrogeologic system. She has provided analysis of radionuclide inventories, graphic representations, and tabular summaries of the results. 
Raziuddin Khaleel, Fellow Engineer, Environmental Modeling, Westinghouse Hanford Company.

B.S. Civil Engineering,

Bangladesh University of Engineering and Technology

M.S. Water Science and Engineering, Asian Institute of Technology

Ph.D. Soil and Water Engineering, Texas A\&M University

Dr. Khaleel has over 25 years of experience in groundwater hydrology and numerical simulations of subsurface flow and transport. He is a key contributor to the Solid Waste PA analysis in the areas of conceptual model development of the hydrogeologic environment, technical direction of modeling runs, and writing of analytical results in various sections of the document.

Allen H. Lu, Fellow Engineer, Environmental Modeling, Westinghouse Hanford Company.

B.S. Naval Navigation and Engineering, Chinese Naval Academy

M.S. Nuclear Physics, Tsin-Hua University, Taiwan

Ph.D. Nuclear Physics, Rensselaer Polytechnic Institute

Or. Lu has been employed at the Hanford Site since 1979. He has been responsible for selecting the source term model and integrating the model with the flow and transport code for the analyses in this document. He also provided technical direction of modeling runs and the writing of sections describing the analytical results. Previously, Dr. Lu has worked in various nuclear engineering projects. He developed a novel technique to measure gas permeability and estimate gas-production in the late 1970's at a low-level radioactive waste burial site in West Valley, NY. He performed benchmark calculations of ${ }^{236} \mathrm{Pu}$ content of ${ }^{238} \mathrm{Pu}$ production at the Fast Flux Test Facility (FFTF) using a general Monte Carlo code for neutron/photon transport. He is an expert in shielding and criticality studies. Dr. Lu has recently been in charge of various modeling studies using the VAMBD-CG flow and transport code.

Paul D. Rittmann, Principal Engineer, Environmental Modeling, Westinghouse Hanford Company.

B.A. Physics, University of Wisconsin

M.S. Physics, Purdue University

Ph.D. Physics, Purdue University

Dr. Rittmann has been employed at the Hanford Site since 1980. He has been using environmental transport and dose models since 1983. He has been responsible for the development and calculation of radionuclidespecific dose estimates for radionuclide release scenarios in this analysis: Dr. Rittmann's current responsibilities include application of mathematical models for estimating environmental doses from long-term waste disposal, from normal operations, and from accidental releases. He is currently a member of the Hanford Environmental Dose Overview Panel, the Health Physics Society, the American Nuclear Society, and the American Academy of Health Physics. 
Marcus I. Wood, Principal Scientist, Solid Waste Disposal, Westinghouse Hanford Company.

B.S. Geology, University of North Carolina

Dr. Wood is currently responsible for the development of the PA analyses for the disposal of solid low-level waste at the Hanford Site. He is the coordinating author of this document and has been largely responsible for the integration and interpretation of the analytical results in this document. He has coordinated similar analyses for the Environmental Restoration Disposal Facility (ERDF), which is planned for disposing of wastes generated in the remediation of Hanford CERCLA sites and the 200 West Area low-level burial grounds. In the past, he has directed numerous projects to quantify the geochemical properties of radionuclides in the Hanford geohydrologic environment. He was also responsible for developing a multifunctional waste package backfill material for isolating spent fuel and high-level waste. 
WHC-SD-WM-TI-730, REV 0

This page intentionally left blank.

6-4 
WHC-SD-WM-TI-730, REV 0

\subsection{REFERENCES}

40 CFR 141, "National Primary Orinking Water Regulations, " Code of Federal Regulations, as amended.

56(138) FR 33050, 1991, U.S. Environmental Protection Agency, "National Primary Drinking Water Regulations: Radionuclides, "Notice of Proposed Rulemaking, Federal Register.

Aaberg, R. L., and W. E. Kennedy, Jr., 1990, Definition of Intrusion Scenarios and Example Concentration Ranges for the Disposal of Near-Surface Waste at the Hanford Site, PNL-6312, Pacific Northwest Laboratory, Richland, Washington.

Baes III, C. F., R. D. Sharp, A. L. Sjoreen, and 0. W. Hermann, 1984a, TERRA: A Computer Code for Simulating the Transport of Environmentally Released Radionuclides through Agriculture, ORNL-5785, Oak Ridge National Laboratory, Oak Ridge, Tennessee (November).

Baes III, C. F., R. D. Sharp, A. L. Sjoreen, and R. W. Shor, 1984b, A Review and Analysis of Parameters for Assessing Transport of Environmentally Released Radionuclides through Agriculture, ORNL-5786, 0ak Ridge National Laboratory, Oak Ridge, Tennessee (September).

Baker, V. R., B. N. Bjornstad, A. J. Busacca, K. R. Fecht, E. P. Kiver, U. L. Moody, J. G. Rigby, D. F. Stradling, and A. M. Tallman, 1991, Quaternary Geology of the Columbia Plateau, Conterminous United States, R. B. Morrison (editor), Geological Society of America, The Geology of North America, Vol. K-2, Boulder, Colorado, pp. 215-250.

Bayl iss, S., F. T. Ewart, R. M. Howse, J. L. Smith-Briggs, H. P. Thomason, and H. A. Wilmott, 1988, The Solubility and Sorption of Lead-210 and Carbon-14 in a Near-Field Environment, Material Research Society Symposium Proceedings, V01. 112, Materials Research Society, New York, New York, pp. 33-42.

Bouwer, H. and R. C. Rice, 1984, Hydraulic Properties of Stony Vadose Zones, Ground Water, vol. 22, pp. 696-705.

Brooks, R. H., and A. T. Corey, 1966, "Properties of Porous Media Affecting Fluid Flow," ASCE J. Irrig. drain. Div., 92(IR2):61-88.

Caggiano, J. A., and D. W: Duncan, 1983, Preliminary Interpretation of the Tectonic Stability of the Reference Repository Location, Cold Creek Syncline, Hanford Site, RHO-BW-ST-19P, Rockwell Hanford Operations, Richl and, Washington.

Carsel, R. F. and R. S. Parrish, 1988, Developing Joint Probability Distributions of Soil Water Retention Characteristics, Water Resour. Res., vol. 24, pp. 755-769. 
Case, M. J., R. L. Dodge, T. G. Frangos, W. R. Hansen, W. E. Kennedy, Jr., D. W. Layton, D. W. Lee, and E. L. Wilhite, 1989, Recommended Format and Content for DOE LOW-Level Waste Disposal Facility Radiological Performance Assessment Report, DOE/LLW-81, U.S. Department of Energy, Washington, D.C.

Conca, J. L., and J. Wright, 1990, Diffusion Coefficients in Gravel Under Unsaturated Conditions," Water Resour. Res., Vol. 26, pp. 1055-1066.

Connelly, M. P., J. V. Borghese, C. D. Delaney, B. H. Ford, J. W. Lindberg, and S. J. Trent, 1992, Hydrogeologic Model for the 200 East Groundwater Aggregate Area, WHC-SD-EN-TI-019, Westinghouse Hanford Company, Richland, Washington.

Connelly, M. P., B. H. Ford, and J. V. Borghese, 1992, Hydrogeologic Model for the 200 West Groundwater Aggregate Area, WHC-SD-EN-TI-014, Westinghouse Hanford Company, Richland, Washington.

Cowan, S. P., 1996, Conditional Acceptance of the Hanford 200 West Area Burial Ground Performance Assessment, memo to Charles Hansen, U.S. Department of Energy, Richland Operations Office, dated June 27, 1996, U.S. Department of Energy, Headquarters, Washington, D.C.

Crank, J., 1975, The Mathematics of Diffusion, 2nd Ed., Oxford University Press, 0xford, England.

Cushing, C. E., editor, 1995, Hanford Site National Environmental Policy Act (NEPA) Characterization, PNL-6415, Rev. 7, Pacific Northwest Laboratory, Richland, Washington.

Delaney, C. N., K. A. Lindsey, and S. P. Reidel, 1991, Geology and Hydrology of the Hanford Site; $A$ Standardized Text for Use in WHC Documents and Reports, WHC-SD-ER-TI-003, Rev. 0, Westinghouse Hanford Company, Richland, Washington.

Dirkes, R. L., R. W. Hanf, R. K. Woodruff, and R. E. Lundgren, 1994, Hanford Site Environmental Report for Calendar Year 1993, PNL-9823, Pacific Northwest Laboratory, Richland, Washington.

Dodge, R. L., W. R. Hansen, W. E. Kennedy, Jr., D. W. Layton, D. W. Lee, S. T. Maheras, S. M. Neuder, E. L. Wilhite, R. C. Curl, K. F. Grahn, B. A. Heath, and K. H. Turner, 1991, Performance Assessment Review Guide for DOE Low-Level Radioactive Waste Disposal Facilities, DOE/LLW-93, Idaho National Engineering Laboratory, Idaho Falls, Idaho.

DOE, 1987, Final Environmental Impact Statement: Disposal of Hanford Defense High-Level, Transuranic and Tank Wastes, DOE/EIS-0113, Vols. 1-5, U.S. Department of Energy, Washington, D.C.

DOE, 1988a, Radioactive Waste Management, DOE Order 5820.2A, U.S. Department of Energy, Washington, D.C. 
DOE, 1988b, Site Characterization P7an, Reference Repository Location, Hanford Site, Richland, Washington, Consultation Draft, DOE/RW-0164, U.S. Department of Energy, Office of Civilian Radioactive Waste Management, Washington, D.C.

DOE, 1988c, Internal Dose Conversion Factors for Calculation of Dose to the Public, D0E/EH-0071 (DE88-014297), U.S. Department of Energy, Washington, D.C.

DOE, 1993, Radiation Protection of the Public and the Environment, Proposed Rule, 10 CFR Part 834, U.S. Department of Energy, Washington D.C.

DOE, 1994, Remedial Investigation and Feasibility Study Report for the Environmental Restoration Disposal Facility, DOE/RL-93-99, Rev. 0, U.S. Department of Energy, Richland Operations Office, Richland, Washington.

DOE, 1995, Implementation Plan, Defense Nuclear Facilities Safety Board Recommendation 94-2, U.S. Department of Energy, Washington, D.C.

DOE, 1996, Guidance for a Composite Analysis of the Impact of Interacting Source Terms on the Radiological Protection of the Public from Department of Energy Low-Level Waste Disposal Faciities, U.S. Department of Energy, Washington, D.C.

DOE-RL, 1993, Radioactive Waste Management, RLID 5820.2A, Rich1and Operations Implementation Directive to DOE Order 5820.2A, U.S. Department of Energy, Richland Operations Office, Richland, Washington.

DOE-RL, 1995, Hanford Site Background: Evaluation of Existing Soil Radionuclide Data, DOE/RL-95-55, Draft A, U.S. Department of Energy, Richland, Washington.

Drese1, P. E., S. P. Luttre11, J. C. Evans, W. D. Webber, P. D. Thorne, M. A. Chamness, B. M. Gillespie, B. E. Opitz, J. T. Rieger, and J. K. Merz, Hanford Site Ground-Water Monitoring for 1993, PNL-10082, Pacific Northwest Laboratory, Richland, Washington.

Eagleson, P. S., 1970, Dynamic Hydrology, McGraw Hill Book Co., New York, New York, $462 \mathrm{p}$.

Ecology, EPA, and DOE, 1996, Hanford Facility Agreement and Consent Order, as amended, Washington State Department of Ecology, U.S. Environmental Protectional Agency, U.S. Department of Energy, 01ympia, Washington.

Ellis, M. W. and G. J. LeBaron, 1995, PUREX Low-Level Waste Radionuclide Characterization, WHC-SD-CP-PLN-028, Rev. 0, Westinghouse Hanford Company, Richland, Washington.

EPA, 1989, Exposure Factors Handbook, EPA/600/8-89/043, U.S. Environmental Protection Agency, Washington, D.C.

Fayer, M. J., M. L. Rockhold, and G. W. Gee, 1991, "Recharge Potential of a Sandy Soi1," EOS (Transactions of the American Geophysical Union), Vol. 72, p. 1074 . 
Fayer, M. J. and T. B. Walters, 1995, Estimated Recharge Rates at the Hanford Site, PNL-10285, Pacific Northwest Laboratory, Richland, Washington.

Ford, B. H., 1993, Groundwater Field Characterization Report for the 200 Aggregate Area Management Study, WHC-SD-EN-TI-020, Rev. 0, Westinghouse Hanford Company, Richland, Washington.

Freeze, R. A. and J. A. Cherry, 1979, Groundwater, Prentice Hal1, New Jersey.

Gardner, W. H., 1986, "Water Content," Methods of Soils Analysis, Part 1, A. Kiute, ed., pp. 493-544, Am. Soc. Agron., Madison, Wisconsin.

Gee, G. W., 1987, Recharge at the Hanford Site: Status Report, PNL-6403, Pacific Northwest Laboratory, Richland, Washington.

Gee, G. W., M. J. Fayer, M. L. Rockhold, and M. D. Campbe11, 1992, "Variations in Recharge at the Hanford Site," Northwest Science, Vol. 66, No. 4, pp. 237-250.

Geomatrix Consultants, Inc., 1996, Probabilistic Siesmic Hazard Analysis, DOE Hanford Site, Richland, Washington, WHC-SD-W236A-TI-002, Rev. 1, Westinghouse Hanford Company, Richland, Washington.

Graham, M. J., M. D. Hall, S. R. Strait, and W. R. Brown, 1981, Hydrology of the Separations Area, RHO-ST-42, Rockwell Hanford Operations, Richland, Washington.

Gilmore, B. G., and W. H. Walters, 1993, Water Erosion Field Tests for Hanford Protective Barriers: FY 1992 Status Report, PNL-8949, Pacific Northwest Laboratory, Richland, Washington.

Hanson, G. L., J. D. Anderson, G. R. Kiel, B. J. McMurray, and N. P. Nisick, 1973, Input and Decayed Values of Radioactive Solid Wastes Buried in the 200 Areas Through 1971, ARH-2762, Atlantic Richfield Hanford Company, Richland, Washington.

Hennig, J. M., 1995, Submittal of Additional Information on the 200 West Area Burial Ground Performance Assessment, memo to J. A. Turi, U.S.

Department of Energy, Headquarters, correspondence number 95-SWT-033, dated January 19, 1995, U.S. Department of Energy, Richland Operations office, Richland, Washington.

HFSUWG, 1992, The Future f.or Hanford: Uses and Cleanup, Final Report for the Hanford Future Site Uses Working Group, Hanford Future Site Uses Working Group, Richland, Washington.

Hills, R. G. and P. J. Wierenga, 1991, Model Validation at the Las Cruces Trench site, NUREG/CR 5716, U.S. Nuclear Regulatory Commission, Washington, D.C.

Hoitink, D. J. and K. W. Burk, 1994, Climatological Data Summary 1993 with Historical Data, PNL-9809, Pacific Northwest Laboratory, Richland, Washington. 
Huyakorn, P. S., and Sorab Panday, 1992, VAM30CG: A Variably Saturated Analysis Model in Three-Dimensions with Preconditioned Conjugate Gradient Matrix Solvers - Documentation and User's Guide, Version 2.4, HydroGeologic, Inc., Herndon, Virginia.

Huyakorn, P. S. and G. F. Pinder, 1983, Computational Methods in Subsurface Flow, Academic Press, New York, New York.

ICRP, 1975, Report of the Task Group on Reference Man, Publication 23, Pergamon Press, New York, New York.

Jenkins, J. F., 1993, Corrosion Behavior of HY-80 Steel Type 304 Stainless Steel, and Incone $]^{\mathrm{R}}$ Alloy 600 at 218-E-12B Burial Ground Hanford, WA, TR-200l-5HR, Naval Facilities Engineering Service Center, Port Hueneme, California.

Jury, W. A., 1985, Spatial Variability of Soil Physical Parameters in Solute Migration: A Critical Review, EPRI Report EA-4228, Electric Power Research Institute, Palo Alto, California.

Kaplan, D. I. and R. J. Serne, 1995, Distribution Coefficient Values Describing Iodine, Neptunium, Selenium, Technetium, and Uranium Sorption to Hanford Sediments, PNL-10379, Sup. 1, Pacific Northwest Laboratory, Richland, Washington.

Kaplan, D. I., R. J. Serne, and N. G. Piepho, 1995, Geochemical Factors Affecting Radionuclide Transport Through Near and Far Fields at a LowLevel Waste Disposal Site, PNL-10379, Pacific Northwest Laboratory, Richland, Washington.

Kennedy, W. E., and D. L. Strenge, 1992, Residual Radioactive Contamination from Decommissioning, Vol. 1, NUREG/CR-5512, Pacific Northwest Laboratory, Richland, Washington.

Khaleel, R. and E. J. Freeman, 1995, Variability and Scaling of Hydraulic Properties for 200 Area Soils, Hanford Site, WHC-EP-0883, Westinghouse Hanford Company, Richland, Washington.

Khaleel, R. and J. F. Relyea, 1996, Correcting Laboratory-Measured Moisture Retention Data for Field Conditions, WHC-EP-0910. Westinghouse Hanford Company, Richland, Washington.

Khaleel, R., J. F. Relyea, and J. L. Conca, 1995, "Evaluation of van Genuchten-Mualem Relationships to Estimate Unsaturated Hydraulic Conductivity at Low Water Contents," Water Resour. Res., Vol. 31, p. 2659-2668.

Khaleel, R., and M. I. Wood, 1990, Performance Assessment Modeling of Flow Transport from a Low-Level Solid Waste Burial Ground: Conceptual Model and Data Requirements, Letter Report to J. L. Scott from J. W. Cammann, Westinghouse Hanford Company, Richland, Washington. 
Kincaid, C. T., J. W. Shade, G. A. Whyattt, M. G. Piepho, K. Rhoads, J. A. Voogd, J. H. Westsik, Jr., M. D. Freshley, K. A. Blanchard, B. G. Lauzon, 1995, Performance Assessment of Grouted Double-Shell Tank Waste Disposal at Hanford, WHC-SD-WM-EE-004, Rev. 1, Westinghouse Hanford Company, Richland, Washington.

Kipp, K. L., and R. D. Mudd, 1973, Collection and Analysis of Pump Test Data for Transmissivity Values, BNWL-1709, [MF 0267] Pacific Northwest Laboratory, Richland, Washington.

Klute, A., 1986, "Water Retention: Laboratory Methods," Methods of Soil Analysis, Part I, edited by A. Klute, pp. 635-660, Am. Soc. Agron., Madison, Wisconsin.

Klute, A. and C. Dirksen, 1986, "Hydraulic Conductivity and Diffusivity: Laboratory Methods," Methods of Soil Analysis, Part I, edited by A. Klute, pp. 687-734, Am. Soc. Agron., Madison, Wisconsin.

Kocher, D. C., 1981, Radioactive Decay Data Tab7es, DOE/TIC-11026, U.S. Government Printing Office, Washington, D.C.

Kozak, M. W., M. S. Chu, T. A. Mattingly, J. D. Johnson, and J. T. McCord, 1990, Background Information for the Development of a Low-Level Waste Performance Assessment Methodology, NUREG/CR-5453, SAND90-0375, Vol. 5.

Law, A. S., K. Panday, D. Denslow, K. Fecht, and A. Knepp, 1996, Hanford Sitewide Groundwater Flow and Transport Model Calibration Report, BHI-00608, Bechtel Hanford, Inc., Richland, Washington.

Ligotke, M. W., 1988, Soil Erosion Rates from Mixed Soil and Gravel Surfaces in a Wind Tunnel: A Preliminary Report, PNL-6677, Pacific Northwest Laboratory, Richland, Washington.

Ligotke, M. W., and D. C. Klopfer, 1990, Soil Erosion Rates from Mixed Soil and Gravel Surfaces in a Wind Tunne7, PNL-7435, Pacific Northwest Laboratory, Richland, Washington.

Ligotke, M. W., 1993, Soil Erosion Rats Caused by Wind and Saltating Sand Stresses in Wind Tunne7, PNL-8479, Pacific Northwest Laboratory, Richland, Washington.

Lindsey, K. A., 1991, Revised Stratigraphy for the Ringold Formation, Hanford Site, South-Centra7 Washington, WHC-SD-EN-EE-004, Westinghouse Hanford Company, Richland, Washington.

Lindsay, K. A., J. L. Slate, G. K. Jaeger, K. J. Swett, and R. B. Mercer, 1994, Geologic Setting of the Low-Level Burial Grounds, WHC-EN-TI-290, Rev. 0, Westinghouse Hanford Company, Richland, Washington.

Lu, A. H. and D. W. Langford, 1993, Verification and the Benchmark Testing of the VAM 3D-CG Flow and Transport Computer Code for use in PA for Hanford, WHC-SD-ER-CSD-005, Richland, Washington. 
WHC-SD-WM-TI-730, REV 0

Mualem, Y., 1976, "A New Model for Predicting the Hydraulic Conductivity of Unsaturated Porous Media," in Water Resour. Res., Vol. 12, No. 3, pp. 513-522.

Mullineaux, D. R., R. E. Wilson, W. F. Ebaugh, R. Fryxell, and M. Rubin, 1978, "Age of the Last Major Scabland Flood of the Columbia Plateau in Eastern Washington," Quaternary Research, Vol. 10, pp. 171-180.

Napier, B. A., R. A. Peloquin, W. E. Kennedy, Jr., and S. M. Neuder, 1984, Intruder Dose Pathway Analysis for the Onsite Disposal of Radioactive Wastes: The ONSITE/MAXII Computer Program, NUREG/CR-3620, U.S. Nuclear Regulatory Commission, Washington, D.C.

Napier, B. A., D. L. Strenge, R. A. Teloquin, and J. V. Ramsde11, 1988, GENII - The Hanford Environmental Radiation Dosimetry Software System, PNL-6584, Pacific Northwest Laboratory, Richland, Washington.

NRC, 1977, Calculation of Annual Doses to Man from Routine Releases of Reactor Effluents for the Purpose of Evaluating Compliance with 10 CFR 50, Appendix I, Regulatory Guide 1.109, Revision 1, U.S. Nuclear Regulatory Commission.

Oztunali, 0. I., B. C. Re', P. M. Moskowitz, E. D. Picazo, and C. J. Pitt, 1981, Data Base for Radioactive Waste Management, NUREG/CR-1759, Vol. 3, U.S. Nuclear Regulatory Commission, Washington, D.C.

Pratt, D. A., R.D. Evans, J. Doughty, and M. Craig, 1995, Low-Level Burial Grounds Disposal Plan, WHC-SD-WM-ES-355, Rev. 0, Westinghouse Hanford Company, Richland, Washington.

Reidel, S. P., K. A. Lindsey, and K. R. Fecht, 1992, Field Trip Guide to the Hanford Site, WHC-MR-0391, Westinghouse Hanford Company, Richland, Washington.

Reidel, S. P., A. M. Tallman, V. C. Johnson, C. J. Chou, S. M. Narbutovski, and J. P. Kiesler, TWRS Complex Site Characterization Plan, WHC-SD-WM-PLN-109, Rev. 0, West inghouse Hanford Company, Richland, Washington.

Rittmann, P. D., 1993, Verification Tests for the July, 1993 Revision to the GENII Radionuclide and Dose Increment Libraries, WHC-SD-WM-TI-596, Westinghouse Hanford Company, Richland, Washington.

Rittmann, P. D., 1994, Dose Estimates for the Solid Waste Performance Assessment, WHC-SD-WM-TI-616, Westinghouse Hanford Company, Richland, Washington.

Rockhold, M. L., M. J. Fayer, G. W. Gee, and M. J. Kanyid, 1990, Natural Groundwater Recharge and Water Balance at the Hanford Site, PNL-7215, Pacific Northwest Laboratory, Richland, Washington.

Routson, R. C., and V. G. Johnson, 1990, "Recharge Estimates for the Hanford Site 200 Areas Plateau," Northwest Science, Vol. 64, pp. 150-158. 
Scheidegger, A. E., 1961, General Theory of Dispersion in Porous Media, J. Geophys, Res., Vol. 66, pp. 3273-3278.

Serne, R. J., W. J. Martin, S. B. McLaurine, S. P. Airhart, V. L. LeGore, and R. L. Treat, 1987, Laboratory Leach Tests of Phosphate/Sulphate Waste Grout and Leachate Adsorption Tests Using Hanford Sediment, PNL6019, Pacific Northwest Laboratory, Richland, Washington.

Serne, R. J., J. L. Conca, V. L. LeGore, K. J. Cantrell, C. W. Lindenmeier, J. A. Campbel1, J. E. Amonette, and M. I. Wood, 1993, Solid-Waste Leach Characteristics and Contaminant-Sediment Interactions Volume 1: Batch Leach and Adsorption Tests and Sediment Characterization, PNL-8889, Vol. 1, Pacific Northwest Laboratory, Richland, Washington.

Serne, R. J., V. L. LeGore, and S. V. Mattigod, 1994, Leaching Tendencies of Uranium and Regulated Trace Metals from the Hanford Site 300 Area North Process Pond Sediments, PNL-10109, Pacific Northwest Laboratory, Richland, Washington.

Serne, R. J. and M. I. Wood, 1990, Hanford Waste-Form Release and Sediment Interaction: A Status Report with Rationale and Recommendations for Additional Studies, PNL-7297, Pacific Northwest Laboratory, Richland, Washington.

Skaggs, R. L., and W. H. Walters, 1981, Flood Risk Analysis of Cold Creek Near the Hanford Site, RHO-BWI-C-120 (PNL-4219), Pacific Northwest Laboratory for Rockwell Hanford Operations, Richland, Washington.

Sheppard, M. I., S. C. Sheppard, and B. D. Amiro, 1991, "Mobility and Plant Uptake of Inorganic ${ }^{16} \mathrm{C}$ and ${ }^{14} \mathrm{C}$-Labelled $\mathrm{PCB}$ in Soils of High and Low Retention," in Health Physics, Vol. 61, No. 4, pp. 481-492.

Sudicky, E. A., 1986, "A Natural Gradient Experiment on Solute Transport in a Sand Aquifer: Spatial Variability and its Role in the Dispersion Process," Water Resour. Res., Vol. 22, pp. 2069-2082.

U.S. Department of the Navy, 1996, Final Environmental Impact Statement on the Disposal of Decommissioned, Defueled Cruiser, Ohio Class, and Los Angeles Class, Naval Reactor Plants, U.S. Department of the Navy, Washington, D.C.

Valero, 0. J., K. J. Templeton, C. D. Westra, M. J. Do, and M. Skumanich, 1996, FY 1996 Solid Waste Integrated Life-Cycle Forecast Volume Summary Volume 1, WHC-EP-0900, Westinghouse Hanford Company, Richland, Washington.

van Genuchten, M. T., 1980, "A.Closed-Form Solution for Predicting the Conductivity of Unsaturated Soils," in Soil Science Society of America J., Vol. 44, pp. 892-898.

van Genuchten, M. Th., F. J. Leij, and S. R. Yates, 1991, The RETC Code for Quantifying the Hydraulic Functions of Unsaturated Soils, EPA/000/0-91/000, U.S. Environmental Protection Agency. 
WHC, 1993, Hanford Site Solid Waste Acceptance Criteria, WHC-EP-0063-4, Westinghouse Hanford Company, Richland, Washington.

WHC, 1994, Environmental Restoration Disposal Facility (Project W-296) Preliminary Safety Analysis Report, WHC-SD-W29-PSAR-001, Rev. 0, Westinghouse Hanford Company, Richland, Washington.

WHC, 1995a, Solid Waste Burial Grounds Interim Safety Basis, WHC-SD-WM-ISB-002, Westinghouse Hanford Company, Richland, Washington.

WHC, 1995b, Waste Specification System, WHC-EP-0846-0, Westinghouse Hanford Company, Richland, Washington.

Wilhite, E. L, , 1996, Preliminary Review of Hanford 200-E LLW PA (U), memo to P. M. Bubar, U.S. Department of Energy, Headquarters, Apri1 3, 1996, Westinghouse Savannah River Company, Savannah River, South Carolina.

Wing, N. R., 1993, Permanent Isolation Surface Barrier: Functional Performance, WHC-EP-0650, Westinghouse Hanford Company, Richland, Washington.

Wood, M. I., R. Khaleel, P. D. Rittmann, A. H. Lu, S. H. Finfrock, R. J. Serne, and K. J. Cantrell, 1995a, Performance Assessment for the Disposal of Low-Level Waste in the 200 West Area Burjal Grounds, WHC-EP-0645, Westinghouse Hanford Company, Richland, Washington.

Wood, M. I., R. Khaleel, P. D. Rittman, A. H. Lu, S. H. Finfrock, and T. H. DeLorenzo, 1995b, Environmental Restoration Disposal Facility Performance Assessment, BHI-00169, Bechtel Hanford, Inc., Richland, Washington.

Wrzeski, J. R., 1996, Comments to Draft Performance Assesment for Disposal of Low-Level Waste in the 200 East Area Burial Ground (WHC-EP-0875, Draft, September 1995), letter to I. K. Teynor, U.S. Department of Energy, Richland Operations Office, dated Apri1 2, 1996, U.S. Department of the Navy, Washington, D.C.

WSRC, 1994, Radiological Performance Assessment for the E-Area Vaults Disposal Facility $(U)$, WSRC-RP-94-218, Westinghouse Savannah River Company, Aiken, South Carolina.

Yang, Y. and C. B. Nelson, 1986, "An Estimation of Daily Food Usage Factors for Assessing Radionuclide Intakes in the U.S. Population," in Health Physics, Vol. 50, No. 2, pp. 245-257. 
WHC-SD-WM-TI-730, REV 0

This page intentionally left blank. 
WHC-SD-WM-TI-730, REV 0

\section{APPENDIX A}

STRATIGRAPHY, LOH-LEVEL BURIAL GROUND SOIL-COLUMN HYDROLOGIC PROPERTIES, 200 AREAS SOILS PROPERTIES, AND CONTAMINANT PLUMES 
WHC-SD-WM-TI-730, REV 0

This page intentionally left blank. 
WHC-SD-WM-TI-730, REV 0

\begin{abstract}
APPENDIX A
STRATIGRAPHY, LOW-LEVEL BURIAL GROUND SOIL-COLUMN HYDROLOGIC PROPERTIES, 200 AREAS SOILS PROPERTIES, AND CONTAMINANT PLUMES
\end{abstract}

\title{
A.1 GEOLOgIC fEATURES AND CONTAMINANT PLUMES IN THE 200 EAST AREA
}

The locations of cross sections and the cross sections for the 218-E-12B burial ground are shown in Figures $A-1$ through $A-4$. Figures $A-5$ through $A-7$ provide similar information for the 218-E-10 burial ground. These stratigraphic relationships were used as the basis for defining the soil column hydrogeologic characteristics for the two burial ground areas.

Existing radionuclide contaminant in the unconfined aquifer underlying the 200 East Area are shown in Figures A-8 through A-14. The primary sources of contamination were B-Pond and various cribs in the 200 East Area. The sources of contamination in Figures A-11 through A-14 are direct discharges to reverse well 216-B-5. Unlike the the ponds and cribs, the reverse well process discharged contaminated liquid directly into the aquifer, thus bypassing the vadose zone. The plumes, particularly the tritium plume, show the general directions of flow to the northwest and southeast, indicating the predominant influence of liquid discharge into B-pond. The sources of contamination in Figures $\mathrm{A}-1$ through $\mathrm{A}-14$ are direct discharges from the reverse wel1 216-B-5. Unlike the ponds and cribs, discharge occurred directly into the aquifer, bypassing the vadose zone. This accounts for the presence of normally sorptive elements (strontium, cesium, cobalt, and plutonium) in the aquifer.

\section{A.2 VADOSE ZONE SOIL PROPERTIES}

Section A.2 discusses procedures for correction of laboratory-measured data on moisture retention, steady state head control method of measuring unsaturated hydraulic conductivity in the laboratory, van Genuchten-Mualem relationships used to fit laboratory-measured data on moisture retention and unsaturated hydraulic conductivity, and van Genuchten-Mualem curve-fitting parameters used in numerical simulations for the final PA. All laboratorymeasured data, including their analysis, are presented for vadose zone soils for the 200 East LLBG sites. Data presented herein and those specifically used in VAM3D-CG modeling are summarized in Tables $3-4$ and 3-5 in Chapter 3.

\section{A.2.1 PROCEDURES FOR CORRECTING MOISTURE RETENTION MEASUREMENTS}

A.2.2.1 Background. As part of work unrelated to this project, boreholes were drilled at the 200 East Area LLBG sites (see Figures A-1 and A-5). The soil samples obtained from boreholes were analyzed at the WHC Geotechnical Engineering Laboratory (GEL) for particle-size distribution, bulk density, moisture retention, saturated and unsaturated hydraulic conductivities. The moisture retention data for the drainage cycle up to $-1,000 \mathrm{~cm}$ of pressure head were measured using "Tempe" pressure cells; the rest of the drainage curve up to $-15,000 \mathrm{~cm}$ was measured using the pressure plate extraction method (Klute 1986). Saturated hydraulic conductivities for the samples were 
measured in the laboratory using constant-head permeameter. The steady state head control method (Klute and Dirksen 1986) was used to measure the unsaturated hydraulic conductivities in the laboratory.

The textural designation used in this work to describe soils conforms with the International Soil Science Society classification (Hillel 1982):

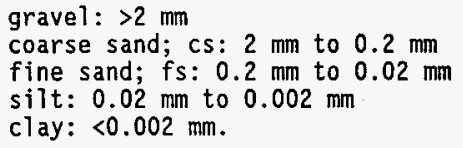

A number of samples from the LLBG sites contained a high percentage of gravel (>2 mm size fraction). Bouwer and Rice (1984) demonstrated that gravel content can have considerable influence on soil moisture characteristics. The approach taken by Bouwer and Rice to correct for gravel assumes that all moisture in the soil is contained in the $<2 \mathrm{~mm}$ size fraction and that the gravel fraction simply reduces the volume of material available to retain and conduct moisture.

A.2.2.2 Correcting the Moisture Retention Curves for Gravel Content. The laboratory-measured moisture retention curve (MRC) is based on the soil fine fraction $(<2 \mathrm{~mm})$ and does not account for the gravel fraction. The laboratory-measured MRC therefore needs to be corrected for any gravel that may be present in a soil sample. The correction can be done using either a mass-based approach (i.e., Gardner 1986) or a volume-based approach (i.e., Bouwer and Rice 1984).

The gravimetric or mass-based procedure presented by Gardner is:

$$
\theta_{b}=\frac{w_{t} p_{b} / \rho_{v}}{1+m_{g} / m_{l}}
$$

where $\theta_{\mathrm{p}}$ is the volumetric moisture content of the bulk soil including gravel, $w_{f}$ is the laboratory-measured gravimetric moisture content of the fine fraction $(<2 \mathrm{~mm}), \rho_{b}$ is the bulk density of the entire sample (including gravel), $\rho_{w}$ is the density of water, and $m_{f}$ and $m_{g}$ are, respectively, the dry masses of the fines and gravel as recovered from the bulk field soil sample.

The volume-based correction procedure described by Bouwer and Rice (1983) is based on the same general principles as equation (1). The massbased approach was used in this work since all parameters in equation (1) were directly measured in the laboratory.

Henceforth we assume that all voiumetric moisture contents have been appropriately corrected for gravel content, and will drop the subscript b on $\theta$. Thus, from here on, all values for $\theta$ specify volumetric moisture contents of the bulk soil sample including gravel where present. 
As was discussed earlier, the steady state head control method (K1ute and Dirksen 1986) was used to measure the unsaturated hydraulic conductivities in the laboratory. The following is a description of the method.

\section{A.2.2 STEADY STATE HEAD CONTROL (SSHC) METHOD}

The experimental setup used for measuring unsaturated hydraulic conductivity using the steady state head control method (Klute and Dirksen 1986) is shown in Figure A-15. It includes a constant-head water supply, a flow cell, tensiometers, and a constant-head outflow system. In general, the flow cells are about $10.2 \mathrm{~cm}$ in diameter and $15.7 \mathrm{~cm}$ in 1 ength; the maximum sample volume is about $300 \mathrm{~cm}^{3}$. The system governing the constant head water supply/constant head outflow includes a Mariotte flask (burette), which is used to maintain the same head on the inflow end. The connecting tubing is put through a rubber stopper at the top of a 50-ml burette to maintain the head level on the outflow end. The flow cell contains end caps, fitted with porous ceramic plates, sealing the ends of the container (using 0-rings) with inlet/outlet valves in each cap. Built into the sides of the flow cell are two tensiometer ports used to house tensiometer/transducer systems.

Approximately $15 \mathrm{~cm}$ of tubing is attached to the smal1 bleed ports on each end of the flow cell. During operation, water is forced through the bleed ports across the ceramic plates and out the inflow/outflow ports to remove air from between the porous $p$ late and the plastic end cap. The heights of the Mariotte bottle and lower burette are adjusted to create the same pressure head across the ceramic plates at each end of the cell. At pressure heads of $-100 \mathrm{~cm}$ or more, a vacuum system as shown in Figure A-15 is used. Starting at near saturation, a series of unit gradient flows are established at progressively decreasing (i.e., more negative) pressure heads in the soil. At each flow, the pressure heads in the tensiometers and the volumetric flow rate through the sample are measured. The procedure is repeated until the most negative value of the desired pressure head is reached. Depending on individual samples, experimental run times varied from about 2 to 6 weeks; the average being about 5 weeks per sample.

For equilibrium downward flow, the difference in hydraulic head between the inlet and outlet is $\Delta \mathrm{H}=\psi_{\mathrm{j}}-\psi_{0}+\mathrm{L}$, where $\psi_{\mathrm{i}}$ and $\psi_{0}$ are the inlet and outlet pressure heads, respectively and $\mathrm{L}$ is the separation distance between the tensiometers. The values for $\psi_{i}$ and $\psi_{0}$ are essentially the same at equilibrium and the unsaturated conductivity $K$ is given by:

$$
K=\frac{Q L}{A(\Delta H)}
$$

where $Q=$ fluid flow and $A=$ cross-sectional area of the sample.

\section{A.2.3 VAN GENUCHTEN-MUALEM RELATIONSHIPS}

Van Genuchten (1980) derived an empirical relationship to describe the moisture retention data:

where $\theta=$ volumetric moisture content 


$$
\theta=\theta_{x}+\frac{\left(\theta_{s}-\theta_{x}\right)}{\left[1+\mid \alpha \psi^{n}\right]^{m}}
$$

$$
\begin{array}{ll}
\theta_{s} & =\text { saturated moisture content } \\
\theta_{r} & =\text { residual moisture content } \\
\alpha & =\text { van Genuchten curve fitting parameter }(1 / \mathrm{cm}) \\
\psi & =\text { matric potential or pressure head }(-\mathrm{cm}) \\
\mathrm{n} & =\text { van Genuchten curve fitting parameter } \\
\mathbf{m} & =1-1 / \mathrm{n} .
\end{array}
$$

The Mualem (1976) model is generally used to predict the hydraulic conductivity from moisture retention data:

$$
\begin{aligned}
& \qquad K\left(S_{\theta}\right)=K_{s} S_{\theta}\left[\frac{f\left(S_{e}\right)}{f(1)}\right]^{2} \\
& \text { where } \quad f\left(S_{e}\right)=\int_{0}^{S_{e}} \frac{1}{\Psi(x)} d x
\end{aligned}
$$

and

$$
S_{\theta}=\frac{\theta-\theta_{x}}{\theta_{g}-\theta_{x}}
$$

and $\ell$ is a pore-connectivity parameter estimated by Mualem (1976) to be about 0.5 as being optimum for many soils.

Using Mualem's model, van Genuchten (1980) derived a closed-form analytic solution to equation (4) to predict the relative hydraulic conductivity $\left(K_{r}\right)$ at a specified volumetric moisture content,

$$
\begin{gathered}
K_{x}=S_{\theta}\left(1-\left[1-S_{\theta}^{1 / m}\right]^{m}\right\}^{2} \\
K(\theta)=K_{s} * K_{x}
\end{gathered}
$$

A computer program, called RETC (van Genuchten et al. 1991), uses a nonlinear, least squares curve fitting procedure to match the laboratory-measured data to van Genuchten-Mualem model.

The analysis is based on the premise that the unsaturated hydraulic conductivity relationships can be predicted using the van Genuchten parameters, Mualem's model, and laboratory-measured saturated hydraulic conductivity estimates. Aiternatively, provided unsaturated conductivity measurements are available, the moisture retention curve-fitting parameters and a single unsaturated conductivity measurement can be used to predict unsaturated conductivities for the desired range of field moisture regime. 
Such a procedure helps to reduce uncertainty in estimated conductivities at low moisture contents (Khaleel et al. 1995).

In this work, since both moisture retention and unsaturated conductivity measurements were available, a simultaneous fitting was performed using both moisture retention and unsaturated conductivity data. During simultaneous fitting, the pore parameter $\ell$ was fixed at 0.5 ; all other parameters $\theta_{r}, \theta_{s}$, $\alpha, K_{s}$, and $n$ with $m=1-1 / n$ were fitted to the data.

\section{A.2.4 VAN GENUCHTEN-MUALEM PARAMETERS}

For the preliminary PA, the existing data on vadose zone soil properties from 200-BP-1 and AP Tank Farm sites in 200 East Area were used. Since then, additional data have been obtained. Moisture retention as well as unsaturated conductivity experiments were performed on samples from boreholes within the 200 East LLBGs. These laboratory data allowed development of van GenuchtenMualem model parameters for vadose zone soils at the LLBGs. For purposes of adequate representation of site hydrogeology, two representative cases were considered: (a) $218-E-12 B$ site, and (b) $218-E-10$ site.

\section{A.2.4.1 Moisture Characteristic Curves for 218-E-12B LLBG Soils.}

Figures A-16 through A-18 illustrate the moisture characteristic curves and van Genuchten-Mualem parameters that were used for 218-E-12B LLBG simulations. The parameters were obtained by a simultaneous fit of both moisture retention and unsaturated conductivity data for samples from borehole 299-E34-1 located within the 218-E-12B LLBG (see Figure $A-1$ ). The saturated $K$ values noted in the unsaturated hydraulic conductivity figures A-16 through A-18 represent the fitted K's obtained as part of the simultaneous fitting procedure. However, for sample 5-0146, in order to obtain a reasonable fit with the measured unsaturated conductivity data, the saturated $K$ was kept fixed at its measured value; the other parameters $\theta_{r}, \theta_{s}, \alpha$, and $n$ with $m=1-1 / n$ were simultaneously fitted to the data.

The unsaturated K's were obtained by the SSHC method, as described before. Also, as discussed earlier, during the simultaneous fit, the poreconnectivity parameter $\ell$ was fixed at 0.5 . Moisture retention data, as needed, were corrected for the gravel fraction following the procedure outlined before. No corrections were required for the saturated and unsaturated $K^{\prime} s$, since these were measured on the bulk samples (including $>2-\mathrm{mm}$ size fraction).

Data presented in Figures A-16 through A-18 were used in VAM3D-CG modeling, and are also summarized in Table 3-4 in Chapter 3.

A.2.4.2 Moisture Characteristic Curves for 218-E-10 LLBG Soils. Figures A-19 through A-2l illustrate the moisture characteristic curves and van GenuchtenMualem parameters that were used for 218-E-10 LLBG simulations. Again, the parameters were obtained by a simultaneous fit of both laboratory-measured moisture retention and unsaturated conductivities for samples from borehole 299-E32-4 located within the 218-E-10 LLBG (see Figure A-5). As before, unsaturated $K$ measurements were obtained by the SSHC method. The moisture retention data were corrected, as needed, for the gravel fraction following the procedure outlined before. No corrections were required for the saturated 
WHC-SD-WM-TI-730, REV 0

and unsaturated K's, since these were measured on the bulk samples. Again, the saturated $K$ values noted in the unsaturated hydraulic conductivity figures A-19 through A-21 represent the fitted $K$ 's obtained as part of the simultaneous fitting procedure.

Data presented in Figures A-19 through A-21 were used in VAM3D-CG modeling, and are also summarized in Table 3-5 in Chapter 3.

\section{A.3 REFERENCES}

Bergeron, M. P., G. V. Last, A. E. Reisnauer, 1987, Geohydrology of a Commercial Low-Level Radioactive Waste Disposal Facility Near Richland, Washington, U.S Ecology, Richland, Washingtion.

Bjornstad, B. N., 1990, Geohydrology of the 218-W-5 Burial Ground, 200 West Area, Hanford Site, PNL-7336, Pacific Northwest Laboratories, Richland, Washington.

Bouwer, H. and R. C. Rice, 1984, "Hydraulic Properties of Stony Vadose Zones," Ground Water, vol. 22, pp. 696-705.

Delaney, C., 1992, W-049-H Borehole Summary Report, WHC-SD-EN-DP-068, Westinghouse Hanford Company, Richland, Washington.

Gardner, W. H., 1986, "Water Content," Methods of Soils Analysis, Part 1, Physical and Mineralogical Methods, A. Klute, ed., Pp. 493-544, Agronomy Monograph No.9, 2nd edition, American Agronomy Society, Madison, Wisconsin.

Gee, G. W., M. L. Rockhold, and J. L. Downs, 1989, Status of FY 1988 SoilWater Study on the Hanford Site, PNL-6750, Pacific Northwest Laboratory, Richland, Washington.

Heller, P. R., 1989, "Physical Analysis for Grout Study," in Simulation of Infiltration of Meteoric Water and Contaminant Plume Movement in the Vadose Zone at the Single-Shell Tank 241-T-106 at the Hanford Site, Smoot, J. L., J. E. Szecsody, B. Sagar, G.W. Gee, and C. T. Kincaid, editors, WHC-EP-0332, Westinghouse Hanford Company, Richland, Washington.

Hillel, D., 1982, Introduction to Soil Physics, Academic Press Inc., Orlando Fiorida.

Hoffman, K. M., 1992, 200-BP-1 Borehole Summary Report for Tasks 2, 4, and 6, WHC-SD-EN-TI-054, Westinghouse Hanford Company, Richland, Washington.

Khalee1, R. J., F. Relyea, and J. L. Conca, 1995, "Evaluation of van Genuchten-Mualem Relationships to Estimate Unsaturated Hydraulic Conductivity at Low Water Contents," Water Resour. Res., vol. 31, pp. 2659-2668. 
K1ute, A., 1986, "Water Retention: Laboratory Methods," in Methods of Soil Anaiysis, Part 1, edited by A. Klute, pp. 635-660, Am. Soc. Agron., Madison, Wisconsin.

Klute, A. and C. Dirksen, 1986, "Hydraulic Conductivity and Diffusivity: Laboratory Methods," in Methods of Soil Analysis, Part 1, edited by A. Klute, pp. 687-734, Am. Soc. Agron., Madison, Wisconsin.

Lindsay, K. A., J. L. Slate, G. K. Jaeger, K. J. Swett, and R. B. Mercer, 1994, Geologic Setting of the Low-Level Burial Grounds, WHC-EN-TI-290, Rev. 0, Westinghouse Hanford Company, Richland, Washington.

Mualem, Y., 1976, "A New Model for Predicting the Hydraulic Conductivity of Unsaturated Porous Media," Water Resour. Res., vol. 12, pp. 513-522.

Rawlins, S. L. and G. S. Campbell, 1986, "Water Potential: Thermocouple Psychrometry," in Methods of Soil Analysis, Part 1, A. Klute, editor, pp. 597-617, Am. Soc. Agron., Madison, Wisconsin.

Relyea, J., 1995, laboratory reports, project files for WHC-EP-0883 Rev. 0, West inghouse Hanford Company, Richland, Washington.

Rockhold, M. L., M. J. Fayer, and P. R. Heller, 1993, Physical and Hydraulic Properties of Sediments and Engineered Materials Associated with Grouted Double-Shell Tank Waste Disposal at Hanford, PNL-8813, Pacific Northwest Laboratory, Richland, Washington.

van Genuchten, M. Th., F. J. Leij, and S. R. Yates, 1991, The RETC Code for Quantifying the Hydraulic Functions of Unsaturated Soils, EPA/600/2-91/065, U.S. Environmental Protection Agency, Washington, D.C.

van Genuchten, M. Th., 1980, "A Closed-Form Equation for Predicting the Hydraulic Conductivity of Unsaturated Soils," Soil Sci. SoC. Am. J., vol. 44 , pp 892-898.

Volk, B. W., 1993, Relating Particle Size Distribution to Moisture Retention Data for Hanford Soils. M.S. Thesis, Washington State University, TriCities, Richland, Washington.

Weekes, D.C. and J.V. Borghese, 1994, Site Characterization Report for the Environmental Restoration Disposal Facility, WHC-SD-EN-ER-005, Rev. 0, Westinghouse Hanford Company, Richland, Washington. 
Figure A-1. Map for the 218-E-12B Burial Ground Showing Locations of Cross Sections.
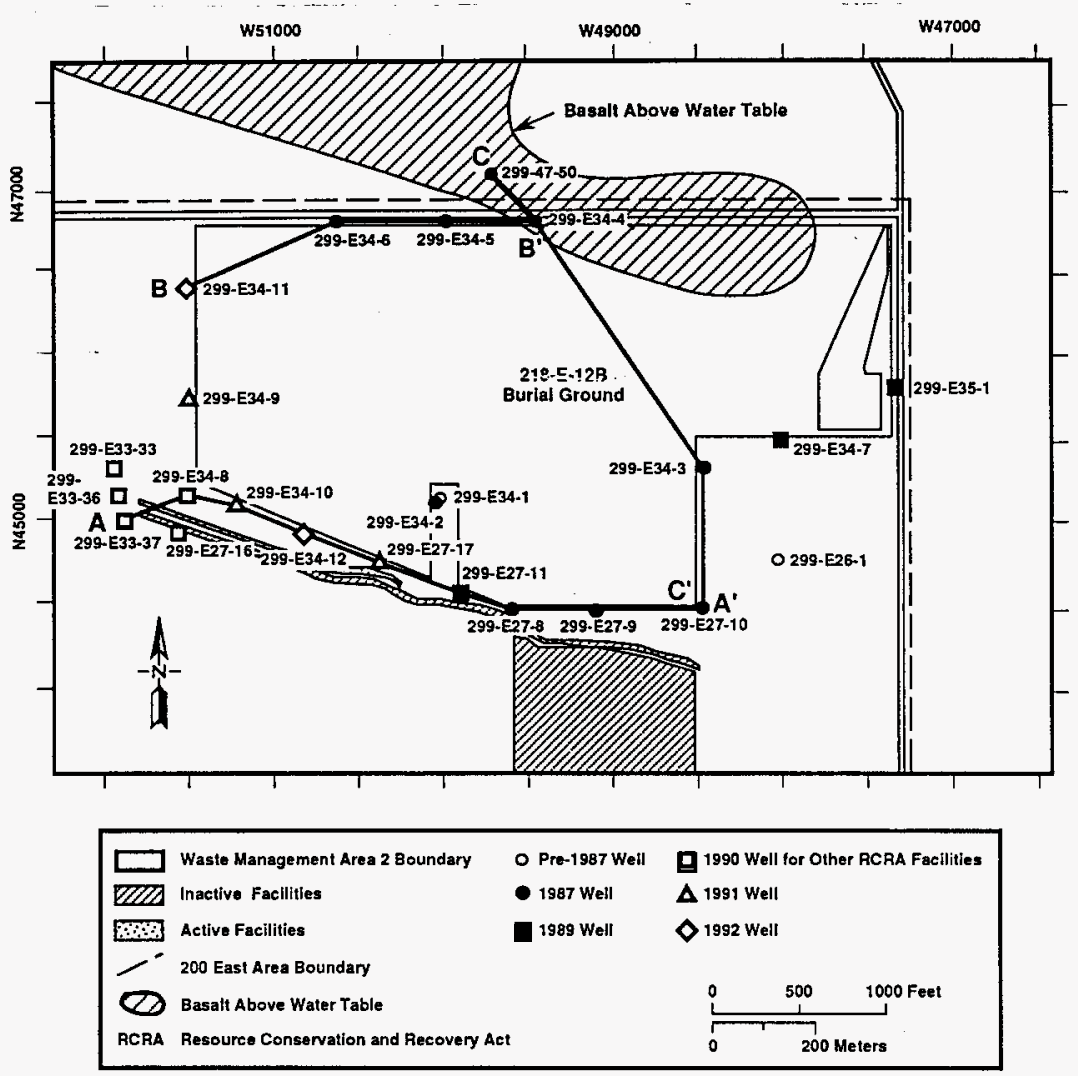

H9403025.1 
Figure A-2. Cross Section A-A' through the 218-E-12B Burial Ground (Lindsay et al. 1994).

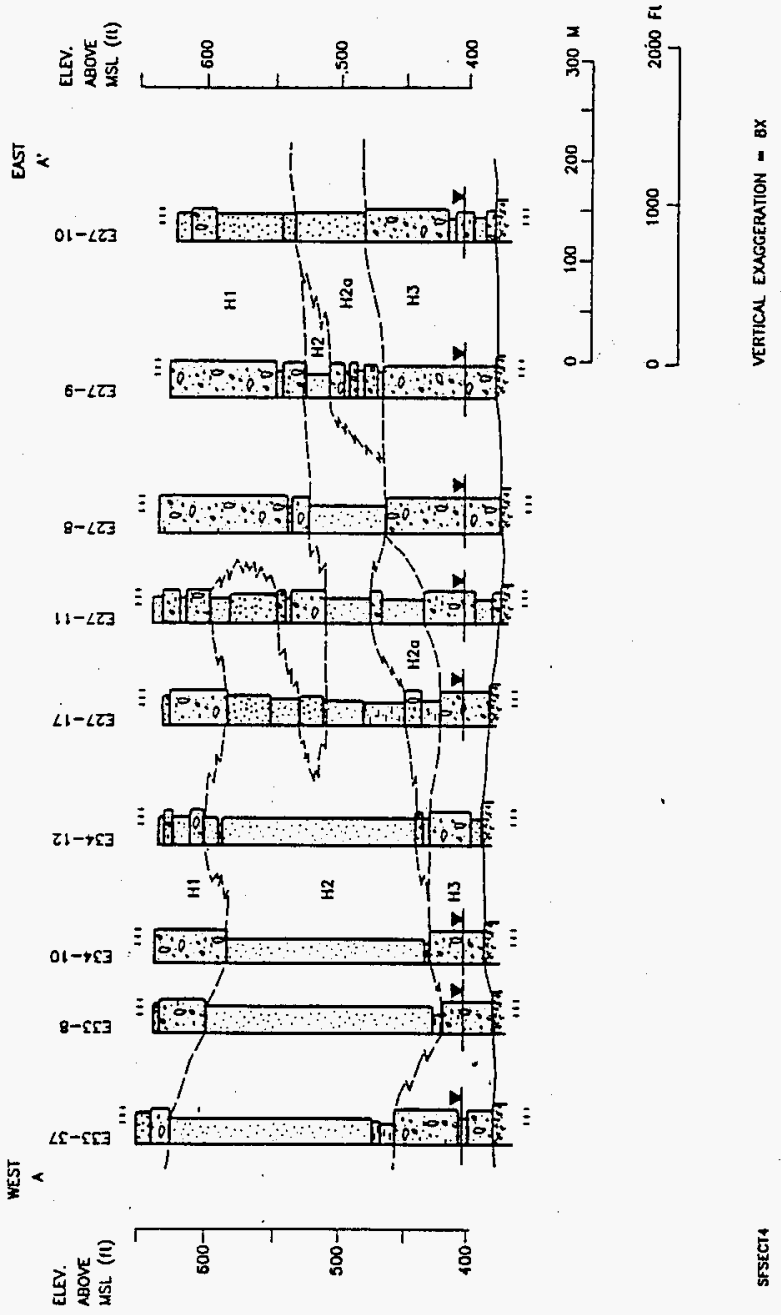


Figure A-3. Cross Section B-B' through the 218-E-12B Burial Ground (Lindsay et al. 1994).

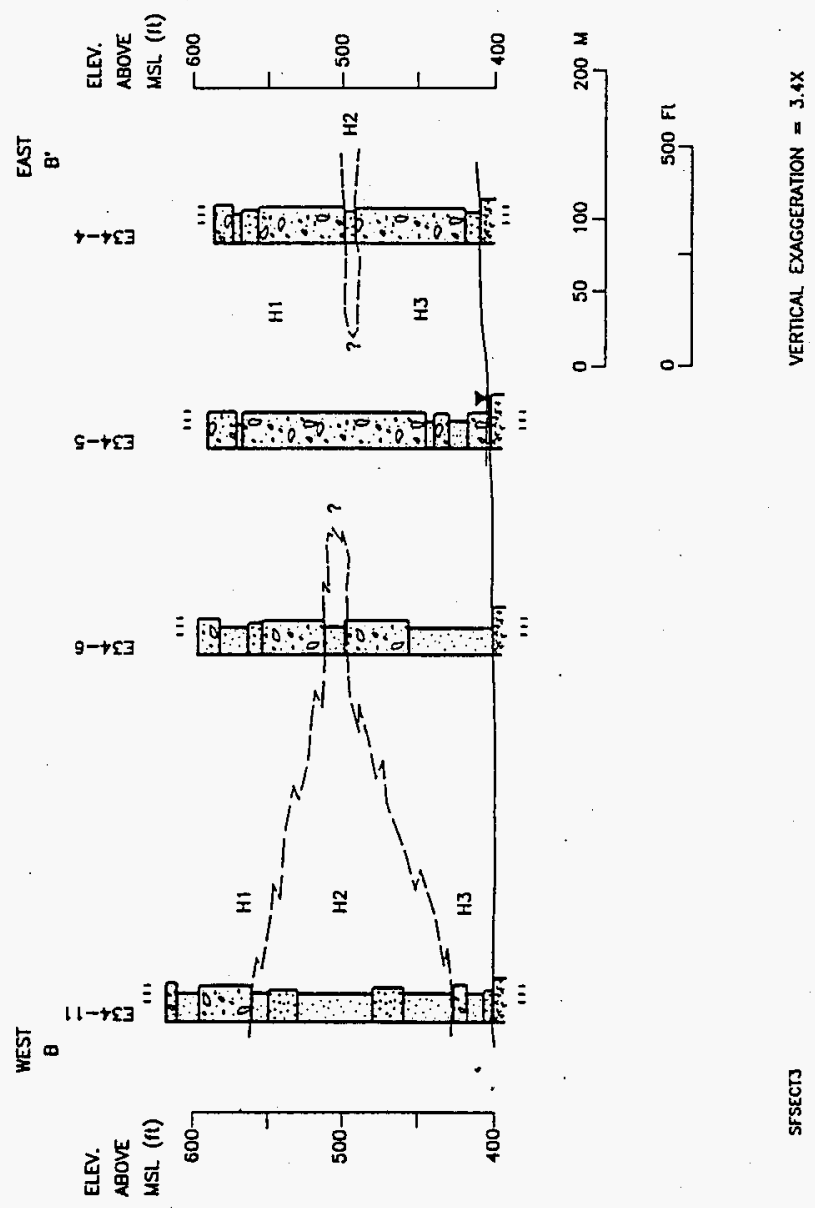


WHC-SD-WM-TI-730, REV 0

Figure A-4. Cross Section C-C' through the 218-E-12B Burial Ground (Lindsay et al. 1994).

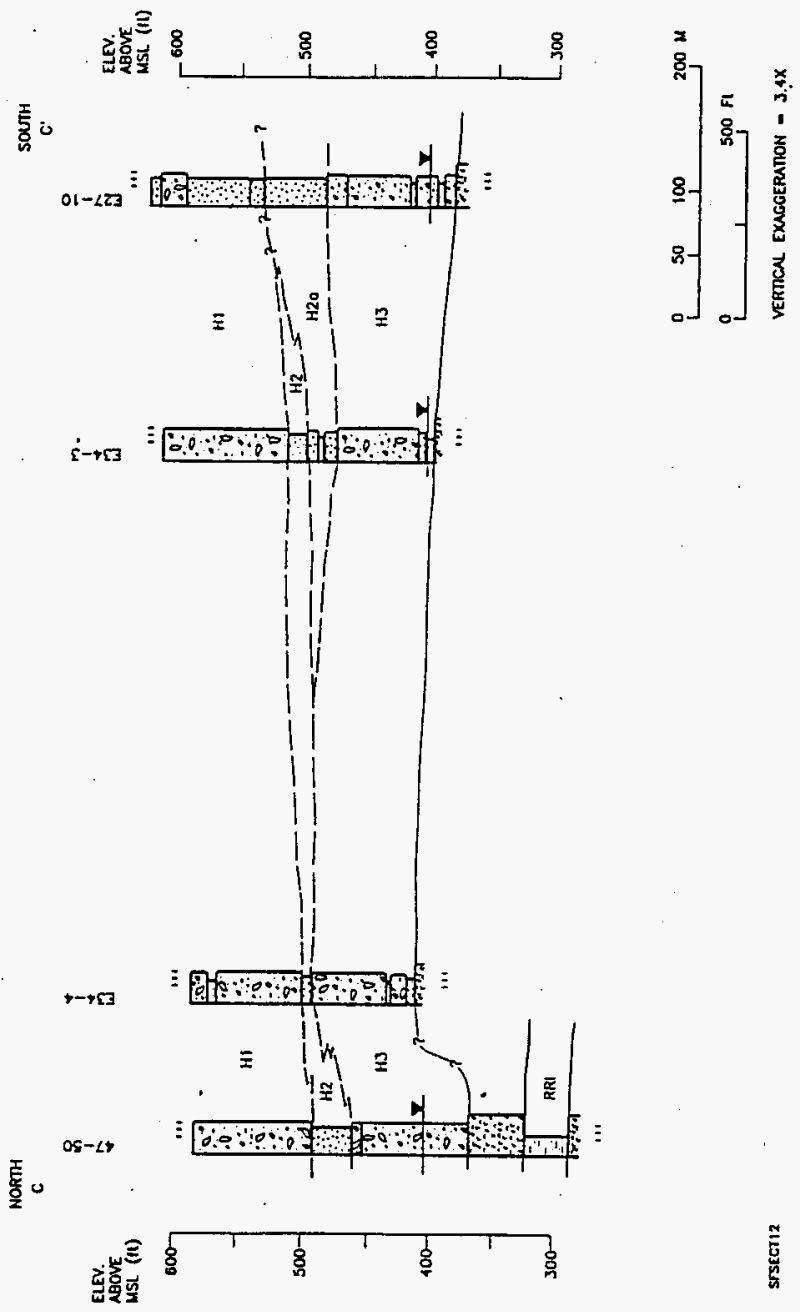


Figure A-5. Map for the 218-E-10 Burial Ground Showing Cross Section Locations.
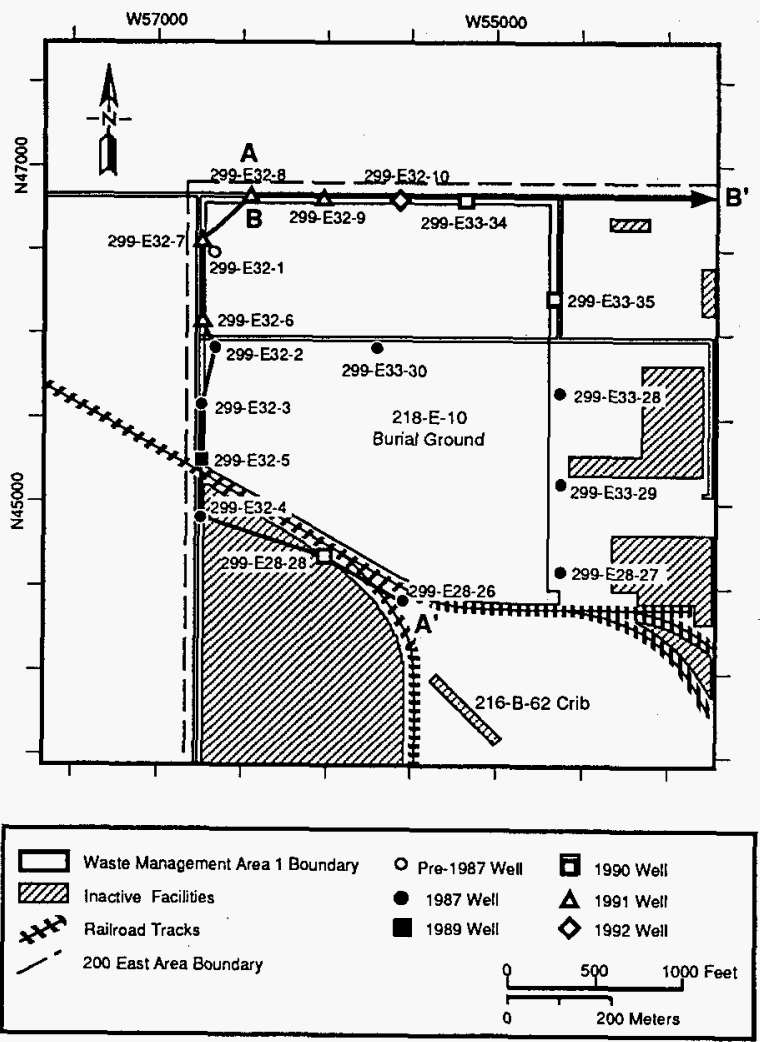

H9403025.5 
Figure A-6. Cross Section A-A' through the 218-E-10 Burial Ground.

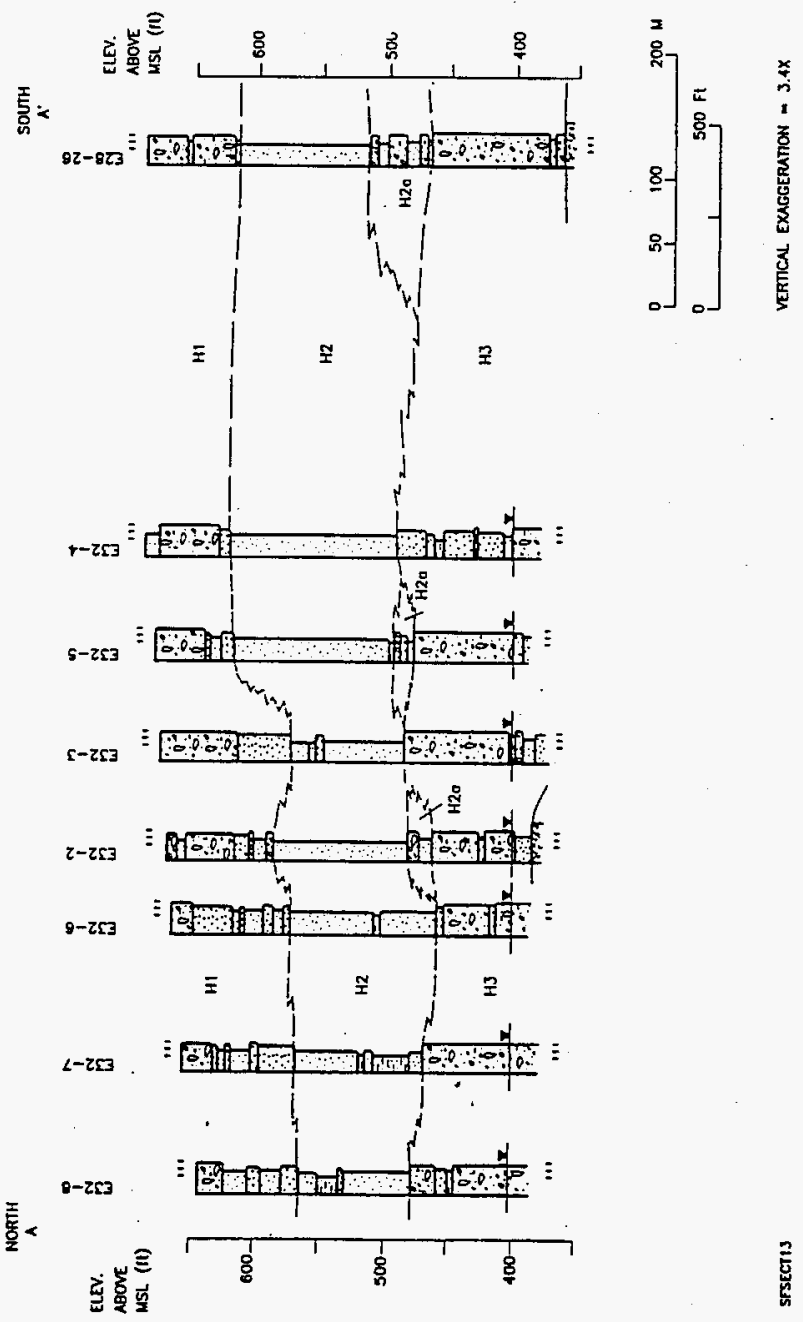


WHC-SD-WM-TI-730, REV 0

Figure A-7. Cross Section B-B' through the 218-E-10 Burial Ground.

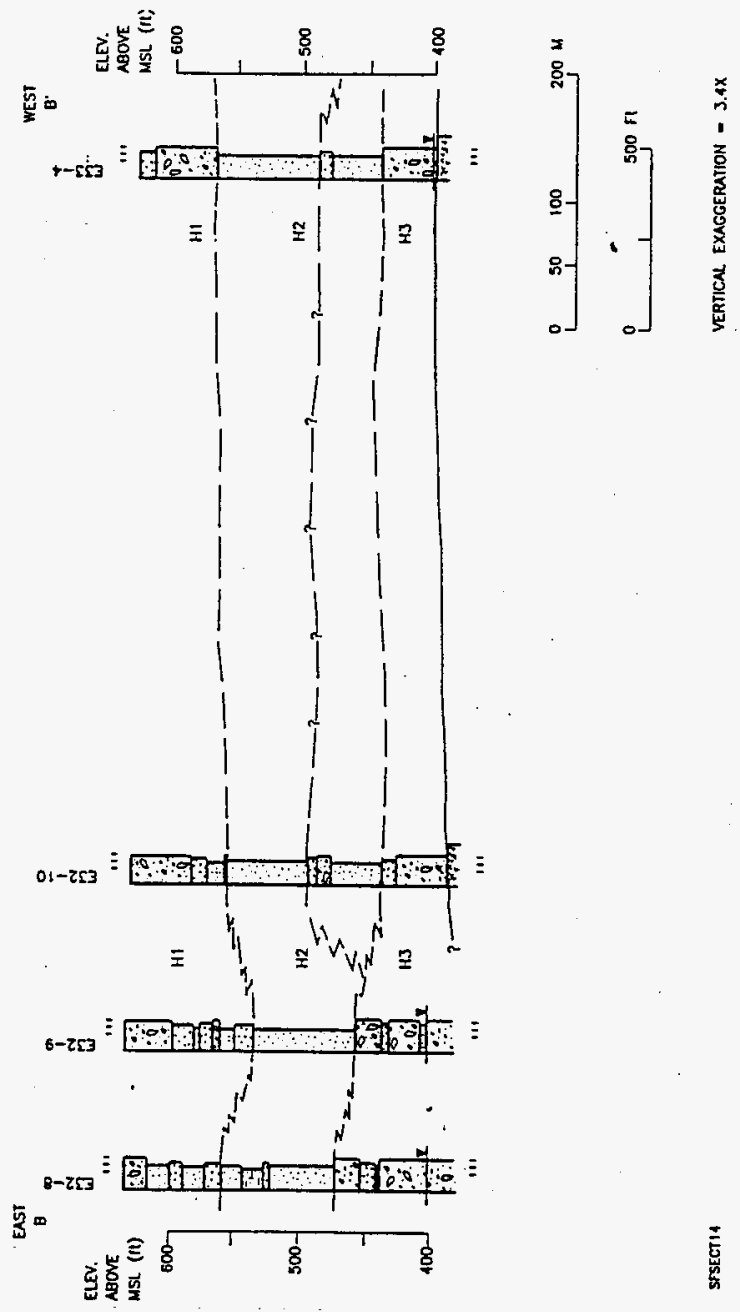


Figure A-8. 200 East Area Tritium Map (from Ford 1993).

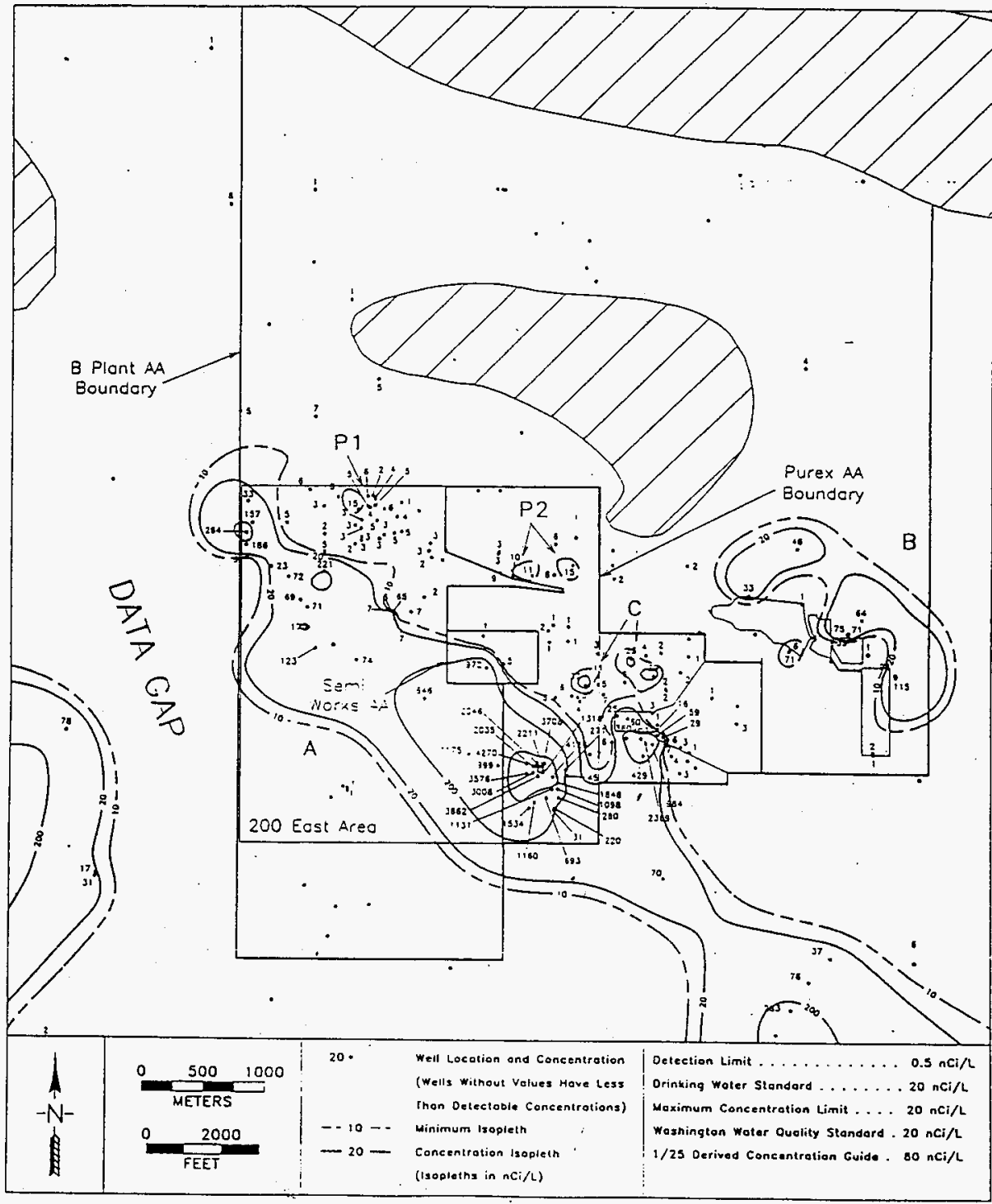


WHC-SD-WM-TI-730, REV 0

Figure A-9. 200 East Area Technitium-99 Map (from Ford 1993).

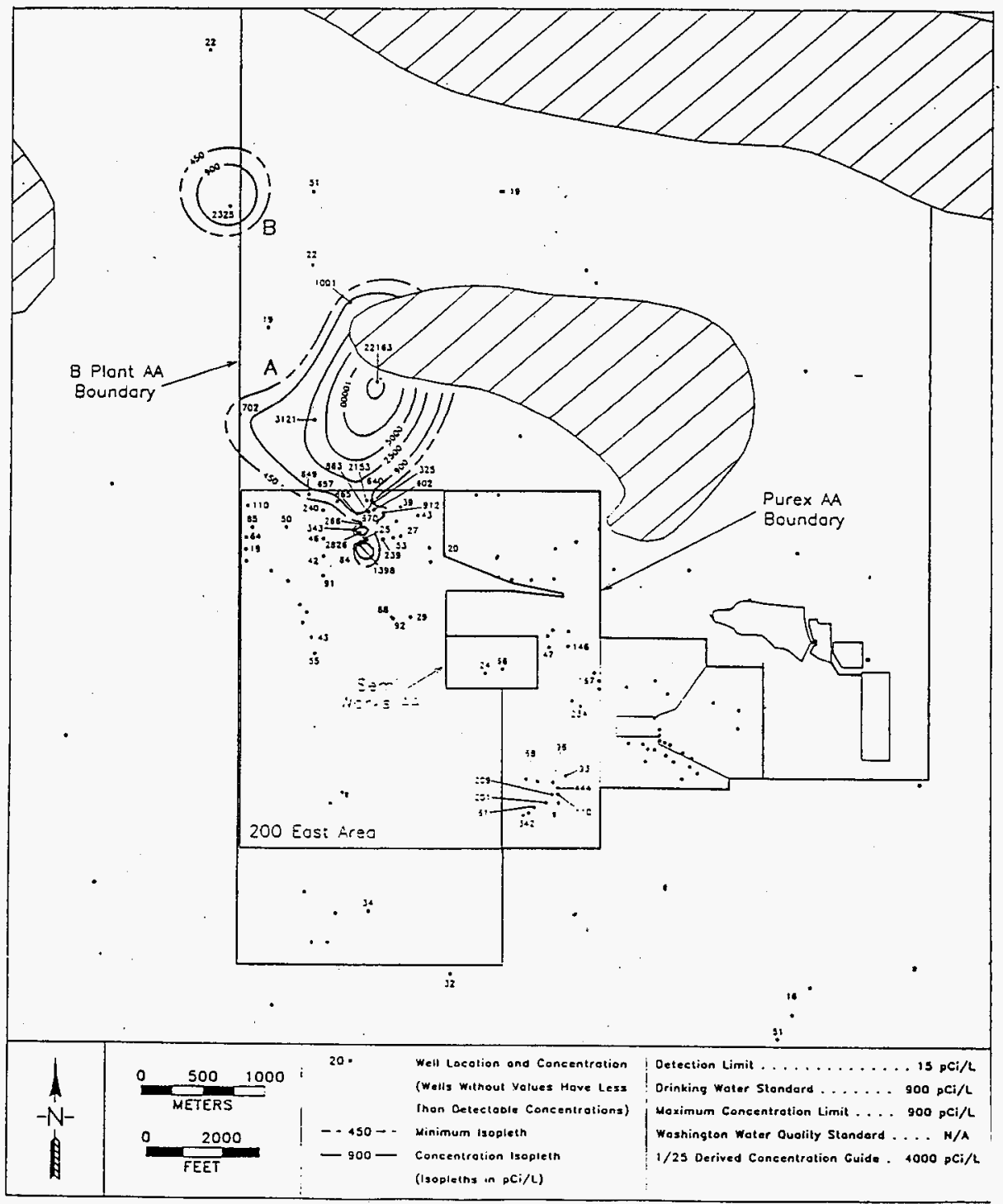


WHC-SD-WM-TI-730, REV 0

Figure A-10. 200 East Area Iodine-129 Map (from Ford 1993).

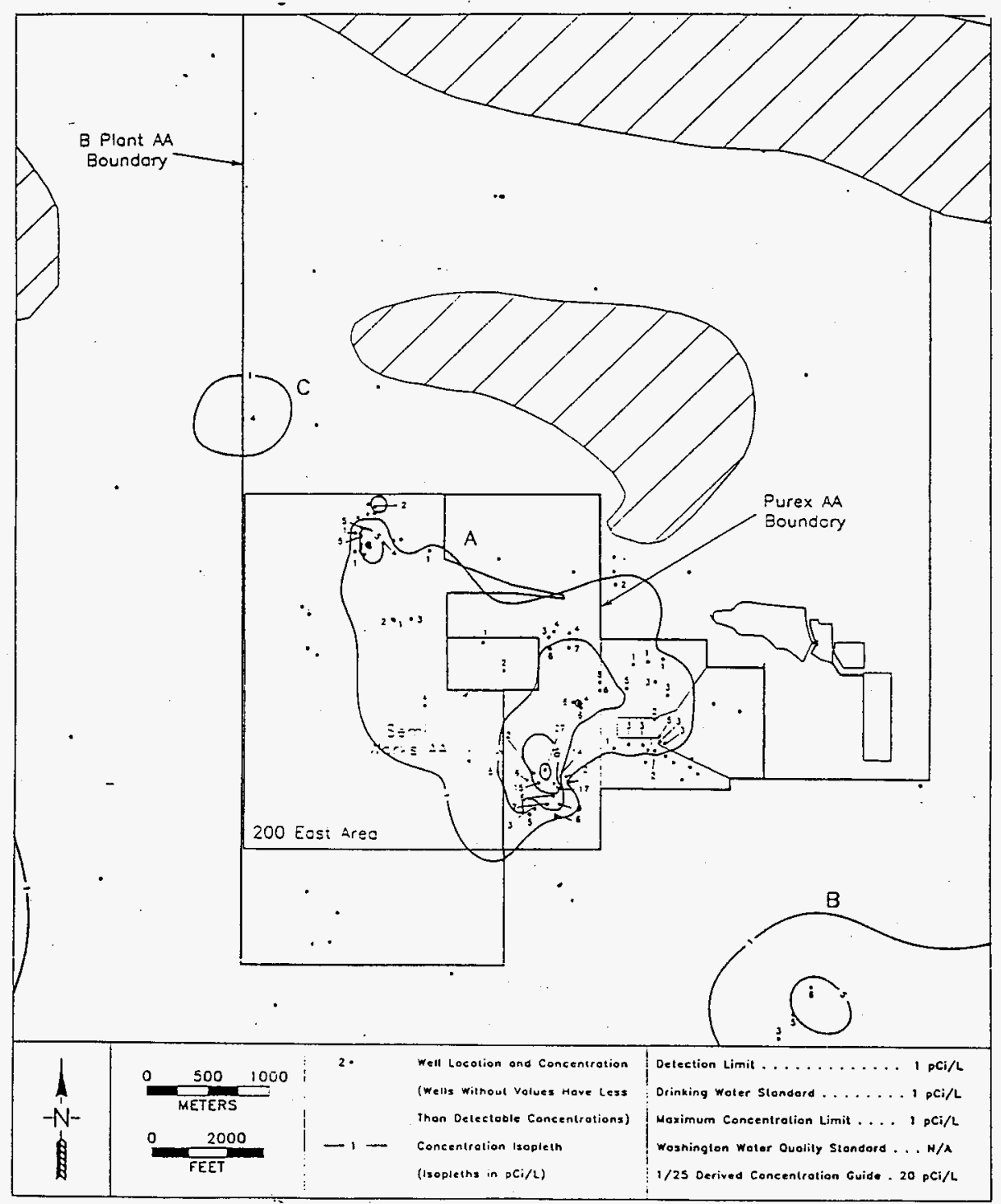


Figure A-11. 200 East Area Strontium-90 Map (from Ford 1993).

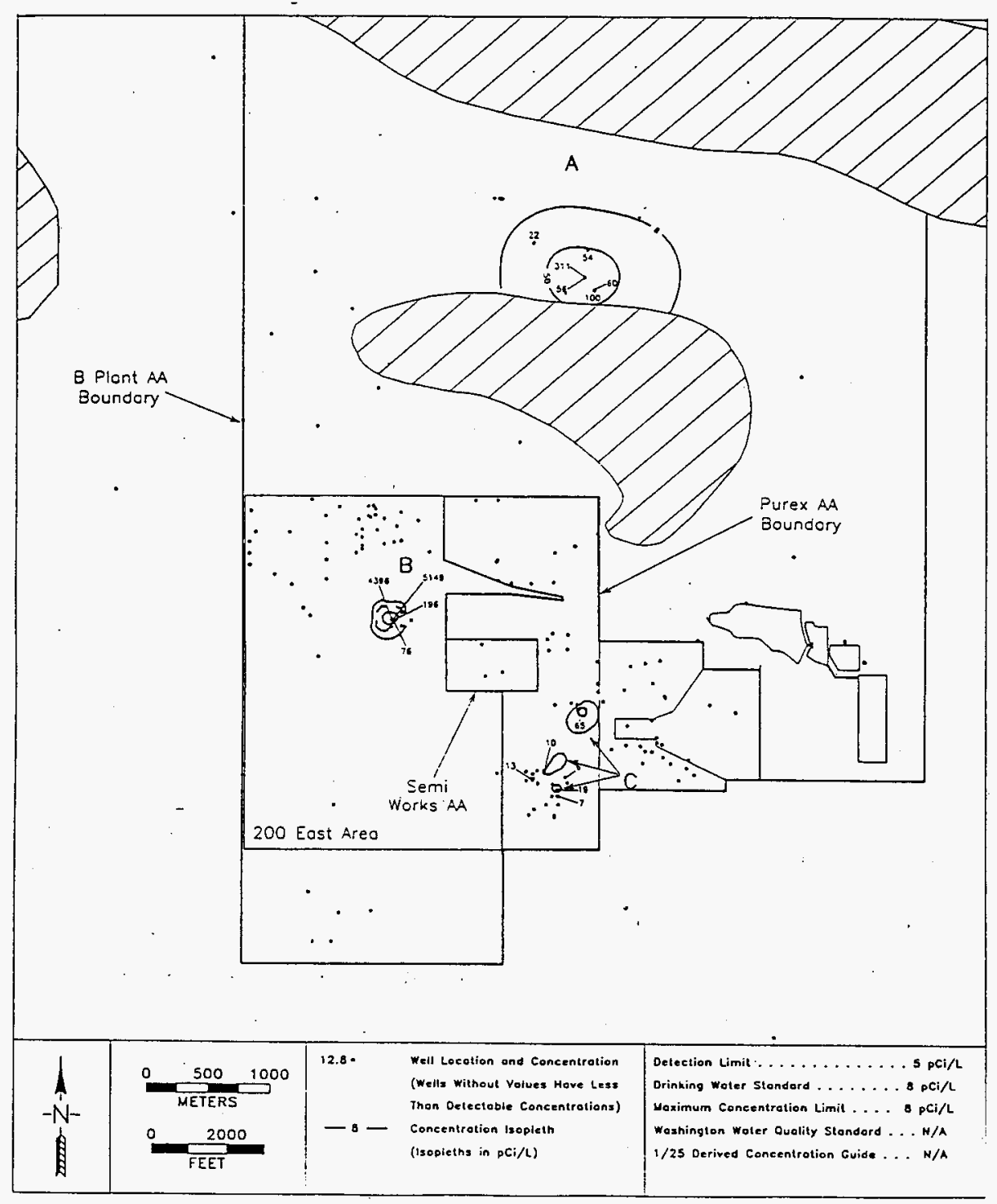


WHC-SD-WM-TI-730, REV 0

Figure A-12. 200 East Area Cobalt-60 Map (from Ford 1993).

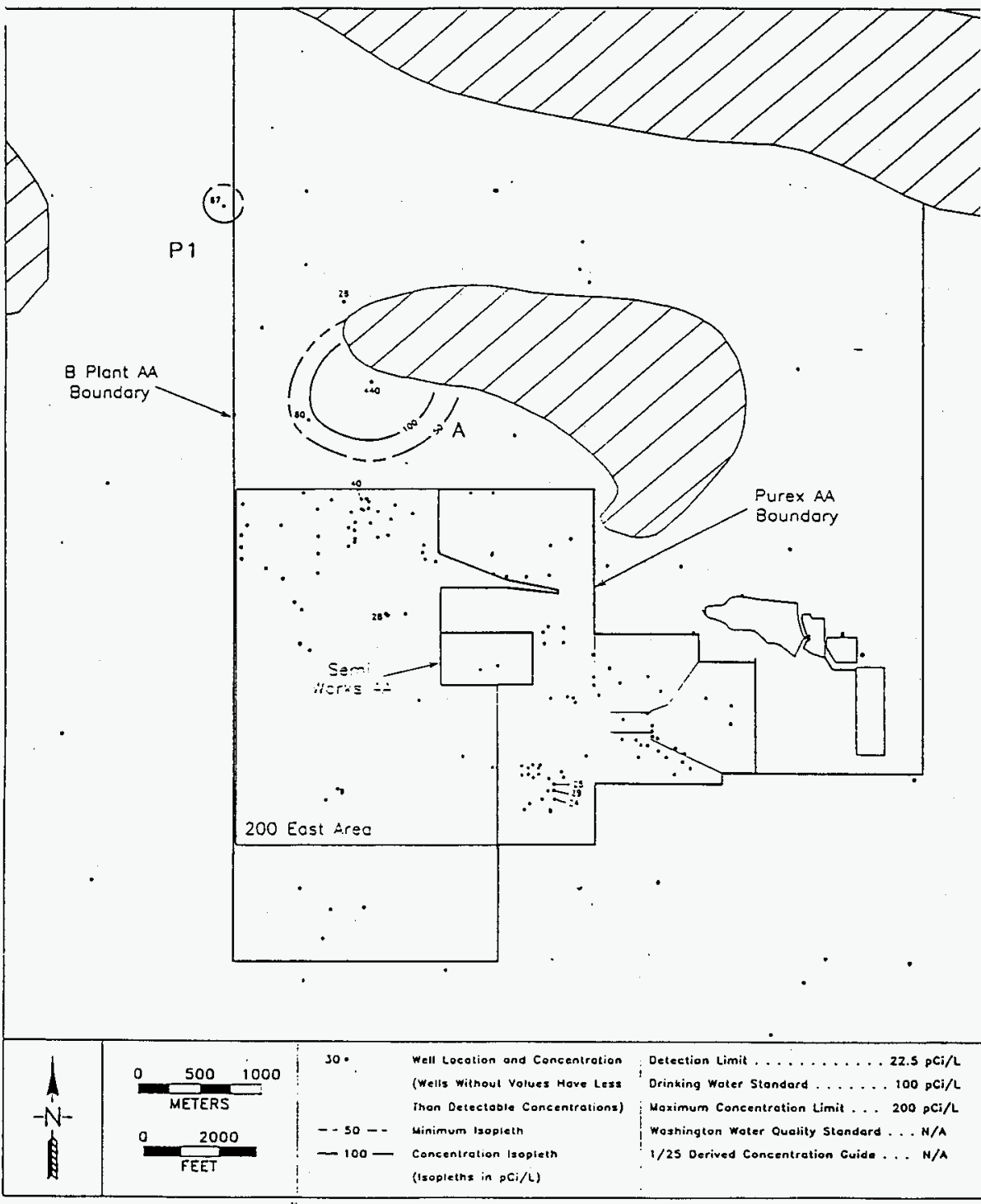


Figure A-13. 200 East Area Cesium-137 Map (from Ford 1993).

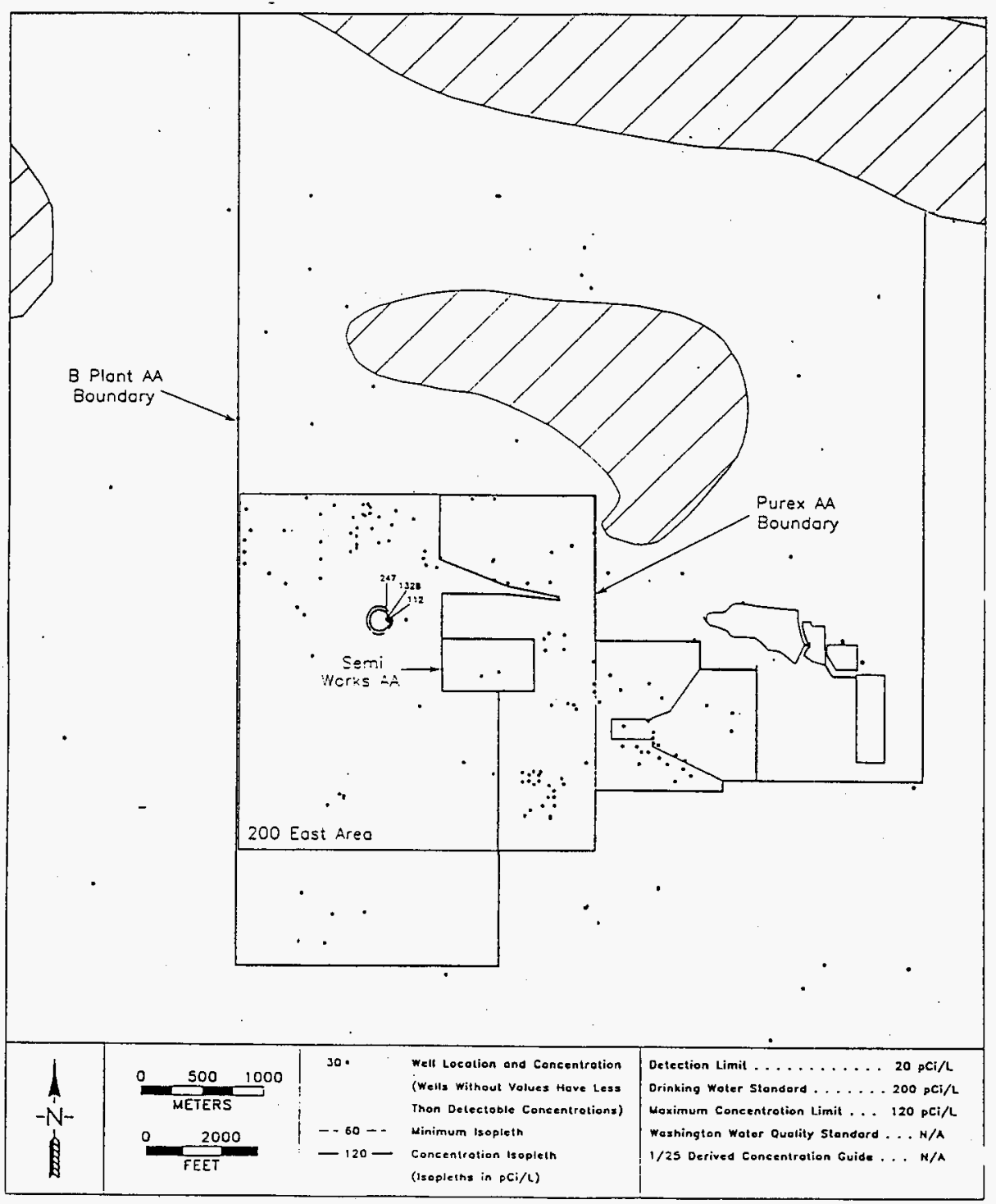


WHC-SD-WM-TI-730, REV 0

Figure A-14. 200 East Area Plutonium Map (from Ford 1993).

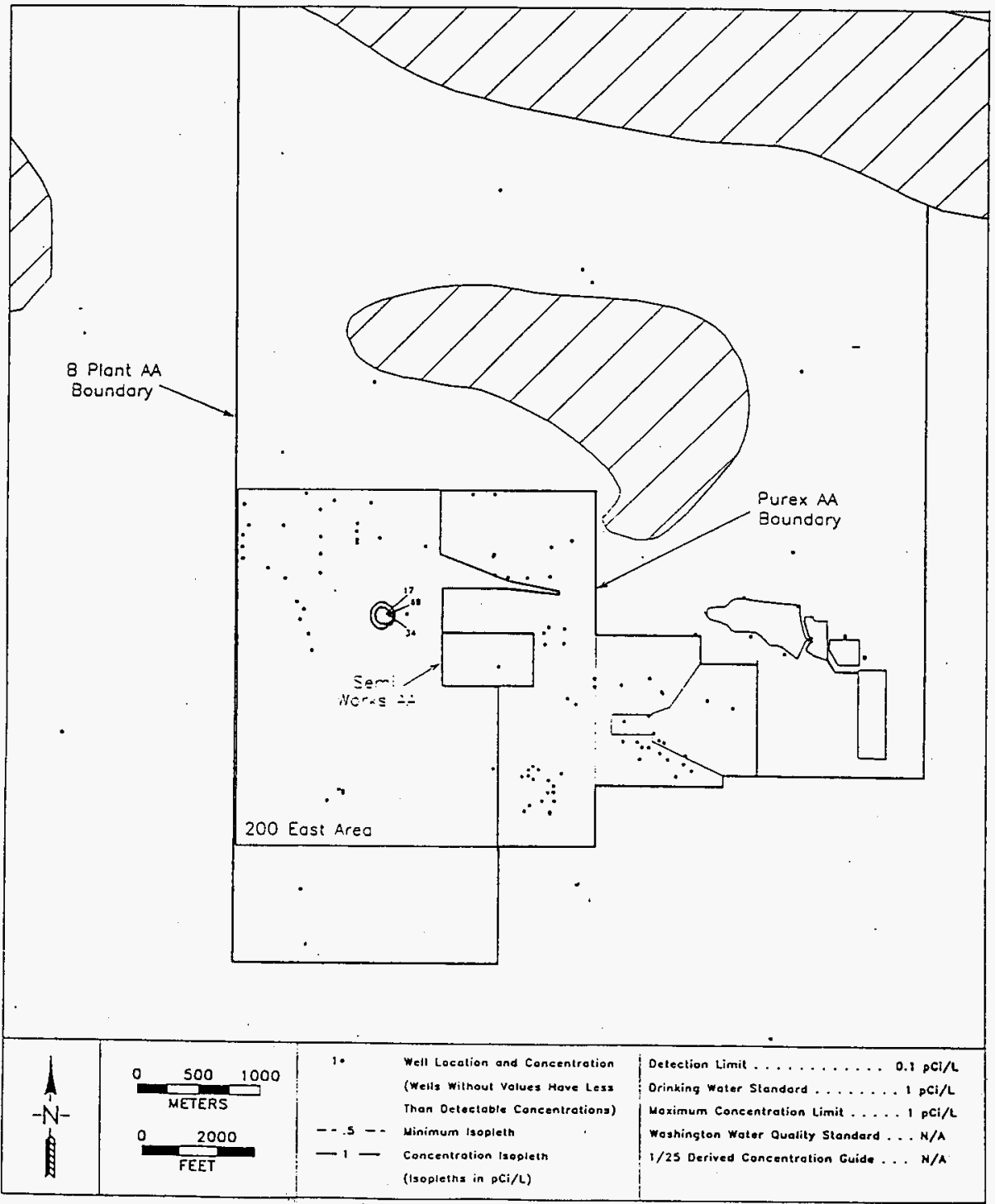


Figure A-15. Schematic of Apparatus Used to Measure Soil Unsaturated Conductivity.

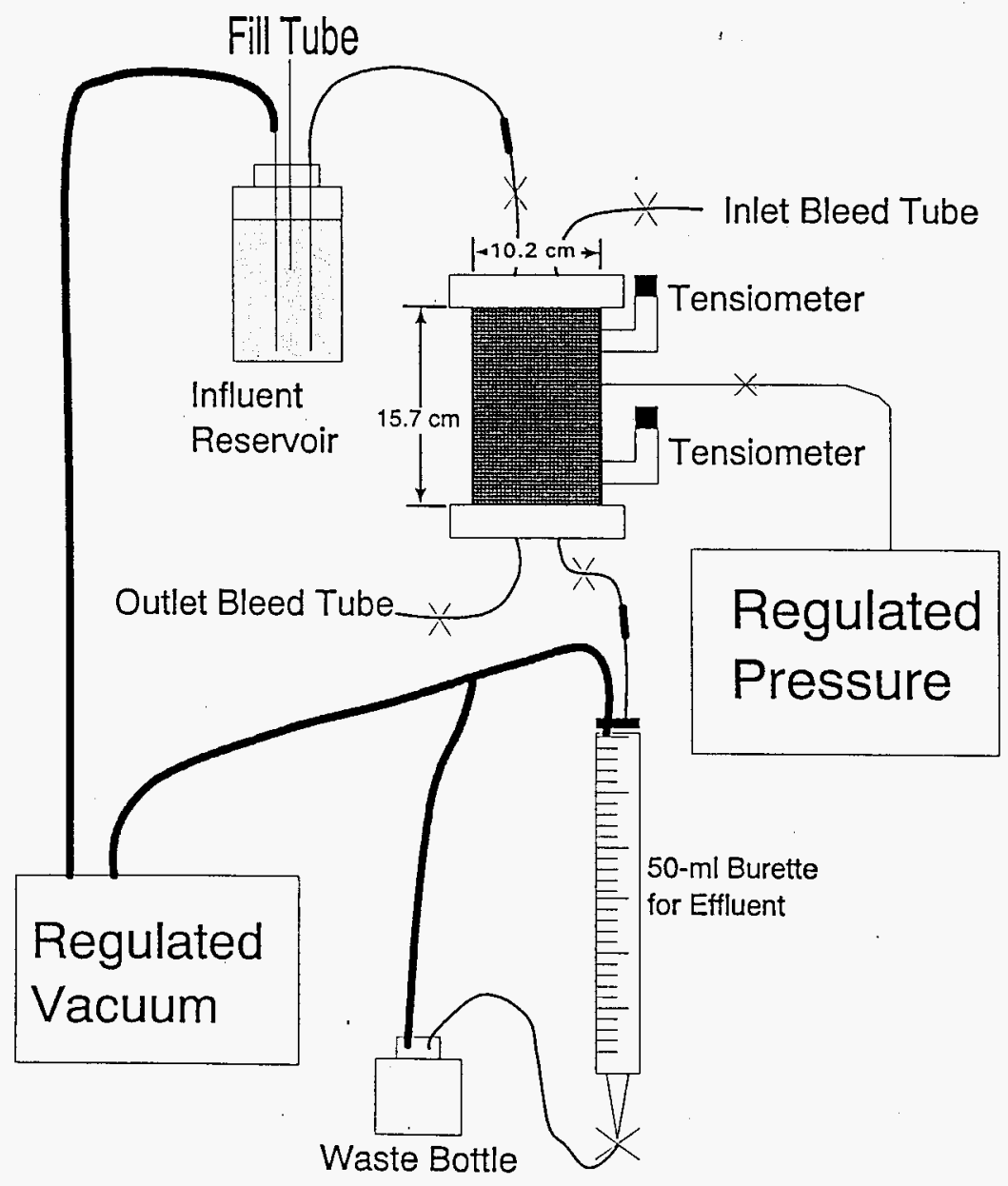



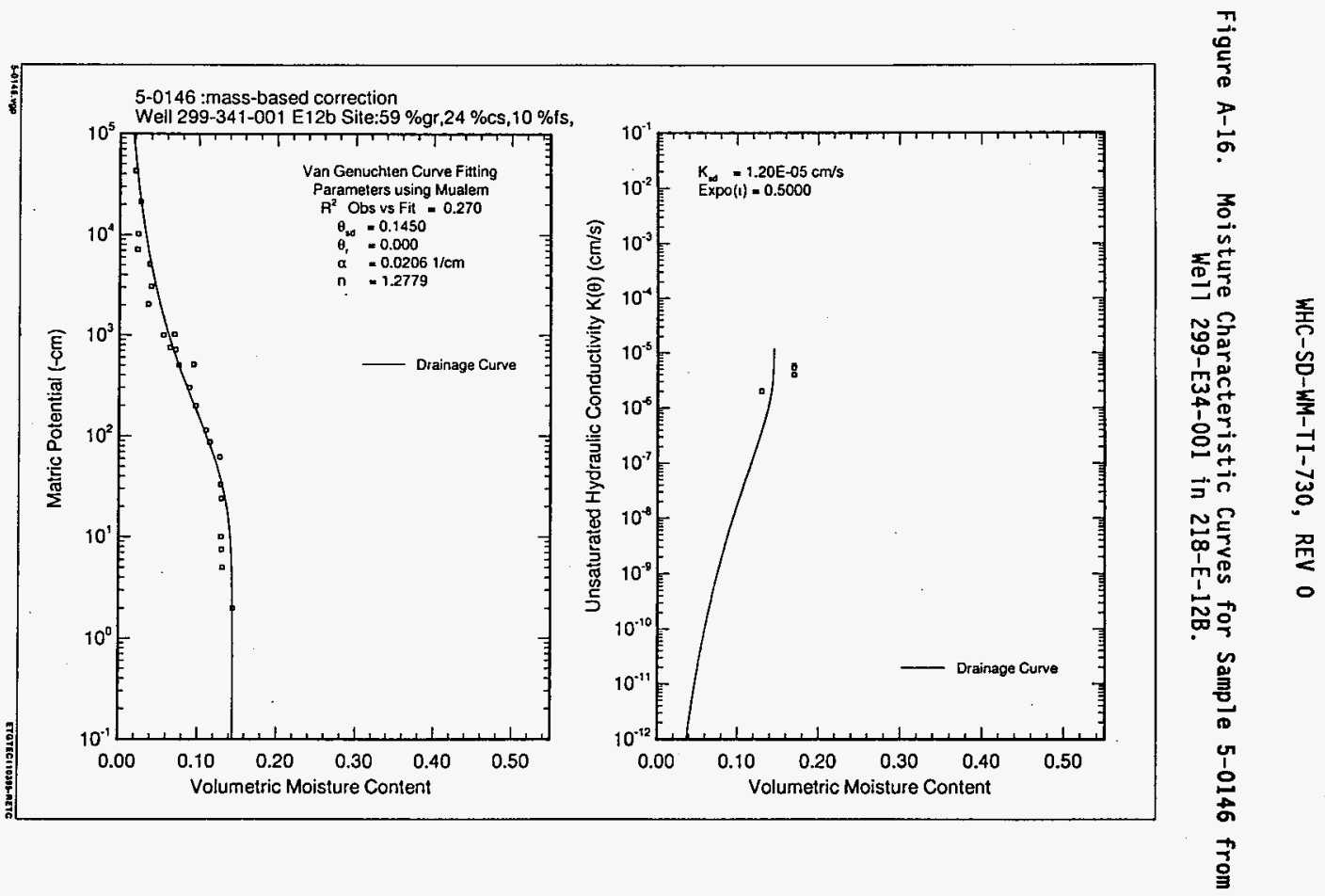
Figure A-17. Moisture Characteristic Curves for Sample 5-0147 from We11 299-E34-001 in 218-E-12B.

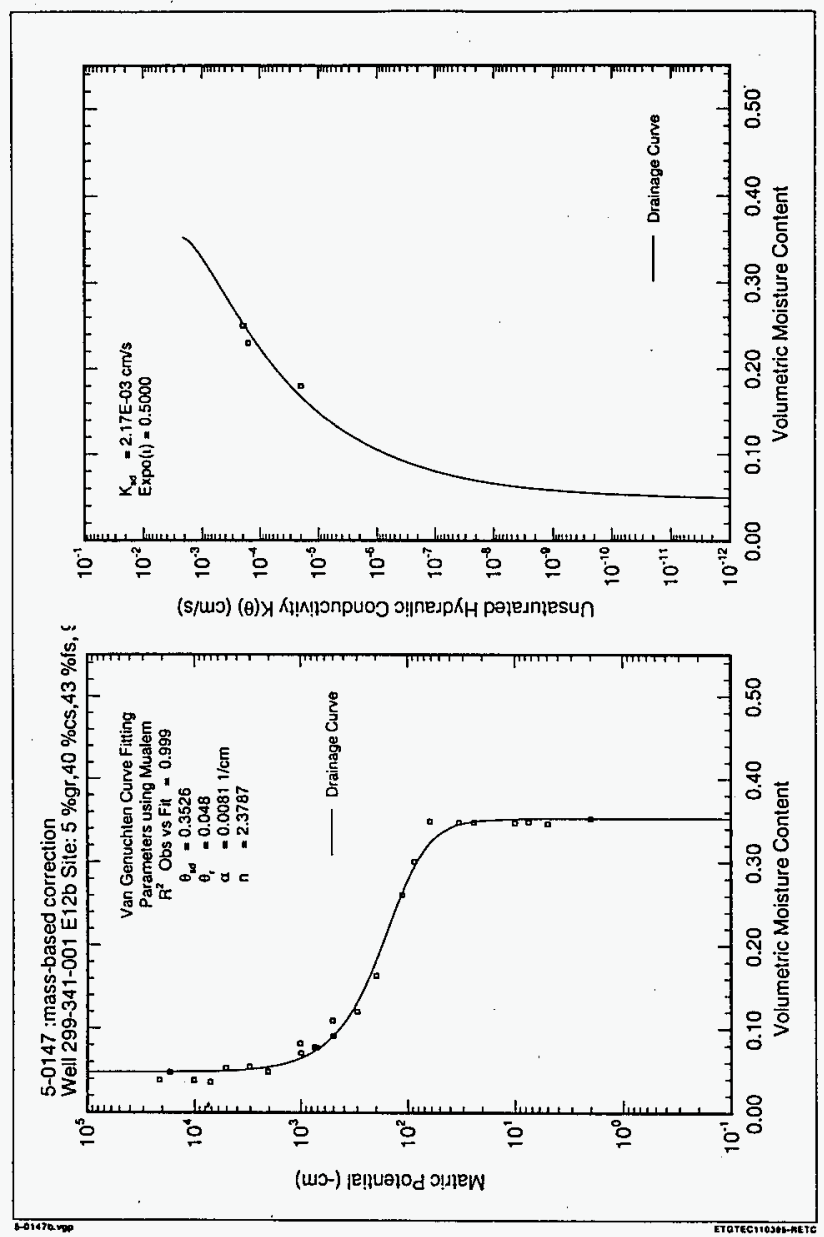


Figure A-18. Moisture Characteristic Curves for Sample 5-0148 from Well 299-E34-001 in 218-E-12B.

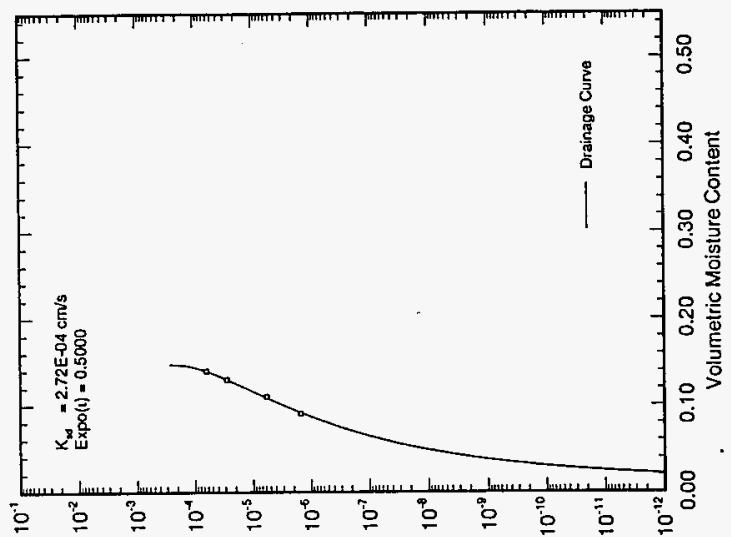

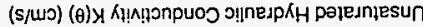

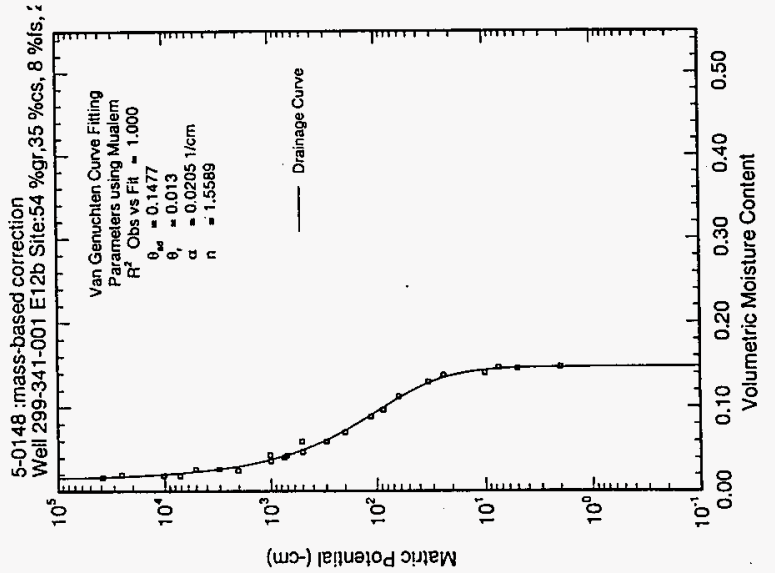

ETafteibatu-nete 


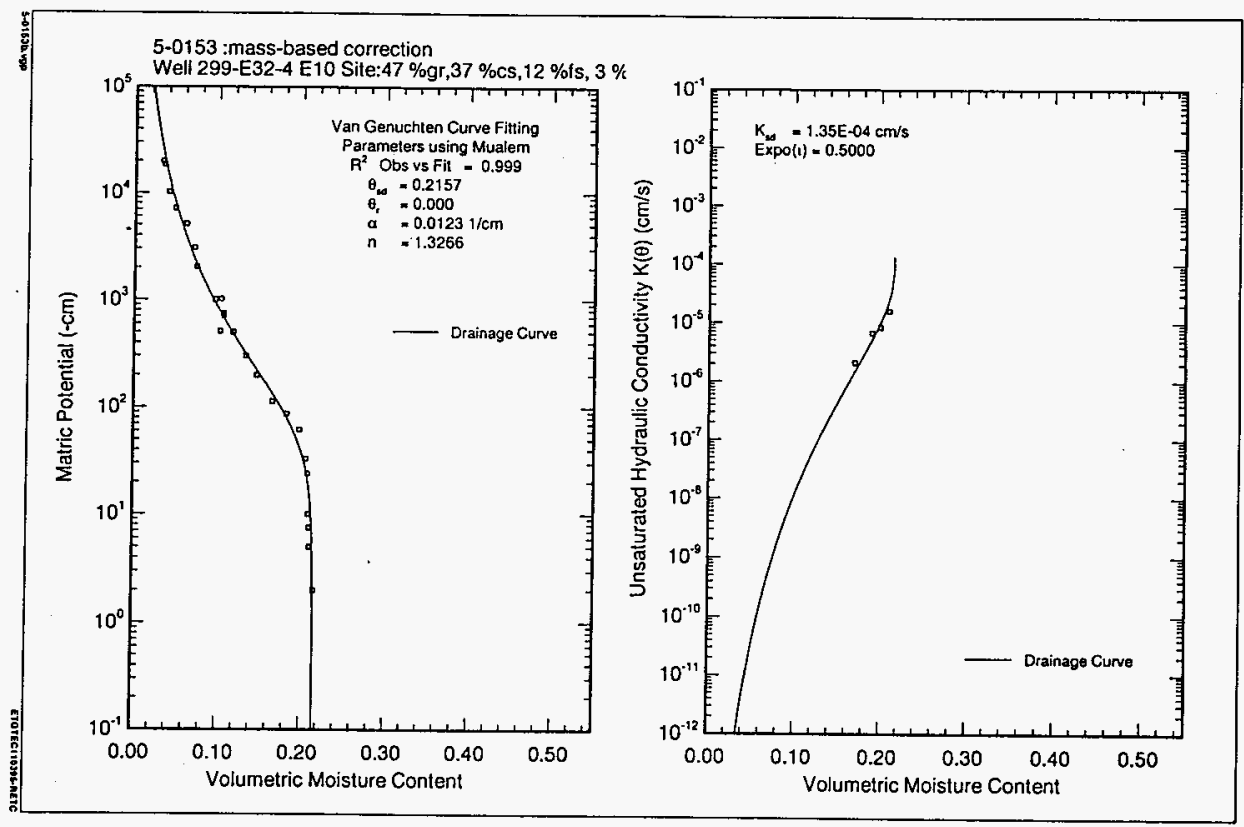


Figure A-20. Moisture Characteristic Curves for Sample 5-0154 from Wel1 299-E32-4 in 218-E-10.

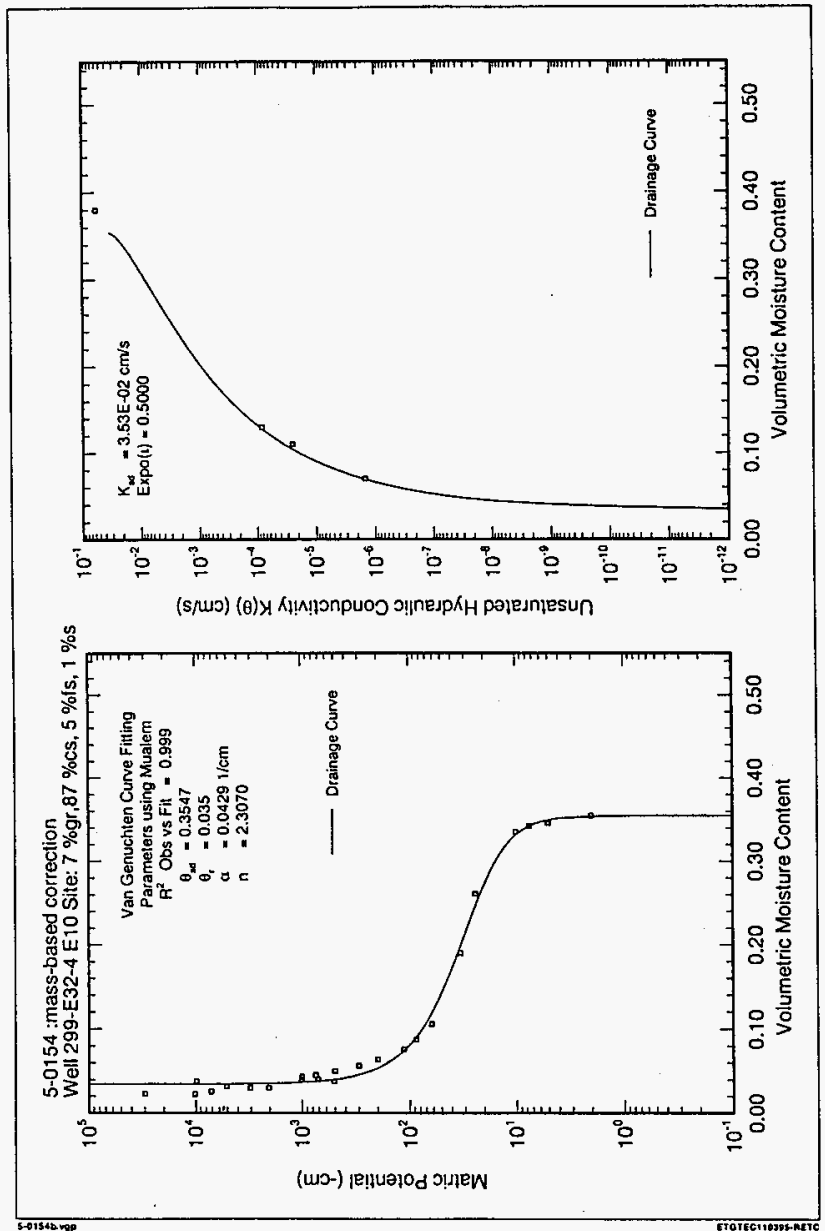


Figure A-21. Moisture Characteristic Curves for Sample 5-0158 from We11 299-E32-4 in 218-E-10.

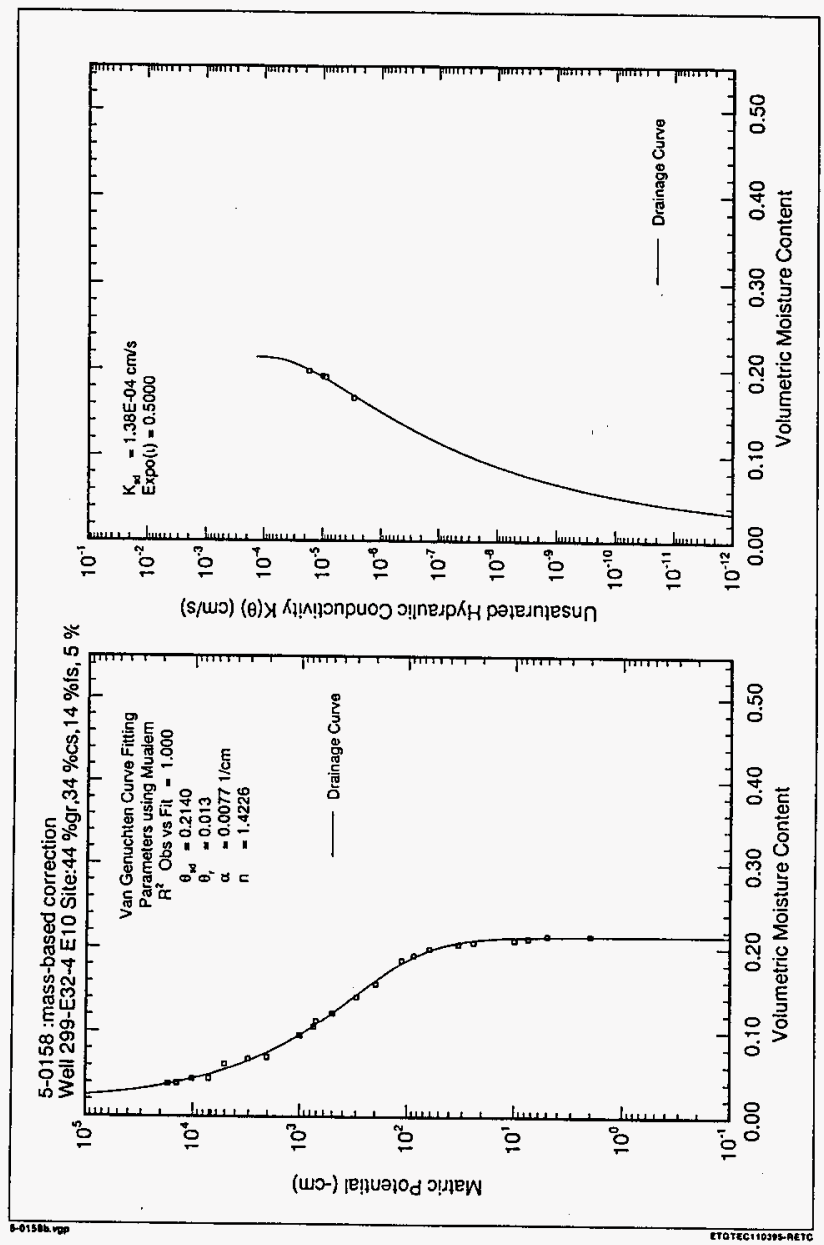




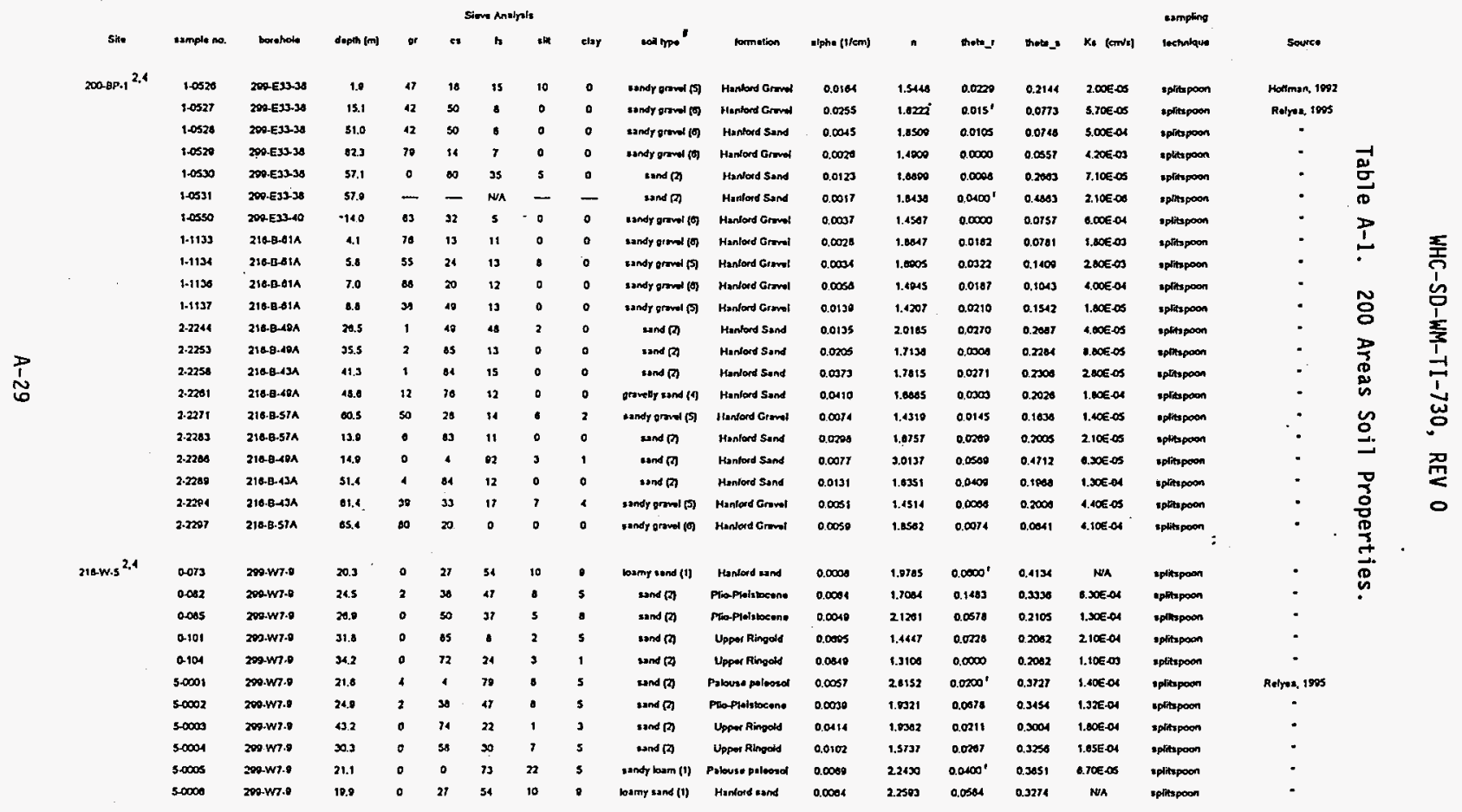




\begin{tabular}{|c|c|c|c|c|c|c|c|c|c|c|c|c|c|c|c|c|c|c|c|}
\hline & 50007 & 2000.477-0 & 40.3 & o & $\infty$ & 13 & s & 2 & Inde (n) & Upper Rhoods & 0.1300 & 1.7017 & 0.0231 & 0.0502 & $3.00 E-03$ & eplitupoon & * & & \\
\hline \multirow[t]{6}{*}{$218 \cdot \mathrm{W} \cdot 5^{1,5}$} & W7.2.05 & 200:wor.02 & 19.8 & 35 & 30 & 11 & 10 & 0 & silty candr growe (f) P & Plopplolitoseno & 0.02102 & 1,4503 & 0.004 & 0.3752 & $0.00 E-02$ & spluspoos & Ejonnstod. 1000 & & \\
\hline & $w 7 \cdot 2 \cdot 04$ & 200.607 .02 & 20.0 & 48 & 30 & 7 & 0 & 0 . & sundy provel ()) & Upper Firoold & 0.0557 & 1.0000 & 0.0233 & 0.2180 & 3.10602 & splisppoom & • & & \\
\hline & w7.2-15t & 200 -wot.02 & $<0.8$ & 32 & $x$ & 15 & 11 & 0 & siny eendy proved (M) & Mudslo Ringold & 0.1021 & 8.3162 & $0.0150^{\prime}$ & 0,3011 & $2,10 E-02$ & ipiaspoon & * & & \\
\hline & w7.2.210 & 200.wor.02 & $\infty .8$ & 30 & is & 18 & - & - & sandy pranel (1) & Misdis: Ringold & 0.068 & $1.7 \mathrm{nes}$ & 0.0812 & 0.1594 & $2.706-03$ & Ipluspoon & - & & \\
\hline & W10-13-As & $200 . w 10-13$ & 13.7 & 0 & 62 & 33 & 5 & 0 & Iand (2) & Henlord Sond & 0.0408 & 2.0072 & 0.0306 & 0.2915 & $5.80 E-02$ & nepliks poon & $\cdots$ & & \\
\hline & w10.13-00 & 200.w10.13 & 24,4 & 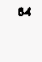 & 25 & - & 5 & 0 & sundy growed (5) & Hantord Grend & 0.275 & 1.3718 & 0.0367 & $0.1 / 81$ & $2.706-02$ & iptirspoon & $\bullet$ & क्ष & \\
\hline \multirow[t]{10}{*}{$241 \cdot \pi \cdot 100^{2,4}$} & $3-02$ to & $200-w 10-100$ & 3.1 & 4 & 30 & 22 & 0 & 0 & 2undy graval (5) & Hanloxd oramed & 0.0115 & 2.2002 & 0.0450 & 0.1854 & $1.00 E-03$ & splitsposon & Rolpes, 1895 & $\frac{2}{10}$ & \\
\hline & 3.0213 & $200 \cdot$ w10.100 & s.e & 'ו & 33 & 30 & 0 & 0 & gramely send $(4)$ & Hanloxd prever & 0.0040 & 2.4233 & 0.0424 & 0.2003 & $1,02 E-03$ & selmposon & - & & \\
\hline & 3.0270 & $200 \cdot \mathrm{w} 10-100$ & 1.8 & 40 & 32 & 20 & 2 & 0 & andy prower () & Manlord graved & 0.0001 & 2.1040 & $0.003 t$ & 0.140 & NA & oplinzpoon & * & I & \\
\hline & 2.0580 & $200 \cdot w 10.106$ & 25.5 & 2 & so & 12 & o & 0 & sund (2) & lisnford and & 0.0010 & 2.0055 & 0.0575 & 0.3443 & T.3BE-OS & uplitspoon & • & $=$ & $\frac{7}{0}$ \\
\hline & 30604 & $200 \cdot w 10-100$ & 42.2 & $\infty$ & 13 & 7 & 0 & - & Bondy grow & Midsie Aingald & 0.0115 & 1.3004 & 0.0000 & 0.0718 & $2.03 E .05$ & Iplitispoon & $\cdot$ & & \\
\hline & $3-0050$ & 200.110 .100 & 30.0 & 03 & 15 & 12 & 10 & 0 & sundy granol (9) & Middle Rhoold & 0.0023 & $1.5 \mathrm{Tes}$ & $0.0100 "$ & 0.1070 & $1.00 E 03$ & oplitzposan & - & 今 & \\
\hline & 30562 & $200 \cdot w 10-100$ & 48.1 & 0 & se & 25 & 10 & 1 & and (1) & Middile Ringold & $0.012 \mathrm{~A}$ & 20004 & 0.0510 & 0.4344 & A.57E.05 & splitimposn & $\cdot$ & О & \\
\hline & 3.005 & 200.W $10-100$ & 48.5 & 0 & 30 & 28 & 28 & 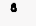 & esndy $\operatorname{los}(1)$ & Mledile Fingold & 0.0036 & 1.0500 & 0.0002 & 0.3200 & NA & eplinposon & $\cdot$ & 2 & 1 \\
\hline & 3.0690 & $290 \cdot \mathrm{W} 10-100$ & 52.2 & o & مد & 30 & 25 & $\cdot$ & sandp looem (1) & Mddde Alinoold & 0.0022 & 1.0051 & $0.0000^{\prime}$ & 0.3200 & NA & oplitspoen & $\cdot$ & $\mathbf{D}$ & 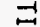 \\
\hline & 30000 & $200-W 10-100$ & 53.7 & o & 39 & 31 & 23 & 7 & "sndy lasm (1) & Niddie Rinootd & 0.0042 & 1.0370 & 0.0504 & 0.3083 & C.SSE DO & Apthapoon & - & $\omega$ & 1 \\
\hline \multirow[t]{6}{*}{ APTANSK ${ }^{1,5}$} & $241 . A P 1 G$ & NA & NA & 38 & 50 & 3 & t & 0 & sandy pravel (s) & Hanford wand & 0.1010 & 2.0473 & 0.0212 & 0.2500 & $1,24 E-03$ & oxemontion & Hellor., 1989 & ㅇ. & \\
\hline & $241 . A P \cdot 2$ & NA & NUA & 0 & $\infty$ & $x$ & 3 & 3 & and $(2)$ & Hantord and & 0.0300 & .00872 & 0.0004 & 0.518 & S.07E-OA & onesvation & - & - & D \\
\hline & $241-A p \cdot 3$ & N/A & $\mathrm{NAN}$ & 0 & 85 & 12 & 2 & 3 & and $(7)$ & Hentord wend & 0.0404 & 3.4876 & 0.002 & $0.434 \mathrm{~s}$ & B.10E-or & enesvation & $\bullet$ & 7 & $<$ \\
\hline & 241.NP.AG & NA & NAN & 10 & 83 & 5 & 2 & $\circ$ & $\operatorname{cond}(A)$ & Hanlord und & 0.0008 & 2.0004 & 0.0418 & 0.4162 & 1.STE-OS & oxemation & $\cdot$ & 윰 & D \\
\hline & 241.AP.S & NA & $\mathrm{NAN}$ & 0 & 7 & 10 & 36 & s & sundy losm (1) & Hanlord sond & 0.0106 & 1.4307 & $0.0 \mathrm{osen}$ & 0.4203 & C.04E-OS & - mearstion & $\cdot$ & 曹 & \\
\hline & $241 . N P \cdot 6$ & NA & NA & $:$ & 34 & 43 & 14 & $\bullet$ & loumy esnd (I) & Manlord annd & 0.0053 & 3.9484 & 0.000 & 0.4040 & D.00E-OS & eneavalion & - & $\frac{3}{\mathbf{t}}$ & \\
\hline \multirow[t]{6}{*}{$C=010 . H^{2.4}$} & 2-1190 & 6p9-48-77 & 8.1 & 14 & 40 & 44 & 2 & - & gravelly eand (t) & Plio-Pliosiocento & 0.0076 & 25329 & 0.0560 & 0.3000 & $5.306-03$ & Aplisspoon & Relyes, 1095 & $n$ & \\
\hline & 2.1170 & 809.46-77 & 8.0 & 22 & 42 & 23 & 3 & - & 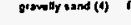 & Mtionplies socenne & $0.00+0$ & 1.9770 & 0.0035 & 03081 & $1,306.04$ & epplisposon & $\cdot$ & & \\
\hline & 2.1178 & $006-46-7 T$ & 13.0 & 1 & 79 & x & 0 & 0 & sand (f) & 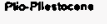 & 0.0223 & 1.7597 & 0.0282 & 0.2230 & 2.006 .02 & aphispoon & $\cdot$ & & \\
\hline & 2-1101 & $009.46-27$ & 14.1 & $\bullet$ & 82 & 10 & 0 & - & sand (2) & Pitiofftios slocenen & 0.0728 & 1.3000 & 0.0230 & 0.2147 & $0.20 E-03$ & eplitspoon & $\because$ & & \\
\hline & 2.1431 & 690-AE-JIA & 20.8 & 一 & - & $\mathrm{N} / \mathrm{A}$ & - & 一 & and (x) & Plio-Pliostocane & 0.0227 & 1.5950 & 0.0832 & 0.2310 & $1.00 E-12$ & spprespoen & - & & \\
\hline & $2 \cdot 1432$ & $690-48-771$ & 27,6 & si & 30 & is & 4. & 0 & eandy growed (5) & Middlo Rimpold & 0.0003 & 1.5028 & 0.0191 & 0.1120 & $1.40 \leq-02$ & aplitspoon & - & & \\
\hline \multirow[t]{3}{*}{ EROF ${ }^{2.6}$} & 1.0037 & $099.36-83 n$ & 74,0 & - & - & N/A & 一 & - & and M & Hanlord and & 0.0281 & 3.2037 & 0.0278 & 0.3743 & $\mathrm{NA}$ & sprisposon & Ralyes, 1095 & & \\
\hline & 40012 & $8080.35-80 \wedge$ & 25.7 & $\circ$ & $\infty$ & $\infty 0$ & 10 & 0 & sand (I) & Hanlord and & 0.0110 & 1.6727 & 0.0566 & 0.3513 & Wh & oplitspoon & Weekes snd Gouphese, 1994 & & \\
\hline & 40545 & $009.35-80 \AA$ & 49.8 & 。 & 27 & 50 & 12 & 5 & losmy sand (1) & Hanlord wand & 0.0000 & 2.2073 & 0.0028 & 0.382 & NA & splitsposen & $\cdot$ & & \\
\hline
\end{tabular}




$$
\text { WHC-SD-WM-TI-730, REV } 0
$$

Table A-1. 200 Areas Soil Properties.

$\ldots \ldots \ldots$

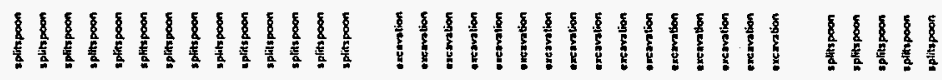

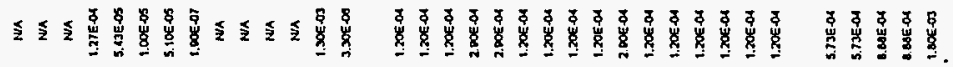

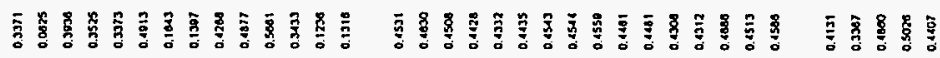

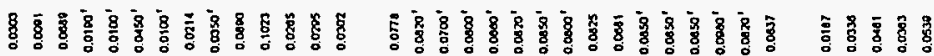

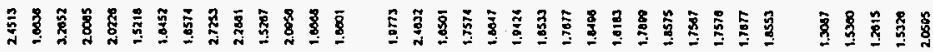

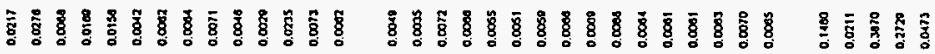

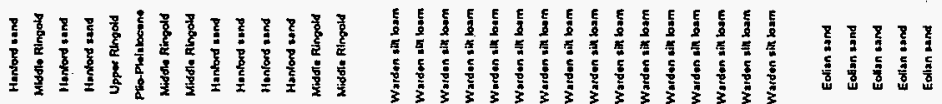

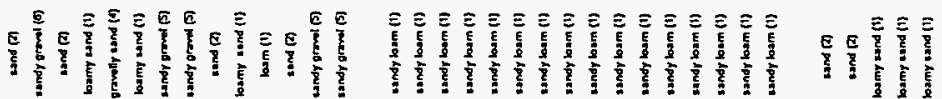

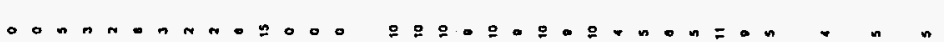

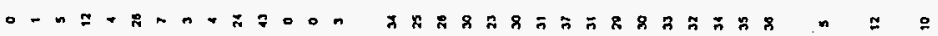

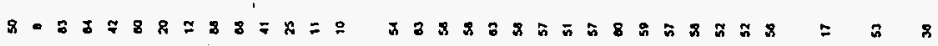

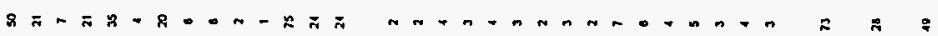
$0200=08=0000=00000000000000-N$

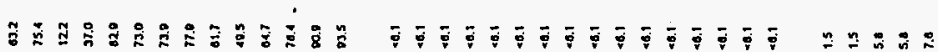

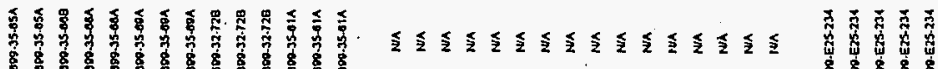

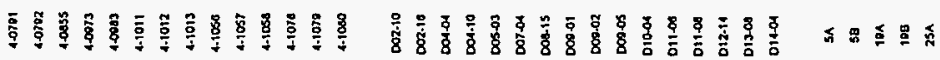
$\stackrel{m}{*}$ 


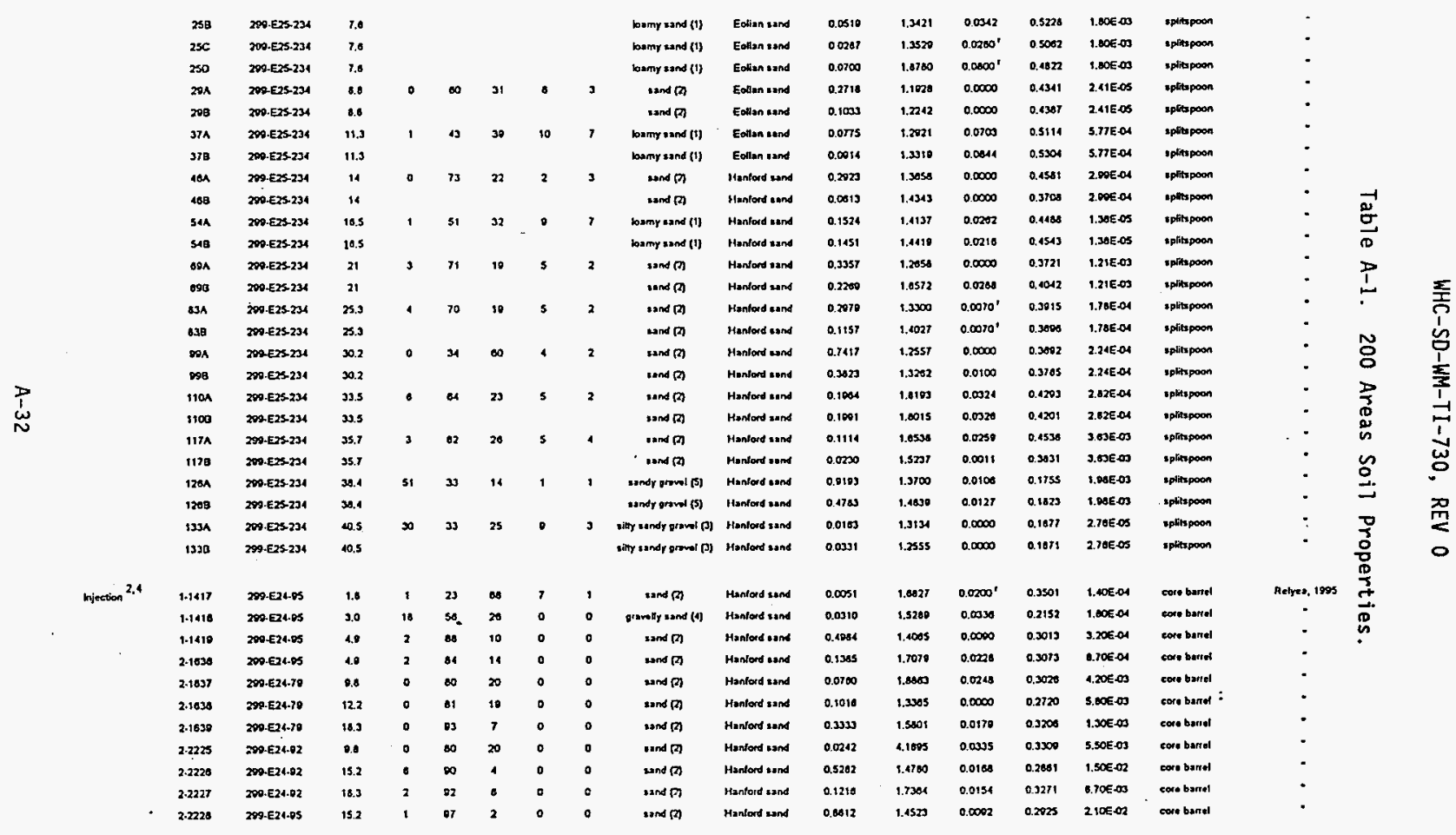


WHC-SD-WM-TI-730, REV 0

Table A-1. 200 Areas Soil Properties.

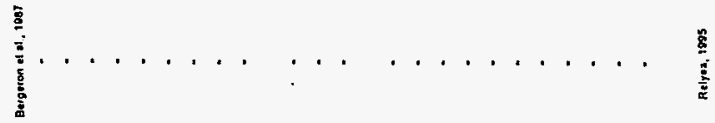

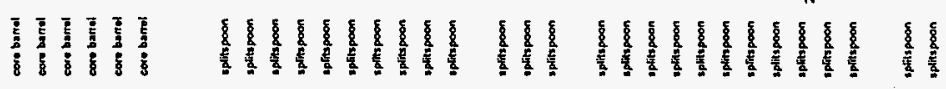

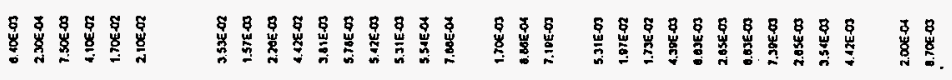

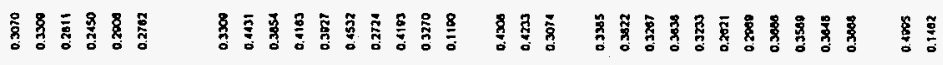

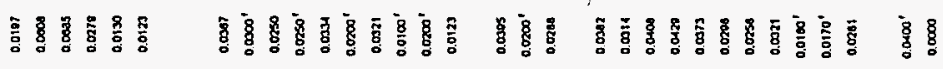

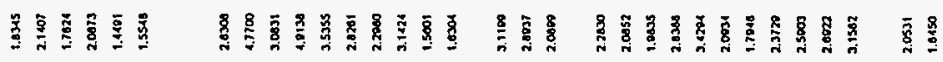

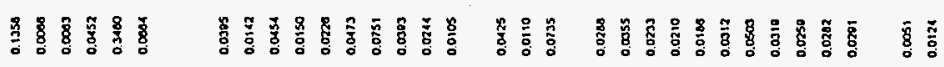

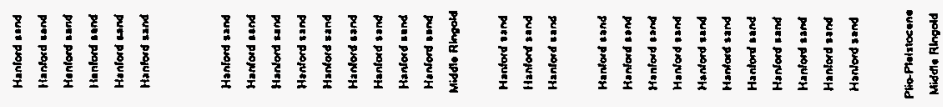

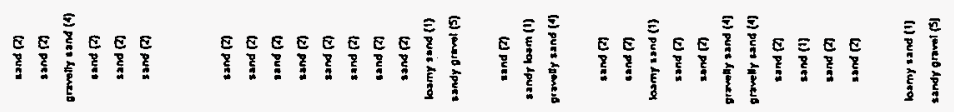

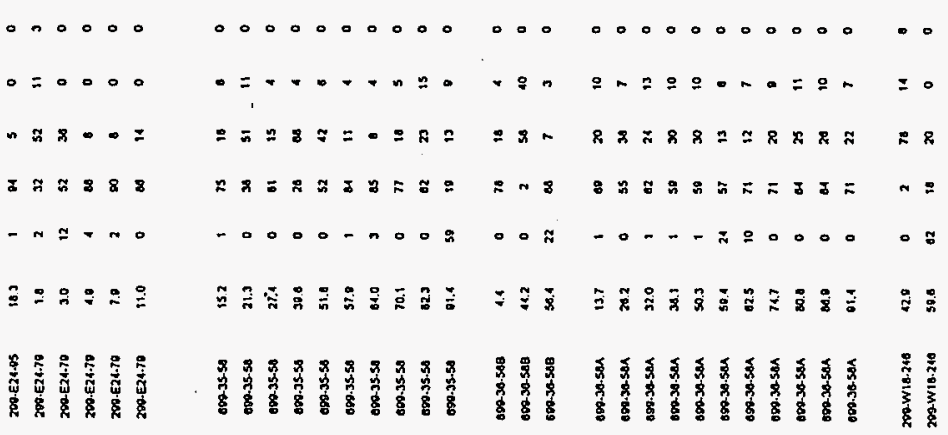

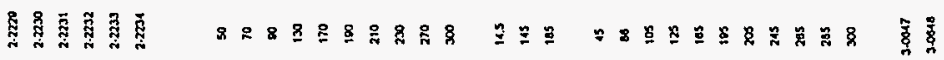

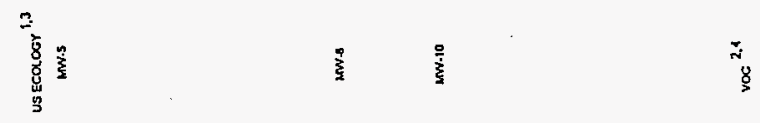




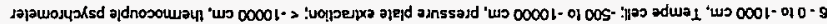

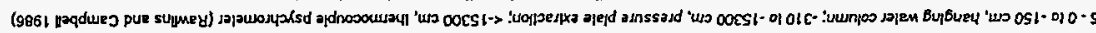
Uoำ

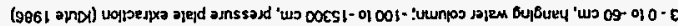

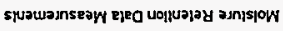

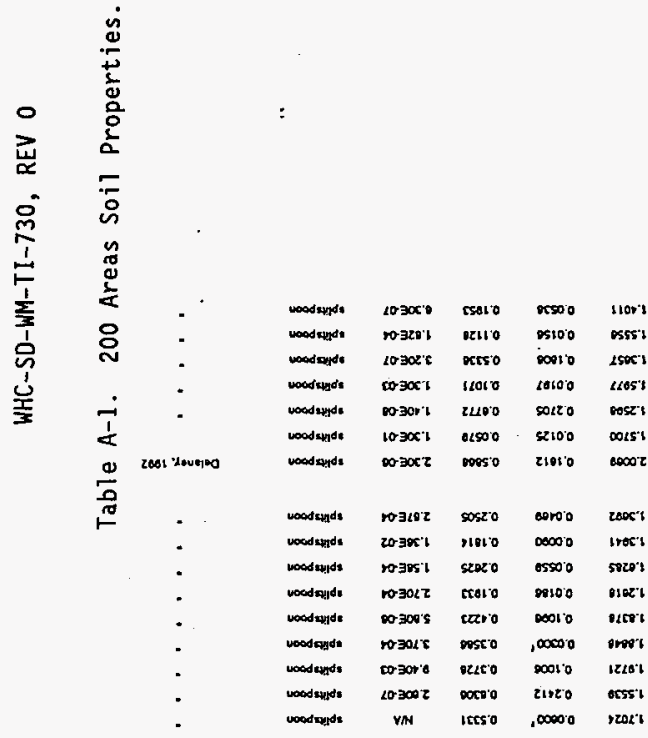

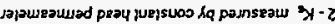

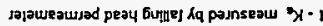

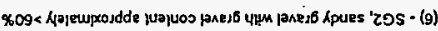

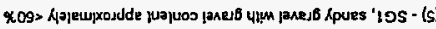

pues knasejo $20 \cdot(p)$

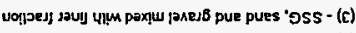

pues's - (z)

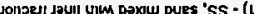
: Suobajeo has,

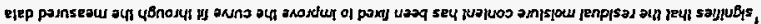

\begin{tabular}{|c|c|c|c|c|c|c|c|c|c|c|}
\hline$r 5000$ & 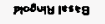 & (5) Inest dpuet & o & 0 & $"$ & $\boldsymbol{u}$ & 59 & 959 & octor-seg & cooser \\
\hline$\$ 8000$ & 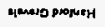 & (c) imase spure & 0 & 2 & - & 01 & $m$ & $\varepsilon \ddot{x}$ & octoreso & 10006 \\
\hline 50000 & pure propueg & (1) weq hpues & $\cdot$ & $u$ & $\alpha$ & sc & 0 & $c o z$ & ecerees & $\cos x \cdot 2$ \\
\hline acooso & 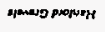 & 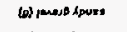 & 0 & r & (i) & $a$ & 59 & 9) & ssiress. & $\operatorname{moc} z$ \\
\hline trioo & pradupy rempl & (1) wer Lpues & 01 & ot & $\boldsymbol{s}$ & ss & 0 & sic & sc:1r-se日 & $500 x \cdot \pi$ \\
\hline 10000 & ppowsy seddn & (o) Imest spoes & 0 & 0 & 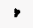 & $m$ & 20 & $2 r z$ & esitrese & rooce \\
\hline$\infty \times \infty 0$ & poduy som & (1) puest dwea & ? & $n$ & os & $z$ & 0 & $I x$ & $2 c-2 r 600$ & soet-2 \\
\hline $5+100$ & purs propsint & (c) imese dpuers lifer & ? & $a$ & at & PC & $x$ & Ne & $\Delta I z-s i n t-s e z$ & Lspere \\
\hline 00100 & probugy mppixe & (s) penos spues & 0 & 0 & a) & or & $z$ & 0.86 & olzstmot & 25905 \\
\hline 20000 & provugy soddn & (v) Laceso dpues dar" & - & $v$ & . & $g z$ & $n$ & $d x$ & olz-sincos & 55908 \\
\hline 01100 & wosatiodores & (s) jacess lpues: & , & , & $\varepsilon$ & $\propto$ & os & ost & siz-sim-osz & rssose \\
\hline $1000^{\prime} 0$ & mesciled and & (i) Puer Aurop & - & $m$ & rs & re & 0 & szr & $\operatorname{sit} 1 \mathrm{mos}$ & c500e \\
\hline 20000 & puAs Propunt & Upuner & r & $r$ & 25 & or & - & $r x$ & Sx-9tMex & 25008 \\
\hline 00200 & cursensiod doth & (1) preen kuted & c & 0 & $r$ & $\mathrm{ss}$ & 0 & $80 \%$ & Lrtasmese & 15000 \\
\hline $0 \times 10^{\prime} 0$ & wesory itstand & (1) werd dpues: & "I & si & ar & or & 0 & s's'. & $1+z+1 M+6 z$ & ospoce \\
\hline 01000 & 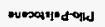 & (1) wex & 21 & or & $\propto$ & or & 0 & l'ir & IrE-9IM-ose & oroose \\
\hline
\end{tabular}


WHC-SD-WM-TI-730, REV 0

\author{
APPENDIX 8 \\ ADDITIONAL WASTE CHARACTERIZATION INFORMATION
}

$B-i$ 
WHC-SD-WM-TI-730, REV 0

This page intentionally left blank.

$B-i j$ 
WHC-SD-WM-TI-730, REV 0

\section{APPENDIX B}

\section{ADDITIONAL WASTE CHARACTERIZATION INFORMATION}

\section{B.1 DERIVATION OF GROUNDWATER-MOBILE RADIONUCLIDE INVENTORY ESTIMATES}

This section describes the methods for estimating inventories of groundwater-mobile radionuclides in low-level waste disposed of in the 200 East Area Low-Level Buria] Ground (LLBG) here. The radionuclides of interest are uranium, ${ }^{99} \mathrm{TC},{ }^{129} \mathrm{I},{ }^{14} \mathrm{C}$, and ${ }^{79} \mathrm{Se}$.

Except for uranium and plutonium mass, radionuclide-specific inventory or concentration estimates have not been provided for most of the low-level waste disposed of in the 200 East Area LLBG. Typically, radionuclide inventories have been reported as "mixed fission products."

129. To estimate inventories of the groundwater-mobile radionuclides ( ${ }^{99} \mathrm{Tc}$, ${ }^{129} \mathrm{I},{ }^{14} \mathrm{C}$, and $\left.{ }^{79} \mathrm{Se}\right)$, process knowledge is used to derive radionuclide-specific inventories from the mixed fission product totals. The relative activities of radionuclides in waste are assumed to be the same as those in irradiated Hanford Site fuel unless other information about processing indicates otherwise. Mixed fission product estimates were calculated by taking the product of an external gamma measurement (mrem/hr) and a multiplication factor. The multiplication factor accounted for the relative activities of gamma-producing radionuclides (based on the reactor inventory calculations) and attenuation factors. Attenuation factors include the shielding effects of packaging material and distance from the package at which radiation measurements were taken.

Having estimated a total fission product activity for a given waste package, specific radionuclide inventories can be calculated by assuming a particular set of fission product radionuclides whose fractions are normalized to unity. For any given radionuclide, multiplication of the total fission product activity by the fractional activity of that radionuclide yields an estimate of its activity in the waste package. The selection of the appropriate mixture of fission products depends on both the fuel cycle and the decay time after the fuel and associated waste are produced. For calculations on Hanford Site waste, an average mixed fission product group of radionuclides was calculated (Hansen et al. 1973). The radionuclides and the ir fractions after 1 year of decay are shown in Table B-1.

Because freshly reacted fuel contains a large fraction of radionuclides with very short half lives (slyear), relative activities change noticeably during the first 10 years of decay. Changes in relative fractions for this mix of radionuclides because of changes in decay time are shown in Table B-2. The major activity radionuclides are shown along with the fractions of the groundwater-mobile radionuclides. As the time increases, ${ }^{90} \mathrm{Sr},{ }^{137} \mathrm{Cs}$ and their daughters become the only major constituents in the mixture. The relative fractions of the groundwater-mobile radionuclides increase by a little more than an order of magnitude over 10 years of decay. 


\section{B.2 ADDITIONAL NAVAL REACTOR COMPARTMENT INVENTORY ESTIMATE INFORMATION}

The U.S. Navy has completed an environmental impact statement to support disposal of reactor compartments in the 200 East Area LLBG (U.S. Department of the Navy 1996). Appendix D is provided from that document and contains detailed information concerning the inventory estimates for the reactor compartment waste.

\section{B.3 REFERENCES}

Hanson, G. L, J. D. Anderson, G. R. Kiel, B. J. McMurray, and N. P. Nisick, 1973, Input and Decayed Values of Radioactive Solid Wastes Buried in the 200 Areas Through 1971, ARH-2762, Atlantic Richfield Hanford Company, Richland, Washington. 
Table B-1. Estimate of Mixed Fission Product Radionuclide Inventory Distribution (Hanson et al. 1973).

\begin{tabular}{|c|c|c|}
\hline Radionuclide & 1-Year Decay & Adjusted to 1 \\
\hline${ }^{90} \mathrm{Sr}$ & $1.88 \mathrm{E}-02$ & $1.99 \mathrm{E}-02$ \\
\hline${ }^{90} \mathrm{Y}$ & $1.88 E-02$ & $1.99 \mathrm{E}-02$ \\
\hline${ }^{106} \mathrm{Ru}$ & $4.05 \mathrm{E}-02$ & $4.29 \quad E-02$ \\
\hline${ }^{106} \mathrm{Rh}$ & $4.05 \mathrm{E}-02$ & $4.29 \mathrm{E}-02$ \\
\hline${ }^{137} \mathrm{Cs}$ & $2.01 \mathrm{E}-02$ & $2.13 \mathrm{E}-02$ \\
\hline $137 \mathrm{mBa}$ & $1.85 \mathrm{E}-02$ & $1.95 \mathrm{E}-02$ \\
\hline${ }^{144} \mathrm{Ce}$ & $2.78 \mathrm{E}-01$ & $2.95 \mathrm{E}-01$ \\
\hline${ }^{144} \mathrm{Pr}$ & $2.78 \mathrm{E}-01$ & $2.95 \mathrm{E}-01$ \\
\hline${ }^{147} \mathrm{Pm}$ & $7.02 \mathrm{E}-02$ & $7.44 \mathrm{E}-02$ \\
\hline${ }^{14} \mathrm{C}$ & $2.80 \mathrm{E}-11$ & $2.96 \mathrm{E}-11$ \\
\hline${ }^{129} \mathrm{I}$ & $4.23 \mathrm{E}-09$ & $4.48 E-09$ \\
\hline${ }^{99} \mathrm{TC}$ & $2.87 \mathrm{E}-06$ & 3.04 E-06 \\
\hline${ }^{79} \mathrm{Se}$ & $4.99 E-08$ & $5.28 \quad E-08$ \\
\hline${ }^{95} \mathrm{Zr}$ & $4.99 E-02$ & $5.28 \mathrm{E}-02$ \\
\hline${ }^{95} \mathrm{Nb}$ & $1.05 \mathrm{E}-01$ & $1.11 \mathrm{E}-01$ \\
\hline $95 \mathrm{~m} \mathrm{Nb}$ & 1.06 E-03 & $1.12 \mathrm{E}-03$ \\
\hline${ }^{93} \mathrm{Zr}$ & $6.46 \quad E-07$ & $6.83 \quad E-07$ \\
\hline${ }^{107} \mathrm{Pd}$ & $8.46 E-09$ & 8.95 E-09 \\
\hline $110 \mathrm{~m} \mathrm{Ag}$ & $2.51 E-06$ & 2.65 E-06 \\
\hline${ }^{110} \mathrm{Ag}$ & 5.02 E-08 & $5.31 \mathrm{E}-08$ \\
\hline${ }^{113 m} \mathrm{Cd}$ & $4.51 E-10$ & $4.78 \quad E-10$ \\
\hline${ }^{119 m} \mathrm{Sn}$ & $4.37 \mathrm{E}-05$ & 4.63 E-05 \\
\hline${ }^{121 m} \mathrm{Sn}$ & 3.94 E-06 & $4.18 E-06$ \\
\hline${ }^{123 m} \mathrm{Sn}$ & $1.85 E-05$ & $1.96 \mathrm{E}-05$ \\
\hline${ }^{126} \mathrm{Sn}$ & $1.11 \mathrm{E}-07$ & $1.17 \quad E-07$ \\
\hline${ }^{125} \mathrm{Sb}$ & $7.99 \quad E-04$ & 8.45 E-04 \\
\hline${ }^{126 m} \mathrm{Sb}$ & $1.11 \mathrm{E}-07$ & $1.17 \mathrm{E}-07$ \\
\hline${ }^{126} \mathrm{Sb}$ & $1.09 \mathrm{E}-07$ & $1.16 \mathrm{E}-07$ \\
\hline${ }^{125 \mathrm{~m}} \mathrm{Te}$ & 2.18 E-04 & $2.31 \mathrm{E}-04$ \\
\hline${ }^{127 \pi} \mathrm{Te}$ & 1. 35 E-03 & $1.43 \mathrm{E}-03$ \\
\hline${ }^{134} \mathrm{Cs}$ & 5.56 E-04 & $5.88 E-04$ \\
\hline${ }^{135} \mathrm{Cs}$ & $5.75 E-08$ & $6.08 E-08$ \\
\hline${ }^{15 i} \mathrm{Sm}$ & 1.94 E-04 & $2.05 \quad E-04$ \\
\hline${ }^{152} \mathrm{Eu}$ & $3.00 \quad E-07$ & $3.18 E-07$ \\
\hline${ }^{154} \mathrm{Eu}$ & $3.04 E-05$ & 3.22 E-05 \\
\hline${ }^{155} \mathrm{Eu}$ & $7.35 E-04$ & $7.79 \mathrm{E}-04$ \\
\hline${ }^{162} \mathrm{Gd}$ & $9.86 E-06$ & $1.04 \mathrm{E}-05$ \\
\hline${ }^{162} \mathrm{~Tb}$ & $9.86 \quad E-06$ & 1.04 E-05 \\
\hline Total & $9.4442 \mathrm{E}-01$ & $1.0000 \quad E+00$ \\
\hline
\end{tabular}


Table B-2. Fractional Quantities of Groundwater-Mobile Radionuclide Inventories and Primary Beta/Gamma Emitters in Mixed Fission Products.

\begin{tabular}{|c|c|c|c|c|c|c|c|c|c|c|}
\hline $\begin{array}{c}\text { Year of } \\
\text { Yaste } \\
\text { Disposal }\end{array}$ & $1945-1972$ & $\begin{array}{c}1973 \\
1983-1985\end{array}$ & 1974,1986 & 1975,1987 & 1976, 1988 & 1977 & 1978 & 1979 & 1980 & $\begin{array}{c}1981-1982 \\
1989- \\
\text { present }\end{array}$ \\
\hline Decay Period & $1 \mathrm{yr}$ & $2 y r$ & $3 \mathrm{yr}$ & $4 \gamma r$ & $5 \mathrm{yr}$ & $6 \mathrm{yr}$ & $7 \mathrm{yr}$ & $8 \mathrm{yr}$ & $9 y r$ & $10 \mathrm{yr}$ \\
\hline Radionucl ide & & & & & & & & & & \\
\hline${ }^{*} \mathrm{Sr}$ & 1.99 E-02 & $4.56 E-02$ & $7.79 \mathrm{E} \cdot 02$ & $1.15 \mathrm{E}-01$ & $1.48 \mathrm{E}-01$ & $1.73 E-01$ & $1.92 \mathrm{E}=01$ & $2.04 E-01$ & 2.13 E-01 & $2.19 \mathrm{E}-01$ \\
\hline${ }^{\infty} Y$ & 1.99 E-02 & 4.56 E-02 & $7.79 \mathrm{E}-02$ & 1.14 E-01 & $1.48 E-01$ & $1.73 E-01$ & 1.92 E-01 & 2.04 E-01 & $2.13 \mathrm{E}-01$ & $2.19 E-01$ \\
\hline${ }^{100} \mathrm{Ru}$ & $4.29 E-02$ & 5.05 E-02 & $4.44 E-02$ & $3.36 E-02$ & $2.23 E-02$ & 1.34 E-02 & $7.68 E-03$ & $4.18 \mathrm{E}-03$ & $2.25 \mathrm{E}-03$ & 1.19 E-03 \\
\hline${ }^{100} \mathrm{Rh}$ & $4.29 \mathrm{E}-02$ & $5.05 \mathrm{E} \cdot 02$ & $4.44 E-02$ & 3.36 E-02 & $2.23 E=02$ & $1.34 E-02$ & $7.68 \mathrm{E}-03$ & $4.18 E-03$ & 2.25 E-03 & 1.19 E-03 \\
\hline${ }^{13} \mathrm{Cs}$ & 2.13 E-02 & $4.88 E-02$ & 8.35 E-02 & 1.23 E-01 & $1.59 \mathrm{E}-01$ & $1.86 E-01$ & 2.07 E-01 & 2.20 E-01 & $2.30 E-01$ & 2.38 E-01 \\
\hline${ }^{137 m \mathrm{Ba}}$ & 1.95 E-02 & $4.48 E-02$ & 7.67 E-02 & $1.13 \mathrm{E}-01$ & $1.46 \mathrm{E}-01$ & $1.71 E-01$ & $1.91 E-01$ & 2.02 E-01 & 2.11 E-01 & $2.18 \mathrm{E}-01$ \\
\hline${ }^{144} \mathrm{Ce}$ & 2.95 E-01 & 2.84 E-01 & 2.04 E-01 & $1.26 \mathrm{E}-01$ & 6.84 E-02 & 3.37 E-02 & $1.58 \mathrm{E}-02$ & 7.02 E-03 & $3.08 E=03$ & 1.34 E-03 \\
\hline${ }^{144} \mathrm{Pr}$ & 2.95 E-01 & $2.84 E-01$ & 2.04 E-09 & $1.26 \mathrm{E}-01$ & 6.84 E-02 & $3.37 E-02$ & $1.58 E-02$ & 7.02 E-03 & 3.08 E-03 & 1.34 E-03 \\
\hline${ }^{149} \mathrm{Pm}$ & 7.44 E-02 & 1.34 E-01 & $1.80 \mathrm{E}-01$ & 2.08 E-01 & $2.11 E-01$ & $1.95 E-01$ & $1.70 \mathrm{E}-01$ & $1.42 \mathrm{E}-01$ & $1.17 \mathrm{E}-01$ & 9.47 E-02 \\
\hline${ }^{14} \mathrm{C}$ & $2.96 E-11$ & $6.95 E-11$ & 1.22 E-08 & $1.83 E-10$ & $2.43 E-10$ & $2.91 E-10$ & $3.32 E-10$ & $3.60 \mathrm{E}-10$ & $3.85 E-10$ & 4.07 E- 10 \\
\hline${ }^{129} I$ & $4.48 \quad E-09$ & $1.05 \varepsilon-08$ & $1.84 E-08$ & 2.77 E-08 & 3.67 E-08 & $4.40 \varepsilon-0.8$ & $5.02 E-08$ & 5.44 E-08 & $5.83 E-08$ & 6.16 E-08 \\
\hline${ }^{n T C}$ & 3.04 E-06 & 7.12 E-06 & $1.25 \varepsilon-05$ & $1.88 \mathrm{E} \cdot 05$ & 2.48 E-05 & 2.98 E-05 & $3.40 \mathrm{E}-05$ & 3.69 E-05 & 3.95 E-05 & 4.17 E-05 \\
\hline${ }^{n} \mathrm{Se}$ & $5.28 E-08$ & 1.24 E-07 & 2.17 E-07 & 3.27 E-07 & 4.32 E-07 & $5.19 \quad E-07$ & 5.91 E-07 & 6.42 E-07 & 6.87 E-07 & 7.26 E- 07 \\
\hline
\end{tabular}


FINAL ENVIRONMENTAL IMPACT STATEMENT ON THE DISPOSAL OF DECOMMISSIONED, DEFUELED CRUISER, OHIO CLASS,

AND

LOS ANGELES CLASS NAVAL REACTOR PLANTS

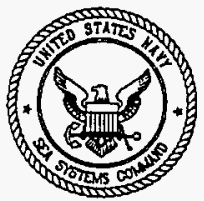

APRIL 1996

UNITED STATES

DEPARTMENT OF THE NAVY

PRINTED ON RECYCLED PAPER 
WHC-SD-WM-TI-730, REV. 0

LONG LIVED RADIONUCLIDES IN IRRADIATED STRUCTURE WITHIN CRUISER, LOS ANGELES, AND

OHIO CLASS REACTOR PLANTS

Appendix D

D-i 
WHC-SD-WM-TI-730, REV. 0

This Page Intentionally Left Blank

D-ii 
Table of Contents

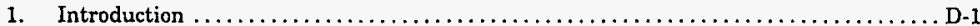

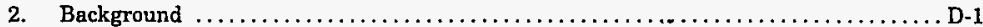

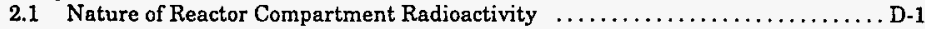

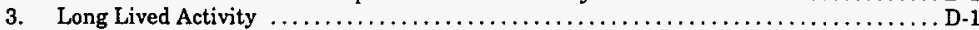

3.1 Long Lived Curie Content of Reactor Vessel

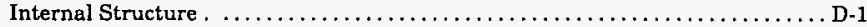

3.2 Long Lived Curie Distribution in Reactor Vessel

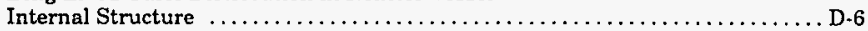

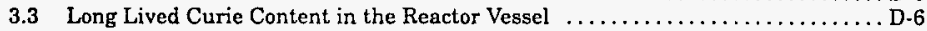

4. Suitability of Reactor Vessel Internal Structure for Shallow Land Burial

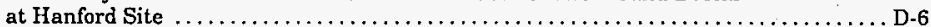

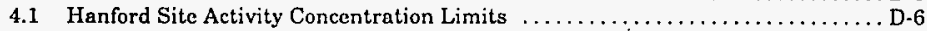

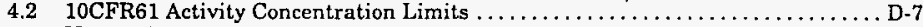

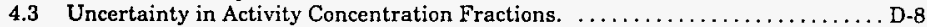

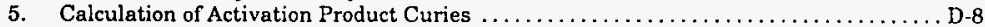

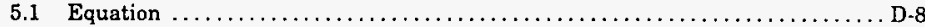

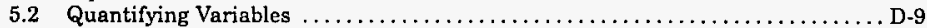

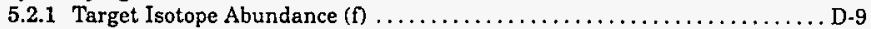

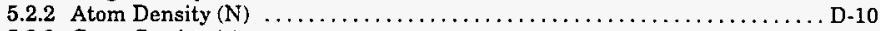

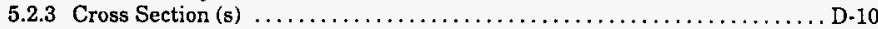

5.2.4 Neutron Flux ( $f$ and Flux Spectrum Correction Factors $\left(f_{c}\right) \ldots \ldots \ldots \ldots$ D-11

5.2.5 Refined Method for Neutron Reaction Rate ......................

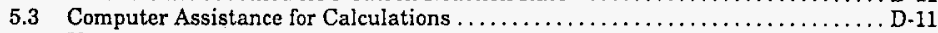

5.4 Uncertainty/Conservatism in Curie Calculations $\ldots \ldots \ldots \ldots \ldots \ldots \ldots \ldots \ldots, \mathrm{D}-12$

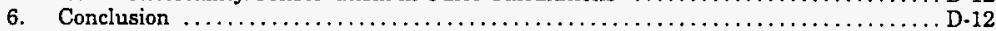

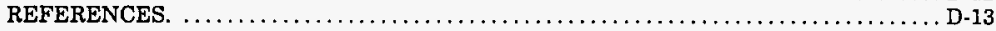

\section{List of lllustrations}

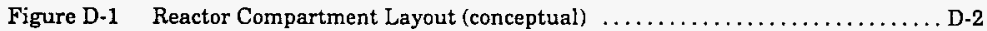

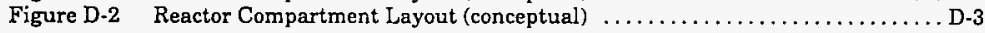

\section{List of Tables}

Table D-1

Table D-2

Table D-3

Table D.4

Long Lived Radionuclides in Activated Structure $\ldots \ldots \ldots \ldots \ldots \ldots \ldots \ldots$ D-4

Reactor Vessel Internal Structure Volume $\ldots \ldots \ldots \ldots \ldots \ldots \ldots \ldots \ldots \ldots \ldots \ldots$

Reactor Vessel Internal Structure Curie Content .......................

Activity Concentration Fractions for Long Lived Activity

Based on Hanford Category 3 Limits (WHC, 1993) ............... D.7

Table D-5 Activity Concentration Fractions for Long Lived Activity

Based on 10CFR61 Class C Limits ......................... D-8

Table D-6 Target Isotopes, Isotopic Abundances, and Target Isotope

Element Concentrations Used for Activity Calculations . . . . . . . . . . D-10 
WHC-SD-WM-TI-730, REV. 0

This Page Intentionally Left Blank

$\sqrt{11}$

D-iv 


\section{INTRODUCTION}

Because of the various materials used in a reactor plant that can become activated during its operation, cruiser, LOS ANGELES, and OHIO class reactor plants contain a variety of radionuclides. The radionuclides include small quantities of long lived radionuclides. These radionuclides, with half-lives ranging from several thousand to several million years, are primarily in structure located within the reactor vessel that has been irradiated and subsequently activated. Less than $0.1 \%$ of the long lived activity is freed from this structure and transported out of the reactor vessel as wear product, a negligible amount. This appendix discusses the type, distribution, and amount of long lived radioactivity found within the irradiated structure of cruiser, LOS ANGELES, and OHIO Class reactor plants, and the methods used to calculate long lived activity within these structures. Specifically, the long lived radionuclides carbon-14, iodine-129, nickel-59, niobium-94, selenium-79, and technetium-99 are considered. Nickel-63, with a half-life of 100 years, is also considered in this appendix due to the presence of many thousands of curies of this radionuclide in activated structure within the reactor vessel.

\section{BACKGROUND}

\subsection{Nature of Reactor Compartment Radioactivity}

Naval Reactor Compartment Disposal Packages encompass the Reactor Compartment, that portion of a ship which supports and contains the ship's nuclear reactor plant. The reactor plant consists of the reactor vessel and associated piping and components that transfer heat from the reactor vessel and generate steam to propel the ship. Figure D-1 provides a simplified conceptual layout of a naval reactor compartment. Figure D-2 provides a simplified conceptual cross section of the reactor vessel showing the conceptual arrangement of the internal structure within the vessel. Neutrons escaping the fuel activate the reactor vessel internal structure and, to a smaller extent, the interior of the reactor vessel and associated structure. Table D-1 provides relevant properties of long lived radionuclides produced by this irradiation. From Figure D-2, the reactor vessel internal structure is essentially cylindrical and primarily composed of Inconel Alloy 600 . Five types of this structure would exist for the cruiser, LOS ANGELES, and OHIO class reactor plant designs. Table D-2 provides the volumes occupied by these reactor vessel internal structures (i.e. volume based on the exterior dimensions of the cylindrical structure). Structure \#1 is the most commonly found and would represent about $60 \%$ of the reactor plants being evaluated. Structures \#2, \#3, \#4, and \#5 would represent about $20 \%, 14 \%, 4 \%$, and $2 \%$ of these plants, respectively.

\section{LONG LIVED ACTIVITY}

\subsection{Long Lived Curie Content of Reactor Vessel Internal Structure}

Since the exact design and operational life of reactor vessel internal structure varies between ship classes, activity will also vary. Estimates of long lived radionuclide activity in reactor vessel internal structure are presented in Table D-3. These estimates are based on a decay period of 1 year after final reactor shutdown of the cruiser, LOS ANGELES, and OHIO class reactor 


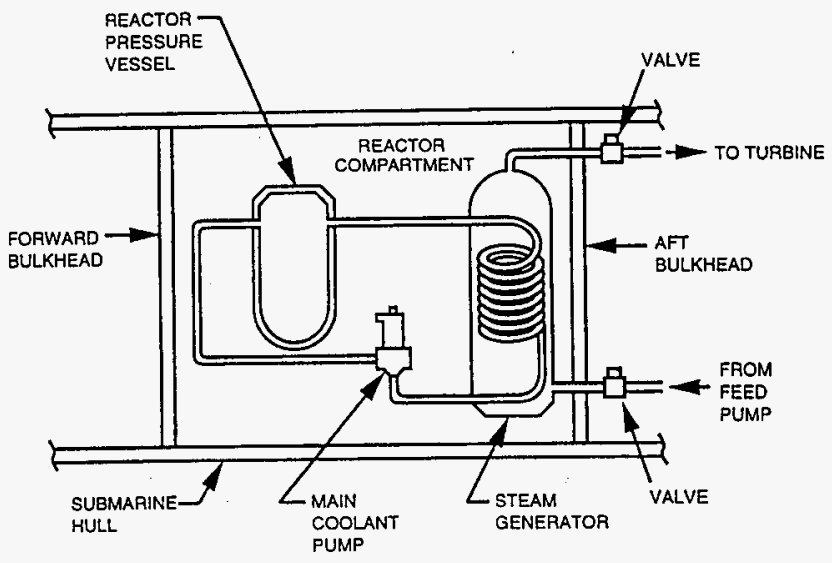

Figure D-1. Reactor Compartment Layout (conceptual) 
WHC-SD-WM-TI-730, REV. 0

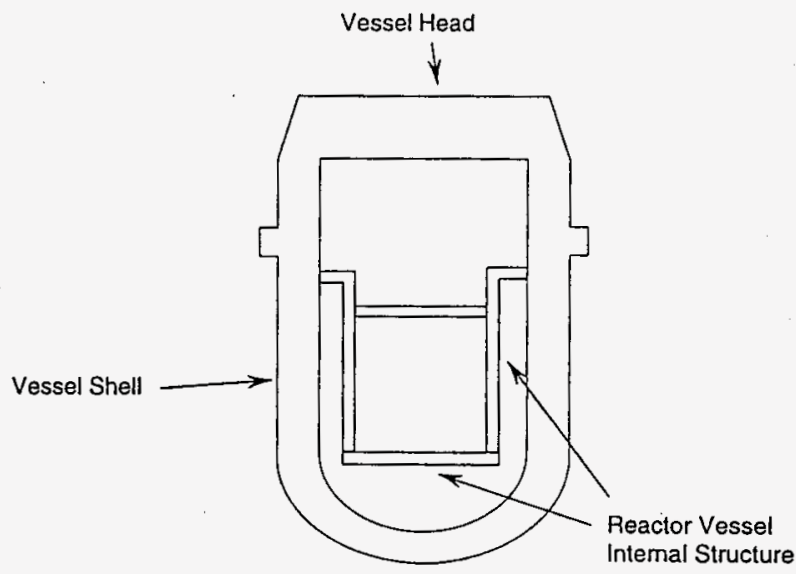

Figure D-2. Reactor Vessel with Internal Structure (conceptual) 
WHC-SD-WM-TI-730, REV. 0

\begin{tabular}{|c|c|c|c|}
\hline Radionuclide & \begin{tabular}{|l|} 
Radiation \\
Emitted 1
\end{tabular} & Energy per Disintegration ${ }^{1}$ & $\begin{array}{l}\text { Half-life } \\
\text { (years) }{ }^{1}\end{array}$ \\
\hline nickel-63 & beta particles & maximum beta $0.066 \mathrm{MeV}$ & 100 \\
\hline carbon-14 & beta particles & maximum beta $0.156 \mathrm{MeV}$ & 5,730 \\
\hline niobium-94 & $\begin{array}{l}\text { gamma rays } \\
\text { beta particles }\end{array}$ & $\begin{array}{l}\text { two in-series gammas: } \\
0.87 \mathrm{MeV}(100 \%) \\
0.70 \mathrm{MeV}(100 \%) \\
\text { maximum beta } 0.47 \mathrm{MeV}\end{array}$ & 20,300 \\
\hline selenium-79 & beta particles & maximum beta $0.15 \mathrm{MeV}$ & 65,000 \\
\hline nickel-59 & $\begin{array}{l}X \cdot \text { rays } \\
e \cdot\end{array}$ & $\begin{array}{l}\text { less than } 0.01 \mathrm{MeV} \\
\text { less than } 0.01 \mathrm{MeV}\end{array}$ & 75,000 \\
\hline technetium-99 & beta particles & maximum beta $0.29 \mathrm{MeV}$ & 213,000 \\
\hline iodine-129 & $\begin{array}{l}\text { X-rays } \\
\text { beta particles } \\
\mathrm{e}^{-}\end{array}$ & $\begin{array}{l}\text { less than } 0.04 \mathrm{MeV} \\
\text { maximum beta } 0.15 \mathrm{MeV} \\
\text { less than } 0.04 \mathrm{MeV}\end{array}$ & $15,700,000$ \\
\hline
\end{tabular}

1: KOCHER, 1981.

Table D-1, Long Lived Radionuclides in Activated Structure

\begin{tabular}{|l|l|l|l|l|l|}
\hline Structure Type: & $\# 1$ & $\# 2$ & $\# 3$ & $\# 4$ & $\# 5$ \\
\hline Volume $\left(\mathrm{m}^{3}\right):$ & 11.0 & 19.2 & 11.0 & 11.0 & 24.0 \\
\hline
\end{tabular}

Table D-2, Reactor Vessel Internal Structure Volume 
WHC-SD-WM-TI-730, REV. 0

\begin{tabular}{|l|r|l|l|l|l|l|}
\hline Radionuclide & $\begin{array}{l}\text { Decay } \\
\text { period } \\
\text { (yr) }\end{array}$ & $\begin{array}{l}\text { Structure } \\
\text { Type \#1 } \\
\text { (curies) }\end{array}$ & $\begin{array}{l}\text { Structure } \\
\text { Type \#2 } \\
\text { (curies) }\end{array}$ & $\begin{array}{l}\text { Structure } \\
\text { Type \#3 } \\
\text { (curięs) }\end{array}$ & $\begin{array}{l}\text { Structure } \\
\text { Type \#4 } \\
\text { (curies) }\end{array}$ & $\begin{array}{l}\text { Structure } \\
\text { Type \#5 } \\
\text { (curies) }\end{array}$ \\
\hline nickel-63 & $\begin{array}{r}1 \\
\text { (con }\end{array}$ & $\begin{array}{l}24,000 \\
751\end{array}$ & $\begin{array}{c}12,600 \\
394\end{array}$ & $\begin{array}{c}18,000 \\
563\end{array}$ & $\begin{array}{l}35,900 \\
1,120\end{array}$ & $\begin{array}{c}7,420 \\
232\end{array}$ \\
& 2000 & 0.023 & 0.012 & 0.017 & 0.034 & 0.007 \\
\hline carbon-14 & 1 & 1.20 & 0.621 & 13.5 & 26.9 & 0.396 \\
& 500 & 1.13 & 0.585 & 12.7 & 25.3 & 0.373 \\
& 2000 & 0.942 & 0.488 & 10.6 & 21.1 & 0.311 \\
\hline niobium-94 & 1 & 0.770 & 0.522 & 0.645 & 1.29 & 0.142 \\
& 500 & 0.757 & 0.513 & 0.634 & 1.27 & 0.140 \\
& 2000 & 0.719 & 0.488 & 0.602 & 1.20 & 0.133 \\
\hline selenium-79 & 1 & $2.22 \times 10^{-5}$ & $1.14 \times 10^{-5}$ & $6.15 \times 10^{-5}$ & $1.23 \times 10^{-4}$ & $3.34 \times 10^{-6}$ \\
& 500 & $2.21 \times 10^{-5}$ & $1.13 \times 10^{-5}$ & $6.12 \times 10^{-5}$ & $1.22 \times 10^{-4}$ & $3.32 \times 10^{-6}$ \\
& 2000 & $2.17 \times 10^{-5}$ & $1.12 \times 10^{-5}$ & $6.02 \times 10^{-5}$ & $1.20 \times 10^{-4}$ & $3.27 \times 10^{-6}$ \\
\hline nickel-59 & 1 & 219 & 116 & 156 & 311 & 63.5 \\
& 500 & 218 & 115 & 155 & 310 & 63.2 \\
& 2000 & 215 & 114 & 153 & 305 & 62.3 \\
\hline technetium-99 & 1 & 0.0287 & 0.0115 & 0.0143 & 0.0286 & 0.00348 \\
& 500 & 0.0287 & 0.0115 & 0.0143 & 0.0286 & 0.00347 \\
& 2000 & 0.0285 & 0.0114 & 0.0142 & 0.0284 & 0.00346 \\
\hline iodine-129 & 1 & $2.01 \times 10^{-10}$ & $3.04 \times 10^{-9}$ & $8.45 \times 10^{-8}$ & $1.69 \times 10^{-7}$ & $4.36 \times 10^{-8}$ \\
& 500 & $2.01 \times 10^{-10}$ & $3.04 \times 10^{-9}$ & $8.45 \times 10^{-8}$ & $1.69 \times 10^{-7}$ & $4.36 \times 10^{-8}$ \\
& 2000 & $2.01 \times 10^{-10}$ & $3.04 \times 10^{-9}$ & $8.45 \times 10^{-8}$ & $1.69 \times 10^{-7}$ & $4.36 \times 10^{-8}$ \\
\hline
\end{tabular}

a: 1 yeat after final shutdown, $\mathbf{5 0 0}$ years and 2,000 years later; Decay constant $=0.693 /$ (half-life of radionuclide in year) .

Table D-3, Reactor Vessel Internal Structure Curie Content 
plants. Five hundred and 2000 year decay estimates are provided for comparison. Further discussion of the calculation method and statistical uncertainty in the quantities presented is provided in section 5 of this appendix.

\subsection{Long Lived Curie Distribution in Reactor Vessel Internal Structure}

Long lived activity is primarily found in the reactor vessel internal structure. Carbon-14 and iodine-129 are concentrated towards the inside of the structure while the other Table D-3 radionuclides are more generally distributed through the structure. Niobium-94 can be predominately found in weld materials used within the reactor vessel internal structure. This material is fused with surrounding base metal and is thus an intrinsic part of the overall structure.

\subsection{Long Lived Curie Content in the Reactor Vessel}

Neutrons that penetrate through the internal structure can activate atoms in the reactor vessel. This results in the long lived radionuclides of Table D-1, but to a much lesser extent than for the internal structure. For estimating long lived activity contained in the reactor vessel, the curie contents provided in Table D-3 for reactor vessel internal structure can be increased by a scaling factor to include long lived curies found in the reactor vessel materials. Scaling factors for this purpose range from 1.05 to 1.20 , depending on the reactor vessel internal structure type. Scaling factors were developed by estimating the nickel-59, nickel-63, and niobium-94 quantities expected in the most highly activated regions of the reactor vessel. Of these three radionuclides, the greatest amount of activation in the reactor vessel, on a percentage basis compared to the internal structure, was for niobium-94. The niobium-94 reactor vessel activities were rounded upwards to produce conservative scaling factors and the resulting niobium-94 based scaling factors were used. Differences in scaling factors between internal structure types result from a number of factors including expected operating life of the reactor plant and design of the internal structure.

\section{SUITABILITY OF REACTOR VESSEL INTERNAL STRUCTURE FOF SHALLOW LAND BURIAL AT} HANFORD SITE

\subsection{Hanlord Site Activity Concentration Limits}

The Department of Energy Hanford Site Solid Waste Acceptance Criteria Document (WHC, 1993) provides activity concentration limits for the Hanford Site. Hanford Category 3 limits are intended to be functionally equivalent to 10CFR61 Class C limits, developed by the Nuclear Regulatory Commission (NRC), in defining a waste suitable for land burial. Both the Hanford and NRC limits are based on a maximum radiological dose to an intruder of $500 \mathrm{mrem} / \mathrm{yr}$. The NRC limits allow for surface oriented agricultural and construction related intruder scenarios (NRC, 1982). The Hanford limits consider site specific characteristics, which eliminates all plausible intruder scenarios except well-drilling (WHC, 1993). Table D-4 presents Hanford activity concentration limits for the radionuclides considered in this appendix, in curies per cubic meter. For comparison to these limits, Table D-4 also presents activity concentration fractions. The curie contents provided in Table D-3 for a 1 year decay period are divided by the structure volumes of Table D-2 to produce activity concentrations in curies per cubic meter. These concentrations are then divided by the Hanford Category 3 limits provided in Table D-4 to produce the decimal fractions shown. Activity concentrations for the entire reactor compartment could be similarly 
WHC-SD-WM-TI-730, REV. 0

calculated based on reactor vessel volume and the radionuclide content of the vessel. These activity concentrations would be lower than those for the internal structure in Table D-4 due to the much larger exterior volume of the reactor vessel compared to the internal structure.

\begin{tabular}{|l|c|c|l|l|l|l|}
\hline & & \multicolumn{5}{|c|}{$\begin{array}{l}\text { Activity Concentration Limit Fractions } \\
\text { for Intemal Structure }\end{array}$} \\
\hline Radionuclides & $\begin{array}{l}\text { Hanford } \\
\text { Category 3 } \\
\text { limit (Ci/m })^{3}\end{array}$ & $\begin{array}{l}\text { Type } \\
\# 1\end{array}$ & $\begin{array}{l}\text { Type } \\
\# 2\end{array}$ & $\begin{array}{l}\text { Type } \\
\# 3\end{array}$ & $\begin{array}{l}\text { Type } \\
\# 4\end{array}$ & $\begin{array}{l}\text { Type } \\
\# 5\end{array}$ \\
\hline nickel-63 & 170,000 & 0.0128 & 0.0039 & 0.0096 & 0.0192 & 0.0018 \\
\hline carbon-14 & 91 & 0.0012 & 0.0004 & 0.0135 & 0.0269 & 0.0002 \\
\hline niobium-94 & 0.56 & 0.125 & 0.0485 & 0.105 & 0.209 & 0.0106 \\
\hline selenium-79 & 83 & $<0.0001$ & $<0.0001$ & $<0.0001$ & $<0.0001$ & $<0.0001$ \\
\hline nickel-59 & 8,300 & 0.0024 & 0.0007 & 0.0017 & 0.0034 & 0.0003 \\
\hline technetium-99 & 1.2 & 0.0022 & 0.0005 & 0.0011 & 0.0022 & 0.0001 \\
\hline iodine-129 & 0.59 & $<0.0001$ & $<0.0009$ & $<0.0001$ & $<0.0001$ & $<0.0001$ \\
\hline
\end{tabular}

a: Limit for radionuclide in activated melal.

\section{Table D-4, Activity Concentration Fractions for Long Lived Activity Based on Hanford Category 3 Limits (WHC, 1993)}

\subsection{CFr61 Activity Concentration Limits}

In 10CFR61, the Nuclear Regulatory Commission (NRC) established activity concentration limits for radioactive materials being disposed of at NRC licensed sites. These limits are not directly applicable to Department of Energy sites (Hanford) but are presented in Table D-5 for the radionuclides considered in this appendix for comparison. Table D-5 presents activity concentration limits for activated metals for Class $C$ waste, in curies per cubic meter. No limit for selenium-79 is found in 10CFR61. Table D-5 also presents activity concentration fractions. The curie contents provided in Table D-3 for a 1 year decay period are divided by the structure volumes of Table D-2 to produce activity concentrations in curies per cubic meter. These concentrations are then divided by the 10CFR61 Class $C$ limits provided in Table $D .5$ to produce the decimal fractions shown.

From Table D-5, activity concentrations are well below 10CFR61 Class C limits for the radionuclides listed. As stated previously, activity concentrations would be reduced further if the reactor vessel internal structure and the less activated reactor vessel were considered together as a whole.

The disposal of cruiser, LOS ANGELES, and OHIO class reactor compartments at the Hanford 218-E-12B burial ground would also meet the intruder and environmental protection standards of 10CFR61 (for radiological dose). Appendix B provides a more detailed discussion of this condition.

D-7 


\begin{tabular}{|l|c|l|l|l|l|l|}
\hline & \multicolumn{5}{|c|}{$\begin{array}{l}\text { Activity Concentration Limit Fractions } \\
\text { for Intemal Structure }\end{array}$} \\
\hline Radionuclides & $\begin{array}{l}\text { Class C } \\
\text { limit (Ci/m } \text { a }^{3}\end{array}$ & $\begin{array}{l}\text { Type } \\
\# 1\end{array}$ & $\begin{array}{l}\text { Type } \\
\# 2\end{array}$ & $\begin{array}{l}\text { Type } \\
\# 3\end{array}$ & $\begin{array}{l}\text { Type } \\
\# \mathbf{4}\end{array}$ & $\begin{array}{l}\text { Type } \\
\# \mathbf{5}\end{array}$ \\
\hline nickel-63 & 7000 & 0.312 & 0.0938 & 0.234 & 0.466 & 0.0442 \\
\hline carbon-14 & 80 & 0.0014 & 0.0004 & 0.0153 & 0.0306 & 0.0002 \\
\hline niobium-94 & 0.2 & 0.350 & 0.136 & 0.293 & 0.586 & 0.0296 \\
\hline nickel-59 & 220 & 0.0905 & 0.0275 & 0.0645 & 0.129 & 0.0120 \\
\hline technetium-99 & 3 & 0.0009 & 0.0002 & 0.0004 & 0.0009 & $<0.0001$ \\
\hline iodine-129 & 0.08 & $<0.0001$ & $<0.0001$ & $<0.0001$ & $<0.0001$ & $<0.0001$ \\
\hline
\end{tabular}

a: Limit for radionuclide in activated metal.

\section{Table D-5, Activity Concentration Fractions for Long Lived Activity based on 10CFR61 Class C Limits}

\subsection{Uncertainty in Activity Concentration Fractions}

Section 5 discusses the calculation of activity in reactor vessel internal structure and conservatisms or uncertainty in the calculation method. In summary, the curie contents presented in Table D-3 are considered reasonably accurate. This accuracy results from assumptions employed in the calculation process. Validation has confirmed the accuracy of the calculation method with measured activities predicted to within plus and minus 30\% (e.g., see SHURE, 1967). Reactor vessel internal structure volumes are also based on accurate construction drawings. The resulting degree of uncertainty in activity concentration fractions would not be sufficient to alter the conditions discussed in the previous sections.

\section{CALCULATION OF ACTIVATION PRODUCT CURIES}

Neutrons interact with nonradioactive atoms (target isotopes) that are found within reactor materials, causing these atoms to become activated to radionuclides. This process is modeled by an equation which relates the flux of neutrons generated by the fuel to properties of the material being irradiated and reactor operation/shutdown times. Neutrons are produced with a range of energies which also must be considered in the model. The basic model equation is thus repeated for different neutron energy groups to sum the contributions of all neutrons to the activation process.

\subsection{Equation}

The following equation is used to calculate curie contents resulting from the activation of material.

$A\left(t_{0}, t_{s}\right)=\left[P V f N \sigma \phi f_{c}\left(1 \cdot e^{-\left(\lambda t_{0}\right)}\right) e^{-\left(\lambda t_{s}\right)}\right] / 3.7 \times 10^{10}$

$t_{0}=$ the operating time for the reactor.

$t_{s}=$ the shutdown time; the time between the end of the operating period $t_{0}$ and the time at which the activity is determined (e.g., if the reactor is shut down in year $\mathrm{X}$ and the curie content is evaluated for year $\mathrm{X}+\mathrm{Y}$, then $\mathrm{t}_{\mathrm{b}}$ [shutdown time] is $\mathrm{Y}$ years. 
WHC-SD-WM-TI-730, REV. 0

$A\left(t_{0}, t_{s}\right)=$ the number of curies of activity contained in a volume of material due to a specific radionuclide for a particular operating time $\left(t_{o}\right)$, and shutdown time $\left(t_{s}\right)$.

$P=$ the fraction of full power of reactor operation during the period $t_{\mathrm{o}}$.

$\mathrm{V}=$ the volume of material activated $\left(\mathrm{cm}^{3}\right)$.

$f=$ the target isotope's abundance in the activated material relative to the abundance of the target isotope's element (the number of atoms of the target isotope per atom of the element).

$\mathrm{N}=$ the atom density (atoms/barn $-\mathrm{cm}$ ) of the target isotope's element in the material activated (e.g., if niobium-93) is the target isotope then niobium is the target isotope's element so the atom density of niobium in the activated material is used).

$\sigma=$ the target isotope's microscopic activation cross section (barns).

$\phi=$ the full power value of the activating neutron flux assigned to the volume (V) of the materia] [neutrons $/\left(\mathrm{cm}^{2}-\mathrm{sec}\right)$ ].

$f_{c}=a$ neutron spectrum correction factor that is consistent with flux and cross section used.

$\lambda=$ the activated radionuclide's decay constant ( 0.693 divided by the half-life of the radionuclide).

$3.7 \times 10^{10}=37,000,000,000$; the number of disintegrations per second for one curie of activity.

Note: In the equation, the exponential term using ts can be approximated by 1 for long lived radionuclides. The exponential term using $t_{0}$ is subtracted from 1 and thus this combination approaches zero for very long lived radionuclides but can vary by orders of magnitude depending on $\lambda$. For long lived radionuclides, curies increase essentially linearly with increasing to.

\subsection{Quantifying Variables}

When using the equation to estimate a radionuclides activity, the following considerations govern values assigned to variables in the equation.

\subsubsection{Target Isotope Abundance (f)}

Table D-6 provides the target isotopes for the long lived radionuclides of Table D-1 and values for the target isotope's abundance, the variable ( $f$, used in the basic equation. Isotopic abundance is given in $\%$ of atoms of the element that are the target isotope. For example, nickel-62 is the target isotope for nickel-63 production and 3.59 percent of the nickel atoms present are assumed to be nickel-62. 
WHC-SD-WM-TI-730, REV. 0

\begin{tabular}{|c|c|c|c|}
\hline $\begin{array}{l}\text { Table D-1 } \\
\text { Radionuclide }\end{array}$ & Target Isotope & $\begin{array}{l}\text { Isotopic Abundance } \\
\text { of Target Isotope } \\
(\%)\end{array}$ & $\begin{array}{l}\text { Concentration of Target } \\
\text { Isotope's Element in } \\
\text { Inconel Alloy } 600 \text { (weight } \\
\%)^{2}\end{array}$ \\
\hline carbon-14 & $\begin{array}{l}\text { carbon- } 13 \\
\text { nitrogen-14 } \\
\text { oxygen-17 }\end{array}$ & $\begin{array}{c}1.10 \\
99.63 \\
0.04\end{array}$ & $\begin{array}{l}0.10^{b} \\
0.013^{c} \\
0.04^{c}\end{array}$ \\
\hline nickel-63 & nickel-62 & 3.59 & $80^{\circ}$ \\
\hline niobium-94 & niobium-93 & 100 & $0.070^{c}$ \\
\hline selenium.79 & selenium-78 & 23.6 & $7.0 \times 10^{.5} \mathrm{c}$ \\
\hline nickel-59 & nickel-58 & 68.27 & $80^{\circ}$ \\
\hline technetium-99 & molybdenum-98 & 24.13 & $0.30^{\mathrm{c}}$ \\
\hline iodine-129 & tellurium-128 & 31.7 & $9 \times 10.7 ., d$ \\
\hline
\end{tabular}

a. Basis for atomic density (N).

b. Upper end of material specification range.

c. From material testing.

d. A significantly higher tellurium concentration of 0.005 wt\% is found in Inconel Alloy X-750 which is also present in the internal structure but in much smaller quantity than Alloy 600.

Table D-6 Target Isotopes, Isotopic Abundances, and Target Isotope Element Concentrations Used for Activity Calculation

\subsubsection{Atom Density (N)}

Atom density is based on the concentration of the element in the material being irradiated. Table D-6 presents element concentrations for Inconel Alloy 600, the primary alloy found in reactor vessel internal structure. Based on results from detailed chemical composition measurements, concentrations for important trace elements have been compiled primarily for use in curie calculations. This work represents an increased level of effort and provides a higher degree of accuracy compared to more common methods for determining element concentrations. In the cases where the material specification required a concentration range for an element, the upper end of the specification range is used. For example, nickel-62 is the target isotope for nickel-63. Nickel would thus be the target isotope's element. For Inconel Alloy 600 in reactor plants, the material specification is $72-80 \%$ nickel, thus $80 \%$ is selected as the element concentration and the atom density corresponding to this higher content is used. This results in a maximum $(N)$ value being used vice an average value.

\subsubsection{Cross Section ( $\sigma$ )}

Neutron energies are divided into "three groups: thermal (energy less than 0.625 electron-volts), epithermal (energy greater than 0.625 electron-volts), and fast (energy over 1 million electron-volts). The equation (section 5.1) is used to calculate the activity generated by each of 
these groups. Resulting curie contents are then summed to obtain a total activity. The appropriate cross section ( $\sigma$ ) used in the equation varies for the different neutron energy groups. Thermal, resonance integral, and fission spectrum values for ( $q$ ) are used for thermal, epithermal, and fast neutrons, respectively. Standard published cross section values are used such as those from Chart of the Nuclides and Isotepes (CHART, 1989).

\subsubsection{Neutron Fiux $(\phi)$ and Fiux Spectrum Correction Factor $\left(f_{c}\right)$}

Neutron fluxes are determined for the three energy groups and coupled to appropriate values for the other variables of the equation to assess the effect of the different neutron energy groups on the production of activated radionuclide. Conservative assumptions on the design and performance of the fuel result in estimated neutron fluxes which are considered conservative. The effects of variations in fuel on neutron fluxes outside the fuel assembly over the fuel assembly life are considered. Flux spectrum correction factors are provided in the ORIGEN (Oak Ridge National Laboratory Isotope Generation) computer program which is used to assist in curie calculations. This program is discussed further in section 5.3.

\subsubsection{Refined Method for Neutron Reaction Rate}

The equation of section 5.1 is repeated for each of the three neutron energy groups in order to account for activation produced by each group. For each energy group, average values for variables are used. The combined terms $\left(\mathrm{N} \mathrm{f}_{\mathrm{c}} \mathrm{O} \phi\right)$ essentially represent a neutron activation reaction rate. This rate for the thermal neutron energy group normally controls the total amount of activity produced (the curie contribution from higher energy neutrons is not significant). However, for some radionuclides, reactions with epithermal and fast neutrons produce significant amounts of activity relative to thermal neutrons. For these radionuclides, when using the equation of section 5.1, the use of average values for the $\left(\mathrm{N}_{\mathrm{c}} \sigma \phi\right)$ variables can generally lead to over predicting activity. To remedy this situation, the epithermal and fast neutron energy groups are divided up into numerous sub groups according to energy level and the effects summed together. This more refined treatment generally results in more realistic calculated activities. Niobium-94 activity is calculated in this manner. For Table D-1 radionuclides, the refined method could potentially be of benefit for selenium-79, technetium-99, and iodine-129 activity. However, this method was not used for Table D-3 because the predicted concentration of these radionuclides was relatively small in comparison to the standards discussed and use of average reaction rate terms generally over predicts activity.

\subsection{Computer Assistance for Calculations}

The ORIGEN (Oak Ridge National Laboratory Isotope Generation) computer program applies the equation to the different energy groups of neutrons produced by the reactor. The effects of each group are summed and the additional activation that occurs from secondary reactions and decay processes is included. Complex reactor power histories are accounted for. Other programs are available for use in this application, such as SPAN5 and CINDER, however, results are relatively insensitive $( \pm 10$ percent) to the calculation method when the atom density of the target isotope's element $(N)$, the activation cross section ( $\sigma$ ), and the neutron flux $(\phi)$ are known. The considerations discussed previously for quantifying these variables ensure that conservatively accurate values of the variables are used. 


\subsection{Uncertainty/Conservatism in Curie Calculations}

No explicit conservatism factors are applied to predicted activities. These activities are considered to be reasonably accurate because of the selection of values for variables and the conservative analysis models used for predicting neutron flux. Several comparisons of activity calculations to actual measurements have been made to qualify the method described in this section. These comparisons have shown that measured activities can be predicted to within plus or minus $30 \%$, with a majority of predictions being much closer to measured values (e.g., see SHURE, 1967).

\section{CONCLUSION}

Long lived activity in cruiser, LOS ANGELES, and OHIO class reactor plants is concentrated in the reactor vessel internal structure. This activity is not in a quantity or form that would cause the reactor compartments to be unsuitable for shallow land burial either under Hanford Site of NRC criteria. The methods used to estimate this activity are reasonably accurate and any uncertainty would not be large enough to affect the aforementioned conclusion. 


\section{REFERENCES}

CHART, 1989 Chart of the Nuclides and Isotopes, General Electric Company, Nuclear Operations, San Jose California, 14th edition (1989).

KOCHER, 1981 Radioactive Decay Data Tables - A Handbook of Decay Data for Application to Radiation Dosimetry and Radiological Assessments, David C. Kocher, Health and Safety Research Division Oak Ridge national Laboratory, 1981, U.S. Dept. of Energy, available as DOE/TIC-11026 from National Technical Information Center, US Dept of Commerce.

NRC, 1982

Final Environmental Impact Statement on 10 CFR Part 61 "Licensing Requirements for Land Disposal of Radioactive Wasten, Volume 1. Summary and Main Report, NUREG-0945-V1, United States. Nuclear Regulatory Commission, Washington, D.C., November 1982.

SHURE, 1967 "Neutron Exposure of the PM-2A Reactor Vessel", K. Shure and Carl T. Oberg, Nuclear Science and Engineering, Vol. 27 (1967), p. 348-359.

WHC, 1993 Hanford Site Solid Waste Acceptance Criteria, WHC-EP-0063-4/UC 721 Westinghouse Hanford Company, Richland, WA, Prepared for the United States Department of Energy, November 1993.

10CFR61 Code of Federal Regulations Title 10 "Energy", Part 61. 
WHC-SD-WM-TI-730, REV 0

\section{APPENDIX C \\ MODELING EQUATIONS, PARAMETER SELECTION, AND \\ PARAMETER VALUES USED FOR THE EXPOSURE PATHWAY ANALYSIS}


WHC-SD-WM-TI-730, REV 0

This page intentionally left blank. 
WHC-SD-WM-TI-730, REV 0

\section{MODELING EQUATIONS, PARAMETER SELECTION, AND PARAMETER VALUES USED FOR THE EXPOSURE PATHWAY ANALYSIS}

In this section, the details needed to quantify the internal and external doses for each exposure pathway are described. Exposure pathways that are assumed in the inadvertent intrusion scenarios, the groundwater pathway scenarios (irrigator and Columbia River) and the atmospheric dispersion scenario are discussed. Section $C .1$ follows the progression of contaminants from soil through plants and animals into the human. Section C.2 considers vapor transport from the soil to the atmosphere to man.

\section{1 MODELS AND PARAMETER VALUES FOR EXPOSURE FROM CONTAMINATED SOIL AND WATER}

In this section the details for each exposure pathway are described. It follows the progression from soil through plants and animals into the human.

\section{C.1.1 Soil Concentration for the Intruder Garden Scenarios}

In the intruder scenarios the initial waste concentration is given. The age of the waste may require additional nuclides (progeny) to be included. The initial soil concentration in the garden is calculated from the assumed volume exhumed and the surface area of the garden. No other calculations are required to determine the initial soil concentration.

The soil concentration decreases with time due to leaching and radioactive decay. Leaching is the process by which radioactive materials migrate from the surface layer of soil into deeper layers below. The driving force behind the leaching process is the application of water to the soil. Leaching is treated as a removal rate constant giving the fraction of the material in the surface layer which is removed per unit of time. It is calculated using the equation shown below.

$$
\lambda_{s}=\frac{P+I-E}{\theta d\left(1+\rho / \theta K_{d}\right)}
$$

where:

$\lambda_{\mathbf{s}}=$ annual average soil ieaching coefficient, fraction removed from a soil layer of thickness "d" per year

$P=$ total precipitation, in centimeters per year

$I=$ total irrigation, assumed to be $82.3 \mathrm{~cm}$ per year $(32.4$ inches $/ \mathrm{yr}$ )

$E=$ total evapo-transpiration, in centimeters per year

$d=$ thickness of soil from which nuclides migrate, in centimeters. This is assumed to be $15 \mathrm{~cm}$ (5.9 inches).

$\rho=$ bulk density of the surface soil, in grams per cubic centimeter. In GENII this is $1.5 \mathrm{~g} / \mathrm{cc}$.

$\theta=$ volumetric water content of the surface soil, milliliters of water per cubic centimeter of soil. A value of $0.4 \mathrm{ml} / \mathrm{cc}$ is assumed. 
$K_{d}=$ distribution coefficient in surface soil for an element, in milliliters per gram.

For input to GENII (Napier 1988), the leaching parameters are placed in the data file named FTRANS.DAT. The values for the nuclides considered in the base case dose assessment are 7 isted in Tables $C-1$ and $C-2$. The following assumptions were used to relate the $\lambda_{\mathrm{s}}$ and $\mathrm{K}_{\mathrm{d}}$ values: $\rho=1.5 \mathrm{~g} / \mathrm{cc} ; \theta=0.4$ $\mathrm{ml} / \mathrm{cc} ; d=15 \mathrm{~cm} ;$ and $P+I-E=15 \mathrm{~cm} / \mathrm{yr}$. Note that the amount of irrigation was the same for all plant types.

For the intruder scenarios, the initial soil concentration in the top layer of soil decreases exponentially with time until the plant type is harvested. This is shown in the equation below.

$$
W^{s}=W_{0} \operatorname{Exp}\left[-\left(\lambda_{s}+\lambda_{r}\right) T\right]
$$

where:

$W^{s}=$ soil concentration after time $T$, in curies per kilogram of soil

$W_{0}=$ initial soil concentration at time of intrusion, in curies per kilogram of soil

$\lambda_{r}=$ radioactive decay constant, namely, the natural logarithm of 2 divided by the radioactive decay half-life in years

$T=$ soil leaching time, in years

The soil leaching times for the ingestion dose pathways differ from those for inhalation and external pathways. The ingestion doses are based on the soil concentration 100 days after intrusion. The inhalation and external dose accumulates during the year after intrusion. These assumptions differ from those coded into GENII, namely no decay or leaching for inhalation and external, and 10 to 30 days of radioactive decay only for ingestion pathways. This later time corresponds to the time between harvest and consumption of the produce.

\section{C.1.2 Soil Concentration for the Groundwater Use Scenarios}

During irrigation, the radioactivity in the irrigation water accumulates in plants and soil differently. For accumulation on plants by direct deposition, the rate of deposition determines the final concentration in the plants. For determining the soil concentration, which determines the root uptake, inhalation and external doses, the total activity remaining in the surface layer of soil at the end of the year is all that matters. These differences are included in the equations below.

The rate of addition of contamination to the soil is given by the equation shown below: The conversion factor from inches of water applied to the soil to units of liters applied per square meter is shown in the equation. 
Table C-1. Transfer Factors in NUREG/CR-5512 (Kennedy and Strenge 1992).

\begin{tabular}{|c|c|c|c|c|c|c|c|c|c|}
\hline \multirow{2}{*}{ Nene } & \multicolumn{3}{|c|}{ Ory Plant/Soil Cone Ratio } & \multirow{2}{*}{$\begin{array}{l}\left(B_{v}\right) \\
\text { Grain }\end{array}$} & \multirow{2}{*}{$\begin{array}{c}\text { Beef } \\
\text { day/kg } \\
\left(F_{0}\right)\end{array}$} & \multirow{2}{*}{$\begin{array}{c}\text { Milk } \\
\text { day/L } \\
\left(F_{2}\right)\end{array}$} & \multirow{2}{*}{$\begin{array}{l}\text { Fish } \\
\left(\mathrm{s}_{p}\right)\end{array}$} & \multirow{2}{*}{$\begin{array}{c}\text { Leaching } \\
\text { per yr } \\
\left(d_{3}\right)^{2}\end{array}$} & \multirow{2}{*}{$\begin{array}{l}\text { Distr } \\
\mathrm{ml} / \mathrm{g} \\
\left(K_{0}\right)\end{array}$} \\
\hline & Leafy & Root & Fruit & & & & & & \\
\hline $\mathrm{H}$ & \multicolumn{6}{|c|}{ (special model) } & 1 & 2.5 & 0 \\
\hline $8 E$ & 1.DE-2 & $1.5 \mathrm{E}-3$ & $1.5 \mathrm{E}-3$ & $1.5 \mathrm{E}-3$ & $1.0 E-3$ & $9.0 \mathrm{E}-7$ & 2 & 2.7TE-3 & 240 \\
\hline$c$ & $7.0 \mathrm{E}-1$ & $7.0 \mathrm{E}-1$ & $7.0 \mathrm{E}-1$ & $7.0 E-1$ & $4.9 E-2$ & $1.1 E-2$ & 4,600 & $9.57 \mathrm{E}-2$ & 6.7 \\
\hline $\mathrm{CL}$ & 70 & 70 & 70 & 70 & 8.0E-2 & $1.5 E-2$ & 50 & $3.39 E-1$ & 1.7 \\
\hline $\mathbf{K}$ & 1.0 & $5.5 \mathrm{E}-1$ & $5.5 E-1$ & $5.5 \mathrm{E}-1$ & $2.0 E-2$ & $7.0 \mathrm{e}-3$ & 1,000 & $3.65 \mathrm{E}-2$ & 18 \\
\hline co & $8.1 E-2$ & $4.0 \mathrm{E}-2$ & $7.0 E-3$ & $3.7 \mathrm{E}-3$ & $2.0 \mathrm{E}-2$ & $2.0 \mathrm{E}-3$ & 330 & $1.11 E-2$ & 60 \\
\hline NI & 2.8E-1 & $6.0 \mathrm{E}-2$ & $6.0 \mathrm{E}-2$ & $3.0 E-2$ & $6.0 \mathrm{E}-3$ & $1.0 \mathrm{E}-3$ & 100 & $1.67 \mathrm{E}-3$ & 400 \\
\hline SE & $2.5 E-2$ & $2.5 \mathrm{E}-2$ & $2.5 E-2$ & $2.5 E-2$ & $1.5 E-2$ & 4. $0 \mathrm{E}-3$ & 170 & 4.75E-3 & 140 \\
\hline SR & 1.6 & 8.1E-1 & $1.7 E-1$ & $1.3 \mathrm{E}-1$ & $3.0 \mathrm{E}-4$ & $1.5 \mathrm{E}-3$ & 50 & $4.37 \mathrm{E}-2$ & 15 \\
\hline$r$ & $1.5 E-2$ & $6.0 \mathrm{E}-3$ & $6.0 E-3$ & $6.0 \mathrm{E}-3$ & $3.0 E-4$ & $2.0 \mathrm{E}-5$ & 25 & $3.50 \mathrm{E}-3$ & 190 \\
\hline $2 R$ & $2.0 \mathrm{E}-3$ & $5.0 \mathrm{E}-4$ & $5.0 \mathrm{E}-4$ & $5.0 \mathrm{E}-4$ & $5.5 \mathrm{E}-3$ & $3.0 \mathrm{E}-5$ & 200 & $1.15 E-3$ & 580 \\
\hline NB & 2. $0 \mathrm{E}-2$ & $5.0 \mathrm{E}-3$ & $5.0 \mathrm{E}-3$ & $5.0 \mathrm{E}-3$ & $2.5 \mathrm{E}-1$ & $2.0 \mathrm{E}-2$ & 200 & $4.16 E-3$ & 160 \\
\hline MO & $2.5 E-1$ & $6.0 \mathrm{E}-2$ & $6.0 E-2$ & $6.0 \mathrm{E}-2$ & $6.0 \mathrm{E}-3$ & $1.5 \mathrm{E}-3$ & 10 & $6.49 E-2$ & 10 \\
\hline IC & 44 & 1.1 & 1.5 & $7.3 \mathrm{E}-1$ & $8.5 E-3$ & $1.0 \mathrm{E}-2$ & 15 & 1.82 & 0.1 \\
\hline $\mathrm{PD}$ & $1.5 \mathrm{E}-1$ & 4.0E-2 & 4. $0 E-2$ & 4.0E-2 & 4.0E-3 & 1. $0 \mathrm{E}-2$ & 10 & $1.28 E-2$ & 52 \\
\hline$C D$ & $5.5 \mathrm{E}-1$ & $1.5 \mathrm{E}-1$ & $1.5 \mathrm{E}-1$ & $1.5 \mathrm{E}-1$ & $5.5 E-4$ & $1.0 \mathrm{E}-3$ & 200 & $1.66 \mathrm{E}-2$ & 40 \\
\hline IN & 4.0E-3 & $4.0 \mathrm{E}-4$ & $4.05-4$ & $4.0 E-4$ & $8.0 \mathrm{E} \cdot 3$ & $1.0 \mathrm{E}-4$ & 100,000 & $1.71 \mathrm{E}-3$ & 390 \\
\hline SN & $3.0 E-2$ & $6.0 \mathrm{E}-3$ & $6.0 \mathrm{E}-3$ & $6.0 \mathrm{E}-3$ & $8.0 E-2$ & $1.0 \mathrm{E}-3$ & 3,000 & $5.12 E-3$ & 130 \\
\hline SB & $1.3 \mathrm{E}-4$ & $5.6 E-4$ & $8.0 E-5$ & $3.0 \mathrm{E}-2$ & $1.0 E-3$ & 1.0E- -4 & 200 & $1.47 \mathrm{E}-2$ & 45 \\
\hline TE & $2.5 E-2$ & 4.0E-3 & $4.05-3$ & $4.0 \mathrm{E}-3$ & $1.5 \mathrm{E}-2$ & $2.0 \mathrm{E}-4$ & 400 & $4.75 E-3$ & 140 \\
\hline 1 & $3.4 \mathrm{E}-3$ & $5.0 \mathrm{E}-2$ & $5.0 E-2$ & $5.0 \mathrm{E}-2$ & $7.0 \mathrm{E}-3$ & $1.0 E-2$ & 500 & $5.26 \mathrm{E}-1$ & 1 \\
\hline CS & $1.3 E-1$ & $4.9 E-2$ & $2.2 E-1$ & $2.6 \mathrm{E}-2$ & 2.0E-2 & $7.0 E-3$ & 2,000 & $2.47 \mathrm{E}-3$ & 270 \\
\hline $\mathrm{BA}$ & $1.5 \mathrm{E}-1$ & $1.5 \mathrm{E}-2$ & $1.5 \mathrm{E}-2$ & $1.5 \mathrm{E}-2$ & $1.5 \mathrm{E}-4$ & $3.5 E-4$ & 200 & $1.28 \mathrm{E}-2$ & 52 \\
\hline SH & $1.0 E-2$ & $4.0 \mathrm{E}-3$ & 4. $0 E-3$ & 4. $0 E-3$ & $5.0 \mathrm{E}-3$ & $2.0 E-5$ & 25 & $2.77 \mathrm{E}-3$ & 240 \\
\hline EU & $1.0 E-2$ & $4.0 E-3$ & $4.0 \mathrm{E}-3$ & $4.0 E-3$ & $5.0 \mathrm{E}-3$ & $2.0 \mathrm{E}-5$ & 25 & $2.77 E-3$ & 240 \\
\hline GD & $1.0 \mathrm{E}-2$ & $4.0 \mathrm{E}-3$ & $4.05-3$ & $4.0 \mathrm{E}-3$ & $3.5 \mathrm{E}-3$ & $2.0 E-5$ & 25 & 2.T7E-3 & 240 \\
\hline RE & 1.5 & $3.5 E-1$ & $3.5 E-1$ & $3.5 \mathrm{E}-1$ & $8.0 \mathrm{E}-3$ & $1.5 \mathrm{E}-3$ & 120 & 4.67E-2 & 14 \\
\hline$P B$ & $5.8 E-3$ & $3.2 \mathrm{E}-3$ & $9.0 \mathrm{E}-3$ & $4.7 \mathrm{E}-3$ & $3.0 \mathrm{E}-4$ & $2.5 E-4$ & 100 & $2.47 \mathrm{E}-3$ & 270 \\
\hline$B 1$ & $3.5 E-2$ & $5.0 \mathrm{E}-3$ & $5.0 \mathrm{E}-3$ & $5.0 E-3$ & 4.0E-4 & $5.0 \mathrm{E}-4$ & 15 & $5.54 \mathrm{E}-3$ & 120 \\
\hline PO & $2.5 E-3$ & $9.0 \mathrm{E}-3$ & $4.0 E-4$ & $4.0 \mathrm{E}-4$ & $3.0 \mathrm{E}-4$ & $3.5 E-4$ & 500 & $4.44 \mathrm{E}-3$ & 150 \\
\hline RN & 0.0 & 0.0 & 0.0 & 0.0 & 0.0 & 0.0 & 1 & 2.5 & 0 \\
\hline FR & \multicolumn{6}{|c|}{ (none given) } & 2,000 & & \\
\hline RA & $7.5 \mathrm{E}-2$ & $3.2 \mathrm{E}-3$ & $6.1 E-3$ & $1.2 \mathrm{E}-3$ & $2.5 \mathrm{E}-4$ & $4.5 E-4$ & 70 & $1.33 \mathrm{E}-3$ & 500 \\
\hline AC & $3.5 \mathrm{E}-3$ & $3.5 \mathrm{E}-4$ & $3.5 E-4$ & $3.5 E-4$ & $2.5 E-5$ & $2.0 E-5$ & 25 & $1.59 \mathrm{E}-3$ & 420 \\
\hline TH & $6.6 E-3$ & $1.2 \mathrm{E}-4$ & $8.5 E-5$ & $3.4 E-5$ & $6.0 \mathrm{E}-6$ & $5.0 E-6$ & 100 & $2.08 E-4$ & 3,200 \\
\hline PA & $2.5 \mathrm{E}-3$ & $2.5 E-4$ & $2.5 E-4$ & $2.5 E-4$ & $1.0 \mathrm{E}-5$ & $5.0 E-6$ & 11 & $1.31 E-3$ & 510 \\
\hline$u$ & $1.7 \mathrm{E}-2$ & $1.4 \mathrm{E}-2$ & $4.0 \mathrm{E}-3$ & 1.3E-3 & 2. DE- 4 & $6.0 E-4$ & 50 & $4.37 \mathrm{E}-2$ & 15 \\
\hline NP & $1.3 E-2$ & $9.4 E-3$ & $1.0 E-2$ & $2.7 \mathrm{E}-3$ & $5.5 E-5$ & $5.0 \mathrm{E}-6$ & 250 & $1.27 \mathrm{E}-1$ & 5 \\
\hline PU & $3.9 E-4$ & $2.0 \mathrm{E}-4$ & $4.5 E-5$ & $2.6 E-5$ & $5.0 \mathrm{E}-7$ & 1.0E-7 & 250 & $1.21 \varepsilon-3$ & 550 \\
\hline AM & $5.8 E-4$ & 4.1E-4 & $2.5 E-4$ & $5.9 \mathrm{E}-5$ & $3.5 E-6$ & $4.0 \mathrm{E}-7$ & 250 & $3.51 E-4$ & 1,900 \\
\hline $\mathrm{CM}$ & $3.0 \mathrm{E}-4$ & $2.4 \mathrm{E}-4$ & $1.5 \varepsilon-5$ & 2.1E-5 & $3.5 E \cdot 6$ & $2.0 E-5$ & 250 & $1.67 \mathrm{E}-4$ & 4,000 \\
\hline
\end{tabular}

Note: Animal fresh forage and stored hay are treated as leafy vegetables. 
WHC-SD-WM-TI-730, REV 0

Table C-2. Transfer Factors from ORNL-5785 (Baes 1984).

\begin{tabular}{|c|c|c|c|c|c|c|c|}
\hline $\begin{array}{l}\text { Nuc } \\
\text { Neme }\end{array}$ & $\begin{array}{l}\text { Lesfy } \\
\text { Vegt. } \\
\left(B_{p}\right)\end{array}$ & $\begin{array}{c}\text { Grains* } \\
\left(B_{p}\right)\end{array}$ & $\begin{array}{c}\text { Beef } \\
\text { day/kg } \\
\left(\mathrm{F}_{b}\right)\end{array}$ & $\begin{array}{c}\text { Milk } \\
\text { day/L } \\
\left(F_{m}\right)\end{array}$ & $\begin{array}{c}\text { Leaching } \\
\text { per yr } \\
\text { (d.) }\end{array}$ & $\begin{array}{c}\text { Distr } \\
\left(x_{d}\right)\end{array}$ & $\begin{array}{c}\text { Atomic } \\
\text { No. } \\
\text { (2) }\end{array}$ \\
\hline $\mathrm{BE}$ & 0.01 & 0.0015 & 0.001 & $9 E-07$ & $1.03 E-3$ & 650 & 4 \\
\hline CL & 70 & 70 & 0.08 & 0.015 & 1.29 & 0.25 & 17 \\
\hline$K$ & 1 & 0.55 & 0.02 & 0.007 & 0.116 & 5.5 & 19 \\
\hline CO & 0.02 & 0.007 & 0.02 & 0.002 & $1.47 E-2$ & 45 & 27 \\
\hline NI & 0.06 & 0.06 & 0.006 & 0.001 & $4.44 E-3$ & 150 & 28 \\
\hline SE & 0.025 & 0.025 & 0.015 & 0.004 & $2.22 \mathrm{E}-3$ & 300 & 34 \\
\hline$S R$ & 2.5 & 0.25 & 0.0003 & 0.0015 & $1.89 E-2$ & 35 & 38 \\
\hline$Y$ & 0.015 & 0.006 & 0.0003 & $2 E-05$ & $1.33 \mathrm{E}-3$ & 500 & 39 \\
\hline $2 R$ & 0.002 & 0.0005 & 0.0055 & $3 E-05$ & $2.22 E-4$ & 3,000 & 40 \\
\hline NB & 0.02 & 0.005 & 0.25 & 0.02 & $1.90 \mathrm{E}-3$ & 350 & 41 \\
\hline Mo & 0.25 & 0.06 & 0.006 & 0.0015 & $3.29 \mathrm{E}-2$ & 20 & 42 \\
\hline IC & 9.5 & 1.5 & 0.0085 & 0.01 & 0.377 & 1.5 & 43 \\
\hline PD & 0.15 & 0.04 & 0.004 & 0.01 & $1.11 \mathrm{E}-2$ & 60 & 46 \\
\hline$C D$ & 0.55 & 0.15 & 0.00055 & 0.001 & $9.85 E-2$ & 6.5 & 48 \\
\hline IN & 0.004 & 0.0004 & 0.008 & 0.0001 & $4.44 E-4$ & 1,500 & 49 \\
\hline SK & 0.03 & 0.006 & 0.08 & 0.001 & $2.66 \mathrm{E}-3$ & 250 & 50 \\
\hline SB & 0.2 & 0.03 & 0.001 & 0.0001 & $1.47 \mathrm{E}-2$ & 45 & 51 \\
\hline TE & 0.025 & 0.004 & 0.015 & 0.0002 & $2.22 E-3$ & 300 & 52 \\
\hline 1 & 0.15 & 0.05 & 0.007 & 0.01 & $1.11 E-2$ & 60 & 53 \\
\hline cs & 0.08 & 0.03 & 0.02 & 0.007 & $6.66 E-4$ & 1,000 & 55 \\
\hline $\mathrm{BA}$ & 0.15 & 0.015 & 0.00015 & 0.00035 & $1.11 E-2$ & 60 & 56 \\
\hline SM & 0.01 & 0.004 & 0.005 & $2 E-05$ & $1.03 \mathrm{E}-3$ & 650 & 62 \\
\hline EU & 0.01 & 0.004 & 0.005 & $2 E-05$ & $1.03 E+3$ & 650 & 63 \\
\hline GD & 0.01 & 0.004 & 0.0035 & $2 E-05$ & $1.03 E-3$ & 650 & 64 \\
\hline RE & 1.5 & 0.35 & 0.008 & 0.0015 & $8.58 E-2$ & 7.5 & 75 \\
\hline PB & 0.045 & 0.009 & 0.0003 & 0.00025 & $7.41 E-4$ & 900 & 82 \\
\hline BI & 0.035 & 0.005 & 0.0004 & 0.0005 & $3.33 E-3$ & 200 & 83 \\
\hline PO & 0.0025 & 0.0004 & 0.0003 & 0.00035 & $1.33 \mathrm{E}-3$ & 500 & 84 \\
\hline $\mathbf{R H}$ & 0 & 0 & 0 & 0 & 2.50 & 0 & 86 \\
\hline$F R$ & 0.03 & 0.008 & 0.0025 & 0.02 & $2.66 E-3$ & 250 & 87 \\
\hline RA & 0.015 & 0.0015 & 0.00025 & 0.00045 & $1.48 \mathrm{E}-3$ & 450 & 88 \\
\hline AC & 0.0035 & 0.00035 & $2.5 E-05$ & $2 E-05$ & $4.44 E-4$ & 1,500 & 89 \\
\hline TH & 0.00085 & $8.5 E-05$ & $6 E-06$ & $5 E-06$ & $4.44 E-6$ & 150,000 & 90 \\
\hline PA & 0.0025 & 0.00025 & $1 E-05$ & $5 E-06$ & $2.67 E-4$ & 2,500 & 91 \\
\hline$u$ & 0.0085 & 0.004 & 0.0002 & 0.0006 & $1.48 \mathrm{E}-3$ & 450 & 92 \\
\hline NP & 0.1 & 0.01 & $5.5 E-05$ & $5 E-06$ & $2.20 \mathrm{E}-2$ & 30 & 93 \\
\hline PU & 0.00045 & 4.5E-05 & $5 E-07$ & $1 E-07$ & $1.48 \mathrm{E}-4$ & 4,500 & 94 \\
\hline AH & 0.0055 & 0.00025 & $3.5 E-06$ & $4 E-07$ & $9.52 E-4$ & 700 & 95 \\
\hline $\mathrm{CM}$ & 0.00085 & $1.5 \mathrm{E}-05$ & $3.5 E-06$ & $2 E-05$ & $3.33 \mathrm{E}-3$ & 200 & 96 \\
\hline
\end{tabular}

*The ratios for Grains were also used on Root Vegetables and Fruit. 


$$
\begin{array}{r}
\text { WHC-SD-WM-TI-730, REV O } \\
D_{p}=C_{W} I_{p}\left(25.4 \mathrm{~L} / \mathrm{m}^{2} / \text { inch }\right) / F_{i}
\end{array}
$$

where:

$D_{p}=$ activity deposition rate due to irrigation of soils growing plant type $p$, in curies per square meter per year $\left(\mathrm{Ci} / \mathrm{yr} / \mathrm{m}^{2}\right)$

$C_{w}=$ irrigation water concentration, in curies per liter $(C i / L)$ at the time irrigation pumping begins

$I_{p}=$ inches of irrigation water applied each year to $p l a n t$ type $p$. For the maximum individual cases, this value is 32.4 inches per year. For the population dose, this value is 25 inches per year (Kincaid 1995).

$F_{i}=$ fraction of the year that irrigation water is applied. The value 0.5 is used since the irrigation is assumed to take place 6 months per year.

The soil concentration in the irrigation model increases due to the application of water, but the increase is offset by the removal of contaminants by leaching and radioactive decay. The function used to represent this is shown in the equation below. The soil concentration has units of $\mathrm{Ci} / \mathrm{kg}$. At the end of the irrigation period, the soil concentration is given by the equation below.

$$
W_{p}^{i}=\frac{F_{i} D_{p}\left(1-\operatorname{Exp}\left[-\left(\lambda_{s}+\lambda_{r}\right) T\right]\right)}{\rho d\left(\lambda_{s}+\lambda_{r}\right)}
$$

where:

$W_{p}^{i}=$ soil concentration due to irrigation, in curies per kilogram of soil

$\lambda_{r}=$ radioactive decay constant, namely, the natural logarithm of 2 divided by the radioactive decay half-life in years

$T=$ soil leaching time, in years. In the GENII program, this time is always one year for irrigation scenarios.

The GENII software also considers reduction in the soil concentration due to uptake in plants and their subsequent harvest. This is a smaller effect which was not included in the spreadsheet.

I.t was not necessary to include the effects of holdup due to the long half-lives of the important nuclides. However, for a few nuclides, the production of daughter activity leads to a small increase in certain doses. Since this effect is small, the calculation of holdup was not included in the spreadsheet.

\section{C.1.3 Concentration in Vegetables}

The calculation of radionuclide concentrations in living plants uses three main routes, (1) root uptake, (2) resuspension to leaves (also called "rain splash"), and (3) direct deposition of irrigation water on foliage. Each of these will be considered separately below. The three uptake routes are then combined to get the total concentration in the vegetables. 
GENII includes the effects of radioactive decay between the time a plant type is harvested and when it is consumed. This time period is called the holdup time. It enters the equations for plant concentration as shown below.

$$
c_{p}=\left(C_{p}^{d}+c_{p}^{f}+c_{p}^{r}\right) \operatorname{Exp}\left(-\lambda_{r} T_{p}^{h}\right)
$$

where:

$C_{p}=$ radionuclide concentration in plant type $p$ at the time it is consumed, in curies per kilogram

$C_{p}^{d}=$ concentration of a radionuclide in plant type $p$ due to direct deposition of irrigation water. The units for $C_{p}^{d}$ are $C i / k g$.

$C_{p}^{r}=$ concentration of a radionuclide in plant type $p$ due to absorption from the soil through the roots. The units for $C_{p}^{r}$ are $\mathrm{Ci} / \mathrm{kg}$.

$\mathrm{C}_{\mathrm{p}}^{f}=$ concentration of a radionuclide in plant type $\mathrm{p}$ due to foliar deposition from soil resuspension. The units for $C_{p}^{f}$ are $\mathrm{Ci} / \mathrm{kg}$.

$T_{p}^{h}=$ holdup time, $i . e$. , the time between harvest and consumption of plant type $p$, in days

It was not necessary to include the effects of holdup due to the long half-lives of the important nuclides. However, for a few nuclides, the production of daughter activity leads to a small increase in certain doses. Since this effect is small, the calculation of holdup was not included in the spreadsheet.

C.1.3.1 Root Uptake into Edible Portions. Root uptake is calculated through a concentration ratio. These ratios are listed in Tables $C-1$ and $C-2$. There are some major differences, therefore, both were used and compared.

Notes for Table $\mathrm{C}-1$ and $\mathrm{C}-2$ are the following. "Leafy" refers to vegetables whose leafy parts are normally eaten. "Root," "Fruit," and "Grains" refers to all other types of vegetables whose reproductive parts are eaten. In applying the ORNL ratios, the "Leafy Vegt." ratios were only applied to Leafy Vegetables. All other vegetable types use the ratios shown under "Grains."

The ratios under both "Leafy Vegt.," "Leafy," "Root," "Fruit" and "Grains" are the $\mathrm{Ci} / \mathrm{kg}$ dry weight of vegetables to $\mathrm{Ci} / \mathrm{kg}$ of soil. For this reason, a dry-to-wet ratio must be used when calculating the plant concentrations from root uptake. The dry-to-wet ratios are listed in Table $\mathrm{C}-3$. The values shown are from GENII Version 1.485 (Napier, 1988).

The plant concentration due to root uptake into the various types of vegetation is described with the equation shown below. In GENII there are four $p 1$ ant types consumed by humans: leafy vegetables, other vegetables, fruit, and grain. There are also two plant types consumed by animals: grass (forage) and grain (stored feed). Forage is treated as a leafy vegetable.

$$
C_{p}^{r}=R_{p} B_{p} W
$$

where:

$R_{p}=$ dry to wet ratio for plant type $p$. See Table $C-3$ for values. 
$B_{p}=$ soil to plant concentration ratio, as $\mathrm{C} i / \mathrm{kg}$ dry weight of vegetables to $\mathrm{Ci} / \mathrm{kg}$ of soil. See Tables $\mathrm{C}-1$ and $\mathrm{C}-2$ for values.

$W=$ soil concentration at the time of harvest, in $\mathrm{Ci} / \mathrm{kg}$ (either $W^{s}$ or $W_{p}^{i}$ )

C.1.3.2 Resuspension of Surface Soil to Foliage (Rain Splash). The resuspension of dust by wind, or water drops splashing soil onto the foliage leads to some contamination of the edible portion of the plant. The concentration of the radionuclide in the plant is approximated by the equation shown below. This method is also used in the GENII program.

$$
C_{p}^{f}=\frac{W R^{a} \rho d V_{d} T_{V} F_{p}^{f}\left\{1-\operatorname{Exp}\left[-\left(\lambda_{w}+\lambda_{r}\right) T_{p}^{f}\right]\right\}}{Y_{p}\left(\lambda_{W}+\lambda_{r}\right)(1 \text { day } / 86400 \mathrm{sec})}
$$

where:

$R^{\theta}=$ resuspension factor, i.e., the ratio of the air concentration to the surface contamination causing it. The GENII value of $1 E-9$ per meter is used to calculate the rain splash onto plants.

$V_{d}=$ diffusion attachment speed, or ground deposition speed, in meters per second. The GENII value of $0.001 \mathrm{~m} / \mathrm{s}$ is used for every nuclide.

$T_{v}=$ translocation factor, i.e., the fraction of what deposits on the foliage that ends up in the edible portions of the plant. See Table $C-3$.

$F_{p}^{f}=$ interception fraction for plant type $p$. The fraction of what falls to the earth that lands on the plant. See Table $\mathrm{C}-3$.

$Y_{p}=$ yield of crop type $p$, in kilograms per square meter (wet weight). Also called the standing biomass. See Table $C-3$.

$\lambda_{w}=$ weathering removal coefficient, 0.0495105 per day, or 18.0713 per year, which corresponds to a 14 day half time.

$\lambda_{r}=$ radioactive decay constant, namely, the natural logarithm of 2 divided by the radioactive decay half-life in days ( 1 year $=365.25$ days)

$T_{p}^{f}=$ exposure time of the plant type $p$ to the airborne contamination depositing on the foliage, in days (also called growing period)

The weathering process removes contaminants from the outer surfaces of the plants due to the action of wind and water. The method used in GENII to compute interception fractions from the standing biomass uses the equation shown below.

$$
F_{p}^{f}=1-\operatorname{Exp}\left(-K_{p}^{f} Y_{p} R_{p}\right)
$$

where:

$F_{p}^{f}=$ interception fraction for plant type $p$. The fraction of what falls to the earth that lands on the plant. See Table C-3.

$\mathrm{K}_{\mathrm{p}}^{f}=$ constant used to relate the standing biomass (dry) and the interception fraction for plant type $p$, in square meters per kilogram

$Y_{p}=$ yield of crop type $p$, in kilograms per square meter (wet weight). Also called the standing biomass.

$R_{p}=$ dry to wet ratio for plant type $p$. See Table $c-3$ for values. 
Table C-3. Dietary Parameters for the Maximum Individual ${ }^{3}$.

\begin{tabular}{|l|l|l|l|l|l|l|l|r|r|}
\hline Type, $p$ & $T_{v}$ & $K_{p}^{f}$ & $Y_{p}$ & $R_{p}$ & $F_{p}^{f_{1}}$ & $I_{p}$ & $T_{p}^{f}$ & $T_{p}^{h}$ \\
\hline Plants Consumed by Humans \\
\hline Leafy & 1.0 & 2.9 & 2.0 & 0.10 & 0.440 & 32.4 & 90 & 1 \\
\hline Other & 0.1 & 3.6 & 2.0 & 0.25 & 0.835 & 32.4 & 90 & 5 \\
\hline Fruit & 0.1 & 3.6 & 3.0 & 0.18 & 0.857 & 32.4 & 90 & 5 \\
\hline Grain & 0.1 & 2.9 & 0.8 & 0.18 & 0.341 & 0.0 & 90 & 180 \\
\hline Plants Consumed by Beef Cattle \\
\hline Forage & 1.0 & 2.9 & 1.0 & 0.20 & 0.440 & 32.4 & 45 & 100 \\
\hline Stored 2 & 0.1 & 2.9 & 0.8 & 0.18 & 0.341 & 32.4 & 90 & 180 \\
\hline Plants Consumed by Milk Cows \\
\hline Forage & 1.0 & 2.9 & 1.5 & 0.20 & 0.581 & 32.4 & 45 & 0 \\
\hline Stored 2 & 0.1 & 2.9 & 1.0 & 0.18 & 0.407 & 32.4 & 90 & 100 \\
\hline
\end{tabular}

1 The values shown were calculated. For direct deposition of nuclides on plants by irrigation water, the interception fraction $\left(F_{p}^{f}\right)$ is 0.25 for all plant types.

2 In GENII, the stored feed model uses the

translocation factor $\left(T_{y}\right)$ and soil-to-plant concentration ratio $\left(B_{p}\right)$ for grain.

${ }^{3}$ These were also used in the exposure scenarios in the double-shelled tank LLW Performance Assessment (Kincaid 1995).

C.1.3.3 Direct Deposition of Irrigation Water on Foliage. The previous two avenues by which contamination reaches the edible portions of the plants apply only to activity which is present in the soil. This section discusses direct deposition of contaminants in irrigation water onto the foliage. The concentration in the edible portion of the plants due to direct deposition on foliage is given in the equation below.

$$
C_{p}^{d}=\frac{D_{P} T_{V} F_{p}^{f}\left\{1-\operatorname{Exp}\left[-\left(\lambda_{W}+\lambda_{r}\right) T_{p}^{f}\right]\right\}}{Y_{P}\left(\lambda_{W}+\lambda_{r}\right)(365 \text { days } / 1 \text { year })}
$$

where:

$D_{p}=$ activity deposition rate due to irrigation of soils growing plant type $p$, in curies per square meter per year $\left(\mathrm{Ci} / \mathrm{yr} / \mathrm{m}^{2}\right)$

$T_{v}=$ translocation factor, i.e., the fraction of what deposits on the foliage that ends up in the edible portions of the plant. See Table $\mathrm{C}-3$. 
$\mathrm{F}_{\mathrm{p}}^{f}=$ interception fraction for $\mathrm{plant}$ type $\mathrm{p}$. The fraction of what falls to the earth that lands on the plant. For direct deposition on plants by irrigating water, the interception fraction takes the value 0.25 for all plant types.

$\lambda_{w}=$ weathering removal coefficient, 0.0495105 per day, or 18.0713 per year, which corresponds to a 14 day half time.

$\lambda_{r}=$ radioactive decay constant, namely, the natural logarithm of 2 divided by the radioactive decay half- 1 ife in days ( 1 year $=365.25$ days)

$T_{p}^{f}=$ exposure time of the $p l a n t$ type $p$ to the airborne contamination depositing on the follage, in days (also called growing period)

$Y_{P}=$ yield of crop type $p$, in kilograms per square meter (wet weight). Also called the standing biomass. See Table C-3.

The plant concentration caused by direct deposition depends on the rate at which water is applied. In the previous two pathways, root uptake and rain splash, the determining factor is the total amount of water (and thus activity) applied to the soil.

\section{C.1.4 Concentration in Animals and Fish}

Radionuclide concentrations in animal products (meat and milk) are derived from two sources, drinking water and feed. In GENII, the cattle used for milk production and meat production are considered separately. Each has its own dietary parameters. These were listed on Table $\mathrm{C}-3$. The nuclide concentrations in drinking water and feed determine the meat or milk concentration through a concentration ratio. These concentration ratios were listed in Tables $\mathrm{C}-1$ and $\mathrm{C}-2$. The equation relating feed and water concentrations to the eventual concentration in meat and milk is shown below.

$$
C_{q}=F_{q}\left[Q_{v}^{q}\left(F_{f}^{q} C_{l}^{q}+F_{s}^{q} C_{g}^{q}\right)+Q_{w}^{q} C_{w}\right]
$$

where:

$C_{q}=$ radionuclide concentration in beef or milk (q), in curies per kilogram

$F_{q}^{q}=$ ratio of the equilibrium concentration of a nuclide in the animal product (beef or milk) to the daily intake by cattle. For beef the units are $\mathrm{Ci} / \mathrm{kg}$ (beef) per $\mathrm{Ci} /$ day, while for milk the units are $\mathrm{Ci} / \mathrm{L}$ (milk) per $\mathrm{Ci} /$ day. See Tables $\mathrm{C}-1$ and $\mathrm{C}-2$ for values.

$Q_{v}=$ amount of fresh forage consumed by beef or milk cattle on an average day, in kilograms per day. The assumed values for beef cattle and milk cows are $68 \mathrm{~kg} / \mathrm{day}$ and $55 \mathrm{~kg} / \mathrm{day}$ (Napier 1988).

$F_{f}^{q}=$ fraction of cattle diet which is forage. In GENII this is 0.75 , and forage (grass and hay) is treated as a leafy vegetable for both types of cattle.

$C_{l}=$ radionuclide concentration in forage (leafy vegetables) the cattle eat, in curies per kilogram. This includes the decay during holdup.

$F_{s}^{q}=$ fraction of cattle diet which is stored feed. In GENII this is 0.25 , and stored feed is treated as a grain.

$\mathrm{C}_{g}^{\mathrm{q}}=$ radionuclide concentration in stored feed (grain) the cattle eat, in curies per kilogram. This includes the decay during holdup.

$Q_{w}^{q}=$ amount of drinking water consumed by cattle, in liters per day. It is assumed (Napier 1988) that the beef cattle drink $50 \mathrm{~L}$ /day, while the milk cows drink $60 \mathrm{~L} / \mathrm{day}$.

$C_{w}=$ irrigation water concentration, in curies per liter $(C i / L)$ 
Radionuclide concentrations in fish are assumed to be at equilibrium with the water in which they are raised. The fish concentration is therefore the product of the water concentration and the concentration ratio for that element as shown in the equation below. The fish concentration ratios are sometimes called bioaccumulation factors.

$$
C_{f}=C_{w} B_{f}
$$

where:

$B_{f}=$ bioaccumulation factor for a given radionuclide in fish, in liters per kilogram. The values assumed are shown on Table C-l.

$C_{f}=$ radionuclide concentration in fish, in curies per kilogram.

\section{C.1.5 Special Models for Tritium}

Tritium in the soil of the intruder's garden is assumed to be unavailable for absorption by the plants. The principal reason is that tritiated water will quickly diffuse or be washed from the garden soil. Tritium in the soil gives a small inhalation dose and even smaller external dose. The main dose pathway is the small amount of soil ingested each day. This is also how the GENII program deals with tritium in the surface layer.

For the scenario using contaminated irrigation water, the concentrations of tritium in food crops, beef and milk are calculated using a specific activity model based on the concentration of tritium in the irrigation water. This same concentration is assumed to exist in the water present in all food items, since the plants and animals obtain nearly all their water from the contaminated source.

The soil concentration of tritium due to irrigation is based on the assumption that all of the soil moisture is contaminated at the same level as the water. The concentration of tritium in the air is calculated from the soil contamination, just as it is for all the nuclides. The formula for soil concentration of tritium is shown below.

$$
W=\theta_{W} C_{W}
$$

where:

$\theta_{\mathrm{H}}=$ mojsture content of soil assumed for the tritium model, in liters per kilogram of soil. The value $0.1 \mathrm{~L} / \mathrm{kg}$ (Kennedy and Strenge 1992) is used for this parameter, but only in the tritium model.

The plants derive nearly all of their water from the irrigation applied, thus the tritium concentration. in the plant water is the same as the ground water. Since the feed given the cattle as well as the water are contaminated with tritium, all of the water in the animal will have the same tritium concentration as the ground water. Using this simple assumption, the tritium concentration in plants, cows and milk is calculated from the equation shown below. 


$$
C_{p}=F_{p}^{W} C_{w}
$$

where:

$F_{p}^{M}=$ fraction of water in produce type $p$, where $p$ refers to meat and milk as well as vegetables. The dry to wet ratio $\left(R_{p}\right)$ can be calculated from this since $R_{p}=1-F_{p}^{*}$.

The tritium model considers the organically bound hydrogen in the produce to be contaminated as well as the water. The specific activity model actually requires that the concentration of tritium in the hydrogen in the water be reproduced throughout the food product. In GENII, an effective water fraction is added to the actual water fraction, and this is used to calculate results. The formula used to adjust the water fractions is shown below. Values for these parameters are shown in Table $\mathrm{C}-4$. Values from ORNL-5785 (water only) are also shown for comparison.

$$
F_{p}^{H}=F_{p}^{H}+\left(1-F_{p}^{H}\right) F_{p}^{H} g
$$

where:

$F_{p}^{w_{2}}=$ effective water fraction in produce type $p$, where $p$ refers to meat and milk as well as vegetables. This water fraction includes hydrogen which is not in the form of water. It is used in place of $F_{p}^{\mathrm{N}}$.

$F_{p}^{H}=$ fraction of hydrogen in the dry produce. The scale factor of 9 converts this to an effective water fraction.

Table C-4. Dietary Parameters Used in the Tritium and Carbon-14 Models.

\begin{tabular}{|l|c|c|c|c|c|c|}
\hline \multirow{2}{*}{ Type, $p$} & \multicolumn{2}{|c|}{ Tritium Model Parameters } & \multicolumn{1}{c|}{$C-14$} & \multicolumn{2}{c|}{ ORNL-5785 } \\
\cline { 2 - 7 } & $F_{p}^{W}$ & $F_{p}^{H}$ & $F_{p}^{W_{2}}$ & $B$ \& F & $F_{p}^{N}$ & $C_{p}^{C}$ \\
\hline Leafy & 0.80 & 0.0625 & 0.9125 & 1.0 & 0.93 & 0.026 \\
\hline Other & 0.80 & 0.0625 & 0.9125 & 1.0 & 0.77 & 0.116 \\
\hline Fruit & 0.80 & 0.0625 & 0.9125 & 1.0 & 0.87 & 0.050 \\
\hline Grain & 0.12 & 0.0625 & 0.6150 & 1.0 & 0.11 & 0.293 \\
\hline Beef & 0.60 & 0.094 & 0.9384 & 0.031 & 0.61 & 0.228 \\
\hline Milk & 0.88 & 0.083 & 0.9696 & 0.012 & 0.85 & 0.069 \\
\hline
\end{tabular}

The water fractions shown above are only used in the tritium model. The water fractions taken from ORNL-5785 were used in the tritium results shown for ORNL-5785 assumptions. 


\section{C.1.6 Special Parameters for Carbon-14}

In GENII, the concentrations of ${ }^{14} \mathrm{C}$ in food crops, beef and milk are calculated using a specific activity model based on the concentration of ${ }^{14} \mathrm{C}$ in the soil. In GENII, the plants are assumed to obtain 90 percent of their carbon from the air, and 10 percent from the soil. The ratio of the ${ }^{14} \mathrm{C}$ concentration in plants to the concentration of carbon in the soil is assumed to be the same in all plant types. This specific activity model is not used in the present calculations.

Based on recent data for ${ }^{14} \mathrm{C}$ uptake in plants (Sheppard 1991 ), ${ }^{14} \mathrm{C}$ will be treated like the other nuclides described earlier. The specific activity model used by GENII on plants is not used here. Parameters found in NUREG/CR-5512 are applied. The soil leaching coefficient is 0.0957 per year based on a Kd of $6.7 \mathrm{ml} / \mathrm{g}$, as well as the other soil parameters discussed earlier. The concentration ratio for all plant types is assumed to be 0.7 , on a dry-weight basis.

Continuing with the NUREG/CR-5512 model for ${ }^{14} \mathrm{C}$, the transfer of ${ }^{14} \mathrm{C}$ into beef and milk are computed using a specific activity model. The concentration of ${ }^{14} \mathrm{C}$ in animal products (beef and milk) is computed using the equation shown below. This equation gives the ratio of ${ }^{14} \mathrm{C}$ activity consumed by the cow, to total carbon consumed by the cow. In the specific activity model, this ratio also holds for the carbon in the cow.

$$
\frac{C_{q}^{C 14}}{C_{q}^{C}}=\frac{Q_{f}^{q} C_{f}^{q}+Q_{h}^{q} C_{h}^{q}+Q_{g}^{q} C_{g}^{q}+Q_{w}^{q} C_{w}}{Q_{f}^{q} C_{f}^{c}+Q_{h}^{q} C_{h}^{c}+Q_{g}^{q} C_{g}^{c}+Q_{w}^{q} C_{w}^{c}}
$$

where:

$$
\begin{aligned}
C_{q}^{c 14}= & \text { concentration of }{ }^{14} \mathrm{C} \text { in animal product } q \text { (beef or milk) consumed by } \\
\text { the human, in } C i / k g & \\
C_{q}^{c}= & \text { concentration of carbon in animal product } q \text { consumed by the human, in } \\
& k g \text { carbon per } k j l \text { logram (wet) of animal product } q \text { (beef or milk) } \\
C_{p}^{c}= & \text { concentration of carbon in animal feed type } p \text {, in } k g \text { carbon per } \\
& \text { kilogram (wet) of plant. In this equation } p \text { refers to fresh forage, } \\
& \text { stored hay, stored grain, and drinking water. The carbon } \\
& \text { concentration of drinking water is small enough that it can be } \\
& \text { ignored. }
\end{aligned}
$$

Using the specific equation above, the effective transfer factor $\left(F_{q}^{c 14}\right)$

for the cattle can be computed from the parameters given. The diet-to-animal product transfer factor is the ratio of the equilibrium ${ }^{i 4} \mathrm{C}$ concentration in the cow to the daily intake of activity.

$$
F_{q}^{c 14}=\frac{C_{q}^{c}}{Q_{f}^{q} C_{f}^{c}+Q_{h}^{q} C_{h}^{c}+Q_{g}^{q} C_{g}^{c}+Q_{w}^{q} C_{w}^{c}}
$$

The effective diet-to-animal transfer factors for ${ }^{14} \mathrm{C}$ was computed from pathway parameters already described. The computed $F$ values for ${ }^{14} C$ are shown in Table $\mathrm{C}-1$. 


\section{C.1.7 Human Intakes and Effective Dose Factors}

Human exposure to radiation is estimated for both internal and external sources. External sources are outside the body. The only source of external exposure in these scenarios is the contaminated soil. Internal sources of exposure are located inside the body, and get there by being inhaled or ingested. Each of these types of exposure will be discussed separately below. The total dose is the sum of the different types of exposure.

C.1.7.1 Internal and External Dose Factors. The internal dose factors (Rittmann 1993a) applied to unit quantities of ingested or inhaled activity are shown in Table C -5 . The GENII internal dose factors from the July 1993 revision are shown only for comparison with the other values. The EPA values are from Federal Guidance Report Number 11 (US EPA 1988) and are also only shown for comparison. The DOE internal dose factors (DOE 1988) were actually used in the calculations. The three collections of internal dose factors are compared by means of ratios in Table $C-6$. All three collections are based on a dose commitment period of 50 years.

External dose rate factors are also shown on Table $C-5$. These are from a large area of soil 15 centimeters thick. The assumed soil density is 1.5 grams per cubic centimeter. The values shown on Table $\mathbf{C}-5$ come from the GENII GRDF.DAT file. The last column shows values from a recent recomputation using EXTDF, a program which is part of the GENII software package. The recalculation increased the dose rate factors by about 15 percent in all cases due to a difference in the assumed soil composition. The original GENII dose factors were based on a composition like that of air. The recalculated values used a composition like that of ordinary concrete.

Five of the nuclides shown in Table $C-5$ are not found in the GENII library. The GENII dose factors for ${ }^{133} \mathrm{Ba},{ }^{150} \mathrm{Eu},{ }^{52} \mathrm{Gd}$, and ${ }^{207} \mathrm{Bi}$ were computed by averaging the values from the EPA and DOE. Dose factors for the fifth nuclide, ${ }^{209} \mathrm{Po}$, are not found in any dose factor collection. Dose factors for ${ }^{209} \mathrm{Po}$ were computed by comparison with ${ }^{210} \mathrm{Po}$. Corrections were made for the energy of the alpha particles emitted, and the decay half-life using the equation shown below.

$$
\text { Dose Factor } \propto \frac{E \alpha}{\lambda_{e f f}}\left[1-e^{\left(-\lambda_{e f f} \star T_{d}\right)}\right]
$$

where:

$E \alpha=$ total alpha energy per decay. For ${ }^{209} \mathrm{Po}$ this is $4.882 \mathrm{Mev}$ per decay, while for ${ }^{210} \mathrm{Po}$ this is $5.3045 \mathrm{Mev}$ per decay (Kocher 1981).

$\lambda_{\text {eff }}=$ effective removal constant, which combines both the biological elimination and the radioactive decay of the nuclide.

$T_{d}=$ dose commitment period used in the dose factor collections shown in Table $C-5$ ( 50 years).

The biological removal halftime for polonium is 50 days (ICRP 30 ). The decay half- 1 ife of ${ }^{209} \mathrm{Po}$ is 102 year, thus its $\lambda_{\text {eff }}$ is 0.01388 per day. The decay half-life of ${ }^{210}$ Po is 138 days, thus its $\lambda_{\text {eff }}$ is 0.01889 per day. Since these are so large, the dose integration term in brackets is always 1 . The 
WHC-SD-WM-TI-730, REV 0

Table C-5. Internal Dose Factors (mrem/pCi) Used in the Spreadsheet.

\begin{tabular}{|c|c|c|c|c|c|c|c|c|c|c|}
\hline \multirow[b]{2}{*}{ Nucl ide } & \multirow[b]{2}{*}{ 千1 } & \multicolumn{3}{|c|}{ Ingestion (mrem/pci) } & \multirow[b]{2}{*}{ Sol } & \multicolumn{3}{|c|}{ Inhalation (mrem/pCi) } & \multicolumn{2}{|c|}{$\begin{array}{l}\text { External } \\
\text { mrenvhr per } \mathrm{Ci} / \mathrm{m}^{2}\end{array}$} \\
\hline & & GENI I & DOE & EPA & & GENII & DOE & EPA & GENII & Redone \\
\hline 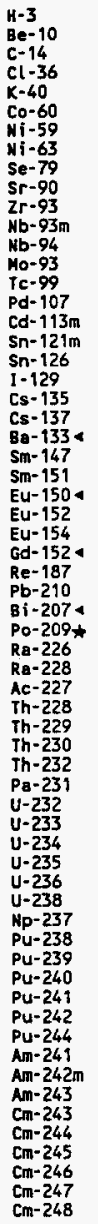 & $\begin{array}{l}(1.00) \\
(5 E-3) \\
(1.00) \\
(1.00) \\
(1.00) \\
(0.30) \\
(0.05) \\
(0.05) \\
(0.80) \\
(0.30) \\
(2 E-3) \\
(0.01) \\
(0.01) \\
(0.80) \\
(0.80) \\
(5 E-3) \\
(0.05) \\
(0.02) \\
(0.02) \\
(1.00) \\
(1.00) \\
(1.00) \\
(0.10) \\
(3 E-4) \\
(3 E-4) \\
(1 E-3) \\
(1 E-3) \\
(1 E-3) \\
(3 E-4) \\
(0.80) \\
(0.20) \\
(0.05) \\
(0.10) \\
(0.20) \\
(0.20) \\
(1 E-3) \\
(2 E-6) \\
(2 E-4) \\
(2 E-4) \\
(2 E-4) \\
(1 E-3) \\
(0.05) \\
(0.05) \\
(0.05) \\
(0.05) \\
(0.05) \\
(0.05) \\
(1 E-3) \\
(1 E-3) \\
(1 E-3) \\
(1 E-3) \\
(1 E-3) \\
(1 E-3) \\
(1 E-3) \\
(1 E-3) \\
(1 E-3) \\
(1 E-3) \\
(1 E-3) \\
(1 E-3) \\
(1 E-3) \\
(1 E-3) \\
(1 E-3) \\
(1 E-3)\end{array}$ & $\begin{array}{l}6.1 \mathrm{E}-08 \\
4.7 \mathrm{E}-06 \\
2.1 \mathrm{E}-06 \\
3.0 \mathrm{E}-06 \\
1.8 \mathrm{E}-05 \\
2.7 \mathrm{E}-05 \\
2.1 \mathrm{E}-07 \\
5.6 \mathrm{E}-07 \\
8.4 \mathrm{E}-06 \\
1.3 \mathrm{E}-04 \\
1.6 \mathrm{E}-06 \\
5.1 \mathrm{E}-07 \\
7.3 \mathrm{E}-06 \\
1.4 \mathrm{E}-06 \\
2.2 \mathrm{E}-06 \\
1.5 \mathrm{E}-07 \\
1.6 \mathrm{E}-04 \\
2.2 \mathrm{E}-06 \\
2.9 \mathrm{E}-05 \\
2.5 \mathrm{E}-04 \\
6.9 \mathrm{E}-06 \\
4.8 \mathrm{E}-05 \\
3.3 \mathrm{E}-06 \\
1.9 \mathrm{E}-04 \\
3.9 \mathrm{E}-07 \\
6.3 \mathrm{E}-06 \\
6.5 \mathrm{E}-06 \\
9.6 \mathrm{E}-06 \\
1.6 \mathrm{E}-04 \\
1.5 \mathrm{E}-08 \\
7.4 \mathrm{E}-03 \\
5.2 \mathrm{E}-06 \\
2.4 \mathrm{E}-03 \\
9.6 \mathrm{E}-04 \\
8.4 \mathrm{E}-04 \\
1.4 \mathrm{E}-02 \\
5.8 \mathrm{E}-04 \\
3.9 \mathrm{E}-03 \\
5.4 \mathrm{E}-04 \\
2.7 \mathrm{E}-03 \\
1.1 \mathrm{E}-02 \\
1.3 \mathrm{E}-03 \\
2.9 \mathrm{E}-04 \\
2.9 \mathrm{E}-04 \\
2.7 \mathrm{E}-04 \\
2.7 \mathrm{E}-04 \\
2.7 \mathrm{E}-04 \\
5.3 \mathrm{E}-03 \\
3.2 \mathrm{E}-03 \\
3.6 \mathrm{E}-03 \\
3.6 \mathrm{E}-03 \\
6.8 \mathrm{E}-05 \\
3.3 \mathrm{E}-03 \\
3.3 \mathrm{E}-03 \\
3.6 \mathrm{E}-03 \\
3.6 \mathrm{E}-03 \\
3.6 \mathrm{E}-03 \\
2.5 \mathrm{E}-03 \\
2.0 \mathrm{E}-03 \\
3.7 \mathrm{E}-03 \\
3.7 \mathrm{E}-03 \\
3.4 \mathrm{E}-03 \\
1.4 \mathrm{E}-02\end{array}$ & $\begin{array}{l}6.3 \mathrm{E}-08 \\
4.2 \mathrm{E}-06 \\
2.1 \mathrm{E}-06 \\
3.0 \mathrm{E}-06 \\
1.9 \mathrm{E}-05 \\
2.6 \mathrm{E}-05 \\
2.0 \mathrm{E}-07 \\
5.4 \mathrm{E}-07 \\
8.3 \mathrm{E}-06 \\
1.4 \mathrm{E}-04 \\
1.6 \mathrm{E}-06 \\
5.3 \mathrm{E}-07 \\
5.1 \mathrm{E}-06 \\
1.3 \mathrm{E}-06 \\
1.3 \mathrm{E}-06 \\
1.4 \mathrm{E}-07 \\
1.5 \mathrm{E}-04 \\
2.0 \mathrm{E}-06 \\
1.8 \mathrm{E}-05 \\
2.8 \mathrm{E}-04 \\
7.1 \mathrm{E}-06 \\
5.0 \mathrm{E}-05 \\
3.2 \mathrm{E}-06 \\
1.8 \mathrm{E}-04 \\
3.4 \mathrm{E}-07 \\
6.2 \mathrm{E}-06 \\
6.0 \mathrm{E}-06 \\
9.1 \mathrm{E}-06 \\
1.5 \mathrm{E}-04 \\
8.3 \mathrm{E}-09 \\
6.7 \mathrm{E}-03 \\
4.9 \mathrm{E}-06 \\
2.0 \mathrm{E}-03 \\
1.1 \mathrm{E}-03 \\
1.2 \mathrm{E}-03 \\
1.5 \mathrm{E}-02 \\
7.5 \mathrm{E}-04 \\
3.9 \mathrm{E}-03 \\
5.3 \mathrm{E}-04 \\
2.8 \mathrm{E}-03 \\
1.1 \mathrm{E}-02 \\
1.3 \mathrm{E}-03 \\
2.7 \mathrm{E}-04 \\
2.6 \mathrm{E}-04 \\
2.5 \mathrm{E}-04 \\
2.5 \mathrm{E}-04 \\
2.4 \mathrm{E}-04 \\
3.9 \mathrm{E}-03 \\
3.8 \mathrm{E}-03 \\
4.3 \mathrm{E}-03 \\
4.3 \mathrm{E}-03 \\
8.6 \mathrm{E}-05 \\
4.1 \mathrm{E}-03 \\
4.0 \mathrm{E}-03 \\
4.5 \mathrm{E}-03 \\
4.3 \mathrm{E}-03 \\
4.5 \mathrm{E}-03 \\
2.9 \mathrm{E}-03 \\
2.3 \mathrm{E}-03 \\
4.5 \mathrm{E}-03 \\
4.5 \mathrm{E}-03 \\
4.1 \mathrm{E}-03 \\
1.6 \mathrm{E}-02\end{array}$ & $\begin{array}{l}6.40 \mathrm{E}-08 \\
4.66 \mathrm{E}-06 \\
2.09 \mathrm{E}-06 \\
3.03 \mathrm{E}-06 \\
1.86 \mathrm{E}-05 \\
2.69 \mathrm{E}-05 \\
2.10 \mathrm{E}-07 \\
5.77 \mathrm{E}-07 \\
8.70 \mathrm{E}-06 \\
1.53 \mathrm{E}-04 \\
1.66 \mathrm{E}-06 \\
5.22 \mathrm{E}-07 \\
7.14 \mathrm{E}-06 \\
1.35 \mathrm{E}-06 \\
1.46 \mathrm{E}-06 \\
1.49 \mathrm{E}-07 \\
1.61 \mathrm{E}-04 \\
2.25 \mathrm{E}-06 \\
2.11 \mathrm{E}-05 \\
2.76 \mathrm{E}-04 \\
7.07 \mathrm{E}-06 \\
5.00 \mathrm{E}-05 \\
3.40 \mathrm{E}-06 \\
1.85 \mathrm{E}-04 \\
3.89 \mathrm{E}-07 \\
6.36 \mathrm{E}-06 \\
6.48 \mathrm{E}-06 \\
9.55 \mathrm{E}-06 \\
1.62 \mathrm{E}-04 \\
9.51 \mathrm{E}-09 \\
7.31 \mathrm{E}-03 \\
5.48 \mathrm{E}-06 \\
2.38 \mathrm{E}-03 \\
1.32 \mathrm{E}-03 \\
1.44 \mathrm{E}-03 \\
1.48 \mathrm{E}-02 \\
8.09 \mathrm{E}-04 \\
4.03 \mathrm{E}-03 \\
5.48 \mathrm{E}-04 \\
2.73 \mathrm{E}-03 \\
1.06 \mathrm{E}-02 \\
1.31 \mathrm{E}-03 \\
2.89 \mathrm{E}-04 \\
2.83 \mathrm{E}-04 \\
2.67 \mathrm{E}-04 \\
2.69 \mathrm{E}-04 \\
2.68 \mathrm{E}-04 \\
4.44 \mathrm{E}-03 \\
3.20 \mathrm{E}-03 \\
3.54 \mathrm{E}-03 \\
3.54 \mathrm{E}-03 \\
6.85 \mathrm{E}-05 \\
3.36 \mathrm{E}-03 \\
3.32 \mathrm{E}-03 \\
3.64 \mathrm{E}-03 \\
3.61 \mathrm{E}-03 \\
3.62 \mathrm{E}-03 \\
2.51 \mathrm{E}-03 \\
2.02 \mathrm{E}-03 \\
3.74 \mathrm{E}-03 \\
3.70 \mathrm{E}-03 \\
3.42 \mathrm{E}-03 \\
1.36 \mathrm{E}-02\end{array}$ & 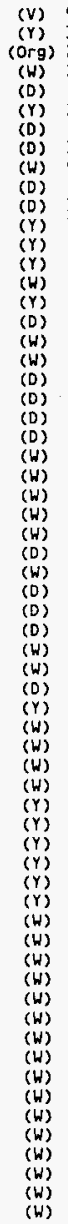 & $\begin{array}{l}9.0 \mathrm{E}-08 \\
3.5 \mathrm{E}-04 \\
2.1 \mathrm{E}-06 \\
2.2 \mathrm{E}-05 \\
1.2 \mathrm{E}-05 \\
2.0 \mathrm{E}-04 \\
1.3 \mathrm{E}-06 \\
3.0 \mathrm{E}-06 \\
9.5 \mathrm{E}-06 \\
2.1 \mathrm{E}-04 \\
3.2 \mathrm{E}-04 \\
3.0 \mathrm{E}-05 \\
3.9 \mathrm{E}-04 \\
2.8 \mathrm{E}-05 \\
9.0 \mathrm{E}-06 \\
1.3 \mathrm{E}-05 \\
1.5 \mathrm{E}-03 \\
1.2 \mathrm{E}-05 \\
1.0 \mathrm{E}-04 \\
1.5 \mathrm{E}-04 \\
4.5 \mathrm{E}-06 \\
3.0 \mathrm{E}-05 \\
7.4 \mathrm{E}-06 \\
7.5 \mathrm{E}-02 \\
3.0 \mathrm{E}-05 \\
2.7 \mathrm{E}-04 \\
2.1 \mathrm{E}-04 \\
2.8 \mathrm{E}-04 \\
2.4 \mathrm{E}-01 \\
5.9 \mathrm{E}-08 \\
2.4 \mathrm{E}-02 \\
1.7 \mathrm{E}-05 \\
1.2 \mathrm{E}-02 \\
8.2 \mathrm{E}-03 \\
4.4 \mathrm{E}-03 \\
6.7 \mathrm{E}+00 \\
3.5 \mathrm{E}-01 \\
2.2 \mathrm{E}+00 \\
3.2 \mathrm{E}-01 \\
1.7 \mathrm{E}+00 \\
1.3 \mathrm{E}+00 \\
6.7 \mathrm{E}-01 \\
1.4 \mathrm{E}-01 \\
1.3 \mathrm{E}-01 \\
1.2 \mathrm{E}-01 \\
1.3 \mathrm{E}-01 \\
1.2 \mathrm{E}-01 \\
6.4 \mathrm{E}-01 \\
3.9 \mathrm{E}-01 \\
4.3 \mathrm{E}-01 \\
4.3 \mathrm{E}-01 \\
8.2 \mathrm{E}-03 \\
4.1 \mathrm{E}-01 \\
4.0 \mathrm{E}-01 \\
4.4 \mathrm{E}-01 \\
4.4 \mathrm{E}-01 \\
4.4 \mathrm{E}-01 \\
3.1 \mathrm{E}-01 \\
2.5 \mathrm{E}-01 \\
4.5 \mathrm{E}-01 \\
4.6 \mathrm{E}-01 \\
4.2 \mathrm{E}-01 \\
1.6 \mathrm{E}+00\end{array}$ & $\begin{array}{l}9.5 \mathrm{E}-08 \\
3.5 \mathrm{E}-04 \\
2.1 \mathrm{E}-06 \\
2.0 \mathrm{E}-05 \\
1.2 \mathrm{E}-05 \\
1.5 \mathrm{E}-04 \\
1.3 \mathrm{E}-06 \\
3.0 \mathrm{E}-06 \\
8.9 \mathrm{E}-06 \\
2.4 \mathrm{E}-04 \\
3.2 \mathrm{E}-04 \\
2.8 \mathrm{E}-05 \\
3.3 \mathrm{E}-04 \\
2.8 \mathrm{E}-05 \\
7.5 \mathrm{E}-06 \\
1.3 \mathrm{E}-05 \\
1.4 \mathrm{E}-03 \\
9.3 \mathrm{E}-06 \\
7.5 \mathrm{E}-05 \\
1.8 \mathrm{E}-04 \\
4.5 \mathrm{E}-06 \\
3.2 \mathrm{E}-05 \\
6.9 \mathrm{E}-06 \\
7.1 \mathrm{E}-02 \\
2.9 \mathrm{E}-05 \\
2.7 \mathrm{E}-04 \\
2.2 \mathrm{E}-04 \\
2.6 \mathrm{E}-04 \\
2.4 \mathrm{E}-01 \\
4.9 \mathrm{E}-08 \\
2.1 \mathrm{E}-02 \\
1.4 \mathrm{E}-05 \\
1.0 \mathrm{E}-02 \\
7.9 \mathrm{E}-03 \\
4.3 \mathrm{E}-03 \\
6.7 \mathrm{E}+00 \\
3.1 \mathrm{E}-01 \\
2.0 \mathrm{E}+00 \\
3.2 \mathrm{E}-01 \\
1.6 \mathrm{E}+00 \\
1.3 \mathrm{E}+00 \\
6.7 \mathrm{E}-01 \\
1.3 \mathrm{E}-01 \\
1.3 \mathrm{E}-01 \\
1.2 \mathrm{E}-01 \\
1.2 \mathrm{E}-01 \\
1.2 \mathrm{E}-01 \\
4.9 \mathrm{E}-01 \\
4.6 \mathrm{E}-01 \\
5.1 \mathrm{E}-01 \\
5.1 \mathrm{E}-01 \\
1.0 \mathrm{E}-02 \\
4.8 \mathrm{E}-01 \\
4.8 \mathrm{E}-01 \\
5.2 \mathrm{E}-01 \\
5.3 \mathrm{E}-01 \\
5.2 \mathrm{E}-01 \\
3.5 \mathrm{E}-01 \\
2.7 \mathrm{E}-01 \\
5.4 \mathrm{E}-01 \\
5.4 \mathrm{E}-01 \\
4.9 \mathrm{E}-01 \\
1.9 \mathrm{E}+00\end{array}$ & $\begin{array}{l}9.60 \mathrm{E}-08 \\
3.54 \mathrm{E}-04 \\
2.09 \mathrm{E}-06 \\
2.19 \mathrm{E}-05 \\
1.24 \mathrm{E}-05 \\
2.19 \mathrm{E}-04 \\
1.32 \mathrm{E}-06 \\
3.10 \mathrm{E}-06 \\
9.84 \mathrm{E}-06 \\
2.47 \mathrm{E}-04 \\
3.21 \mathrm{E}-04 \\
2.92 \mathrm{E}-05 \\
4.14 \mathrm{E}-04 \\
2.84 \mathrm{E}-05 \\
8.33 \mathrm{E}-06 \\
1.28 \mathrm{E}-05 \\
1.53 \mathrm{E}-03 \\
1.19 \mathrm{E}-05 \\
1.01 \mathrm{E}-04 \\
1.74 \mathrm{E}-04 \\
4.55 \mathrm{E}-06 \\
3.19 \mathrm{E}-05 \\
7.81 \mathrm{E}-06 \\
7.47 \mathrm{E}-02 \\
3.00 \mathrm{E}-05 \\
2.68 \mathrm{E}-04 \\
2.21 \mathrm{E}-04 \\
2.86 \mathrm{E}-04 \\
2.43 \mathrm{E}-01 \\
5.44 \mathrm{E}-08 \\
2.33 \mathrm{E}-02 \\
2.00 \mathrm{E}-05 \\
1.18 \mathrm{E}-02 \\
8.58 \mathrm{E}-03 \\
4.86 \mathrm{E}-03 \\
6.72 \mathrm{E}+00 \\
3.45 \mathrm{E}-01 \\
2.16 \mathrm{E}+00 \\
3.26 \mathrm{E}-01 \\
1.64 \mathrm{E}+00 \\
1.28 \mathrm{E}+00 \\
6.59 \mathrm{E}-01 \\
1.35 \mathrm{E}-01 \\
1.32 \mathrm{E}-01 \\
1.23 \mathrm{E}-01 \\
1.25 \mathrm{E}-01 \\
1.18 \mathrm{E}-01 \\
5.40 \mathrm{E}-01 \\
3.92 \mathrm{E}-01 \\
4.29 \mathrm{E}-01 \\
4.29 \mathrm{E}-01 \\
8.25 \mathrm{E}-03 \\
4.11 \mathrm{E}-01 \\
4.03 \mathrm{E}-01 \\
4.44 \mathrm{E}-01 \\
4.40 \mathrm{E}-01 \\
4.40 \mathrm{E}-01 \\
3.07 \mathrm{E}-01 \\
2.48 \mathrm{E}-01 \\
4.55 \mathrm{E}-01 \\
4.51 \mathrm{E}-01 \\
4.14 \mathrm{E}-01 \\
1.65 \mathrm{E}+00\end{array}$ & 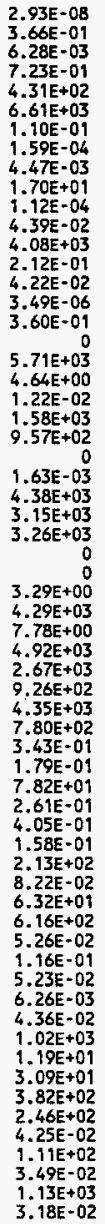 & 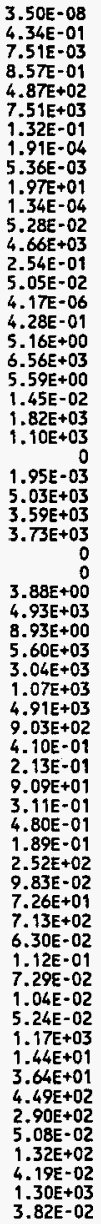 \\
\hline
\end{tabular}

IGENII values for these nuclides were obtained by averaging the DOE and EPA values.

Hall Po-209 internal dose factors are estimated from Po-210, as described in Section C.1.7.1.

- The External Dose Rate Factors are described in more detail in Section C.1.7.1. 
Table C-6. Ratios of GENII and EPA Internal Dose Factors to DOE Internal Dose Factors. (Differences less than 10 percent not shown)

\begin{tabular}{|l|c|c|c|c|}
\hline \multirow{2}{*}{ Nuclide } & \multicolumn{2}{|c|}{ Inhalation } & \multicolumn{2}{c|}{ Ingestion } \\
\cline { 2 - 5 } & GENII & EPA & GENI I & EPA \\
\hline $\mathrm{Be}-10$ & & & 1.11 & 1.11 \\
\hline $\mathrm{Co}-60$ & 1.34 & 1.46 & & \\
\hline $\mathrm{Se}-79$ & & 1.11 & & \\
\hline $\mathrm{Sr}-90$ & 0.89 & & & \\
\hline $\mathrm{Nb}-94$ & 1.18 & 1.26 & 1.42 & 1.40 \\
\hline $\mathrm{Tc}-99$ & 1.20 & 1.11 & 1.72 & 1.12 \\
\hline $\mathrm{Sn}-121 \mathrm{~m}$ & 1.27 & 1.28 & 1.12 & 1.13 \\
\hline $\mathrm{Sn}-126$ & 1.33 & 1.34 & 1.15 & 1.15 \\
\hline $\mathrm{I}-129$ & 0.84 & & 0.89 & \\
\hline $\mathrm{Ba}-133$ & & 1.13 & & \\
\hline $\mathrm{Sm}-151$ & & & 1.14 & 1.14 \\
\hline $\mathrm{Re}-187$ & 1.20 & 1.11 & 1.75 & 1.15 \\
\hline $\mathrm{Pb}-210$ & 1.11 & & & \\
\hline $\mathrm{Bi}-207$ & 1.21 & 1.43 & & 1.12 \\
\hline $\mathrm{Po}-209$ & 1.20 & 1.16 & 1.20 & 1.19 \\
\hline $\mathrm{Ra}-226$ & & & 0.87 & 1.20 \\
\hline $\mathrm{Ra}-228$ & & 1.13 & 0.70 & 1.20 \\
\hline $\mathrm{Th}-228$ & 1.11 & & 0.77 & \\
\hline $\mathrm{U}-238$ & & & 1.12 & \\
\hline $\mathrm{Np}-237$ & 1.30 & & 1.35 & 1.14 \\
\hline $\mathrm{Pu}-238$ & 0.85 & 0.85 & 0.84 & 0.84 \\
\hline $\mathrm{Pu}-239$ & 0.85 & 0.84 & 0.83 & 0.82 \\
\hline $\mathrm{Pu}-240$ & 0.85 & 0.84 & 0.83 & 0.82 \\
\hline $\mathrm{Pu}-241$ & 0.82 & 0.83 & 0.79 & 0.80 \\
\hline $\mathrm{Pu}-242$ & 0.84 & 0.86 & 0.81 & 0.82 \\
\hline $\mathrm{Pu}-244$ & 0.84 & 0.84 & 0.83 & 0.83 \\
\hline $\mathrm{Am}-241$ & 0.85 & 0.85 & 0.81 & 0.81 \\
\hline $\mathrm{Am}-242 \mathrm{~m}$ & 0.81 & 0.82 & 0.83 & 0.84 \\
\hline $\mathrm{Am}-243$ & 0.85 & 0.85 & 0.81 & 0.80 \\
\hline $\mathrm{Cm}-243$ & 0.88 & 0.88 & 0.87 & 0.87 \\
\hline $\mathrm{Cm}-244$ & & & 0.87 & 0.88 \\
\hline $\mathrm{Cm}-245$ & 0.84 & 0.84 & 0.82 & 0.83 \\
\hline $\mathrm{Cm}-246$ & 0.84 & 0.84 & 0.83 & 0.82 \\
\hline $\mathrm{Cm}-247$ & 0.86 & 0.85 & 0.84 & 0.83 \\
\hline $\mathrm{Cm}-248$ & 0.86 & 0.87 & 0.84 & 0.85 \\
\hline
\end{tabular}


ratio of ${ }^{209} \mathrm{Po}$ to ${ }^{210} \mathrm{Po}$ internal dose factors is shown below. This ratio was applied to the ${ }^{210} \mathrm{Po}$ inhalation and ingestion dose factors to arrive at the ${ }^{209}$ Po internal dose factors.

$$
\frac{\text { Po-209 Dose Factor }}{\text { Po-210 Dose Factor }}=\frac{4.882 \mathrm{Mev} * 0.01889 \text { per day }}{5.3045 \mathrm{Mev} * 0.01388 \text { per day }}=1.252
$$

C.1.7.2 Internal Exposure from Ingested Activity. The ingestion dose is calculated from the ingestion dose factor and the quantity of radioactivity consumed in food, soil and water. The ingestion dose is calculated using the general equation below.

$$
H_{\text {ing }}=\left(Q_{w}^{h} C_{w}+Q_{s}^{h} W+\sum_{p} Q_{p}^{h} C_{p}\right) D_{i n g}\left(1.0 \times 10^{12} p C i / C i\right)
$$

where:

$H_{i n g}=\quad$ the ingestion dose, in mrem

$Q_{M}^{h}=$ amount of drinking water consumed annually by the human, in liters per year. The value $730 \mathrm{~L} / \mathrm{yr}$ is used.

$Q_{s}^{h}=$ amount of soil consumed annually by the human, in kilograms per year. The value $0.0365 \mathrm{~kg} / \mathrm{yr}$ is used (EPA 1989).

$Q_{p}^{h}=$ amount of produce type $p$ the human consumes each year, in kilograms (or liters for milk) per year. Values are 1 isted in Table 3-2 of

WHC-SD-WM-Ti-730, Rev. O (main document). Note that $p$ refers to meat and milk as well as vegetables.

$C_{p}=$ radionuclide concentration in plant or animal type $p$ at the time it is consumed by the human, in curies per kilogram (or curies per liter for milk). Includes an insignificant amount of decay during holdup prior to consumption.

$D_{\text {ing }}=\quad$ internal dose factor for ingestion, in mrem per picocurie ingested. Values are shown on Table C-5.

C.1.7.3 Internal Exposure from Inhaled Activity. The activity inhaled in the course of a year depends on the volume of air inhaled during the year, as well as the average air concentration. The average air concentration is estimated from an average mass loading of particulate material in the air. The material in the air is assumed to have the same concentration as the soil. Thus the equation for inhaled activity is shown below.

$$
H_{i n h}=M_{a} V_{a} D_{i n h}\left(1.0 \times 10^{12} p C i / C i\right) W\left\{1-\operatorname{Exp}\left[-\left(\lambda_{s}+\lambda_{r}\right) T_{h}\right]\right\} /\left(\lambda_{s}+\lambda_{r}\right)
$$

where:
$\mathrm{H}_{\mathrm{inh}}=$
inhalation dose, in imrem
$D_{\text {inh }}=$
internal dose factor for inhalation, in mrem per picocurie inhaled. Values are shown on Table $\mathrm{C}-5$.
$M_{a}=\quad$ average mass concentration in the air during the year, in kilograms per cubic meter. The GENII value $\left(1 \mathrm{E}-07 \mathrm{~kg} / \mathrm{m}^{3}\right)$ is used for the inhalation dose calculation. 
$V_{a}=$ daily average breathing rate, in cubic meters per hour. The value for Reference Man $\left(0.95 \mathrm{~m}^{3} / \mathrm{hr}\right.$, in ICRP 23) is used.

$T_{h}=$ inhalation time, in hours. This is the number of hours per year that the individual is breathing the average air concentration. The 4680 hour value for maximum individuals was derived using Table 3-1.

Note that the nuclide intake is accumulated over the time $T_{h}$. The equation shows how leaching from the surface layer is included. "This portion of the calculation differs from GENII in that GENII does no decay or leaching when computing inhalation dose. GENII assumes the air concentration remains constant during the year.

In reality, the respirable dust loading of the air is lower than the assumed $100 \mu \mathrm{g} / \mathrm{m}^{3}$. The EPA air quality standard is $50 \mu \mathrm{g} / \mathrm{m}^{3}$, which is normally attainabie. However, the soil contaminants are found with the small diameter fraction of the surface soil. Hence the concentration of nuclides in the airborne dust is higher than the concentration in the bulk soil. These two effects are assumed to offset one another, so that $100 \mu \mathrm{g} / \mathrm{m}^{3}$ adequately represents the resuspended activity concentration.

For populations, the inhalation exposure time was increased from 4,680 hours per year to 8,766 hours per year. This increase is related to the broader distribution of radioactivity in the environment from widespread use of the Columbia River for irrigation.

C.1.7.4 External Exposure. The GENII program calculates external dose from surface contamination using unit dose factors computed by the EXTDF program. The EXTDF program uses parts of the ISOSHLD program to calculate dose

equivalent rates from external sources for user entered geometry data. Values from the GENII library (GRDF.DAT) are shown in Table C-5. These values have been converted from the SI units to $\mathrm{mrem} / \mathrm{hr}$ per $\mathrm{Ci} / \mathrm{m}^{2}$. The values for the added nuclides were calculated using EXTDF and the new values are shown on Table C-5. External dose to the intruder and the irrigator is calculated using the formula shown below.

$$
H_{\text {ext }}=\rho d D_{\text {ext }} W\left\{1-\operatorname{Exp}\left[-\left(\lambda_{s}+\lambda_{r}\right) T_{e}\right]\right\} /\left(\lambda_{s}+\lambda_{r}\right)
$$

where:

$$
\begin{aligned}
& H_{\text {ext }}=\quad \text { total external dose, in mrem } \\
& D_{\text {ext }}=\text { external dose rate factor for exposure to radiation from } \\
& \text { contaminated soil, in mrem/hr per } \mathrm{Ci} / \mathrm{m}^{2} \text {. Values are shown on } \\
& \text { Table C-5. } \\
& d=\text { thickness of soil from which nuclides migrate, in centimeters. The } \\
& \text { GENII value for this is } 15 \text { centimeter. } \\
& \rho=\text { bulk density of the surface soil, in grams per cubic centimeter. In } \\
& \text { GENII this is } 1.5 \mathrm{~g} / \mathrm{cc} \text {. } \\
& T_{0}=\quad \text { time exposed to external radiation sources in the soil, in hours. } \\
& \text { The effective exposure time for maximum individuals is } 3260 \text { hours, } \\
& \text { from Section 1.1. }
\end{aligned}
$$

Note that the dose is accumulated over the time $T_{h}$. The equation shows how leaching from the surface layer is included. For the intruder scenario 
this portion of the calculation differs from GENII in that GENII does no decay or leaching when computing inhalation dose. GENII assumes the soil concentration remains constant during the year.

For populations, the external exposure time was increased from 3,260 hours per year to 4,383 hours per year. This increase is related to the broader distribution of radioactivity in the environment from widespread use of the Columbia River for irrigation.

External dose to the Columbia River population from recreational activities was computed using GENII for several radionuclides. The average person spends 10 hours swimming and 17 hours on the river shoreline each year (Kincaid, 1993). These recreational activities increase the average external dose by approximately four percent. Therefore, the external dose from recreational activities is not explicitly included in the population dose estimates.

\section{C.1.8 Comparison of Spreadsheet Versus GENII Dose Estimates}

In this section, a comparison of results using the spreadsheet calculations and the GENII code is used.

C.1.8.1 Special Input Assumptions for the Comparisons. The comparisons were done using the NUREG/CR-5512 concentration ratios. In addition, since GENII does not allow input of internal dose factors, the spreadsheet used the values that are currently in GENII (Rittmann, 1993a). These were shown on Table C-5.

The comparisons were done for each nuclide in the spreadsheet. Three intrusion scenarios were used: 100 year decay with leaching, 100 year decay without leaching, and 500 year decay without leaching. Two irrigation scenarios were also used, with and without leaching. Only one population dose was computed, without leaching.

To compare the parts of the vegetation model (root uptake, rain splash, and direct deposition by irrigation water), special input files (DEFAULT. IN and FTRANS.DAT) were prepared for GENII. These are shown at then end of this appendix, along with the other GENII input files. Note that asterisks mark those lines which were changed from the GENII defaults. A special version of FTRANS.DAT was used to set the leaching coefficients to zero for the nonleaching runs. The two main input files used for the intruder and irrigator comparison tables are also attached. These show the inhalation and external exposure times, as well as the food and water consumption rates.

C.1.8.2 Comparison Results. The tables below ( $\mathrm{C}-7$ and $\mathrm{C}-8$ ) summarize the observed differences. All spreadsheet results were divided by the corresponding GENII results. Nuclides with differences less than 10 percent are not shown. If one column for a nuclide has a difference greater than 10 percent, then the other differences are also shown. In some cases; entire columns were deleted. This was true for the irrigated farm inhalation, external, soil ingestion and drinking water. Table columns are described below. 
Table C-7. Dose Ratios (Spreadsheet Divided by GENII) After Intrusion. Differences less than 10 percent are not shown.

\begin{tabular}{|l|c|c|c|c|c|c|}
\hline \multicolumn{5}{|c|}{ Post-Intrusion Scenario -- 100 Years - Leaching } \\
\hline Nuclide & Inhale & Extern & Soil & Root & Rain & Total \\
\hline H-3 & 4.24 & 4.43 & 4.23 & & & 4.41 \\
\hline C-14 & & & & & & 108.26 \\
\hline Ci-36 & 1.15 & 1.14 & 1.16 & 1.25 & 1.31 & 1.25 \\
\hline Co-60 & 0.92 & 0.92 & 0.92 & 0.90 & 0.96 & 0.92 \\
\hline Tc-99 & 2.79 & 2.85 & 2.67 & 3.70 & 3.75 & 3.71 \\
\hline I-129 & 1.32 & 1.31 & 1.30 & 1.48 & 1.46 & 1.44 \\
\hline Ra-228 & 0.90 & 0.89 & 0.90 & 0.89 & 0.90 & 0.89 \\
\hline Ac-227 & 0.96 & 0.98 & 0.98 & 0.88 & & \\
\hline Th-228 & 0.84 & 0.80 & 0.84 & 0.67 & 0.91 & 0.84 \\
\hline Th-229 & & & & 0.60 & & \\
\hline Np-237 & & & & 1.11 & 1.10 & \\
\hline \multicolumn{1}{|c|}{ Post-Intrusion Scenario -- 100} & Years -- No Leaching \\
\hline C-14 & & & & & & 103.22 \\
\hline Co-60 & 0.87 & 0.92 & 0.92 & 0.91 & 0.92 & 0.93 \\
\hline Ra-228 & 0.90 & 0.89 & 0.90 & 0.89 & 0.90 & 0.89 \\
\hline Ac-227 & & & & 0.88 & & \\
\hline Th-228 & 0.84 & 0.80 & 0.84 & 0.67 & 0.91 & 0.84 \\
\hline Th-229 & & & & 0.60 & & \\
\hline Post-Intrusion Scenario & & & & & 0.800 & Years -- N0 Leaching \\
\hline C-14 & & & & & & 98.35 \\
\hline Co-60 & 0.73 & 0.73 & 0.74 & 0.75 & 0.79 & 0.73 \\
\hline Cd-113m & 0.89 & 0.93 & 0.89 & 0.96 & 0.96 & 0.94 \\
\hline Ra-228 & 0.68 & 0.68 & 0.72 & 0.72 & 0.75 & 0.72 \\
\hline Ac-227 & & & & & \\
\hline Th-229 & & & & & & \\
\hline Cm-248 & & & & & & \\
\hline
\end{tabular}


Table C-8. Dose Ratios (Spreadsheet Divided by GENII) for Irrigation Scenarios. Differences less than 10 percent are not shown.

\begin{tabular}{|c|c|c|c|c|c|}
\hline \multicolumn{6}{|c|}{$\begin{array}{c}\text { Irrigated Farm Scenario -- With or Without } \\
\text { Leaching }\end{array}$} \\
\hline Nuclide & Root & Rain & Direct & Beef & Milk \\
\hline $\mathrm{C}-14$ & & & 0.31 & 1.12 & 0.81 \\
\hline $2 r-93$ & & & & & 1.25 \\
\hline Tc-99: & & & & 1.16 & 1.26 \\
\hline$A C-227$ & 0.89 & & & & 0.74 \\
\hline Th-228 & 0.77 & 1.11 & & 0.85 & 0.044 \\
\hline Th-229 & 0.62 & & & 0.42 & 0.17 \\
\hline Th-232 & & & & & 1.15 \\
\hline Pu-244 & & & & & 0.28 \\
\hline $\mathrm{Am}-242 \mathrm{~m}$ & & & & & 0.44 \\
\hline \multicolumn{6}{|c|}{$\begin{array}{l}\text { 1The Tc-99 difference only occurs if leaching } \\
\text { is allowed. }\end{array}$} \\
\hline \multicolumn{6}{|c|}{$\begin{array}{c}\text { Columbia River Population Scenario -- NO } \\
\text { Leaching }\end{array}$} \\
\hline Nuclide & Vege & & Beef & Milk & Fish \\
\hline$c-14$ & 0.16 & & 1.13 & 0.75 & \\
\hline$Z r-93$ & & & & 1.66 & \\
\hline $\mathrm{Pb}-210$ & & & & 0.84 & 0.36 \\
\hline$A C-227$ & & & & 0.71 & \\
\hline Th-228 & & & 1.16 & 0.065 & 1.27 \\
\hline Th-229 & & & 0.54 & 0.16 & \\
\hline Th-232 & & & & 1.30 & \\
\hline $\mathrm{Pu}-244$ & & & & 0.85 & \\
\hline$A m-242 m$ & & & & 0.40 & \\
\hline
\end{tabular}




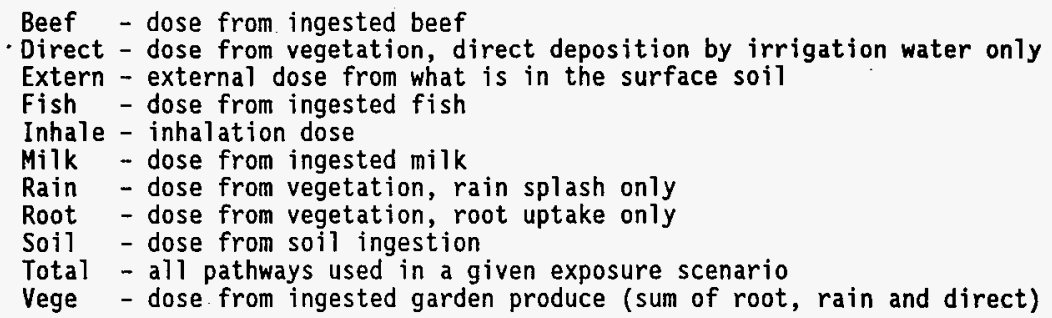

For the intruder's garden, the spreadsheet computes the effect of contaminant leaching differently than GENII. The spreadsheet computes the annual dose allowing for continuous exposure during the year that leaching occurs. GENII computes the soil concentration at the end of the year and assumes this existed throughout the entire year. GENII thus underestimates the inhalation, external, and soil ingestion doses for nuclides which are mobile in the soil $\left({ }^{3} \mathrm{H},{ }^{36} \mathrm{Cl}\right.$, ${ }^{99} \mathrm{TC}$, and $\left.{ }^{129} \mathrm{I}\right)$. For these nuclides the dose ratios are greater than one. Note that the dose ratios increase for the vegetable pathways (Root and Rain). This difference is due to the assumed growing period. In the spreadsheet the vegetables grow for 100 days, and then are harvested. In GENII, however, the vegetables grow for the entire year, and then are harvested. For mobile nuclides, this leads GENII to further lower the amount used in the dose calculation, and increases the dose ratios.

For the intruder's garden, the spreadsheet gives lower doses than GENII for ${ }^{60} \mathrm{Co}$, ${ }^{228} \mathrm{Ra}$, and ${ }^{228} \mathrm{Th}$. These dose ratios are different because GENII does not compute radioactive decay along with leaching during the year of exposure. Since these nuclides have comparatively short half-lives and are not mobile, the difference is noticeable.

For the intruder's garden, the spreadsheet gives noticeably lower doses yia root uptake than GENII for ${ }^{228} \mathrm{Ra},{ }^{227} \mathrm{AC},{ }^{228} \mathrm{Th}$, and ${ }^{229} \mathrm{Th}$. Note that the ${ }^{228} \mathrm{Ra}$ difference is due to the difference in its progeny nuclide ${ }^{228} \mathrm{Th}$. The differences for ${ }^{227} \mathrm{Ac}$, ${ }^{228} \mathrm{Th}$ and ${ }^{229} \mathrm{Th}$ are due to the spreadsheet assumption that the progeny nuciides $\left({ }^{223} \mathrm{Ra},{ }^{224} \mathrm{Ra}\right.$, and $\left.{ }^{225} \mathrm{Ra}\right)$ are in radioactive equilibrium with the parents. However, GENII computes the actual amounts in the plants based on the different concentration ratios. Since the radium concentration ratios are roughly an order of magnitude larger than thorium or actinium, the amount of the progeny is much greater than is assumed by the spreadsheet. Thus the GENII doses are larger and the dose ratios are less than one for some pathways.

For ${ }^{14} \mathrm{C}$, the vegetation doses are based on different models. GENII gives zero dose, while the spreadsheet gives quite a bit. The total doses are radically different.

At 500 years of prior decay, there begins to be noticeable departures from the spreadsheet decay calculation for nuclides with short half-lives. Evidently, a calculation is performed in GENII, that introduces differences in the decay calculation after 50 or so half-lives. The difference for ${ }^{248} \mathrm{Cm}$ external dose comes about because the spreadsheet ignores the ingrowth of ${ }^{240} \mathrm{U}$. The other differences are as described before. 
For the irrigated farm the leaching computations are similar in both GENII and the spreadsheet. The differences shown in Table $C-8$ are largely due to the different treatment of short-lived progeny nuclides. The following
nuclides illustrate this: ${ }_{210} \mathrm{~Pb}\left({ }^{210} \mathrm{Po}\right),{ }^{222} \mathrm{Ac}\left({ }^{223} \mathrm{Ra}\right),{ }^{228} \mathrm{Th}\left({ }^{224} \mathrm{Ra}\right),{ }^{229} \mathrm{Th}$ $\left({ }^{225} \mathrm{Ra}\right),{ }^{244} \mathrm{Pu}\left({ }^{240} \mathrm{U}\right)$, and ${ }^{242 \mathrm{~m}} \mathrm{Am}\left({ }^{242} \mathrm{Cm}\right)$. The principle progeny nuclide is shown in parentheses. In each case, the progeny nuclide is found in the cow (or fish) in higher than equilibrium amounts. Therefore, GENII gives larger doses than the spreadsheet, since the spreadsheet assumes the progeny nuclides are always present in equilibrium amounts.

The differences for ${ }^{93} \mathrm{Zr}$, ${ }^{99} \mathrm{TC}$, and ${ }^{232} \mathrm{Th}$ for Beef and Milk follow from differences in the calculation of soil leaching and progeny ingrowth during the growing period.

\section{2 CONCENTRATION IN VEGETABLES}

In GENII, the calculation of radionuclide concentrations in living plants uses three main routes, (1) root uptake, (2) resuspension to leaves (also called "rain splash"), and (3) direct deposition of irrigation water on

foliage. Each of these will be considered separately and then combined to get the total concentration in the vegetables.

GENII includes the effects of radioactive decay between the time a plant type is harvested and when it is consumed. This time period is called the holdup time. It enters the equations for plant concentration as shown below.

$$
C_{p}=\left(C_{p}^{d}+C_{p}^{f}+C_{p}^{r}\right) \operatorname{Exp}\left(-\lambda_{r} T_{p}^{h}\right)
$$

where:

$C_{p}=$ Radionuclide concentration in plant type $p$ at the time it is consumed, in $\mathrm{Ci} / \mathrm{kg}$

$C_{p}^{d}=$ Concentration of a radionuclide in plant type $p$ due to direct deposition of irrigation water. The units for $C_{\text {d }}$ are $\mathrm{Ci} / \mathrm{kg}$

$c_{p}^{r}=$ Concentration of a radionuclide in plant type $p$ due to absorption from the soil through the roots. The units for $\mathrm{C}_{\mathrm{p}}^{\mathrm{r}}$ are $\mathrm{Ci} / \mathrm{kg}$

$C_{p}^{f}=$ Concentration of a radionuclide in plant type $p$ due to foliar deposition from soil resuspension. The units for $C_{p}^{f}$ are $\mathrm{Ci} / \mathrm{kg}$

$T_{p}^{h}=$ Holdup time, i.e., the time between harvest and consumption of plant type $p$, in days:

It was not necessary to include the effects of holdup in the spreadsheet due to the long half-lives of the important nuclides. However, for a few nuclides, the production of daughter activity made a small increase in certain doses. Since the four nuclides missing from GENII decay to stable isotopes, the effects of holdup were not included. 


\section{C.2.1 Root Uptake into Edible Portions}

Root uptake is calculated through a concentration ratio. These ratios are tabulated below in Tables $\mathrm{C}-1$ and $\mathrm{C}-2$. Two sources are used for the numbers. The first is GENII, which provides no references to the literature. The second is ORNL-5785, which is extensively documented in ORNL-5786. There are some major differences, therefore, both were used and compared.

\section{C.3 AIR TRANSPORT OF BURIAL GROUND EMISSIONS USING ISC2}

The atmospheric dispersion of chronic airborne emissions from the surface of a burial ground was estimated using the ISC2 programs from the U.S. Environmental Protection Agency. The ISC2 programs were used two ways, as a check. The first was to treat the air emissions source as a point. The second approach was the more realistic treatment as an extended source. The extended source was assumed to be a square 316 meters by 316 meters. Hanford Site wind data collected at the Hanford Meteorological Station for the years 1983 to 1991 was used. Note that the source was divided into 36 smaller squares to improve accuracy at small distances. All input files are provided in Tables $\mathrm{C}-10$ through $\mathrm{C}-13$.

Results for the chronic release case (ISCLT) are shown on the table below. The release occurs over the better part of one year. The wind direction ESE had the largest concentrations for most of the distances. The normalized integrated exposure $(X / Q)$ is the final air concentration divided by the total release rate of the source.

Distance is measured from the center of the square. The distances from the outer edge of the square are found by subtracting 171 meters from the table distance. The 171 meters is the distance from the center of the square to the edge at an angle of $22.5^{\circ}$ from perpendicular. As the distance from the burial site increases, the average air concentration decreases.

The largest annual average integrated exposure will not exceed 1.0E-04 seconds per cubic meter at the boundary in the ESE direction. The annual inhalation dose is the product shown below. The only nuclides considered are tritium and ${ }^{14} \mathrm{C}$. The only other nuclide with volatile emissions is ${ }^{222} \mathrm{Rn}$, which is limited by the surface emanation rate rather than the projected dose downwind.

$$
\text { Annual Inhalation Dose }=Q \bullet(X / Q) \cdot B R \cdot D F
$$

where:

$Q=$ annual curies released into the air from the burial ground

$X / Q=$ normalized jntegrated exposure, in seconds per cubic meter, the value $1.0 \mathrm{E}-04 \mathrm{~s} / \mathrm{m}^{3}$ was used, based on Table $\mathrm{C}-9$.

$B R=$ inhalation rate for reference $\operatorname{man}, 3.33 \mathrm{E}-04 \mathrm{~m}^{3} / \mathrm{second}$ for 1 ight activity, and $2.67 \mathrm{E}-04 \mathrm{~m}^{3} /$ second averaged over 24 hours.

DF = inhalation dose factor for the nuclide being released. Values for tritium and ${ }^{14} \mathrm{C}$ are 95 and $2100 \mathrm{rem} / \mathrm{Ci}$ inhaled. 
Table C-9. Air Concentrations and Normalized Integrated Exposures (X/Q) from Chronic Releases. (Release rate is $1.0 \mathrm{gram} / \mathrm{second}$ )

\begin{tabular}{|c|c|c|c|c|}
\hline \multirow{2}{*}{$\begin{array}{c}\text { Distance } \\
\text { meters }\end{array}$} & \multicolumn{2}{|c|}{ Air Conc, $\mu \mathrm{g} \mathrm{m}^{-3}$} & \multicolumn{2}{|c|}{$\mathrm{X} / \mathrm{Q}, \mathrm{sec} \mathrm{m}^{-3}$} \\
\cline { 2 - 5 } & Point & Area & Point & Area \\
\hline 221 & 71.047 & 62.088 & $7.10 \mathrm{E}-05$ & $6.21 \mathrm{E}-05$ \\
\hline 241 & 61.644 & 53.525 & $6.16 \mathrm{E}-05$ & $5.35 \mathrm{E}-05$ \\
\hline 271 & 50.730 & 44.308 & $5.07 \mathrm{E}-05$ & $4.43 \mathrm{E}-05$ \\
\hline 321 & 38.183 & 33.959 & $3.82 \mathrm{E}-05$ & $3.40 \mathrm{E}-05$ \\
\hline 371 & 29.921 & 26.815 & $2.99 \mathrm{E}-05$ & $2.68 \mathrm{E}-05$ \\
\hline 421 & 24.128 & 21.599 & $2.41 \mathrm{E}-05$ & $2.16 \mathrm{E}-05$ \\
\hline 471 & 19.900 & 17.811 & $1.99 \mathrm{E}-05$ & $1.78 \mathrm{E}-05$ \\
\hline 521 & 16.718 & 15.000 & $1.67 \mathrm{E}-05$ & $1.50 \mathrm{E}-05$ \\
\hline 671 & 10.763 & 9.823 & $1.08 \mathrm{E}-05$ & $9.82 \mathrm{E}-06$ \\
\hline 871 & 6.882 & 6.384 & $6.88 \mathrm{E}-06$ & $6.38 \mathrm{E}-06$ \\
\hline 1,171 & 4.204 & 3.971 & $4.20 \mathrm{E}-06$ & $3.97 \mathrm{E}-06$ \\
\hline 2,171 & 1.549 & 1.500 & $1.55 \mathrm{E}-06$ & $1.50 \mathrm{E}-06$ \\
\hline 5,171 & 0.411 & 0.405 & $4.11 \mathrm{E}-07$ & $4.05 \mathrm{E}-07$ \\
\hline 10,000 & 0.155 & 0.154 & $1.55 \mathrm{E}-07$ & $1.54 \mathrm{E}-07$ \\
\hline & & & & \\
\hline
\end{tabular}

The combination of $X / Q, B R$ and $D F$ leads to the following scenario dose factors: for tritium, $2.5 \times 10^{-6}$ rem $\mathrm{Cj}^{+1}$ released; for ${ }^{14} \mathrm{C}, 5.6 \times 10^{-5}$ rem $\mathrm{Ci}^{-1}$ released. As an example of how these numbers are used, suppose a burial ground is projected to release 10 curies of ${ }^{14} \mathrm{C}$ over the course of a year. Then the largest inhalation dose from ${ }^{14} \mathrm{C}$ near the burial ground would be $5.6 \times 10^{-4} \mathrm{rem}$.

\section{C.4 REFERENCES}

Baes III, C. F., R. D. Sharp, A. L. Sjoreen, and 0. W. Hermann, 1984a, TERRA: A Computer Code for Simulating the Transport of Environmentally Released Radionuclides through Agriculture, ORNL-5785, Oak Ridge National Laboratory, Oak Ridge, Tennessee.

Baes III, C. F., R. D. Sharp, A. L. Sjoreen, and R. W. Shor, 1984b, A Review and Analysis of Parameters for Assessing Transport of Environmentally Released Radionuclides through Agriculture, ORNL-5786, Oak Ridge Nationa? Laboratory, Oak Ridge, Tennessee. 
DOE, 1988, Internal Dose Conversion Factors for Calculation of Dose to the Public, DOE/EH-0071 (DE88-014297), U.S. Department of Energy, Washington, D.C.

EPA, 1988, Limiting Values of Radionuclide Intake and Air Concentration and Dose Conversion Factors for Inhalation, Submersion, and Ingestion, EPA520/1-88-020, Federal Guidance Report Number 11, U.S. Environmental Protection Agency, Washington, D.C.

EPA, 1989, Exposure Factors Handbook, EPA/600/8-89/043, U.S. Environmental Protection Agency, Washington, D.C.

EPA, 1992, User's Guide for the Industrial Source Complex (ISC2) Dispersion Models, Volume I, EPA-450/4-92-008a, U.S. Environmental Protection Agency, Washington, D.C.

ICRP, 1975, Report of the Task Group on Reference Man, ICRP Publication 23, International Commission on Radiological Protection, Pergamon Press, New York, New York.

Kennedy, W. E. and D. L. Strenge, 1992, Residual Radioactive Contamination from Decommissioning, Volume 1, NUREG/CR-5512, Pacific Northwest Laboratory, Richland, Washington.

Kincaid, C. T., J. W. Shade, G. A. Whyatt, M. G. Piepho, K. Rhoads, H. A. Voogd, J. H. Westsik, Jr., M. D. Freshley, K. A. Blanchard, and B. G. Lauzon, 1995, Performance Assessment of Grouted Double-Shell TankWaste Disposal at Hanford, WHC-SD-WM-EE-004, Rev 1, Westinghouse Hanford Company, Richland, Washington.

Kocher, D. C., 1981, Radioactive Decay Data Tables, DOE/TIC-1026, U.S. Government Printing Office, Washington, D.C.

Napier, B. A., D. L. Strenge, R. A. Teloquin, and J. V. Ramsde11, 1988, GENIIThe Hanford Environmental Radiation Dosimetry Software System, PNL-6584, Pacific Northwest Laboratory, Richland, Washington.

Rittmann, P. D., 1993, Verification Tests for the July 1993 Revision to the GENII Radionuclide and Dose Increment Libraries, WHC-SD-WM-TI-596, Westinghouse Hanford Company, Richland, Washington.

Rittmann, P. D., 1993, GRTPA-A Program to Calculate Human Dose from PORFLOW output, WHC-SD-WM-UM-018, Westinghouse Hanford Company, Richland, Washington.

Sheppard, M. I., S. C. Sheppard, and B. D. Amiro, 1991, "Mobility and Plant Uptake of Inorganic ${ }^{14} \mathrm{C}$ and ${ }^{14} \mathrm{C}$-Labelled PCB in Soils of High and Low Retention," in Health Physics, Vol 61, No. 4, pp 481-492. 
WHC-SD-WM-TI-730, REV 0

This page intentionally left blank. 
WHC-SD-WM-TI-730, REV 0

\section{APPENDIX D \\ COMPILATION OF VAM3D-CG BENCHMARKING, VERIFICATION, AND CALIBRATION DOCUMENTATION}

Note: This appendix carries the number of the documents of which it originally was a part. 
WHC-SD-WM-TI-730, REV 0

This page intentionally left blank.

$D-\mathbf{i} \mathbf{i}$ 
JUL $11^{35} 1994$

2. To: (Receiving Organization)

Distribution
ENGINEERING DATA TRANSMITTAL

3. From: (Orıginatıng Organızatıon)

Environnental Risk \&

Performance Assessment

6. Cog/Proj Enge: AH IU

5. Proj/Prog/Deovioiv: Environmental Restor.

8. Originator Remarks:

Supporting Document Approval Request. Commențs Welcome

1. EOT 123309
$\begin{gathered}\text { Page } 1 \text { of 经 } \\ \text { Nelated EDT No: } \\ \text { NA }\end{gathered}$
7. Purchase Order No:
NA

9. Equip/Component No:

NA

10. System/BIdg/Facilıty:

NA

12. Major Assm Owg No:

NA

13. PermitPermit Application No

NA

14. Required Response Date:

$-94$

\begin{tabular}{|c|c|c|c|c|c|c|c|c|}
\hline \multicolumn{5}{|c|}{ DATA TRANSMITTED } & \multirow{2}{*}{$\frac{\text { (F) }}{\begin{array}{c}\text { Impact } \\
\text { Level }\end{array}}$} & \multirow{2}{*}{$\begin{array}{c}\text { (G) } \\
\text { Reason } \\
\text { for } \\
\text { Trans- } \\
\text { mittal }\end{array}$} & \multirow{2}{*}{$\begin{array}{c}\text { (H) } \\
\text { Origi- } \\
\text { nator } \\
\text { Dispo- } \\
\text { sition }\end{array}$} & \multirow{2}{*}{$\begin{array}{c}\text { (I) } \\
\text { Receiv- } \\
\text { er } \\
\text { Dispo- } \\
\text { sition }\end{array}$} \\
\hline $\begin{array}{c}\text { (A) } \\
\text { rem } \\
\text { No. }\end{array}$ & (B) DocumentDrawing No. & $\begin{array}{l}\text { (C) Sheet } \\
\text { No. }\end{array}$ & $\begin{array}{l}\text { (D) Rev } \\
\text { No. }\end{array}$ & (E) Title or Descriptron of Data Transmitted & & & & \\
\hline 1 & WHC-SD-ER-CSWD-OO5 & & 0 & Verification and Benchmark Testing & $z_{50}$ & 1 & 1 & 1 \\
\hline & & & & of the VAM3D-CG Flow and Transport & & & & \\
\hline & & & & Computer code for Use in & & & & \\
\hline & & & & Performance Assessment at Hanford. & & & & \\
\hline & & & & & & & & \\
\hline & & & & & & & & \\
\hline & . & & & & & & & \\
\hline & & & & & & & & \\
\hline
\end{tabular}

16.

KEY

Impact Levei (F)

1. 2.3. or 4 SEe MRP 5.43

and $E P, 1.7$

\begin{tabular}{|ll} 
& \multicolumn{2}{c}{ Reason for Iransmittal (G) } \\
\hline 1. Approval & 4. Review \\
2. Release & 5. Post-Review \\
3. Information & 6. Dist (Recespt Acknow. Required)
\end{tabular}

Disposition (H) \& (1)

1. Approved 4. Reviewed novcomment

2. Approved wicomment

5. Reviewed wicomment

3. Disapproved wicomment 6 . Receipt acknowledged

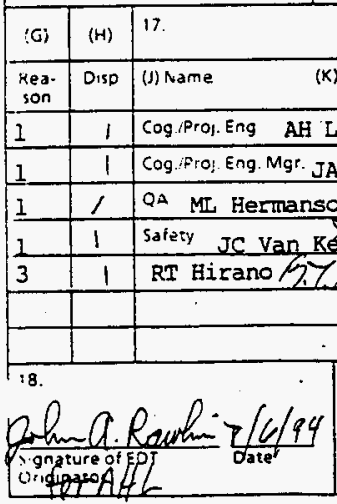

SIGNATURE/DISTRIBUTION

1(See Impact Level for required signatures)

(K) Signature

(L) Date (M) MSIN

(J) Name

(K) Signature

(L) Date

(G)

(G) (H)

$7 / 17 \%$ HO-36

1

-

.

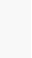




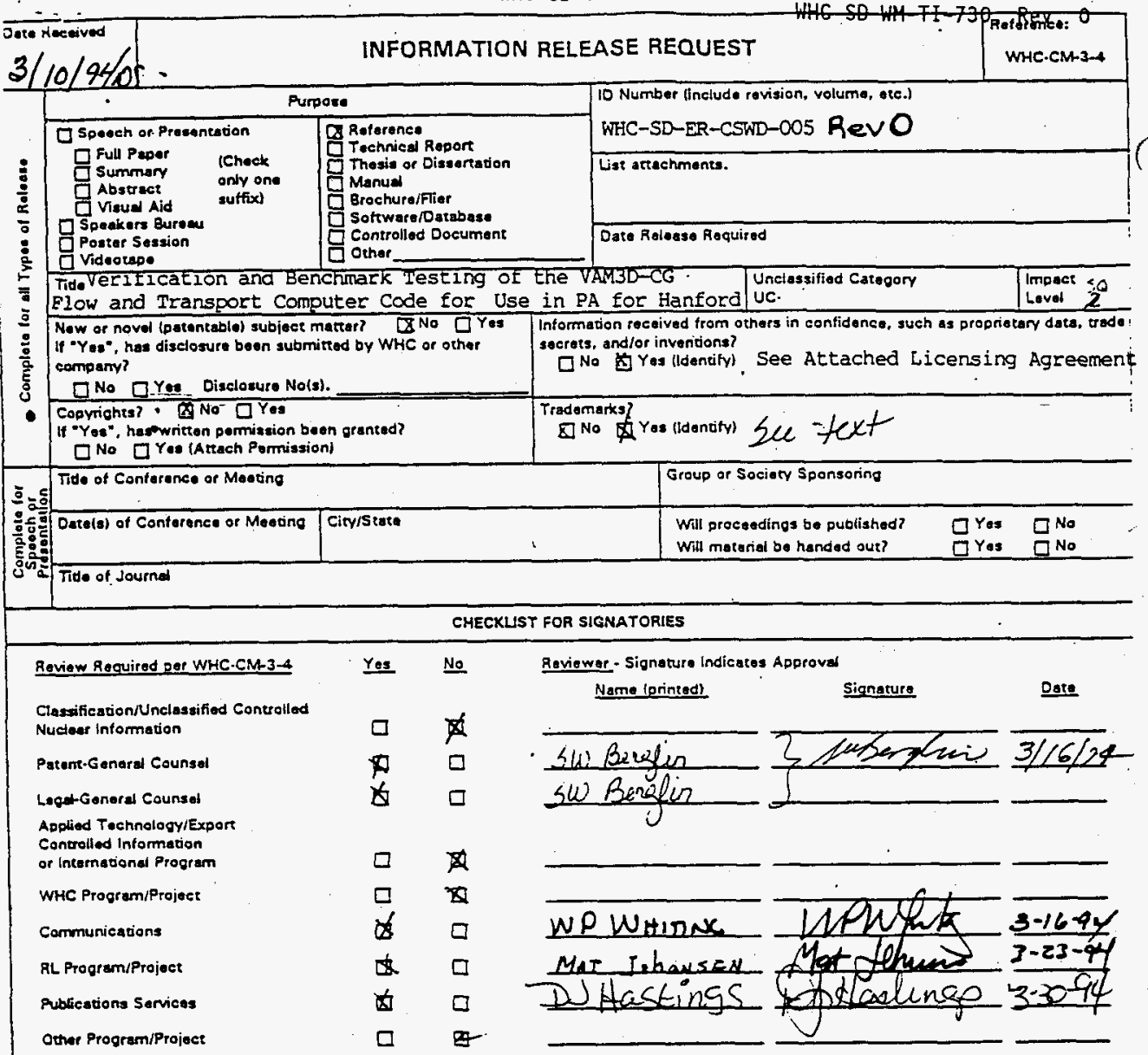

Information confarms to all applicable requirements. The sbove information is certified to be correct. 
2. Title

Verification and Benchmark Testing of the VAM3O-CG Flow and Transport Computer Code for Use in Performance Assessment at Hanford

5. Key Words

Verification Benchmark VAM3D-CG Code

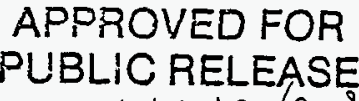
613019L/
6. ReY No.

0

3. Number
WHC-SD-ER-CSWD-OO5

6. Author

Mane: A. H. Lu

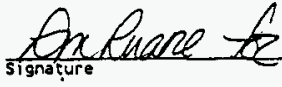

g्र००2 2 organization/charge code $869+01 \mathrm{~J} 8 \mathrm{~d} 85$

\section{Abstract}

Testing of the verBo-cG computer code, Version 2.4b, was condueted to establish confidence that the cocte is ready for use in performance assessment applications at the Mantord site. VAu30-LG is a proprietary product of HydroGeologic, Ins.. of Herndon, VA.

This report deseribes the technical basis, approech, and results of the testing. Varification and benchmarking used to check the capabilities and limitations of the code.

Three sets of testing problens were performed: 1. Reproduction of the verification and benchmark testing problems published by the vendor (Hydroceologic, Inc.) in the user's manual, 2. two benchmart testing problems relevent to performance assessment apolieations at Hanford, and 3. verification of the VAMBO-CG source code as installed on the siliticon Graphics, inc. workstation.

In general, the test results showed excellent agreement with the first and third sets of problems. Both maximn difference and RRMS values are negligible. The difference can be explained by rounding errors between the two computers.

For the second set of problems, the solutions showed very good overall agreenent

then plotted even though VAVBO- CQ and the benchmark code employ significantly different solution techniques. Although minor discrepancies exist, the code should perform well for the PA.

8. R POSE NDD USE OF DOCUMENI - Th documer was prepared for so wh the U.S. Deportment of figy and its intectors. It to to U.S. De only to perfory direet, or intont te work fonder for publit. Wease unti eviewed.

PATENT status document copy, since it is ans ted in advance of patent arance, is made available in eqfidend. olely for use in fifol te of work under conjects with the U.S. Depertine of Energ This doement is not be published its content stherwise dis wated or used fop purposes other tha. specifico bove before petent agoval for sin release or wse has been se, led, uoon request, from We Patent unsel, U.S. Depertment of E Gy field office, Richland, wh.

DISClaimes - This report was prepared as an account of work sponsored by en agency of the United States Government. Mei ther the United states Government nor amy agency thereot, nor any of their enployees, nor any of their contractors, subcontrsctors or their enployess, makes amy warranty, express or fuplifed, or assumes any legal tiability or responsibility for the accuracy, campleteness, or any third party's use or the results of such use of any information, apoaratu, product, or process disclosed, or represents that fts use would not intringe privately ouned rights. Raference herein to amy specific comercial product, process, or service by trace nams, tradenerk, manufacturer, or otherwise, does not neceasarily constitute or imply its endorsentent, reconmendation, or fevoring by the United states Govermment or any agency thereof or its contractors or subcontractors. The views and opinions of authors expressed herein do not necessarily state or reflect those of the United States Goverrment or amy sgency thereof.

10. RELEASE STAMP

OFFICIAL PELEASE BY WHAC DATE JUL 111994 35 station a 
SOFTAARE :ICEASE AGAEENEAT

EHEIHEERING HORXSIATIOHS SOFTWARE

betrean

HYOKOGEDLGIC SOFTHARE SALES

and

YETINGHOUSE MAHFORD CORPANY

This Sottware Licensa Agratment ("Agrenmene"), made this $i=$ day of Hovember. 19e3, is encarzd into betaen Hyorsogedogic Sortware sales ("Liensor") ind Westinghouse Haniord Company ("Licansae"), a prime eanteaetor ot the U.S.

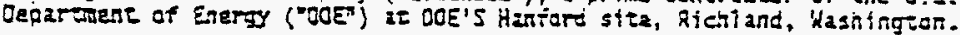

Thts Agreenane, Licansea's Order and the grovisions of PHH-14-012 entitied TERUS AHO CONDIIIOHS APPLICABLE TO SOFTARE LICGHSE AGREZHENTS, wriC aTe atzached herato and incarparazzo harain, eqliectively consititura the gntire

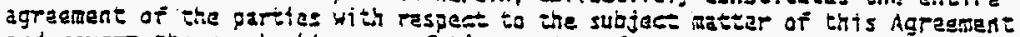
and govern the use by Lieansea of Lieansor's softare produet(s), iesntified as MaGilass, YakzD, and VAMSO Comoutar code ("Sortarare"), inciuding ralazed doevuzentact an ("Documentation").

THE GARTIE HERETO AERE TO THE FOLLOULE TEHS AND COHDTTIONS:

1. Licansor hateby grants to Licengeg a nonexelusiye licanse ts usa tre Softure in any maening-roadabie form on a single manufaceurer aulti-jiationn

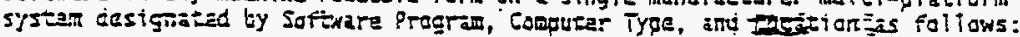

Frogram: VAH20

Type: sitfor Graphics Crtmson

Lecation: 1200 Geerge Washington hay

Fiogram: VAViso, Ist copy

Type: Sitiean Grantics Crimson

Lecseton: 2200 Gcorge Hastington Way

Pregras: Yamid, znd eapy

Tyoe: SiTicon Graphics personai iris

Location: Steyens Canter, 7 to Eutiding

Bragtan: Vhatlasi

TYFe: iEM RISE 5000

Lecation: 3200 Gtarge Washington Way.

Licansor grants to Licanseg the right ta azk elanges or andificetion to tha Softwarg at Licarsae's expenso to meet Licansed's joectfic reguirament. Any

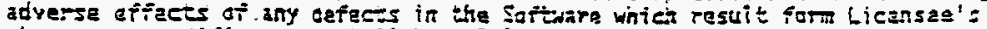
ehanges or medificzitans shali be soleiy the jesponstbitity of licensea.

Ownerzhip and titie to soct changes and wodifications shall vest in bissnist but bjeansor grants to Licarsese a lf canja to use suei changes ane modlftcations pursuant ta the tarms and condtions of this Agregaent. 


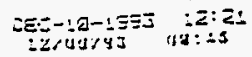
$=$

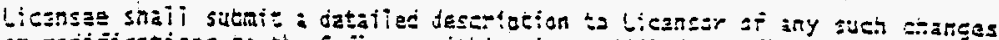

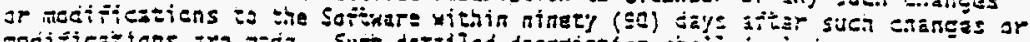

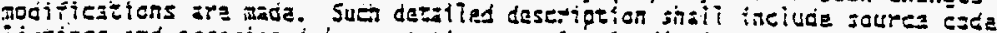
i istings and associacad dectmentation, to eleirly distunetish the chances or

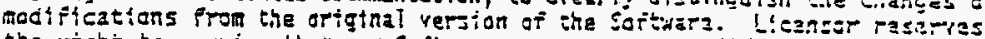
the right to require that iny Sotwars so enanged or actified je given a sew jasignation to ivaid eshiuston.

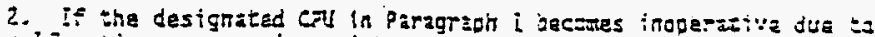

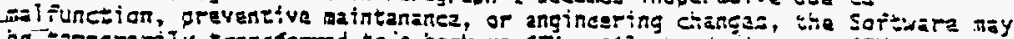

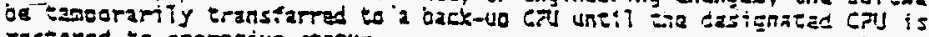
restored to operativa status.

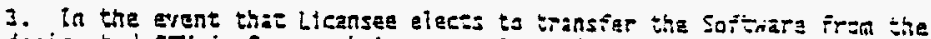
designated crl in.paragraph I to a nexiy dasignatad Gitl, Licanser may co so a 10 additional easi; provided, howeyer, that Licansae sinali jive licanser

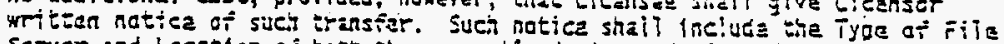

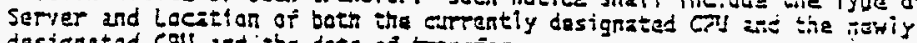
designated cou and tha date of transier.

4. In the avent that Licansae cicetz to rapiace the coy on which the soivare

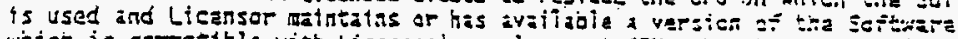

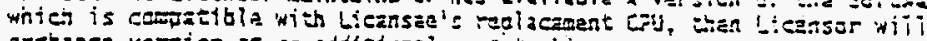
exciange yersion at ac actíticnal cast to Lieanses.

j. Licansor shall grovida Licansa with ane axehine-razizjie cany of the

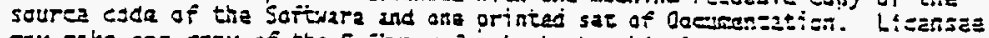

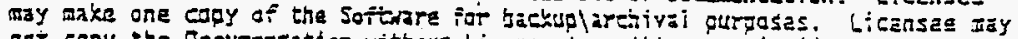
not eapy the docimentation without Licansor's urttien peraissign. Liesnaor

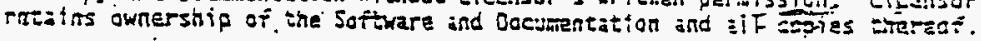

6. Any futurz updater and/or upgrades to the Sottara shaii be governed ay this AgTaement.

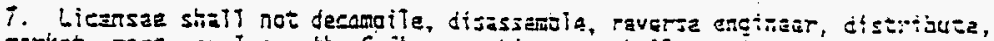
markat, rent, or lesse the Sortware. Licenses sizii net in any way moti fy the

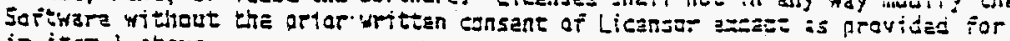
in $i \tan 1$ abeva.

a. Licanse achnowiedges that Licansor renresents that the soividare ind Qceinentetion constitute or contain groprietary information of Licansor and/or third jarties. Aeserdingly, Lieznses agreses to hotd sue- softwars, and other

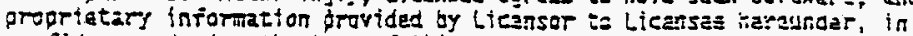

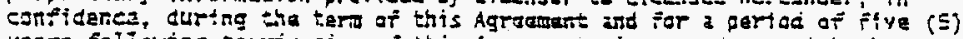
vears foliowing tarminasion of this dgreament, in aceordenen with the tzres ot this Agreament; grovides, however, that Licansea shall nos be in yitlation of

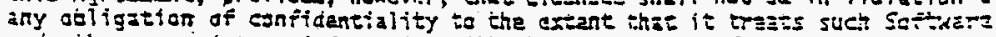
and other groprtetiry information with the same deqres oi cara and canificantiality as it trazs its own propriety intormatian of a simitar nature. ATl sueh software and other prooriaty intortition straij je so

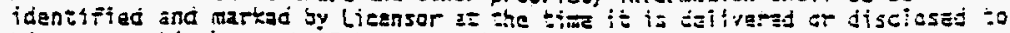
Licensas. Licensen shali haye no obtigation to iole ia en:idenca suci

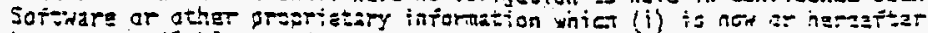

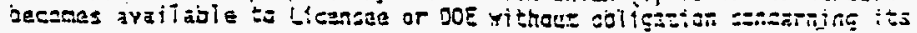




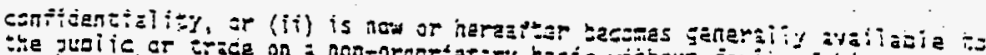

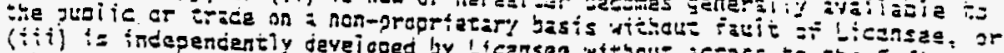

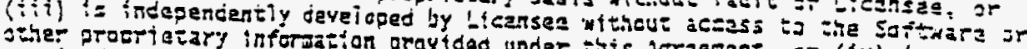

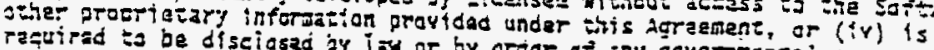
esurt of comatent jurisciction.

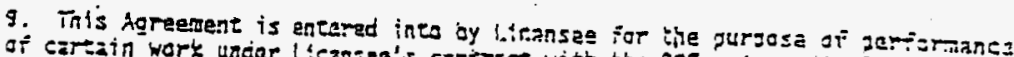

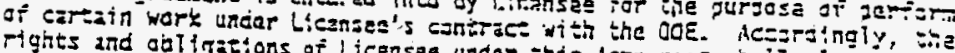

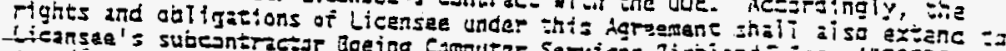

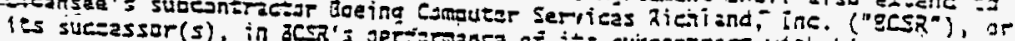

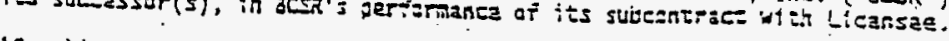

10. Lfcenser watrants that it owns or has bie right to licznsa the sortirarz.

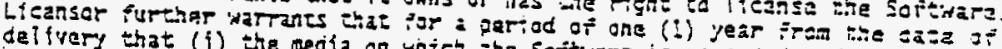
delfvery that (i) the media on which the Sortivare is recarced and the uscumentation are free from defecs in matariais and workmansitio under norai

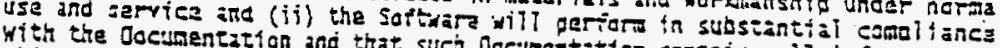
which is reasonabiy necassary sued Documantatien esniains alf information on the camouter harcwers and for use of the Sortware grovided that. it is usad designed. In tha syent and with the operazing systen for which it was

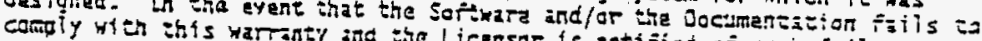

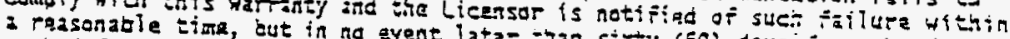

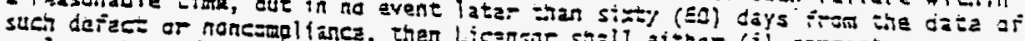

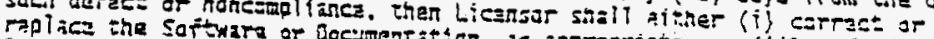

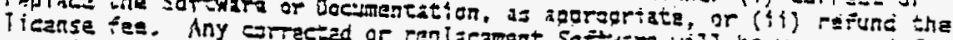

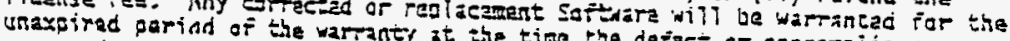
oceuried or ainery (Sd) days, whicjeyer is Tonger.

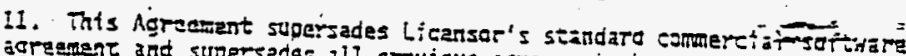

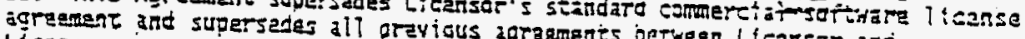
Licenseg.

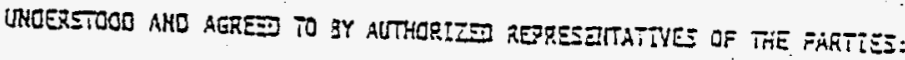

LESTINGSOUSE HAHFURO COMPAYY

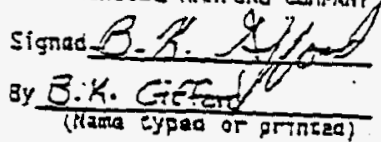

Titre Pracuremot Snecialst

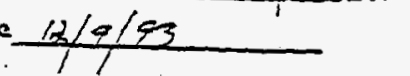

HYOROGEOLOGZC SOFTHARE SALE: signed Dath S. Hudatlein. By P S. Huut born

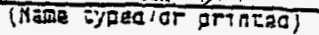
iltie President oate $12 / 10 / 43$ 


\title{
Verification and Benchmark Testing of the VAM3D-CG Flow and Transport Computer Code for Use in \\ Performance Assessment at Hanford
}

\author{
A. H. LU and D. H. Langford \\ Westinghouse Hanford Company
}


Verification and Benchmark Testing of the VAM3D-CG Flow and Transport Computer Code for Use in

Performance Assessment at Hanford

Allen Lu and Dave Langford

\section{ABSTRACT}

Testing of the VAM3D-CG computer code, Version 2.4b, was conducted to establish confidence that the code is ready for use in performance assessment applications at the Hanford site. VAM3D-CG is a proprietary product of HydroGeologic, Inc., of Herndon, Virginia.

This report describes the technical basis, approach, and results of the testing. Verification (comparisons with known solutions) and benchmarking (code-to-code comparisons) were used to check the capabilities and limitations of the code to simulate diverse hydrological and geological conditions pertinent to performance assessment applications. Emphasis was on numerical stability and accuracy. Graphical comparisons and calculation of relative root mean square (RRMS) values were used as indicators of accuracy and consistency.

Three sets of testing problems were performed: 1 . reproduction of the verification and benchmark testing problems published by the vendor (HydroGeologic, Inc.) in the user's manual, 2. two benchmark testing problems: a. a model of the vadose zone flow and transport due to the operation of the 216-U-17 crib in the 200 West Area. b. a cross section model consisting of a sloping clay layer. and 3 . verification of the VAM3O-CG source code as installed on the Silicon Graphics, Inc. (SGI) workstation. The selected tests were performed to show that the VAM3D-CG code on the SGI produces the same results as those previously obtained on the Cray computer which is no longer in service.

In general, the test results showed excellent agreement with the first and third sets of problems. Both maximum difference and RRMS values are negligible. The differences can be explained by rounding errors between the two computers.

For the second set of problems, the solutions showed very good overall agreement when plotted, even though VAM3D-CG and the benchmark code employ significantly different solution techniques. Although minor discrepancies exist, the two codes should perform equally well in terms of performance assessment applications at Hanford. 
Table of Contents

1.0 INTRODUCTIOH . . . . . . . . . . . . . . . . . . . . . . . I

2.0 GOVERNING AND SUPPLEMENTARY EqUATIONS ................. 2

3.0 CODE DESCRIPTION . . . . . . . . . . . . . . . . 4

4.0 Performance indicators . . . . . . . . . . . . . . . . . 5

5.0 VERIFICATION OF THE VAM3O-CG RESULTS WITH THE VENDOR'S PUBLISHED

RESULTS . . . . . . . . . . . . . . . . . 5 .

5.1 TRANSIENT ONE-DIMENSIONAL HORIZONTAL FLOW IN A SOIL SLAB ${ }^{*} \cdot{ }^{*} 7$

5.2 TRANSIENT VERTICAL INFILTRATION IN A SOIL COLUMN . . . . . . . 7

5.3 TRANSIENT TWO-DIMENSIONAL FLOW IN A RECTANGULAR SOIL SLAB . . 8

5.4 TRANSIENT TWO-DIMENSIONAL TRANSPORT IN A RECTANGULAR SOIL

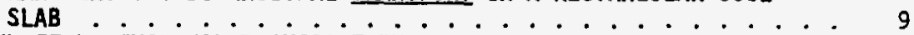

5.5 THREE-DIMENSIONAL TRANSPORT IN UNIFORM GROUNDWATER FLOW . . . 9

6.0 BENCHMARK TESTS: MODEL FOR THE 217-U-17 CRIB, 200 WEST AREA * . 10

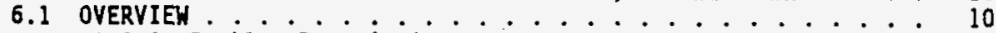

6.1.1 Problen Description ................ 11

6.1.2 Computational Grid .......................... I1

6.1.3 Flow and Transport Paraneters :........... 12

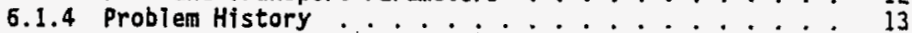

6.2 EXECUTIOH OF THE MODELS .................. 13

6.2.1 Steady State Flow Run (run1) . . . . . . . . . . . 13

6.2.2 Dynamic Flow Run (run2) .............. 14

6.2.3 Coupled Flow and Transport (runj) ......... 14

6.3 COMPARISON OF PORFLO-3 AND VAM3D-CG CONTOUR PLOTS . . . . . . 15

6.3.1 Flow field Results ................. 15

6.3.2 Contaminant Transport Results ............ 16

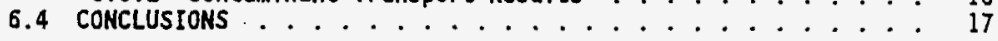

7.0 BENCHMARK TESTS: FLOW AROUND A CLAY CAP . . . . . . . . . . . 30

7.1 OVERVIEW . . . . . . . . . . . . . . . 30

7.1.1 Problem Description ............. . . 30

7.1 .2 Computational Grid............... 30

7.1.3 Material Properties .............. 31

7.2 EXECITION OF THE MODELS . . . . . . . . . . . . . . . . . 32

7.3 COMPARISON OF PORFLO-3 AND VAMBD-CG CONTOUR PLOTS . . . . . . 32

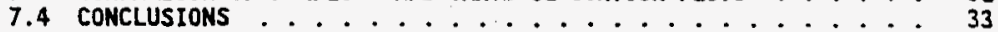

8.0 VERIFICATION OF THE VAM3D-CG SOURCE CODE AS IMSTALLED ON THE SGI . . 38

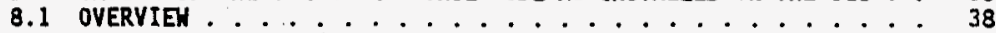

8.2 TEST CASE ID: $v 3 \mathrm{~d} 7$ (Run $* 2$ IN THE REFERENCED DOCUMENT) $: 38$

8.3 TEST CASE ID: V3dt7CP. (RUN \# 2C IN REFERENCED DOCUNENT) . . . 39

8.4 TEST CASE ID: V3d7C (CONT. OF RUN \# 2C) ......... 40

9.0 conclusions . . . . . . . . . . . . . . . . . . 42

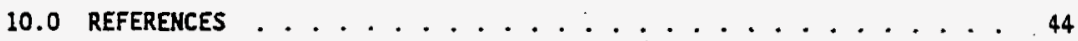


WHC-SD-ER-CSWD-005

Rev. 0

List of Tables

Table 6.1 Flow Parameters ................... . . 12

Table 6.2 Transport Parameters ................. 13

Table 7.1 Material Properties for Clay Cap Model . . . . . . . . 31

Table 7.2 Initial Conditions for Clay Cap Model ........... 31

Table 8.1 Hydraulic Characteristics................ 39

List of Figures

Figure 6.1 Idealized Longtitudinal Cross-Section of Stratigraphy

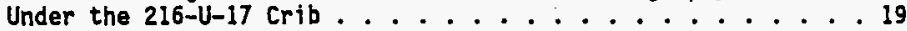

Figure 6.2 216-U-17 Crib Mode1, Finite Element Grid . . . . . . . . . 20

Figure 6.3 216-U-17 Crib Model, Material Boundaries . . . . . . . . 20

Figure 6.4 216-U-17 Crib Mode1, Boundary Conditions . . . . ..... . 21

Figure 6.5 216-U-17 Crib Model, PORFL0-3, Pressure at $0.0 \mathrm{yr}$ 216-U-17 Crib Model, VAM3D-CG, Pressure at $0.0 \mathrm{yr} . \ldots 22$

Figure 6.6 216-U-17 Crib Mode1, PORFL0-3, Pressure at $1.0 \mathrm{yr}$ 216-U-17 Crib Model, YAM3D-CG, Pressure at $0.99 \mathrm{yr} . \ldots 23$

Figure 6.7 216-U-17 Crib Model, PORFLO-3, Pressure at 3.0 yr 216-U-17 Crib Model, VAM3D-CG, Pressure at $3.05 \mathrm{yr}$. . . . . 24

Figure 6.8 216-U-17 Crib Mode1, PORFL0-3, Pressure at $5.0 \mathrm{gr}$ 216-U-17 Crib Model, VAM30-CG, Pressure at $5.12 \mathrm{yr} \ldots 25$

Figure 6.9 216-U-17 Crib Mode?, PORFLO-3, Saturation at 5.0 yr 216-U-17 Crib Model, VAM3D-CG, Saturation at $5.12 \mathrm{yr} . . .26$

Figure 6.10 216-U-17 Crib Model, PORFLO-3, Concentration at $1.0 \mathrm{yr}$ 216-U-17 Crib Model, VAM3D-CG, Concentration at .99 yr ... 27

Figure 6.11 216-U-17 Crib Model, PORFLO-3, Concentration at $3.0 \mathrm{yr}$ 216-U-17 Crib Model, VAM3D-CG, Concentration at 3.05 yr. . . . 28

Figure 6.12 216-U-17 Crib Model, PORFLO-3, Concentration at 5.0 yr 216-U-17 Crib Model, VAM3D-CG, Concentration at $5.12 \mathrm{yr} . .29$

Figure 7.1 Clay Cap Model, Conceptual Domain . . . . . . . . . . . 34

Figure 7.2 Finite Element Grid, Orthogonal Clay Cap Model . . . . . . 35 


$$
\begin{array}{cc}
\text { WHC-SD-TI-730 } & \text { WHC-SD-WM-TI-730, Rev. } 0 \\
\text { WHC-SD-ER-CSWD-005 } & \text { Rev. } 0 \\
\text { List of Figures Continued } &
\end{array}
$$

Figure 7.3 Material Boundaries, Orthogonal Clay Cap Model . . . . . . 35

Figure 7.4 Clay Cap Model PORFL0-3, Pressure at 1000 yr Clay Cap Model VAM3D-CG, Pressure at $1000 \mathrm{yr} \ldots . . . . . .36$

- Figure 7.5 Clay Cap Model, PORFl0-3, Saturation at $1000 \mathrm{yr}$

Clay Cap Model, VAM3D-CG, Saturation at $1000 \mathrm{yr}$. . . . . 37

Figure 8.1 Materials for Solid Waste Geometry . . . . . . . . . . . 41 


\subsection{INTRODUCTION}

VAM3D-CG is a model of fluid flow and mass transport in saturated and unsaturated ground water systems. Modeling is performed in one, two, or three dimensions, using a finite element technique. A user's guide, published by the vendor, contains a full description of the software. VAM3D-CG (Huyakorn and Panday, 1993) is a proprietary product of HydroGeologic, Inc., of Herndon, Virginia.

The primary objective of this report is to examine the capabilities and Iimitations of VAM $30-C G$, Version $2.4 \mathrm{~b}$ in performance assessment applications at the Hanford Site. The examining process follows a general approach used in evaluating and/or certifying computer codes, i.e., verification (comparisons with known solutions) and benchmarking (code-to-code comparisons). Three sets of testing problems were performed and are presented in this report.

1. Verification of the VAM30-CG Version 2.4b with the vendor's (HydroGeologic, Inc.) published resuits (Huyakorn and Panday, 1993);

2. Benchmarking the VAM30-CG simulated results with the results simulated by PORFLO-3 Version 1.2 (Sagar and Runchal, 1990; Runchal and Sagar, 1992) - selected problems have the complexity and features relevant to performance assessment applications at Hanford; and

3. Verification of the VAMBD-CG source code as installed on the Silicon Graphics, Inc. (SGI) workstation. Since previous Solid Waste

Performance Assessment simulations were performed on the Hanford Cray computer, selected tests (Wood et al., 1993) were performed to show that the VAM3D-CG code on the SGI, produces the same results as those on the Cray.

Because of its nonlinearity, analytical solutions to unsaturated flow equations are rare. Therefore, the verification of the accuracy with which VAM 3D-CG approximates the solution to the unsaturated flow equation is performed by comparisons to other numerical approximations rather than by the standard use of analytical solutions. Only one analytical solution was selected by the vendor for verification in a saturated flow and transport problem.

Additional testing of the VAM3D-CG code using data from a field experiment (Sisson and Lu, 1984) is described by Lu and Khaleel (1993). The results from independent verification and benchmark testing of an earlier version of the VAM $30-C G$ code were reported by Huyakorn and Panday (1993). The 20 version (VAM2D) of VAM30-CG Was validated by Kool and Wu (1991) using the field data from the Las Cruces Trench Study.

This report is organized as follows. The governing equations used for unsaturated flow and contaminant transport modeling are presented in Section 2. Brief descriptions of the VAM3O-CG code are presented in Section 3. The performance indicators used as the acceptance criteria for the test problems are discussed in Section 4 . Verification of VAM3D-CG results with the vendor's published results is described in Section 5 . Benchmarking of the VAM30-CG results for the 215-U-17 Crib with those obtained by PORFLO-3, 
Version 1.2, is discussed in Section 6 . Benchmarking of the VAM3D-CG results for flow around a clay cap with those obtained by PORFLO-3, Version 1.2, is discussed in Section 7 . Section 8 contains the verification of the VAMBD-CG source code as installed on the SGI workstation. The conclusions are given in Section 9 and references are listed in Section 10 .

\subsection{GOVERNING AND SUPPLEMENTARY EQUATIONS}

To perform a variably saturated flow analysis, the VAM30-CG code uses the pressure head or hydraulic head as the dependent variable if a rectangular grit is used. For an orthogonal curvilinear grid, the dependent variable is the hydraulic head. The governing equation for water flow in a variably saturated soil is written as:

$$
\frac{\partial}{\partial x_{1}}\left[\rho_{w} K_{i j} k_{z w}\left(\frac{\partial \psi}{\partial x_{j}}+e_{j}\right)\right]=\frac{\partial}{\partial t}\left(\rho_{w} \phi S_{w}\right)-\rho_{w} q
$$

where

$$
\begin{aligned}
\rho_{w} & =\text { density of water } \\
\psi & =\text { pressure head } \\
K_{1 j} & =\text { saturated hydraulic conductivity tensor } \\
k_{r w} & =\text { relative permeability with respect to the water phase } \\
x_{j} & =(i=1,2,3) \text { a set of orthogonal spatial coordinates } \\
t & =\text { time } \\
e_{j} & =\text { unit vector assumed to be vertically upward } \\
S_{\psi} & =\text { water phase saturation } \\
\phi & =\text { effective porosity } \\
q & =\text { volumetric flow rate via sources (or sinks) per unit volume. }
\end{aligned}
$$

The pressure head $\psi$ and hydraulic head $p$ are related as $p=\psi+z$ where $z$ is in the vertical upward direction. form:

For a slightly compressible fluid, equation (2.1) can be written in the

$$
\frac{\partial}{\partial x_{i}}\left[K_{t j} k_{r w}\left(\frac{\partial \psi}{\partial x_{j}}+e_{j}\right)\right]=\left(S_{w} S_{g}+\phi \frac{d S_{w}}{d \psi}\right) \frac{\partial \psi}{\partial t}-q
$$

The specific storage coefficient is defined as

$$
S_{s}=\rho_{w} g(\phi B+\alpha)
$$

where $g$ is the gravitational constant and $\alpha$ and $B$ are coefficients of compressibility of the porous medium and water, respectively. 
In order to solve the variably saturated flow problem, two supplementary equations need to be specified (i.e. the relationships of relative permeability versus water saturation, and pressure head versus water saturation). These functions are given by (Brooks and Corey, 1966):

$$
k_{\mathrm{rw}}=S^{n}
$$

- and (van Genuchten, 1976):

$$
k_{r w}=S_{\theta}^{1 / 2}\left[1-\left(1-S_{\theta}^{1 / Y}\right)^{Y}\right]^{2}
$$

where $n$ and $\gamma$ are empirical parameters and $S_{\text {e }}$ is the effective water saturation defined as $S_{e}=\left(S_{w}-S_{w r}\right) /\left(1-S_{w r}\right)$ with $S_{w r}$ being referred to as the residual water saturation.

The relationship of pressure head versus water saturation is described by the following function (van Genuchten, 1976; Mualem, 1976):

$$
\begin{aligned}
\frac{S_{N}-S_{N T}}{1-S_{w r}} & =\frac{1}{\left[1+\left(\alpha\left|\psi-\psi_{a}\right|\right)^{\top}\right]^{\gamma}} & & \text { for } \psi<\psi_{a} \\
& =1 & & \text { for } \psi \geq \psi_{a}
\end{aligned}
$$

where $\alpha$ and $B$ are empirical parameters, $\psi_{\mathrm{a}}$ is the air entry pressure head value, and $S_{\mathrm{Mr}}$ is the residual water saturation. The parameters $B$ and $y$ are usualiy related by the equation $r=1-1 / B$. The Brooks-Corey and $v a n$ Genuchten functions for the moisture retention and relative permeability characteristics can be measured in the laboratory for a given soil.

The governing equation for three-dimensional transport of a nonconservative component in a variably saturated soil takes the form

$$
\begin{array}{cc}
\frac{\partial}{\partial x_{1}}\left(D_{i j} \frac{\partial c}{\partial x_{j}}\right)-\frac{\partial}{\partial x_{1}}\left(v_{i} c\right)=\frac{\partial}{\partial t}\left[\phi S_{\nu} c+\rho_{s}(1-\phi) c_{s}\right]-q c^{*} \\
+\lambda\left[\phi S_{\nu} c+\rho_{s}(1-\phi) c_{s}\right] & i, j=1,2,3
\end{array}
$$

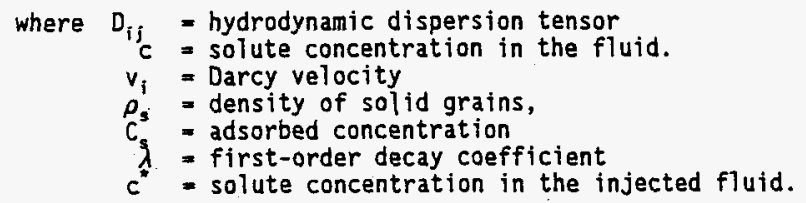


Assuming the relation between adsorbed and solution concentration is described by a linear equilibrium, equation (2.7) can be expressed as

$$
\frac{\partial}{\partial x_{i}}\left(D_{1 j} \frac{\partial c}{\partial x_{y}}\right)-\frac{\partial}{\partial x_{i}}\left(v_{i} C\right)=\frac{\partial}{\partial t}\left(\phi S_{w} R C\right)+\lambda \phi S_{w} R C-q C^{*}
$$

where $R$ is the retardation defined as

$$
R=1+\frac{\rho_{s}(1-\phi) k_{d}}{\phi S_{\psi}}=1+\frac{\rho_{g} k_{d}}{\phi S_{w}}
$$

with the bulk density $\rho_{3}$ being defined as $(1-\phi) \rho_{s}$.

The hydrodynamic dispersion tensor components are computed using the following constitutive relations for homogeneous systems (Scheidegger, 1961):

$$
D_{i j}=\alpha_{T}|V| \delta_{i j}+\left(\alpha_{5}-\alpha_{T}\right) \frac{V_{i} v_{j}}{|V|}+\tau D \circ \delta_{i j}
$$

where $\alpha_{L}$ and $\alpha_{T}$ are longitudinal and transverse dispersivities, respectively, $\delta_{i j}$ is the Kronecker delta, $D^{\circ}$ is the bulk molecular diffusion coefficient, and $\tau$ is the tortuosity.

\subsection{CODE DESCRIPTION}

The VAM $30-C G$ code is briefly described in this section. Detailed descriptions of the numerical methods implemented in the code are given in the users' manua T (Hayakorn and Panday, 1993).

VAM3D-CG Version 2.4b is a three-dimensional finite element code used for simulating saturated-unsaturated groundwater flow and transport with variable water table positions and highly non-linear soil moisture conditions. The Galerkin and upstream weighted residual procedures are employed for solving the flow and transport equations (Equations 2.1 or 2.2 and 2.7 or 2.8, respectively). Preconditioned Conjugate Gradient (PCG) and ORTHOMIN techniques are used to solve the large symmetric and asymmetric matrix equations. Element matrices are generated using influence coefficient formulas, thus avoiding costly numerical integration. The code can easily be adapted for one-, two- or three-dimensional applications, including. axisymetric configurations.

VAM30-CG was placed under configuration management in mid 1993. This ensures the source and executable codes are carefully controlled, and the results are traceable to the code which created them. The current effort examines Version 2.4b of the source code, dated August 13, 1993 (the vender has released multiple revisions of Version $2.4 \mathrm{~b}$ ). 
The bulk of the tests which follow were run on an SGI workstation, under the operating system IRIX Release 4.0.5C, System V. This includes most of the VAM $30-C G$ resuits and all of the PORFLO-3 results. Additional runs were made on a Cray XMP12-32 computer, operating under UNICOS 6.0 , in an effort to verify the installation of VAM3D-CG as it was moved to the SGI.

When VAM3D-CG was moved to the SGI environment, two changes were made to the code. First, a traceability record was added to the top of the output

- files. File traceability is often a necessary feature, when the results must be archived for a number of years, or when multiple versions of the modeling code are released. Second, the system dependent routines were separated from the numeric modeling software. This allows the code to be moved between operating systems, without making modifications to the source code files which do the actual computation.

\subsection{PERFORMANCE INDICATORS}

Various performance indicators can be used to evaluate the accuracy of the results generated by the numerical models. Quantitative indicators of model performance include maximum difference, maximum relative difference, root mean square error and relative root mean square error. The relative root mean square error (RRMS) was adopted as the performance indicator for the first and third sets of test problems. The RRMS indicator is defined by the following formula:

$$
R R M S=\sqrt{\frac{\sum_{i=1}^{k}\left(\left(r_{1}-n_{i}\right) / r_{i}\right)^{2}}{k}}
$$

where $r_{i}=$ reference solution at point $\mathbf{j}$

$n_{i}=$ numerical solution at point $i$ by the VAM3D-CG Version $2.4 b$ on the SGI

$k=$ number of comparison points.

For the first set of testing problems, the reference solutions are the results calculated by the vendor using a different version of the VAM $3 D-C G$ code. For the third set of problens, the reference solutions are the results calculated by the VAM3D-CG Version 2.4b on the Cray XMP12-32 operating under UNICOS 6.0.

Magnusen et at (1990) used the RRMS error as a performance indicator for comparing numerical and analytical solutions. They defined four performance categories: 1. Excellent - RRMS s 0.01, 2. Good - RRMS $30.05,3$. Acceptable RRMS $=0.10$, and 4 . unacceptable - RRMS $\geq 0.10$. 
In this application, since we verify different versions of the VAM3D-CG operating on different computers, smail errors are expected. Thus, we define arbitrarily the acceptable RRMS $\leq 0.01$.

For the second set of problems, significant differences were expected in the resuits near the source term and boundaries between the VAM3D-CG code and the benchmarked code, PORFLO-3 Version 1.2. The RRMS performance indicator was not used as an acceptance criteria. Some of the reasons these differences occurred were:

- Different geometries (PORFLO-3 uses a finite difference scheme, while VAM3D-CG uses a finite element approach. Consequently, the nodal Toeations do not match between the models).

- Different handling of boundary conditions (e.g. PORFLO-3 places its first computational node well within the domain, while VAM30-CG places that node on the boundary).

- Different material boundaries' (PORFLO-3 places the material boundaries mid-way between nodes, while VAM30-CG places them on the nodes).

- Different calculation methods (e.g. PORF10-3 uses the concept of internodal conductivity and results in several averaging methods at users' choice, while VAM3D-CG approximates the hydraulic conductivity as a function of space over the area or volume of the finite element).

Instead, graphical comparisons were made as the primary comparison for the two benchmark testing problems. Although only a subjective judgement on the degree of agreement between the two codes can be made, overail agreement in terms of the prediction of the ultimate performance objectives should be emphasized.

\subsection{VERIFICATION OF THE VAM3D-CG RESULTS WITH THE VENDOR'S PUBLISHED RESULTS}

The following testing problems described in the user's guide were rerun to verify accuracy of the new code Version 2.4b on the SGI workstation.

- Transient one-dimensional horizontal flow in a soil slab.

o Transient vertical infiltration in a soil column

- Transient two-dimensional flow in a rectangular soil slab

- Transient two-dimensional transport in a rectanguiar soil slab

0 . Three-dimensional transport in uniform groundwater flow.

A detailed description of these testing problems, values of the physical parameters used in the simulations, numerical results, and comparisons between the vendor's version and Version. 2.4b, are presented. RRMS values in this section use a threshold of $1.0 \mathrm{e}-3 \mathrm{~cm}$ for pressure head and $1.0 \mathrm{e}-3 \mathrm{~g} / \mathrm{cm}^{3}$ for concentration (data points below this limit are not compared). 
Rey. 0

\subsection{TRANSIENT ONE-DIMENSIONAL HORIZONTAL FLOW IN A SOIL SLAB}

\section{Problem Description}

The purpose of this probiem is to test the implementation of the Galerkin finite element formulation and the nonlinear iterative schemes for a case where there is no gravity effect. A rectangular grid comprised of $2 \times 2 \times 21$ nodes was used for simulation. Fixed pressure head values equal $0.0 \mathrm{~cm}$ on one end, and $-83.33 \mathrm{~cm}$ on the other end were used. The soil was assumed to be homogeneous and isotropic with a saturated hydraulic conductivity of $1 \mathrm{~cm} / \mathrm{d}$ and a porosity of 0.45 . Twenty time steps were taken.with $\Delta t=0.01$ days.

The-soil moisture characteristics used in the simulation correspond to the Brooks-Corey equation with $n=1$ and $S_{w r}=0.3333$ (see eq. 2.4). The selected water saturation function corresponds to the van Genuchten equation with $\alpha=-$ $0.01 \mathrm{~cm}^{-1}, \mathrm{~B}=1$, and $\gamma=-1$. $\psi_{\mathrm{a}}$ is assumed to be $0.0 \mathrm{~cm}$ (eq. 2.6).

The pressure head profiles and the water saturation profiles computed by VAM30-CG were compared by the vendor' to those computed by the UNSAT2, a twodimensional Galerkin finite element code, documented in Neuman et al. (1974) and David and Neuman (1983). The vendor documented good agreement between the two numerical solutions. The VAM30-CG input and output files, p421.dat and p421. out, were provided by the vendor.

2. Comparison of the Vendor's Version with Version 2,4b Numeric Data

\begin{tabular}{|l|l|l|l|}
\hline $\begin{array}{c}\text { Time } \\
\text { (Days) }\end{array}$ & $\begin{array}{l}\text { Range of Variable } \\
\text { Pressure Head }(\mathrm{cm})\end{array}$ & $\begin{array}{c}\text { Max. Difference } \\
(\mathrm{cm})\end{array}$ & RRMS \\
\hline 0.1 & $-83.330-0.0$ & $1.0 \mathrm{e}-3$ & $1.896 \mathrm{e}-5$ \\
\hline 0.2 & $-83.330-0.0$ & $1.0 \mathrm{e}-3$ & $6.962 \mathrm{e}-6$ \\
\hline
\end{tabular}

In this section, the RRMS values use a threshold of $1.0 \mathrm{e}-3 \mathrm{~cm}$ for pressure-head value and $1.0 \mathrm{e}-3 \mathrm{~g} / \mathrm{cm}^{3}$ for concentration. Values at the boundary nodes were excluded from RRMS calculation.

\subsection{TRANSIENT VERTICAL INFILTRATION IN A SOIL COLUMN}

\section{Problem Descriotion}

This problem is concerned with one-dimensional infiltration in an unsaturated zone. It was selected to test the nonlinear finite element formulation for a case that included gravity effects. A rectangular grid comprised of $41 \times 2 \times 2$ nodes was used for simulation. Initially, values of the pressure head of the soil column were $-70.0 \mathrm{~cm}$. At later time the pressure head at the lower end was maintained at zero. A no-flow boundary condition was applied at the top end. Fifteen time steps were taken with $\Delta t=0.01$ days. 


\section{WHC-SD-TI-730 \\ WHC-SD-WM-TI-730, Rev. 0 \\ WHC-SD-ER-CSWD-005 \\ Rev. 0}

The soil moisture characteristics used in the simulation correspond to the Brooks-Corey equation with $n=1$ and $S_{w r}=0.3333$. The selected water saturation function corresponds to the var Genuchten equation with $\alpha=-0.01$ $\mathrm{cm}^{-1}, B=1$, and $\gamma=-1$. $\psi_{\mathrm{a}}$ is assumed to be $0.0 \mathrm{~cm}$.

Results were compared by the vendor with both UNSAT2 and VAM2D solutions. From the graphics, the vendor concluded that the solution from the VAM3D-CG agrees well with both UNSAT2 and VAM2D solutions. The VAM3D-CG input and output files, p422.dat and 422.0ut, were provided by the vendor.

2. Comparison of the Vendor's Version with Version 2. 4b Numeric Data

\begin{tabular}{|l|l|l|l|}
\hline $\begin{array}{c}\text { Time } \\
\text { (Days) }\end{array}$ & $\begin{array}{l}\text { Range of Variable } \\
\text { Pressure Head (cm) }\end{array}$ & $\begin{array}{c}\text { Max. Difference } \\
(\mathrm{cm})\end{array}$ & RRMS \\
\hline 0.1 & $-90.00--0.0$ & $5.40 \mathrm{e}-2$ & $7.652 \mathrm{e}-4$ \\
\hline 0.2 & $-90.00--0.0$ & $3.70 \mathrm{e}-2$ & $5.338 \mathrm{e}-4$ \\
\hline
\end{tabular}

\subsection{TRANSIENT TWO-DIMENSIONAL FLOW IN A RECTANGULAR SOIL SLAB}

\section{Problem Description}

The purpose of this problem is to test the finite element formulation for a two-dimensional unsaturated flow involving gravity, and a prescribed head and flux boundary condition. A rectangular grid comprised of $11 \times 16 \times 2$ nodes was used for simulation. Initial pressure head values were $-90.0 \mathrm{~cm}$, boundary conditions: $\psi=6-y$ for $6 \mathrm{~cm} \leq y \leq 10 \mathrm{~cm}$ on the left upper corner nodes, $-90 \mathrm{~cm}$ on all right side nodes, and no flow for all other boundary nodes. The soil properties were kept the same as those used in section 5.2 . Time step values were generated within the code using the algorithm: $\Delta t_{1}=$ 0.01 days, $\Delta t_{k}=1.2 * \Delta t_{k-1} .10 .05$ days for $k=2, \ldots, 15$.

The vendor compared VAM3D-CG results with those obtained from the UNSAT2 code, and they agreed we11. VAM3D-CG input and output files, p423.dat and p423. out, were provided by the vendor.

2. Comparison of the Vendor's Version with Version 2.4b Numeric Data

\begin{tabular}{|l|l|l|l|}
\hline $\begin{array}{c}\text { Time } \\
\text { (Days) }\end{array}$ & $\begin{array}{c}\text { Range of Variable } \\
\text { Pressure head }(\mathrm{cm})\end{array}$ & $\begin{array}{c}\text { Max. Difference } \\
(\mathrm{cm})\end{array}$ & RRMS \\
\hline 0.074 & $-90.00--0.0$ & $3.00 \mathrm{e}-3$ & $1.703 \mathrm{e}-5$ \\
\hline 0.254 & $-90.00--0.0$ & $2.00 \mathrm{e}-3$ & $8.645 \mathrm{e}-4$ \\
\hline
\end{tabular}


Rev. 0

\subsection{TRANSIENT TWO-DIMENSIONAL TRANSPORT IN A RECTANGULAR SOIL SLAB}

\section{Problem Descriotion}

This problem corresponds to the two-dimensional unsaturated flow problem described in 5.3. It is concerned with the transport of a nonconservative solute in a rectangular soil slab. Boundary conditions for the transport were on the upper left five nodes with all values 1.0. Initial conditions were 0.0 - $\mathrm{g} / \mathrm{cm}^{3}$. Parameters used were: longitudinal dispersivity, $\alpha_{L}=1 \mathrm{~cm}$; transverse dispersivity, $\alpha_{T}=0.0 \mathrm{~cm}$; apparent molecular diffusion, $D_{0}=0.01 \mathrm{~cm}^{2} / \mathrm{d}$; decay coefficient, $\lambda=0.001 \mathrm{~d}^{-1}$; bulk density, $\rho_{\mathrm{B}}=1.46 \mathrm{~g} / \mathrm{cm}^{3}$; and distribution coefficient, $k_{d}=0.308 \mathrm{~cm}^{3} / \mathrm{g}$.

The solution obtained is compared by the vendor with the corresponding Galerkin solution obtained by using the FEMWASTE-code (Yeh and Ward, 1981). The vendor concluded that the overall agreement between the two numerical solutions was reasonable. The VAM3D input and output files, p433.dat and p433. out, were provided by the vendor.

2. Comparison of the Vendor's Version with Version 2.4b Numeric Data

\begin{tabular}{|l|l|l|l|}
\hline $\begin{array}{c}\text { Time } \\
\text { (Days) }\end{array}$ & $\begin{array}{l}\text { Range of Variable } \\
\text { Conc. }\left(\mathrm{g} / \mathrm{cm}^{3}\right)\end{array}$ & $\begin{array}{c}\text { Max. Difference } \\
\left(\mathrm{g} / \mathrm{cm}^{3}\right)\end{array}$ & RRMS \\
\hline 0.074 & $0.001--1.0$ & $1.0 \mathrm{e}-5$ & $7.761 \mathrm{e}-5$ \\
\hline 0.258 & $0.001--1.0$ & $1.0 \mathrm{e}-5$ & $6.573 \mathrm{e}-5$ \\
\hline
\end{tabular}

\subsection{THREE-DIMENSIONAL TRANSPORT IN UNIFORM GROUNDWATER FLOW}

\section{Problem Descriotion}

The purpose of this problem was to verify the transport finite element formulation in VAM3D-CG by comparing the results. With the analytical solution and the other two numerical models for a full three-dimensional transport problem. The problem concerned contaminant transport from a small volume source (land disposal) situated on top of a shallow unconfined aquifer. The transport occurred in the saturated zone of the aquifer with steady uniform groundwater flow. The Darcy velocity flow velocity was assumed to be $1.61 \times 10^{-}$ $\mathrm{m} / \mathrm{d}$ parallel to the horizontal axis. The source term was a constant contaminant mass flux at a rate of $140.8 \mathrm{~g} / \mathrm{d}$. 
Because of its symmetry with respect to the $x-y$ plane, only one half of the region was modeled. A rectangular grid comprised of $2430(30 \times 9 \times 9)$ nodes was selected. Nodal spacings were constant in the $y$ and $z$ directions. The values of $\Delta y$ and $\Delta z$ are $2.5 \mathrm{~m}$ and $3.7 \mathrm{~m}$, respectively. The $x$-coordinates of the grid line selected were $-36,-19,-10,-4,0,4,10,17,24,31,38,46,54$, $62,70,78,96,105,114,123,132,141,150,159,168,177,186,195$, and 204 $\mathrm{m}$, respectively. Twenty time steps were taken with $\Delta t=100$ days. Parameters used were: longitudinal dispersivity, $\alpha_{L}=4 \mathrm{~m}$; transverse dispersivity, $\alpha_{1}=$ $0.8 \mathrm{~m}$; and porosity, $\phi=0.35$.

A general analytical solution for such a problem can be found in Yeh (1981). The solution was implemented into a computer code referred to by thevendor as the AT123D analytical model. Results computed by VAM3D-CG were compared by the vendor with the AT123D and additional three-dimensional finite element codes, MAST3D and STACE3D. The vendor concluded that these numerical solutions exhibited reasonable agreement with the analytical solution. The VAM $3 D-C G$ input and output files, $p 432$. dat and $p 432$.out, were provided by the vendor.

2. Comparison of the Vendor's Version with Version 2.4b Numeric Data

\begin{tabular}{|c|c|c|l|}
\hline $\begin{array}{c}\text { Time } \\
\text { (Days) }\end{array}$ & $\begin{array}{l}\text { Range of Variable } \\
\text { Conc. }\left(\mathrm{g} / \mathrm{cm}^{3}\right)\end{array}$ & $\begin{array}{c}\text { Max. Djfference } \\
\left(\mathrm{g} / \mathrm{cm}^{3}\right)\end{array}$ & RRMS \\
\hline 1000 & $0.001-1367$ & $1.0 \mathrm{e}-7$ & $4.810 \mathrm{e}-7$ \\
\hline 1400 & $0.001--1367$ & $1.0 \mathrm{e}-4$ & $7.476 \mathrm{e}-7$ \\
\hline 2000 & $0.001--1368$ & $1.0 \mathrm{e}-5$ & $7.169 \mathrm{e}-7$ \\
\hline
\end{tabular}

\subsection{BENCHMARK TESTS: MODEL FOR THE 217-U-17 CRIB, 200 WEST AREA}

\subsection{OVERVIEY}

This problem is based on a model of vadose zone flow and transport due to operation of the $216-U-17$ crib in the 200 West Area. The model was originally implemented with PORFLO-3, Version 1.2 (Runchal et al., 1992; KTine, 1993) and is described in the Groundwater Impact Assessment (GIA) report for the 216-U-17 Crib (Reidel et at, 1993). All numeric values used. in this effort have been taken from that document. The results from VAM $30-C G$ are compared with the PORFLO-3 results, to benchmark the correctness of VAM3O-CG (Huyakorn et. al., 1993).

A lengthy series. of $216-U-17$ crib simulations was performed in support of the GIA. This problem.represents only one of those models. It is presented here solely for the purpose of benchmarking. 


\subsubsection{Problem Description}

The 216-U-17 Crib is a waste water disposal site for operations in the 200 area. The floor of the crib is about $3 \mathrm{~m}$ wide, $3 \mathrm{~m}$ below the ground surface, and $46 \mathrm{~m}$ ( $150 \mathrm{ft}$ ) in length. The crib is backfilled with gravel, and covered with a polyethylene barrier. Waste water enters the crib through a perforated fiberglass reinforced pipe which is buried in the gravel. The pipe measures $46 \mathrm{~m}$ in length by $15.24 \mathrm{~cm}(6 \mathrm{in})$ in diameter. From the entry point at the west end of the crib, the pipe slopes downward $0.2 \%$.

The discharge into the crib was substantially below the design capacity. Therefore, for the purposes of this modeling, the fluid source is assumed to be at the-uppermost 20 meters of the discharge pipe.

The spatial domain for the model (See Figure 6.1) extends downward from the mean elevation of the pipe. Several layers of sedimentary soil and rock are present below the Crib. The water table lies 65 meters below the ground surface, and the domain extends 30 meters down into the water table. The model extends $100 \mathrm{~m}$ to both the east and west from the west end of the crib (Reidel et a), 1993).

Flow modeling began by determining a steady state flow field under the crib, before aperation began. The steady flow field was the starting point for simulation of coupled (simultaneous) flow and transport. The particular case used for the present study of the counterpart VAM3D-CG model is identified in Section 5.1.4.1.1 of the GIA report (Reidel et al, 1993).

Both PORFLO-3 and VAMBO-CG used a hydraulic head formulation of the pressure equation. The results were converted to pressure head prior to plotting.

\subsubsection{Computational Grid}

The computational grid for VAM3O-CG was taken directly from the PORFLO-3 grid. The nodes of the finite element grid were placed mid-way between the nodes of the finite difference grid. Thus, each cell of the PORFLO-3 grid was translated into a finite element, except boundary cells. Material boundary locations were preserved by this. construction, and both models had the same grid resolution.

For VAM30-CG, the grid had 3705 elements and 7656 nodes. All elements were regular quadrilaterals, arranged in a 57 by 65 rectangular grid. The grid is plotted in Figure 6.2, while material boundaries are plotted in Figure 6.3. A two dimensional model was used. The thickness of the model, $\Delta y$, was set to $2 \mathrm{~m}$. A fully three dimensional solution was generated, using finite element connectivity. 
Rev. 0

\subsubsection{Flow and Transport Parameters}

The flow properties are listed in Table 6.1. The hydraulic conductivities were taken as isotropic. The specific storage was set uniformly to $0.2 \mathrm{~m}^{-1}$ for all materials. A van Genuchten model was used for the unsaturated flow characteristics. The porosity used was taken from the diffusive porosity in the PORFLO-3 model.

VAM3D-CG allows the van Genuchten gamma to be specified directly. These values were set to zero, which forces the code to compute gamma from the beta values, $r=(1-1 / B)$.

The nominal rain water recharge rate was set to $10 \mathrm{~cm} / \mathrm{yr}$. When $\mathrm{crib}$ operation begins, the crib receives a constant water recharge flux of 109.5 $\mathrm{m} / \mathrm{yr}$, evenly spread over the floor of the crib source zone $(x=0$ to $x=20)$. The contaminant boundary concentrations are set to unity along the fluid flux boundary, to model the inflow of contaminants into the domain.

For the transport properties,' identical values were assumed for all of the material zones. These are listed in Table 6.2 .

For the PORFLO-3 runs, the flow properties were averaged at cell interfaces using a geometric mean. The transport properties were averaged using a harmonic mean.

Table 6.1 Flow Parameters

\begin{tabular}{|c|c|c|c|c|c|}
\hline Zone & $\begin{array}{l}\text { Hyd Cond } \\
\text { (m/yr) }\end{array}$ & Porosity & $\begin{array}{c}\text { Residual } \\
\text { Saturation }\end{array}$ & $\begin{array}{c}\text { alpha } \\
(1 / \mathrm{m})\end{array}$ & beta \\
\hline 1 & $6.224 \mathrm{E}+02$ & 0.3660 & $8.000 \mathrm{E}-03$ & $8.547 \mathrm{E}+01$ & $1.343 \mathrm{E}+00$ \\
\hline 2 & $7.200 \mathrm{E}-01$ & 0.3420 & $2.300 \mathrm{E}-02$ & $7.770 \mathrm{E}+00$ & $1.683 \mathrm{E}+00$ \\
\hline 3 & $7.637 \mathrm{E}+02$ & 0.3720 & $0.000 \mathrm{E}+00$ & $2.320 \mathrm{E}+00$ & $1.189 \mathrm{E}+00$ \\
\hline 4 & $8.520 \mathrm{E}+03$ & 0.4960 & $1.020 \mathrm{E}-01$ & $2.786 \mathrm{E}+01$ & $1.371 \mathrm{E}+00$ \\
\hline 5 & $3.950 \mathrm{E}+01$ & 0.4270 & $4.100 \mathrm{E}-02$ & $1.060 \mathrm{E}+01$ & $1.473 \mathrm{E}+00$ \\
\hline 6 & $3.950 \mathrm{E}+01$ & 0.4270 & $4.100 \mathrm{E}-02$ & $1.060 \mathrm{E}+01$ & $1.473 \mathrm{E}+00$ \\
\hline 7 & $3.471 \mathrm{E}+03$ & 0.3720 & $1.900 \mathrm{E}-02$ & $1.368 \mathrm{E}+01$ & $1.288 \mathrm{E}+00$ \\
\hline 8 & $3.950 \mathrm{E}+01$ & 0.4270 & $4.100 \mathrm{E}-02$ & $1.060 \mathrm{E}+01$ & $1.473 \mathrm{E}+00$ \\
\hline 9 & $2.610 \mathrm{E}+01$ & 0.4490 & $6.000 \mathrm{E}-02$ & $5.800 \mathrm{E}-01$ & $3.145 \mathrm{E}+00$ \\
\hline 10 & $8.390 \mathrm{E}+00$ & 0.5160 & $0.000 \mathrm{E}+00$ & $1.470 \mathrm{E}+00$ & $1.196 \mathrm{E}+00$ \\
\hline 11 & $1.638 \mathrm{E}+01$ & 0.3350 & $0.000 \mathrm{E}+00$ & $1.470 \mathrm{E}+00$ & $1.397 \mathrm{E}+00$ \\
\hline 12 & $1.073 \mathrm{E}+01$ & 0.4180 & $4.100 \mathrm{E}-02$ & $8.826 \mathrm{E}+00$ & $2.387 \mathrm{E}+00$ \\
\hline 13 & $8.521 \mathrm{E}+02$ & 0.2620 & $8.800 \mathrm{E}-02$ & $8.826 \mathrm{E}+00$ & $2.387 \mathrm{E}+00$ \\
\hline
\end{tabular}


Table 6.2. Transport Parameters

\begin{tabular}{|c|c|c|c|c|c|}
\hline Zone & $\begin{array}{c}\text { Alpha L } \\
(\mathrm{m})\end{array}$ & $\begin{array}{c}\text { Alpha } T \\
(\mathrm{~m})\end{array}$ & $\begin{array}{c}\text { Diffusivity } \\
\left(\mathrm{m}^{2} / \mathrm{yr}\right)\end{array}$ & $\begin{array}{c}\text { Decay } \\
(1 / \mathrm{yr})\end{array}$ & Sorption \\
\hline All & 1.00 & 0.100 & $3.00 \mathrm{E}-02$ & 0.00 & 0.00 \\
\hline
\end{tabular}

\subsubsection{Problem History}

This model was originally executed by PORFLO-3 in 1990, using a coarser grid. That model showed some oscillatory wetting-drying behavior under the crib. The more recent model (Reidel et al, 1993) employed a finer grid and did not show the oscillatory behavior. The current effort with VAM3D-CG duplicates the finer grid model. This provides a benchmark for the techniques used by VAM3D-CG. Version 2.46 of VAMBD-CG was used for the modeling.

The VAMBD-CG model was originally constructed and executed as an integration test of the VAM30-CG pre-processor, PREPRO. That input and output was used extensively in this effort.

The original VAM3D-CG input material types were modified, in order to be consistent with the material zoning used in the PORFLO-3 executions: One boundary flux value was found to be incorrect (node 7565 ) in the original input file in PORFLO-3. The error was about $15 \%$ at one node out of 116 nodes. This was corrected, but the results did not change noticeably on the output graphs.

\subsection{EXECUTION OF THE MODELS}

Three runs of VAM3D-CG were made with this problem. The first generated initial conditions for the flow field. A second run modeled only fiuid flow, to ensure the results were comparable with PORFLO-3. The third run modeled coupled fluid flow and mass transport.

\subsubsection{Steady State Flow Run (run1)}

This sets up a steady state flow field under the crib to act as initial conditions for the transient flow. The crib itself was assigned hydrautic properties equal to the surrounding soils.

The top of the domain was assigned a uniform fluid flux value of 10 $\mathrm{cm} / \mathrm{yr}$. The sides of the domain, in the unsaturated zone, were set to zero flux boundaries. In the saturated zone, the heads were set to 0.04 on the east end of the domain, and 0.0 on the west end of the domain. The bottom boundary was assigned fixed values, linearly interpolated from the east to west boundary values. 
Initial conditions were set by estimating the appropriate head for the given recharge rate, assuming a unit gradient driving force. These were placed into an initial conditions file (TAPE8) for input to VAM3D-CG. This file was taken from the original VAM3D-CG integration tests. The flow model was executed for 700 years. ( 1740 time steps), when a near steady state solution was reached.

The results of this run were used as initial conditions for the transient flow and transport models. Note that the initial pressures used in the PORFLO-3 comparisons are taken from the first time step of the coupled flow and transport model, and not from this steady, state run.

\section{- 6.2.2 Dynamic Flow Run (run2)}

VAM3D-CG was set up to run the dynamic flow fields, using the steady state flow field as initial conditions.

The boundary conditions remained unchanged, except the region above the crib. The source boundary extends 'from $x=0$ to $x=20$, and is $2 m(=\Delta y)$ in width. For the corresponding PORFLO-3 model, crib operation discharged 2190 $\mathrm{m}^{3} / \mathrm{yr}$ of fluid into a boundary area of $20 \mathrm{~m}^{2}$, for a boundary flux of 109.5 $\mathrm{m} / \mathrm{yr}$. The same fluid flux was used for the source boundary for VAM3D-CG. For the remainder of the crib, boundary fluid flux is set to zero, due to the polyethylene barrier over the crib. The boundary conditions are displayed in Figure 6.4.

The model was run for ten years. The initial time steps were set to $1.0 E-7 \mathrm{yr}$, and increased to $0.005 \mathrm{yr}$. In the finished model, an additional 0.2 yr of modeling time was added, to ensure a plot file record was written. after the final time of 10 years. A total of 1449 time steps were taken.

The flow field was plotted, and compared with results from PORFLO-3. The plotted time values were not identical. However, within the 7 imit of a visual comparison between the plots, both codes produced substantially similar results.

\subsubsection{Coupled Flow and Transport (run3)}

The fluid flow model was again run, with the addition of simultaneous mass transport. The boundary and initial conditions for fluid flow remained as before. Initial conditions for concentration were set to zero.

Boundary conditions for concentration were set to zero at the bottom of the domain, and zero diffusive flux along the east and west sides of the domain. Above the effluent source zone $(x=0$ to $x=20)$, boundaries were set to a fixed value of 1 . The transport equation is linear, and the results can be scaled to any desired boundary value. 
For the remaining boundary above the crib $(x=20$ to $x=46)$, the concentrations were set to a zero diffusive flux value. The boundary nodes outside the crib $(x<0$ and $x>46)$ were set to fixed values of zero: This avoids a false boundary source due to the rain water recharge in that region.

Time stepping for the coupled flow and transport model were the same as for the flow model.

\subsection{COMPARISON OF PORFLO-3 AND VAM3D-CG CONTOUR PLOTS}

Contour plotting was selected as the primary comparison between the PORFLO-3 and VAMBD-CG models. This produces only a subjective judgement on the agreement between the two codes. However, PORFLO-3 uses a finite difference scheme, while VAM3D-CG uses finite elements. Since the nodal coordinates to not match between the modeis, they are of limited value in direct data comparisons.

Where data gradients are small, contour plots tend to exaggerate minor difference between data sets. This also makes it difficult to compare regions where the data are nearly constant. Therefore, the comparison between plots must be done judiciously.

Some systematic differences are expected in the contour plotting of the results. Graphics processing normally uses linear interpolation between values at the nodes of a model. However, PORFLO-3 places the material boundaries mid-way between nodes. Accurate interpolation of the data would also include material properties within adjoining cells.

In VAM3D-CG, the state variables are modeled to a quadratic accuracy within each element, which is one order higher than the plotting. In addition, VAM $30-C G$ does not permit an easy method for plotting data at predetermined times. Therefore, the VAMBD-CG results are plotted at times which differ slightiy from those of PORFLO-3.

\subsubsection{Flow Field Results}

The fluid pressures are plotted in Figures 6.5 through 6.8. Each figure shows the corresponding results between the two models. Plotting times for PORFLO-3 were $0,1,3$, and 5 years. For VAM3D-CG, results were plotted at times $3.5 \mathrm{E}-6,0.99,3.05$, and 5.12 years.

Some very minor differences in the initial conditions are noted between PORFLO-3 and VAMBD-CG. These could be due to differences in the finite difference and finite element modeling techniques, or in the data interpolation schemes. Also, one or both of the models might not have reached a true steady state when the dynamic model initial conditions were generated. The differences are very minor, and not considered significant. 
Rev. 0

At time 1.0, the flow fields are very similar. The wetting fronts are in nearly the same positions, although VAM3D-CG generates higher pressure values behind the wetting front. In the plots, the VAM3D-CG data is 0.01 years behind the PORFLO-3 data.

At time 3.0, the flow fields are very nearly equivalent. The PORFLO-3 wetting front lags slightly behind the VAM $3 D-C G$ front at the west end of the domain. All other contours shown match up fairly well.

At time 5.0, the wetting fronts again match up very well. The saturated pressures show some minor differences at the west end of the crib, but otherwise agree for the range of pressures shown. Near the bottom of the unsaturated zone, the PORFLO-3 contours are slightly lower than the VAM30-CG contours. PORFLO-3 apparently responds to the approaching fluid column faster than VAM3D-CG. This may result from a small amount of numeric diffusion, but the difference is simati.

Plots of the fluid saturations were made at time 5.0 for both models. These are shown in Figure 6.9. These al so match up fairiy well. Some conspicuous discrepancies are present, but these are probably very minor differences which are accentuated by the use of contour curves.

\subsubsection{Contaminant Transport Resuits}

The concentration contours are plotted in Figures 6.10 through 6.12 . Results were taken from the same times as those used for the pressure plots.

When the VAM3D-CG results were plotted, the contours at very smail concentration values were found to be "unstable." The 0.0001 contour at time 0.99 wandered about the plot, and included many disconnected islands. This is not unusual in a finite elenent model, especially when the Peclet number limitation is approached. Small contour values which displayed this behavior were omitted from the VAM3D-CG plots.

At time 1.0, a reasonable match between contour curves is seen. Both models show an inordinate diffusion towards the zero concentration boundary nodes along the top of the domain, as expected. PORFLO-3 moves the contaminant into the domain slightly faster, except towards the sandy gravel layer (zone 3 ) below and to the west of the crib.

At time 3.0, the match is good below the crib and to the east of the crib. In the region towards the sandy gravel Tayer (zone 3), VAM3D-CG moves. the contaminant faster than does PORFLO-3. In both models, relatively small concentration values are involved.

At time 5.0, the overall match is still good. PORFL0-3 has moved the contaminant down farther. However, only the smaller contour levels show a significant difference. As with the flow equation, this may be due to a small amount of numeric diffusion. The simulation time values also differ sijightly ( 5.0 versus 5.12 years). The material moving through the sandy gravel layer is now very nearly the same in both models. 
PORFLO-3 also appears to be better enforcing the no flux boundary condition at the west boundary. This may be a plotting artifact: VAM3D-CG models the elements using quadratic accuracy, while the plotting interpolation is linear.

\subsection{CONCLUSIONS}

This problem involves a complex, two dimensional model. The programs PORFLO-3 and VAMBO-CG employ significantly different solution techniques. However, the solutions show very good overall agreement when plotted.

A reasonable acceptance criteria cannot be stated for the numeric data comparisons, due to differences in grid structures. A subjêctive criteria would at best involve the location of the wetting and transport fronts in the computed solutions.

From the graphics, the wetting fronts (Pressure $=0.0$ ) are usually within a one meter of each other vertically, and a few meters horizontally. They are much closer over most of their lengths. The few exceptions are likely to be regions where the pressure gradients are low, and small differences in pressure create large placement errors in the contour curves.

The transport fronts were examined by looking at the $C=0.2$ and $C=0.75$ contours. Higher and lower values tend to be in low gradient regions, where the small differences in concentration lead to larger errors in the placement of contour curves. As before, these curves are usually within one meter vertically, a few meters horizontally, and generally much better. The main exceptions are at early times, where:

a) The front has recently passed the interface between the crib and the sandy soil.

b) The front is approaching the partial sandy gravel layer (zone 3 ).

Since the contaminant transport properties are uniform, these discrepancies are probably due to differences in the flow fields. Again, this may result from the averaging of hydraulic properties at the boundaries of a thin layer. Once the front passes through a thin layer, the comparison is fairly good (which may be indicative of a good averaging scheme).

By the chosen criteria, the comparison of PORFLO-3 and VAM3D-CG is fairly good. Results from either model should be reasonably accurate. The major differences found between PORFLO-3 and VAM3D-CG are:

1) PORFL0-3 appears to move low leveis of material (fluid and contaminants) through the domain slightly faster than VAM3D-CG. This may be due to minor numeric diffusion inherent to that model.

2) VAM30-CG does not compute entirely stable contaminant concentrations at the Tower concentration values. This is typical of finite element models, especially when the element resolution is marginal. 
3). In this problem, a narrow material zone (zone 3) caused a temporary difference in the transport rates across that zone, when concentrations were low. This difference disappeared at later times, when concentration values increased. This may result from differences in the modeling of the interface between elements (cells).

4) The peak pressures computed by VAM3D-CG were higher than those computed by PORFLO-3. This may be due to large pressure gradients crossing a narrow zone (zone 1), and the treatment of the boundary between two zones of highly differing material properties. This is a localized problem, and the overall transport across the domain does not appear to be significantly affected.

Items 1 through 3 may be important if the first arriva $\overline{7}$ of a contaminant must be determined. For very small concentration values, PORFLO-3 reports faster arrival times. Although VAM3D-CG computes slower arrival times, it does not give stable concentration values.

Items 3 and 4 are significant when a model employs thin layers of materials, and adjacent zones have large differences in properties. Each zone in a grid must have enough cells (elements) to model the expected behavior. In particular, PORFLO-3 averages at material boundaries must not be allowed to affect the overall performance of the model. One should probably avoid using data (e.g., fluxes) near such a boundary, especially at early times.

All of these discrepancies are minor, and may result from using slightly under-resolved computational grids. However, both codes tend to be run in that mode, since they execute significantly faster with fewer nodes. 
FIGURE 6.1 IDEALIZED LONGITUDINAL CROSS-SECTION OF STRATIGRAPHY UNDER THE 216-U-17 CRIB.

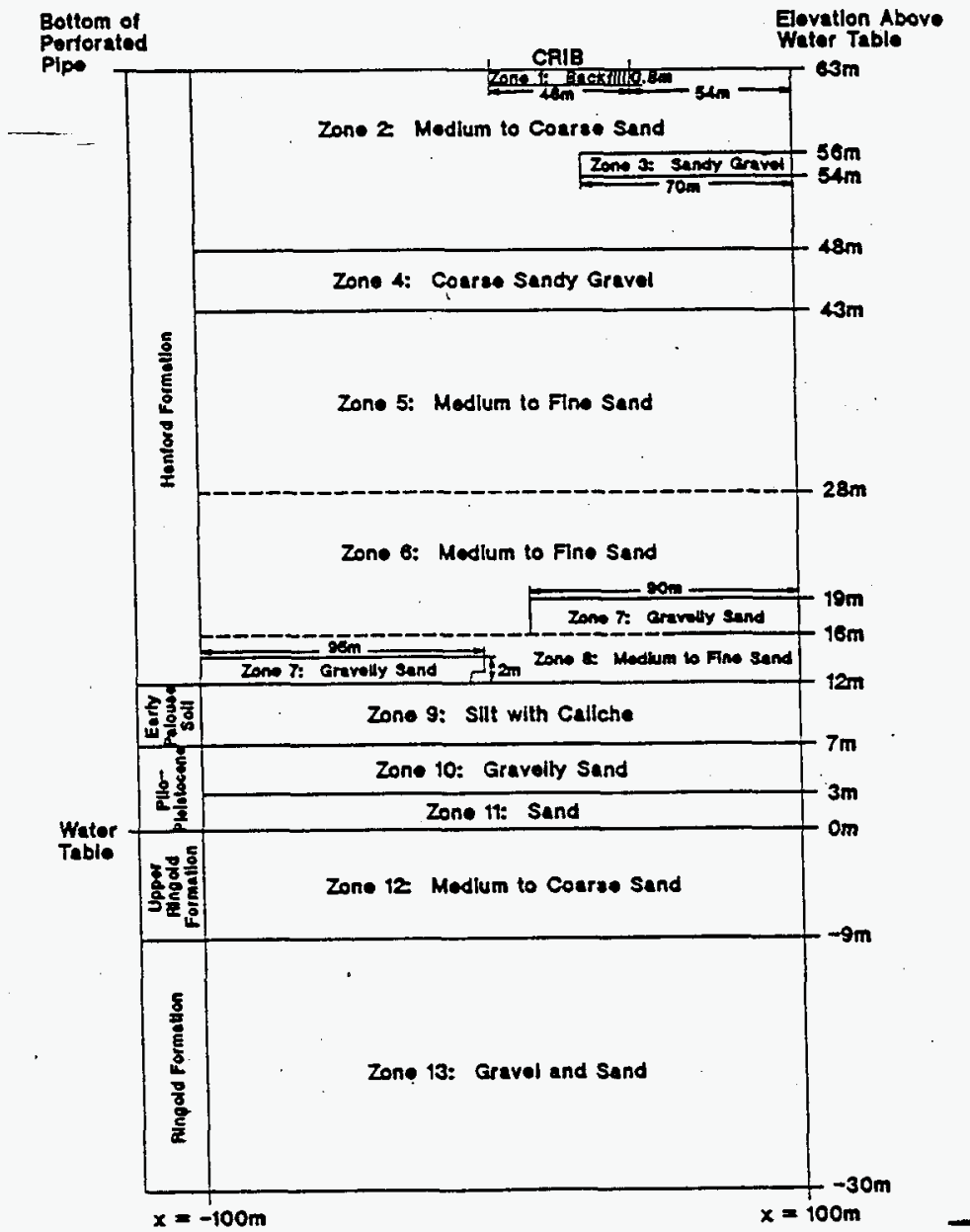




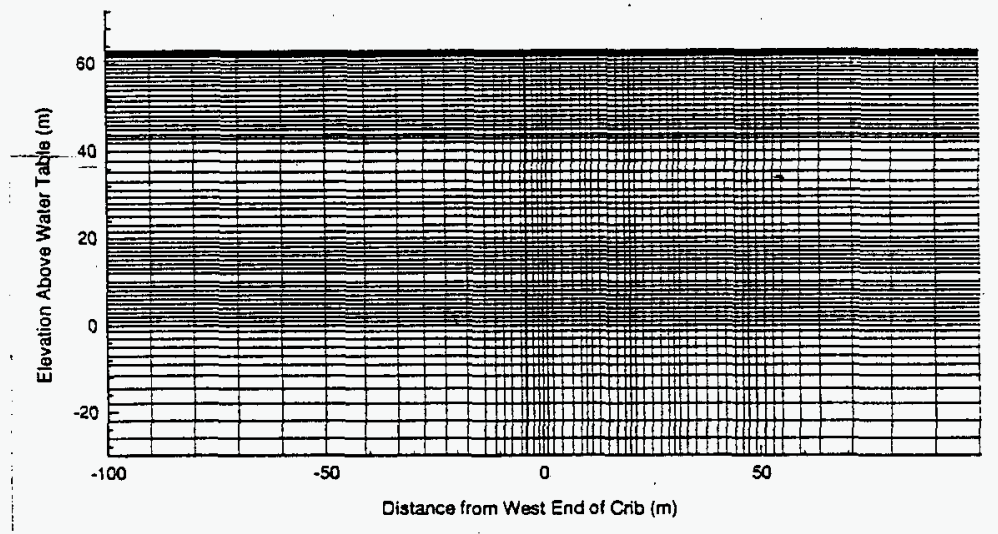

Fig. 6.2

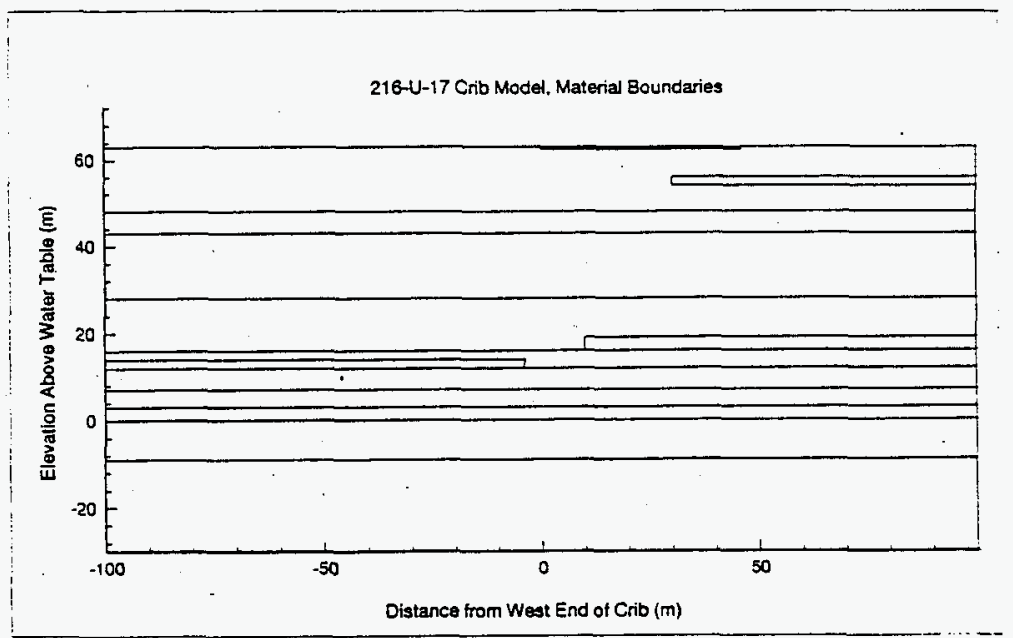

Fig. 6.3 


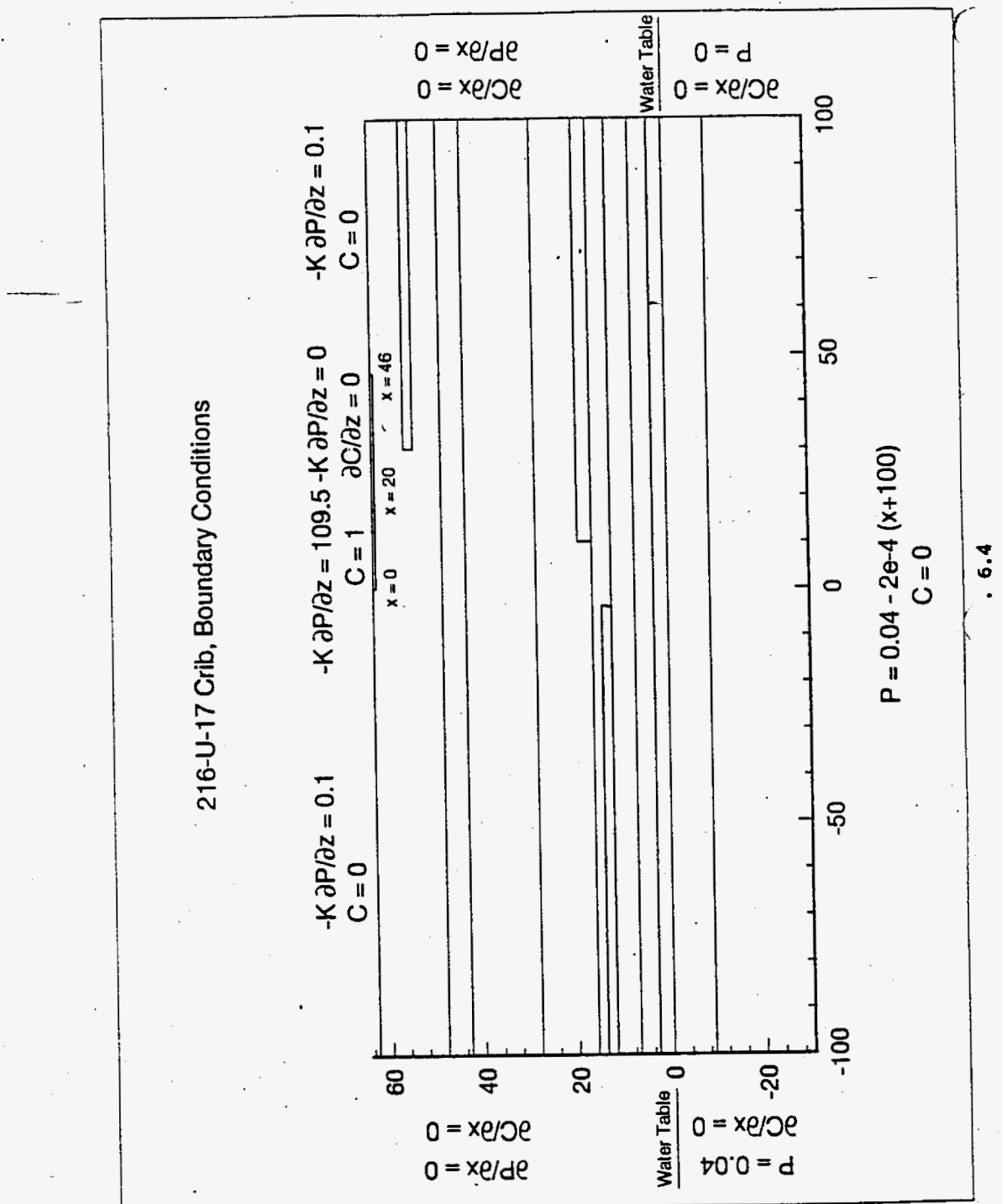


WHC-SD-TI-730

WHC-SO-WM-TI-730, Rev. O

WAC-SD-ER-CSND-O05

Rev. 0

Figure 6.5

216U-17 Crib, PORFLO-3. Pressute at $0.0 \mathrm{yr}$

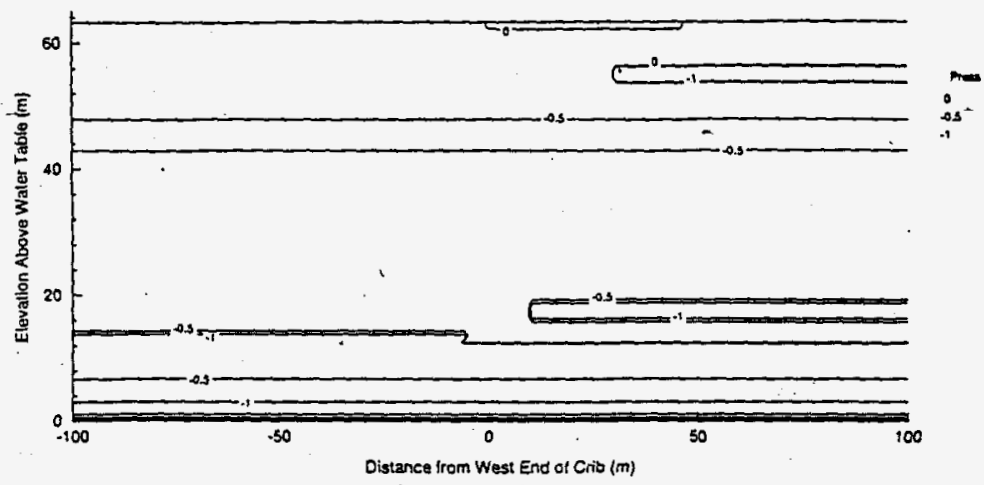

2i6-U-17 Crib, VANBOCG. Pressure at $0.0 \mathrm{y}$

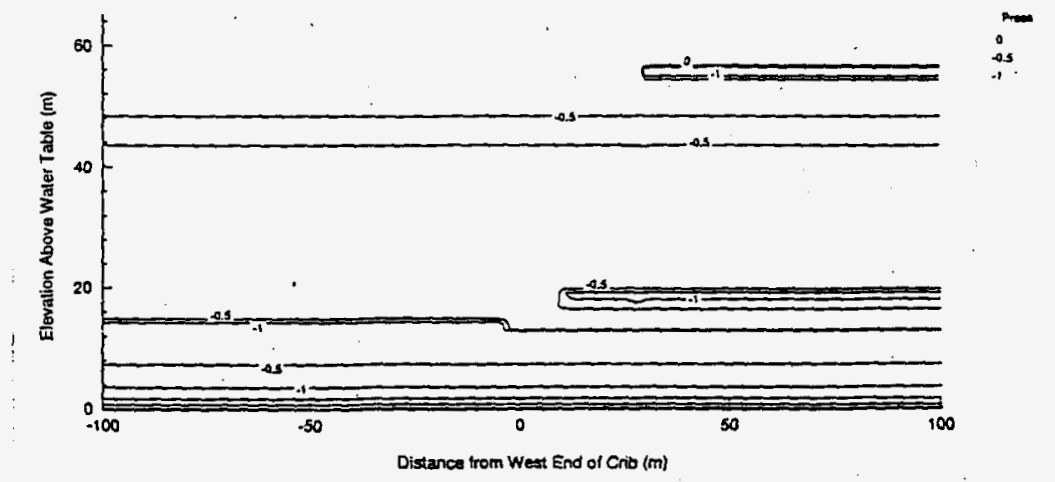




$$
\text { WHC-SD-TI-730 WHC-SD-WM-TI-730, Rev. } 0
$$

WAC-SD-ER-CSND-COS

Rev. 0

Figure 6.6

216-U-17 Crib, PORFLO-3, Preseure at $1.0 \mathrm{yr}$

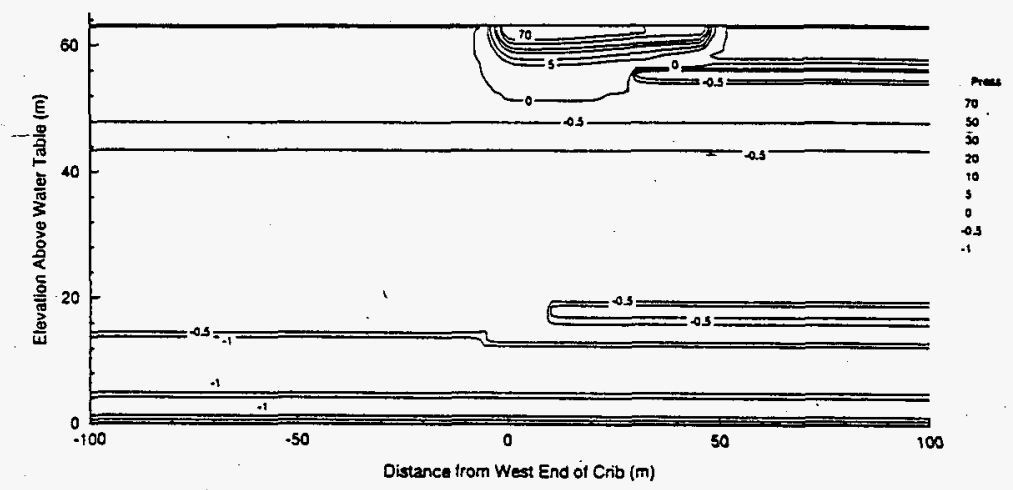

216-U-17 Crib, VAMBOCG, Pressure at $0.99 \mathrm{yr}$

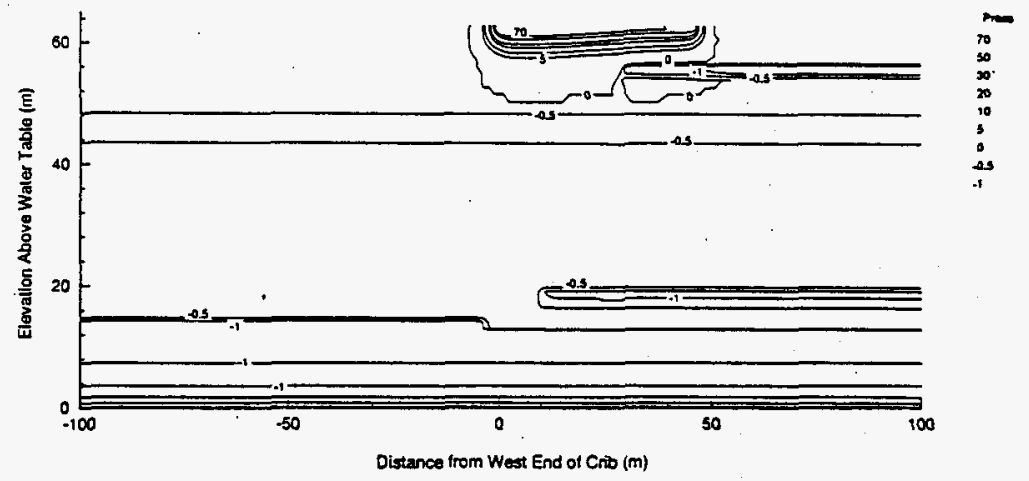


WHC-SD-TI-730 WHC-SD-WM-TI-730, Rev. 0

WAC-SD-ER-CSAD-005

Rev. O

Figure 6.7

216-U.17 Crib, PORFLO-3. Pressute at $3.0 \mathrm{yr}$

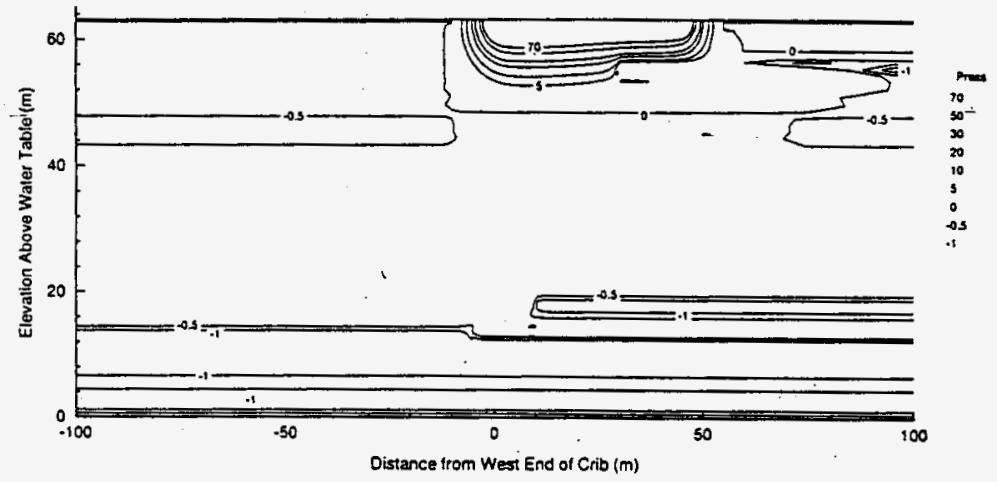

216-U-17 Crib. VAMzOCG. Pressura at 3.05 yt

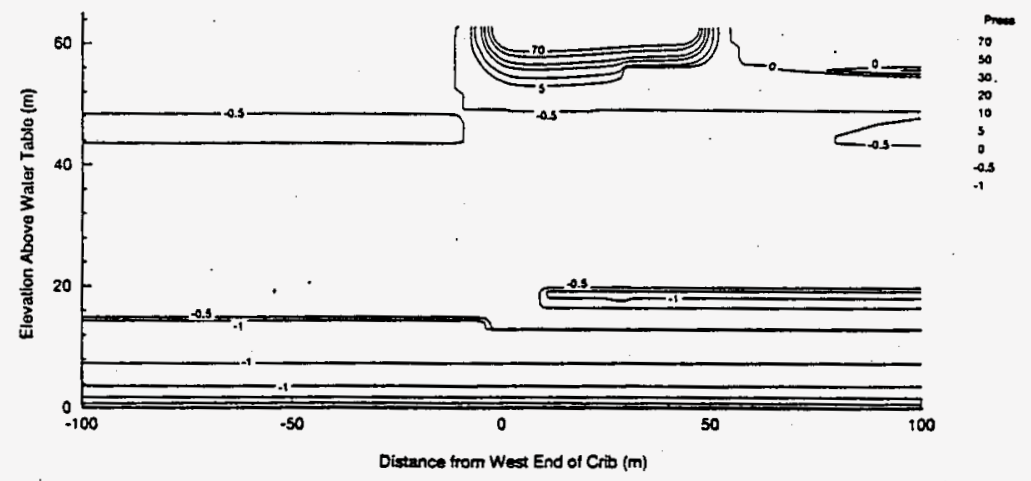


WHC-SD-TI-730 WHC-SD-WM-TI-730, Rev. 0

WBC-SD-ER-CSAD-DO5

Rev. 0

Figure 6.8

215-U-i7 Crib. POAFLO-3, Pressure at 5.0 yr

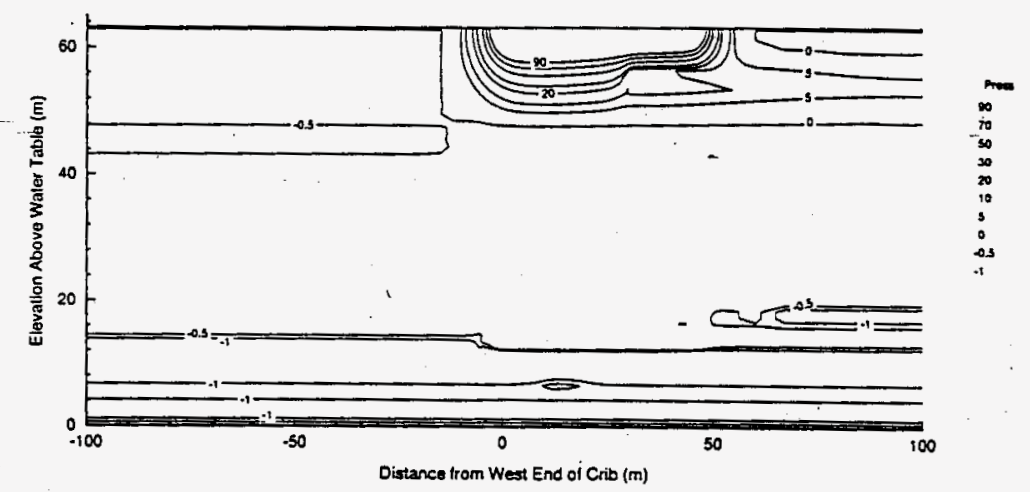

216-U17 Crib. VAM3DCG, Pressure at 5.12 yr

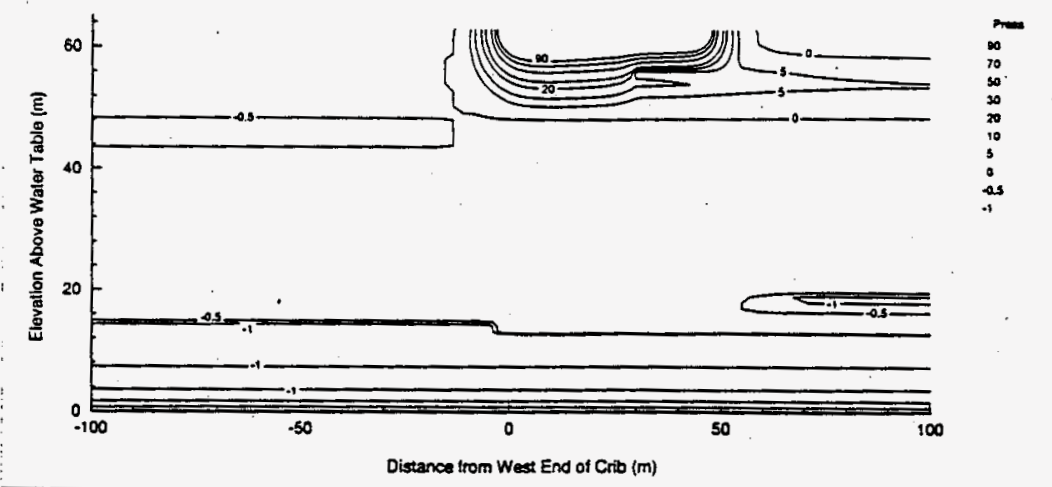


WHC-SD-TI-730 WHC-SD-WM-TI-730, Rev. 0

WAC-SD-ER-CSND-005

Rev. O

Eigure 6.9

216-U-17 Crib, PORFLO-3, Saturation at $5.0 \mathrm{yr}$

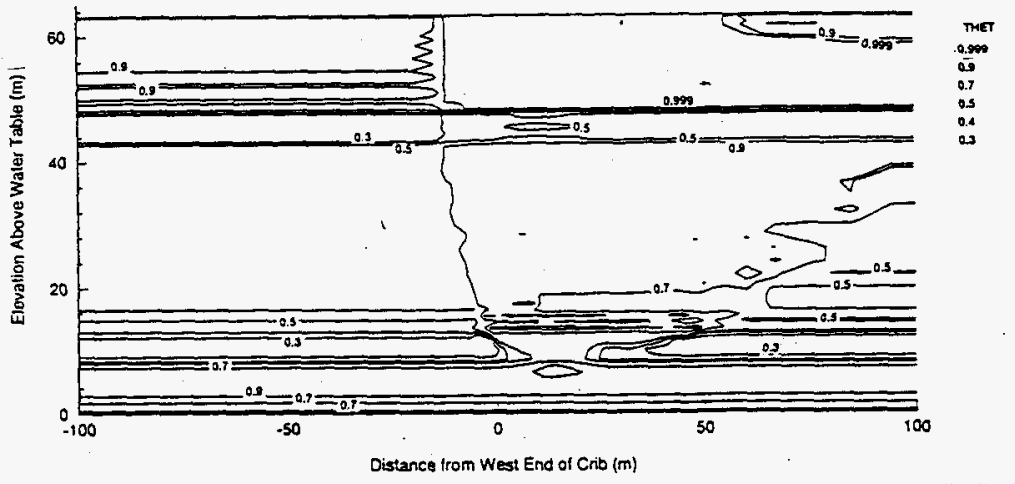

216-U-17 Crib, VAM3DCG, Saturation at 5.12 yr

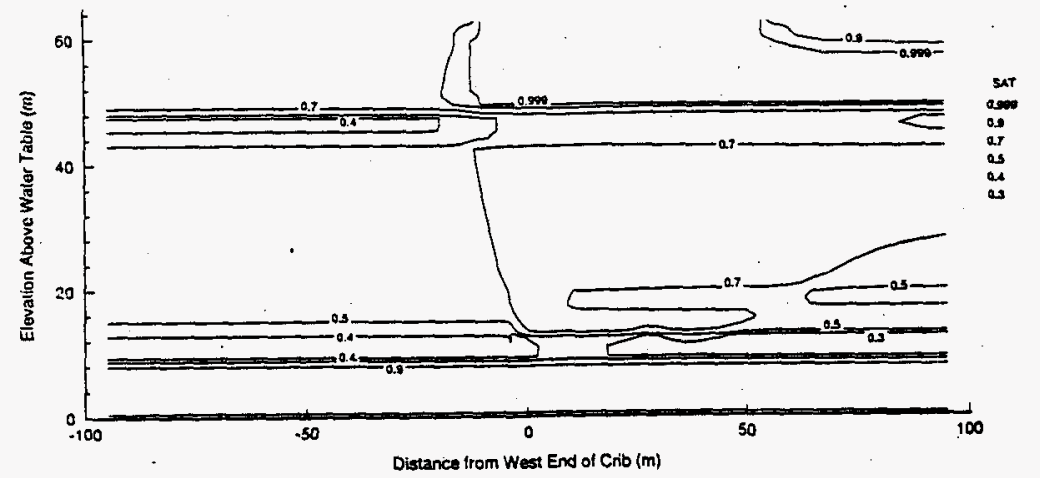


WHC-SD-TI-730

WHC-SO-WM-TI-730, Rev. 0

WAC-SD-ER-CSND-DO5

Rev. 0

Figure 6.10

216-U17 Crib. PORFLO-3, Concentration at $1.0 \mathrm{yr}$

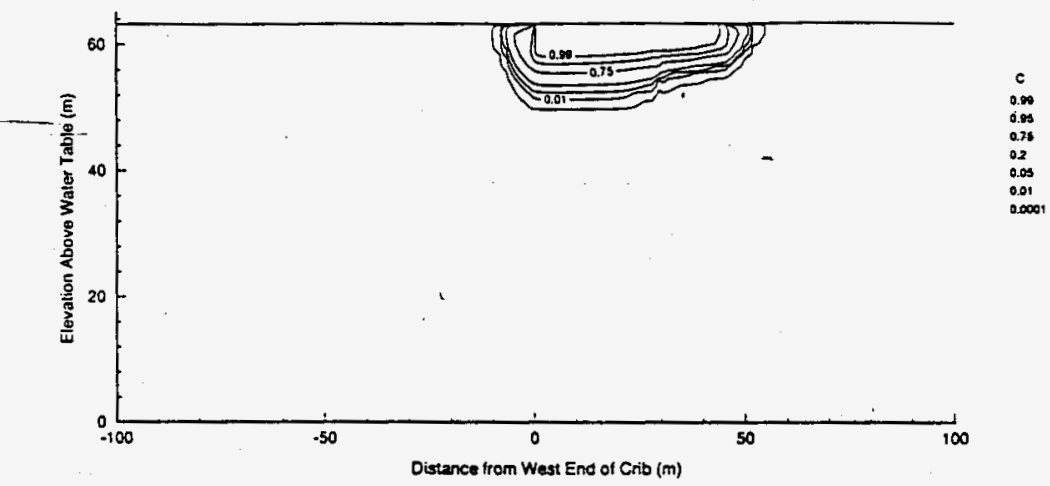

216-U17 Crib, VAM3DCG. Concentration at $0.99 \mathrm{yr}$

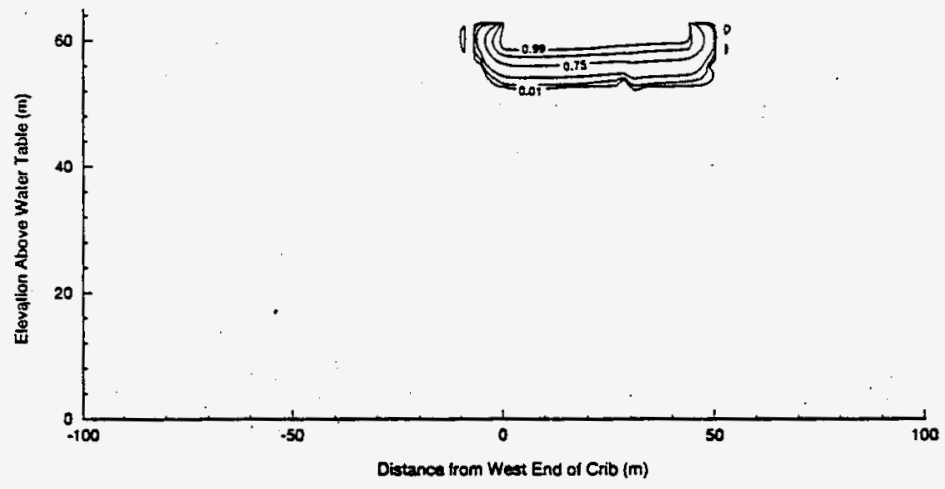


WHC-SO-TI-730 WHC-SD-WM-TI-730, Rev. 0

WEC-SD-ER-CSAD-OO5

Rev. 0

Figure 6.11

216-U-17 Crib, PORFLO-3, Concentration at $3.0 \mathrm{yr}$

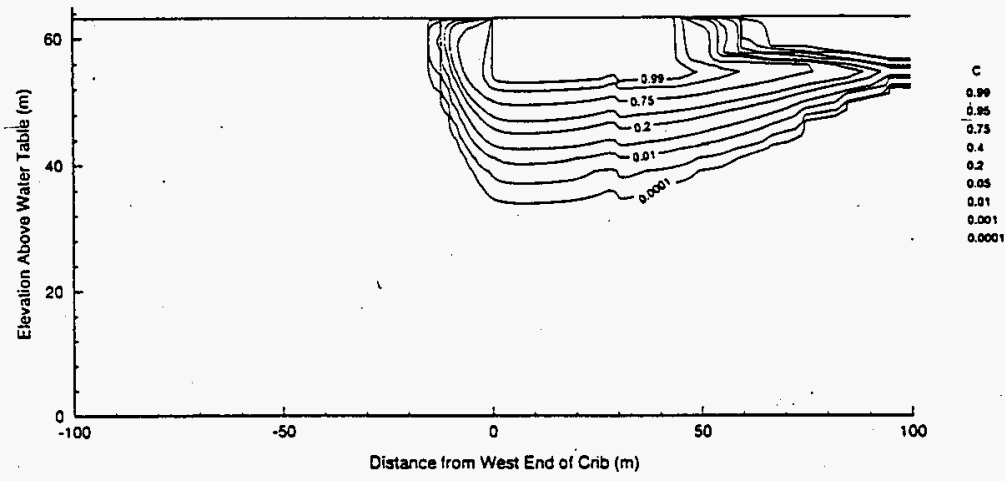

216-U-17 Crib, VAM3DCG, Concentration at $3.05 \mathrm{yr}$

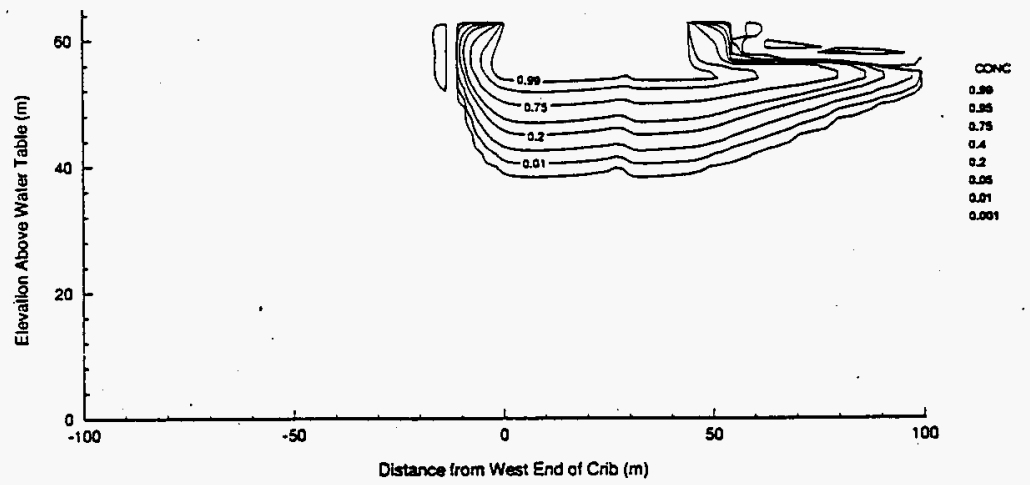


Figure 6.12

216-U17 Crib, POAFLO-3, Concentration at $5.0 \mathrm{yr}$

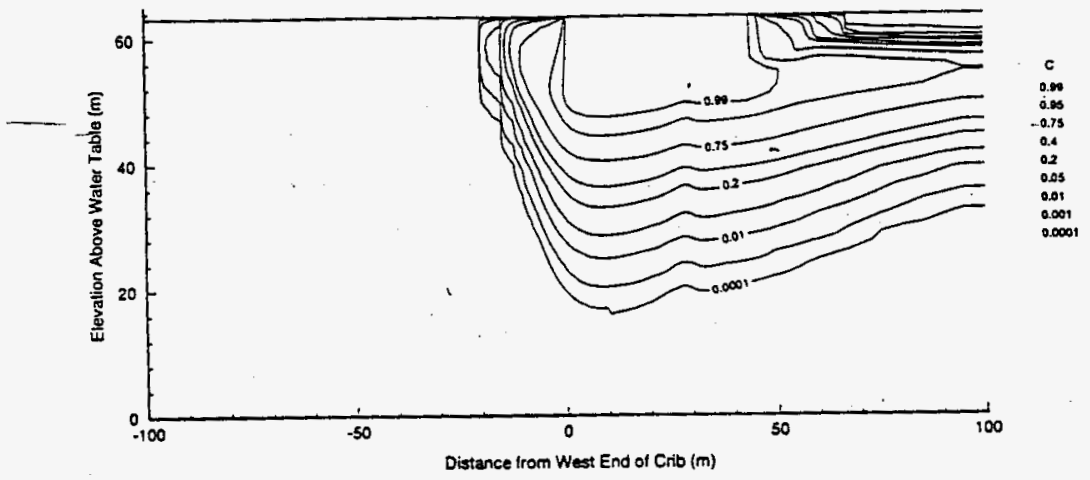

216-U-17 Crib, VAM3DCG, Concentration at 5.12 yt

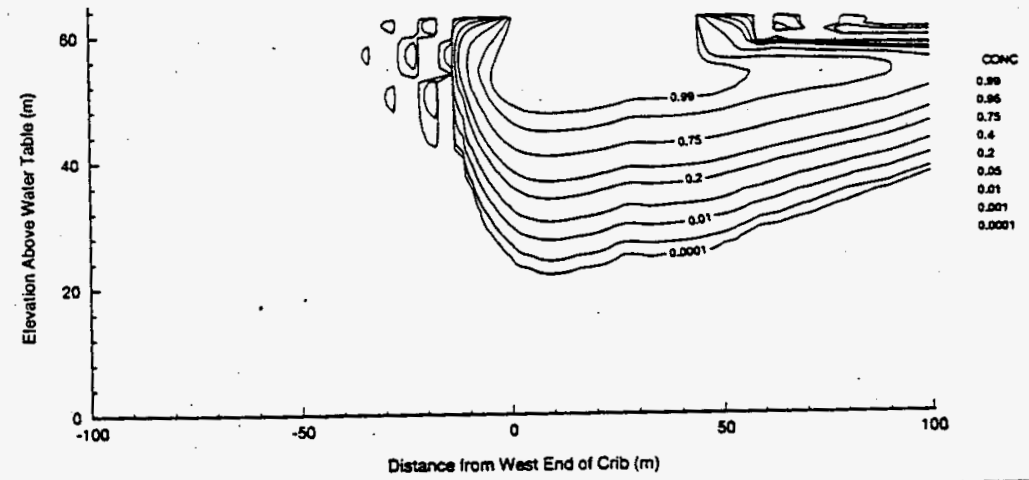




\subsection{BENCHMARK TESTS: FLOW AROUND A CLAY CAP}

\subsection{OVERVIEW}

This problem models unsaturated fluid flow through and around a sloping clay layer, that is embedded within a coarse sandy material. This is part of the cover required by the Resource and Conservation Recovery Act (RCRA) for hazardous waste landfills in Title 40 of the Code of Federal Requiations (40 CFR).

The model has previously been executed by PORFLOW (Version 2.394) for benchmarking against other codes (e.g., TRACR3D). Those results have been pubTi-shed (Kincaid et. al., 1993). In the present effort, the VAM3D-CG output is compared against results from PORFLO-3, Version 1.2.

\subsubsection{Problem Description}

Figure 7.1 shows the conceptual configuration of the moder. The domain is 36 meters wide and 6 meters deep, consisting of backfill soil. A sloping clay layer is embedded within the backfill, which is 28 meter long by 0.6 meter-thick.

Water enters the system along the upper boundary, with a recharge rate of $0.1 \mathrm{~cm} / \mathrm{yr}$. A no flow condition is enforced along the side boundaries, while the bottom boundary has a fixed pressure value. A steady state solution is sought for the problem. Both VAM3O-CG and PORFLO-3 were executed in a dynamic mode, allowing the solution to develop for 1000 years.

The lower boundary was set to a pressure head of -4.815 meters. This corresponds to a volumetric water content of 0.04058 in the backfill soil, and is consistent with a nominal flow rate of $0.1 \mathrm{~cm} / \mathrm{yr}$. The initial conditions are uniform water saturations of 0.265958 in the backfill (pressure $=-0.675$ ), and 0.9241 in the clay cap (pressure $=-8.9284$ ). The backfill is thus somewhat wetter than the steady state solution, while the clay is somewhat drier.

\subsubsection{Computational Grid}

The simulation was performed in two dimensions, using a vertical cross section. The problem was run three times; twice with VAM $30-C G$ and once with PORFLO-3. The first execution with VAM3D-CG used regular rectanguiar elements, with a stair stepping approximation to the clay cap. The second VAM $30-C G$ execution used curvilinear elements to portray the cap. PORFLO-3 is a finite difference model, and is restricted to a rectangular grid. 
The VAM3D-CG stair stepped model is shown in Figures 7.2 and 7.3. A total of 2160 elements and 4550 nodes are used. All elements in the grid were 0.4 meters wide. Above and below the layer containing the clay cap, the elements were 0.3 meters high. Within the horizontal layer containing the cap, each element was 0.2 meters high. The stair stepping is distinctly different than that used by the PORFLO-3 model. This should provide insight into the relative errors expected in the 'stepped' region, due to the steps.

The curvilinear grid for the second execution used 1137 elements and 2442 nodes. Fifteen "pinch nodes" were used to reduce the grid resolution where possible. Curvilinear elements were constructed to model the clay layer as a slanting structure in the domain, rather than as stair stepped. The results of this model were generally in agreement with the orthogonal grid model, but showed some non-physical perturbations. These may have been due to input errors, VAM $3 D-C G$ errors, and/or post-processing errors. Since the error(s) involved could not be traced, those results are not presented here.

The PORFLO-3 grid was a uniform and rectangular array of 6072 grid cells $(92 \times 3 \times 22,1800$ computational cells). Each cell was 0.4 meters wide $(\Delta x)$ by 0.3 meters high $(\Delta z)$. The model depth $(\Delta y)$ was one meter.

\subsubsection{Material Properties}

Material properties are shown in Table 7.1. A van Genuchten model for unsaturated flow was implemented. The van Genuchten gamma was set to the default value of $(1-1 / B)$. Hydraulic conductivities were taken as isotropic.

Table 7.2 indicates the pressure heads, moisture content, and total hydraulic conductivities corresponding to the initial saturation values, for the specified material properties.

Table 7.1: Material Properties for the Clay Cap Model

\begin{tabular}{|c|c|c|c|c|c|c|}
\hline Material & $\begin{array}{c}\text { Specific } \\
\text { Storage }\end{array}$ & $\begin{array}{c}\text { alpha } \\
(1 / \mathrm{m})\end{array}$ & beta & $\begin{array}{c}\text { Sat Hyd K } \\
(\mathrm{m} / \mathrm{yr})\end{array}$ & $\begin{array}{c}\text { Resid. } \\
\text { Sat }\end{array}$ & Porosity \\
\hline Backfill & $1.0 \mathrm{E}-5$ & 8.6 & 1.742 & 9467. & 0.018 & 0.376 \\
\hline Clay & $1.0 \mathrm{E}-5$ & 0.054 & 1.324 & 0.002966 & 0.00 & 0.448 \\
\hline
\end{tabular}

Table 7.2: Initial Conditions for the Clay Cap Model

\begin{tabular}{||c|c|c|c|c|}
\hline Material & $\begin{array}{c}\text { Moisture } \\
\text { Content }\end{array}$ & $\begin{array}{c}\text { Total Hyd K } \\
(\mathrm{m} / \mathrm{yr})\end{array}$ & $\begin{array}{l}\text { Capillary } \\
\text { Pressure } \\
(\mathrm{m})\end{array}$ & Saturation \\
\hline Backfill & 0.132129 & 1.81097 & -0.675000 & 0.265958 \\
\hline Clay & 0.413997 & $2.08506 E-4$ & -8.92876 & 0.924100 \\
\hline
\end{tabular}




\subsection{EXECUTION OF THE MODELS}

VAM3D-CG was executed using the pressure formulation of the flow equations. The storage term was computed directly as the time derivative of the saturation. Full three dimensional modeling and finite element connectivity were used.

PORFL0-3 generated hydraulic heads as the output variable. These were converted to pressure heads for the comparison between the models.

Both PORFLO-3 and VAM3D-CG were run for 1000 years. Both models required very small initial time steps, on the order of $1.0 \mathrm{E}-5$. Both models also developed convergence difficulties at later times, between 0.1 and 5.0 years. The plotted pressure heads at 1000 years indicate that a steady state solution has not quite been reached.

The rectangular VAM30-CG model required just over $5000 \mathrm{cpu}$ seconds to execute 321 time steps. The curvilinear grid reduced this to roughly $1500 \mathrm{cpu}$ seconds for 285 steps, although the savings does not offset the extra analyst time required to build the input data set. PORFL0-3 required 467 cpu seconds for 224 time steps. No attempt was made to optimize the time stepping for each model. The VAM3D-CG output file indicates much larger time steps could be taken after the initial instabilities were past.

\subsection{COMPARISON OF PORFLO-3 AND VAMBO-CG CONTOUR PLOTS}

Contour plots of the VAM3D-CG and PORFLO-3 pressure head results are shown in Figure 7.4. Similar plots for saturation are given in Figure 7.5.

The pressure heads displayed in Figure 7.4 show relatively good agreement. Different stair stepping schemes were used to represent the sloped clay cap layer in each model. This is particularly noticeable at the $\psi=-4.2$ meter contour level above the clay layer. While the pressure contours do follow each other relatively well, one must be cautious when using a stair stepped model, as pressure values near the steps can be locally inaccurate.

The PORFLO-3 domain remains slightly drier than the VAM3D-CG domain. This difference is not serjous, but is noticeable when the plots are laid over each other. Contour plotting does tend to exaggerate the differences between data sets, especially when the gradients are small. The likely cause of the difference is the nodal averaging schemes at the boundaries between material types. PORFLO-3 uses a harmonic mean hydraulic conductivity, while the finite element model VAMBD-CG need not compute such averages.

The saturation curves are shown in Figure 7.5. These curves are not very useful, since the steady state saturations in the each material are determined largely by the boundary conditions. The curves follow the material boundaries; the porous backfill is relatively dry, while the clay is relatively wet. 
Rev. 0

\subsection{CONCLUSIONS}

This problem models the steady state response of a single, low conductivity layer embedded within a higher conductivity material. The saturated conductivities of the two materials differ by roughiy six orders of magnitude. However, both models compute substantially identical results.

The primary differences in the results from the two models include:

1) The PORFLO-3 domain remains slightly drier than the VAM3D-CG domain, as shown by the plots. This is probably due to the conductivity averaging scheme used by PORFLO-3 at material boundary interfaces. The PORFLO-3 grid resolution may be marginal, as in many places the clay layer is only two cells wide.

2) The differences in the stair stepping produce local difference in the head values. The stair stepping scheme produces inaccurate heads near the material boundary, which must be considered if flow or heads in that region are important to the overall model.

3) The transients below the 'clay layer are not necessarily reproducible between models. Since the unsaturated flow equation is non-linear, some solutions will produce "chaotic" behavior.

These differences are very minor. Overall, VAM3D-CG compares quite favorably with PORFLO-3. 


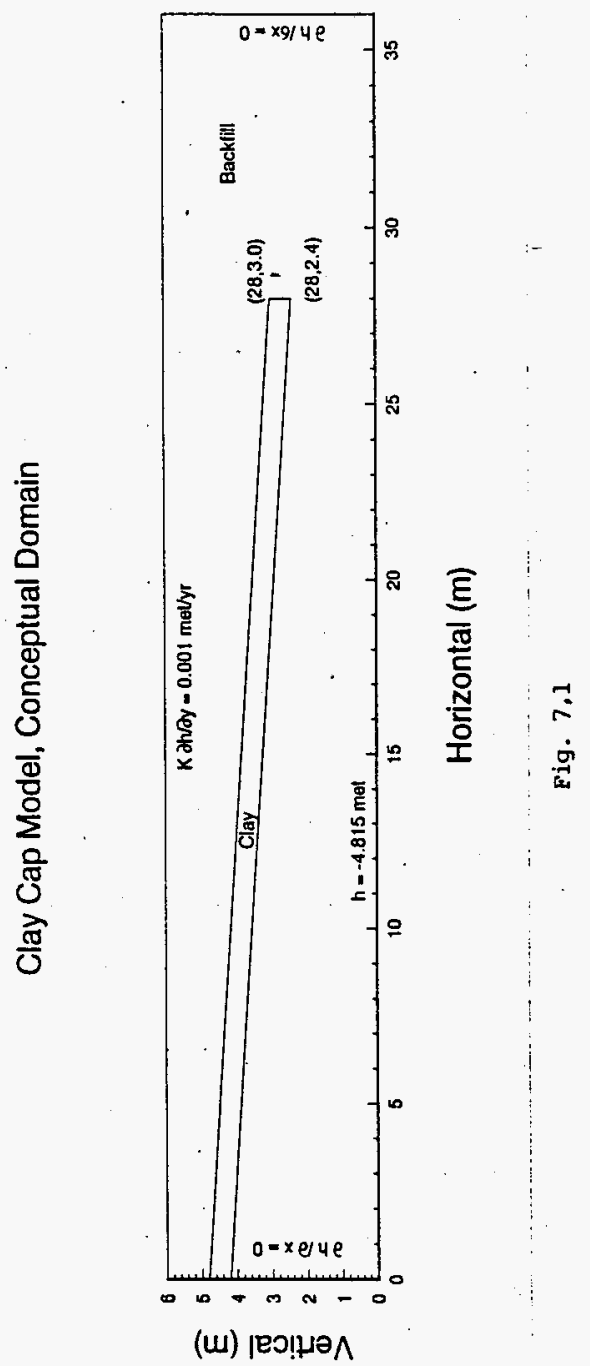



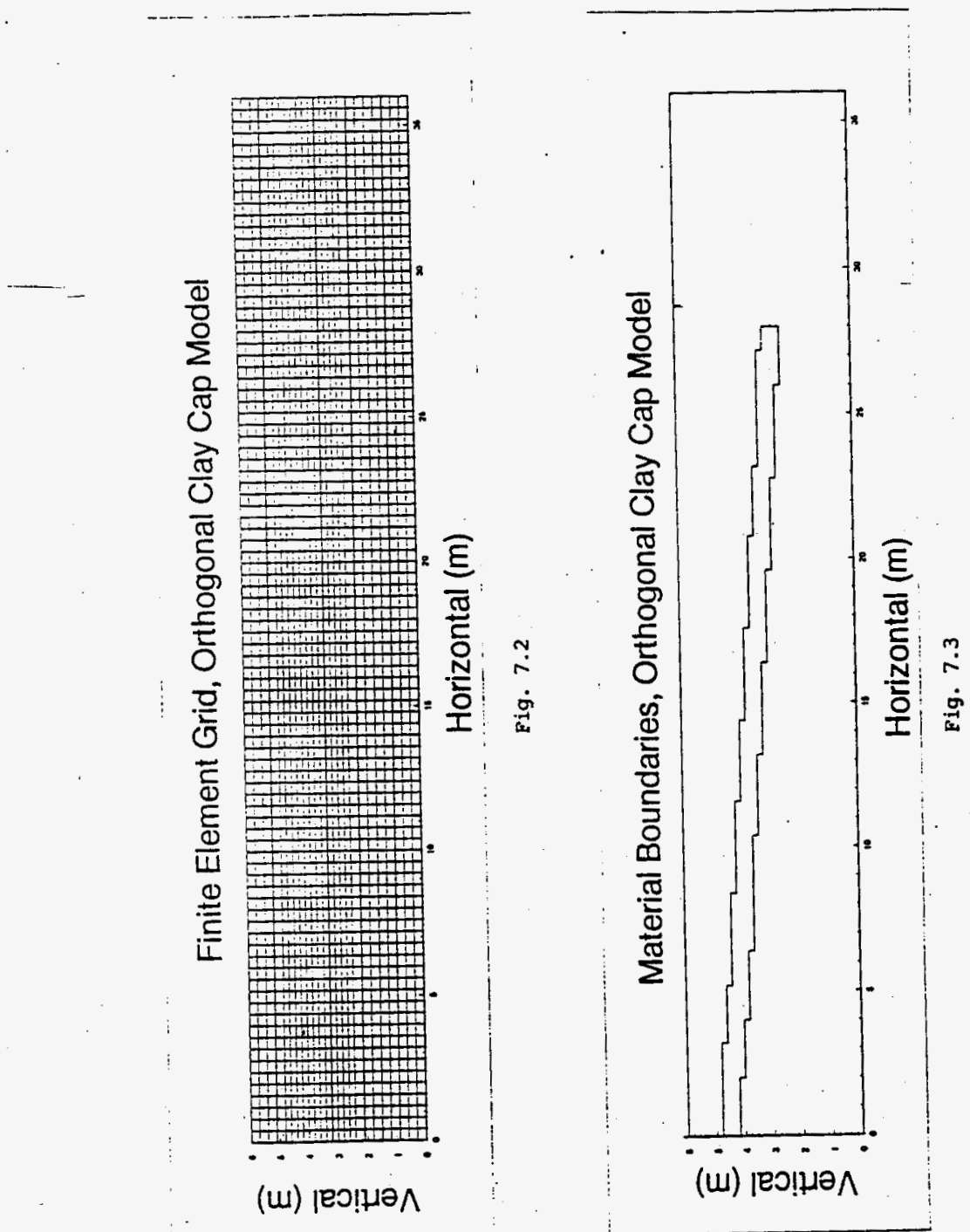
WHC-SD-TI-730

WHC-SD-WM-TI-730, Rev. 0

WEC-SD-ER-CSND-005

Rev, 0

Figure 7.4
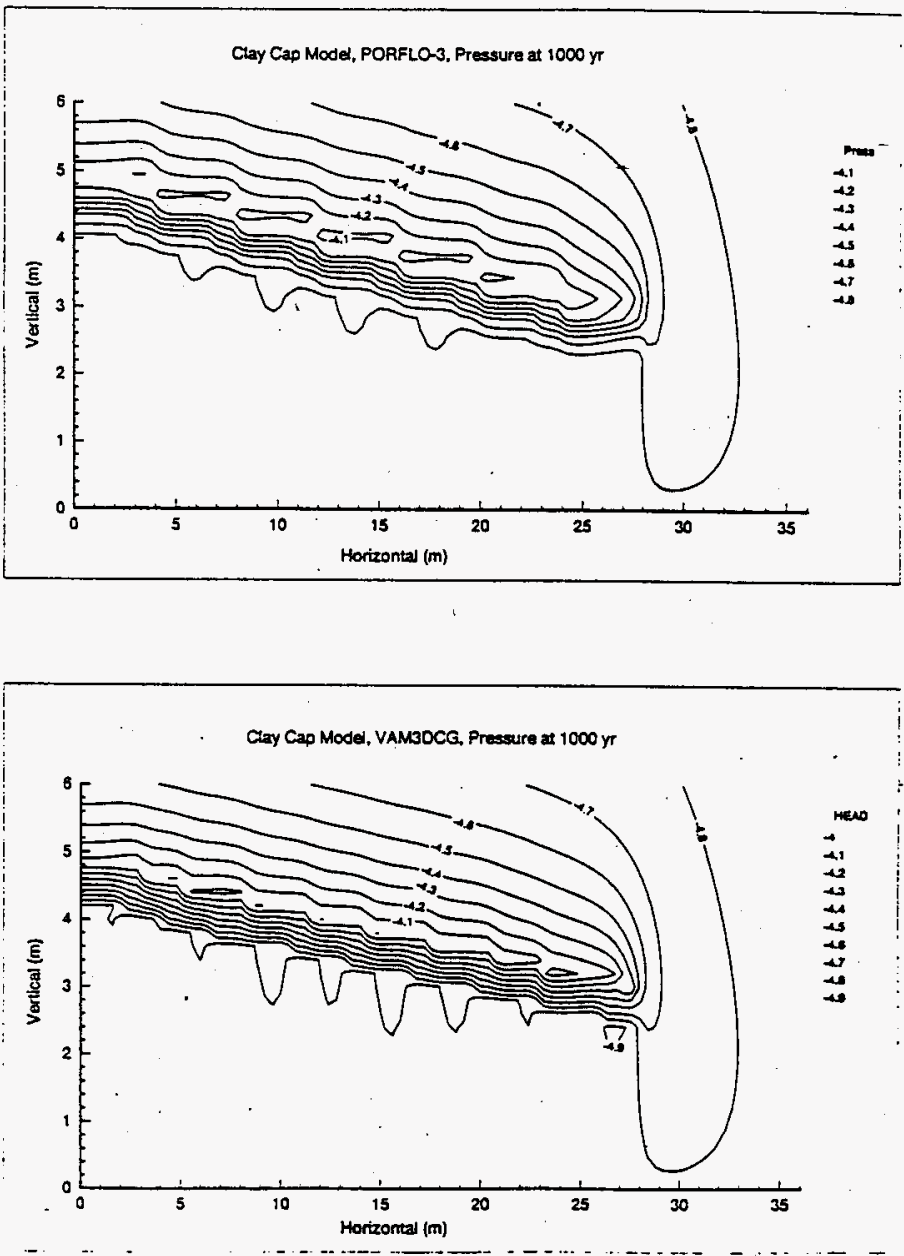

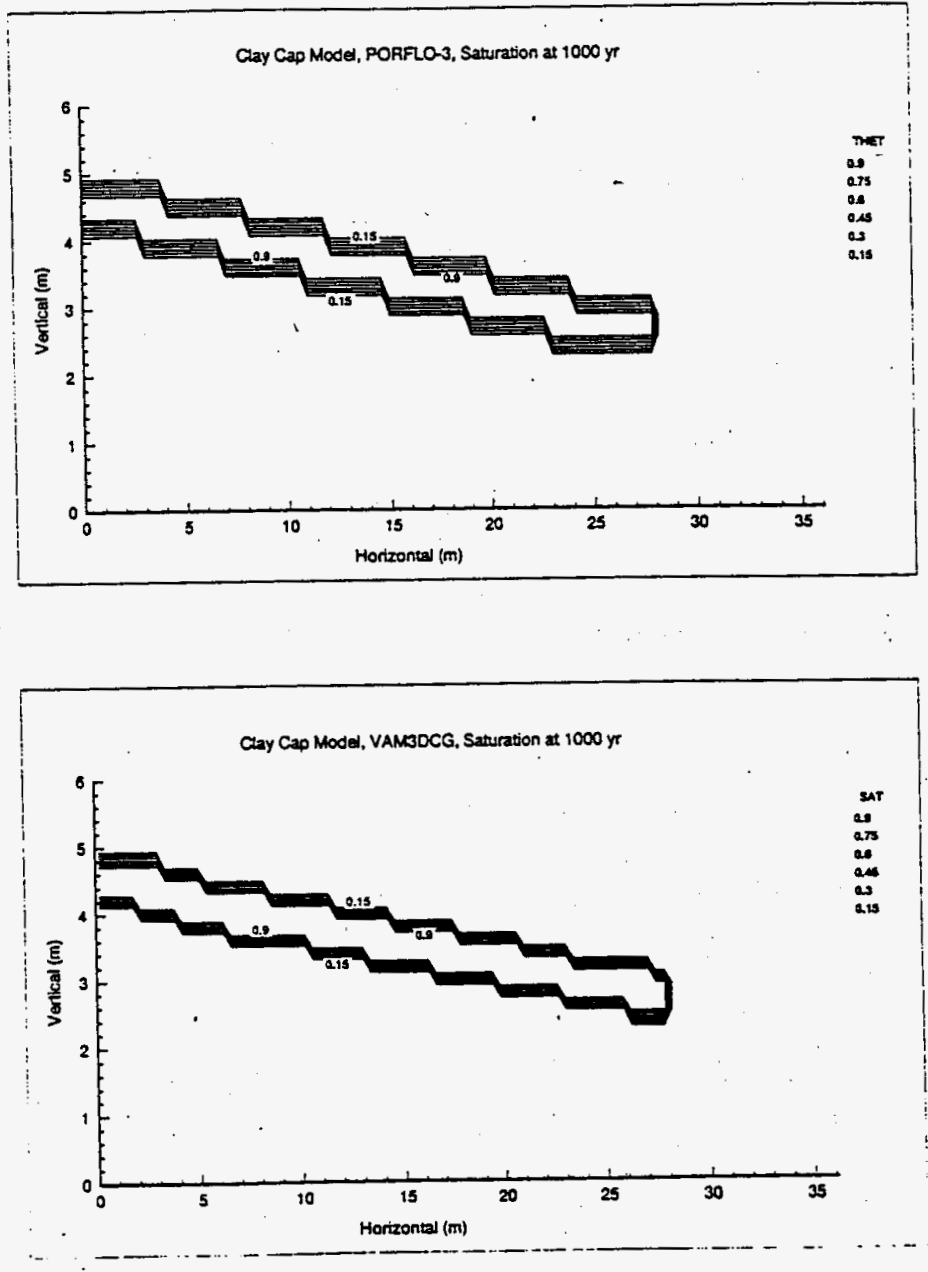


\subsection{VERIFICATION OF THE VAM3D-CG SOURCE CODE AS IMSTALLED ON THE SGI}

\subsection{OVERVIEW}

The newly received Version 2.4b of the VAM3D-CG on the SGI is compared with the previous version on the Cray. Three test cases are included. These cases were originally part of analyses (Run numbers 2 and $2 c$ ) performed for "Performance Assessment for the Disposal of LoW-level Waste in the 218-W-5 Burial Ground (Wood et al., 1993)". The first case is a steady-state flow run. The second case is the corresponding transport run. The third case is a continued run of case 2 after the source term was completely depleted from the -trench.

\subsection{TEST CASE ID: v3d7 (RUN \# 2 IN THE REFERENCED DOCUMENT)}

\section{Problem Description}

Conceptualiy, this problem was a steady infiltration of $0.5 \mathrm{~cm} / \mathrm{yr}$ of recharge water into a $160-m$ thick, saturated-unsaturated soil column. A five layer stratigraphy representing the vadose zone and the unconfined aquifer beneath the W-5 burial ground was modeled. The model layout used the geologic information gathered from borehole 299-W7-9. As shown in Figure 8.1, a rectangular soil slab with an open trench on the top is selected for simulation.

A total of four moisture characteristic curves (see Table 8.1) representing four upper units (Hanford, Early Palouse, Plio-Pleistocene, and Upper-Ringold) were selected for the model simulations. The laboratorymeasured moisture retention data and unsaturated hydraulic conductivity were fitted simultaneousiy with the van Genuchten-Mualem equation using the computer code RETC. The four formation types, Hanford, Early Palouse, PlioPleistocene, and Upper-Ringold are referred to as material types $1,2,3$, and 4 , respectively (Table 8.1 ). Since no samples were available in the middle Ringold unit, material type 5 is the same as material type 4. 
Table 8.1 Hydraulic Characteristics

\begin{tabular}{|l|l|l|l|l|l|l|l|l|}
\hline \begin{tabular}{|l|l|l|l|l|} 
Sample \\
$\#$
\end{tabular} & $\begin{array}{l}\text { Formation } \\
\text { Type } \\
\text { (Mat.\#) }\end{array}$ & $\begin{array}{l}\text { Depth } \\
(\mathrm{m})\end{array}$ & $\theta_{s}$ & $\theta_{r}$ & $\begin{array}{c}\alpha \\
(1 / \mathrm{m})\end{array}$ & $B$ & $\begin{array}{c}K_{\mathrm{s}} \\
(\mathrm{m} / \mathrm{yr})\end{array}$ & $\begin{array}{l}\rho_{\mathrm{b}} \\
(\mathrm{g} / \\
\mathrm{cm}^{\prime}\end{array}$ \\
\hline $0-069$ & $\begin{array}{l}\text { Hanford } \\
(1)\end{array}$ & 3.05 & 0.301 & 0.000 & 9.45 & 1.2515 & 6496.4 & 2.29 \\
\hline $0-072$ & $\begin{array}{l}\text { E.P } \\
(2)\end{array}$ & 19.82 & 0.391 & 0.056 & 0.90 & 2.0877 & 517.12 & 1.81 \\
\hline $0-082$ & $\begin{array}{l}\text { Plio } \\
(3)\end{array}$ & 24.70 & 0.455 & 0.127 & 4.86 & 1.3520 & 1892.2 & 1.43 \\
\hline $0-107$ & $\begin{array}{l}\text { U.R. } \\
(4)\end{array}$ & 40.40 & 0.317 & 0.025 & 9.16 & -1.807 & 5203.4 & 1.59 \\
\hline
\end{tabular}

where $\alpha$ and $B$ are van Genuchten parameters, $\theta_{s}$ and $\theta_{r}$ are the saturated and residual moisture contents, respectively, and $\rho_{\mathrm{b}}$ is the soil bulk density.

2. File Differences:

\begin{tabular}{||l|l|l|l|}
\hline Time (year) & $\begin{array}{l}\text { Range of Variable } \\
\text { Pressure Head (m) }\end{array}$ & $\begin{array}{l}\text { Max Difference } \\
(\mathrm{m})\end{array}$ & RRMS \\
\hline Steady state & $-8.533--86.70$ & $-1.192 \mathrm{e}-7$ & $4.419 \mathrm{e}-9$ \\
\hline
\end{tabular}

\subsection{TEST CASE ID: v3dt7cp (RUN \# 2C IN REFERENCED DOCUMENT)}

- 1. .. Problem Description.

The purpose of this problem concerns the transport of a nonconservative contaminant with $K_{d}=10$. A transient-flux boundary condition was imposed at the bottom of the trench. The flux was chosen to reflect a $0.5 \mathrm{~cm} / \mathrm{yr}$ infiltration rate with moderate dispersion. The model uses the flow field from probiem v3d7. Six hundred time steps $(0.5 \mathrm{yr})$, from zero to 300 years were taken. A longitudinal dispersivity of $1.0 \mathrm{~m}$, a transverse (lateral) dispersivity of $0,1 \mathrm{~m}$ and an effective molecular diffusion coefficient of $2.95 \times 10^{-7} \mathrm{~cm}^{2} / \mathrm{sec}\left(9.30 \times 10^{-4} \mathrm{~m}^{2} / \mathrm{yr}\right)$ were used in the simulations. 
2. File Differences:

\begin{tabular}{|l|l|l|l|}
\hline Time (year) & $\begin{array}{l}\text { Range of variable } \\
\text { Conc. }\left(\mathrm{C} i / \mathrm{m}^{3}\right)\end{array}$ & $\begin{array}{l}\text { Max Difference } \\
\text { Conc. }\left(\mathrm{Ci} / \mathrm{m}^{3}\right)\end{array}$ & RRMS \\
\hline 30.0 & $1.46 \mathrm{e}-6--1.46 \mathrm{e}-3$ & $-1.323 \mathrm{e}-23$ & 0.0 \\
\hline 150.0 & $4.99 \mathrm{e}-6-4.99 \mathrm{e}-3$ & $-1.694 \mathrm{e}-21$ & 0.0 \\
\hline 300.0 & $4.39 \mathrm{e}-6--4.39 \mathrm{e}-3$ & $-2.220 \mathrm{e}-16$ & 0.0 \\
\hline
\end{tabular}

Comments: RRMS values use a threshold of 1.0e-3 times max value (data points below this limit are not compared).

\subsection{TEST CASE ID: $v 3 \mathrm{~d} 7 \mathrm{C}$ (CONT. OF RUN \# 2c)}

\section{Problem Description}

Since the contaminants have' a long resident time in the unsaturated and saturated zones due to a high $K_{d}$ value, the model uses the final results from problem v3dt7cp as the initial conditions and continues the simulation. The model simulates transport from 300 to 800,300 years. The model uses flow field from problem $v 3 d 7$ and the final results from problem v3dt7cp as initial conditions. 800 time steps $(0.5 \mathrm{yr})$ were taken.

\section{File Differences:}

\begin{tabular}{|l|l|l|l|}
\hline Time (year) & $\begin{array}{l}\text { Range of Variable } \\
\text { Conc. }\left(\mathrm{Ci} / \mathrm{m}^{3}\right)\end{array}$ & $\begin{array}{l}\text { Max Difference } \\
\left.\text { Conc. (Ci/m } \mathrm{m}^{3}\right)\end{array}$ & RRMS \\
\hline 50,300 & $1.52 \mathrm{e}-7--1.52 \mathrm{e}-4$ & $3.683 \mathrm{e}-12$ & $3.997 \mathrm{e}-9$ \\
\hline 400.300 & $1.97 \mathrm{e}-9-1.97 \mathrm{e}-6$ & $-1.776 \mathrm{e}-15$ & $5.635 \mathrm{e}-9$ \\
\hline 800,300 & $1.12 \mathrm{e}-13-1.12 \mathrm{e}-13$ & $-2.608 \mathrm{e}-18$ & $1.260 \mathrm{e}-7$ \\
\hline
\end{tabular}

For the probiems in this section, both maximum difference and RRMS values are negligible. The differences can be explained by rounding errors between the two computers. 
WHC-SD-TI -730

WAC-SD-ER-CSND-005

Figure 8.1

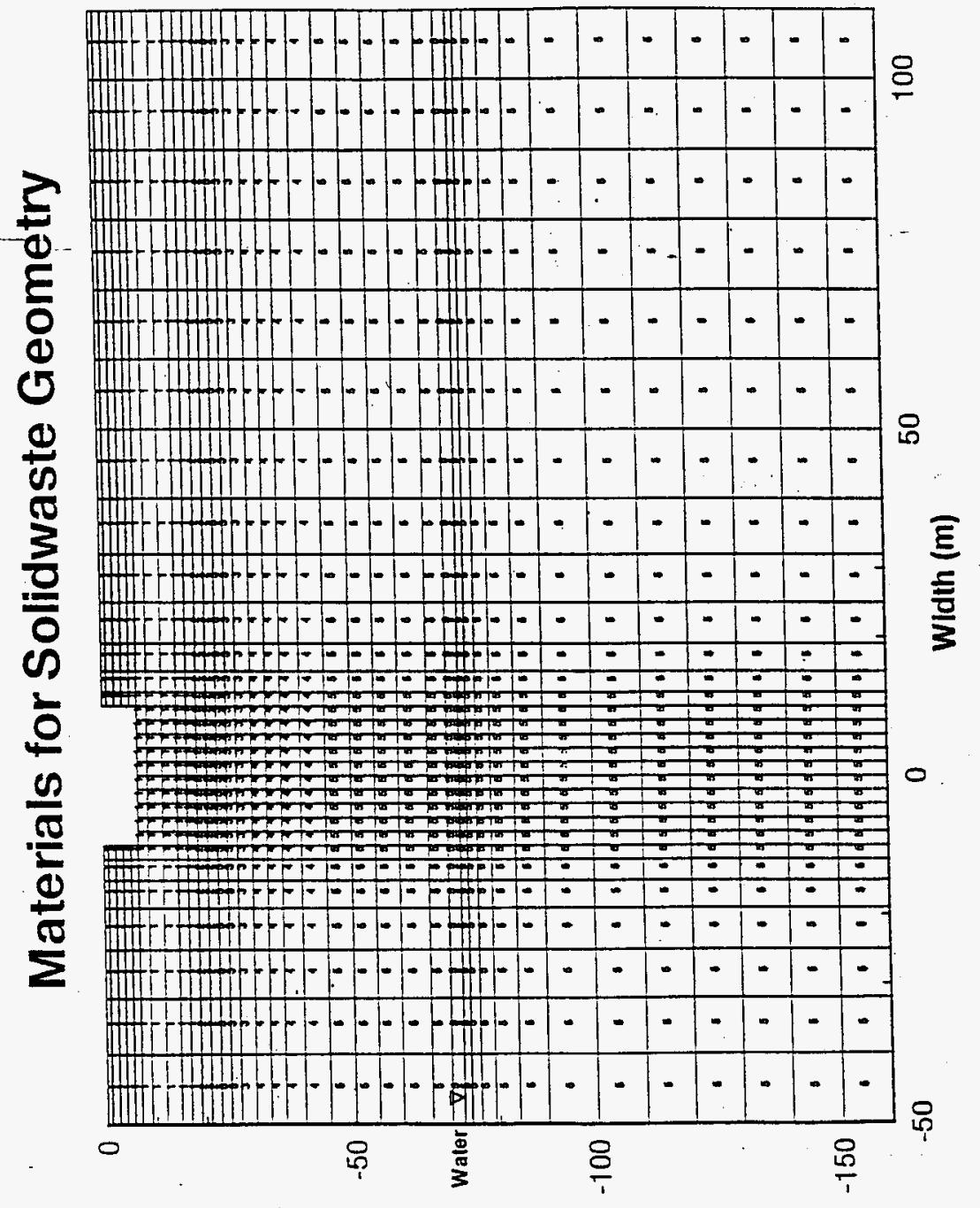

(w) updəa 


\subsection{CONCLUSIONS}

Three sets of test problems were selected to examine the general capabilities and 1 imitations of the VAM $30-C G$ Code. The first set of test problems was used to show that the VAM3D-CG Version 2.46 code on the SGI produces the same results as those published by the vendor in the users' manual. The test problems were originally selected for the verification of numerical schemes and the demonstration of the major capabilities of the VAM3D-CG code.

The third set of test problems was seiected to show that the VAM $30-C D$ Version 2.46 on the SGI workstation produces the same results as those previously obtained on the Westinghouse Hanford Cray computer which is no tonger. in service.

The test results showed excellent agreement with the first and third sets of problems. In these comparisons, both maximum difference and RRMS values are negligible. The differences can generally be explained as rounding errors between computers.

The second set of test problems was selected to examine the abilities of the VAM $30-C G$ code to accurately solve the flow and transport problems relevant to performance assessment applications at Hanford. For this purpose, a comparison was made with the PORFLO-3 code for the simulation of two problems.

For the second set of problems, reasonable acceptance criteria cannot be stated for the numeric data comparisons, due to the differences in grid structures. Subjective criteria would at best involve the location of the wetting and transport fronts in the computed solutions.

For the 216-U-17 Crib problem, the solutions showed very good overall agreement when piotted, even though VAM3D-CG and PORFLO-3 employ significantiy differant solution techniques. The main difference occurs at an eariy time when the front has recently passed the interface between the crib and the sandy soil and the front is approaching the partial sandy gravel layer (zone 3 ). This may result from differences in the modeling of the interface between materials. PORFLO-3 uses an averaging scheme at material boundaries, while VAM3O-CG need not compute such averages. The differences are generally enhanced when a model employs thin layers of materials, and adjacent zones have large differences in properties. To minimize the impact on the overall performance of the model, each zone in a grid must have enough elements to model the expected behavior.

For the clay cap problem, the steady state response of a single, low conductivity layer embedded within a higher conductivity material was modeled. The saturated conductivities of the two materials differ by rough six orders of magnitude. However, both models compute substantially identical results. 
Though the overall agreement in the results is satisfactory, minor differences exist at several locations. The differences can again be - attributed to the conductivity averaging scheme used by PORFLO-3 at material boundary interfaces.

Although minor discrepancies exist on both benchmark testing problems, the two codes should perform equally well in terms of performance assessment applications at Hanford. 


\subsection{REFERENCES}

Brooks, R. H., and A. T. Corey, 1966. Properties of porous media affecting Fuidflow, ASCE J. Irrig. Drain. Div., 92(IR2):51-88.

Davis, L. A., and 5. P. Neuman, 1983. Documentation and User's Guide: UNSATI-Variably Saturated Flow Model, U.S. Nuclear Regulatory Commission, NUREG/CR 3390, Washington, D.C.

Huyakorn, P. S. and S. Panday "VAM3D-CG - Variably Saturated Analysis Model in Three-Dimensions with Preconditioned Conjugate Gradient Matrix Solvers, Version 2.4b, Documentation and User' Guide," 1993, HydroGeoLogic, Inc. Herndon, VA.

Kincaid, C. T., J. W. Shade, G. A. Whyatt, M. G. Piepho, K. Rhoads, J. A. Voogd, J. H. Westsik, Jr., M. D. Freshley, K.A. Blanchard, and B. G. Lauzon. "Performance Assessment of Grouted Double-Shell Tank Waste Disposal at Hanford," 1993, WHC-SD-WM-EE-004, Rev.0.

KI ine, N. W., 1993, "Certification of Version 1.2 of the PORFLO-3 Code For the Hanford Cray Computer," WHC-SD-ER-CSWD-003, Rev.0.

Magnuson, S. O, R. G. Baca, and A. J. Sondrup. "Independent Verification and Benchmark Testing of the PORFLO-3 Computer Code, Version 1.0", 1990. EGG-BG-9175, Idaho National Engineering Laboratory, Idaho Falis, Idaho.

Mualem, Y., 1984, "Anisotropy of Unsaturated Soil," Soil Sci. Soc. Am. J., pp. $513-522$.

Neuman, S. P., R. A. Feddes, and E. Bresler, 1974. Finite element simulation of flow in saturated-unsaturated soils considering water uptake by plants, Hydrodynamics and Hydraulic Engineering Laboratory Report for Project No. ALO-SWC-77, Haifa, Israel.

Lu, A. H. and R. Khaleel, "Calibration/Testing of VAM3D-CG Computer Code Using Injection Test Site Data at Hanford, "Internal Letter: J. A. Rawl ins to M. J. Lauterbach, "Fiscal Year 1993 M-29-02 Milestone Document," 25350-JAR93-059, October 14, 1993.

Reidel, S. P., V. G. Johnson, and N. W. Kl ine. "Groundwater Impact Assessment for the 216-U-17 Crib, 200 West Area", 1993. WHC-EP-0664. Westinghouse Hanford Company, Richiand, WA.

Runchä, A. K., and B. Sagar. 1992. PORFLOW: A Model for Fluid Flow, Heat, and Mass Transport in Multifluid, Multiphase, Fractured or Porous Media Users Manual, Version 2.4. ACRi/O16/REV.G, Analytical and Computational Research, Inc., Los Angeles, California.

Sagar, B. and A. K. Runchal, 1990, "PORFL0-3: A Mathematical Model for Fluid Flow, Heat, and Mass Transport in Variabiy Saturated Geological Media, Theory and Numerical Methods, Version 1.0", WHC-EP-0042, Westinghouse Hanford Company, Richland, WA. 
Scheidegger, A. E., 1951. General theory of dispersion in porous media, J. Geophys. Res., v.66, pp.3273-3278.

Sisson, J. B. and Allen H. Lu, "Field Calibration of Computer Models for Application to Buried Liquid Discharges: A Status Report", RHO-ST-46 p, August 1984.

van Genuchten, R., 1978, "Calculating the Unsaturated Hydraulic Conductivity with a New Close-Form Analytic Model," Report 78-WR-08, Water Resources Program, Department of Engineering, Princeton University, Princeton, New Jersey.

Wood M. I., R. Khaleel, P. D. Rittmann, A. H. Lu, R. J. Serne, and -K. j. Cantrell, "Performance Assessment for the Disposal of Low-Level Waste in the 218-W-5 Burial Ground", WHC-EP-0645 Draft, July 1993.

Yeh, G. T. and D. S. Ward, 1981, FEMWASTE: A finite-element model of waste transport through saturated-unsaturated porous media, Rep. ORNL-5601, Oak Ridge National Lab., Oak Ridge, Tennessee, 137pp.

Yeh, G.T., 1981. AT1230: Analytical transient one-, two- and three-dimensional simulation of transport in the aquifer system, Oak Ridge National Lab., Tennessee, Report no. ORNL -5602 . 
ENGINEERING DATA TRANSMITTAL

2. To: (Receiving Organization)

Distribution

5. Proj./Prog./Dept.foiv.:

$0 \mathrm{M621}$

8. Originator Remarks:

Requesting approval for supporting. document.
3. Fron: (Originating organization) Environmental Modeling

6. Cog. Engr.:

D. W. Langford

1. EDT 602814

4. Related EDT No.:

123309

7. Purchase Order Mo.:

$N / A$

9. Equip./Component Ho.:

$N / A$

10. System/Btdg./Facility:

$N / A$

11. Receiver Remarks:

12. Major Assm. Dwg. Ha.: N/A

13. Permi t/Permit Applieation No.: $N / A$.

16. Required Response Date: $-5-17-95.5-26 \cdot 95$

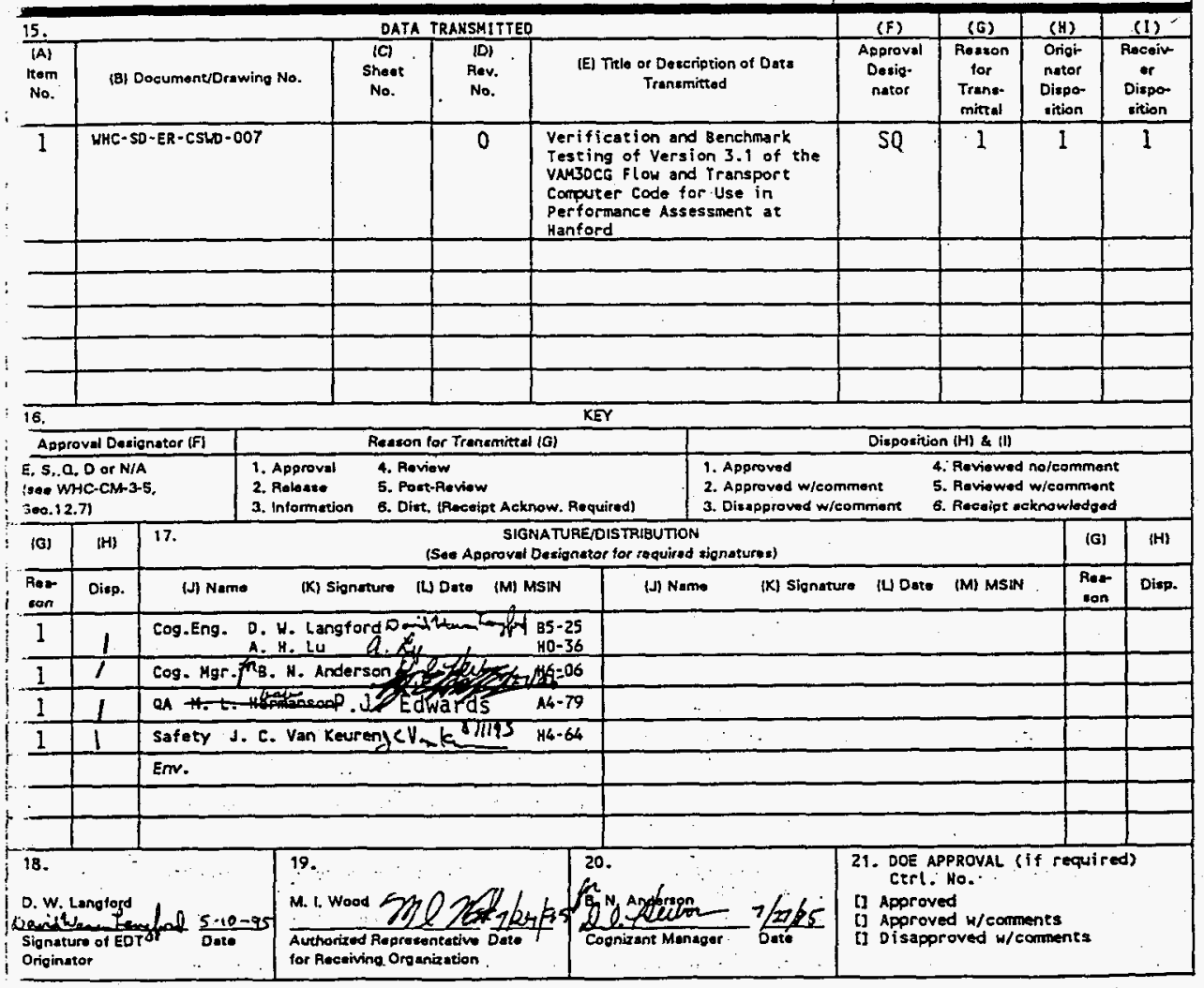

$w-7400-172-2(06 / 96)$ GEF097 
WHC-SD-11-13U

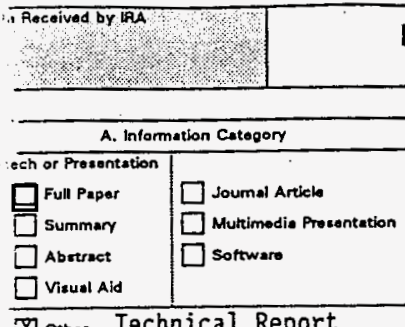

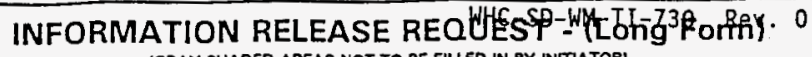

(GRAY SHADED AREAS NOT TO BE FILLED IN BY INITLATOR)

1. COMPLETE THIS SECTION FOA ALL DOCUMENTS

8. Document iD Number (include rov.., vol.. ate.)

WHC-SD-ER-CSWD-007, ReV. 0

C. Wret attechmente (i.o., sopyright penmie tion, copyright trenster)

[O] othar Technica] Report

Document Title

rification and Benchmark Testing of Version 3.1 of the VAM3DCG Flow and ansport Computer Code for Use in Performance Assessment at Hanford

E. WHC Projec: or Program

Environmental

Restoration

Disposal Fac/

Solid-Wste Perf

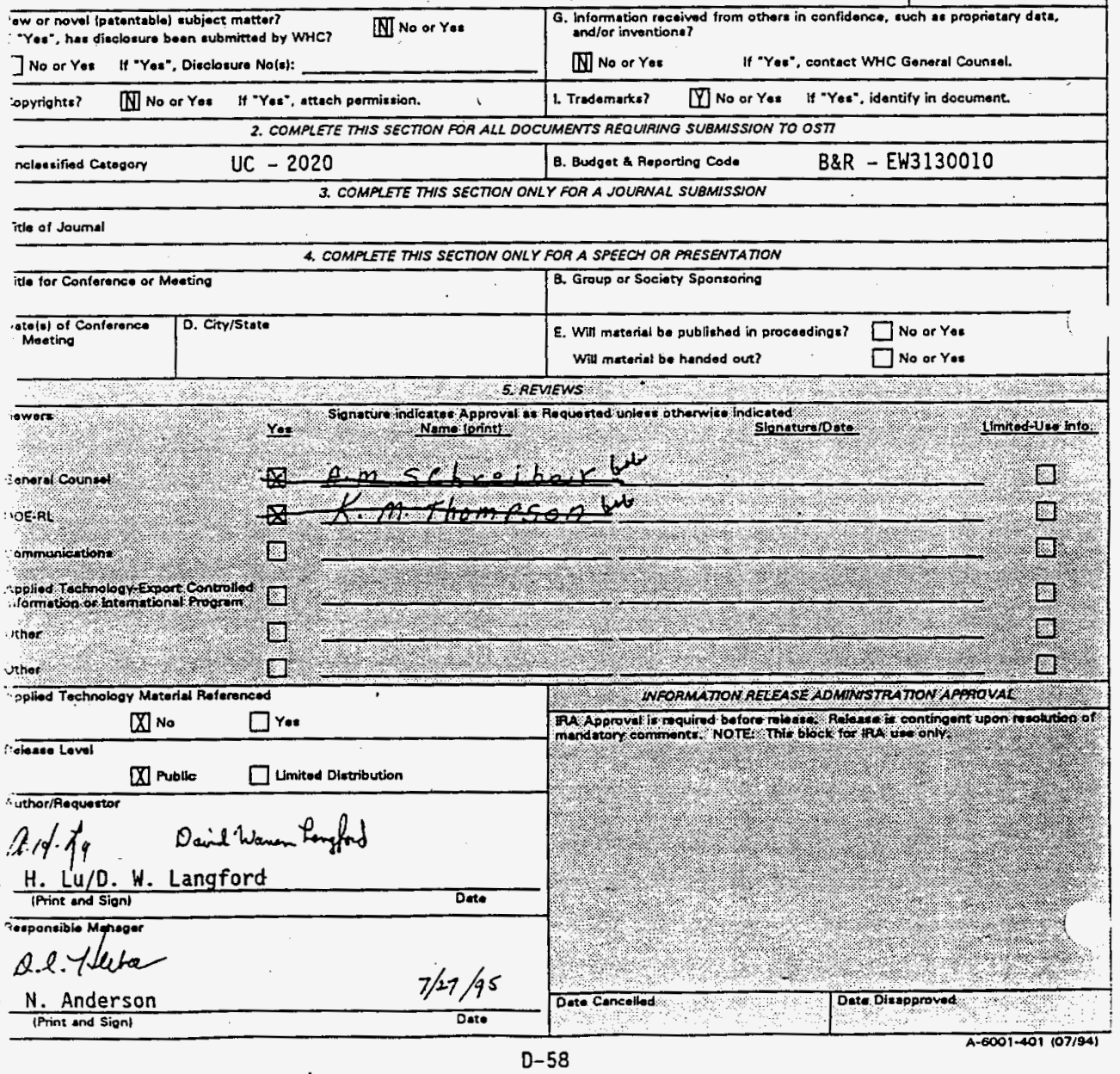




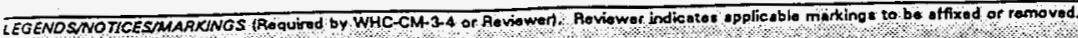

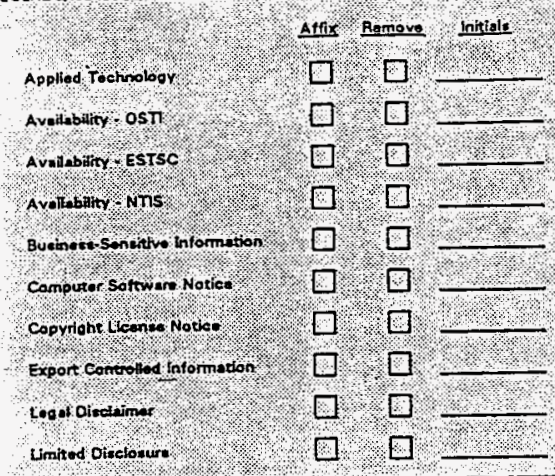

MANOATOAY COMMENTS fLET only mandaton commants hert All other comments shill be mado on the document and retumed to the euthor. 1

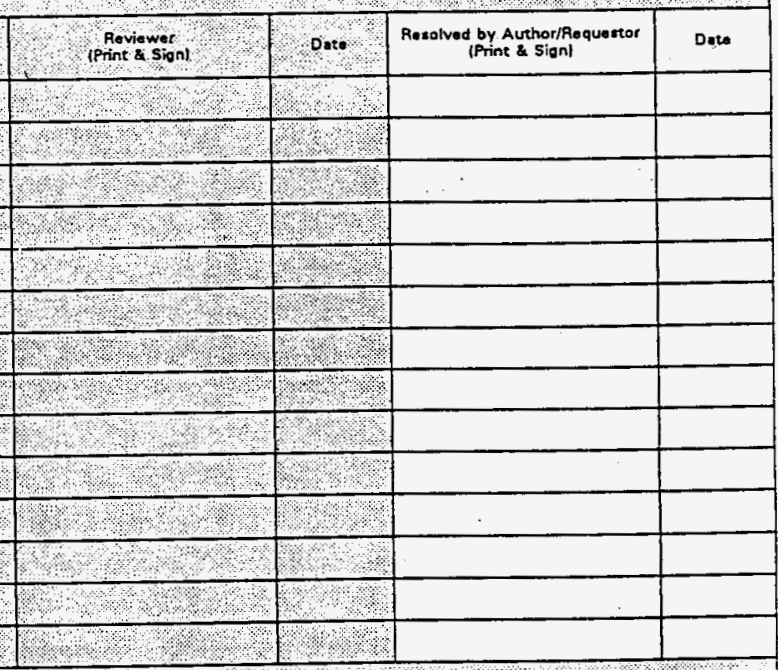

\section{ontan Uer onh}

Patont stoturs

podochional Informetion

Programmetio Nottor

Progriotervi Intormition

puroose ond Un

Thentolisentution

Trad monk 0 ofelainer

४ै०े।

other

Affix Bompas, nitallo

\$?

212

$\$ 2$

[1,

म1\%

20

125

ए?

$\$$
Roviewer Print \& Sign 


\begin{tabular}{|c|c|}
\hline $\begin{array}{l}\text { 2. Iitle } \\
\text { Verification and Benchmark Testing of Version } 3.1 \\
\text { of the VAM } 30 C G \text { Flow and Transport Computer Code } \\
\text { for Use in Performance Assessment at Hanford }\end{array}$ & $\begin{array}{l}\text { 3. Number } \\
\text { WHC-SD-ER-CSWD-007 }\end{array}$ \\
\hline $\begin{array}{l}\text { 5. Key Words } \\
\text { Verification } \\
\text { Benchmark } \\
\text { VAM } 30 \text { CG Code }\end{array}$ & $\begin{array}{l}\text { 6. Author } \\
\text { Hame: A. H. Lu/D. W. Langford } \\
\text { Signature } \\
\text { Organization/Charge Code OM621/XR5019 }\end{array}$ \\
\hline
\end{tabular}

\section{Abstract}

The VAMBDCG computer code is a proprietary software product marketed by HydroGeologic, Inc., of Herndon, Virginia. It is a model of saturated and unsaturated fluid flow and contaminant transport in a heterogeneous porous continuum. Version 2.4b of VAM3OCG has been formally tested and accepted for use in performance assessment activities and has been applied to the disposal of low-level waste in the 218-W-5 burial ground. Modeling for the Environmental Remediation Disposal Facility (ERDF) is being performed with Version 3.1, which has new features specific to the ERDF model.

This report documents a comparison between the previous version of VAM3DCG (2.4b) against the newer version (3.1). The tests performed here duplicate the origina? test process for VAM3DCG. The purpose of this work is to establish whether or not Version 3.1 of the VAM3DCG code is functioning correctly and is acceptable for present modelling studies. Inherent in the scope of this work is verification that existing features from Version $2.4 \mathrm{~b}$ are still functional in Version 3.1 , and that new features which distinguish Version 3.1 from Version 2.4 b are also functioning correctly. 
Rev. 0

Document Title: Verification and Benchmark Testing of Version 3.1 of the VAM3DCG Flow and Transport Computer Code for Use in

Performance Assessment at Hanford

Prepared by:

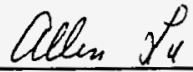

A. H. Lu, Principa] Scientist

$\frac{4 / 27 / 95}{\text { Date }}$

Oend Waxen Lan fad

D. H. Langford, Princibal Software Engineer

$\frac{5 / 10 / 45}{\text { Date }}$

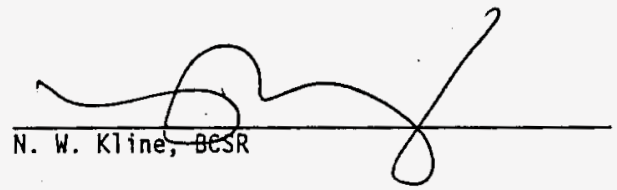

Reviewed by:

Q. l. Yeulo

Approved by:

Risk Assessment and Environmental Modeling 


$$
\begin{gathered}
\text { WHC-SD-TI-730 } \\
\text { WHC-SD-ER-CSWD-007 } \\
\text { Rey. } 0 \\
\text { Table of Contents }
\end{gathered}
$$

1.0 INTRODUCTION . . . . . . . . . . . . . . . . . . . . . 1

2.0 MODIFICATIONS FOR VERSION $3.1 \ldots \ldots \ldots \ldots$

3.0 TESTS EXECUTED . . . . . . . . . . . . . . . . . . . . . 2

4.0 CRITERIA FOR ASSESSING THE TEST RESULTS . . . . . . . . . . . 3

5.0 TEST RESULTS . . . . . . . . . . . . . . . . . . . . . . 4

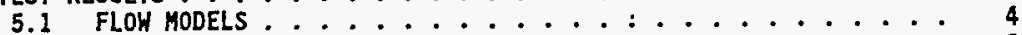

5.2 TRANSPORT MODELS .......................... 5

$5.3216-\mathrm{U}-17$ CRIB MODEL ................. 6

5.3.1 Flow Field Comparison .............. 7

5.3 .2 Transport Comparison .............. 8

6.0 CONCLUSIONS . . . . . . . . . . . . . . . . . 9

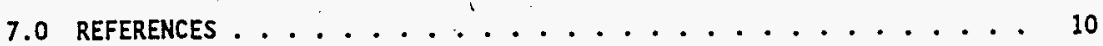

FIGURES

1. Concentration Contours for Test HVPTNO, VAM3DCG

Version 3.1 and 2.46 at Time 0.0774 ............. 11

2. Concentration Contours for Test HVPTNO; VAM3DCG

Version 3.1 and 2.46 at Time $0.258 \ldots \ldots$. . . . . . . . . 12

3. Concentration Contours for Test HVPTNO, VAM3DCG

Version 3.1 and 2.46 at Time $0.508 \ldots \ldots 13$

4. Simulation Domain for 216-U-17 Crib Kodel ............ 14

5. VAMBDCG Version $2.4 \mathrm{~b}, \mathrm{Z}$ Darcy Velocities at Time 5.24 Years . . . . . . . . . . . . . . . 15

6. VAM3OCG Version 3.1, Z Darcy Velocities at

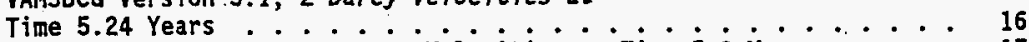

7. PORFLo-3 Version $1.2, z$ Darcy Velocities at Time 5.0 Years . . . . 17

8. VAM3DCG Version $2.46, Z$ Darcy Velocities at Time 10 Years Without Upwinding ............... 18

9. VAM3DCG Version $2.4 b$, Concentration at Time 5.24 Years . . . . . 19

10. VAM3DCG Version 3.1 , Concentration at Time 5.24 Years . . . . . 20

11. PORFL0.3 Version 1.2 , Concentration at Time 5.0 Years . . . . . 21

12. VAM3DCG Version $2.4 b$, Concentrations at Time 10.0 Years . . . . . 22

13. VAM3OCG Version 3.1 , Concentrations at Time 10.0 Years . . . . . 23

14. VAM3DCG Version $2.4 b$, Concentrations at Time 10 Years Without Upwinding ................. 24

15. VAM3DCG Version 3.1 , Concentrations at Time 10 Years Without Upwinding .............. 25 
WHC -SD-TI-730

WHC-SD-ER-CSWD-007

WHC-SD-WM-TI-730, Rev. 0

Rey. 0

\subsection{INTRODUCTION}

The VAM3DCG computer code is a proprietary software product marketed by HydroGeologic, Inc., of Herndon, Virginia. It is a model of saturated and unsaturated fluid flow and contaminant transport in a heterogeneous porous continuum. Version 2.4b of VAM3OCG has been formally tested and accepted for use in performance assessment activities (Lu et. al., 1994), and has been applied to the disposal of low-level waste (LLW) in the $218-W-5$ burial ground (Wood et al., 1994). Modeling for the Environmental Remediation Disposal Facility (ERDF) is being performed with Version 3.1, which has new features specific to the ERDF model.

This report documents a comparison between the previous version of VAM3DCG (2.4b) against the newer version (3.1). The tests performed here duplicate the original test process for VAM3DCG. The purpose of this work is to establish whether or not Version 3.1 of the VAM3DCG code is functioning correctiy and is acceptable for present modelling studies. Inherent in the scope of this work is verification that existing features form Version 2.46 are still functional in Version 3.1 , and that new features which distinguish Version 3.1 from Version 2.46 are also functioning correctly.

\subsection{MODIFICATIONS FOR VERSION 3.1}

Version 3.1 of VAM3OCG was created by HydroGeologic, Inc., in late 1993, to provide enhanced modeling capabilities. The software documentation included only an abbreviated list of changes (Huyakorn et. al., 1994, Addendum). A full jist of the known changes is presented below.

a. Version 3.1 allows the use of the Newton-Raphson iteration with Finite Difference matrix connectivity. Previous versions did not allow this, but defaulted to Finite Element connectivity when Newton-Raphson was requested. This was the major incentive for creating the new version.

b. New matrix solvers have been installed. These should improve computational speed and convergence for some flow models. The new solvers roughly double the size of the executable code.

c. The dynamic adjustment of time stepping has been improved. This provides faster convergence than the previous version.

d. For some classes of problems, the concentration tolerance (CTOL, card group 4, columns 61-70) is used in version 3.1, while version. 2.4b would either ignore that value, or use it in a different manner. Care should be taken to ensure sufficiently small values are used for all problems.

e. The treatment of pinch nodes (transition elements) has been improved.

f. Previous versions of VAM3DCG would add restart information to the end of the restart file (TAPE8). That information was not directly usable when TAPE8 was binary. Version $3: 1$ rewinds the restart file, and overwrites the existing information. 


$$
\begin{gathered}
\text { WHC-SD-TI-730 } \\
\text { WHC-SD-ER-CSWD-007 } \\
\text { ReV. } 0
\end{gathered}
$$

If TAPE8 is used for both input and output, the input data is lost, and shoutd be archived prior to running VAM3OCG.

g. When Version 3.1 halts due to non convergence, the final state of the model is written to the output file. Previous versions would not provide this information.

h. A minor change was made to the header of the nodal plot file (TAPE10). After the $Q A$ header on the output file, previous versions placed a Character $* 33$ text record. Version 3.1 replaces this with a Character $* 28$ record.

-This is only a problem for binary plot files. Note that some FORTRAN codes may read this file without difficulty (compiler dependent).

i. The implementation of upstream weighting (upwinding) for permeability has been changed. HydroGeologic indicates some errors were found in the previous versions, which have been corrected in version 3.1 .

With these changes, the new code is better able to model areas of high recharge which are immediately adjacent to areas of low recharge. This has been a desirable feature, due to the nature of many of the models which are examined at the Hanford site.

Several revisions were made to the software by the vendor, prior to delivering a fully functional copy of version 3.1. Each was dated to uniquely identify the code. The revision examined here was received by the Westinghouse Hanford Company on July 11, 1994, and is labeled with that date.

\subsection{TESTS EXECUTED}

A suite of 58 test problems is available for testing new versions of VAM3DCG. Many were provided by HydroGeologic, Inc., although most have been collected from VAM3DCG users. They represent both simple tests of multiple options, as well as realistic flow and transport models for the Hanford site.

Each test problem was run with VAM $30 C G$ versions $2.4 \mathrm{~b}$ and 3.1 . An initial comparison of the print files was made. This was done to help ensure code defaults were the same for both versions, and to identify when those defaults were different. Note, however, that VAMBDCG does not identify all defaulted options in the print file.

A secondary comparison was made between the nodal concentrations for each test problem. The results between the two code versions were not expected to be identical, for the following reasons:

a. New solvers have been installed. Different numeric processes are being used (in most cases) to generate a solution.

b. Convergence tolerances for the flow can be made only so small, before convergence difficulties arise. 
Rev. 0

A summary of the differences between results was compiled for each test problem. The full summary of each comparison is maintained by the code custodian. Because that documentation is lengthy, it-is not reproduced here. That summary included the following information:

a. Minimum, maximum, and average data values. If any of these values differed between the two VAM3DCG versions, an average between the data sets was noted in the full summary.

b. Average difference.

c. Root Mean Square (RMS) difference.

d. Relative Root Mean Square (RRMS) difference, defined as:

$$
R R M S=\sqrt{\frac{1}{N} \sum_{k=1}^{N}\left(\frac{D_{2.4 k}-D_{3.1 k}}{D_{2.4 k}}\right)^{2}}
$$

where $D_{2.4 k}=$ Value at node $k$, VAM3DCG, Version $2.4 \mathrm{~b}$.

$D_{3.1 k}=$ Value at node $k$, VAM3DCG, Version 3.1 .

$N=$ Number of nodes in the model.

Oniy nodes with values $\left(=D_{2,4 k}\right)$ greater than $0.1 \%$ of the maximum were used in computing the RRMS, because smaller values tend to reflect noise in the calculations.

e. Maximum difference.

\subsection{CRITERIA FOR ASSESSING THE TEST RESULTS}

Magnusen et. al (1990) used the RRMS as the primary performance indicator, and defined four performance categories: 1. Excellent - RRMS $\leq 0.01,2$. Good $=$ RRMS $\leq 0.053$. Acceptable - RRMS $\leq 0.10$, and 4 . Unacceptable - RRMS $\geq 0.10$. For this application, the RMS and RRMS differences were both used. A test was considered immediately successful if the RMS value was less than i\% of the data range, and the RRMS value was less than 0.01 .

Tests which failed these criteria were examined more closely to determine the cause. The improvements made to VAM3DCG are expected to generate superior results in at least some problems. A subjective judgement of graphic comparisons was used in some cases to determine agreement or disagreement.

Maximum differences in the data were also examined. This information is local in nature, and does not provide any sense of the overall comparison. It is also misleading when oscillations occur in transport problems due to a large Peclet number. For most of the problems, the maximum differences 
WHC-SD-TI -730

WHC-SO-ER-CSWD-007

WHC-SD-WM-TI-730, Rev. 0

Rev. 0

closely followed the trend of the RRMS data. None of the maximum differences were large enough to be considered significant.

\subsection{TEST RESULTS}

of the 58 test problems, 28 gave differences larger than the specified criteria. Each of these were examined in more detail to determine the cause of the discrepancies. These are discussed below.

The 216-U-17 Crib model, discussed in Section 5.3, represents the most complex and rigorous test probiem currently avallable and thus is considered of primary importance. Some minor difficulties were encountered in comparing version $2.4 \mathrm{~b}$ against version 3.1 for that problem. Also, a number of software characteristics were uncovered in executing this test. Therefore, the discussion of this model has been separated from the general discussion of the results.

\subsection{FLOW MODELS}

Seven flow models were found to give RRMS differences larger than 0.01 . These were examined in further detail, and the following causes are given below.

a. Usage of different program options (3 problems). VAM3DCG, version 3.1 , can implement Finite Difference connectivity with Newton-Raphson iteration to convergence. Version $2.4 \mathrm{~b}$ could not do this, and defaulted to Finite Element connectivity. When this happened, version 3.1 also defaulted to full lumping in the element matrix, regardless of the user specifications. The flow field differences were greatiy reduced when both codes were run with Finite Element connectivity.

b. Pinch nodes in the finite element grid ( 2 problems). Pinch nodes are handled differently by the two code versions. A maximum RRMS of 0.05 was noted, although the maximum error was 1.8 meters (head), out of a range of 96 meters. This is not excellent agreement, but is considered acceptable. Plots of the data compared favorably.

c. Differences in the upwinding scheme ( 1 problem). This was a difficulty of the 216-U-17 Crib model, which is discussed later.

d. Undetermined (2 problems). These problems had maximum RRMS values of 0.015 and 0.011 . These are only marginally outside the desired limit, and are not considered unacceptable due to overriding graphic comparisons.

Large convergence tolerances also created some difficulties. The new matrix solvers use a difference scheme for solving the Finite Element equations. The convergence tolerance is therefore critical in getting agreement between the two versions. Several problems required that the flow tolerance be reduced before acceptable results could be attained. 
WHC-SD-TI -730

WHC-SD-ER-CSWD-007

WHC-SD-WM-TI-730, Rev. 0

Rev. 0

\subsection{TRANSPORT MODELS}

Twenty-one transport problems gave RRMS differences greater than 0.01 . In all cases, such differences could be explained by one or more of the following:

a. Small concentration values. A small absolute difference in a small datum can produce a large relative difference at that point. Contaminant 'fronts' are marked by small concentration values, resulting in a large RRMS value.

This difficulty is inherent in the RRMS calculation for transport phenomena. The use of an RRMS cut-off value of $0.1 \%$ was intended to circumvent this probiem, but was not entirely successful. Increasing the cut-off value was not considered appropriate, because it could mask significant problems in the comparisons.

b. Use of different flow fields (13 problems). Small differences in the flow field can produce significant differences in the transport processes, especially in regions of contaminant fronts. These differences were reduced when the same flow field (i.e., from either Version 2.4b or Version 3.1) was used for both executions of the transport problem.

c. Large Peclet numbers ( 9 problems). Instabilities resulting from a large Peclet number were not consistent between the two versions. This produced numerical differences which were much larger than the functional agreement between data sets.

In many cases, the instabilities were greatiy reduced in Version 3.1 . The vendor indicates this is typical of the new matrix solvers.

d. Pinch nodes in the finite element grid (2 problems). A maximum RRMS of 0.28 was noted when the same flow field was used for both runs. The bulk of this value appears to result from differences in small value concentrations as a transport front crosses a line of pinch nodes.

Large convergence tolerances were also a problem. Version 3.1 appears to use the transport convergence tolerance at times when Version $2.4 \mathrm{~b}$ would simply ignore the value. These errors were reduced or el iminated when the tolerance was reduced. A reasonably small tolerance (CTOL, card group 4, columns 61-70) should be used in all transport problems.

One test problem modeled transport for eight hundred thousand years. By that time, the maximum concentrations were seven orders of magnitude below the original source values. While the RRMS differences were large (up to 1.2), the numerical results for both models are primarily noise.

Contour plots of a pinch node transport problem (HVPTNO) are shown in Figures 1 through 3. Both models used the flow field from Version 2.4b. The numerical comparison of concentrations produced an RRMS value of 0.28 . However, the plots agree well at early times. Significant differences appear only after the transport front crosses the pinch nodes. Because pinch nodes are an approximation that improves computational efficiency, the difference is considered acceptable. 


\subsection{6-U-17 CRIB MODEL}

The 216-U-17 Crib at the southern end of the 200 West Area of the Hanford Site was constructed in 1987 and became the disposal facility for process condensate from the Uranium Trioxide $\left(U_{3}\right)$ Plant on January 31, 1988. At the time of preparation of the Groundwater Impact Assessment (GIA) report for the 216-U-17 Crib (Reidel et al., 1993), it was reported that discharge to the crib would cease in June 1995 when the $\mathrm{UO}_{3}$ Plant was to become connected to the Liquid Effluent Treatment Facility. Although the expected operational lifetime of the crib was about seven and a half years, much of the time the $\mathrm{UO}_{3}$ Plant operated in standby mode; some of that time $\mathrm{UO}_{3}$ Plant operation was suspended (e.g., from $7 / 89$ to $8 / 92$ ). Discharges to the crib were generally less than planned capacity.

Early numerical modeling of the impact of use of the crib on groundwater quality and in terms of extent of vadose zone contamination was conducted for the Liquid Effluent Study (WHC, 1990), using Version 1.1 of the PORFLO- $3^{*}$ computer code. More extensive modeling was performed in 1993 and reported in the GIA. The later models were constructed and executed with Version 1.2 of the PORFLO-3 code (Runchal et al., 1992; KI ine 1993). All of those modeling results were reviewed internally and released for public scrutiny. Model results consistently predicted that fluid and contaminants discharged through the 216-U-17 Crib would not reach groundwater before 1994. So far this prediction has proven to be true, which partially validates the model results. The relative success of the work in modeling the 216-U-17 Crib makes the models attractive for code benchmarking. The documented PORFLO-3 results are physically reasonable and are at least partially validated after the fact by absence of evidence of any groundwater arrivals due to crib operation.

The present base case model simulates water seepage and contaminant transport in terms of relative concentration as documented in Section 5.1.4.1 of the GIA. Figure 4 shows the structure of the domain. Several layers of porous material are present, having widely varying material properties. The flow model is highly nonlinear, and thus represents a very rigorous test of the software. The initial capillary heads in the vadose zone range from 0.0 (top of the water table) to just over $1 \mathrm{~m}$. However, the relative permeabilities vary up to six orders of magnitude within this range.

Averaged flux of fluid through the crib is $109 \mathrm{~m} / \mathrm{yr}$. The saturated hydraulic conductivity (Ksat) in the crib is $622.4 \mathrm{~m} / \mathrm{yr}$. The material immediately below the crib has a Ksat of just $0.72 \mathrm{~m} / \mathrm{yr}$. Thus fluid is forced into the underlying soil by buildup of a large pressure gradient.

The thin layers of sand and gravei (materials 3, 4, and 7) have relatively large Ksat values $(764$ to $8520 \mathrm{~m} / \mathrm{yr}$ ). Most of the remaining saturated conductivities are between 8 and $40 \mathrm{~m} / \mathrm{yr}$. Zone 7 is only one element in width (one cell wide in the PORFLO-3 model). All other zones are at least two elements in width. decay).

The contaminant is a conservative species (i.e., no retardation and no

"PORFLO-3 is a trademark of Analytic and Computational Research, Inc. 


$$
\begin{gathered}
\text { WHC-SD-TI-730 } \\
\text { WHC-SO-ER-CSWD-007 } \\
\text { Rev. } 0
\end{gathered}
$$$$
\text { WHC-SD-WM-TI-730, Rev. } 0
$$

The time frame of interest was zero to five years. Some tests were done on longer simulations, which are briefly discussed. However, the extended tests are not considered meaningful, due to the severe nonlinear nature of the problem, the large forcing boundary condition, and the great many time steps which had to be taken with a relatively large convergence tolerance.

Some minor changes were also made in this model over previous executions. PORFL0-3 uses different porosities for flow and transport, and this was aiso attempted in VAM3OCG. PORFLO-3 was started from a computed steady state flow condition, whereas VAM3DCG was started originally from a piecewise continuous initial pressure field. A difference was found in the input file usage of molecular diffusivity between PORFLO-3 and VAM3DCG, which wascorrected. No significant differences were observed in the results due to these changes.

\subsubsection{Flow Field Comparison}

The initial flow field comparison between VAM3DCG Versions was fairly poor. The convergence tolerance was reduced from 0.11 to 0.05 , and the comparison improved. Smaller tolerances could not be used, due to convergence difficulties. Both flow solutions involved many iterations of reduced time steps. Consequently, the accuracy of the capillary head is comparable with the tolerance, which is fairly large, given the initial conditions. When smaller time steps were taken, the comparison again improved.

The largest RRMS value for the hydraulic heads was 0.0058 at the end time of 5.24 years, which is within the acceptable range. The maximum absolute difference between data sets was 0.6 meters, from a range of 360 meters. The largest differences occurred near the edges of the crib and at the botton of the moving column of fluid, where hydraulic heads were small and conductivity gradients were large.

Plots of the $Z$ direction Darcy velocities are shown in Figures 5 and 6 for the two versions of VAM3DCG. Darcy velocities are used because they include contributions from both the capillary head gradient and the head itself (i.e., the relative permeability). This makes them more informative than plots of the head, particularly for a highly nonlinear problem. The two plots compare quite wel1, with the Version 3. I results lagging oniy slightly behind those from Version 2.4b. A comparable plot from PORFLO-3 at time 5.0 years is shown in Figure 7 . This agrees fairly well with the VAM3DCG plots, although the $V_{z}=-2.5$ contour line is slightly lower. Such differences were expected, due to the severe nonlinearity of the relative permeabilities in zones 5 and 6 .

Extended runs were made out to thirty years. Convergence difficulties were encountered between 6 and 8 years. This is the time at which the fluid front reaches material types 7 through 10 (see Figure 4). Those materials undergo a relatively rapid saturation and the total hydraulic conductivities change several order of magnitudes quickly. Further convergence difficulties were encountered at about 17 years.

The original VAM3OCG runs for this problem used the upwinding option for permeabilities. Both codes were re-run without the upwinding option. Version $2.4 b$ required smaller time steps when upwinding is disabled. Version 3.1 ran to completion, but included several iterations of reduced time steps. For 
Rev. 0

Version 2.4b, the $Z$ direction Darcy velocities became unstable by ten years. This is shown in Figure 8 . Version 3.1 did not display any instabilities, although it gave slightly smaller flow rates in the vadose zone beneath the crib.

The vendor indicates there was an error in the upwind calculations for Version 2.4b, so both executions of Version 2.4b for this model are suspect. When both Versions of the code are run without the upwinding option, the RRMS difference improves slightly, up until the time of the flow instability. Because of the instability, Version $2.4 \mathrm{~b}$ needs the upwinding option for this problem in order to produce reasonable results.

The VAMBOCG extended runs did not compare well with PORFLO-3. In particutar, PORFI0-3 transports fluid into and through the vadose zone faster than VAMBDCG. This discrepancy is likely due to the highly noninear material properties and the differences in the modeling techniques.

\subsubsection{Transport Comparison}

The initial transport comparison between the two versions of VAM3DCG was poor. This was due entirely to the differences in the velocity calculations. When the corrections were made to the flow models, the concentrations also improved. Plats of the concentration contours are shown in Figures 9 and 10 for the two versions of VAM3DCG. The comparable PORFLO-3 plot is shown in Figure 11. All three plots show good agreement.

The RRMS differences between the two versions of VAM3OCG are stili fairly large, ranging from 1.4 at an early time down to 0.1 at time 1.57 years. This is due to 1 arge values of the Peclet number just below the Crib; the maximum computed concentrations are about $40 \%$ larger than the fixed boundary value. Problems of this nature were not reported for the PORFLO-3 models.

Extended runs were also made out to time 10.0 years. The RRMS values at the later times range from 0.04 to 0.39 , with the best values in the 7 to 8.5 year range. However, the VAM3DCG plots are still in good agreement. These are shown in Figures 12 and 13.

Without the upwinding option, both versions of VAM3OCG gave noticeably slower travel times for the contaminants. This is shown in Figures 14 and 15 . Without upwinding, the transport front (contour level 0.5 ) reaches about 5 meters below the water table by 10 years. With upwinding, it reaches about 13 meters below the water table. Note that the concentrations from Version $2.4 \mathrm{~b}$ are effected by the flow instability (see Figure 8 ).

Comparison with PORFLO-3 at later times is fairly poor due to the differing fluid transport rates in the vadose zone. 


$$
\begin{gathered}
\text { WHC-SD-TI-730 } \\
\text { WHC-SD-ER-CSWD-007 } \\
\text { ReV. } 0 \\
6.0 \text { CONCLUSIONS }
\end{gathered}
$$

The overall comparison between Versions $2.4 \mathrm{~b}$ and 3.1 of VAM3DCG is fairly good. Given well behaved problems and the same program options, the two versions gave results which usually agreed within one per cent. Only two simple problems fell outside the acceptance criteria, and both were only marginaliy beyond that criteria.

Several exceptional problems were encountered, which did not immediateiy meet the acceptance criteria. These fell into the following four categories:

-ar- Pinch node models. The vendor indicates that improvements were made in the handling of pinch nodes. Since explicit solutions are not readily available for those problems, one cannot easily validate the new scheme.

b. Upwinding models. The vendor indicates an error was fixed in the upwinding scheme. Analysis of the 216-U-17 Crib model supports this contention.

c. Peclet number distartions. This problem arises whenever too few elements are used to model a transport front. The new solvers handle the difficuity better that the previous solvers.

d. Transport front models. This difficulty is more a problem with the design of the acceptance criteria than with the numerical models. However, better criteria were not immediately available, and the chosen scheme was preferable to a scheme that might have masked potential errors.

The user should also be aware of a number of characteristics of the new software, as follows:

1. Save a copy of the input restart file before restarting a simulation run. This file is overwritten by the output restart file. The input restart data cannot easily be recovered.

2. Use small concentration tolerances. The new matrix solvers use an implicit method, and must have a reasonable value. While the concentration equation is linear and converges quickly, the results may be in error by as much as the tolerance.

3. Avoid non-convergence problems in nonlinear flow models. The automatic time step reduction is useful in continuing through difficult flow regimes. However, the results may be in error by as much as the convergence tolerance. If more than a few non convergence problems are reported by the software, smaller time steps should be considered.

4. Using the upwinding option for flow permeabilities will effect the transport rates through the simulation domain. Typically unwinding can be expected to hasten flow and transport.

The differences between the PORFLO-3 and VAM3OCG results (Section 5.3) are outside the scope in this report. However, the problems were discussed in the previous report (Lu and Langford 1994). Minor discrepancies do exist due 


$$
\begin{gathered}
\text { WHC-SD-TI-T30 } \\
\text { WHC-SD-ER-CSWD-007 } \\
\text { ReV. } 0
\end{gathered}
$$

to the fact that the two codes employ substantially different numerical techniques. However, the two codes showed very good overall agreement and should perform equally well in terms of performance assessment application at Hanford.

Most of the discrepancies between Versions $2.4 \mathrm{~b}$ and 3.1 result from improvements in modeling techniques. Version 3.1 contains several corrections and enhancements over earljer versions of the software, which makes it a visibly superior model. Therefore, VAM3DCG Version 3.1 should be clearly preferred over Version 2.4b for the complex modeling being performed at Hanford.

\subsection{REFERENCES}

Huyakorn, P. S. and S. Panday, 1994, "VAM3OCG - Variably Saturated Anatysis Model in Three Dimensions with Preconditioned Conjugate Gradient Matrix Solvers, Documentation and User's Guide, Version 3.1", HydroGeoLogic, Inc., Herndon, Virginia.

Kline, N. W., 1993 "Certification of Version 1.2 of the PORFLO-3 Code for the Hanford CRAY" Computer," WHC-SD-ER-CSWD-003, Rev. 0, Westinghouse Hanford Company, Richland, Washington.

Lu, A.H. and D. W. Langford, 1994, "Verification and Benchmark Testing of the VAM3OCG Flow and Transport Computer Code for Use in Performance Assessment at Hanford", WHC-SD-ER-CSWD-005, Westinghouse Hanford Company, Richland, Washington.

Magnuson, S. O., R. G. Baca and A. J. Sondrup, 1990, "Independent Verification and Benchmark Testing of the PORFLO-3 Computer Code, Version 1.0", EGG-BG-9175, Idaho National Engineering Laboratory, Idaho Fal is, Idaho.

Reidel, S. P., V. G. Johnson and N. W. Kline, 1993, "Groundwater Impact Assessment for the 216-U-17 Crib, 200 West Area," WHC-EP-0664, Westinghouse Hanford Company, Richiand, Washington.

Runcha], A. K., B. Sagar, and N. W. Kline, 1992, "PORFL0-3: A Mathematical Model for Fluid Flow, Heat, and Mass Transfer in Variably Saturated Geologic Media, Users Manual, Version 1.2", WHC-EP-0385, Westinghouse Hanford Company, Richland, Washington.

WHC, 1990, Liquid Effluent Study Final Project Report," WHC-EP-0367, Westinghouse Hanford Company, Richland, Washington.

Wood, M. I., R. Khaleel, P. D. Rittmann, A. H. LU, S. Finfrock, R. J. Serne and K. J. Cantre11, 1994, "Performance Assessment for the Disposal of Low-Leve 1 Waste in the 218-W-5 Burial Ground," WHC-EP-0645 (Draft), Westinghouse Hanford Company, Richland, Washington.

"CRAY is a registered trademark of Cray Research, Inc. 
Rev. 0

Figure 1. Concentration Contours for Test HWPTNO, VAM3DCG Version 3.1 and 2.46 at Time 0.0774 .

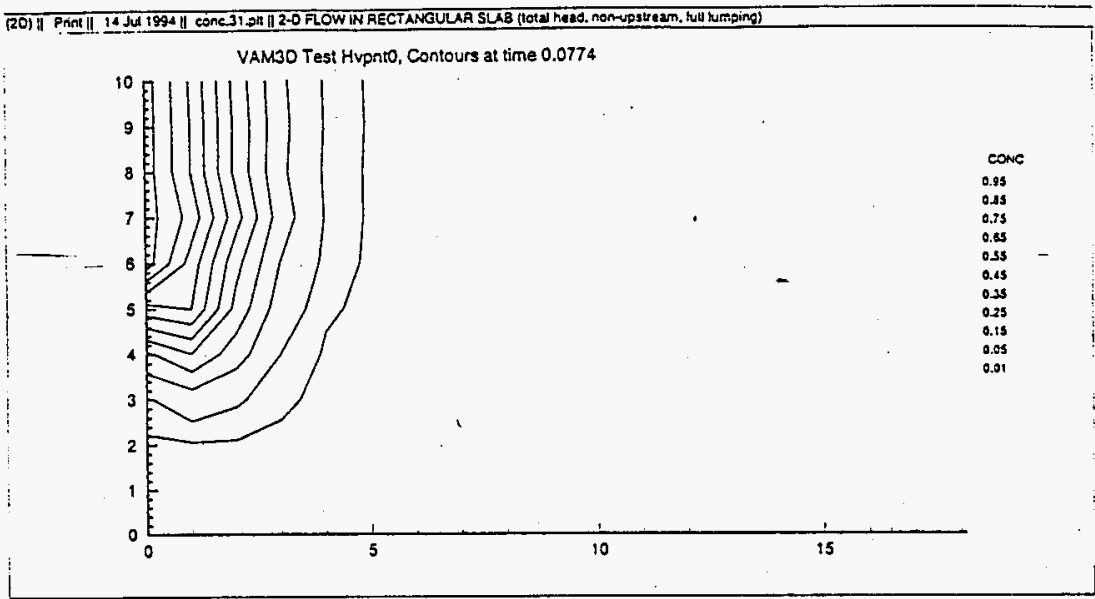

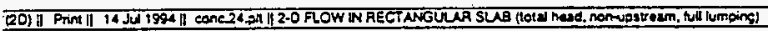

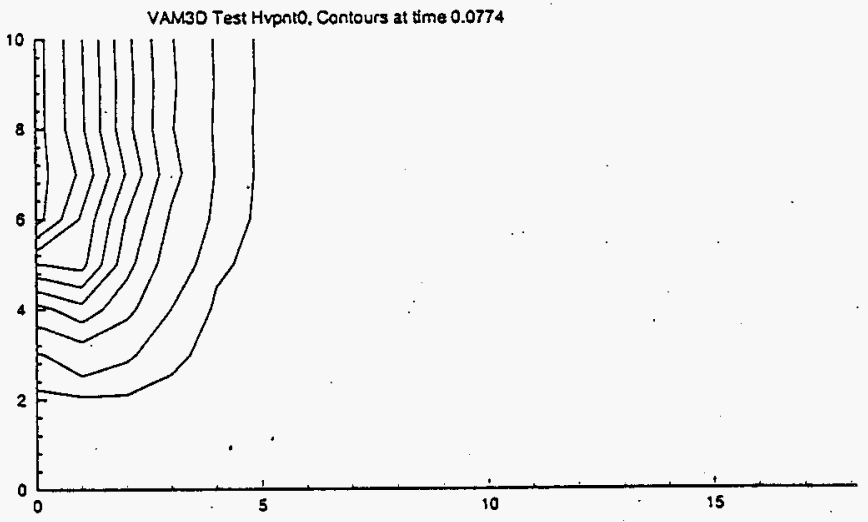




\section{WHC-SD-ER-CSWD-007 \\ Rev, 0}

Figure 2. Concentration Contours for Test HYPTNO, VAM3DCG Version 3.1 and 2.46 at Time 0.258.

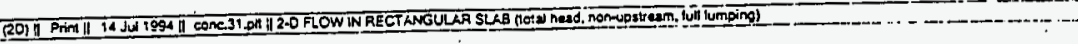

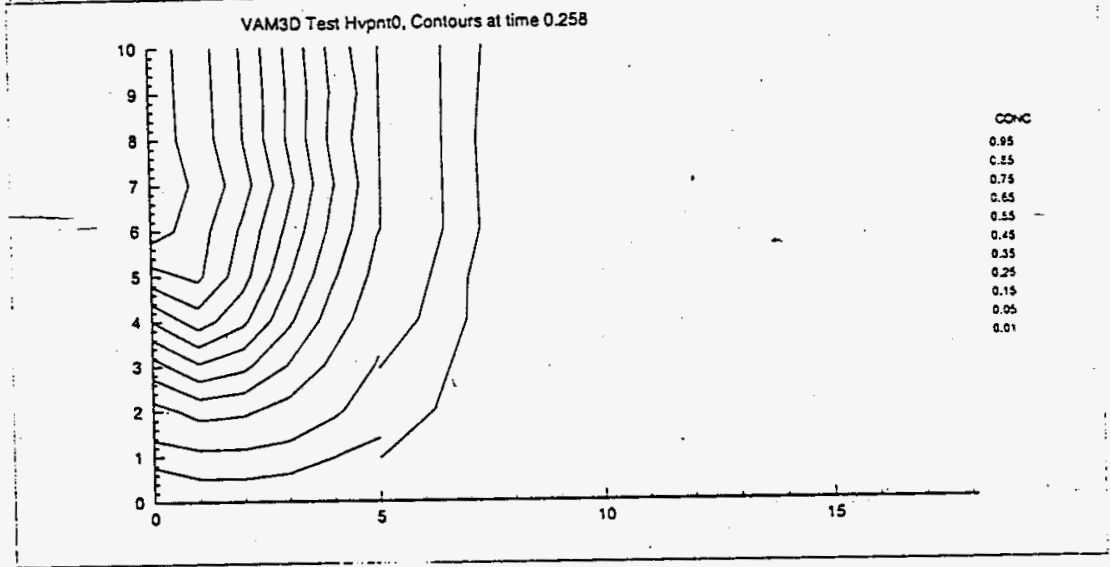

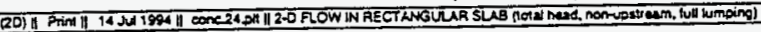

VAM3D Test Hvpnto, Contouts at time 0.258

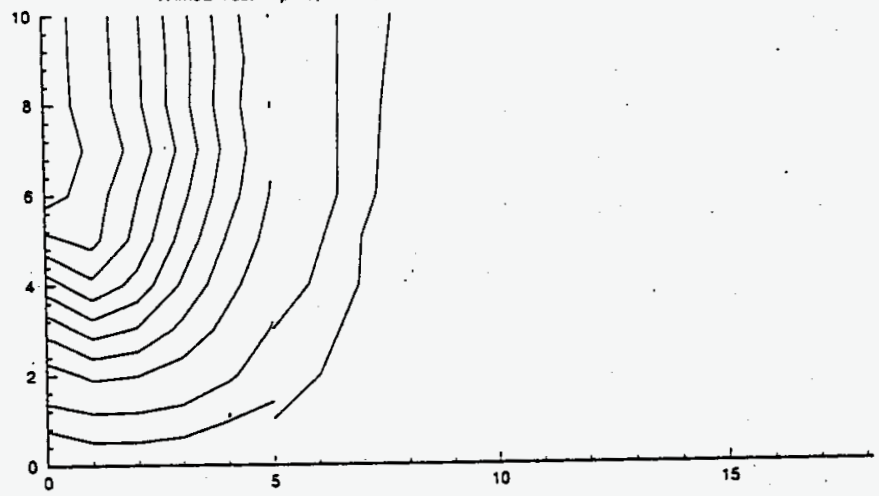


WHC-SD-TI-730

WHC-SD-ER-CSWD-007

Rev. 0

Figure 3. Concentration Contours for Test HVPTNO, VAM3DCG Version 3.1 and 2.46 at Time 0.508 .
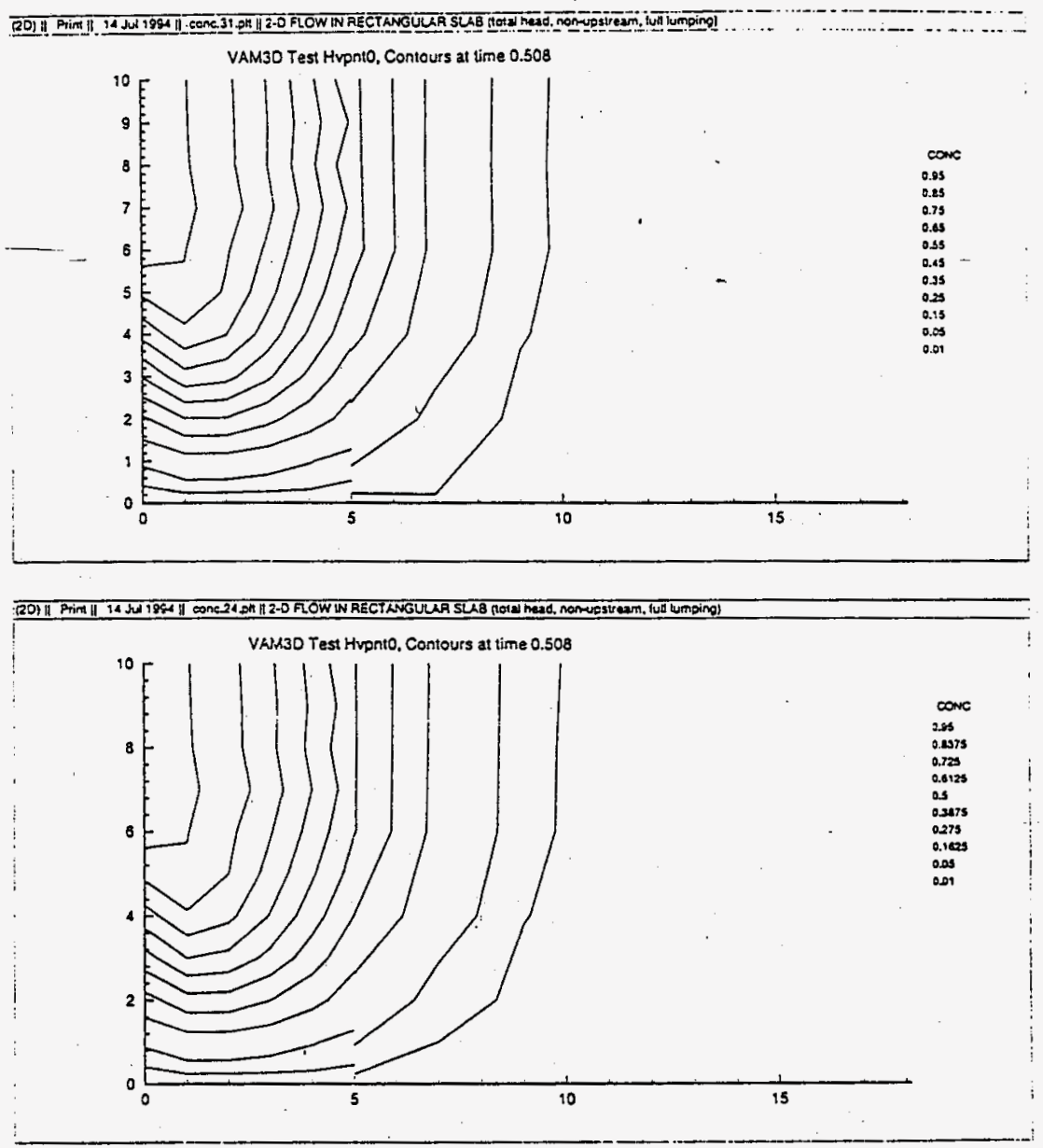


\section{WHC-SD-TI-730 \\ WHC-SD-ER-CSWD-007 \\ Rev. 0}

Figure 4. Simulation Domain for 216-U-17 Crib Model.

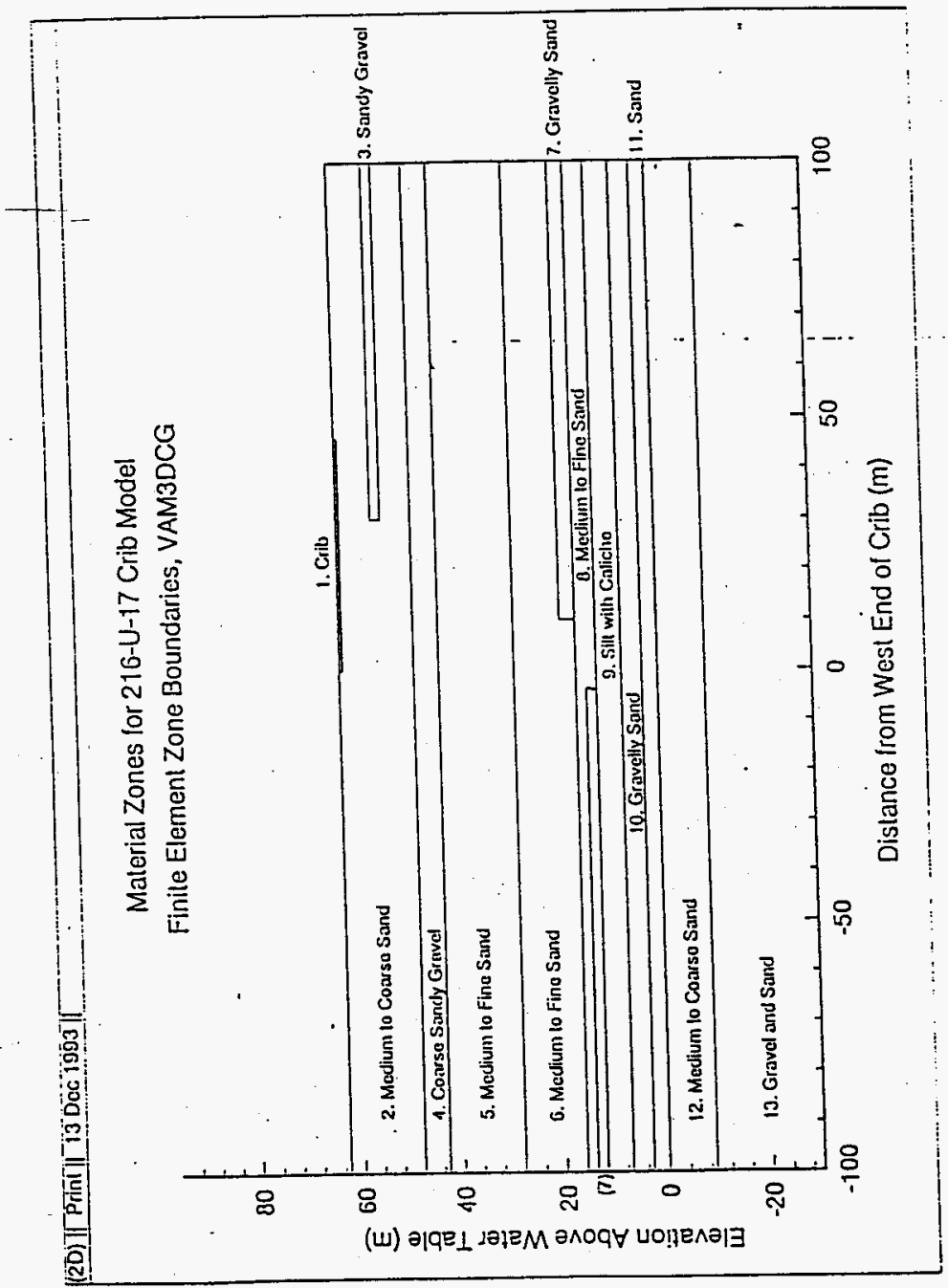




WHC-SD-TI-730
WHC-SD-ÉR-CSWD-007
Rev. 0

WHC-SD-WM-TI-730, Rev. 0

Figure 5. VAM3DCG Version 2.4b, $Z$ Darcy Velocities at Time 5.24 Years.

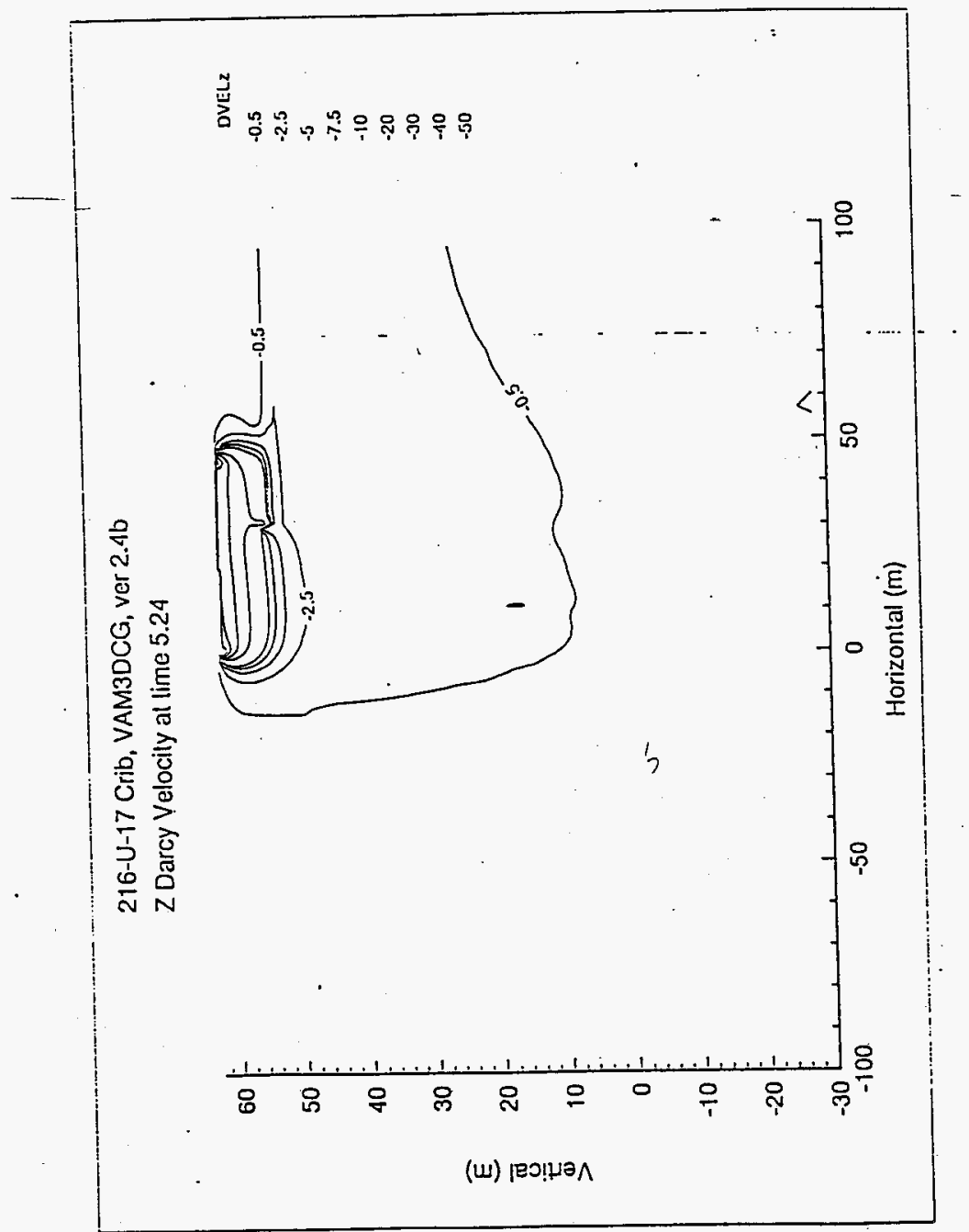


Figure 6. VAM3DCG Version 3.1, Z Darcy Velocities at. Time 5.24 Years.

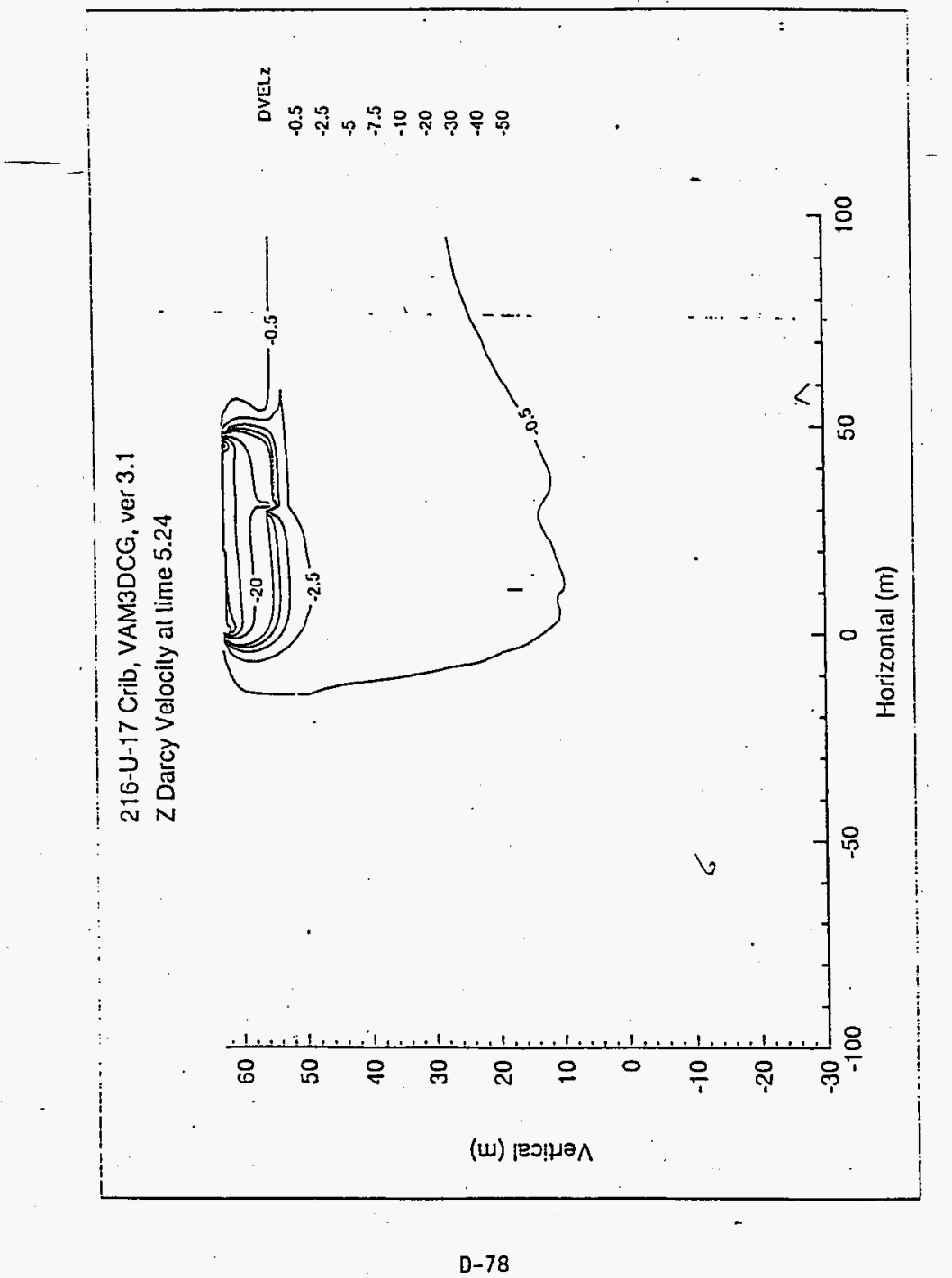




$$
\begin{gathered}
\text { WHC-SD-TI-730 } \\
\text { WHC-SD-ER-CSWD-007 } \\
\text { Rev. } 0
\end{gathered}
$$

Figure 7. PORFLO-3 Version 1.2, 2 Darcy Velocities at. Time 5.0 Years.

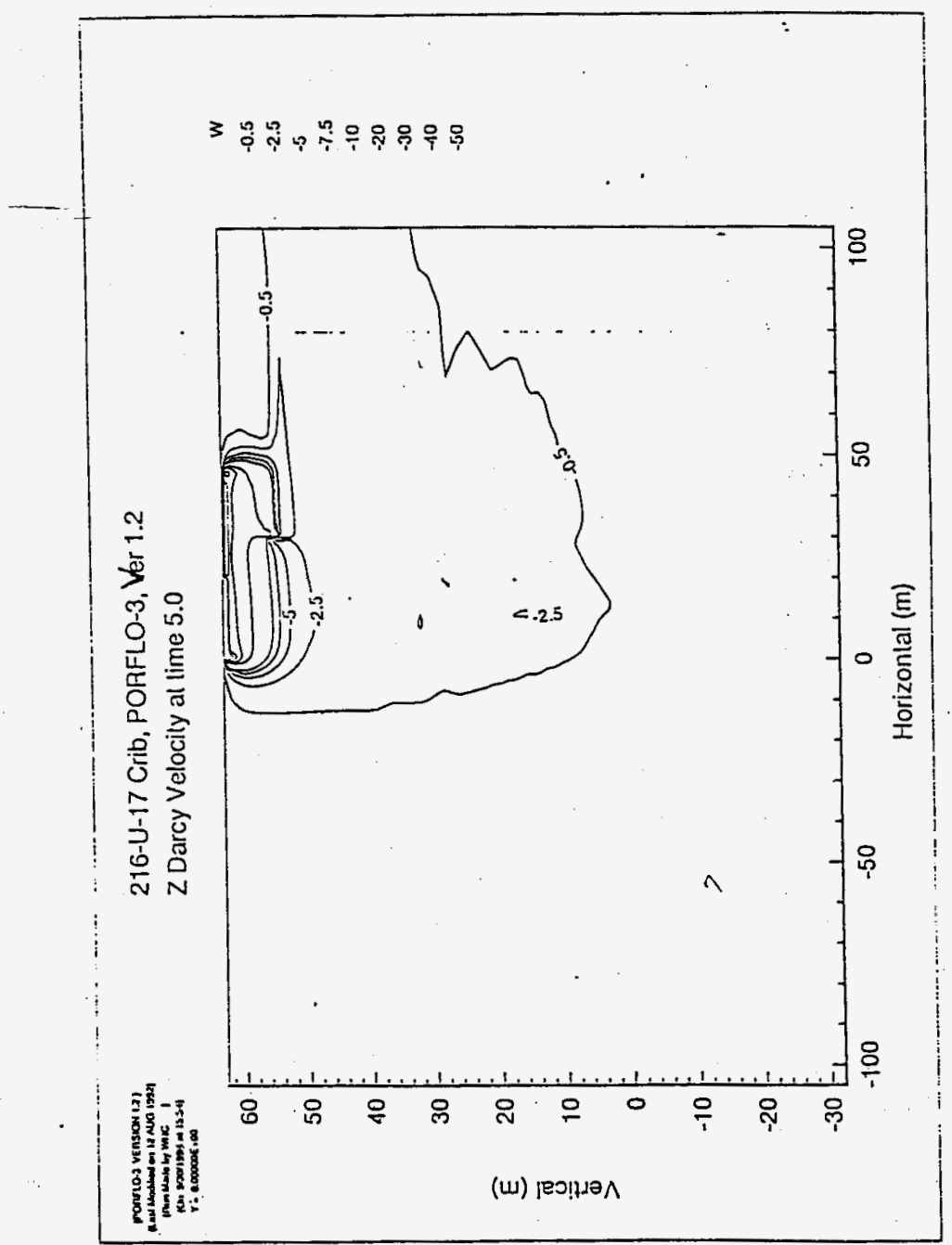




$$
\begin{aligned}
& \text { WHC-SD-TI-730 } \\
& \text { WHC-SD-ER-CSWD-007 } \\
& \text { ReV. } 0
\end{aligned}
$$

Figure 8. VAM3DCG Version 2.4b, $z$ Darcy Velocities at Time 10 Years Without Upwinding.

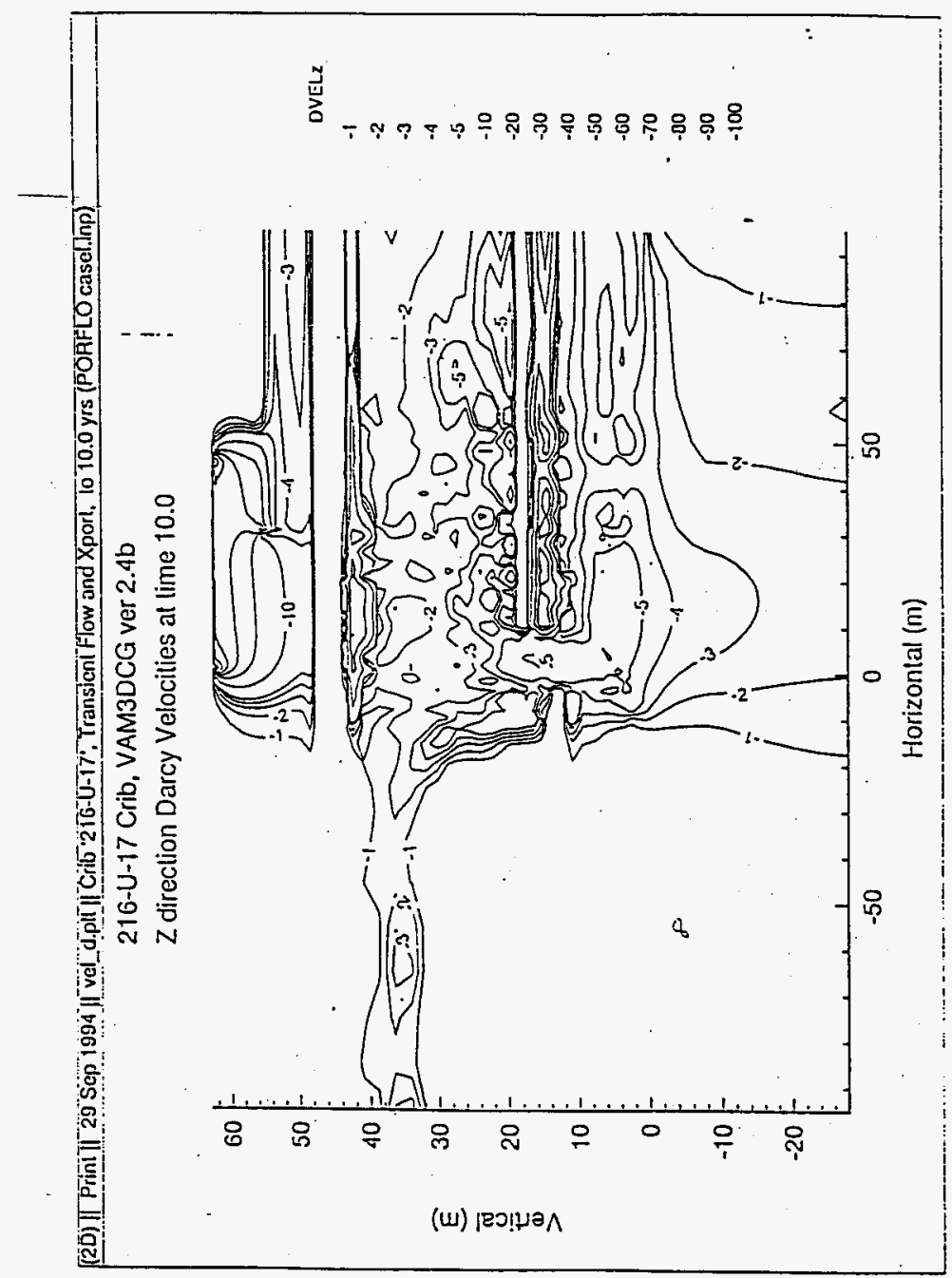




$$
\begin{gathered}
\text { WHC-SD-TI-730 } \\
\text { WHC-SD-ER-CSHD-007 } \\
\text { ReV. } 0
\end{gathered}
$$

Figure 9. VAM3DCG Version 2.4b, Concentration at Time 5.24 Years.

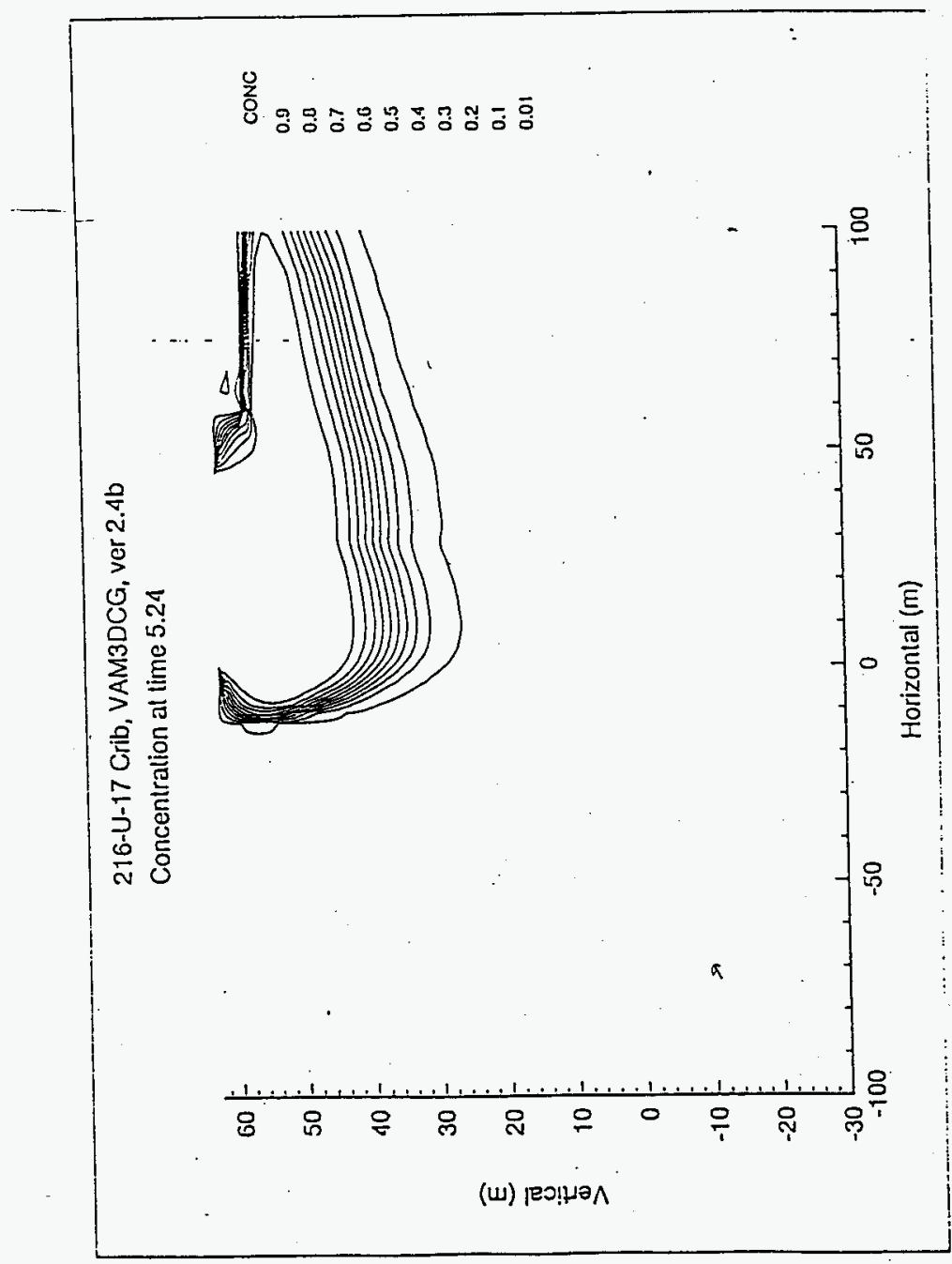




WHC-SD-TI-730 WHC-SD-WM-TI-730, Rev. 0
WHC-SD-ER-CSWD-007
Rev. 0

Figure 10. VAM3OCG Yersion 3.1, Concentration at Time 5.24 Years.

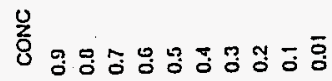

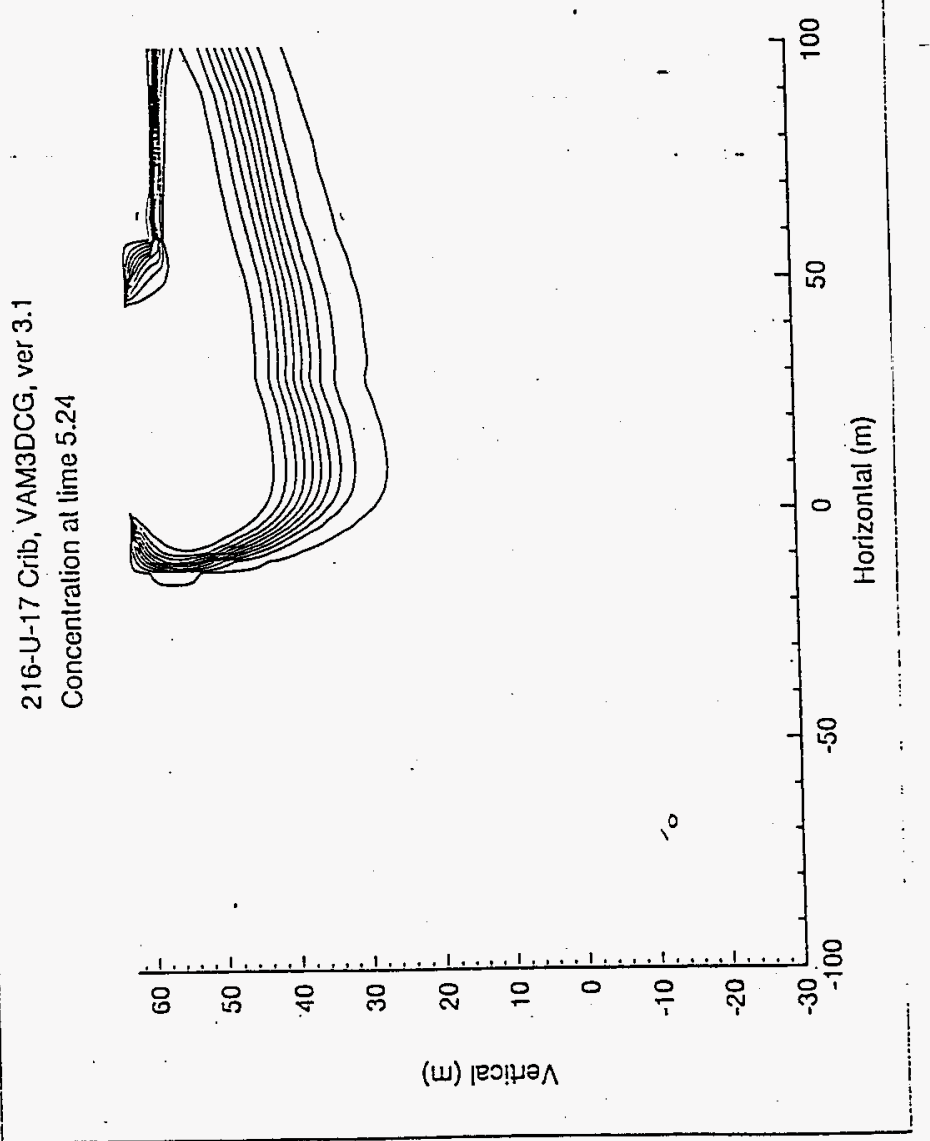


Rev. 0

Figure 11. PORFL0-3 Yersion 1.2, Concentration at Time 5.0 Years.

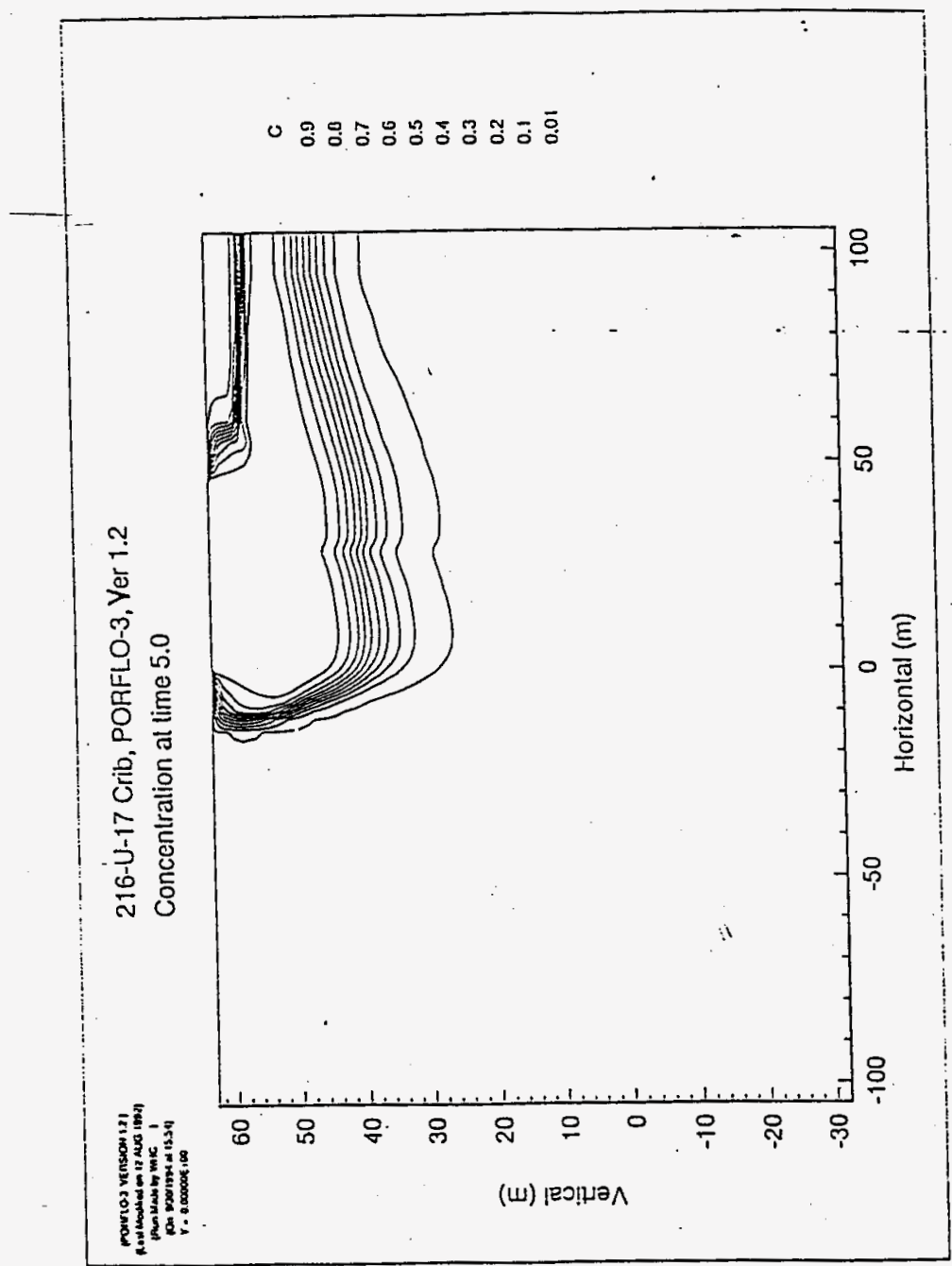


WHC-SD-TI-730

WHC-SD-ER-CSWD-007

Rev. 0

Figure 12. VAM3DCG Version 2.4b, Concentrations at Time 10.0 Years.

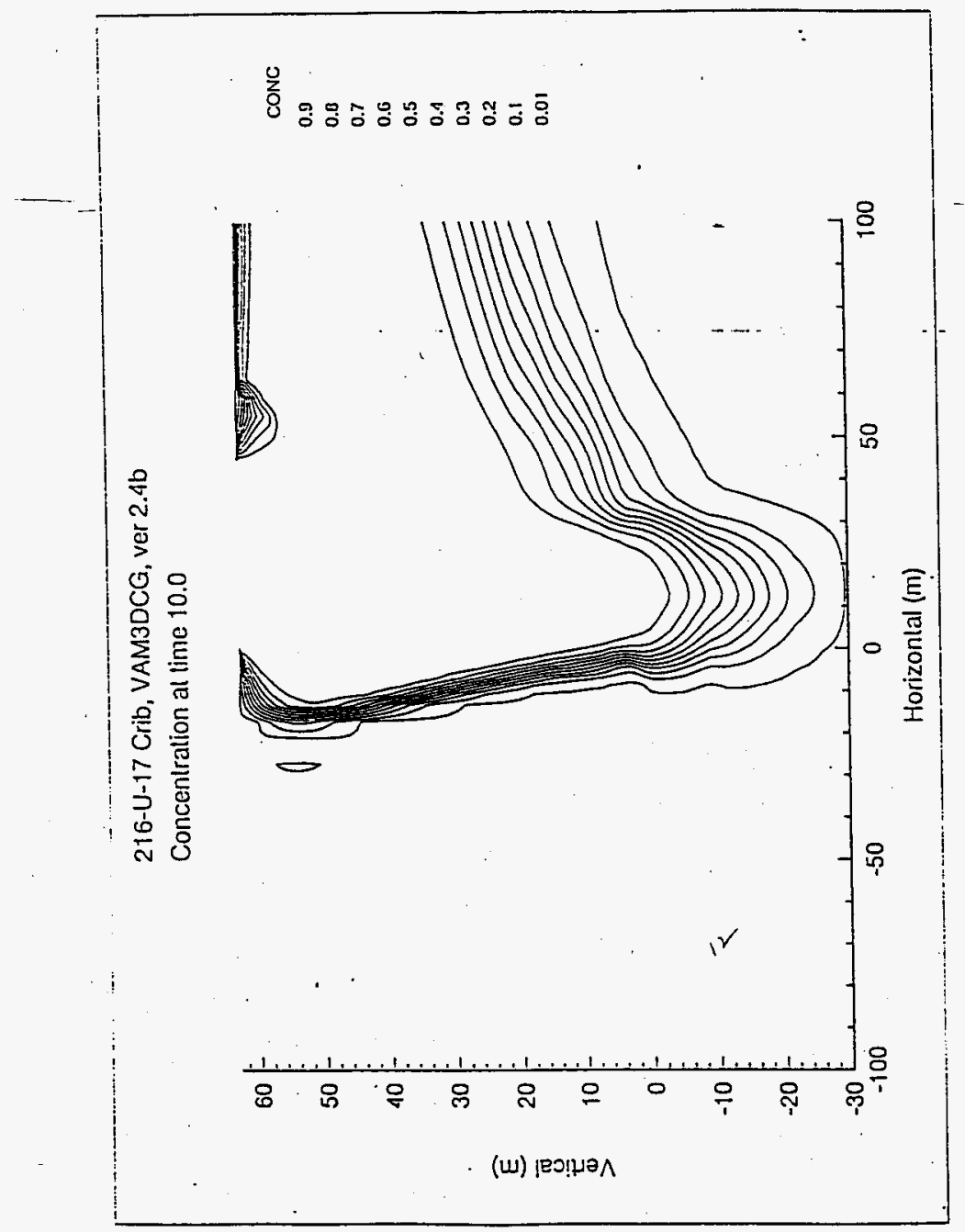




$$
\begin{aligned}
& \text { WHC-SD-TI-730 } \\
& \text { WHC-SD-ER-CSWD-007 } \\
& \text { Rev. } 0
\end{aligned}
$$

Figure 13. VAM3DCG Version 3.1, Concentrations at Time 10.0 Years.

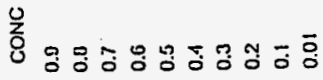

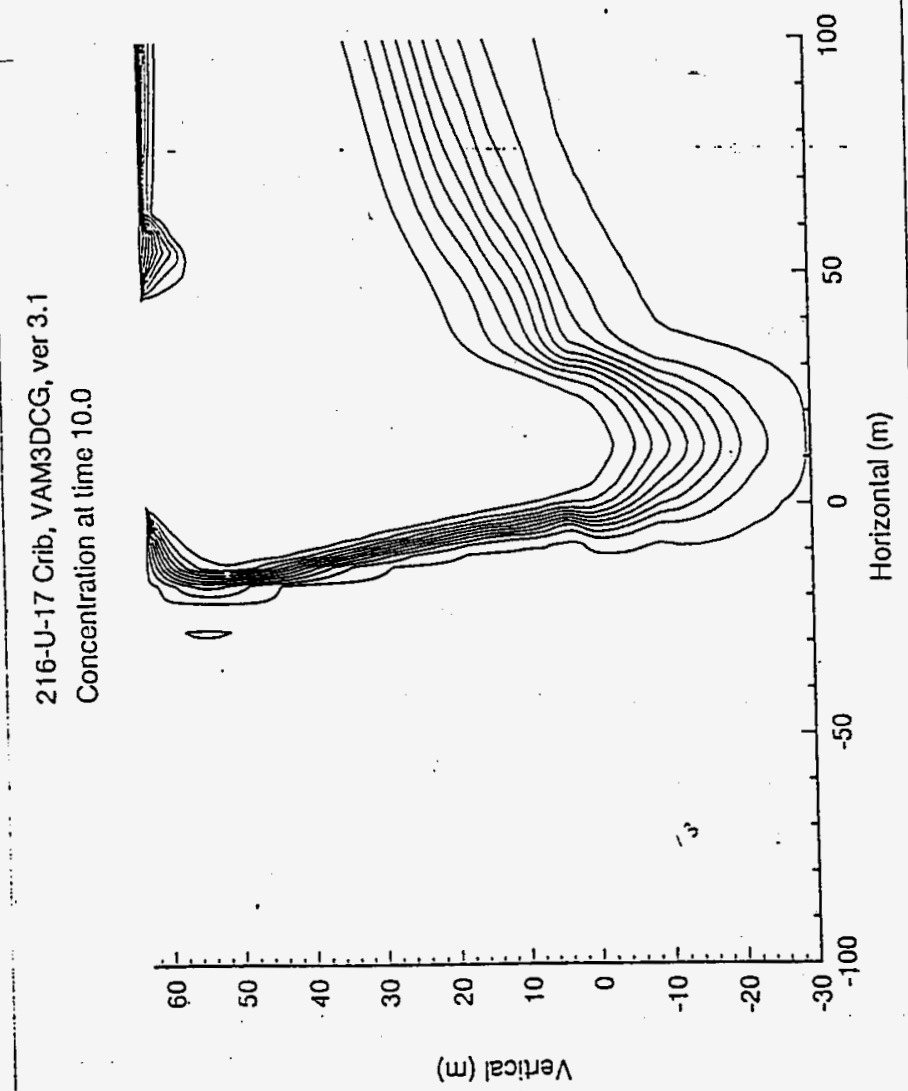




$$
\begin{gathered}
\text { WHC-SD-TI-730 } \\
\text { WHC-SD-ER-CSWD-007 } \\
\text { Rev. } 0
\end{gathered}
$$

Figure 14. VAM3DCG Version 2.4b, Concentrations at Time 10 Years Without Upwinding.

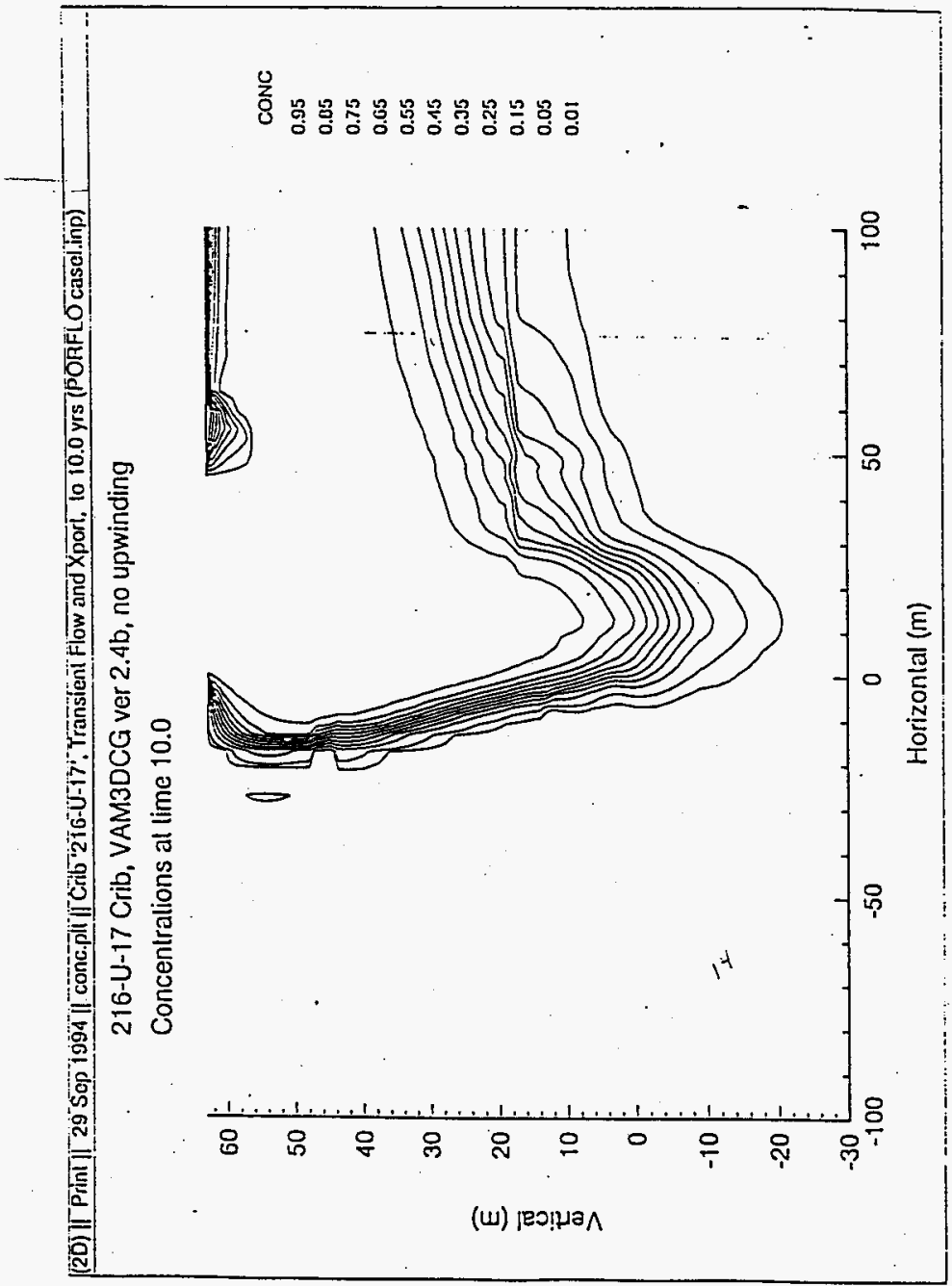




$$
\text { Rev. } 0
$$

Figure 15. VAM3DCG Version 3.1, Concentrations at Time 10 Years Without Upwinding.

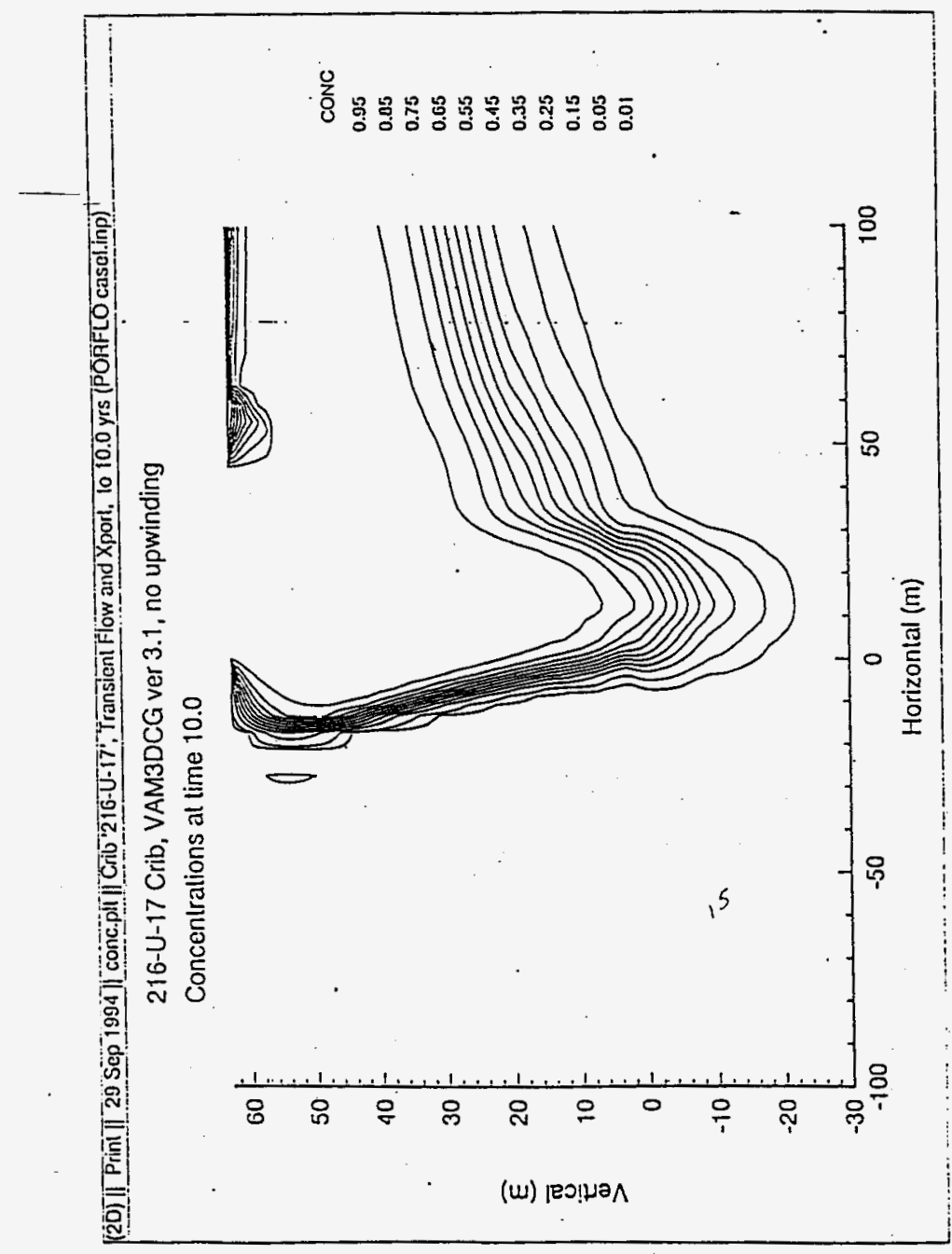




\title{
CALIBRATION/TESTING OF VAM3D-CG COMPUTER CODE USING INJECTION TEST SITE DATA AT HANFORD
}

A. H. Lu and R. Khaleel

\begin{abstract}
A test facility comprised of an injection well at the center and a radial array of 32 monitoring wells was constructed in 1980 at the Department of Energy Hanford Site in southeastern Washington. The facility was used in late 1980 and early 1981 to conduct an infiltration and multiple tracer (i.e., chloride, nitrate, barium, rubidium, strontium-85 and cesium-134) test, in which $45,000 \mathrm{~L}$ of liquid (in eleven increments) were injected at a depth of $4.7 \mathrm{~m}$ over a period of 133 days. Three-dimensional-water content profiles, in layered, coarse sediments, were monitored to a depth of $18 \mathrm{~m}$, by down-hole neutron probe measurements. The initial water contents were measured at 30-cm increments over the $300-$ to $1800-\mathrm{cm}$ depths in all 32 observation welis.. In situ ganma energy analysis data were collected to determine the distribution. of radioactive tracers. The unique three-dimensional nature of the experiment, measurement of water content and radioactive tracers in situ, and the use of multiple injections provide an important data base to validate multidimensional, unsaturated zone flow and transport models. A multidimensional, finite-element code is used to model'the moisture plume at the injection site. Laboratory-measured moisture retention and unsaturated hydraulic conductivity data were obtained for the sediments. The model includes effects of layered heterogeneity, hysteresis, and saturationdependent anisotropy. The preliminary results suggest that saturationdependent anisotropy, enhanced by textural heterogeneities, is a significant process at the injection site. Extensive lateral spreading is suggested by both field data and modeling. Assuming a heterogeneous but isotropic medium for modeling resuit in predictions of significant vertical movement that did not occur during the field experiment.
\end{abstract}




\subsection{INTRODUCTIOH}

The report summarizes the progress made during the Fisc the calibration/testing of the flow model for VAMEE-CE using the Injection Test Site. in 200 East Area (Figure 1). The field experiment was conducted in 1980 and 1981 to provide data on the subsurface movement of weter and contaminants at the Hanford site (Sisson and $L U, 1984$ ).

The field data suggest an extensive lateral spraacing oi the moisture plume. Extensive lateral spreading has also been obsared at other sites at Hanford (e.g., Routson-et al., 1979; Price et al., 1979). Sisson and Lu compared field data from the Injection Site to those from a numerical model. Assuming a uniform isotropic media for the simulation resuited in predictions of moisture movement past the 18-a depth. This deep poyement did not occur at the field site. The spreading was conjectured by sisson and Lu as the result of sediment layering and anisotropy in hydraulic properties; they suggested that improved estimates of model parameters and model satup using information of the "natural" moisture content correlated with the site lithology should be considered a fruitful direction for further study.

As noted earlier, the field observations of Routson $e t \equiv 1$. (1979) and Price et al. (1979) suggest extensive lateral sprasding of the roisture plume in Hanford sediments. Gelhar et al. (1985) suggest that the iateral migration is enhanced if the soil is stratified, the initiai moisture contant is low, the size of. application area is small relative to the size of unsaturated zone, and the liquid application rate is low. These conditions are similar to those at the injection site. The dependence of lataral movement on moisture content suggests a moisture-dependent anisotropy of hydraui ic conductivity. This is in accordance with the stochastic theory of Yeh et al. (1985a,b,c), who indicate that in stratified soils the effective hydraulic conductivity tensor is anisotropic with a tension-dependent dearee o' anisotropy. Other studies (e:g., Mualem, 1984; Mantoglou and Gelhar, 1987; Bear et al., 1987; McCord et al., 1991) also suggest that at higher tansions (Iow moisture contents) in stratified sediments lateral flow may be imortant. This is due to the fact that at a high tension, hydraulic conductivities. of fine-textured soils are relatively high and water may prefer to sproad iateraily in finer soils than to move vertically through coarser soils.

VAM30-CG computer code (Huyakorn and Panday, 1991) is a threedimensional, variably saturated flow and transport code. The flow model is based on the pressure head form of Richards' equation, wile the transport model is based on the advection-dispersion equation. The primary objective of this study is to test the applicability of VAM3D-CG comuter code in simulating the moisture movement in the unsaturated subsuriaca sadiments at the Injection Test Site. A second objective is to gain insight in field mechanisms, especially moisture-dependent anisotrooy, in controlling lateral migration at the field site. 


\subsection{FIEID DATA}

\subsection{Brief Description of Field Experiment}

The field data for the Injection Test site in the 200 East Area at Hanford Site are documented in Sisson and Lu (1984). A recent report (Fayer et al. 1993) combines the information in Sisson and Lu with unpubi ished laboratory and field data on the hydrauic properties of the sediments and core data collected at the end of the experiment. The entire experiment was conducted between 0 - and 20-in depths, WEII within the Hanford Formation (about 60-m deep) and well above the watar tabie (about 90-m deep). A plan view of the well system consisting of an injection wall surrounded by 32 0.152-m (6in) diameter observation wells is shown in Figure 2. A pump delivered each solution from a storage tank to tise injection well, which was the only source of water and tracers to the sediments. Each observation well was constructed from three $6.1-\mathrm{m}(20-\mathrm{ft})$ sections and one $1.52-\mathrm{m}(5-\mathrm{ft})$ section of $0.152-\mathrm{m}$ (6in.)-diameter schedule 40 steel casing. The well numbering scheme is also shown in Figure 2.

Each injection consisted of filijng the hoiding tank, adding the tracers, mixing the water and tracers, and then injecting the solution. About $3800 \mathrm{~L}$ (1000 gal) of water were deliversed For each of ten consecutive weekly injections. An additional injection was executed nine'weeks later. A 20-mL solution of the radiological tracsers ${ }^{35} s$ and ${ }^{15}{ }^{5} s$ were injected for first seven consecutive weekly injections. Tre tracer including calcium salts and additional sorbing tracers, bariur and rubidium. ${ }^{134} \mathrm{Cs}$ was chosen because it is a gamma emitter and undergoes sirong sorption by the sediments. ${ }^{85} \mathrm{Sr}$ was chosen because it is a ganna emitier but is moderately sorbed by sediments.

The cumulative volumes of liquid injection-for injection 1 to 6 are presented in.Figures 3 . The observation-that these lines are nearly paralle] and straight indicates a neariy canstant infiTtration rate.

Field data was obtained by iowering sansors to the desired depths in the observation wells. The sensors used in the experiment included neutron probes, Geiger-Muiler (Gi) probes, gamma energy analysis probes, and gammaganma probes.

Three Campbel1-Pacific Nuciear (C?N) neutron probes were used. The diameter of the probes was slightly jess than $5.08-a m(2-i n)$, smaller than the internal diameter of the 15.2-cm (6-in) well casing. A single caibration equation was generated for the three prabes from data obtained from two sets of calibration standards (Sisson and Lu, 1994).

During installation of the ebservation wells, most of drilled sediments were deposited an the ground. The sediments from the selected depths in three wells, however, were collected in plastic bags as they were biown out of the wells. Eight samples were collectad fram well A-7 (E24-79), three samples were collectad from well E-1 (E24-22), and six samples were collectad from well E-7 (E24-95). 


\subsection{Site Lithology}

Figure 4 is lithologic cross sections sketched from the driller's logs.

$\therefore$ Figure 4 shows one of the cross sections, $W-E$ cross section, based on the information from $A$ and $E$ well series.

In view of Figure 4, five general units or horizons are present. From top to the bottom their general characteristics are as follows.

The first interval consists of sitty fine- to medium-grained sand. It is not clear from the logs if the silts occur mixed with the sands or as interbeds. On one of the cross sections, several boreholes show medium- to coarse-grained sand and gravel locally overiying this silty interval. The interval covers approximately from the land suriace to about $3 \mathrm{~m}$ depth and varies from place to place.

The second interval is dominated by medium- to coarse-grained sand and gravel. Based on the examination of probable outcrop analog for this type of deposit, this material probably consists of variably interbedded horizons of sand and gravel. The scale of interbed in outcrops generally ranges from 0.5 to $2 \mathrm{ft}$. Many of these gravel and sand beds may display an "open-framework" texture. On the basis of the $\log$ descriptions, it is probable that much of this interval is open-framework gravel dominated. The interval covers approximately from about $3 \mathrm{~m}$ to $6 \mathrm{~m}$ depth and varies from place to place.

The third interval is comprised of a variety of deposits. In general it appears to be dominated by medium- to coarse-grained sand. This sand contains numerous lenticular interbeds of gravel and silty sand. Based on the examination of outcrops of potentially analogous deposits, this interval is very well stratified, displaying cross-bedding, horizontal bedding, and channel cut-and-fil1. The interval covers approximately from about 6 in to 12 $m$ depth and varies from place to place.

The fourth interval is dominated by coarse-grained sand and gravel. Several lenses containing little or no gravel and dominated by medium- to coarse-grained sand also are found. Outcrop analogs indicate strata such as this interval dominated by sand and containing both random, unbedided pebbles, and gravel interbeds. The interva] covers approximately from about 12 a to 16 a depth and varies from place to place.

The lowest horizon consists of fine- to coarse-grained sand with minor interbedded silt. The sands, again based on outcrop analogs, are very well stratified. The interval covers approximately from about $16 \mathrm{~m}$ to $18 \mathrm{~m}$ depth and varies from place to place. 


\subsection{Initial Moisture Content}

The selected initial moisture contents measured from 32 observation . wells are plotted in Figures 5 a through $5 d$. Figure 5 a displays the moisture content profiles for wells $A-1, A-3, A-5$ and $A-7$. Figures $5 b, 5 c$ and $5 d$ show the moisture content profiles for we $17 \mathrm{~s} B-2, B-4, B-6$ and $B-8, C-1, C-3, C-5$ and $\mathrm{C}-7$, and $\mathrm{D}-2, \mathrm{D}-4, \mathrm{D}-6$ and $\mathrm{D}-8$, respectively.

The moisture profile data generally corresponds to observed geologic trends in the monitoring wells. Generally, increased moisture contents occur at two main lithologic changes: a. Where there are marked changes from one lithology to another, and $b$. where significant silt-rich deposits, either silty sands or silt beds, occur. On most of the sections the uppermost increased moisture content areas, generally above $7.5 \mathrm{~m}$, occur because of a combination of the preceding two factors. The major moisture increases observed between 10 and $12.5 \mathrm{~m}$ almost all correspond with zones where a significant number of silt-rich sands and silt interbeds occur. Most of the high moisture zones near the base of the sections, between 15 and $17.5 \mathrm{~m}$, correspond to a change from coarse-grained sand and gravel above to fine- to coarse-grained sand below. A few logs suggest silt-rich zones may aiso be present and these could also be a factor contributing to the presence of this lowermost high moisture zone. At several locations there are high moisture zones that do not correspond to anything observed during driliing. It seems most likely that these zones, which are generally in the middle of the sections between 8 and $15 \mathrm{~m}$, correspond to unlogged silt-rich intervals.

\subsection{Field Data Visualization}

Figure-Ga shows the moisture contents as function of time at a radius. of $1 \mathrm{~m}$ and a depth of $6 \mathrm{~m}$. The time span in this plot is 150 days after the first injection began. The distinct response of the soit moisture content to the ten weekly injections is clearly apparent. After ten weekly injections, the moisture contents generally decline but at a slightly different rate. This indicates that the retention capabilities of the soils in the four welis are different. Figure 6 b shows the data at a radius of $2 \mathrm{~m}$ and a depth of $6 \mathrm{~m}$. A similar distinct response to the ten weekly injections is shown. Figure $\sigma c$ shows the data at a radius of $3 \mathrm{~m}$ and a depth of $6 \mathrm{~m}$. The moisture contents in the A weil (east) are generally the highest, whereas those in the $E$ well (west) the lowest. This suggests a preferential flow corresponding to probabiy variably silt-rich interbedded horizons or lenses. Figure $6 d$ shows a similar feature with the most preferential flow being in the south-east ( $H$ well) and the lowest in the north-west ( $D$ well).

Figures 7 a through $7 d$ show the moisture contours at the cross sectionseast-west, northeast-southwest, north-south, and northwest-southeast, respectively, at 59 days after the first injection began. Again, we see a preferential flow. The moisture plume are generally separated vertically into two layers. The second-layer plume shows a downward but mostiy eastward enhancement ( $F$ igure $7 \mathrm{a}$ ) and a downward but mostiy south-eastward enhancement (Figure $7 d$ ). The high moisture contents generaity corresponds to silt-rich deposits, either silty sands or silty beds. 


\subsection{MODEL SET-UP}

\subsection{Strategy of Calibration/Testing}

Approaches of this study were to: a. correlate the initial moisture data taken from the 32 obserration wells and the lithology of the injection site. The lithology of the site was depicted based on driller's logs. This information was used to interpret the initial moisture contents and to set up model layers for the injection site; $b$. assign soil properties to each layer from available soit samples taken from the site at various depths; and $c$. analyze a number of difiterent modeling scenarios which differ in processes. Among the physical processes modeled are isotropy, hysteresis, and saturation dependent anisotrany.

In this paper, focus was on the water movement. An accurate description of water movement is an essential first step in assessing the migration of solute which is of uitizate environmental concern.

\subsection{Finite Element Mesh}

Figure 8 sincws the finite el ement mesh used with soil type numbers. The elements were contigures for axial symetric flow in a,cylindrical coordinate system with layers based on initial moisture contents and available characteristic curres analyzed from soil samples. The water was injected evenly at three nedal points at depths $4.5,5.1$, and $5.7 \mathrm{~m}$ on the left edge, respectively. At these injection elements, the water flux was specified so that the flux intesrates over the surface equaled the rate of injection.

\subsection{Soil Characteristics}

Construction of a geometric model to represent injection site is 1 imited by the scale of geologic hetarogeneity (see Figure 4) and amount of hydrologic data available to distinguish them. Ten soil samples were used to represent ten horizons. The intervals of each horizon were estimated from the observation of initial joisture contents shown in Figures 5 a through $5 d$. Soit type numbers 1 and 2 correspond to the first lithologic interval. The soil type number 3 corresponds to the second Tithologic interval. Soil type number 4, 5, and 6 correspond the third iithologic interval. Two high moisture spikes embodied in the interval (see Figures 5a through 5d) suggested that three soil types should be used. The soil type number 7 corresponds to the fourth 1 ithologic interral. Soil type numbers 9 and 10 correspond to the fifth lithologic isterval. 
A total of 10 from 17 samples analyzed to generate the moisture retention and unsaturated hydraulic conductivity curves were used to represent 10 soil types. The laboratory-measured moisture retention data and unsaturated hydraulic conductivity were fitted simultaneously with the van Genuchten-Mualem equation using the computer code RETC (van Genuchten, 1978). An unsaturated flow apparatus (UFA ${ }^{T H}$ ), based on the centrifuge technique, was used to measure the unsaturated hydraulic conductivities (Conca and Wright, 1990).

\subsection{Model Initial Condition}

Model is a simplified reality. For each stratified layer, the heterogeneity is treated as an equivalent homogeneous system because of lacking of hydrologic data available to distinguish them. A direct employment of the heterogeneous initial moisture contents did not produce a stable initial flow field. The unit gradient theory was used to estimate the model initial condition by assuming a constant recharge rate. Using the average initial moisture contents at various depths (see Figures 5 a through $5 d$ ) and the characteristic curves, we estimate the recharge rate for the injection site to be less than $2 \mathrm{~cm} / y e a r$. The estimate was crude and uncartainty was large, but it showed a remarkable consistency for all the soil types, including the one showing the highest moisture spike.

A steady-state computer run using $2 \mathrm{~cm} / \mathrm{yr}$ recharge rate was performed and the results were used as initial head input for calibration/testing run. The vertical moisture distribution of the model initial condition is shown in Figure 9. The model initial moisture content distribution provides a fairly! good simulation for the highest moisture spike occurring at $10 \mathrm{~m}-12 \mathrm{~m}$ depth, but fail to show the high moisture-spike occurring at $5 \mathrm{~m}-7.5 \mathrm{~m}$ depth. "There were no samples taken at that depth for moisture characteristic curves.

\subsection{MODEL SCENARIOS}

The preceding visualizations of the liquid movement suggest some inherent complexities in modeling the physical process itself. This is due to the fact that the system parameters are not constant, but vary in some manner about their nominal values. 
As discussed earlier, the influence of spatial heterogeneities in soil properties on field-scale flow has been investigated by several researchers (Yeh et al., 1985a,b,c and Mantoglou and Gelhar, 1987). Yeh et al. (1985 b) developed the following expression for anisotropy as a function of the pressure head:

$$
a=\frac{\left(K_{s} k_{z}\right)_{x}}{\left(K_{s} k_{z}\right)_{z}}=\exp \left[\frac{\sigma_{\varepsilon}^{2}+\sigma_{\beta}^{2} H^{2}}{I+\bar{\lambda} A \cos \gamma}\right]
$$

where $\sigma_{f}^{2}=$ variance of $\ln \mathrm{K}_{\mathrm{s}}$ random field,

$\sigma_{8}^{2}=$ variance of the slope of the $\ln K$ vs. $\hat{\psi}$ relationship,

$H=$ mean value of $\psi$,

$\lambda=$ correlation length for both $I n K_{3}$ and $B$ random field in the direction perperidicular to stratification,

$A=$ mean siope of in K vs. $\psi$, and

$y=$ angle between the soil layer stratification and the horizontai.

$\left(K_{s} k_{r}\right)_{x},\left(K_{s} k_{r}\right)_{z}$ are conductivities parallel and perpendicular to stratification, where $K_{s}$ is the saturated conductivity and $k_{r}$ is the relative conductivity. Equation (1) was incorporated in the numerical flow code VAM20 (Kool and Wu, 1991) in a straight-forward-manner. Provided the necessary statistical parameters are known, it allows evaluation of this aspect of the stochastic unsaturated flow theory in a deterministic flow simulation. Using equation (1), Mccord et al. (1991) has reported a good qualitative agreement between the field observations of flow behavior in unsaturated soil and the model simulations.

VAM30 has been modified to simulate the effect of saturation dependent anisotropy on unsaturated flow by using equation (1) to evaiuate anisotropy as a function of pressure head (Huyakorn and Panday, 1992). This requires input values of variabies $\sigma_{f}^{2}, \sigma_{8}^{2}, \lambda$ and $\gamma$. The parameter $A$ can be treated either as an input variable or be evaluated by VAMBD as the derivative of the $\ln \left[k_{r}(\psi)\right]$ relation.

In this study,. simulation scenarios are postulated representing various conceptual models of key processes controlling flow at the injection site. Based on the field data and experience gained in previous modeling effort (Sisson and Lu, 1984), four different model simulation scenarios were evaluated. 
1. Non-uniform, isotropic media with spatial variation of hydraulic properties and initial conditions reflecting initial field moisture contents as close as possibie.

2. Same as scenario 1, except that the effects of hysteres is in the moisture retention curves are. included in the model simulations.

3. Same as scenario 1, with the exception that the saturationdependent anisotropy is included in the model simulation.

4. A variant of scenario 4 with a smaller correlation length.

\subsection{Scenario 1: Mon-uniform, isotropic Media.}

Two sets of moisture retention data, drying and wetting, were analyzed in the Taboratory. For drying (drainage) curves, an option was chosen in RETC run to fit model parameters to measured moisture retention and hydraulic conductivity data simuitaneously. In this process, $K_{3}$ value is not fixed. For wetting (imbibition) curves, an option was chosen to fit retention parameters to measured moisture retention data. The fitted retention parameters are subsequently used to predict the hydraulic conductivity functions. This option assumes that the initial estinates for $K_{s}$ remain unaltered during the parameter optimization process. The fitted parameters for both drying and wetting curves are listed in Table 1 . For one of the material types, $\frac{\pi}{\pi} 6$, both drying and wetting moisture retention and hydraulic conductivity curves are dispiayed graphically in Figures 10-a and 10-b, respectively.

Only drying curves are used in scenario 1. The horizontal and vertical conductivities were assumed to be equal for all the soit types.

\subsection{Scanario 2: Same as 1, but with hysteresis}

This scenario was designed to evaluate the possible influence of soit moisture hysteresis on the infiltration and redistribution of water. The VAMBD computer code has the ability to model the hysteresis in the $\theta(\psi)$ relation, using the procedure described by Kool and Parker (1987). In addition to the retention curves and hydraulic conductivity curves (drying) used in scenario 1 , a set of wetting curves are also used in the numerical simulation. The horizontal and vertical conductivities were again assumed to be identical for all the soil types. 
4.3 Scenario 3: same as 1, but with saturation dependent anisotropy

This scenario examines the effect of the saturation dependent anisotropy on the lateral spreading. Equation 1 provides an expression for the anisotropy ratio, but not for the actual, directional reiative permeabilities themselves. To implement equation 1, McCord et al (1991) suggest the following empirical equations

$$
k_{x}=K_{s} k_{z}^{\mu} ; \quad k_{z}=K_{s} \frac{k_{z}^{\mu}}{a} \quad \text { for } 0 \dot{2} \mu \leq 1
$$

They indicate that the approach worked well with $\mu=0.8$ in a model of a very wet sand.

An empirical logarithmic interpolation procedure was developed by Kool, and $H_{u}$ (1991) which ensures, that both $K_{x}$ and $K_{\text {z }}$ decrease with increasing suction head when they applied equation I in the Las Cruces soil. The algorithm has been implemented in VAM3D-CG and was employed in this study.

The $\sigma_{f}^{2}$ (see eq. 1) was estimated based on constant-head permeameter measurements of $K_{5}$ in the laboratory for 17 samples taken from the injection site during drilling. The estimates for $A$ and $\sigma_{\beta}{ }^{2}$ were obtained using following procedure: a. transform the fitted unsaturated $K(\theta(\psi)$ ) data using $k(\theta(\psi))=k_{s} e^{-s t}$; b. abtain slope of in $k_{r}$ vs. $\psi$ plot. Generally, two distinct $B$ values can be inferred for each sample. The fit for one of samples is showed in Figure 11. The B value characterizing the wet end of the curve was used; and $c$. inean and variances for $17 \mathrm{~B}$ values were then obtäined. The correlation length $\lambda$ was estimated from the variogram using data set of saturated conductivity from the injection sita. The variogram plot is presented in Figure 12.

The statistical parameters used in scenario 3 are:

$$
\sigma_{f}^{2}=3.54 ; \sigma_{3}^{2}=3.50 \mathrm{~m}^{-2} ; \lambda=2.50 \mathrm{~m} ; \text { and } A=3.78 \mathrm{~m}^{-1} \text {. }
$$

\subsection{Scenario 4 : same as scenario 4 , but with $\lambda=0.50 \mathrm{~m}$}

Since the data used for the variogran are scarce and the predicted anisotropy ratio is quite sensitive to the chosen values of $\lambda$, scenario 4 is a variant of scenario.3 using a smaller correlation length of $\lambda=0.5 \mathrm{~m}$. The other statistical parameters renain the same as scenario 3. 
Examples of moisture-dependent anisotropy relations as modeled by VAM30CG for scenarios 3 and 4 are shown in Figures $13 a$ and $13 b$, respectively. These figures show relative conductivity as a function of pressure head. The solid curve represents the isotropic case in which conductivity is given by. the van Genuchten function. The dashed line and the dotted dashed line with triangle symbols represent an anisotropic case with the anisotropy ratio computed by equation (I).

Figures $14 \mathrm{a}$ and $14 \mathrm{~b}$ show the anisotropy ratios calculated by equation (1) with two different correlation lengths, respectively.

\subsection{MODEL EYALUATION CRITERIA}

Numerical results based on various model scenarios are compared with the field measurements. A visual comparison of field data and simulated resuits are presented as: a. contour plots at chosen times; and b. moisture content history plots at various radii and depths.

In addition to visua] comparisons, spatial moments of water contents are computed and compared. This provides a quantitative measure of the goodness of fit of model predictions with the field data. To accommodate the fact that different initial water content distributions are used; we evaluate the flow simulations on the basis of the water content changes, $\theta$, rather than actual water contents, where

$$
\theta(r, z, t)=\theta(r, z, t)-\theta(r, z, t=0)
$$

$r$ and $z$ are components of the cylindrical coordinates. The ij-th spatial-moment of the water content change, $M_{f}(t)$ in an axial symmetric model. is defined as (Freyberg, 1986; Kool and Hu, 1991):

$$
M_{i j}(t)=2 \pi \sum_{i=1}^{N} I_{i} \theta\left(I_{i}, z_{i}, t\right) I_{i}^{k} z_{i}^{\frac{1}{1}} V_{1}
$$

where $V_{i}$ is the volume associated with measurement $i$. Of special interest are the lower-order moments, i.e., the zero, first and second moments, respectively. The central moments of interest are computed from:

$$
\begin{aligned}
& \Delta \theta=M_{00} / V_{T} \\
& I_{c}=M_{10} / M_{00} \\
& z_{c}=M_{01} / M_{00}
\end{aligned}
$$




$$
\begin{aligned}
& \sigma_{z=}^{2}=M_{20} / M_{00}-x_{c}^{2} \\
& \sigma_{z z}^{2}=M_{02} / M_{00}-z_{c}^{2}
\end{aligned}
$$

The zero-order central moment $\Delta \theta$ measures total mass change in the simulation domain. The first-order moments $r_{c}$ and $z_{z}$ indicate the change in location of the moisture plume's radial and vertical center of mass, respectiveiy. The second-order non-central moments $\sigma_{\mathrm{pr}}{ }^{2}$ and $\sigma_{z z}{ }^{2}$ measure spreading in the horizontal and vertical directions, respectively.

\subsection{MODEL RESULTS AND COMPARISONS}

In this section, we compare the field data and the model prediction at various times and locations. The visual comparison is presented first and followed by spatial moment analyses. Ten different soil types were used for all simulation scenarios, but soil properties such as hysteresis and saturation dependent anisotropy were varied according to model scenario assumptions.

\subsection{Visual Comparison}

For visual comparison, two different plots are presented: a. the contour plots of average moisture contents measured at the field at four chosen times, followed by the corresponding predictions calculated by four model scenarios; and $b$. the history plot comparisons of the field data with each scenario predictions at chosen depths and radii.

\subsubsection{Contour Plot Comparison}

Figures 15 a through $15 \mathrm{~d}$ show the field-measured average moisture content contours at $t=1.25,13.2,22.2$, and 31.2 days, respectiveiy, after the first injection began. The first five injections took place at time intervals, $t=0.58-0.98$ days, $7.45-7.89$ days, $14.40-14.82$ days, $21.38-21.75$ days, and $28.39-28.77$ days, respectively. Since an axial symmetric model was used, average field data were used for comparison. The average was obtained by summing up the moisture contents over four wells at the same radius and depth and dividing it by four. These figures indicate how the liquid migrates through the sediments in an axial average sense. Generally, we see that the moisture movement is anisotropic and stratified. An enhancement of lateral water movement occurs at intervals generally corresponding to the high initial moisture spikes. A downward break-through occurred at the region near the injection well where the moisture contents were high. As a result, a fingering of the moisture contours is exhibited. e.g. At $t=13.2$ days, the moisture contour (marked $\# 2$ ) has moved radially over $6 \mathrm{~m}$ at a depth of $5.4 \mathrm{~m}$ and over $3 \mathrm{~m}$ and $3.5 \mathrm{~m}$ at depths $8 \mathrm{~m}$ and $9.5 \mathrm{~m}$, respectively. A similar 
fingering phenomenon occurs at higher moisture contours as well. it $t=2 ? .2$ days, the moisture contour of $\frac{42}{\pi 2}$ has progressed to the detactad lizit $(r=3$ ?
and the lowest finger has migrated over $5 \mathrm{~m}$.

We see a fast lateral water movement during and after the first tro injections. The low moisture contour levels remained relatively steady aftar 22.2 days when the fourth injection had just completed. Compared to the contour plot at $t=22.2$ days, the upper part. of the plume at $t=31.2$ days (two and half days after the fifth injection completed) remain relativeiy stisdy and the high moisture contours dissipated downward and then migrated iateraiiy along the lower preferential paths. Up to this time, a vertical fiow berrier has been seen at a depth of $11.5 \mathrm{~m}$.

Figures 16 a through 16 d show the corresponding contour plots of the moisture contents calculated by scenario 1. Compared to the field data (sea figures 15 a through $15 \mathrm{~d}$ ), the model overpredicts the downward moverent and underpredicts the horizontal spread of the moisture plume, especiaily at the depths of 5-7 m. At $t=31.2$ days, the model predicts that the moisture piume has moved down past the 17 in depth at a radius of 1 in. This deep rovernent did not occur. At $t=31.2$ days, the predicted moisture contents at the depths ot 8-12 $\mathrm{m}$ are general7y higher than the measured ones.

Figures 17 a through $17 \mathrm{~d}$ show the contour plots of moisture cantents calculated by scenario 2. Compared to scenario 1, the inclusion of the hysteretic.process resulted in some noticeable local variations, howeyer, the results showed no significant change in size and shape of the moisture piume. It is seen that accounting for hysteresis does not enhance the Tataral spreading. The mode? computed scanning curves in the moisture saturation vs pressure head relation to determine the appropriate saturation path for every element in the model domain when reversals from wetting to drying, or vice versa occur. The wetting and drying curves were measured from laborator: The hysteratic phenomenon was attributed to pore scale effect. Since the wetting and drying curves were employed regardless of directions (yertical or horizontal), it is not likely resulted in an anisotropic flow.

The stochastic theory (Mantoglou and Gelhar, 1987a,b,c) attributas the large-scale hysteresis to the spatial soil variability. In this interpretation, as demonstratad in the paper, a vertical flow plume in a stratified soils could result in an enhanced lateral flow.

Figures 18 a through $18 \mathrm{~d}$ show the contour plots of moisture centents predicted by scenario 3 . The simulation predicts a sightly larger degrze oi horizontal spread and a lesser downward movement of the moisture piume tian those predicted by scenarios 1 and 2 . Compared to the field data, the horizontal spread is still very much underpredicted by the model. It is because that the anisotropy ratios are small for the moisture contcurs oi level 2 and above. In view of the Figure 10-a, the anisotropy ratios are less than two when the capillary pressure heads are less than 1 m, which corresponds to the moisture contours of level 2 and above for most retantion curves used for the simulation. Compared to the field observation, a sull tar and fatter fingers were appeared at later times due to the layers in mich soit hydrautic properties were different. 
Figures $19 \mathrm{a}$ through $19 \mathrm{~d}$ show the contour plots of moisture contents predicted by scenario 4 which used a smaller correlation length and kept other parameters the same as that in scenario 3 . The decrease in the correlation length from $\lambda=2.5 \mathrm{~m}$ to $\lambda=0.5 \mathrm{~m}$ resulted in a substantial increase of the anisotropy ratios (see Figure 10-b). The inclusion of this scenario is because of the 1 imited samples, especially the short distance pairs, warranting a sensitivity run. Among the four scenarios considered, the scenario 4 predictions compare most favorably with the field data. However, compared to the fieid data, the horizontal spread is still underpredicted, especially at depths of 5-7 m.

\subsubsection{History Plot Comparison}

The following comparisons are intended to examine the resuits of the four model scenarios in response to the infi7tration and redistribution at chosen depths and radii.

Figures 20a through 20d and 2la through 21d show the comparison of calculated moisture contents by scenario 1 with the measured ones at the depths of 6.0 and $8.4 \mathrm{~m}$, respectively. The measured data at four wells display along with the results generated by the model. At each depth, the comparisons are made at radii of $1 \mathrm{~m}, 2 \mathrm{~m}, 3 \mathrm{~m}$, and $4 \mathrm{~m}$. At a depth of $6 \mathrm{~m}$, the model shows a good agreement at a radius of $1 \mathrm{~m}$. However, the model underpredicts at radii of $2 \mathrm{~m}, 3 \mathrm{~m}$ and $4 \mathrm{~m}$. In these piots, we see that water was detected in an early time at wells $\mathrm{B}-4$ and $\mathrm{H}-4$ which are 4-m away from the injection well. Meanwhile, the water simulated by the model hasn't reached the wells which are 3-m away, even at the end of 35 simulation days. At a depth of $8.4 \mathrm{~m}$, the model shows a good agreement at a radius of $1 \mathrm{~m}$, a good to fair agreement at the radij of $2 \mathrm{~m}, 3 \mathrm{~m}$ and $4 \mathrm{~m}$.

Figures $22 a$ through $22 d$ and 23 a through $23 d$ show a similar comparison of calculated moisture contents by scenario 2 with the measured ones. Scenario 2 includes the hysteretic process in the model simulation. Again, at a depth of $6 \mathrm{~m}$, the model shows a good agreement at a radius of $1 \mathrm{~m}$ and underpredicts at radii of $2 \mathrm{~m}, 3 \mathrm{~m}$ and $4 \mathrm{~m}$. At a depth of $8.4 \mathrm{~m}$, the modei shows a good agreement at a radius of $i \mathrm{~m}$, a good to fair agresment at the radii of $2 \mathrm{~m}, 3$ $m$ and $4 \mathrm{~m}$. The peaks in response to the infiltration at radij of $1 \mathrm{~m}$ and $2 \pi$ are slightiy different from that depicted in scenario 1. The wetting curve: was selected by the code during the period of the infiltration, and the drying curve was selected during the redistribution. These local variations didn't result in a significant lateral migration.

Figures 24 a through $24 d$ and 25 a through $25 d$ show a comparison of calculated moisture contents by scenario 3 with the measured ones. Scenario 3 includes the saturation dependent anisotropy in the model calculation. At the depth of $6 \mathrm{~m}$, the model shows a good agreement at $r=1 \mathrm{~m}$ and underpredicts at $r=2,3$, and $4 \mathrm{~m}$. At a depth of $8.4 \mathrm{~m}$, the model shows good agreement at a radius of $1 \mathrm{~m}$ and some improvement at radii of $2 \mathrm{~m}$ and $3 \mathrm{~m}$ in comparison with scenarios 1 and 2 . 
Figures 26a through $26 \mathrm{~d}$ and 27 a through $27 \mathrm{~d}$ show a camparison of calculated moisture contents based on scenario 4 with the measured ones. depth of $6 \mathrm{~m}$, the model shows a good agreement at a radius oi $1 \mathrm{~m}$, a significant improvement at radii of $2 \mathrm{~m}$ and $3 \mathrm{~m}$ comaring to the other scenarios: At a depth of $8.4 \mathrm{~m}$, the model shows an exceilient to good agreement at all radil.

\subsubsection{Overview of Visual Comparison}

A comparison of the four model scenarios with the fieid data suggests that scenario 4 provides the most favorable fit. Scenario I generally underpredicts the lateral movement of the moisture plume and overpredicts the vertical penetration. Scenario 2 shows a similar irend as scanario 1 but with noticeable local variations. The effect of hysterssis on the lateral water movement is insignificant. In the model the hysteresis was simulated indistinguishably in the horizontal and vertical direction. However, the stochastic theory (Mantoglou and Gelhar, 1987) demonstrated that a vertical water movement in a stratified soil shouid exhibit a large-scale hystaretic phenomenon.

Inclusion of the process of saturation-depencent anisotropy in the mode? could partialiy account for the extensive lataral spreading of the plume which occurred in the field. The anisotropy ratio is sensitive to the correlation length. A.better fit for scenario 4 with a salier corritation length suggests that the soil textural heterogeneity is underescimated by the limited soil sampies that are available.

\subsection{Spatial Moments Analysis}

The following section provides a quantitative assessment, using spatial moment estimates, of a number of aspects of the preceding visual comparison of the moisture movement. Note that the moisture contents jeasured in the field show considerable variability in space which can be attributed to smali-scale heterogeneities within the sediments. Soatial maments of the noisture plume distribution only provides a larger-scale, integrated measures of the water movement.

Figure 28 shows the zero-order mowent calcuiations. In this calculation, the zero moment is the change of the integrated total mass over a cylindrical section with the depths from $3 \mathrm{~m}$ to $16 \mathrm{~m}$ and the radi i from 0 to 8 m. For the field-measured data, we assume the moisture eontent of each annulus with a depth of $0.3 \mathrm{~m}$ is represented by the average of 4 measurements from the wells located at the middle radius of the annulus. The solid line represents the total volumetric water injected. Camparef to the total mass injected, the integrated total mass for field-neasured data is consistently higher by up to 35 percent. The reasons for the discrepanc: are unclear. One kind of errors conjectured is the over-representation or the preferential flow region. The measured history plots presented in Figures ba through sd show a preferential flow in the welis at the esst, south-sist, and south; and much less flow in the welis at the north, nor-h-west, ard wes:. Since only four 
flow paths are intercepted and recorded at a radius of every meter, the average might be misrepresented by the higher moisture fiow path. The other kinds of errors might be attributed to the calibration and measuraments. The measurement was done manually by lowering sensors to the desired depths in each of the observation wells. Two measurement errors night have been generated: a. readings in a single observation well vere recorded as one time; and $b$. the probe location (centered or decentraiized) may afrect its sensitivity. Quantifying the errors, however, is difoicuit.

Figure 29 shows a comparison of measured and caicuiated first-order moments. The first-order moments $r_{c}$ and $z_{c}$ indicate the change in location of moisture plume's center of mass in a cylindrical coorcinetes. Calculations were made at five different times: a. 1.25 days, right atiar the first injection completed; b. T.25 days, the plume has gona six-day radistribution after the first injection completed; c. 13.2 days; before the third injection begins; d. 22.2 days, right after the 4 th injection completed; and e. 34.2 days, before the 6 th injection took place.

The results are consistent with what the yisuai comoarisons have shown. The center of mass of the field plume anoved fast during and atter first two injections and remained relatively steady afteraards.

A relatively steady movement was seen for the caicuiated center of mass for all scenarios. Scenarios 1 and 2 underpredict radiai movement and overpredict the vertical downward movement of the pilue's center of mass. Scenario 3 show a slight improvenent in the lataral migration of the moisture plume. A significant improvement in the lateral spresding was saen in scenario 4 but still underpredicted compared to the fieid data. The degree of underprediction might slightly be overestimated in view of the zero-moment calculation which indicates a possible systematic error in the moisture content measurements.

The values of the first and second spatial moments at chosen times are presented in Table 2. The values of second moment confirged conclusions from the previous discussions. $3 . e$. The field ata show iuse spatial variability and more spreading both horizontally and verticaily than the calculated ones. However, the horizontal spreading of the piume calculated by scenario 4 is most closely to that observed in the fieid. 
Table 2. Spatial Moments of Simulated and Observed Moisture Plumes

\begin{tabular}{|c|c|c|c|c|c|}
\hline Moments & $I$ & 2 & 3 & $\underset{4}{\text { enario }}$ & Field \\
\hline \multicolumn{6}{|c|}{$t=1.25$ days } \\
\hline r. (m) & 1.25 & 0.735 & 1.18 & 1.28 & 2.36 \\
\hline$z_{-}(\mathrm{m})$ & -6.58 & -6.40 & -5.18 & -5.41 & -6.93 \\
\hline$\sigma_{-1}^{2}\left(m^{2}\right)$ & 0.302 & -1.90 & 2.75 & 3.25 & 2.10 \\
\hline$\sigma_{m}{ }^{2}\left(m^{2}\right)$ & 2.160 & 1.73 & 1.60 & 0.97 & 4.16 \\
\hline \multicolumn{6}{|c|}{$t=34.2$ days } \\
\hline$r_{-}$(m) & 2.03 & 1.97 & 2.08 & 2.76 & 4.21 \\
\hline$z$. (m) & -10.30 & -10.40 & -9.87 & -7.85 & -8.38 \\
\hline$\sigma_{n}^{2}\left(m^{2}\right)$ & 0.37 & 0.68 & 0.79 & 2.27 & 3.89 \\
\hline$\sigma .^{2}\left(m^{2}\right)$ & $4 . \div 7$ & 5.43 & 5.04 & $3.11^{\prime}$ & 6.83 \\
\hline
\end{tabular}

\subsection{CONCLUDING REMARKS}

The preliminary results suggest that both structural layering and saturation-dependent anisotropy are significant processes at the injection site. Results of seenario 2 show that hysteresis is not a significant factor to cause an enhanced water lateral movement in this experiment, at least in the way hysteresis was treated in the mode].

The initial moisture contents are consistent with the Jithologic information gathered from the driller's logs. The enhanced lateral movement of the moisture plume is generally confined in two layers in which the initial moisture contents have high moisture spikes. The 7 ithologic information suggests a finer but highily heterogeneous soil texture in these layers. The field data suggested that the downward brak-through occurred in the region near the injection well where the moisture contents were high. As a resuit, the moisture contours exhibited a fingering phenomenon.

Inclusion of the process of saturation-dependent anisotropy in the mode] could partialiy account for the extensive lateral spreading of the plume which occurred in the field. The anisotropy ratio is sensitive to the correlation length. A better fit for scenario 4 with a smaller correlation length suggests that the soit textural heterogeneity is underestimated by the limited soif samples that ar a availabie. 
The spatial moment analyses showed a consistent conclusion with the visual comparisons. The zero moment anaiysis, which accounts for the change - of the total water mass, indicated that the integrated field water mass was consistently higher (up to $35 \%$ ) than the water mass injected. A poor calibration of the neutron probes were suspected. The first moment analys is showed that the field data exhibited a fast lateral spreading during the first two or three injections. And then the center of mass remained relatively steady. The second spatial moment analysis showed that the field data exhibited more spatial variability than the calculated ones. However, the horizontal spreading of the plume calculated by scenario 4 is most closely to that observed in the field.

A deficiency of the saturation-dependent anisotropy theory for this application was noted that the relative conductivities calculated with the anisotropy ratio computed from equation (I) increase with decreasing pressure in the dry end of the curves. 


\section{REFERENCES.}

Bear, J., C. Braester, and P. C. Menier, 1987, "Effective and Relative Permeabilities of Anisotropic Porous Media," Transport in Porous Media, 2, pp.301,316.

Conca, J.L. and J. Hright, 1990. "Oiffusion coefficients in grave? under unsaturated conditions. Water Resour. Res., v. 26, pp. 1055-1060.

Fayer, M. J., J. B. Sisson, W. A. Jordan, A. H. Lu, P. R. Heller and T. J. Nichoison, "Subsurface Injection of Radioactive Tracers," NUREG/CR5996, PNL-8499, February 1993.

Freyberg, 0. L., "A Natural Gradient Experiment on Solute Transport in a Sand aquifer, 2. Spatial Moments and the advection and Dispersion of Nonreactive Tracers," Water Resour. Res., 22(13), 2031-2046, 1986.

Huyakorn, P. S. and S.'Panday, "VAM3d-CG - Variabiy Saturated Analysis Model in Three-dimensions with Preconditioned conjugate Gradient Matrix Solvers: Documentation and User's Guide, Version 2.2", HGL-89-02, July 1991

Kool, J. 8., and J.C. Parker, 1987. Development and evaluation of close-form expressions for hysteric soil hydraulic properties, Water Resour. Res., 23: 105-114

Kool, J. B., and Y. S. Wu, 1991. Validation and Testing of the VAM2D Computer Code, NUREG/CR-5795.

Mantoglou, A. M. and L. W. Gelhar, 1987a, "Stochastic Modeling of large -ScaTe Transient. Unsaturated Flow Systems, "Water Resour. Res., 23(1), $37-46$.

Mantoglou, A. M. and L. W. Gelhar, 1987b, "capillary Tension Head Variance, Mean Soil Moistur Content, and Effective specific Soil Moisture Capacity of Transient Unsaturated Flow in Stratified Soild," Water Resour. Res., 23(1), 47-56.

Mantogiou, A. M. and L. W. Gelhar, 1987c, "Effective Hydraulic Conductivities of Transient Unsaturated Fiow in Stratified Soils, " Water Resour. Res., 23(1), 57-67.

McCord, J. T., D. B. Stephens, and J. L. Wilson, "Hysteresis and StateDependent Anisotropy in Modeling Unsaturated Hill Slope Hydralogic Processes," Water Resour. Res., 27(7), 1501-1518, 1991.

Muaiem, Y., 1984, "Anisotropy of Unsaturated Soil," soil Sci. Soc. Am. J., pp. 513-522.

Price, S. M., R. B. Kasper, M. K. Additon, R. M. Smith and G. V. Last. 1979. "Distribution of Plutonium and Americium Beneath the 216-Z-1A 
Crib: A Status Report. Rockwell International Report RHO-ST-17, Richl and, WA.

Routson, R. C., W. H. Price, D. J. Brown and K. R. Fecht. 1979. "High Level Waste Leakage from the 241-T-106 Tank at Hanford. Rockwell International Report RHO-ST-17, Richland, WA.

Sisson, J. B. and Allen H. Lu, "Field Calibration Of Computer Modeis for Application to Buried Liquid Discharges: A Status Report", RHO-ST-46 P, August 1984.

van Genuchten, R., 1978, "Calculating the Unsaturated Hydraulic conductivity with a New Close-form Analytic Medel," Report 78-WR-08, Water Resources Program, Department of Engineering, Princeton University, Princeton, New Jersey.

Yeh, T.-C. Jim, L. W. Gelhar, and A. L. Gutjahr, 1985a, "Stochastic Analysis of Unsaturated Flow in Heterogeneous Soils, 1. Statisticaliy Isotropic Media," Water Resour. Res., 21(4), 447-456.

Yeh, T.-C. Jim, L. W. Gelhar, and A. L. Gutjahr, 1985b, "Stoctiastic Analys is of Unsaturated flow in Heterogeneous Soils, 2. Statistically Anisotropic Media With Variable $\alpha$, "Water Resour. Res., 21(4), 457-464.

Yeh, T.-C. Jim, L. W. Gelhar, and A. L. Gutjahr, 1985e, "Stochastic Analys is of Unsaturated flow in Heterogeneous Soils, 3. Observations and Applications," Water Resour. Res., 21(4), 465-471. 
Injection Test Site

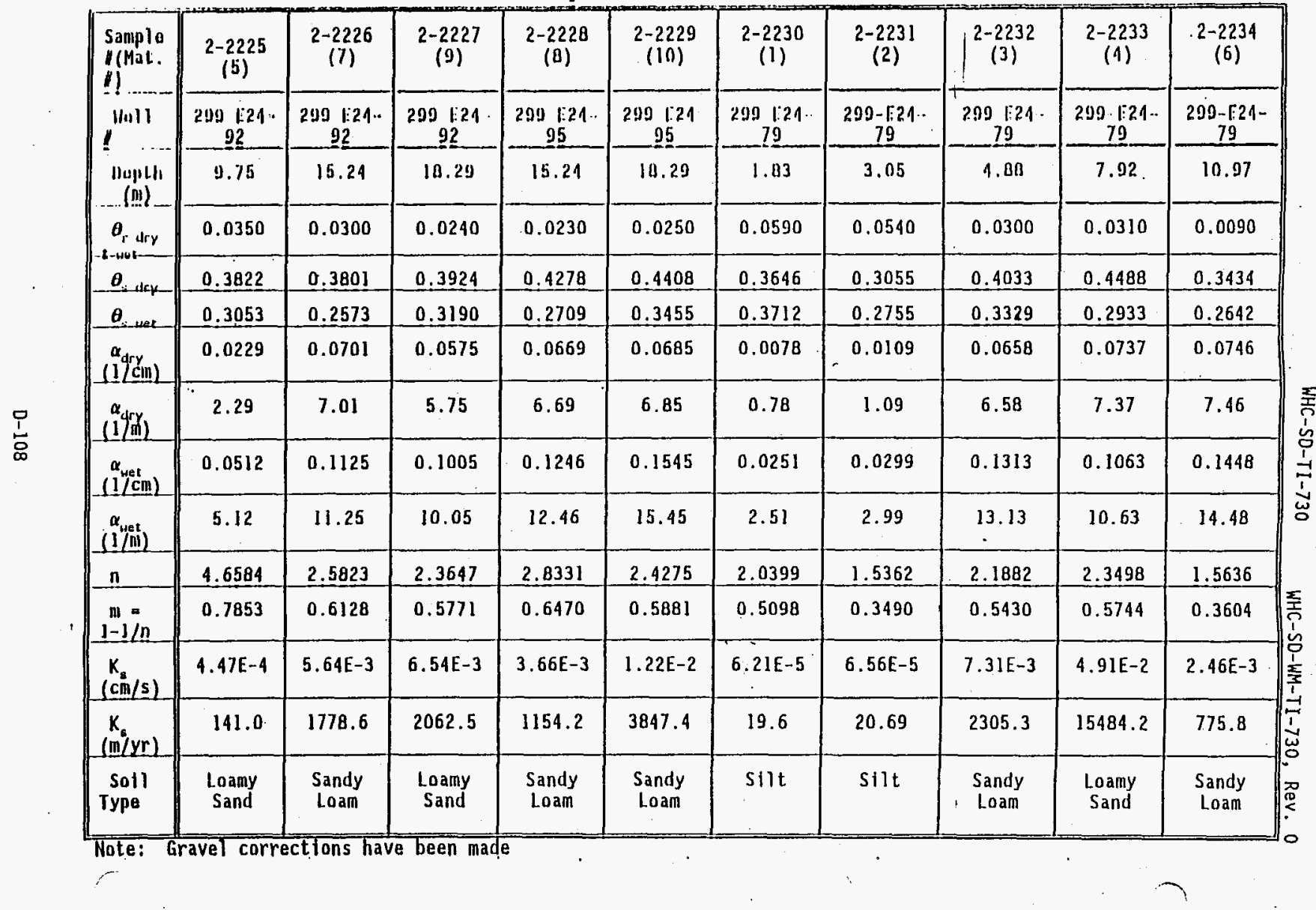




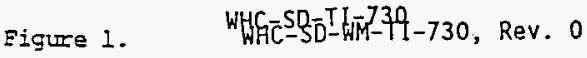

Location of Injection

Experiment in 200 East Area

of the Hanford Site
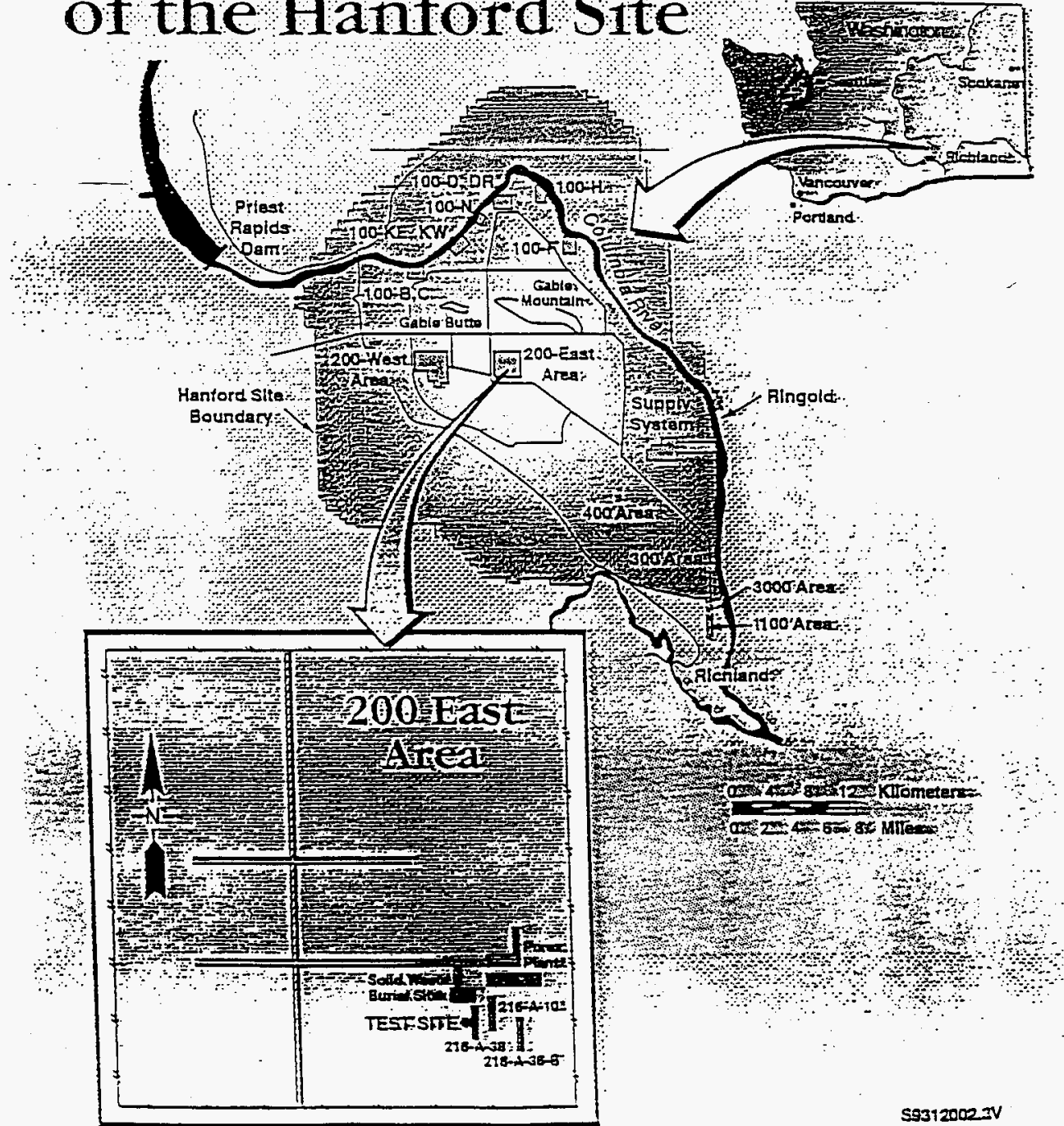


\section{Plan View of Wells and Construction Details}
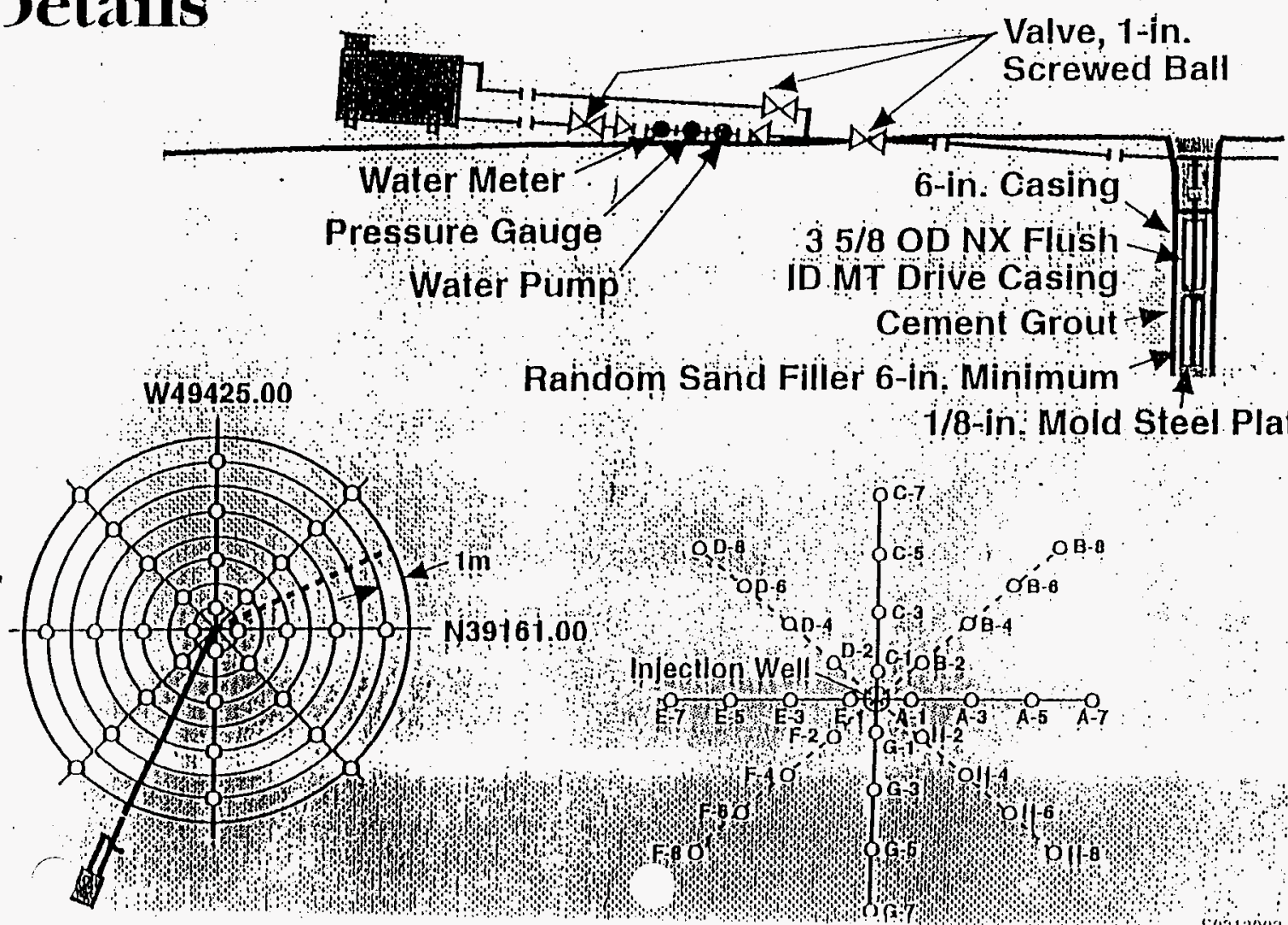
1/8-in Mold Steel Plate 
WHC $-50-11-730$

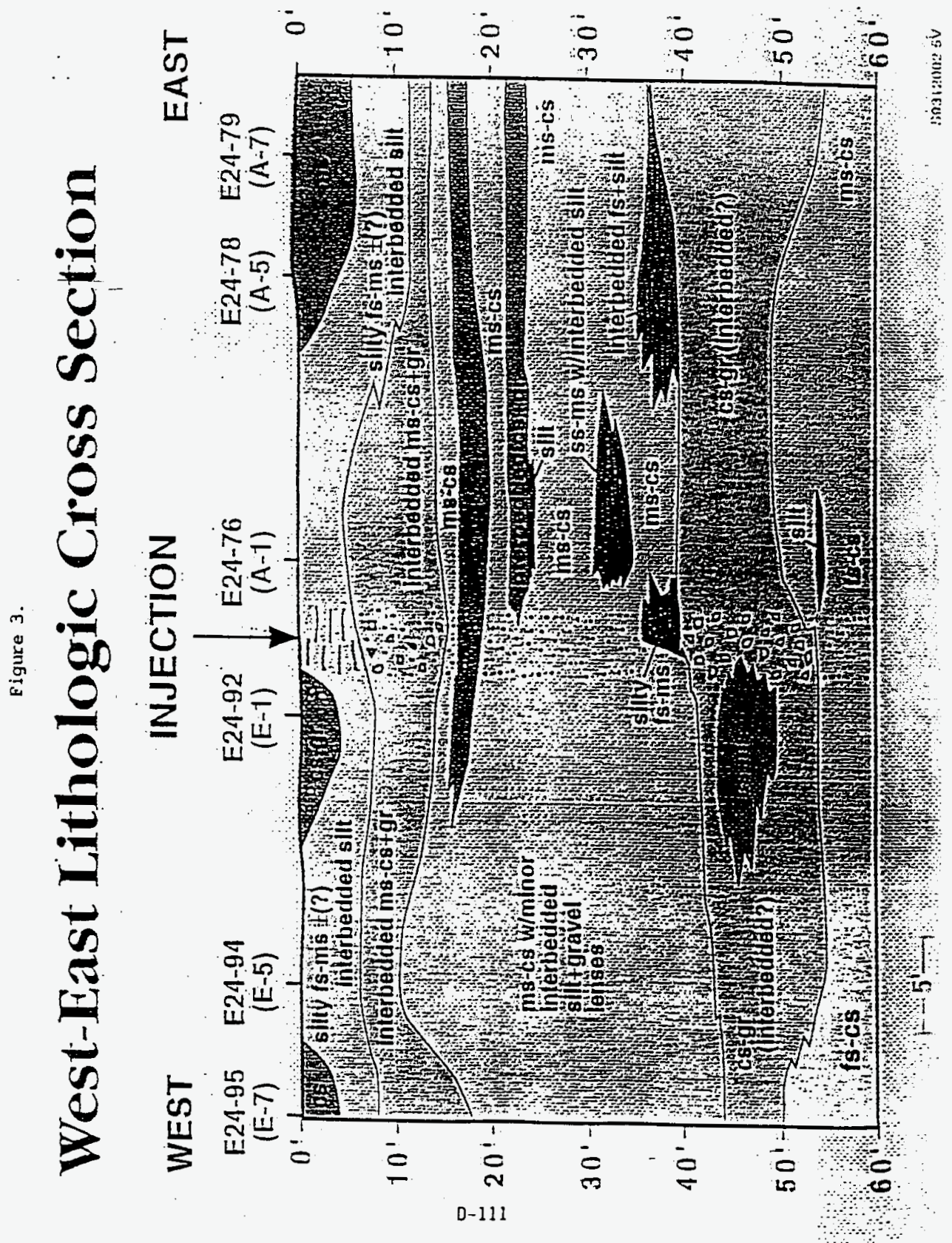


Figure 4.

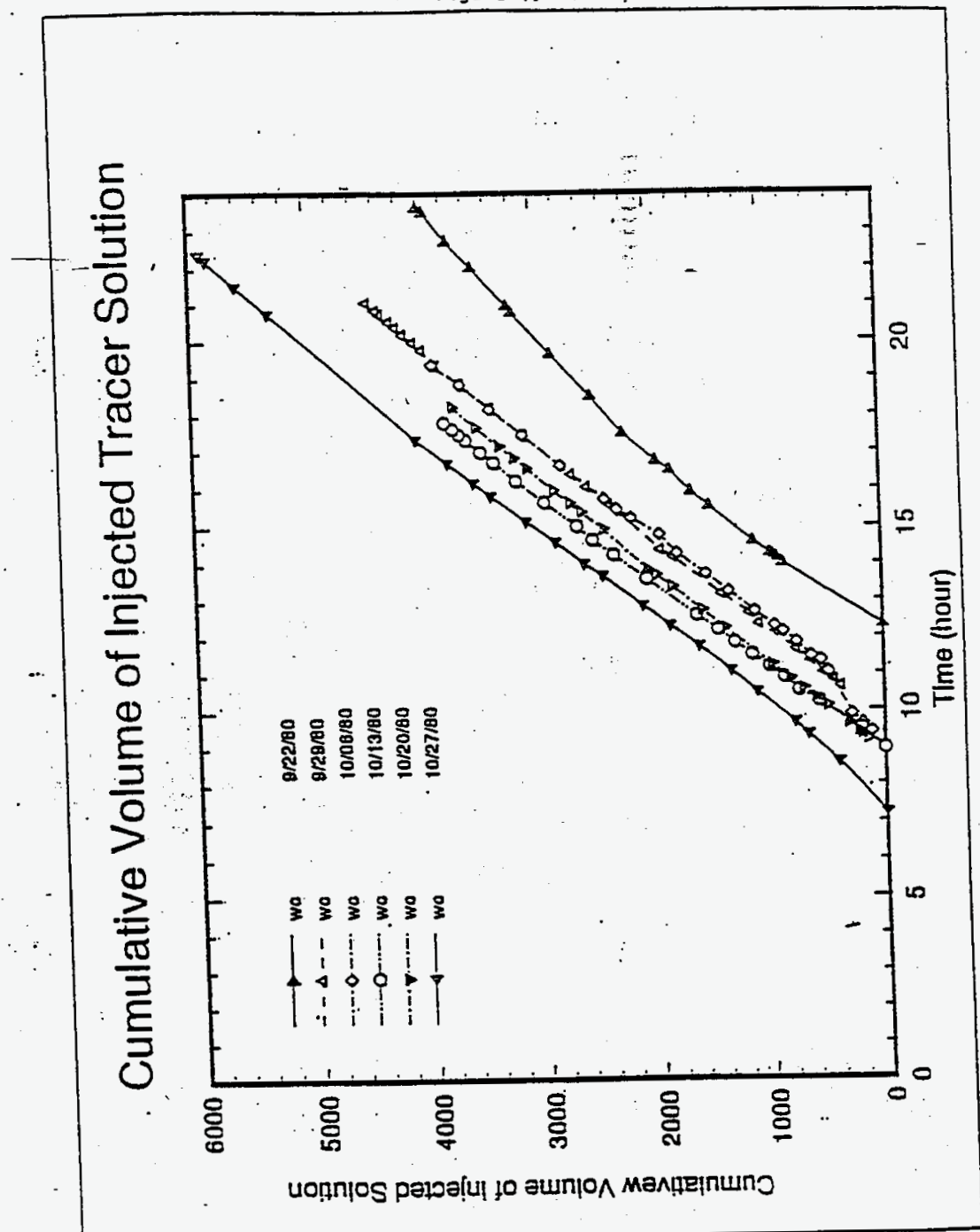


WHC-SD-TI-730 WHC-SD-WM-TI-730, Rev. 0

Figure 5-b.

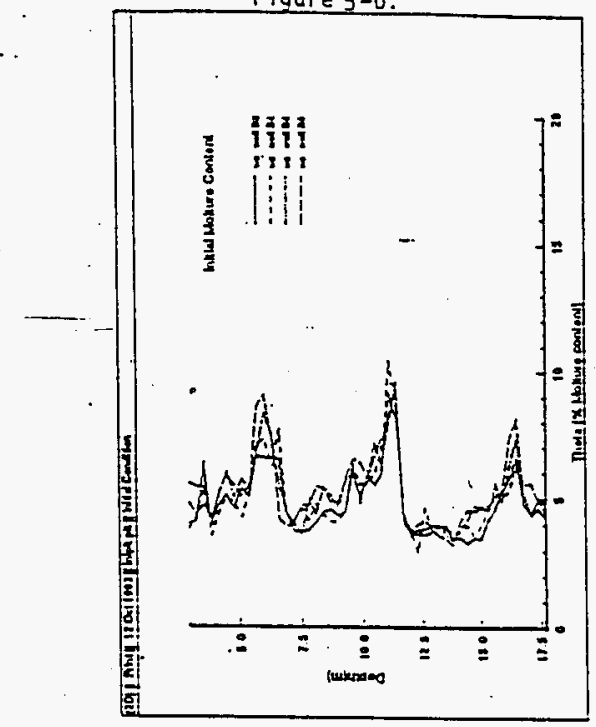

Figure 5-a.

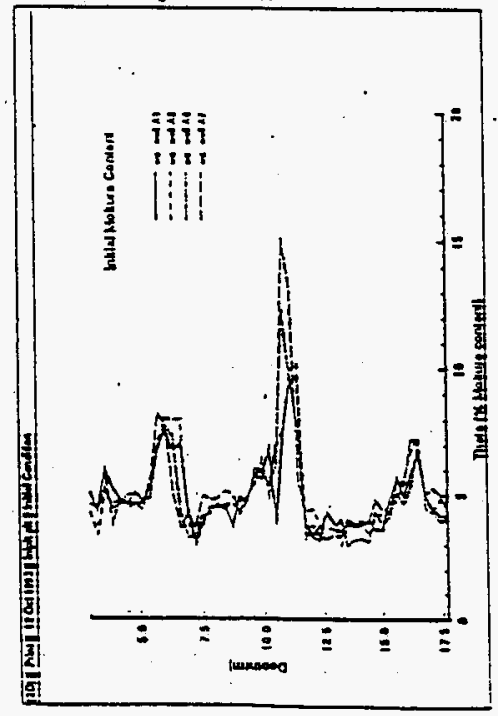

Figure 5-d.

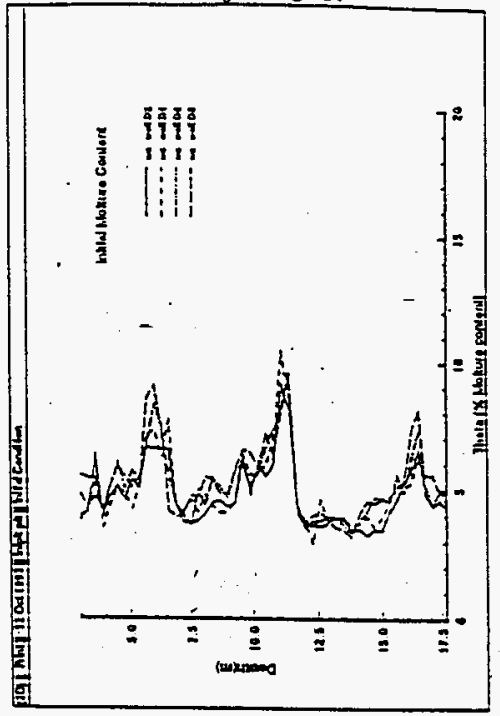

Figure ${ }^{5}-c$.

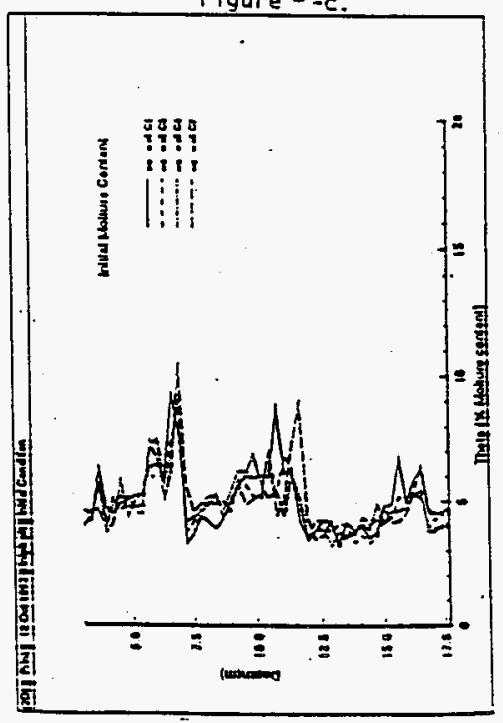

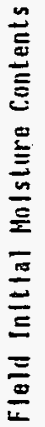


Eidure 5 -3.

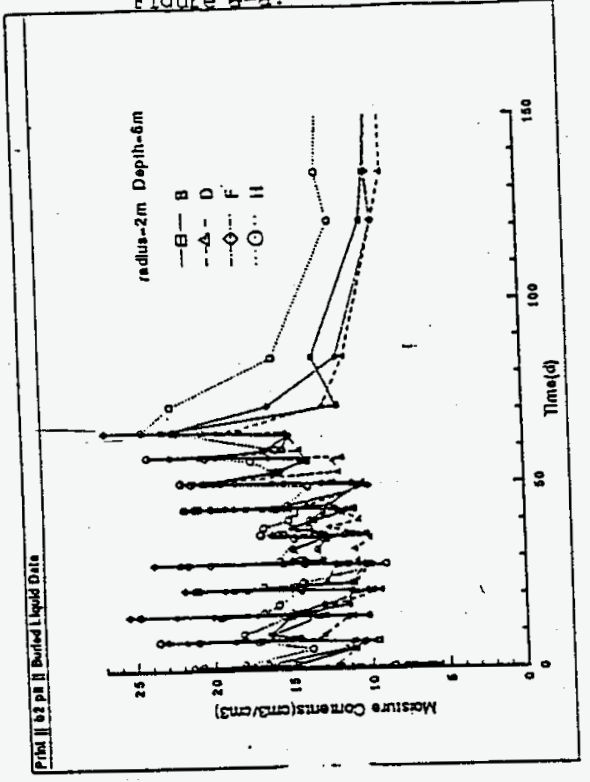

Figure E-b.

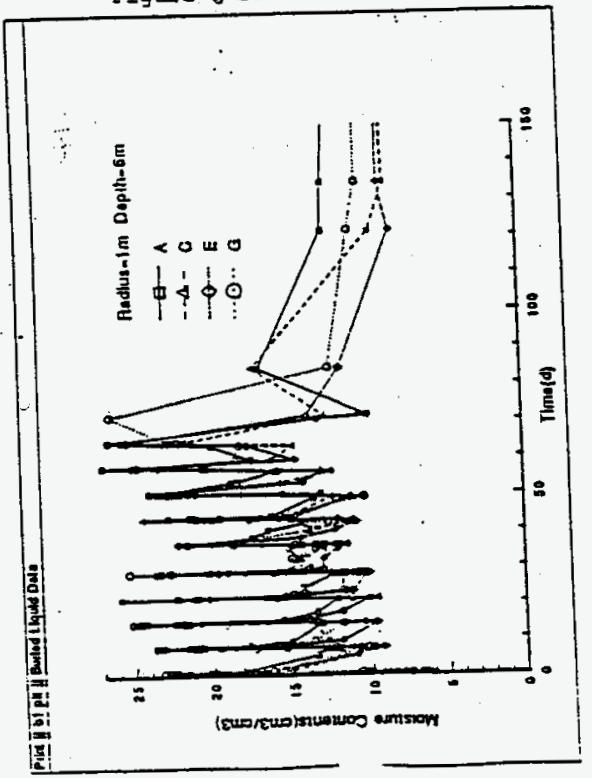

WHC-SD-WM-TI-730, ReV. 0

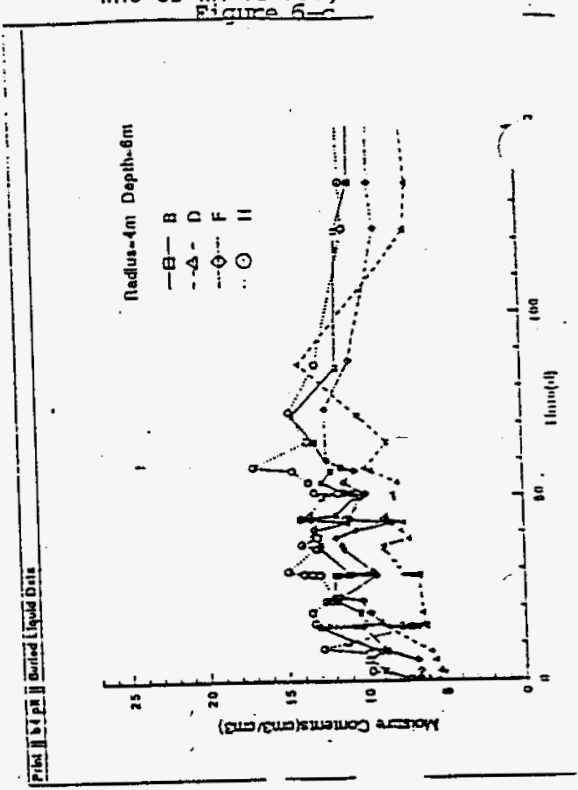

Figure E-d.

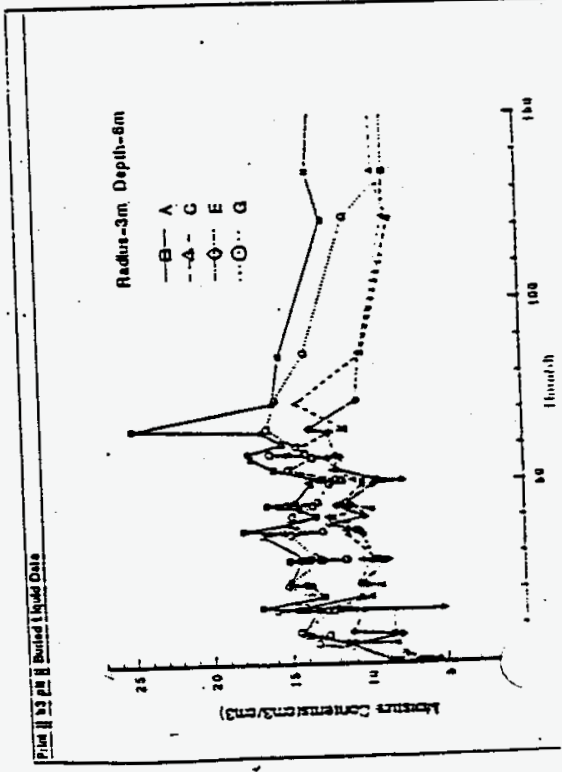



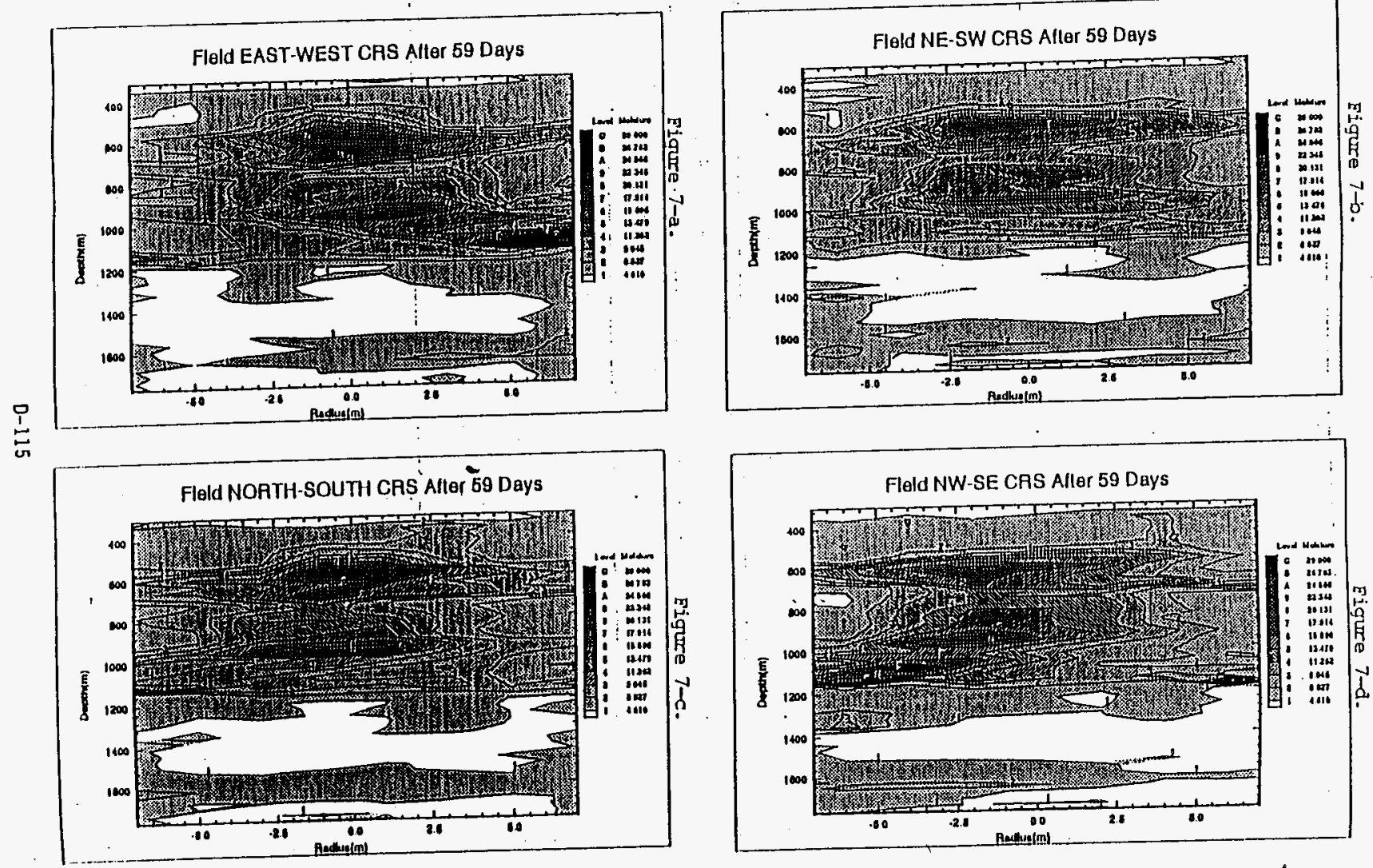

촣

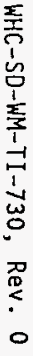


Bigure 9. Model Initiai Moisc= snesers

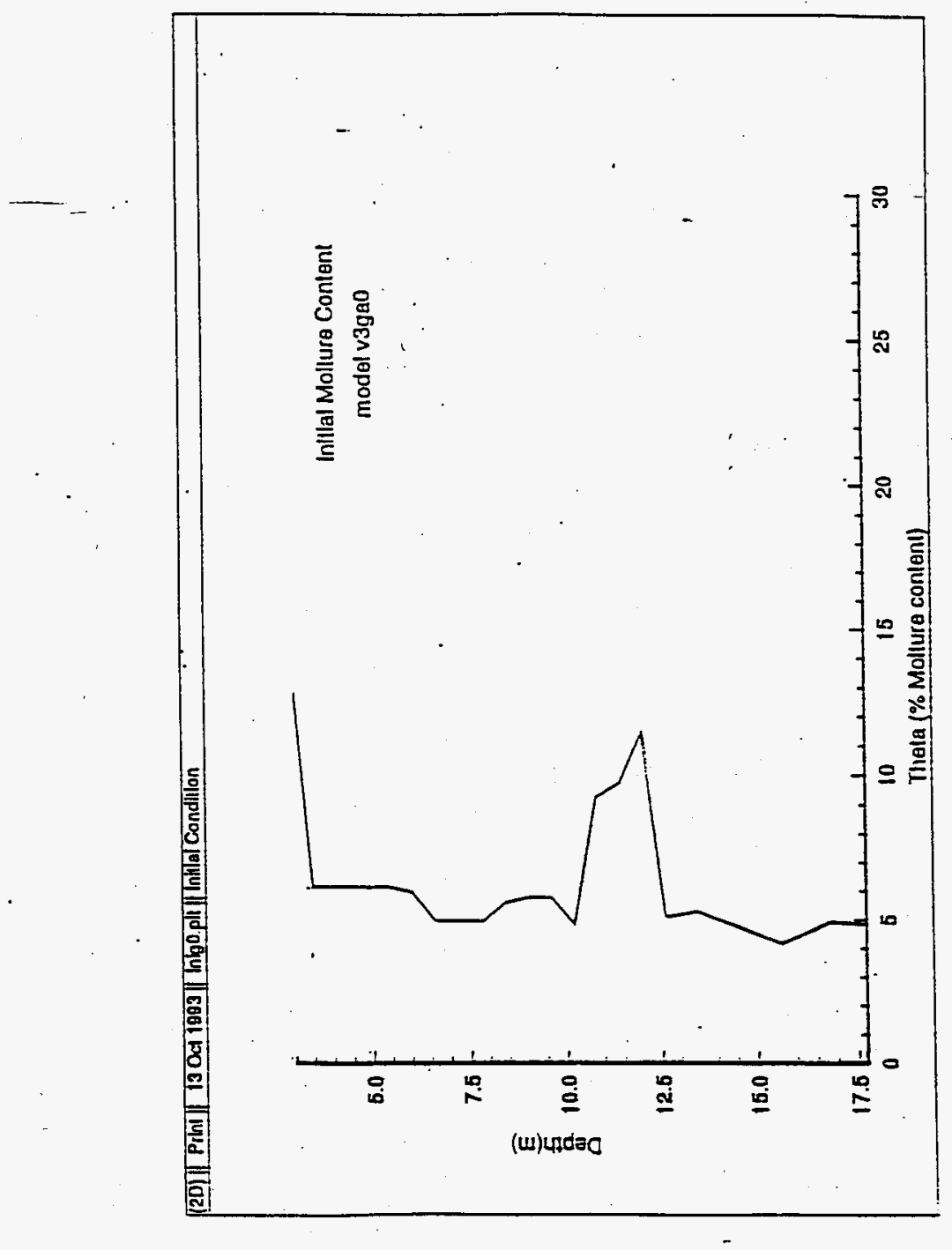



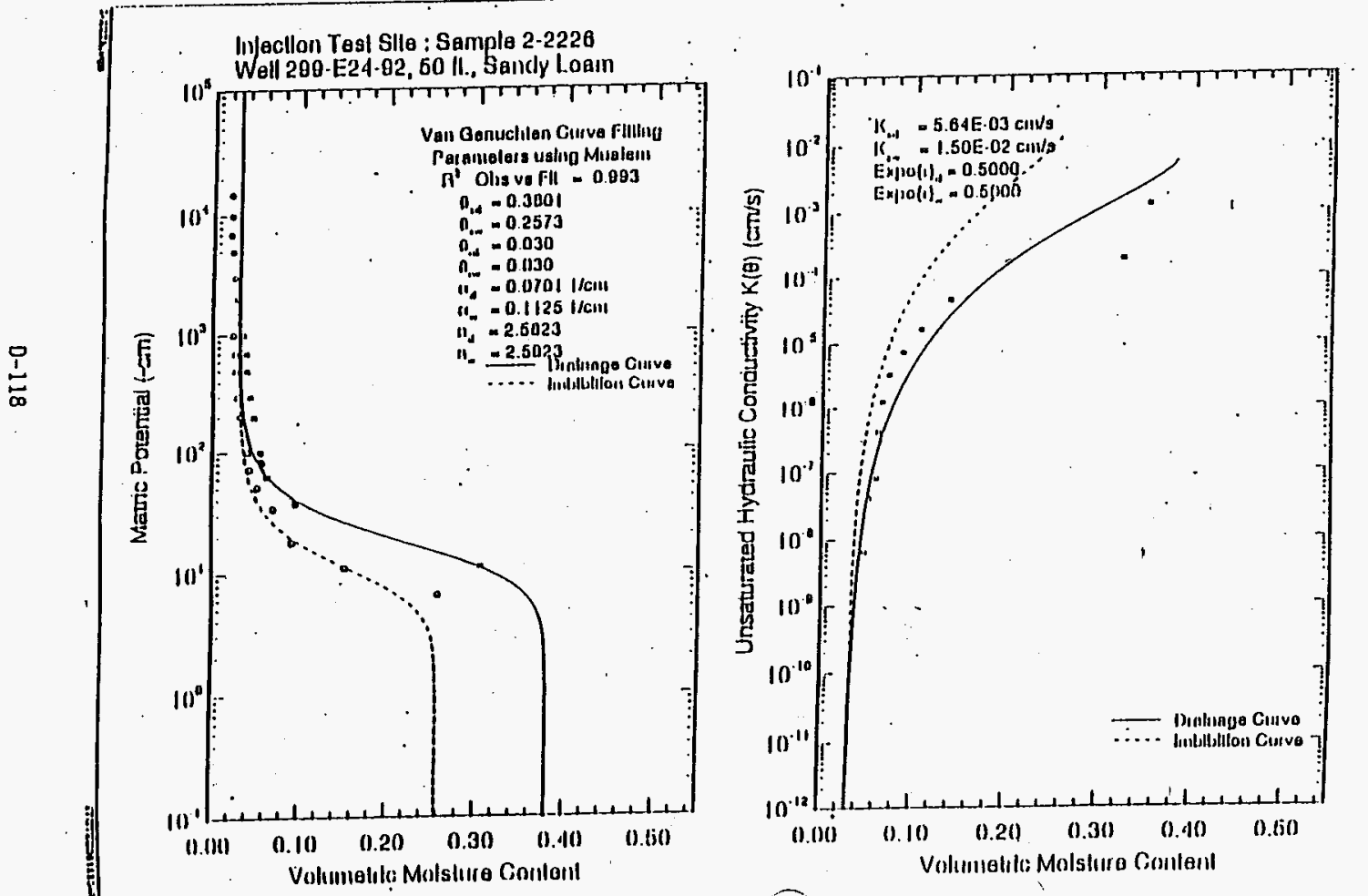
Figure 12 Variogram

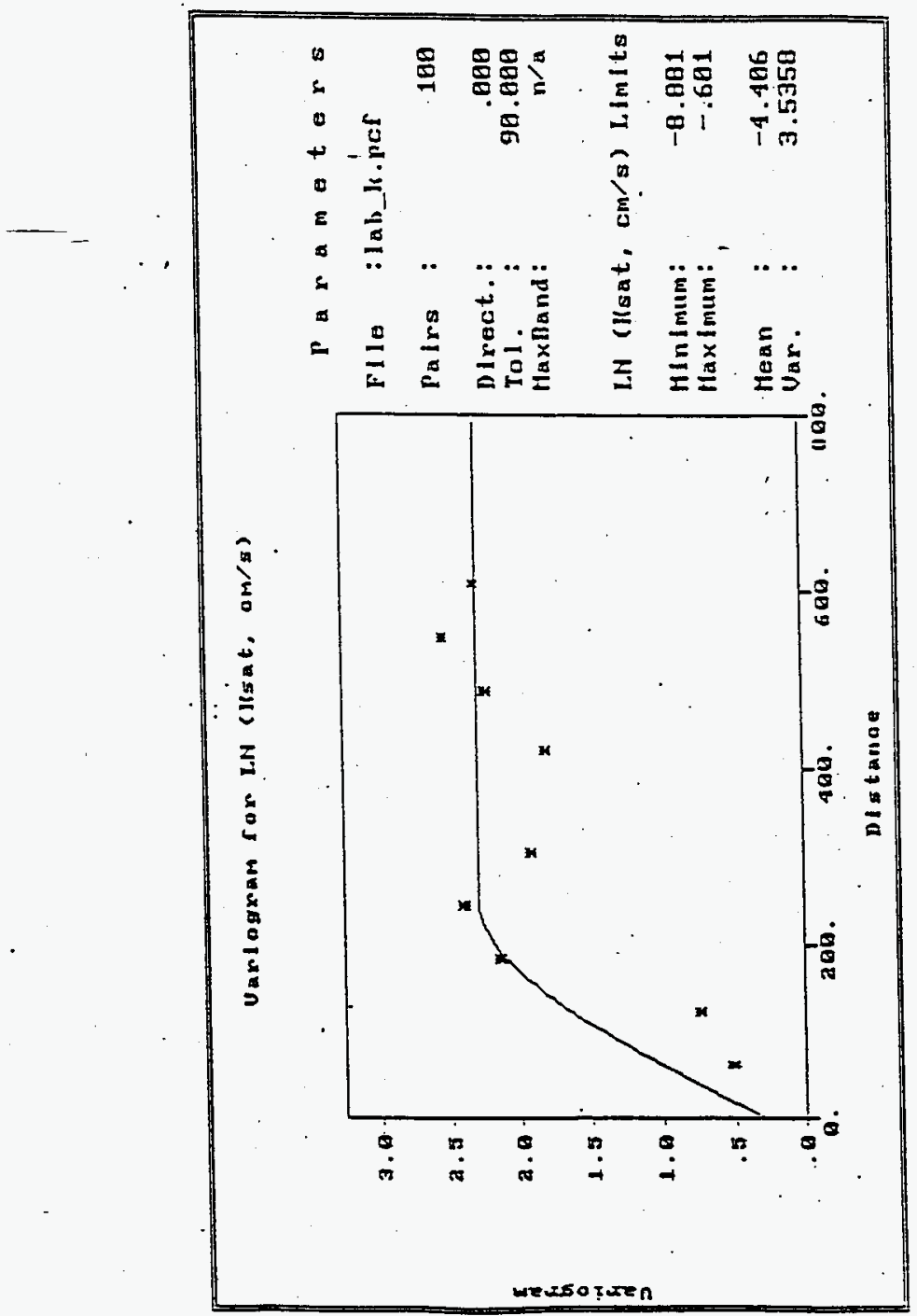



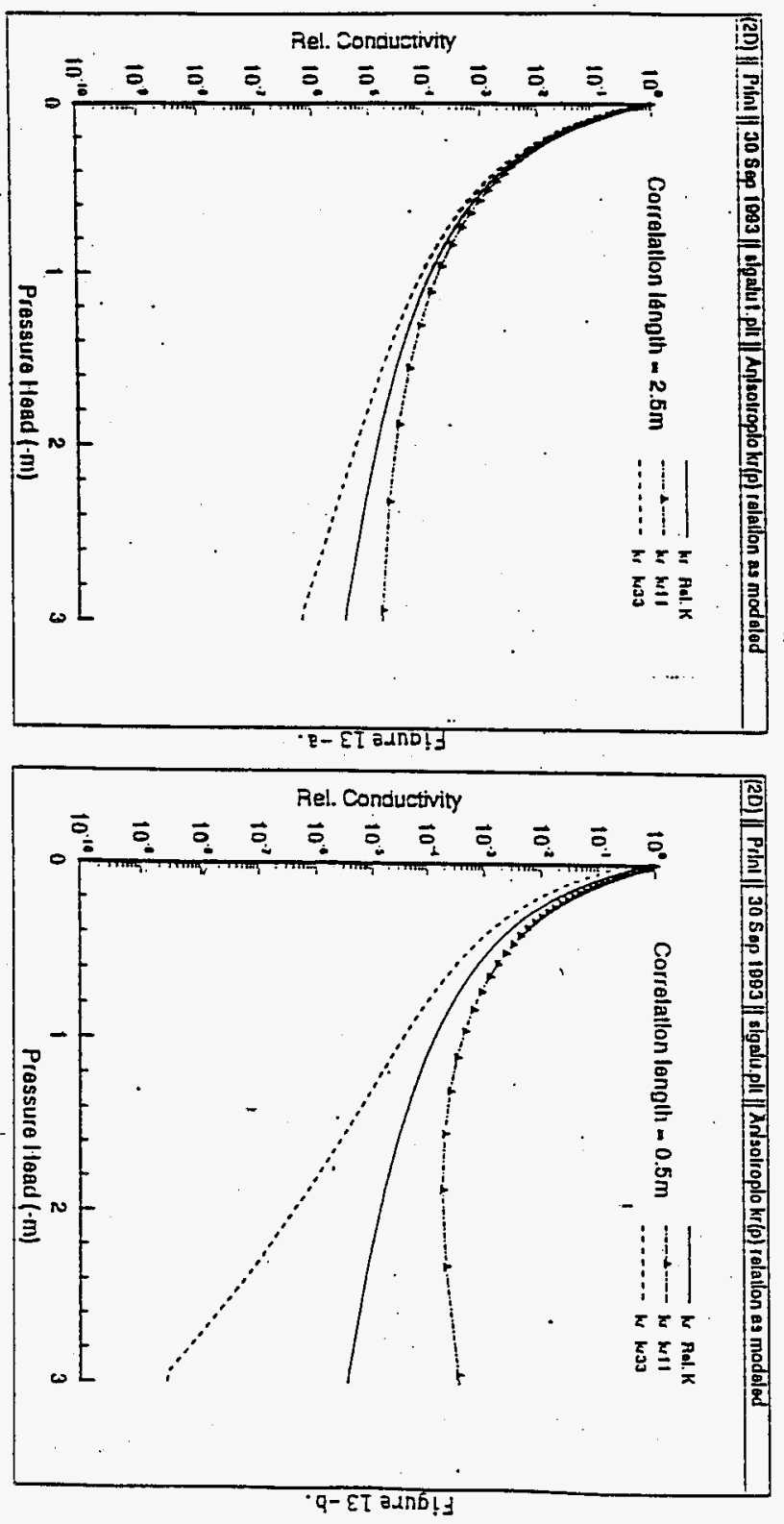


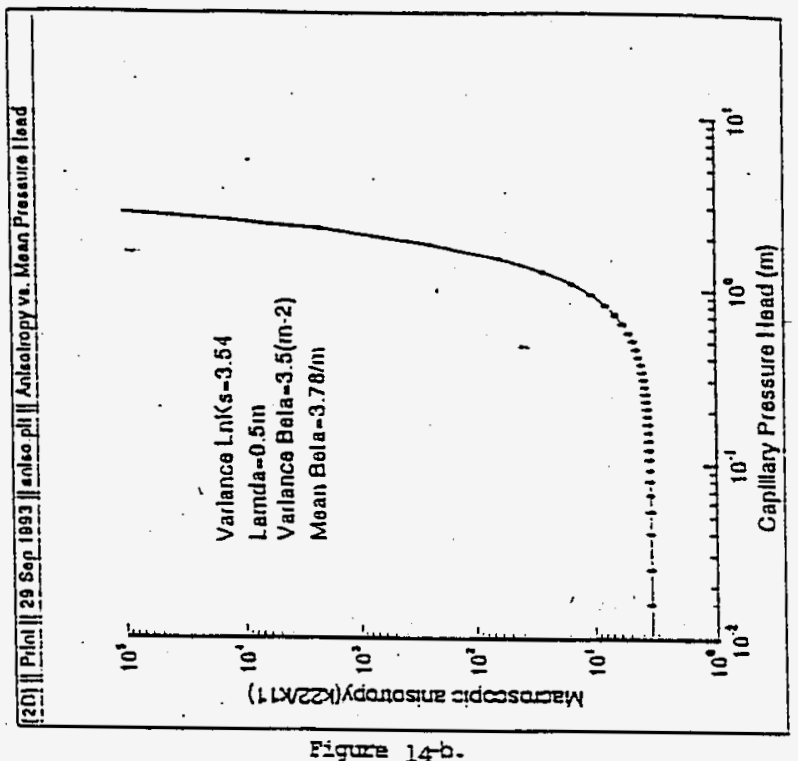

Fig죨 14-b.

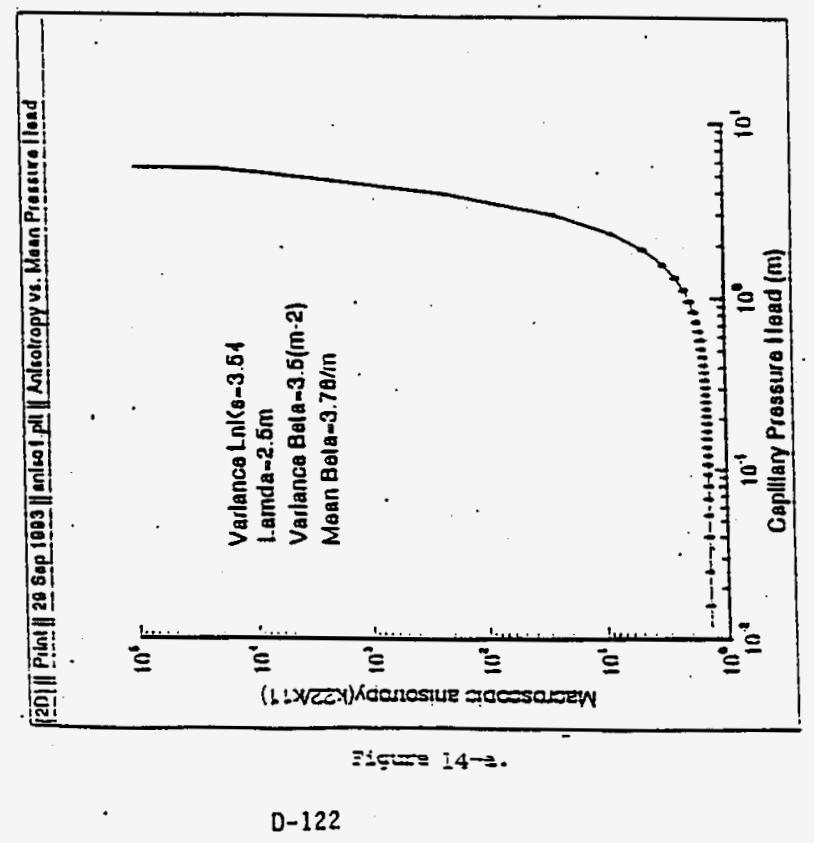




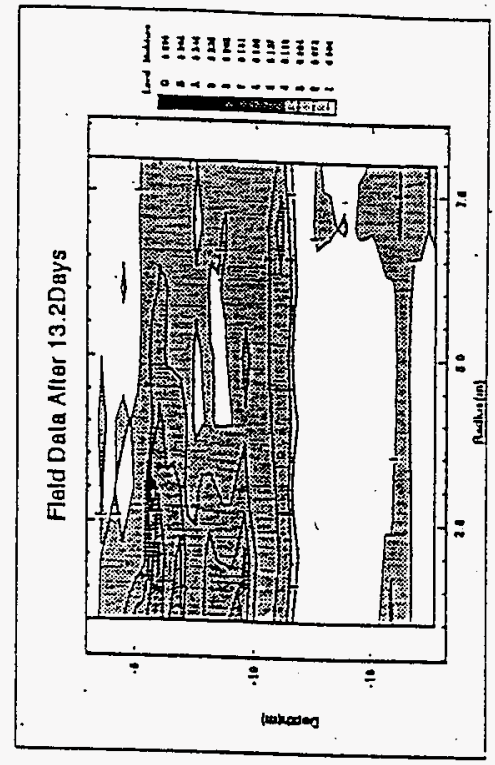

Eigure 15-b.

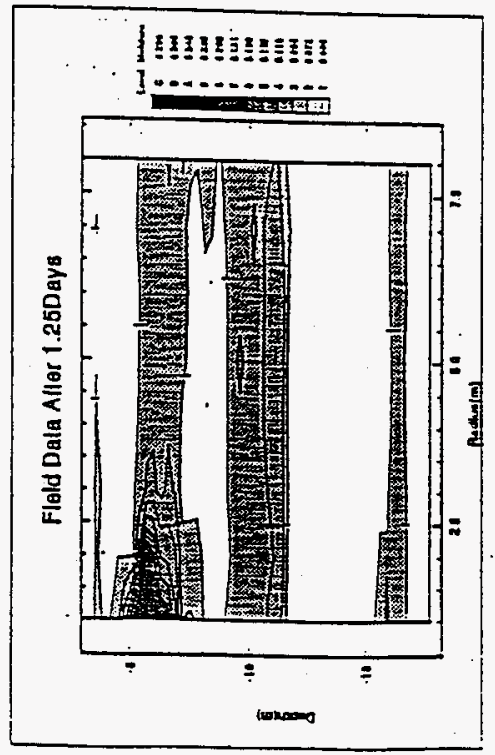

초는 I5-3.

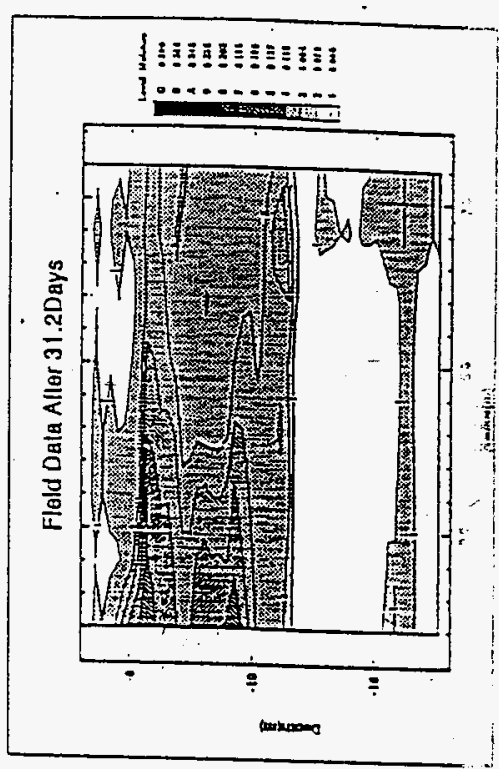

Figre 15-0.

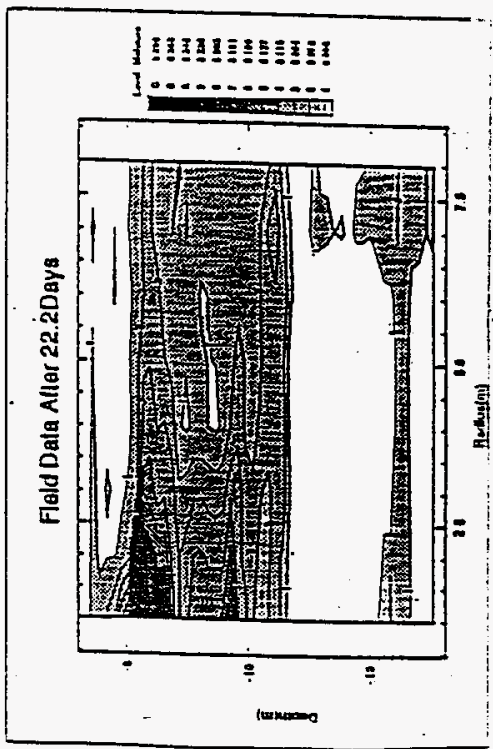

Eigute 15.2. 
WHC-SD-TI-730 WHC-SD-WM-TI-730, Rev. 0

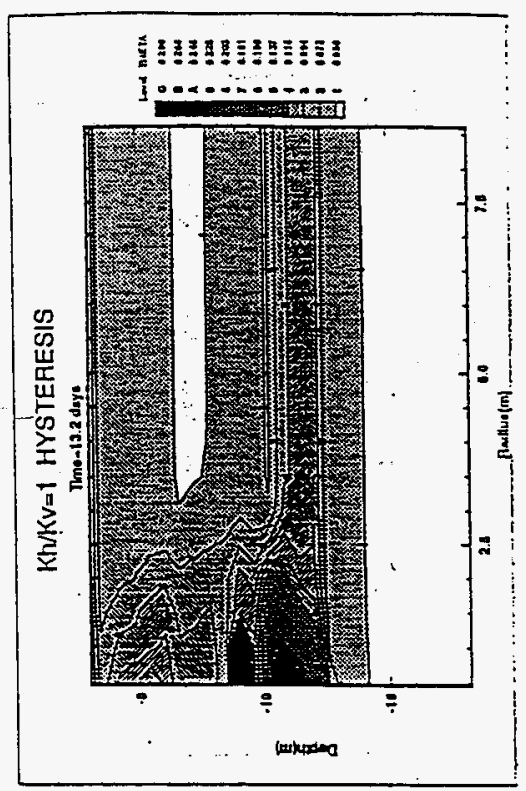

Eigure 17-b.

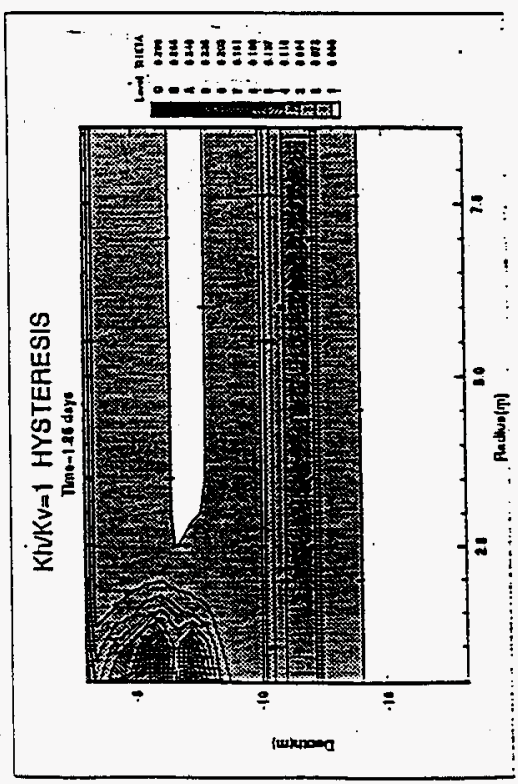

Ficure 17-a.

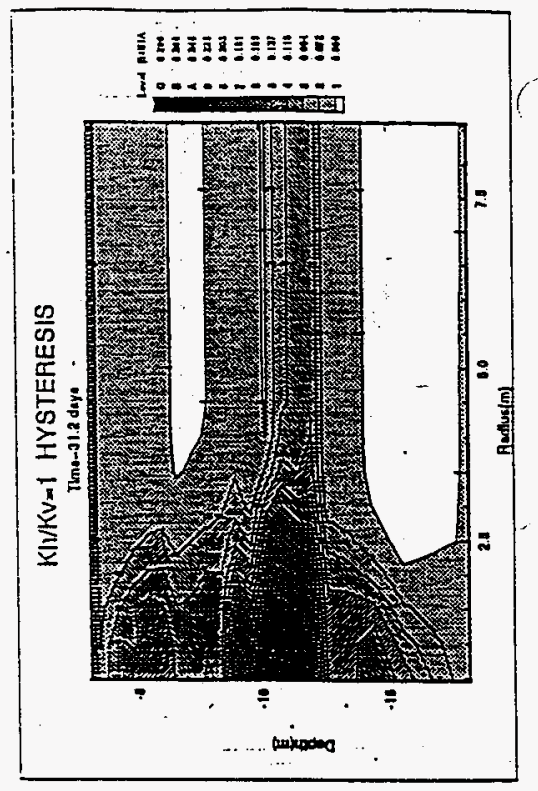

Figure 17-d. ....

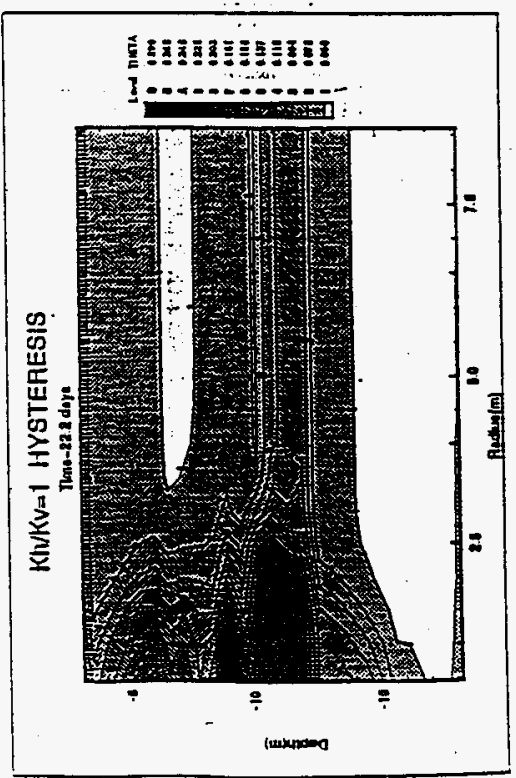

Sigure $17-c$. 
WHC-SD-WM-TI-730, Rev. 0

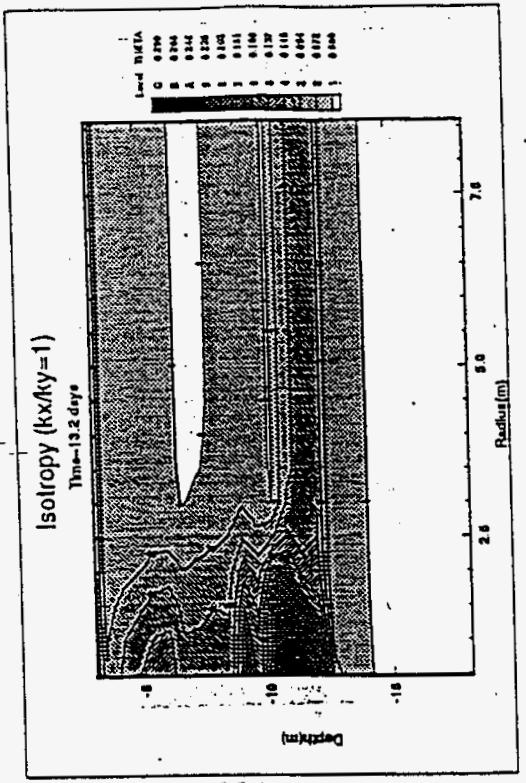

Figure 16-b. . .......

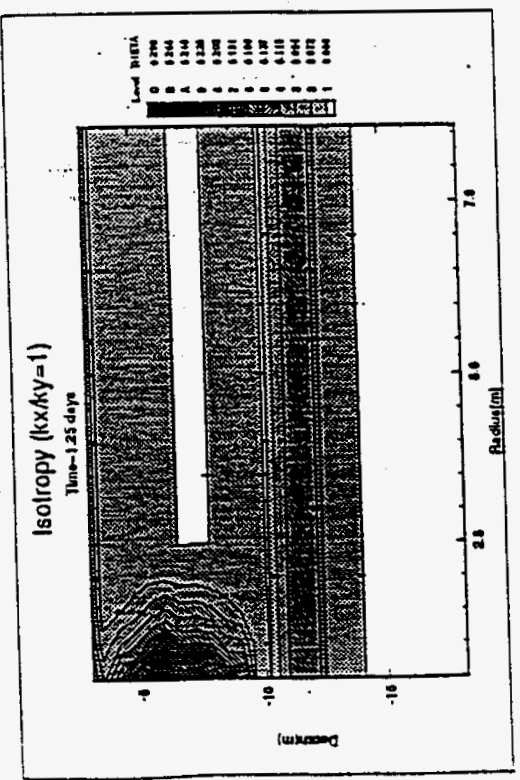

Eigure 16 $\rightarrow$ a.

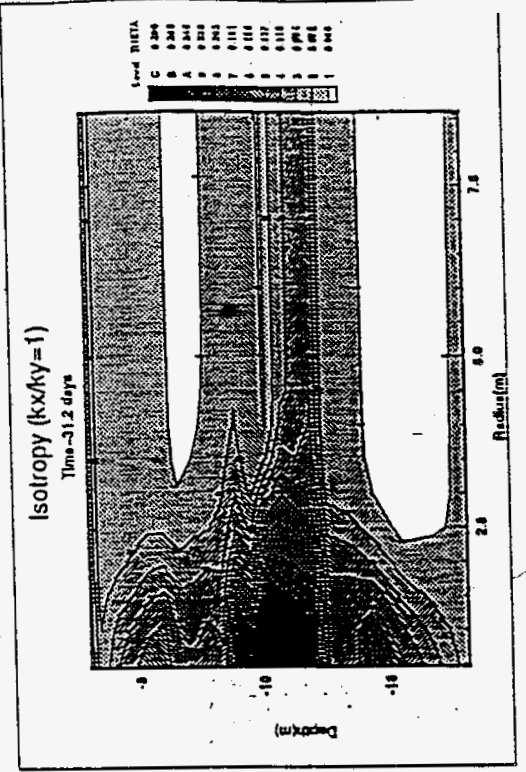

Figure 16-d..

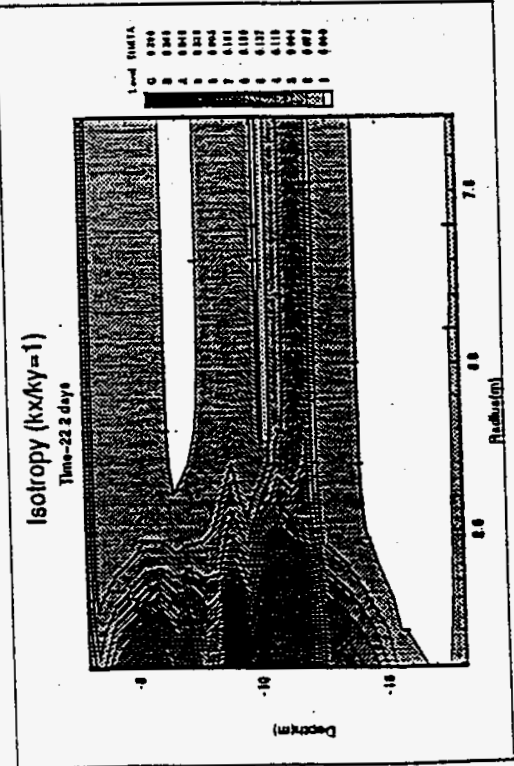

Eqgure $16-c$. 


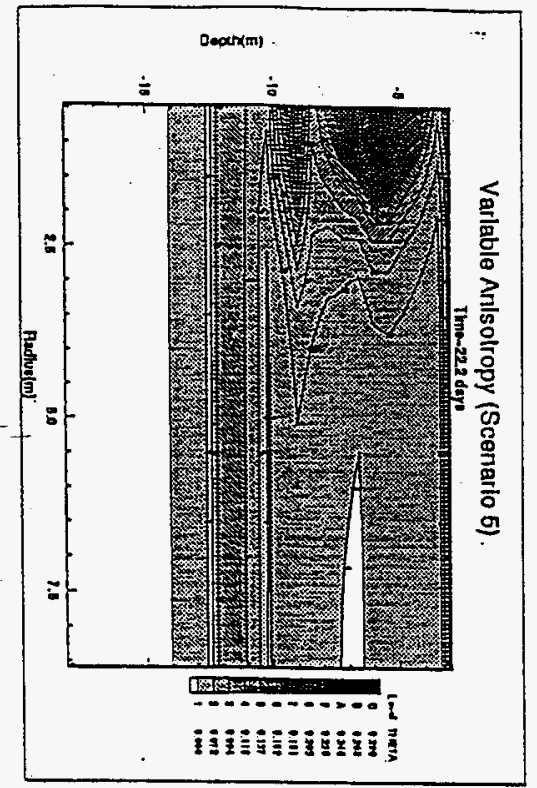

Figure 19-b.

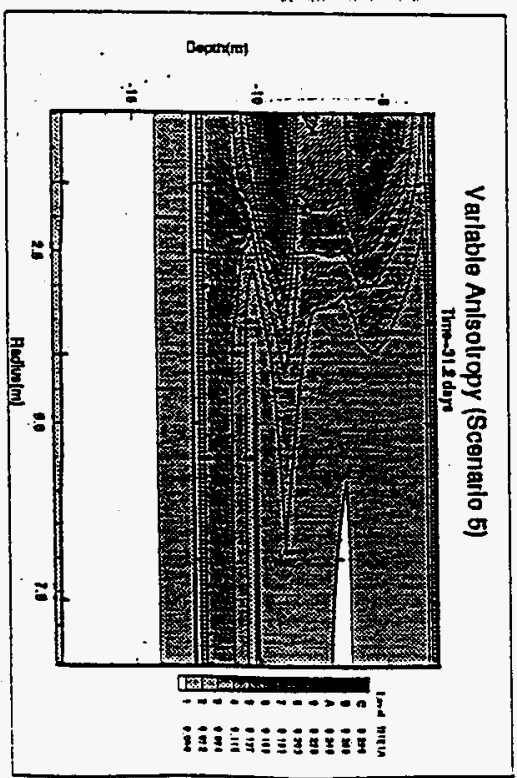

Eigure 10. 3 .

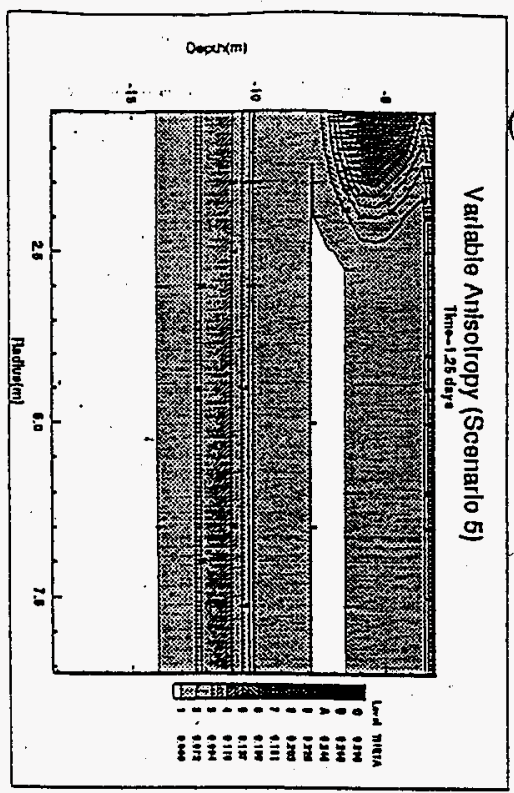

Eigure 190 .

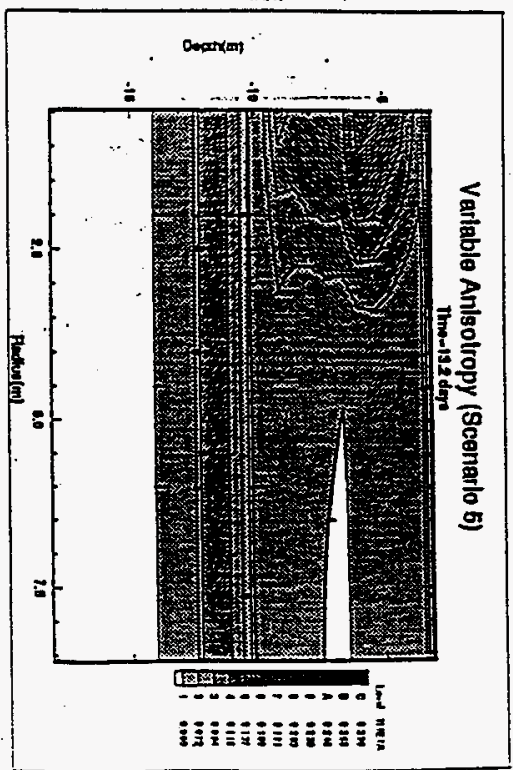

Eigure 19-c. 


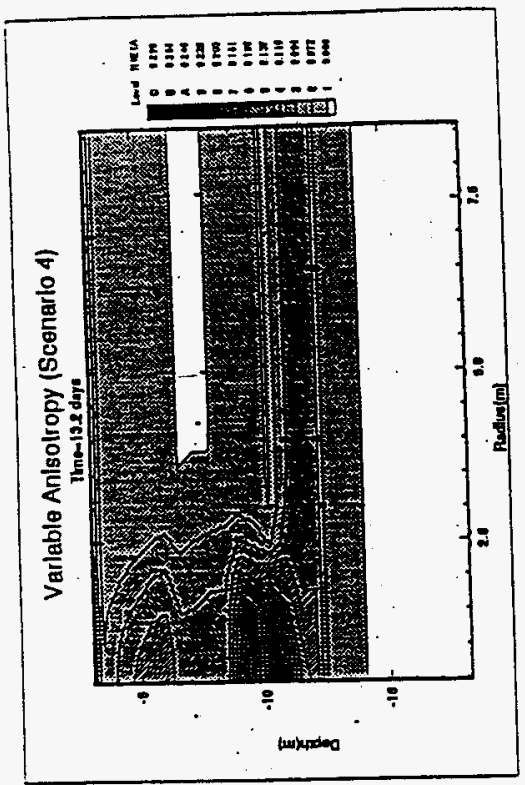

Eigure 18-b.

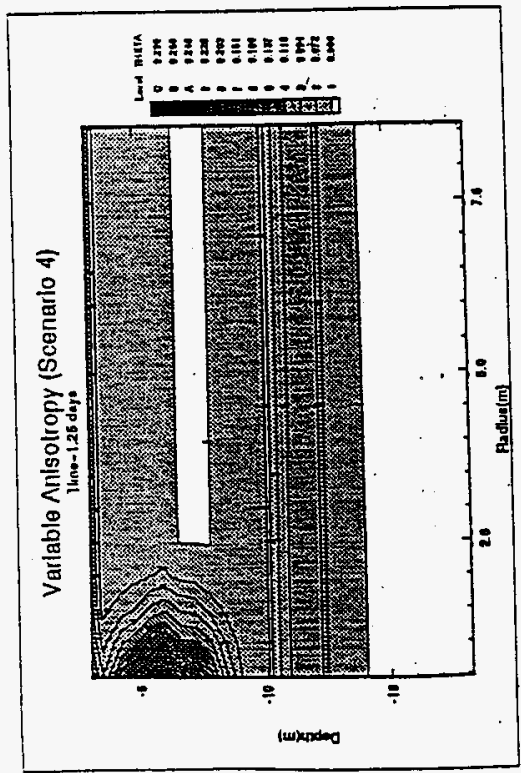

Eigure 18-a.

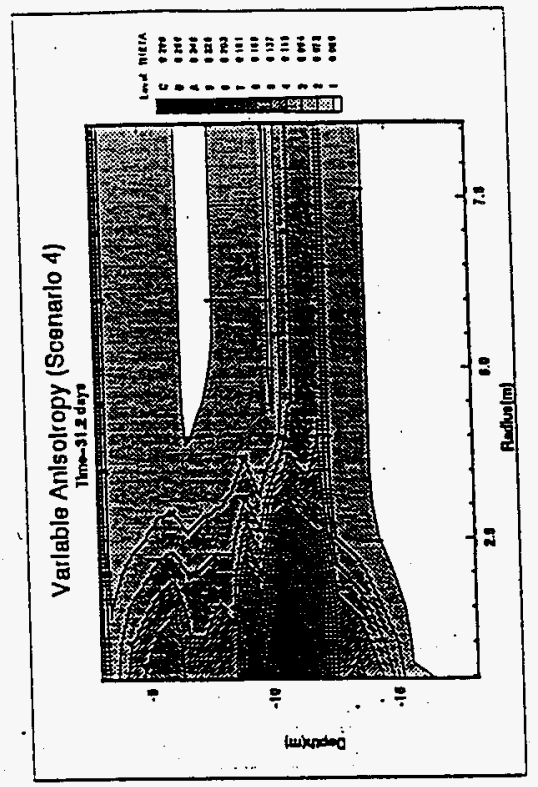

Eigure 18-d.

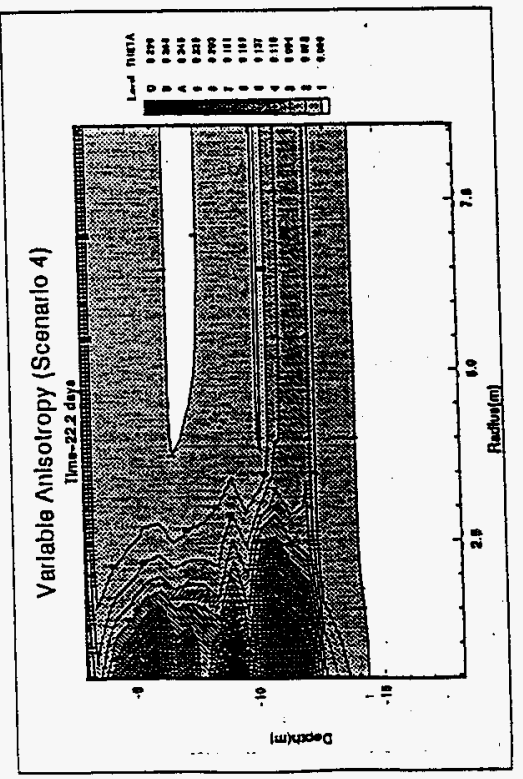

Figure 18-c. 

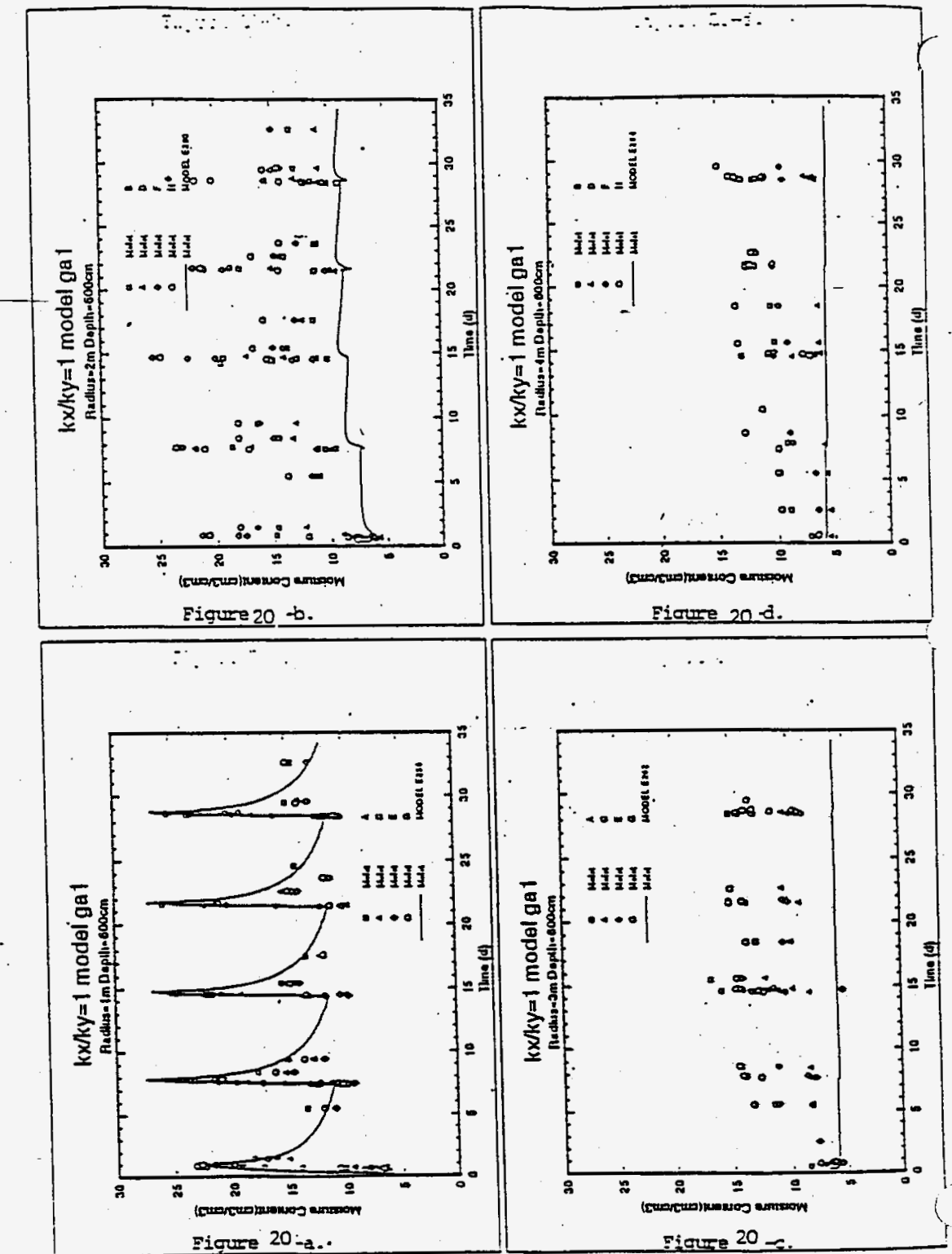

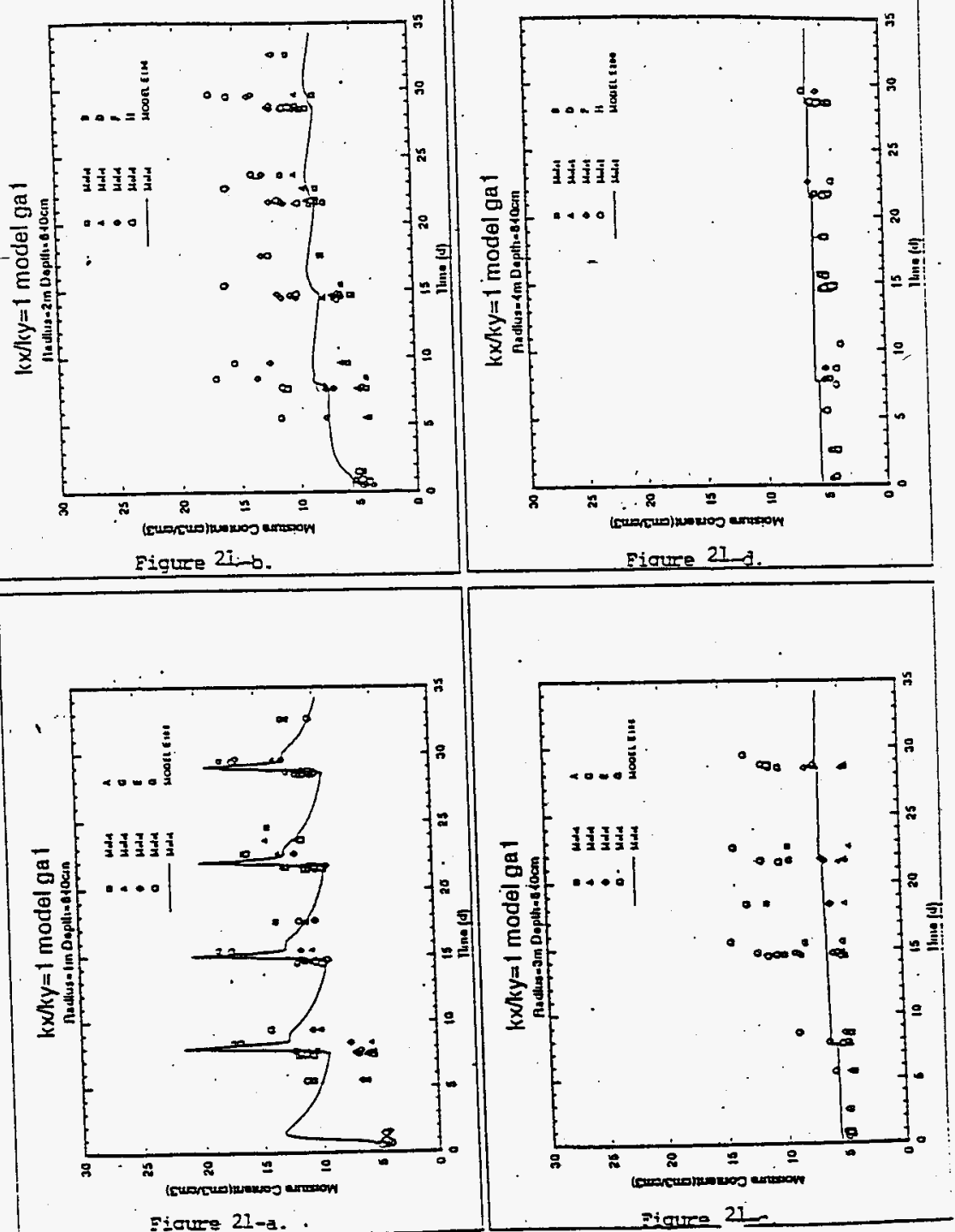

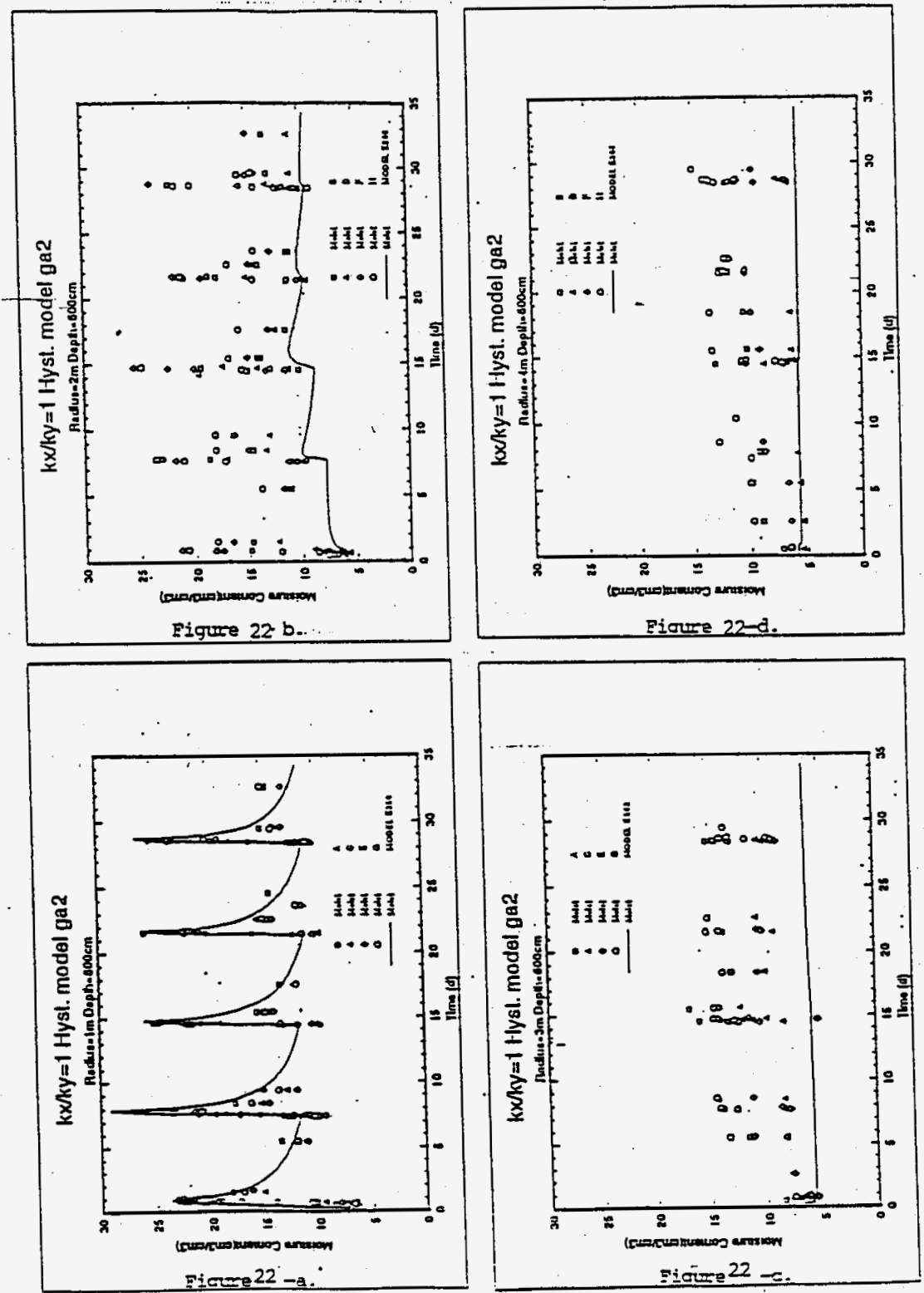

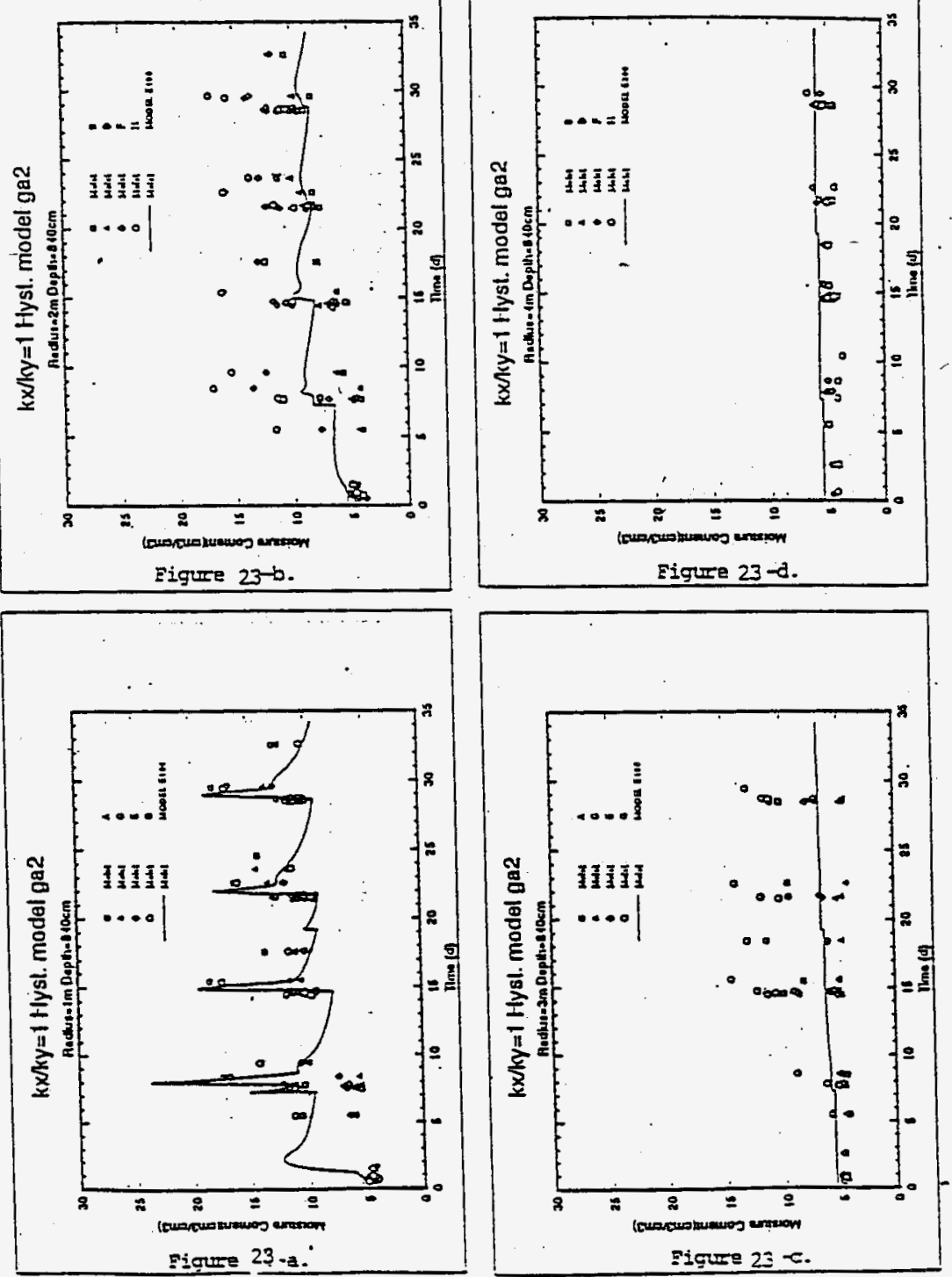

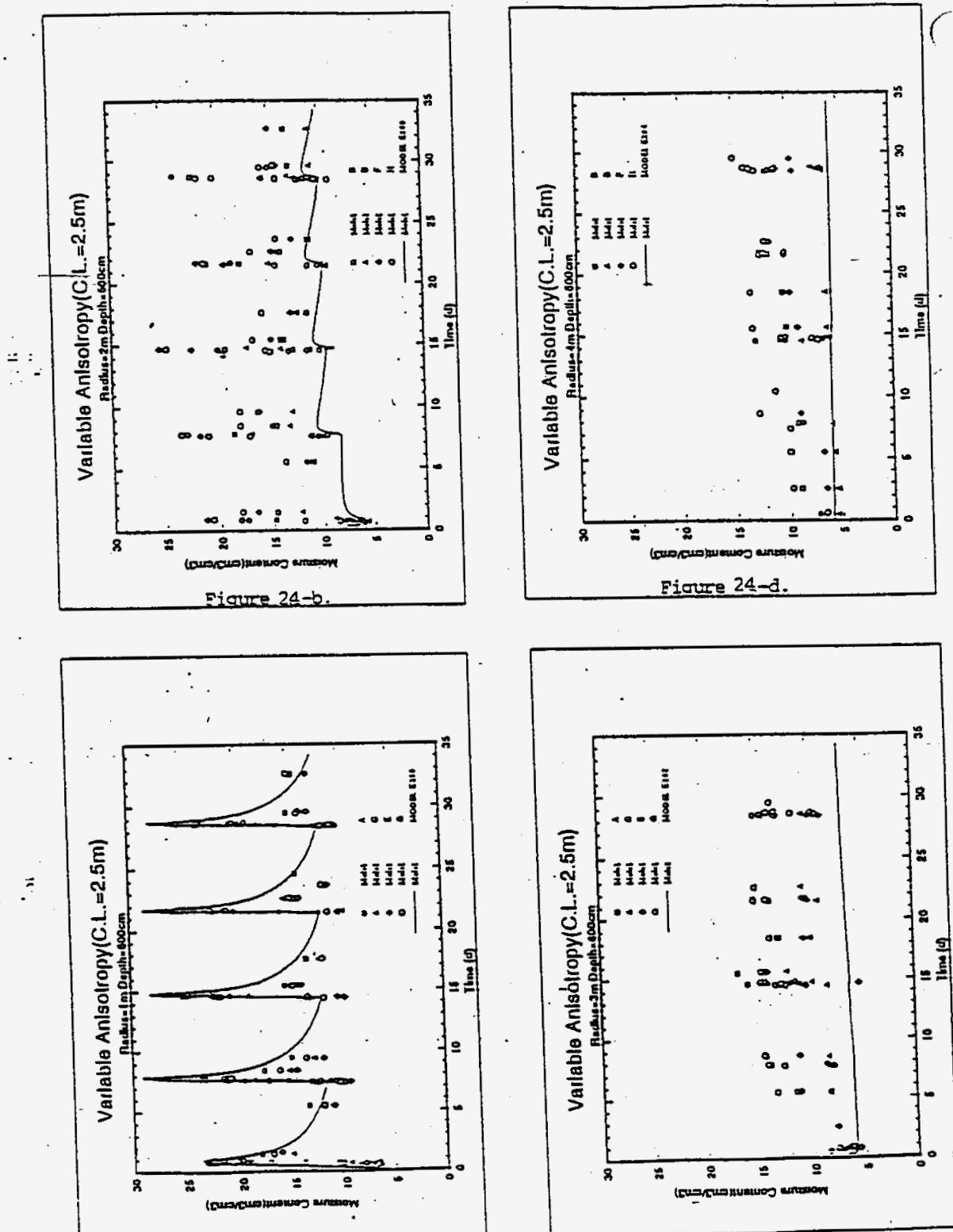

Sigure 24-3.

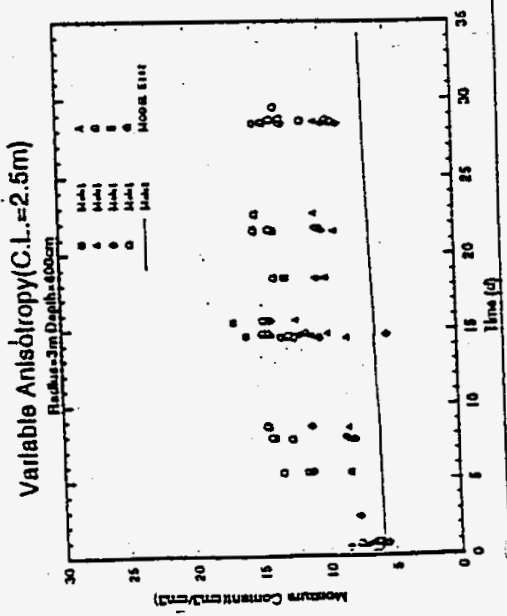




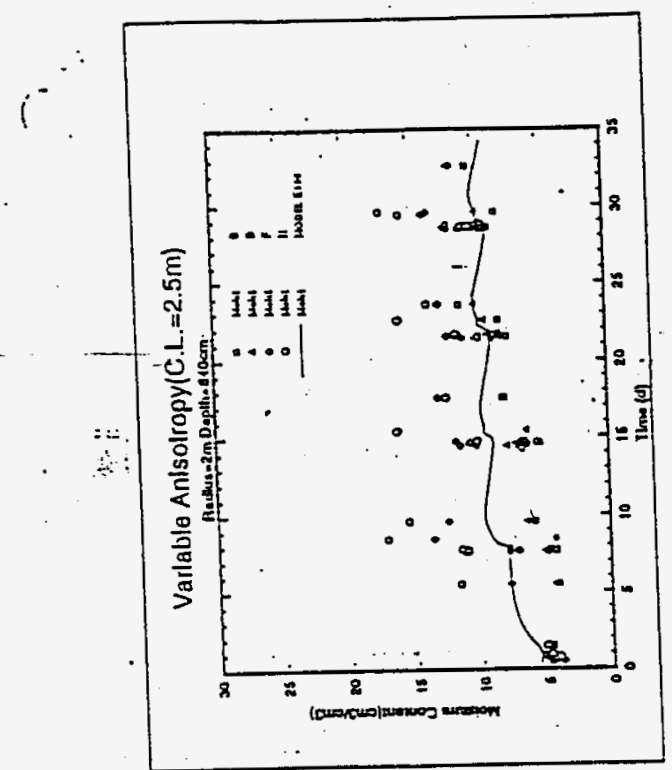

Figure 25 b.

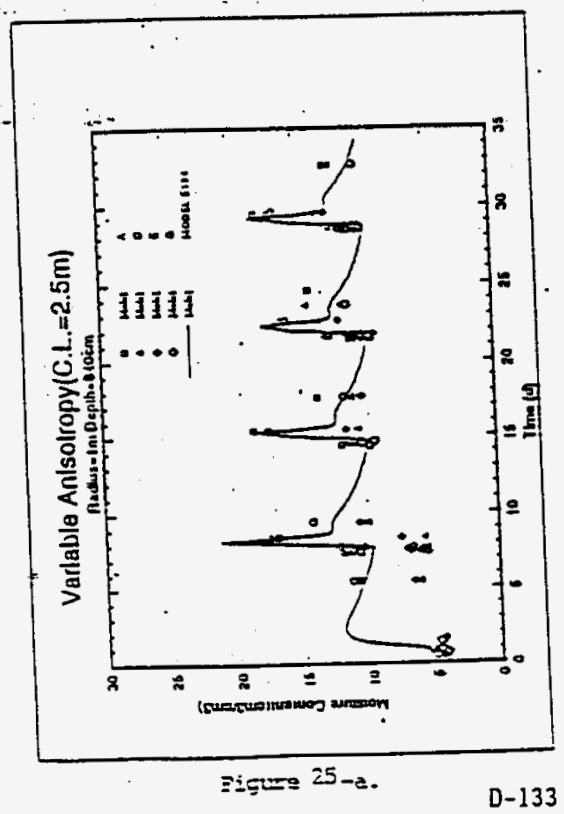

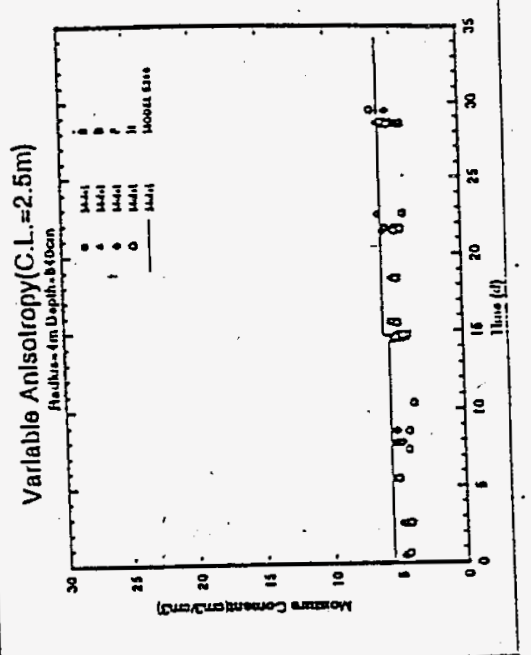

जigure 25 -d.

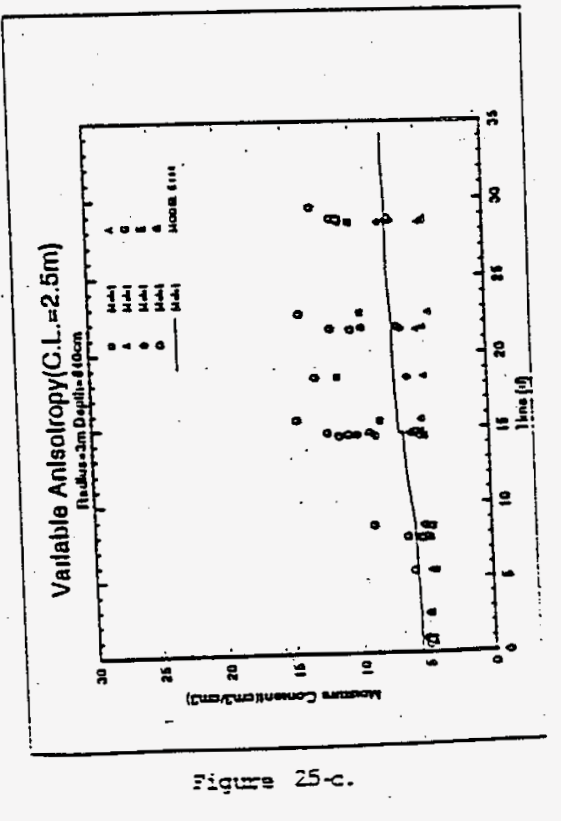



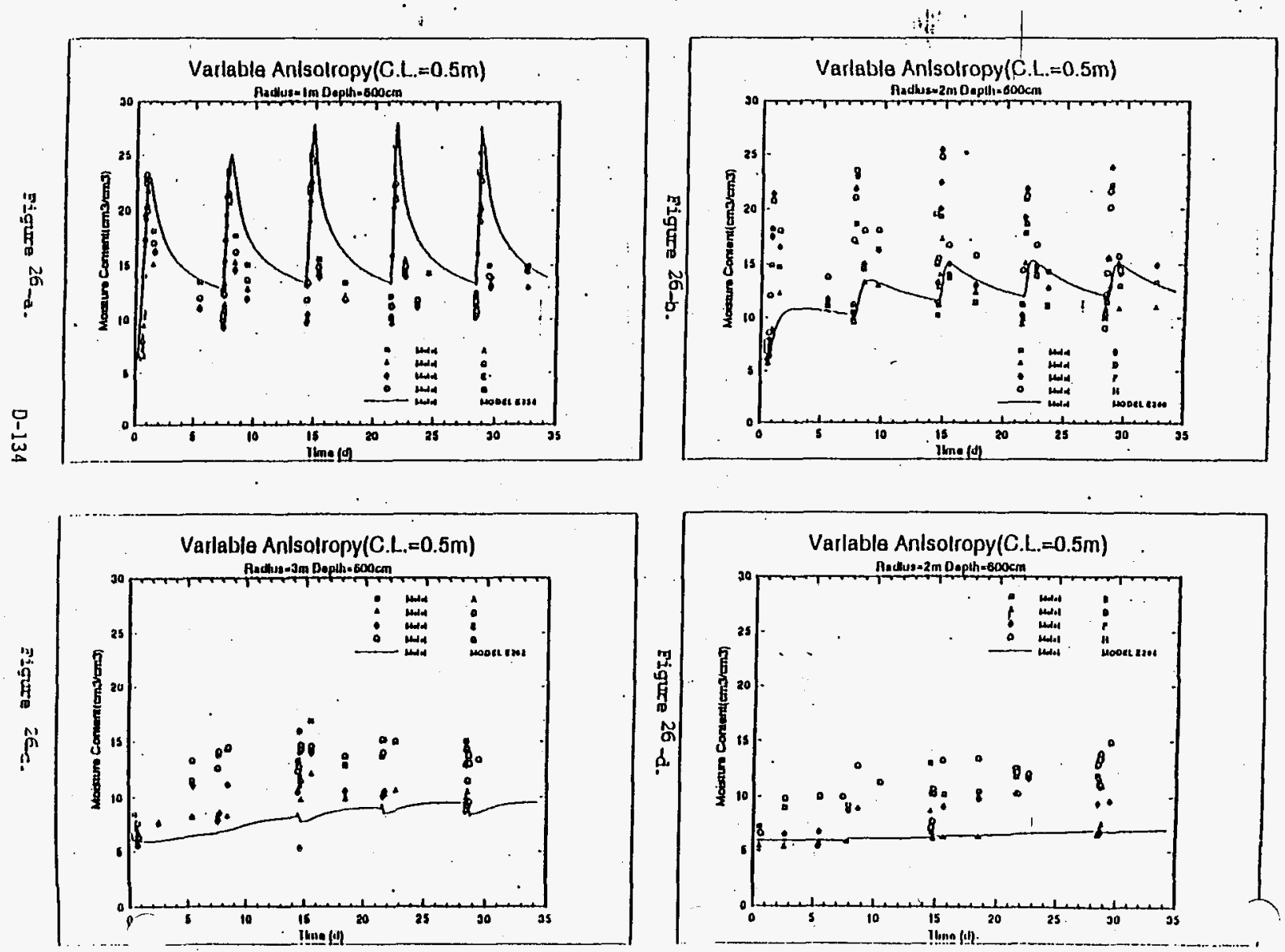


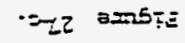

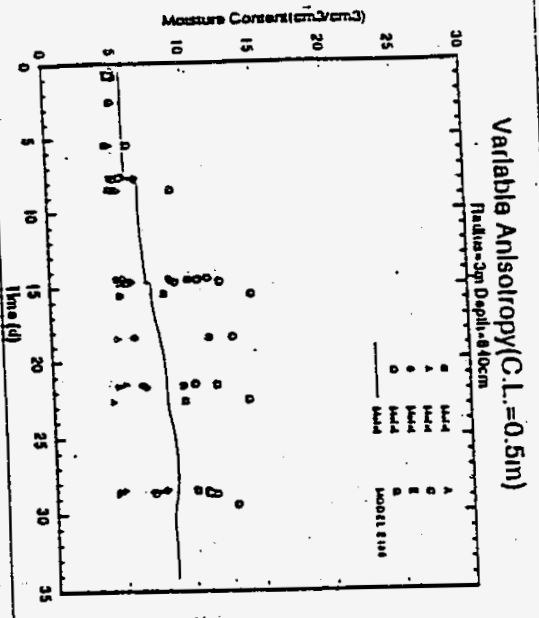

•p-lz әлn5т

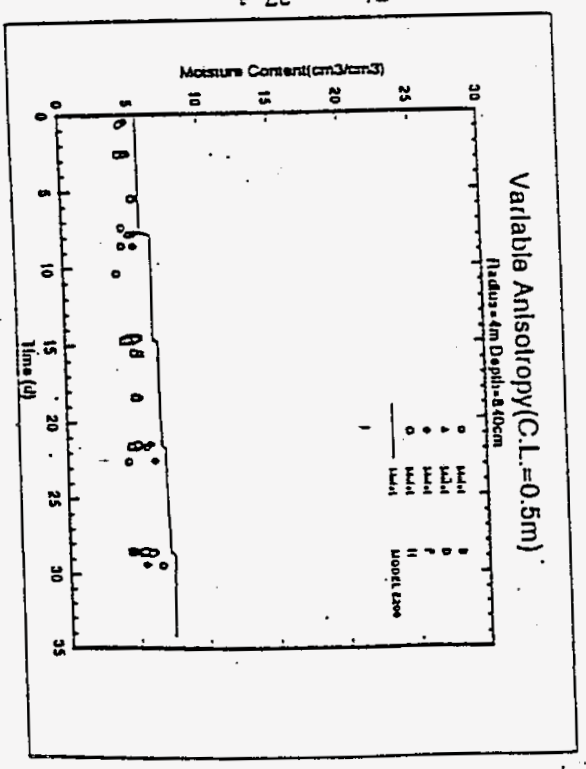

・ーーะ
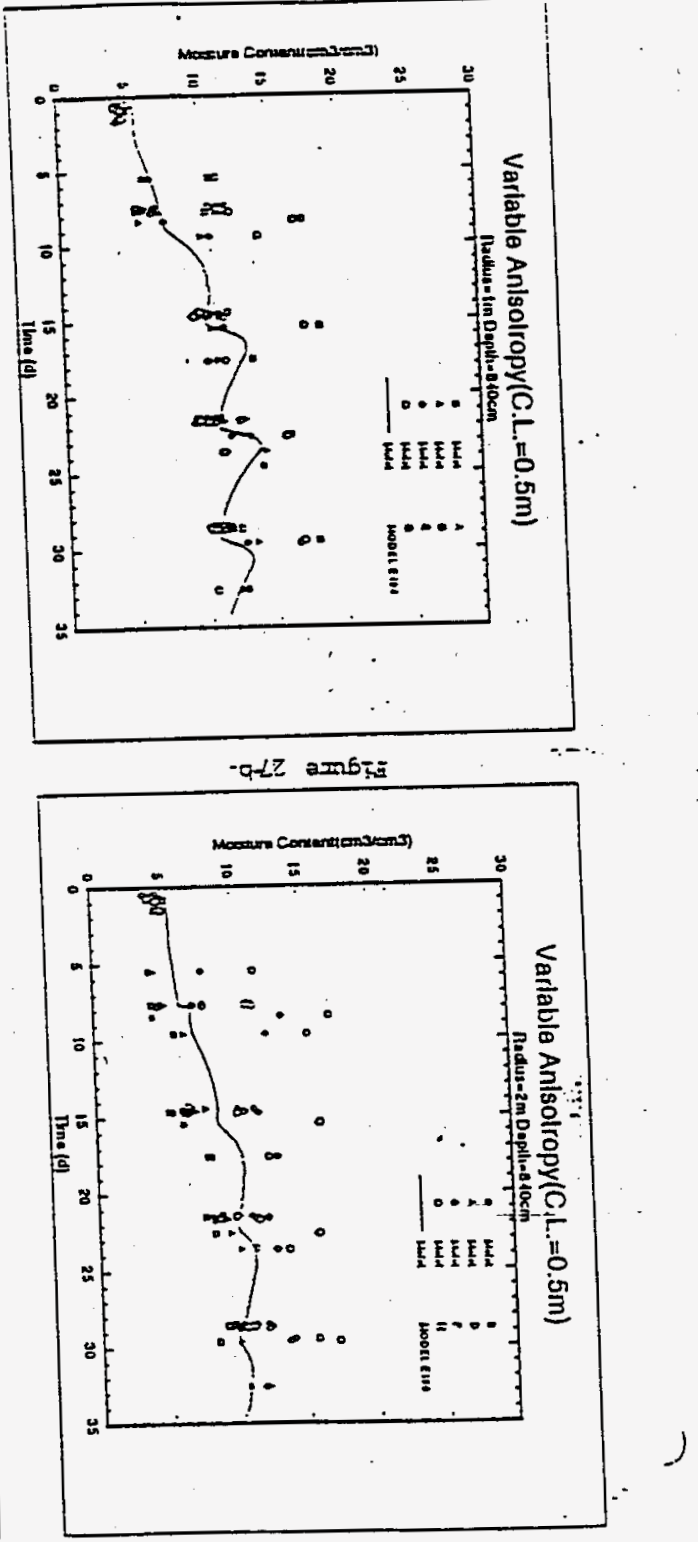


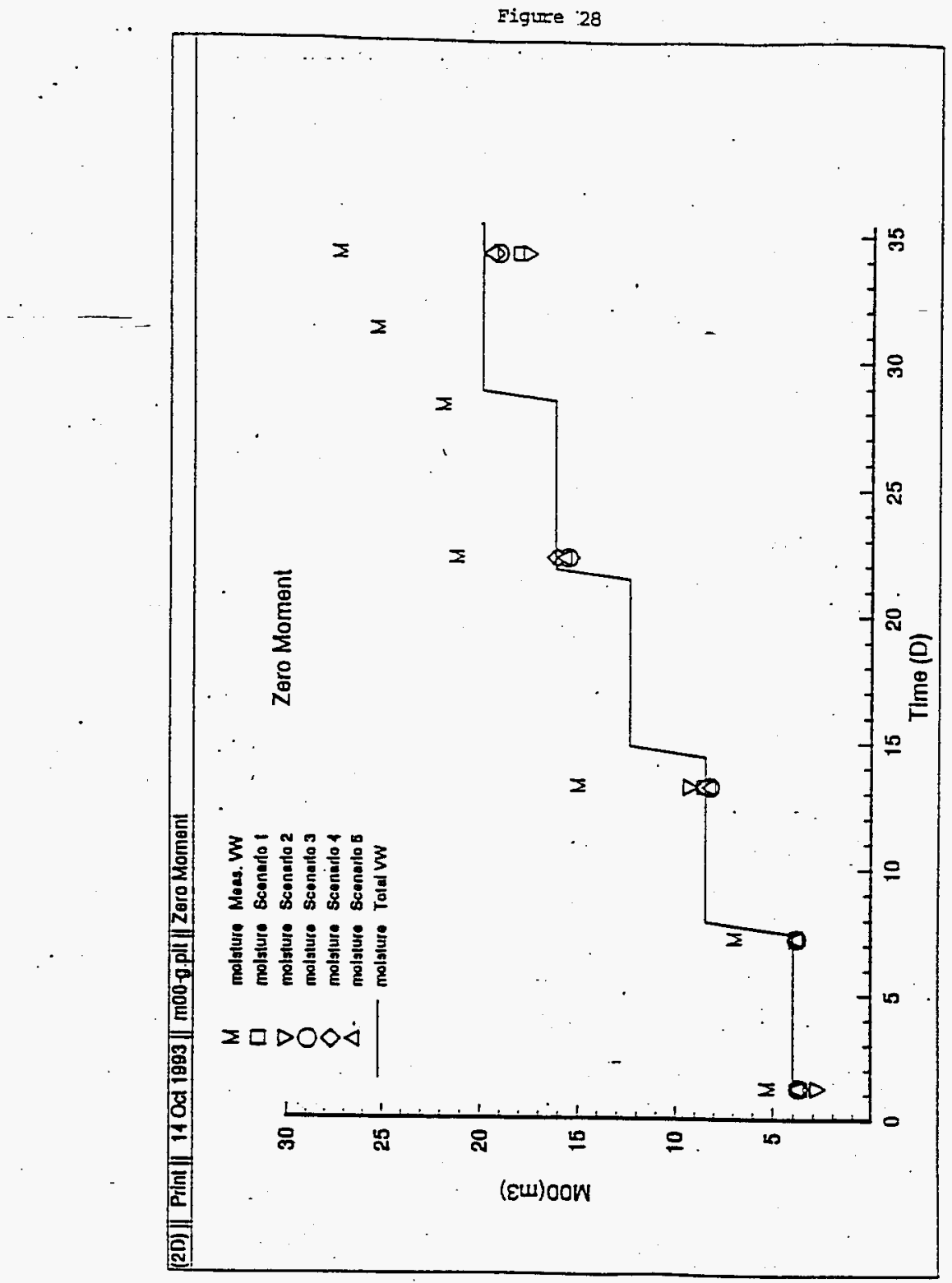


Eigure 29

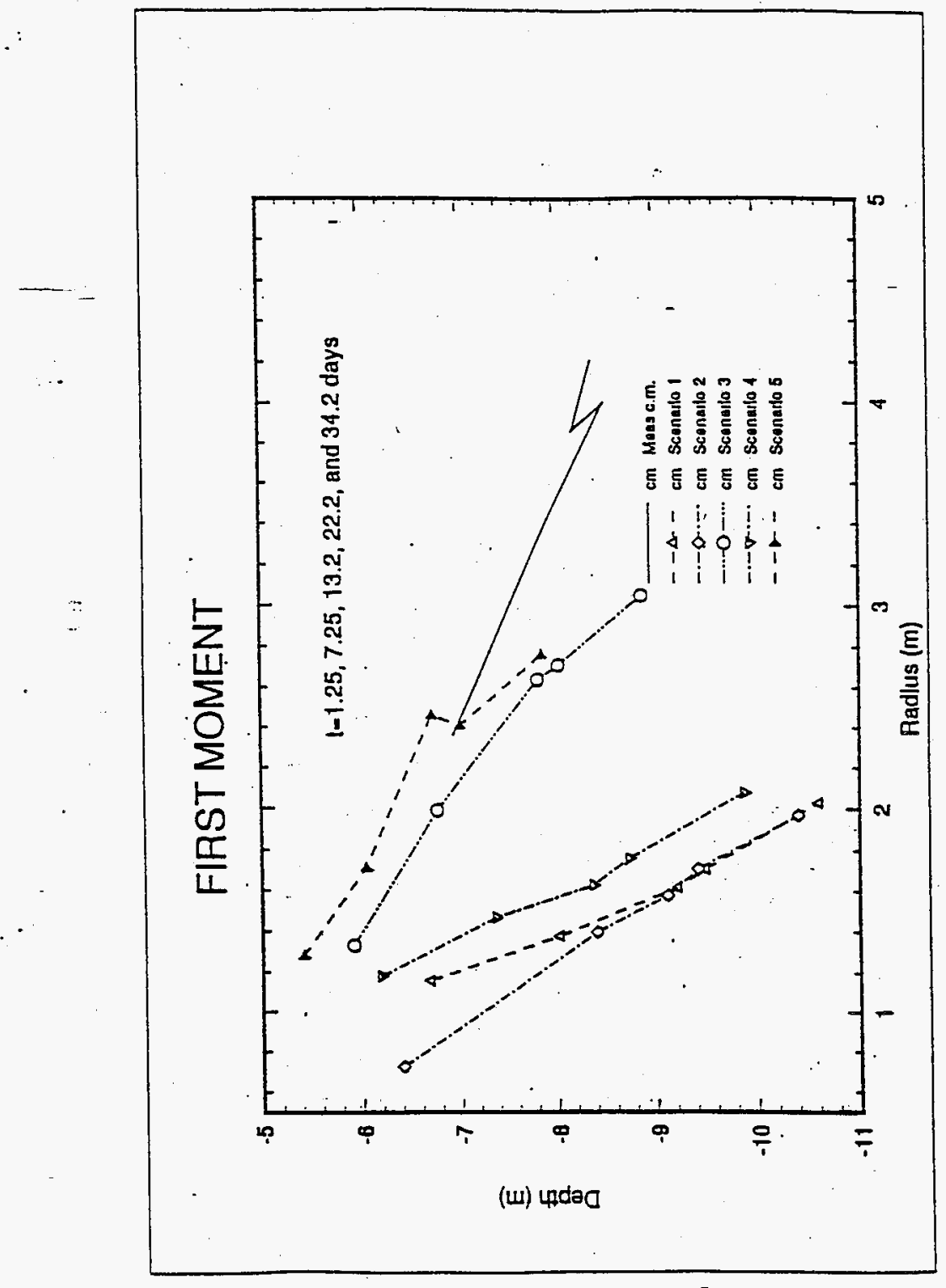


WHC-SD-WM-TI-730, Rev. 0

THIS PAGE INTENTIONALLY LEFT BLANK

D- 138 
WHC-SD-WM-TI-730, REV 0

This page intentionally left blank. 
WHC-SD-WM-TI-730, REV 0

\section{APPENDIX E}

APPLICATION OF THE SITEWIDE MODEL TO

218-E-10 AND 218-E-12B SITES

$E-i$ 
WHC-SD-WM-TI-730, REV 0

consists of variably indurated clay, altered mud and sand, fine to coarse sand, and multi-lithologic gravel.

The Pre-Missoula Gravels are up to $25 \mathrm{~m}$ thick, contain less basalt than the underlying Ringold Gravel and the overlying Hanford deposits, have a distinctive white or bleached color, and sharply truncate underlying strata. The pre-Missoula gravels are approximately time equivalent to the early"Palouse" soil and the Pio-Pleistocene alluvium. The gravels are interpreted as mainstream deposits of the Columbia River (Delaney et al. 1991). The Hanford formation consists of gravel, fine- to coarse-grained sand, and silt and was deposited as a result of cataclysmic flooding of the Pasco Basin during three different episodes Pleistocene glaciation.

The unconfined aquifer is contained within the Ringold Formation and the Hanford formation of the Pasco Basin. This basin is bounded by Umtanum Ridge, Yakima Ridge, and the Rattlesnake Hilis on the west; Rattlesnake Mountain on the southwest; the Saddle Mountains to the north; and the Palouse Slope on the east. The Columbia River traverses through the basin and forms the northern and eastern boundary of the unconfined aquifer for the Hanford site. The top of the Columbia River basalts is generally considered to form the bottom of the unconfined aquifer. The top of basalt is based on surface geologic maps of the Pasco Basin (Reidel and Fecht 1994a and 1994b) over 300 boreholes drilled into the basalt sequence.

The sources of natural recharge to the unconfined aquifer are the areas of high relief west of the Hanford Site. From the recharge areas, the ground water flows down-gradient to the discharge areas at the northern and eastern edge of the site, primarily the Columbia River. The Yakima River is another recharge source on the south of Hanford Site. The recharge from Yakima River prevents contamination from the 200 Areas from moving southward toward the city of Richland.

Two drainage basins, Cold Creek and Dry Creek, receive an annual average precipitation of about $41 \mathrm{~cm}$, compared to that at Hanford of about $16.5 \mathrm{~cm}$. In addition to surface runoff from the drainage basins, there is ground-water recharge from the basins across the western boundary of the site. Water from Cold Creek and Dry Creek infiltrates the streambeds and migrates to the water table. In addition there is considerable irrigation in the basins that provide seasonal recharge to the unconfined aquifer system west of the Site.

There is also a potential for groundwater. recharge to the unconfined aquifer along the southwest boundary of the Site, i.e., from runoff along the front of Rattlesnake mountain. However, the recharge is thought to be small.

Natural areal recharge from the precipitation at the Hanford Site is highly variable, ranging from near zero to more than $10 \mathrm{~cm} / \mathrm{yr}$ depending on the vegetation and soil texture. Recharge is generally negligible when soils are fine-grained with a vegetative cover (Johnson 1993, Routson et al. 1988, Gee 1987, Rockhold et al., 1990). When soils are coarse-grained and there is no vegetation, recharge is likely during the years of high precipitation. Fayer and Walters (1995) developed a natural recharge map based on the data from the lysimeters, tracer studies, neutron probe measurements, and computer modeling. In that map, two distinct recharge zones are apparent: a slightly high recharge zone ranging from 2 to $5 \mathrm{~cm} / \mathrm{yr}$ distributed over mainly in the southeast of the 200 East Area extending to the Columbia River; a low 
WHC-SD-WM-TI-730, REV 0

\author{
APPENDIX E \\ APPLICATION OF THE SITEWIDE MODEL TO \\ 218-E-10 AND 218-E-12B SITES
}

A. H. Lu

\title{
E.1 INTRODUCTION
}

This appendix briefly describes the development of the Hanford Sitewide Model and its application to the performance assessment.

A sitewide groundwater model for the Hanford Area has been developed and calibrated for multiple purposes. The development and calibration of the sitewide model are described in detail by Law et al. (1996). The primary objectives to use the sitewide model for this performance assessment are: (1) to develop a conceptual model describing the general flow field for the postHanford era, (2) to ensure that hydrogeologic parameters used for both the site wide model and the small scale disposal facility model are consistent and adequately simulate the site hydrogeologic characteristics, and (3) to evaluate the regional distribution and concentration trends of contaminant plumes emanating from the 200 East Area LLBG.

A summary of sitewide model development and calibration is discussed in Sections E.2, E.3, and E.4. An overview of the conceptual model for the Hanford unconfined aquifer is described in Section 2. Emphasis is placed on the description of the recharge and discharge characteristics of the Hanford Site. In Section 3, the model setup, boundary conditions, and hydrogeologic parameter selections are described. A brief discussion of the model

calibration is provided in Section 4. The application of the sitewide model to the 218-E-10 and 218-E-12B sites for the post-Hanford era is discussed in Section 5. A comparison of the simulated water levels with pre-Hanford data is provided. Such comparison provides additional confidence that flow field characteristics have been correctly simulated. An evaluation of the dilution factor is also provided to check the consistency between the large scale model and cross section model. Section 6 discusses uncertainties inherent in the site-wide model application to the 200 East Area LLBG that could influence hydraulic flow regime and contaminant plume distribution estimates. The implications of these uncertainties on the conservatism of the chosen hydrogeologic conceptual model relative to groundwater contamination from released radionuclide inventory and dose calculations is discussed.

\section{E.2 CONCEPTUAL MODEL AND DATA FOR THE UNCONFINED AQUIFER}

The geology of the Hanford Site is described in detail in DOE (1988) and Delaney et al. (1991). Significant geologic features used in the site-wide model are discussed below. The Hanford Site lies within the Pasco basin, a structural and topographic basin in south-central Washington State. The major stratigraphic units are, in ascending order, the Columbia River Basalt Group, the Ringold Formation, Pre-Missoula Gravel, and the Hanford formation. The Columbia River Basalt Group is composed of a thick sequence $(>5,000 \mathrm{~m})$ of basalts that form the bedrock in the Columbia Basin. The Ringold formation 
recharge zone of less than $0.5 \mathrm{~cm} / \mathrm{yr}$ distributed over most of the other areas of the Hanford Site. Areas of high recharge ranging from 5 to $10 \mathrm{~cm} / \mathrm{yr}$ are scattered over parts of the 200 West Area, 200 East Area, 100 Area, and in the vicinity of WPPSS near the Columbia River.

The Columbia River along the northern and eastern boundary of the site is a discharge zone for the unconfined aquifer. This was true under pre-Hanford conditions and remains so today. River fluctuations influence the unconfined aquifer for several hundred feet from the river's edge, but over a year's time these fluctuations cancel out.

\section{E. 3 HANFORD GROUND-WATER FLOW AND TRANSPORT MODEL}

\section{E.3.1 Mode1 Setup}

VAM $3 D-C G$, a three-dimensional, finite-element code (Huyakorn and Panday 1994), was used to simulate moisture movement and contaminant transport at the Hanford Site. Testing of the VAM3D-CG Computer code, version 3.1 and its previous version $2.4 \mathrm{~b}$, was conducted to establish confidence that the code is ready for use in performance assessment applications at the Hanford Site (Lu and Langford 1994, Lu and Langford 1995).

The model grid consists of six layers with 2,474 elements and 2,611 nodes per layer. It has a total of 14,844 elements and a total of 18,277 nodes. A horizontal finite element grid size of $600-\mathrm{m} \times 600-\mathrm{m}$ was selected with element heights varying depending on the saturated thickness of the aquifer and the high-conductive pre-Missoula/Hanford formation. Vertical discretization was performed using 6 elemental layers, the top three (layers 4,5 , and 6) reside in the pre-Missoula/Hanford formation, where it exists.

\section{E.3.2 Hydrogeologic Properties}

The hydrogeologic properties of the aquifer materials within the system control the magnitude of flow and determine the configuration of the water table, or upper limit of the saturated zone. Direction of flow is controlled by the aquifer properties along with the locations of recharge and discharge.

Eighteen hydrogeologic material zones were used to characterize various sediments. The material identification numbers for the upper layers (layers 4,5 and 6 ) and lower layers (1ayers 1,2, and 3 ) are shown in Figures $E-1$ and E-2, respectively. The hydraulic property input data, such as hydraulic conductivities, specific storage, and porosity are listed in Table E-1.

\section{E.3.3 Boundary Conditions}

Boundary conditions are applied to the model as conceptualized in previous section. Inflow boundaries along Cold Creek, Dry Creek, and Yakima River are prescribed head conditions, with head values supplied from observed water table elevations in the region. This enables the ground water recharge to be computed by the model for comparison with other information to evaluate the reasonableness of the model. The recharge to the groundwater system from 
WHC-SD-WM-TI-730, REV 0

the Rattlesnake Mountain front on the southwest boundary of the model is assumed to be negligible. Quantitative information is not available but the amount is believed to be small if not negligible.

The model treats the Columbia River as a boundary that is held constant in time but variable in distance along the river, with numerical values obtained from five river-stage gauges (four in 100 Area; one in 300 Area) over one-year period (1992-1993). The river stage elevation values themselves are undocumented. The data used to determine the values were collected according to the protocol described in the report by Campbell (1994), and the transducer equipment and its operation are described in Campbell and Newcomer (1992). The head values are compared with the pre-Hanford water table map which shows river stages interpolated from water table contours. This comparison implies that the average annual river stages are relatively stable over the decades. The Priest Rapids Dam average yearly discharge data supports this assessment. The average yearly discharge is 105 kilo-cubic-feet per sec (kcfs) in 1992, which is in good comparison to the average of $118 \mathrm{kcfs}$ over the period of 1960-1994 (McMahan, 1995).

A no-flow boundary condition was used at the bottom of the model that is taken to be the top of the lower mud unit of the Ringold Formation where it exists; otherwise it is the top of basalt. Also, the Gable Mountain, Gable Butte, and a subcrop of the Umtanum Ridge are treated as elements of "zero" hydrautic properties so that there is no flow in those elements.

The model assumes no recharge from precipitation. Most of Hanford site is vegetated and the upper soil layers are relatively fine grained. Slightly higher recharge areas are downstream of most waste storage and disposal sites. Although the recharge in the 200 Areas where processing of nuclear fuels has taken place is relatively high, in view of a high volume of the artificial discharges resulting from Hanford operations, the natural recharge is thought to have no or minor effects on the direction of groundwater flow.

\section{E.4 GROUND-WATER MODEL CALIBRATION}

A three-phase calibration (Law et al. 1996) was performed. The initial phase was to calibrate the model to the steady-state period of 1976-1979. During this period, the water table position remained relatively constant and the volumes of waste water disposed to ground remained relatively constant during this time. The second phase started with the steady-state calibrated model of 1979, and simulated the period of 1979 through 1993 in a transient mode. The calculated water table conditions were compared to observed conditions at 8 and $14 \mathrm{yr}$ (i.e., for 1988 and 1993 conditions). The final phase was to confirm the hydraulic calibration by simulating the movement of tritium plume.

\section{E.4.1 Steady-State Calibration (1979)}

Groundwater generally flows from regions of recharge to regions of discharge. The general flow pattern is interrupted locally by groundwater mounds and the basalt outcrops and subcrops at the Hanford Site. The groundwater mounds were beneath the high volume disposal sites: $U$ Pond in the 200 West Area, B Pond east of 200 East Area, and Gable Mountain Pond north of 
200 East Area. They resulted from artificial recharge from liquid disposal at a rate that exceeded the ability of the sediments to transmit this water (Graham et a1. 1981).

The artificial recharge resulting from Hanford operations provided the source term and is input at nodes along the top boundary of the model. The flux boundaries at 1979 were estimated from records reported by S1inger (1980): the discharge at three high-volume disposal sites, U Pond, B Pond, and Gable Mountain Pond; the discharge at moderate volume disposal sites, 216-s-10 and 216-s-11 cribs near $U$ pond; and the discharge at moderate volume disposal site, 216-A37-1 crib in 200-East Area. U pond began receiving waste discharges in 1944 and was decommissioned and covered over in 1984. B-pond began receiving waste water in 1945. Two expansion ponds were constructed in 1984 adding 50\% more capacity (Zimmerman et al., 1986). Gable Mountain Pond began receiving waste water in 1957. Decommissioning of Gable Mountain Pond began in 1984, but it continued to receive reduced waste water discharges. There are a number of low-volume discharge sites, but they were assumed to have no direct impact on the unconfined aquifer flow directions.

Several cases were run to determine how best to represent boundary conditions resulting from natural areal recharge on the west and southwest sides of site. It was decided to use constant head boundary conditions only for the calibration exercise to quantify the inflow from the recharge area. Constant head boundary conditions are the result of the natural recharge from Cold Creek and Dry Creek and artificial recharge from $U$ Pond discharge conditions. These conditions are, therefore, correct only for the 1979 hydrologic flow conditions.

The simulated and measured water tables representing the 1979 steadystate flow conditions are shown in Figure E-3. The calibrated water table agrees favorably with the field measurements (Law et al. 1996).

After calibration, inflow fluxes from the boundary nodes were used to replace those fixed head boundary nodes (six planar nodes multiplied by seven layer nodes, for a total of forty two nodes). The model reproduced the water tables and flow streamlines under 1979 conditions. These influx boundary conditions represent the natural recharge conditions under 1979 conditions and are expected to be representative of average conditions over time unless regional precipitation characteristics change drastically. Recharge to the system from Cold Creek is $4.34 \mathrm{cfs}$ and Dry Creek is $16.6 \mathrm{cfs}$, which compares to field estimates of $1-10 \mathrm{cfs}$ inflow. The model simulated discharge of 51.9 cfs from the unconfined aquifer to the Columbia River.

\section{E.4.2 Transient Simulation and Comparison}

The calibrated steady-state simulation representing December 1979 conditions was next used as the initial condition for a transient simulation of 14 years. Nine nodes were assigned for flux boundary conditions representing ponds and cribs that have been discharging large volumes of water to ground surface. Some cribs were grouped together because a coarse grid size is used in the model. Flux boundary condition over the ponds and cribs were varied annually in a stepwise fashion to represent annual average recharge at the respective locations. The selected facilities represent about $95 \%$ of the liquid disposed to the ground (Law et a1. 1996). Figures E-4 shows 
95\% of the liquid disposed to the ground (Law et al. 1996). Figures E-4 shows the simulated and measured water table levels at 8 year, respectively, representing 1988 conditions. Figure E-5 shows the simulated and measured water table levels at 14 year, respectively, representing 1993 conditions. These water table levels were compared to the observed values, and were in agreement to within the calibration targets (Law et al. 1996).

Figure E-6 shows the water table changes that occurred between 1988 and 1979. The mound in the 200 West Area was noted to decline while the mound in the east of 200 East Area was seen to increase. The decreases in 200 West Area were due to the reduced recharge in the area. Similarly, the increases in the east of 200 East Area were due to the increased recharge to $B$ pond. Figure E-7 shows the water table changes that occurred between 1993 and 1988 . The mound declined significantly in the east of 200 East Area due to the decreasing recharge to $B$ pond during this period.

Figures E-8 and E-9 show the pathlines for 1988 and 1993 , respectively, representing various particle travel times and flowpaths. Each mark represents 5 years travel time. In both plots (figures $E-8$ and $E-9$ ), the particle flowpaths originate in the same locations but some of them end in different locations because of a significant change of the flow field that occurred in the vicinity of $B$ pond. One of the pathlines that moves from west to east and then to southeast for 1988 moves from west to east and then to northeast for 1993. The other (south border of 200 West Area) that moves from west to east and then to southeast for 1988 moves from west to east and then to north for 1993. These shifts in direction are consistent with the change in $B$ Pond recharge during this time frame.

\section{E.4.3 Tritium Plume Calibration (1979-1993)}

The calibration was performed by analyzing historical tritium plumes behavior at the Hanford Site from December 1979 to December 1993. The simulation used the flow field generated by the calibrated flow model over the same time period. Mechanisms that govern the movement of the tritium plume include advection, dispersion and decay. The adsorption is assumed to be negligible. The decay constant of $0.0564 \mathrm{yr}^{-1}$ is based on the $12.3 \mathrm{yr}$ halflife of tritium.

The advection of the tritium plumes is controlled primarily by the calibrated flow field. The longitudinal dispersivity $A_{\perp}$, transverse dispersivity $A_{T}$, and vertical dispersivity $A_{V}$ are additional parameters which regulate the simulated behavior of the tritium plumes. The dispersivity is generally scale dependent and results from the spatial and temporal variations of the flow field. Gelhar et al. (1992) compiled dispersivity values determined from field tests at 59 different sites including two investigations at the Hanford Site. One of investigation examined the 200 East tritium plume using two-dimensional transport model. They came up with dispersivity values of $A_{L}=30.5 \mathrm{~m}$ and $A_{T}=18.3 \mathrm{~m}$ (Ahlstrom et al., 1977).

The calibration of tritium transport model was initiated by including the observed 1979 tritium distribution with the calibrated steady-state flow model. Transient simulations ran through 1993. Boundary conditions included a zero concentration for inflow at Cold and Dry Creeks and the Yakima river, and zero normal concentration gradient condition at the discharge nodes along the 
Columbia river. The annual average tritium mass inflow was provided at inflow locations (cribs and ponds) consistent with the flow.model. A net of $2.78 \times 10^{11} \mathrm{pCi}$ of tritium was injected during the $14 \mathrm{yr}$ simulation period. The injected tritium mass was much less than the existing total mass in the aquifer (i.e. the observed 1979 tritium plume).

The initial tritium plume (measured in 1979) is presented in Figure E10. The simulation used dispersivity values described above. The dispersivity values were then adjusted to reproduce the tritium plumes measured in 1988 and 1993 . The final adjusted longitudinal dispersivity $A_{1}$, transverse dispersivity $A_{T}$, and vertical dispersivity are $30.5 \mathrm{~m}, 3 \mathrm{~m}$ and 3 , respectively. The $A_{L}$ value remains the same as calculated from twodimensional transport model of 200 -East tritium plume study reported in Ahlstrom et al. (1977), but the $A_{T}$ value was six time smaller than that obtained by Ahistrom et a1. (1977). This change in the $A_{r}$ value is expected because a three-dimensional model was used in this calibration rather than a two-dimensional model. The ratio of $A_{T} / A_{L}$ is about $1 / 10$ and is consistent with ratios in the literatures (Gelhar et ai. 1992).

The simulated results of tritium distribution in 1988 and 1993 are presented in Figures $E-11$ and $E-12$, respectively. The tritium units were converted to $\mathrm{pC} i / L$ to compare with the measured values. The comparison of the measured and simulated tritium plumes in 1988 and 1993 are presented in Figures E-13 and E-14, respectively (Dresel et a1. 1994, reproduced by Bechtel Hanford Incorporated). For the 14-yr simulation period, the domain lost a net $2.16 \times 10^{14} \mathrm{pCi}$, with $1.75 \times 10^{13} \mathrm{pCi}$ being discharged across the boundary into the Columbia River, and $1.98 \times 10^{14} \mathrm{pCi}$ having decayed. The tritium plumes compare fairly well with the field data.

\section{E.5 APPLICATION OF THE SITEWIDE MODEL TO THE DISPOSAL SITES}

To apply the sitewide groundwater model to the $218-\mathrm{E}-10$ and $218-\mathrm{E}-12 \mathrm{~B}$ sites, the post-Hanford flow conditions were projected by assuming that the artificial recharges from $U$ Pond, B Pond, Gable Mountain Pond and other cribs have completely ceased and the mounds underneath these discharge sites have dissipated. The transient state of the dissipating mounds can be ignored because the contaminant flux for conservative radionuclides will take several hundreds of years to reach the unconfined aquifer, given the expected average infiltration rate of $<0.5 \mathrm{~cm} / \mathrm{yr}$.

The projected Hanford flow conditions were then used as the basis to project a representative contaminant plume emanating from the $218-E-10$ and 218-E-12B LLBG. Relative downstream concentrations of the contaminant were calculated at different distances from the source and compared with the cross section model result for consistency.

\section{E.5.1 Post-Hanford Water Table}

Figure E-15 shows the result of a steady-state simulation representing post-Hanford water levels. Figure E-16 shows the simulated pathlines for the Post-Hanford era. Comparison of Figure E-15 with Figure 2-8, a water table map of the Hanford site, January 1944, shows a similar configuration. 
Assuming that there will be no significant changes in the regional recharge and discharge characteristics, the post-Hanford water table configuration should be very similar to the pre-Hanford water table configuration. If the assumption is correct, the predicted water table in the post-Hanford era can be verified by water level measurements in pre-Hanford era or during its early days in operation. Because the spatial hydraulic property distribution is time invariant, close comparison would, therefore, provide confidence that selection of the generalized hydraulic property distribution over the site is reasonably accurate on a regional scale.

Zimmerman et a1. (1986) examined how liquid discharges to ground have changed the configuration of the water table with time from 1950 through 1980 at the Hanford Site. The hydrographs for selected wells presented in the report started as early as 1950 . The measurements at 1950 were used for comparison in this study. Although Hanford operation started at 1944, only wells near $U$ Pond; B Pond; and $T$ Pond, which have significant discharges during the early days in operation, would be affected. The well locations used for comparison are presented in Figure E-17 along with the predicted water table contours for post-Hanford. Only well w20 (399-8-1) is not on the plot because it is in the 300 Area near the Columbia River. Figure E-18 shows the predicted aquifer thickness in the vicinity of 200 East Area. A five meter contour of the aquifer thickness runs across both $218-E-10$ and 218-E-12B sites. Generally, the unconfined aquifer thickness declines from the south to north across the sites as the basalt bedrock approaches the surface to the north.

The comparison between the predicted post-Hanford water levels and the measured water levels in 20 selected wells are presented in table E-2. They are generally in a good agreement except for four wells. One of the exceptions is well 699-25-70 (w9) at which the measurement is lower than the predicted one by $4.6 \mathrm{~m}$. However, the predicted water levels and measurements agree very well at the downstream well (w12) and upstream well (w5). The other significant discrepancy is well 699-55-89 (w2) at which the measured water level is $3.9 \mathrm{~m}$ higher. This happened in the area in which the hydraulic gradient was the highest; the water level dropped from $130 \mathrm{~m}$ to $124 \mathrm{~m}$ in 1.2 $\mathrm{km}$ distance. The other two wells are 699-55-70 (w7) and 699-50-30 (w16). In these wells the measured water-levels are $2.7 \mathrm{~m}$ and $2.8 \mathrm{~m}$ lower that predicted ones, respectively. Both wells are in the vicinity of the basalt outcrops.

The water level measurements in well 299-45 42 (W14, Figure E-17) and we11 299-26-1 (W8, Figure E-17) in 1950 were $124.7 \mathrm{~m}$ and $119.3 \mathrm{~m}$, respectively. These values compare favorably with $124.4 \mathrm{~m}$ and $119.2 \mathrm{~m}$ (see Table E-2) in the post-Hanford model prediction. This comparison implies a close gradient value over $1.8 \mathrm{~km}$ near the sites.

These comparisons indicate that the generalized model of the flow field is reasonable. However, the existence of the discrepancies in the comparison in some areas indicates the existence of local heterogeneities in the geohydrologic properties. The sitewide model does not have sufficient resolution to accurately predict the local scale behavior of the aquifer. Thus, site specific data are essential for an accurate prediction for a specific site. When site specific data are not sufficient or a long-term prediction is required, conservatism should be adopted in developing conceptual model for a site. In summary, the ability to represent local variability with the regional model is limited by the availability of input 
data (e.g., the areal density of well locations and amount of hydrologic data) and the adequacy of the numerical discretization that can reasonably be configured to perform the analyses.

\section{E.5.2 Contaminant Transport}

The sitewide model was used for estimation of the contaminant distribution at hypothetical downstream wells. The purpose of this analysis was to show general flow directions of the contaminants and their distribution from the disposal sites to the river. Figure E-19 shows the simulated pathlines from the $218-E-10$ and $218-E-12 B$ sites to the Columbia River, and the selected well locations along the pathlines.

Two solute flux boundary conditions were assigned at locations underneath $218-E-10$ and $218-E-12 \mathrm{~B}$ sites, respectively. Each source area has dimensions of $20 \mathrm{~m}$ (in the direction west-east) by $600 \mathrm{~m}$ (in the direction north-south). A constant solute flux was obtained by assuming a concentration, $\mathrm{C}_{0}$, of $0.1 \mathrm{Ci} / \mathrm{m}^{3}$ in the interstitial water throughout the disposal sites and being carried out by a recharge water of $0.5 \mathrm{~cm} / \mathrm{yr}$. The source term is similar to the source term used in the cross sectional model, but this analysis ignored the cascade effect in the trench and the vadose zone transport to simplify the analysis. The cascade effect has no significant impact on long-term groundwater concentration estimates. In essence, the transport analysis begins with the release of contaminants into the unconfined aquifer at the water table.

Simulated Results. The results of the model simulation are presented in Figure E-20 representing the contaminant concentration contours at the element layer 4 at $t=800 \mathrm{yr}$. The contaminant plumes from $218-E-12 B$ are generally moving from west to east and then discharging to the river. However, the contaminant plumes at $218-E-10$ are split in two routes: The main route is from south to north and then turn east along the Gable Mountain and eventually join the plume from 218-E-12B. The other route is from west to east and then joining the plume from 218-E-12B: The concentration contours which were interpreted from the output of the model runs by TECPLOT, a commercial software program. The following history plots provide model results at selected locations.

The concentration history plots for wl and w2, which are downstream wells from the $218-E-10$ site, are presented in Figure $E-21$. The concentrations at the well s w1 and $\mathrm{w} 2$ are $4.66 \times 10^{-5} \mathrm{Ci} / \mathrm{m}^{3}$ and $2.94 \times 10^{-5} \mathrm{Ci} / \mathrm{m}^{3}$, respectively. Since the incoming concentration was $0.1 \mathrm{Ci} / \mathrm{m}^{3}$, the concentration values at the wells can be converted to dilution factors at the locations. The well dilution factors for wells $w 1$ and $w 2$ are $4.66 \times 10^{-4}$ and $2.94 \times 10^{-4}$, respectively. The concentration history plots for $w 3, w 4$, $w 5$ and w6, downstream wells from the $218-E-12 B$ site, are presented in Figure $E-22$. The dilution factors for wells $w 3, w 4, w 5$, and w6 are $8.85 \times 10^{-4}, 2.74 \times 10^{-4}$, $1.43 \times 10^{-4}$, and $7.24 \times 10^{-5}$, respectively.

Two conclusions are drawn from this calculation:

- The concentration values are generally diminished as the well location moves away from the source locations. 
WHC-SD-WM-TI-730, REV 0

- The dilution factor of $8.85 \times 10^{-4}$ at well w3, $600 \mathrm{~m}$ from the source term obtained from this calculation is reasonably close to the dilution factor of $1.4 \times 10^{-3}$ estimated at $100 \mathrm{~m}$ downstream well for the base case $2 a$. The comparison shows a consistent dilution factor estimate for the cross sectional model and the large-scale Sitewide model.

\section{E.6.0 SITEWIDE MODELING UNCERTAINTIES AND IMPLICATIONS FOR THE PA RESULTS}

The sitewide model results described above and comparison with the smaller scale disposal facility analysis that is the primary focus of the PA indicates reasonable agreement on groundwater contamination estimates. However, there are also limitations on the degree of consistency that can be reached in regional versus local-scale evaluation.

In addition to the regional versus local characterization issues, projection of future local conditions is considered to be more uncertain in this part of the. Hanford Site because the saturated aquifer thickness declines rapidiy from south to north across 200 East Area, as the basalt bedrock approaches the surface to the north.

A study to evaluate the potential for transport of nickel radioisotopes from the 218-E-12B Burial Ground (Rhoads et al., 1994) postulated unsaturated sediments beneath the LLBG, rather than the $5 \mathrm{~m}$ thickness predicted in this analysis. The postulation was based on two-dimensional CFEST simulations under an assumption of a low recharge condition and supported by the measurements of the adjacent wells. In 1992, aquifer thickness was estimated at 1.2 to 5.9 meters for wells 299-E34-7, 299-E34-3, 299-E26-1, and 299-E27-10 which lie progressively south of the site. In late 1995 thickness appears to be $0.4 \mathrm{~m}$ to $5.2 \mathrm{~m}$.

However, the desaturation condition should be limited to the vicinity of the site. Weil 299-E26-1 that is located less than $1 \mathrm{~km}$ south to the burial ground recorded water level of $119.3 \mathrm{~m}$ in 1950, which is consistent with sitewide model prediction in the post-Hanford era (see Table E-2). The aquifer thickness at wells 299-E24-7 and 299-E24-18 further south were estimated to be more than 25 meters in 1994 . The sitewide model predicts the thickness at these wells at $22 \mathrm{~m}$ in the post-Hanford era.

The implications of a zero aquifer thickness on groundwater contamination estimates are worth considering because the no aquifer thickness interpretation can be dismissed absolutely. The primary impact should be on the travel time for the contaminants reaching to accessible aquifer. If the sediment beneath the burial ground were unsaturated, the streamlines in the flow model would not occur directly below the burial ground. The contaminated water from the disposal sites would percolate through vadose zone and flow across the top of the basalt until it reached the unconfined aquifer. Because the basalt tops beneath the burial ground slopes toward the south, flow lines should simply be displaced to the south in the west to east direction shown by the current simulations. A downstream compliance well would be placed at the nearest location where a minimum 5-m aquifer thickness would be predicted to occur. A 5-m well screen is typically used for drawing water in the area. This location is necessarily farther away than the currently placed compliance well (100 m downstream) and would result 
in predictions of longer travel times and some additional dilution of peak radionuclide concentrations.

One major assumption used in the calibration analysis was that natural recharge over the Hanford Site has no impact on the hydrologic flow regime. This assumption was considered reasonable during Hanford operation years because of the high volume of artificial recharges. However, the assumption may not be valid for the post Hanford conditions.

Two sensitivity runs were performed using the assumed natural areal recharge rates of $0.5 \mathrm{~cm} / \mathrm{yr}$ and $5 \mathrm{~cm} / \mathrm{yr}$ over the entire Hanford Site. The low recharge case is a close approximation of the natural areal recharge map developed by Fayer and Walters (1995). For the case of the lower recharge rate, $0.5 \mathrm{~cm} / \mathrm{yr}$, the water table map and the pathlines are presented in Figures $E-23$ and E-24, respectively. The water table map and flow field are very similar to the case with no natural recharge (see Figures E-15 and E-16). The impact on the flow field appear to be minor for the low recharge case.

For the high recharge case of $5 \mathrm{~cm} / \mathrm{yr}$, the water table map and pathlines are presented in Figures E-25 and E-26, respectively. The pathlines originating in the 200 East Area would be generally northward toward the river. This is consistent with the PNL studies depicted in the report by Rhoads et al. (1992, 1994) assuming a similar recharge rate. The water levels generated by the high recharge case are much higher than the water levels in the pre-Hanford (1944) conditions, particularly in the 200 West Area which show differences of $12 \mathrm{~m}$ in the water level (i.e., aquifer thickness) contour. The aquifer thickness in the vicinity of 200 East Area for $5 \mathrm{~cm} / \mathrm{yr}$ recharge case is presented in Figure E-27. A twelve meter contour of the aquifer thickness runs across the sites instead of $5-\mathrm{m}$ contour for the low recharge case. This high recharge case is not justified by current cilimate and the recharge studies performed in the Hanford Site.

If we consider the potential effects of this flow regime on groundwater contamination predictions, we qualitatively predict that low contamination concentrations will result because of high recharge. That is because the water table underlying the 200 East Area LLBG will reside in a higher permeability zone causing the contaminant to mix with a larger volume of uncontaminated water which would result in lower concentration in the downstream wells.

Two hydraulically distinct layers exist near the water table underneath the 200 East Area LLBG. Material zones (\#16 and \#7) with saturated conductivity values of $1.13 \times 10^{6} \mathrm{~m} / \mathrm{yr}$ and $2.6 \times 10^{4} \mathrm{~m} / \mathrm{yr}$ were used in the model underneath the $218-E-12 B$ site. Similarly, two material zones (\#17 and \#12) with saturated conductivity values of $1.83 \times 10^{6} \mathrm{~m} / \mathrm{yr}$ and $8.99 \times 10^{4} \mathrm{~m} / \mathrm{yr}$ were used in the model underneath the $218-E-10$ site. The high conductivity zone lies above the low conductivity zone. In the base case model, the lower conductivity zone was assumed to be contaminated because the predicted water levels for the post-Hanford era reside in the low conductivity zone for low recharge conditions. Both low-conductivity values of $8.99 \times 10^{4} \mathrm{~m} / \mathrm{yr}$ and $2.6 \times 10^{4} \mathrm{~m} / \mathrm{yr}$ were used for base case to model the 218-E-10 and $218-\mathrm{E}-12 \mathrm{~B}$ sites, respectively. If the water levels reside in the high-conductivity zone because of enhanced infiltration, a higher volume of water would participate in mixing and result in lower concentration in the downstream wells. The relative dilution would be substantial (e.g., roughly proportional to the 
ratio of hydraulic conductivity values). Thus, it is concluded that the base case conditions used in this analysis yield conservatively high groundwater concentration estimates.

Table E-1. Element Material-Zone Flow Properties.

$\begin{array}{rl}\text { Zone } & K_{x x}(m / y)^{b} \\ 1 & .800 E+03 \\ 2 & .190 E+04 \\ 3 & .500 E+04 \\ 4 & .650 E+04 \\ 5 & .140 E+05 \\ 6 & .720 E+05 \\ 7 & .260 E+05 \\ 8 & .300 E+05 \\ 9 & .430 E+05 \\ 10 & .550 E+05 \\ 11 & .770 E+05 \\ 12 & .899 E+05 \\ 13 & .140 E+06 \\ 14 & .300 E+06 \\ 15 & .750 E+06 \\ 16 & .113 E+07 \\ 17 & .183 E+07 \\ 18 & .213 E+07\end{array}$

aTaken from Law et a1. (1996)

$\begin{array}{lll}\mathrm{K}_{w}(\mathrm{~m} / \mathrm{y}) & \mathrm{K}_{3 z}(\mathrm{~m} / \mathrm{y}) & \mathrm{S}_{\mathrm{s}}^{\mathrm{c}} \\ .800 \mathrm{E}+03 & .800 \mathrm{E}+02 & .100 \mathrm{E}-05 \\ .190 \mathrm{E}+04 & .190 \mathrm{E}+03 & .100 \mathrm{E}-05 \\ .500 \mathrm{E}+04 & .500 \mathrm{E}+03 & .100 \mathrm{E}-05 \\ .650 \mathrm{E}+04 & .650 \mathrm{E}+03 & .100 \mathrm{E}-05 \\ .140 \mathrm{E}+05 & .140 \mathrm{E}+04 & .100 \mathrm{E}-5 \\ .720 \mathrm{E}+05 & .720 \mathrm{E}+04 & .100 \mathrm{E}-05 \\ .260 \mathrm{E}+05 & .260 \mathrm{E}+04 & .100 \mathrm{E}-05 \\ .300 \mathrm{E}+05 & .300 \mathrm{E}+04 & .100 \mathrm{E}-05 \\ .430 \mathrm{E}+05 & .430 \mathrm{E}+04 & .100 \mathrm{E}-05 \\ .550 \mathrm{E}+05 & .550 \mathrm{E}+04 & .100 \mathrm{E}-05 \\ .770 \mathrm{E}+05 & .770 \mathrm{E}+04 & .100 \mathrm{E}-05 \\ .899 \mathrm{E}+05 & .899 \mathrm{E}+04 & .100 \mathrm{E}-05 \\ .140 \mathrm{E}+06 & .140 \mathrm{E}+05 & .100 \mathrm{E}-05 \\ .300 \mathrm{E}+06 & .300 \mathrm{E}+05 & .100 \mathrm{E}-05 \\ .750 \mathrm{E}+06 & .750 \mathrm{E}+05 & .100 \mathrm{E}-05 \\ .113 \mathrm{E}+07 & .113 \mathrm{E}+06 & .100 \mathrm{E}-05 \\ .183 \mathrm{E}+07 & .183 \mathrm{E}+06 & .100 \mathrm{E}-05 \\ .213 \mathrm{E}+07 & .213 \mathrm{E}+06 & .100 \mathrm{E}-05\end{array}$

Porosity

$0.10 E+00$

$0.25 E+00$

$0.10 E+00$

$0.10 E+00$

$0.25 E+00$

$0.25 E+00$

$0.10 E+00$

$0.25 E+00$

$0.25 E+00$

$0.25 E+00$

$0.25 E+00$

$0.25 E+00$

$0.25 E+00$

$0.25 E+00$

$0.25 E+00$

$0.25 E+00$

$0.25 E+00$

${ }^{b} K_{x x}, K_{x y}$, and $K_{2 z}$ are principle components of hydraulic conductivity tests.

${ }^{\mathrm{c}} \mathrm{S}_{\mathrm{s}}$ is specific storage. 
Table E-2. Comparison of Predicted Post-hanford Water-Levels with that Measured at 1950.

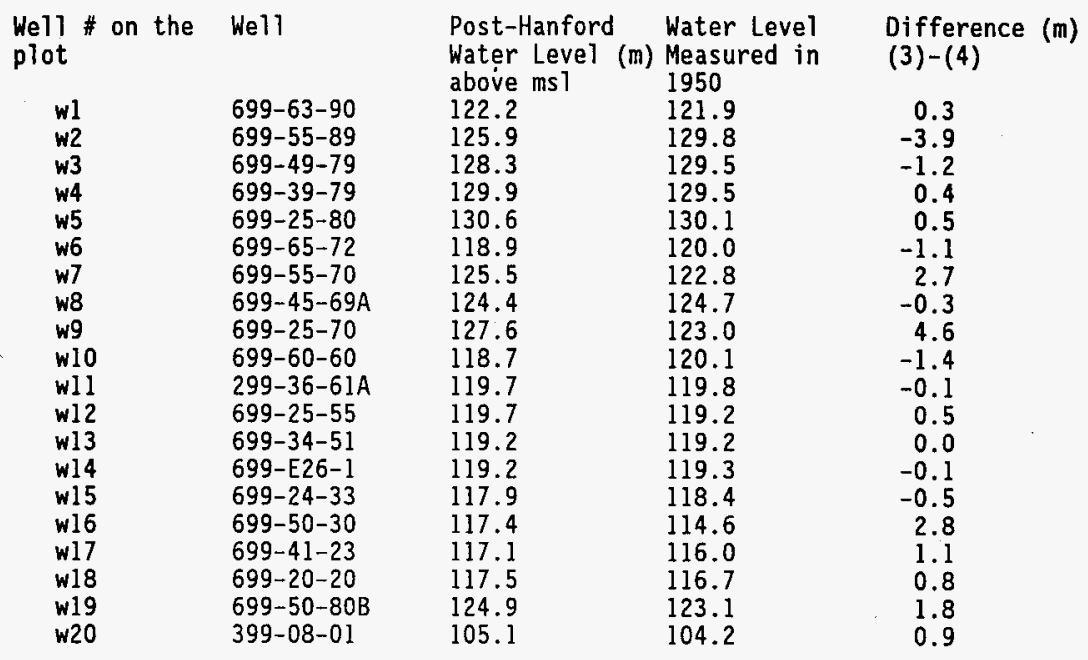




\section{E.7 REFERENCES}

Ahlstrom, S. W., H. P. Foote, R. C. Arnett, C. P. Cole, and R. J. Serne, 1977, Multicomponent Mass Transport Model: Theory and Numerical Implementation (Discrete-Parce7-Random-walk Version), BNWL-2127, Battelle Northwest Laboratory, Richland, Washington.

Campbe11, M. D., 1994, Monitoring Groundwater and River Interaction Along the Hanford Reach of the Columbia River, PNL-9437, Pacific Northwest Laboratory, Richland, Washington.

Campbel1, M. D. and D. R. Newcomer, 1992, Automatic Measurement of Water Levels Within the 300-FF-5 Boundary, PNL-7874, Pacific Northwest Laboratory, Richland, Washington.

Conneliy, M. P., J. V. Borghese, C. D. Delaney, B. H. Ford, J. W. Lindberg, and S. J. Trent, 1992a, Hydrogeologic Model for the 200 East GroundWater Aggregate Area, WHC-SD-EN-TI-019, Westinghouse Hanford Company, Richl and, Washington.

Connelly, M. P., J. V. Borghese, C. D. Delaney, B. H. Ford, J. W. Lindberg, and S. J. Trent, 1992b, Hydrogeologic Model for the 200 West GroundWater Aggregate Area, WHC-SD-EN-TI-014, Westinghouse Hanford Company, Richland, Washington.

Delaney, C. D., K. A. Lindsey, and S.P. Reidel, 1991, Geology and Hydrology of the Hanford Site; Standardized text for Use in Westinghouse Hanford Company Documents and Reports, WHC-SD-ER-TI-003, Westinghouse Hanford Company, Richland, Washington.

DNFSB, 1994, Low-Level Waste Disposal Policy for Department of Energy Defence Nuclear Facilities, Technical Report-2, Defence Nuclear Facilities Safety Board, Washington, D.C.

DOE, 1988, Consultation Oraft Site Characterization P7an, DOE/RW-0164, Vols. 1-9, Office of Civilian Radioactive Waste Management, U.S. Department of Energy, Washington, D.C.

Dresel, P. E., S. P. Luttrell, J. C. Evans, W. D. Hebber, P. D. Thorne, M. A. Chamness, B. M. Gillespie, B. E. Opitz, J. T. Rieger, and J. K. Merz, 1994, Hanford Site Ground-Water Monitoring for 1993, PNL-10082, Pacific Northwest Laboratory, Richland, Washington.

Dove, F. H., C. R. Cole, et a1., Assessment of Effectiveness of Geologic Isolation Systems: AEGIS Technology Demonstration for a Nuclear Waste Repository in Basalt, PNL-3624, Pacific Northwest Laboratory, Richland, Washington.

Fayer, M. J. and T. B. Walters, 1995, Estimated Recharge Rates at the Hanford Site, PNL-10285, Pacific Northwest Laboratory, Richland, Washington.

Gee, G. W., 1987, Recharge at the hanford Site: Status Report, PNL-6403, Pacific Northwest Laboratory, Richland, Washington. 
Gelhar, L. W., C. Welty, and K. R. Reyfeldt, 1992, A Critical Review of FieldScale Dispersion in Aquifers, Water Resources Research 26(10):2339-2351.

Graham, M. J., M. D. Ha11, S. R. Strait, and W. R. Brown, 1981, Hydrology of the Separations Area, RHO-ST-42, Rockwe11 Hanford Operations, Richland, Washington.

Gutknecht, P. J., W. A. Rice, C. R. Cole, M. D. Freshley, 1980, Pasco Basin Hydrometerological Study, PNL-3855, Pacific Northwest Laboratory, Richland, Washington.

Huyakorn, P.S. and S. M. Panday, 1994, VAM3DCG: Variably Saturated Analysis Model in Three Dimensions with Preconditioned Conjugate Gradient Matrix Solvers; Documentation and User's Guide, Version 3.I, HydroGeoLogic, Inc., Herndon, Virginia.

Johnson, V. J. 1993, Westinghouse Hanford Company Operational Ground-Water Status Report, 1990-1992, WHC-EP-0595, Westinghouse Hanford Company, Richland, Washington.

Law A., S. Panday, C. Denslow, K. Fecht, and A. Knepp, 1996, Hanford Sitewide Ground-Water Flow and Transport Model, BHI-00608 Rev. 0, Bechtel Hanford, Inc. Richland, Washington.

Lu, A. H. and D. W. Langford, 1994, Verification and Benchmark Testing of the VAM3DCG Flow and Transport Computer Code for Use in Performance Assessment at Hanford, WHC-SD-ER-CSWD-005, Westinghouse Hanford Company, Richland, Washington.

Lu, A. H. and D. W. Langford, 1995, Verification and Benchmark Testing of Version 3.1 of the VAMBDCG Flow and Transport Computer Code for Use in Performance Assessment at Hanford, WHC-SD-ER-CSWD-007, Westinghouse Hanford Company, Richland, Washington.

McMahan, W. J., 1995, Faxing discharging tables compiled by the United States Geological Survey, Pasco, Washington.

Reide1, S. P., and K. R. Fecht, 1994a, Geologic Map of the Priest Rapids $1 ; 100,000$ Quadrangle, Washington, Washington Division of Geology and Earth Science Resources Open-File Report, 94-13, 22p,1 plate.

Reidel, S. P., and K. R. Fecht, 1994b, Geologic Map of the Priest Rapids $1 ; 100,000$ Quadrangle, Washington, Washington Division of Geology and Earth Science Resources Open-File Report, 94-8, 22p, 1 plate.

Rockhold, M. L., M. J. Fayer, G. W. Gee, and M. J. Kanyid, 1990, Natural Ground-Water Recharge and Hater Balance at the Hanford Site, PNL-7215, Pacific Northwest Laboratory, Richland, Washington.

Routson, R. C., M. R. Fuchs, and W. A. Jordan, 1988, Recharge Estimate for the Hanford Site 200 Areas Plateau, WHC-EP-0046, Westinghouse Hanford Company, Richland, Washington. 
Slinger, G. J., 1980. Radioactive Liquid Wastes Discharged to Ground in the 200 Areas During 1979, RHO-CD-79-34 4Q, Rockwell Hanford Operations, Richland, Washington.

Thorne, P. D. and D. R. Newcomer, 1992, Summary and Evaluation of Available Hydraulic Property Data for the Hanford Site Unconfined Aquifer System, PNL-8337, Pacific Northwest Laboratory, Richland, Washington.

Zimmerman, D. A., A. E. Reisenauer, G. D. Black, and M. A. Young, 1986, Hanford Site water Table Changes 1955 through 1980 - Data Observation and Evaluation, PNL-5506, Pacific Northwest Laboratory, Richland, Washington. 
Figure E-1. Material Zone Map of Upper Layers $(4,5,6)$.

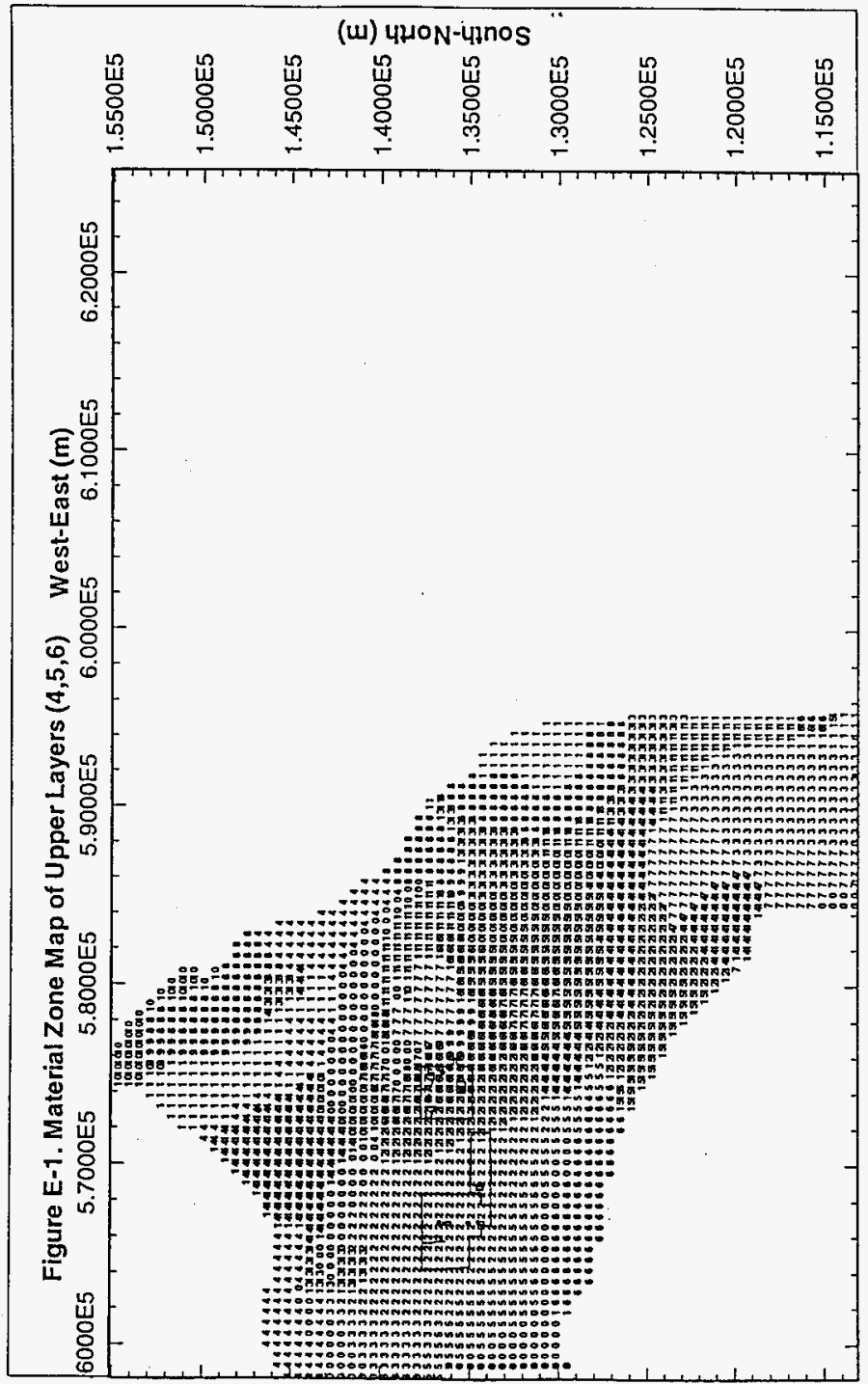


Figure E-2. Material Zone Map of Lower Layers $(1,2,3)$.

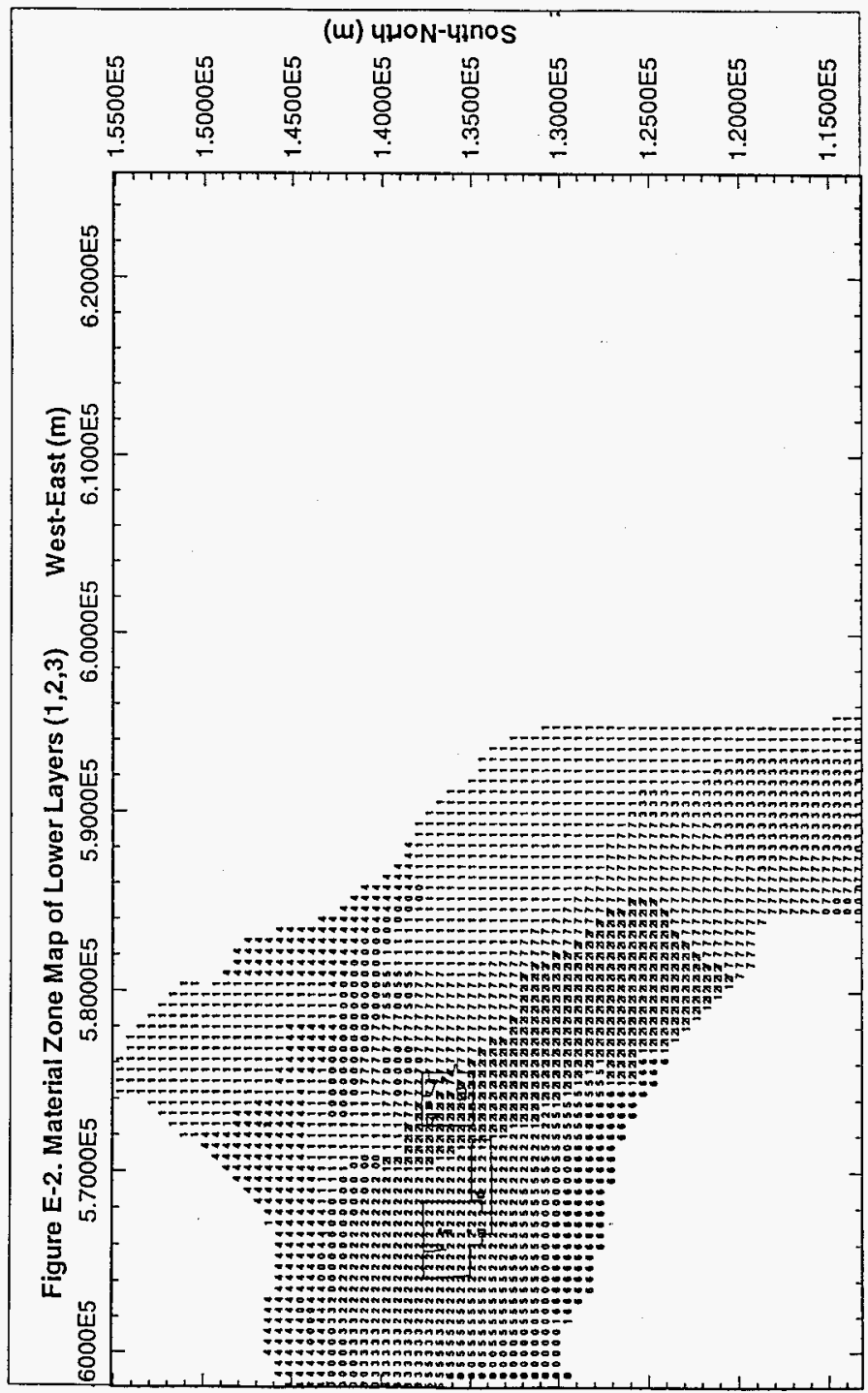




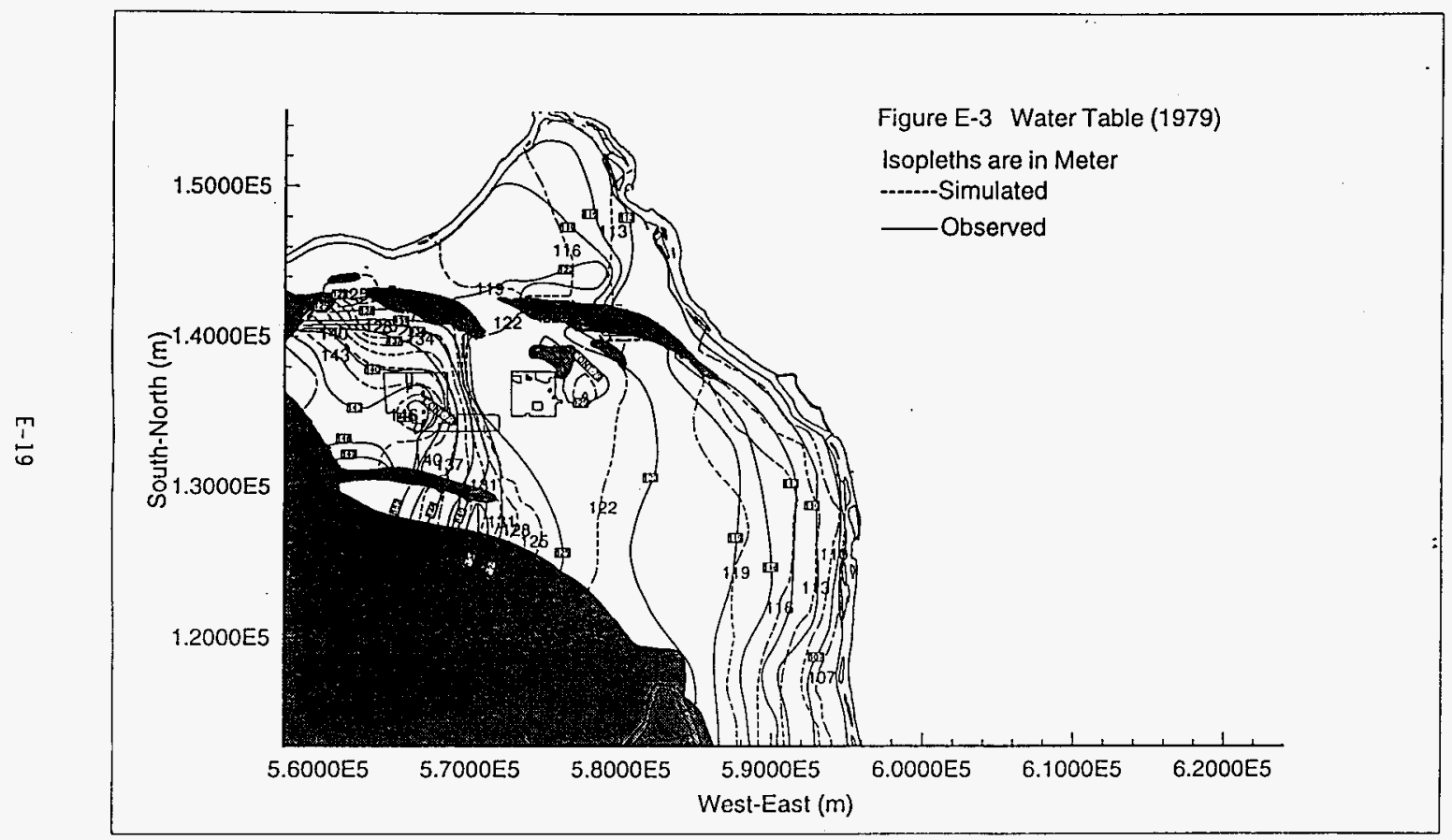

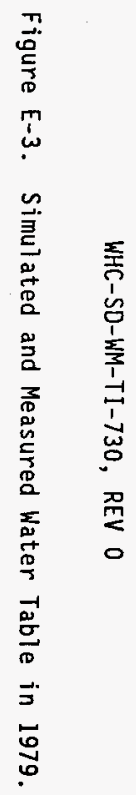


Figure E-4. Simulated and Measured Water Table in 1988.

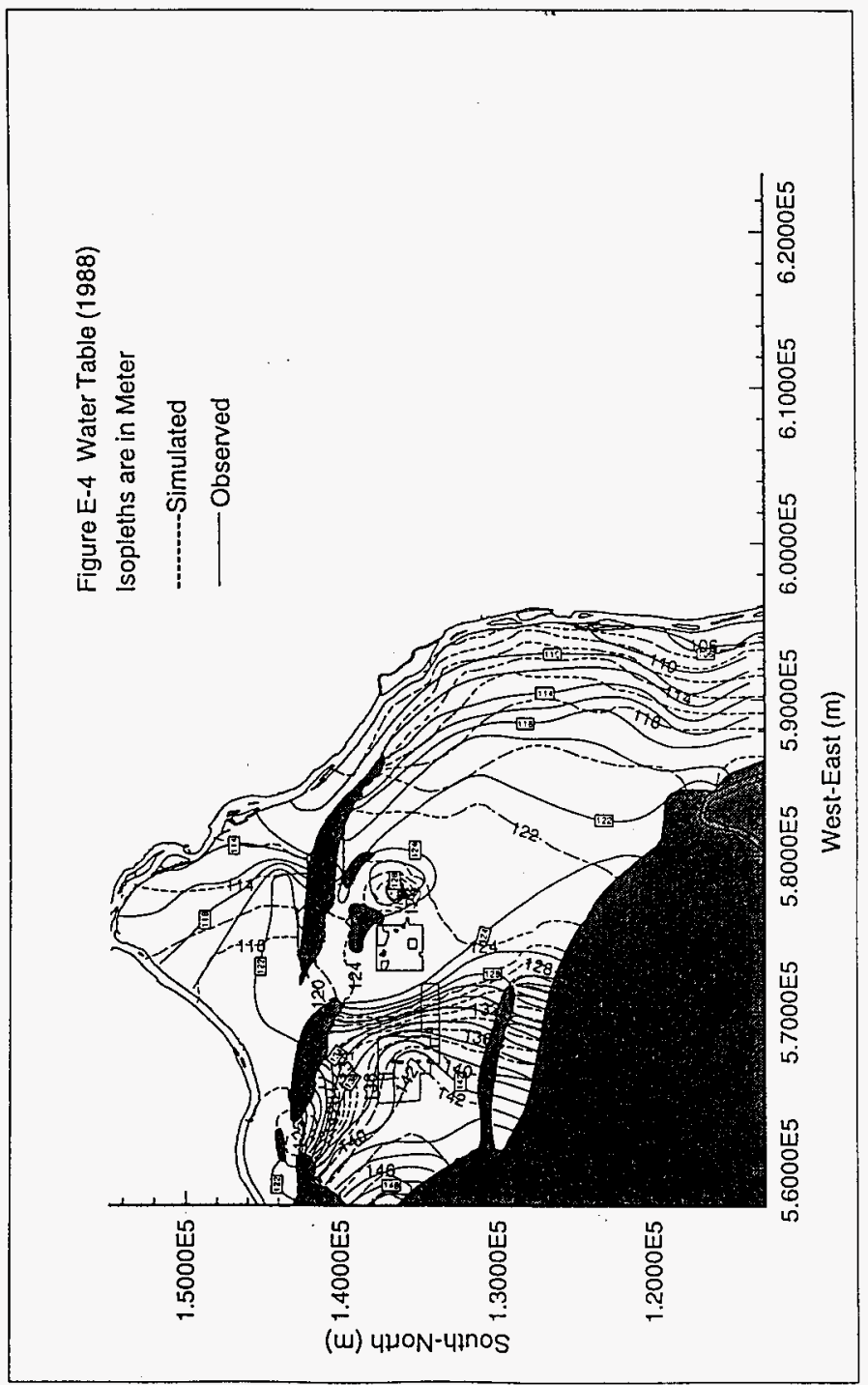




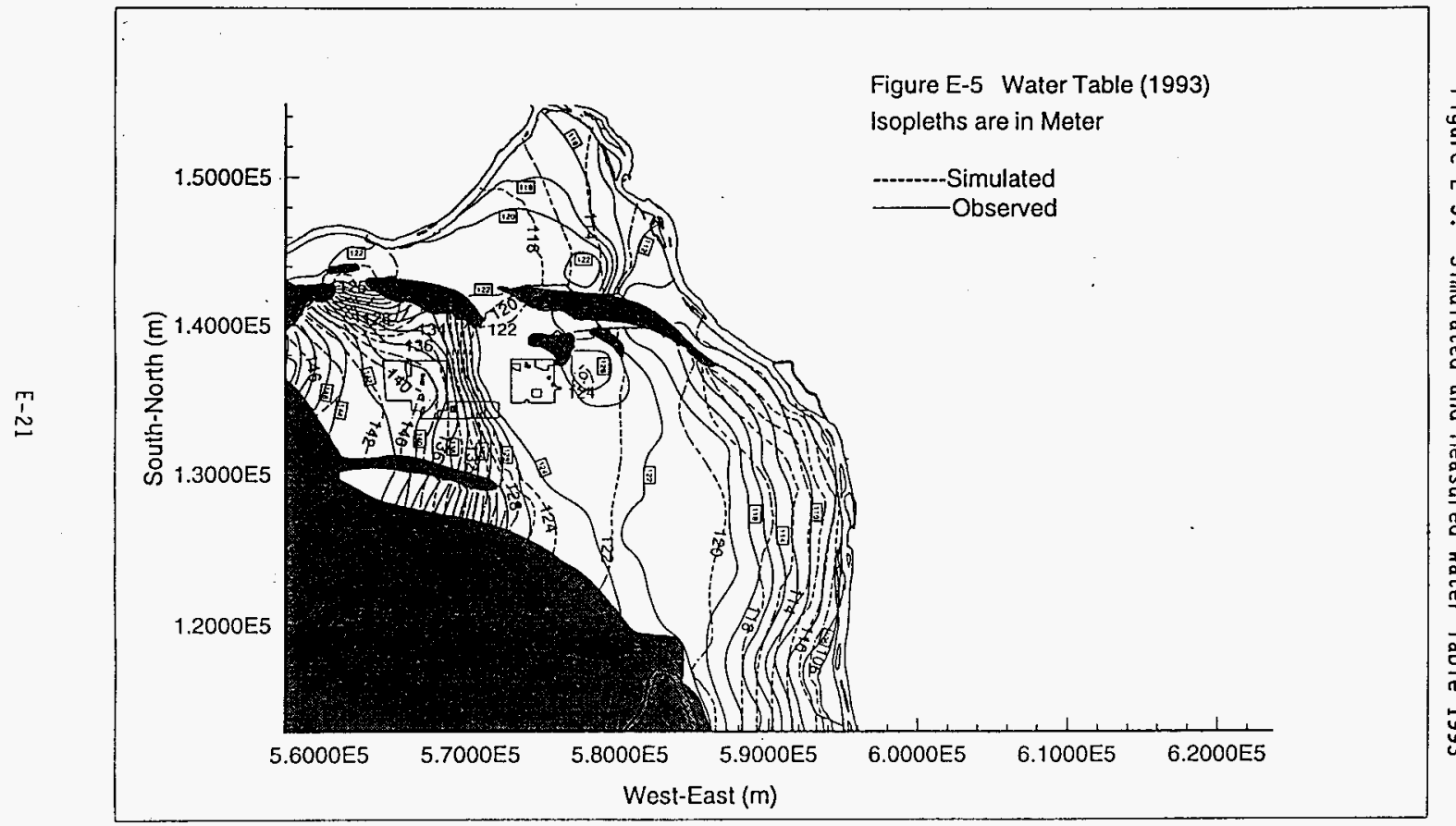

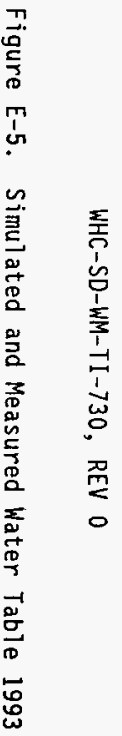


WHC-SD-WM-TI-730, REV 0

Figure E-6. Water Table Level Changes Between 1979 and 1988.

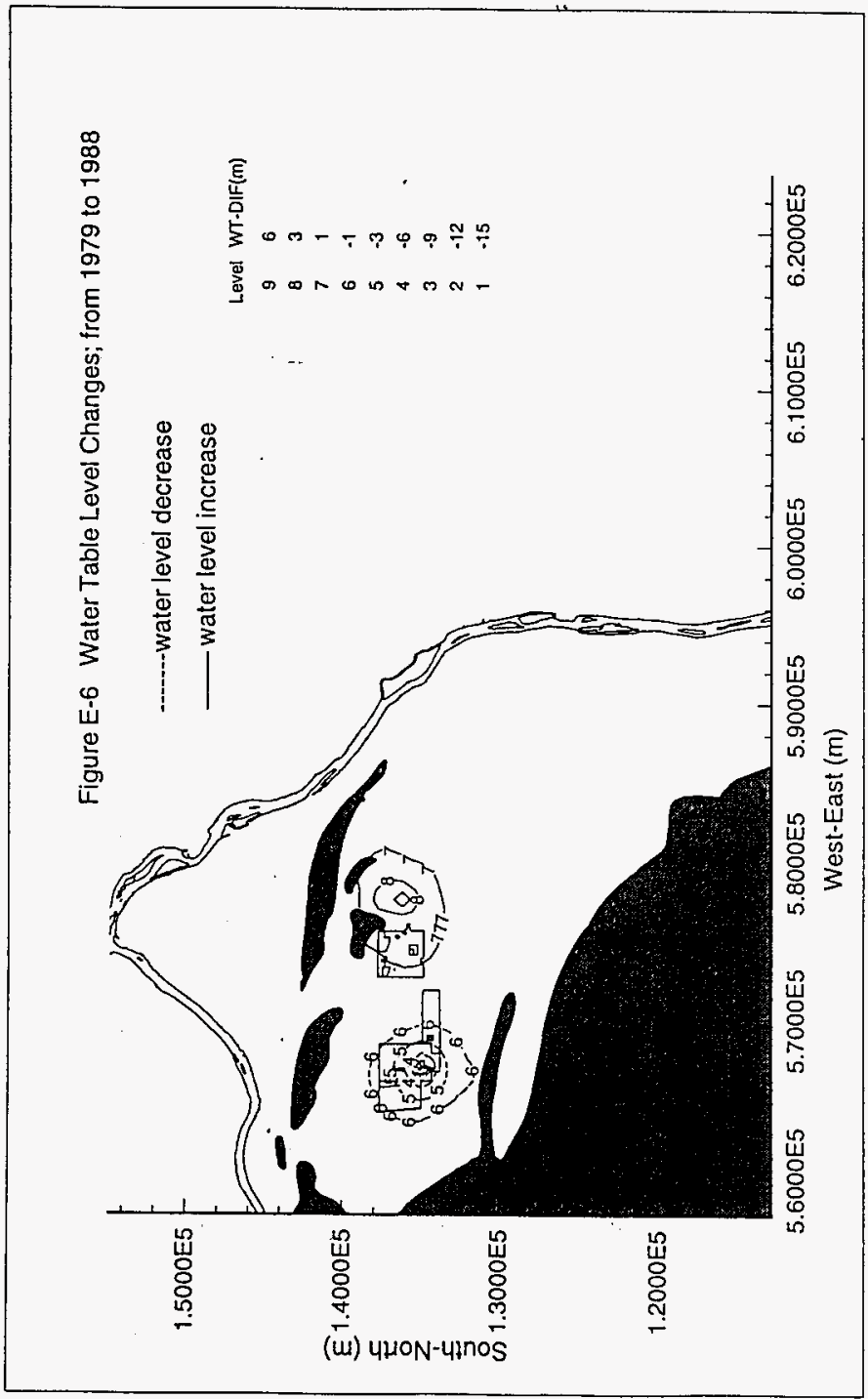


WHC-SD-WM-TI-730, REV 0

Figure E-7. Water Table Level Changes Between 1988 and 1993.

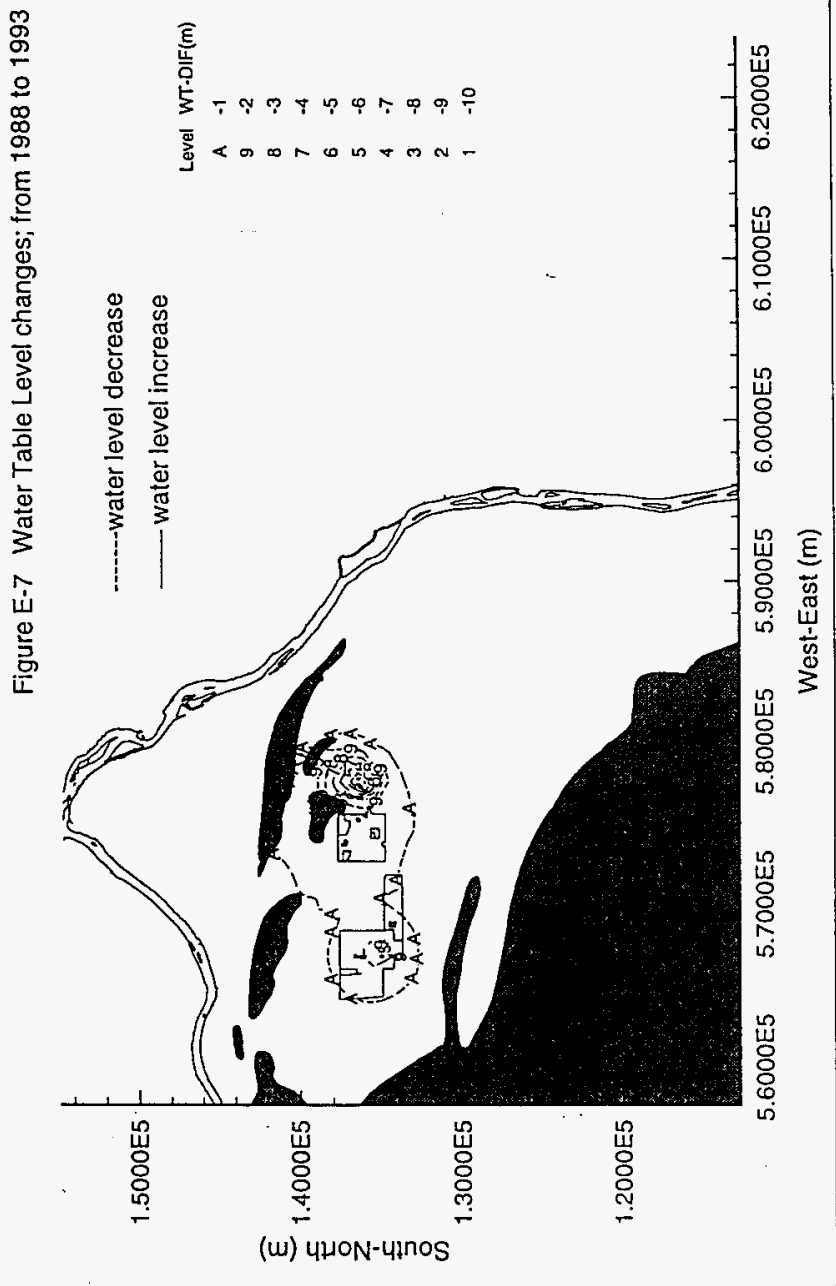




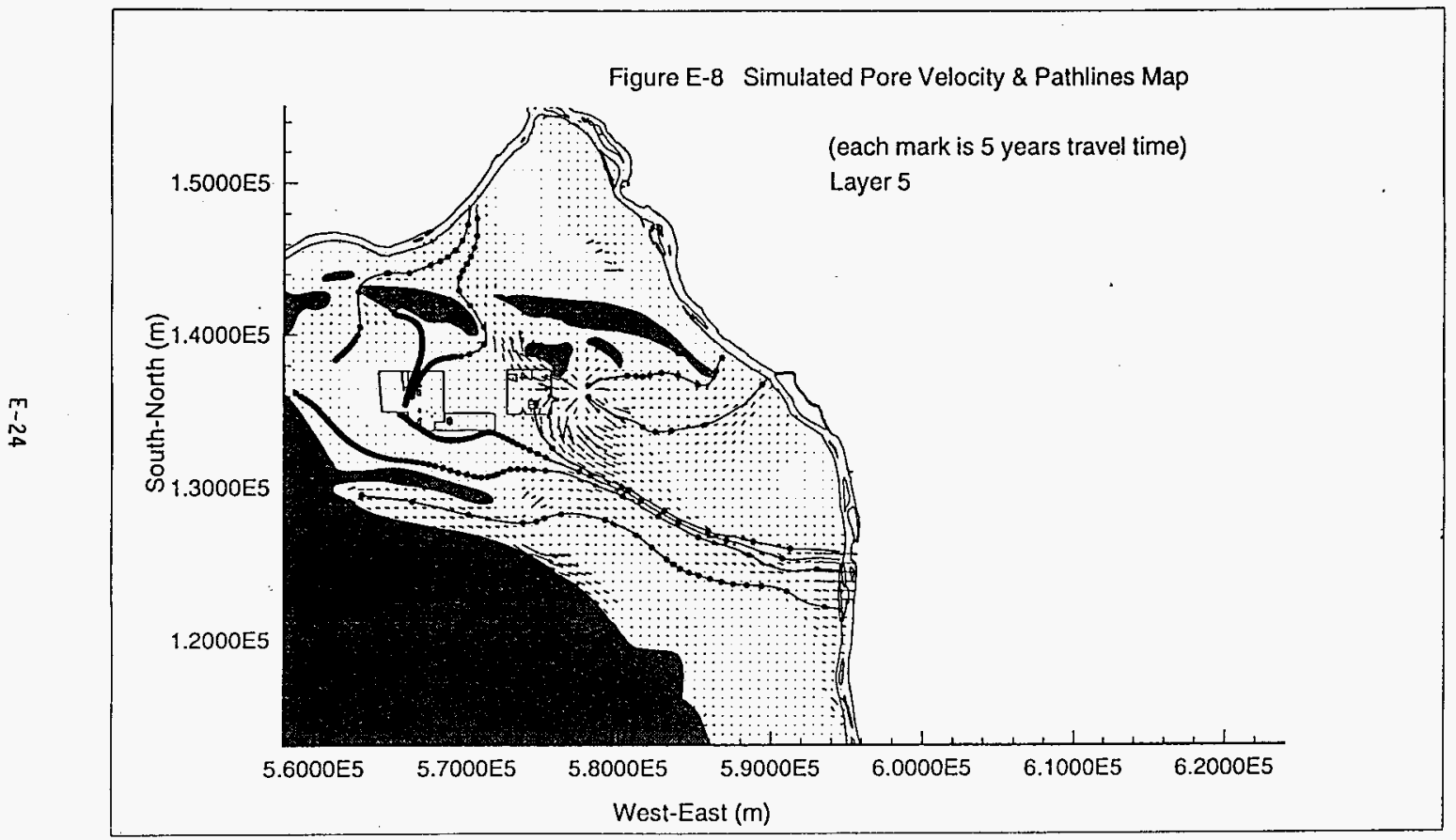


WHC-SD-WM-TI-730, REV 0

Figure E-9. 1993 Simulated Pore Velocity Stream Lines.

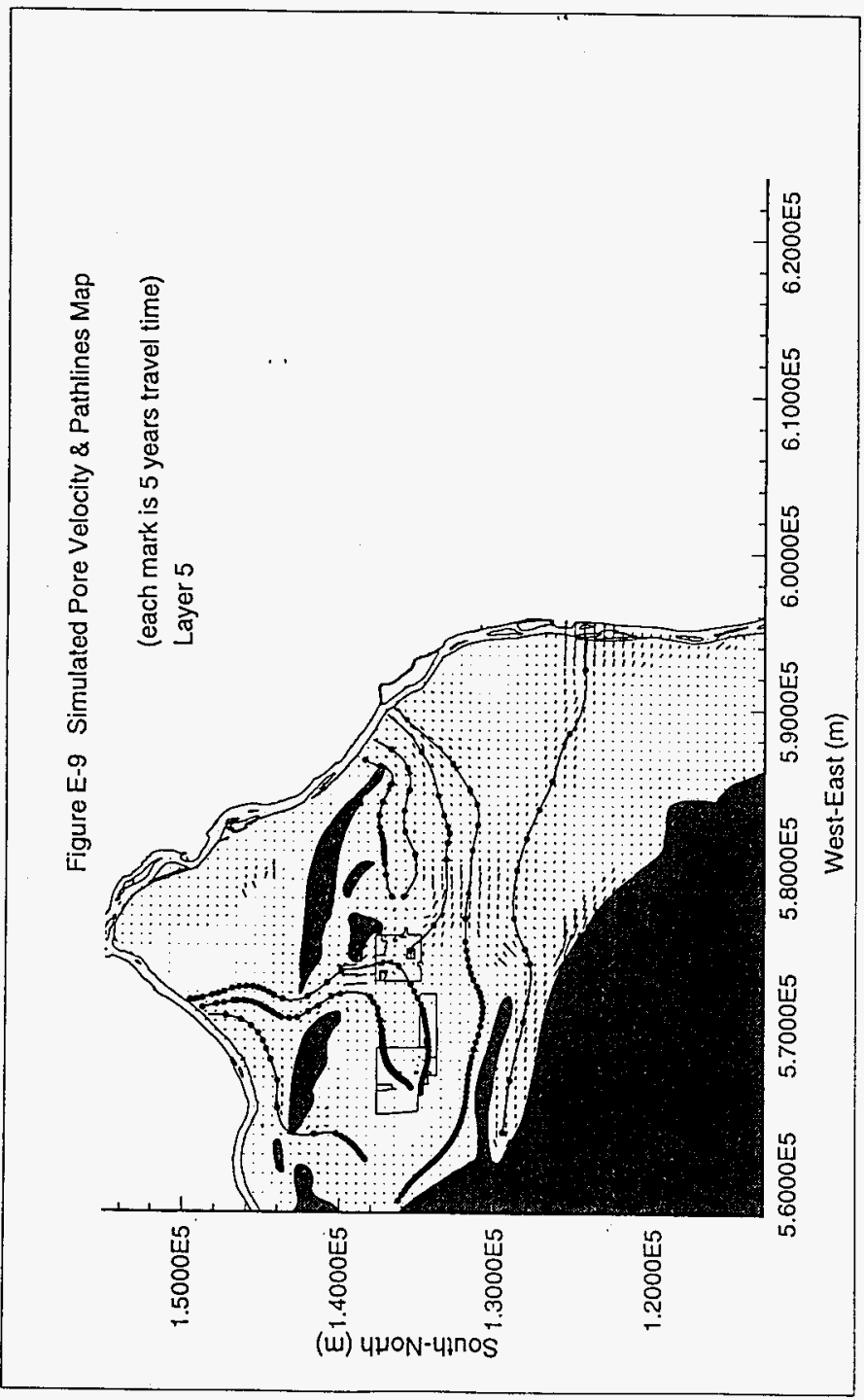




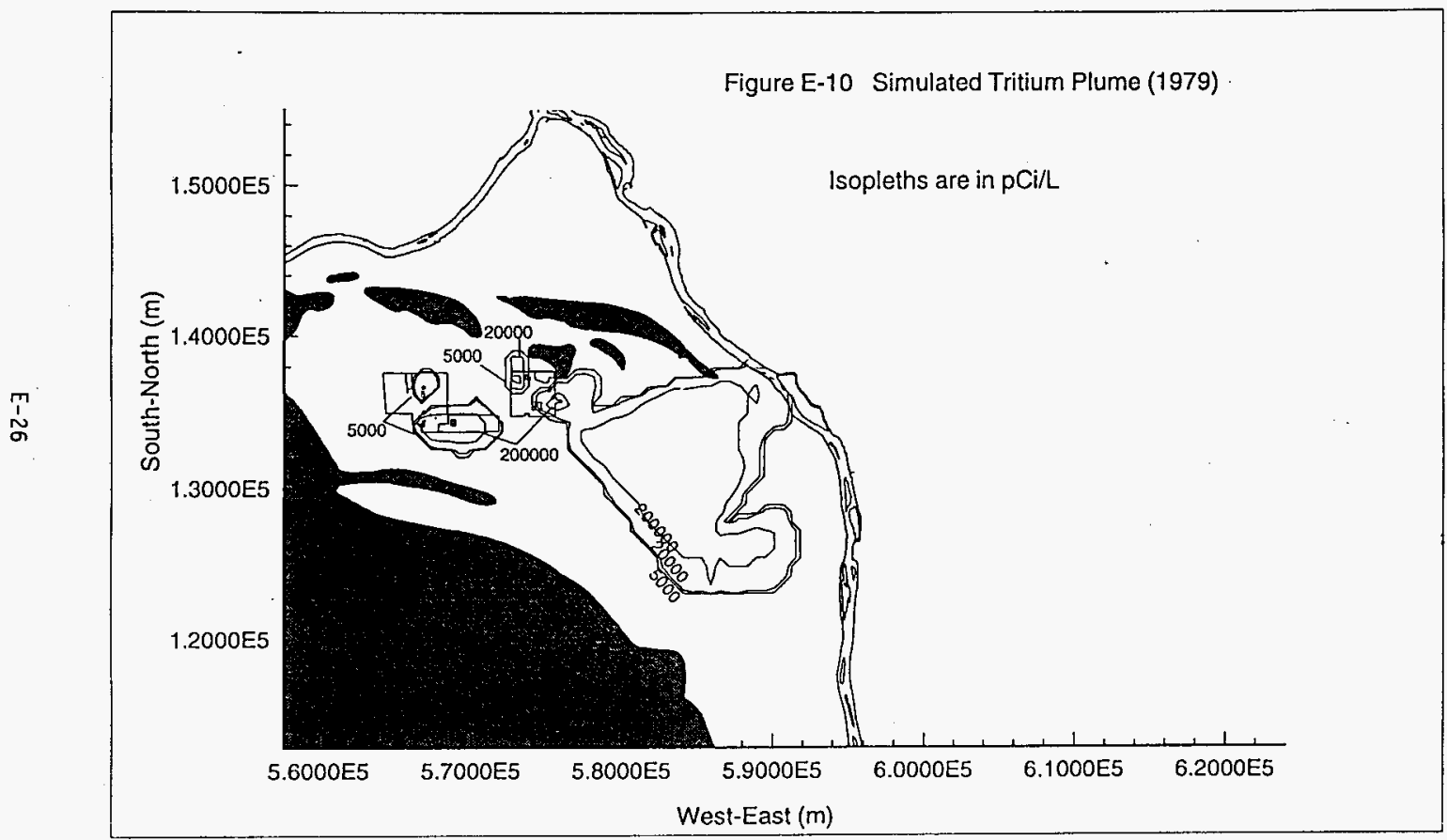

울

ت. 
WHC-SD-WM-TI-730, REV 0

Figure E-11. 1988 Simulated Tritium Plume.

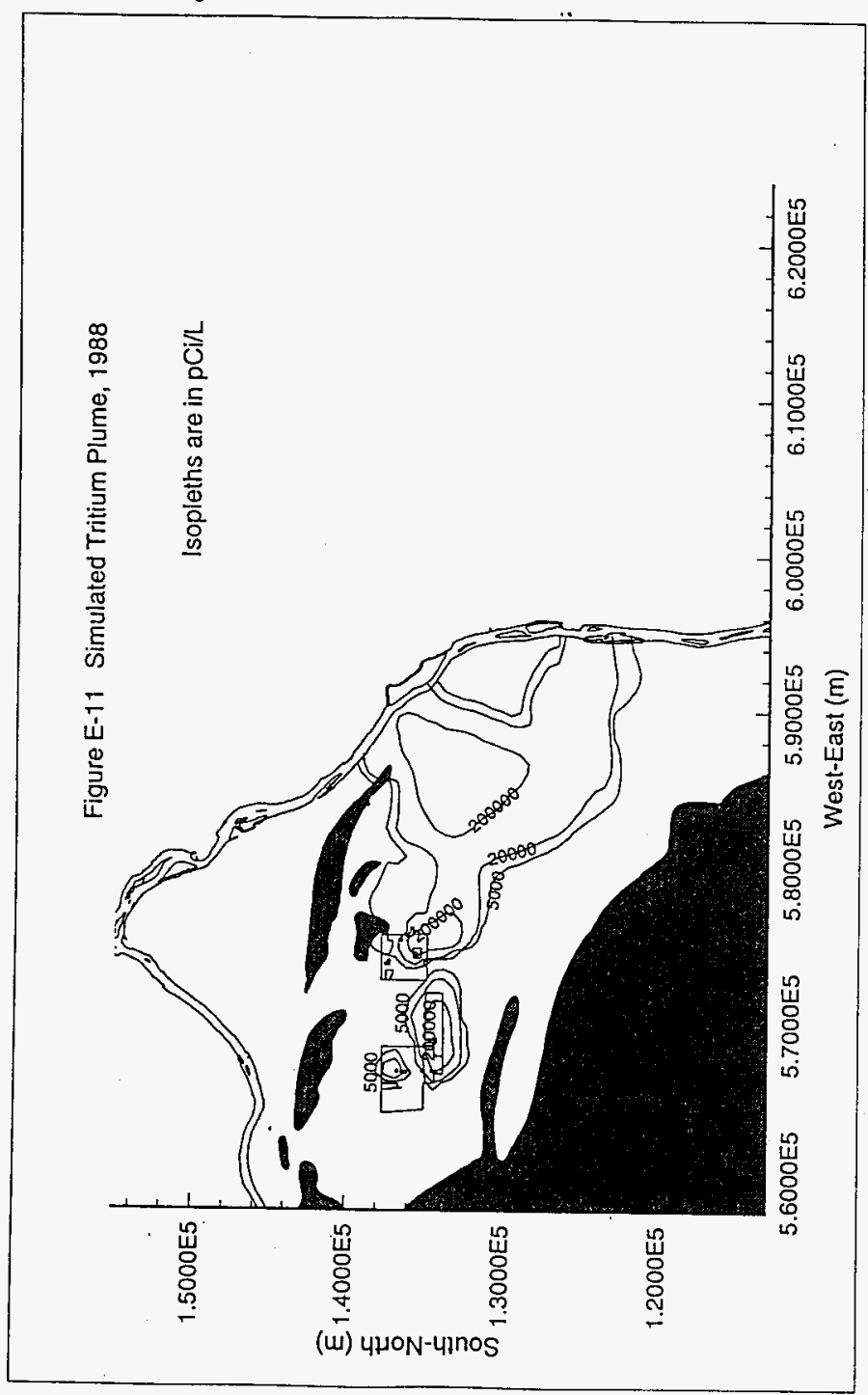


WHC-SD-WM-TI-730, REV 0

Figure E-12. 1993 Simulated Tritium Plume.

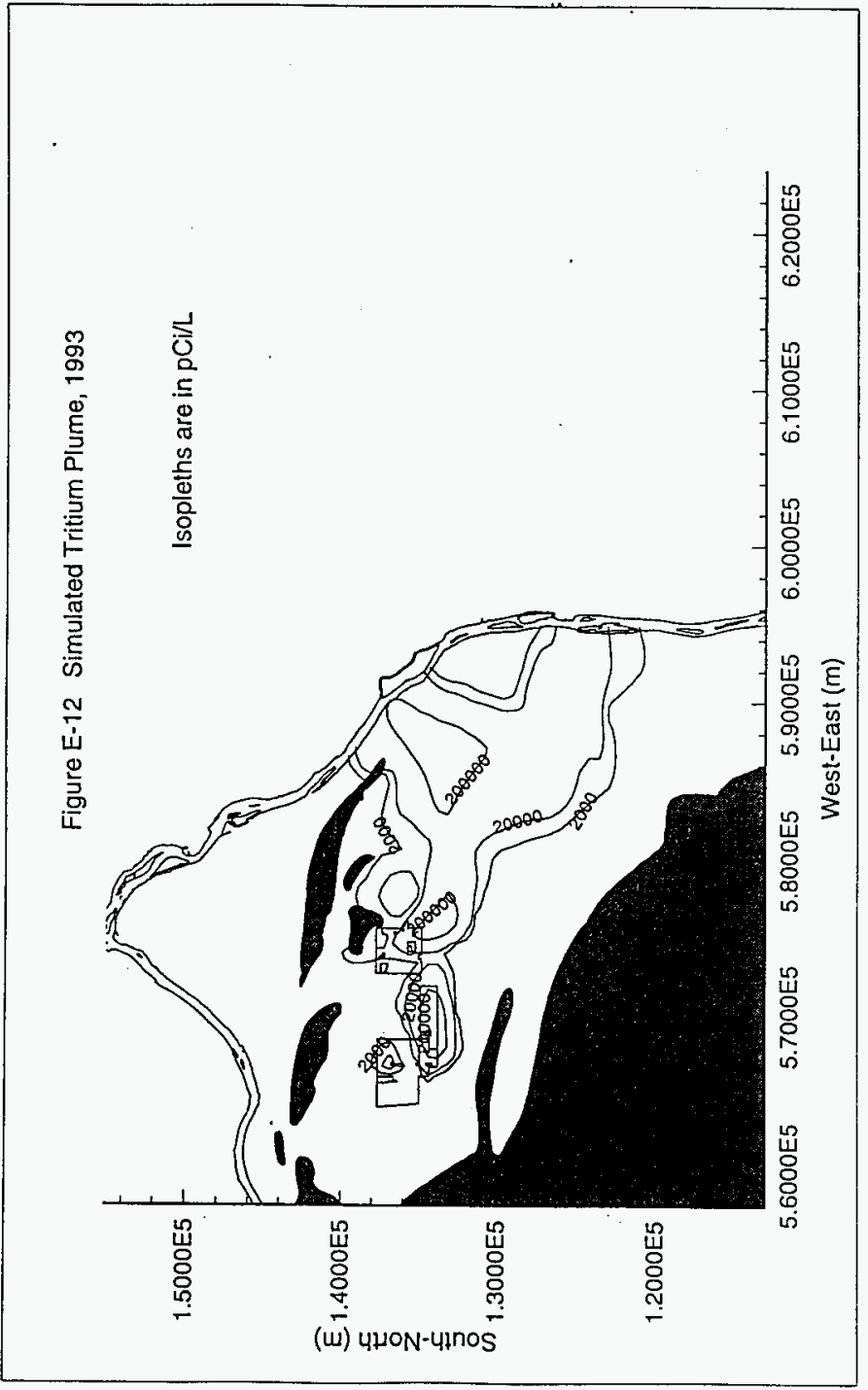


WHC-SD-WM-TI-730, REV 0

Figure E-13. 1988 Measured Tritium Plume.

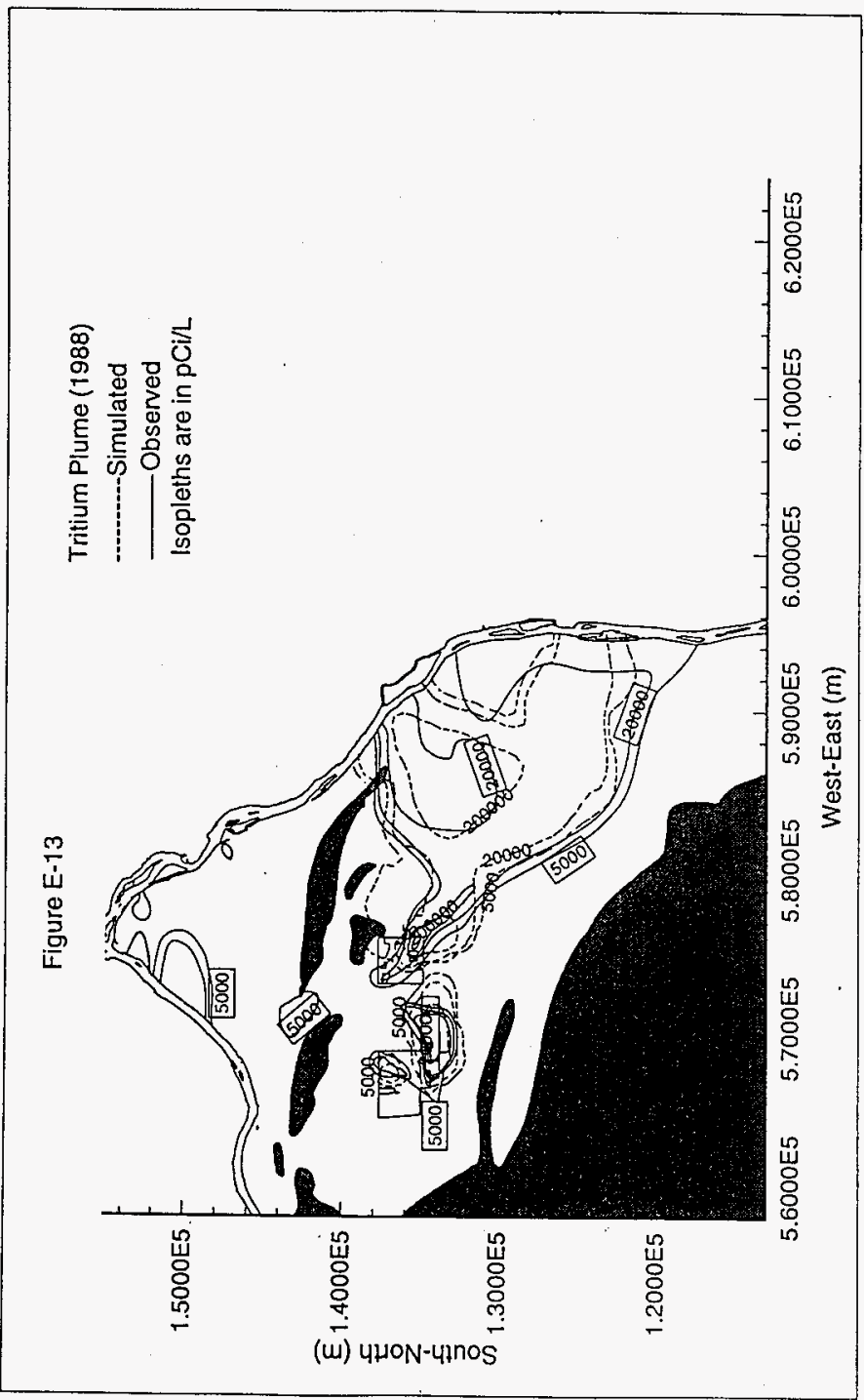


WHC-SD-WM-TI-730, REV 0

Figure E-14. 1993 Measured Tritium Plume.

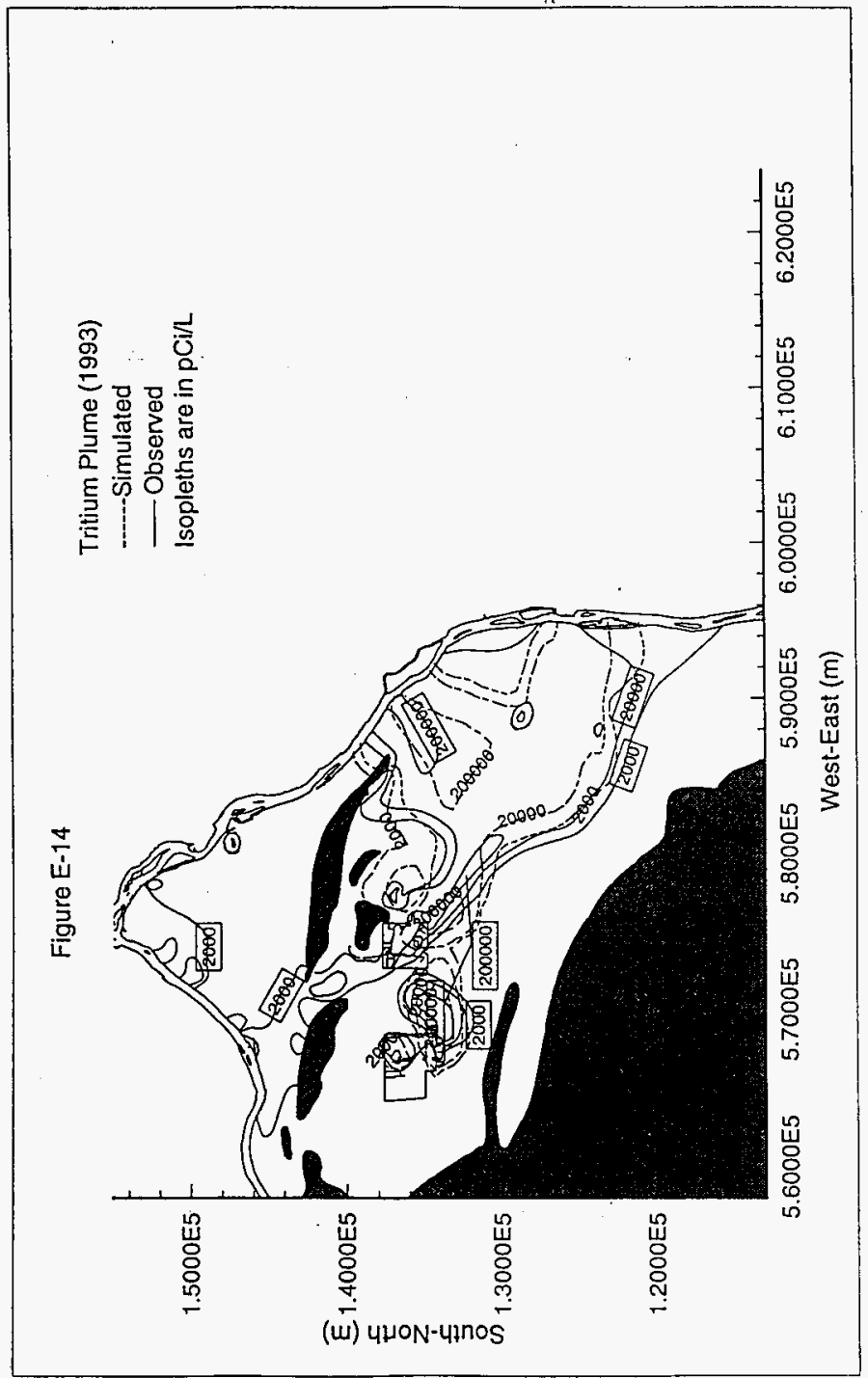


WHC-SD-WM-TI-730, REV 0

Figure E-15. Simulated Post-Hanford Water Table.

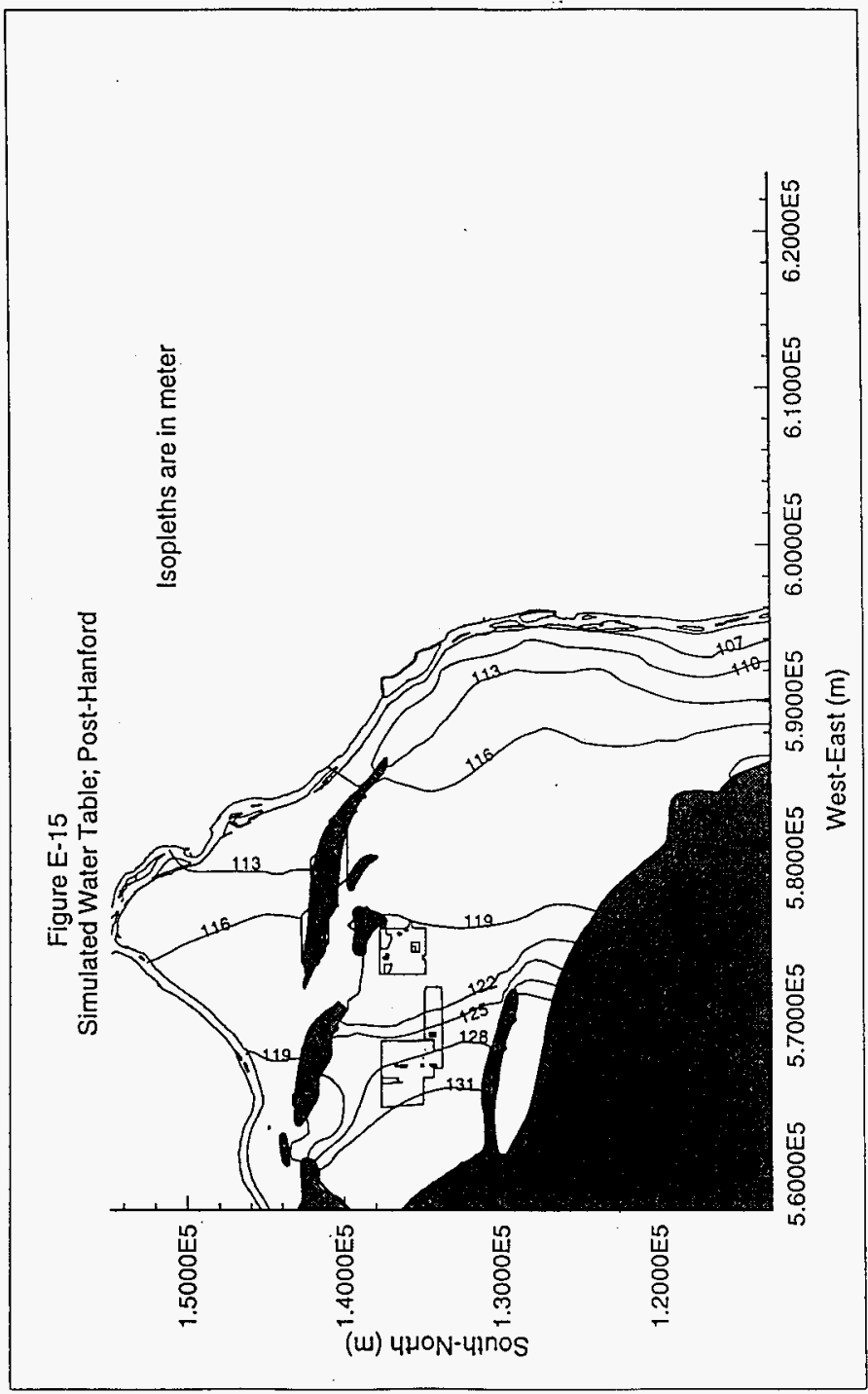




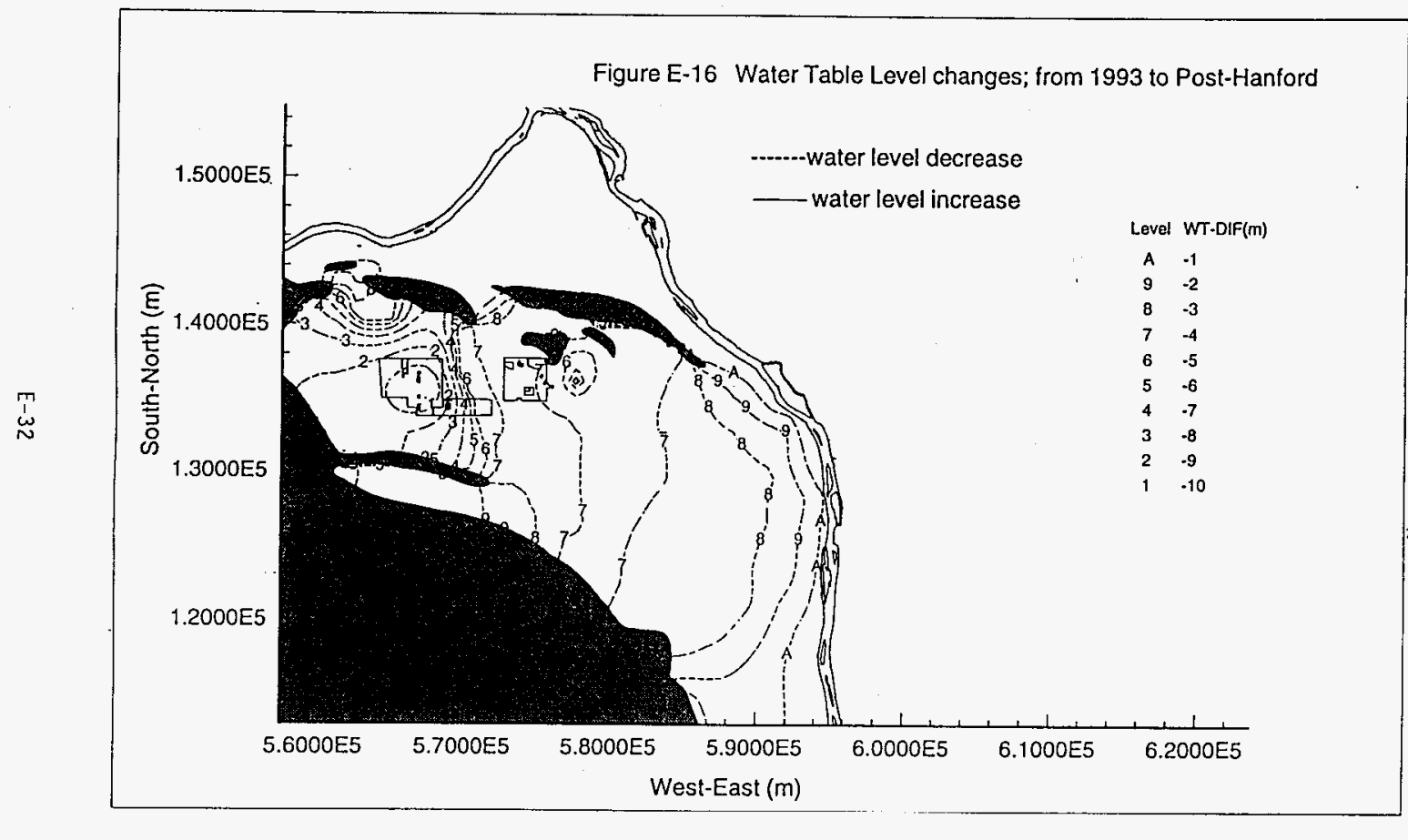




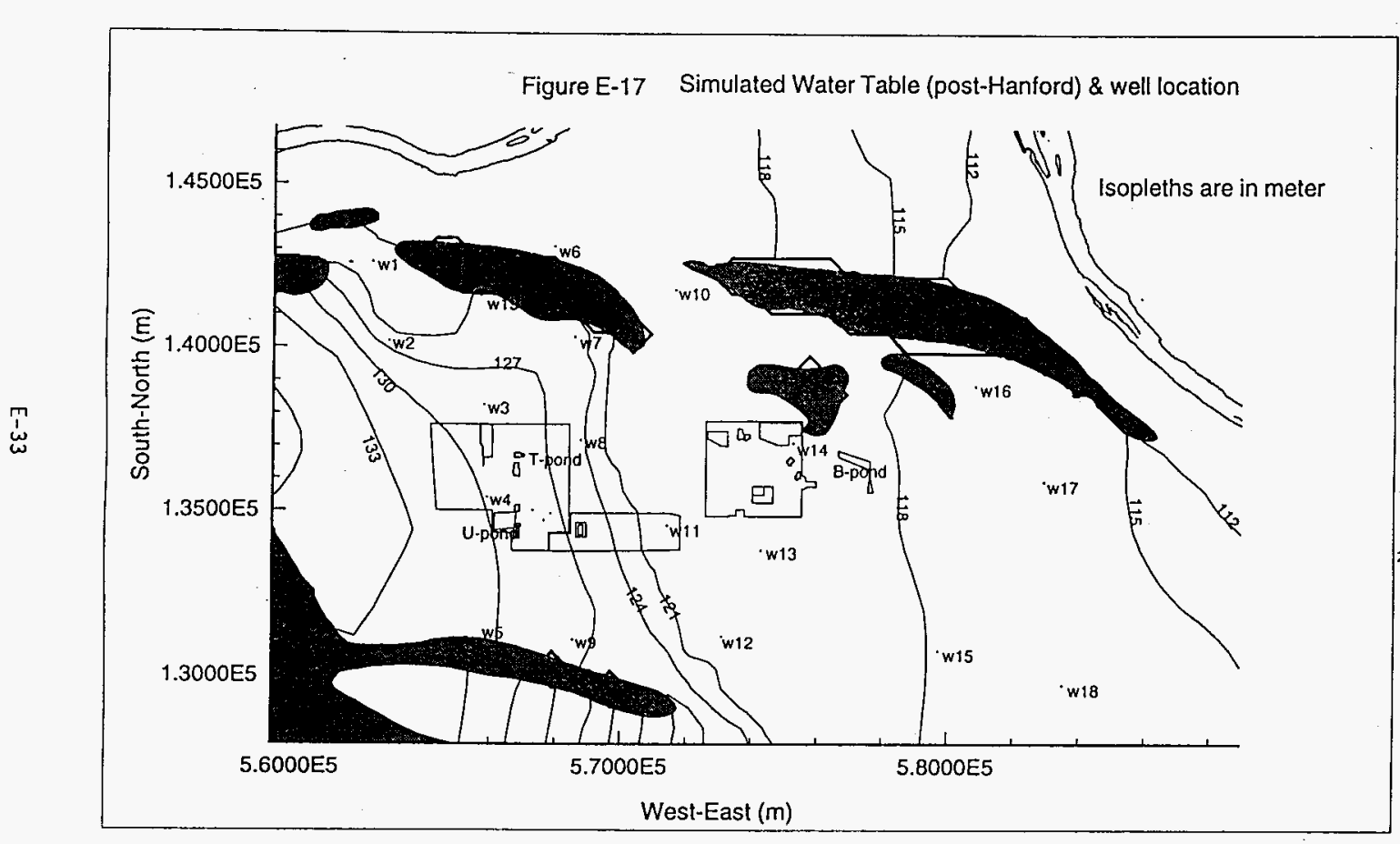




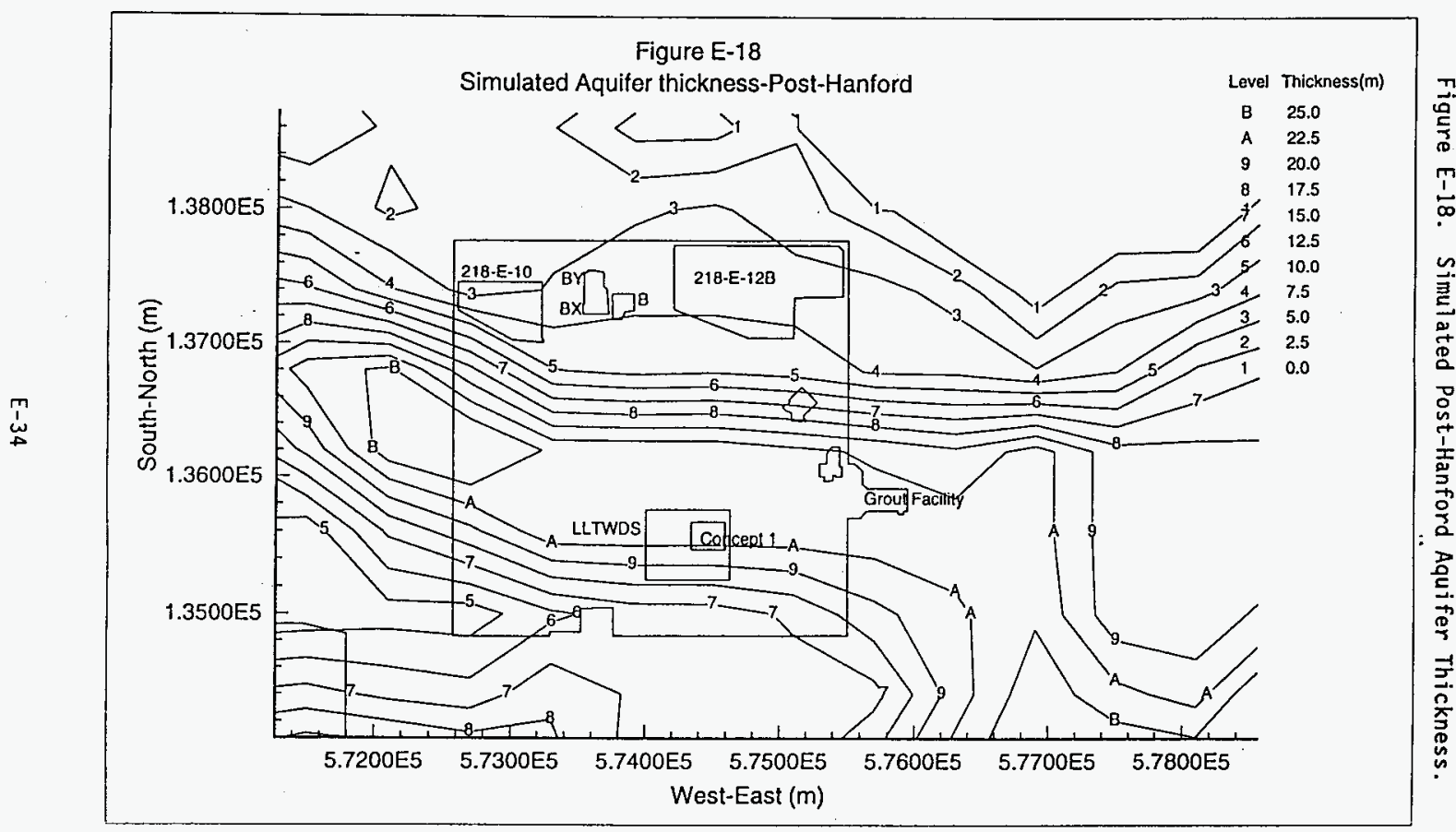

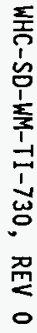


Figure E-19. Simulated Post-Hanford Pore Velocity Stream Lines and Hypothetical Downstream Well Locations.

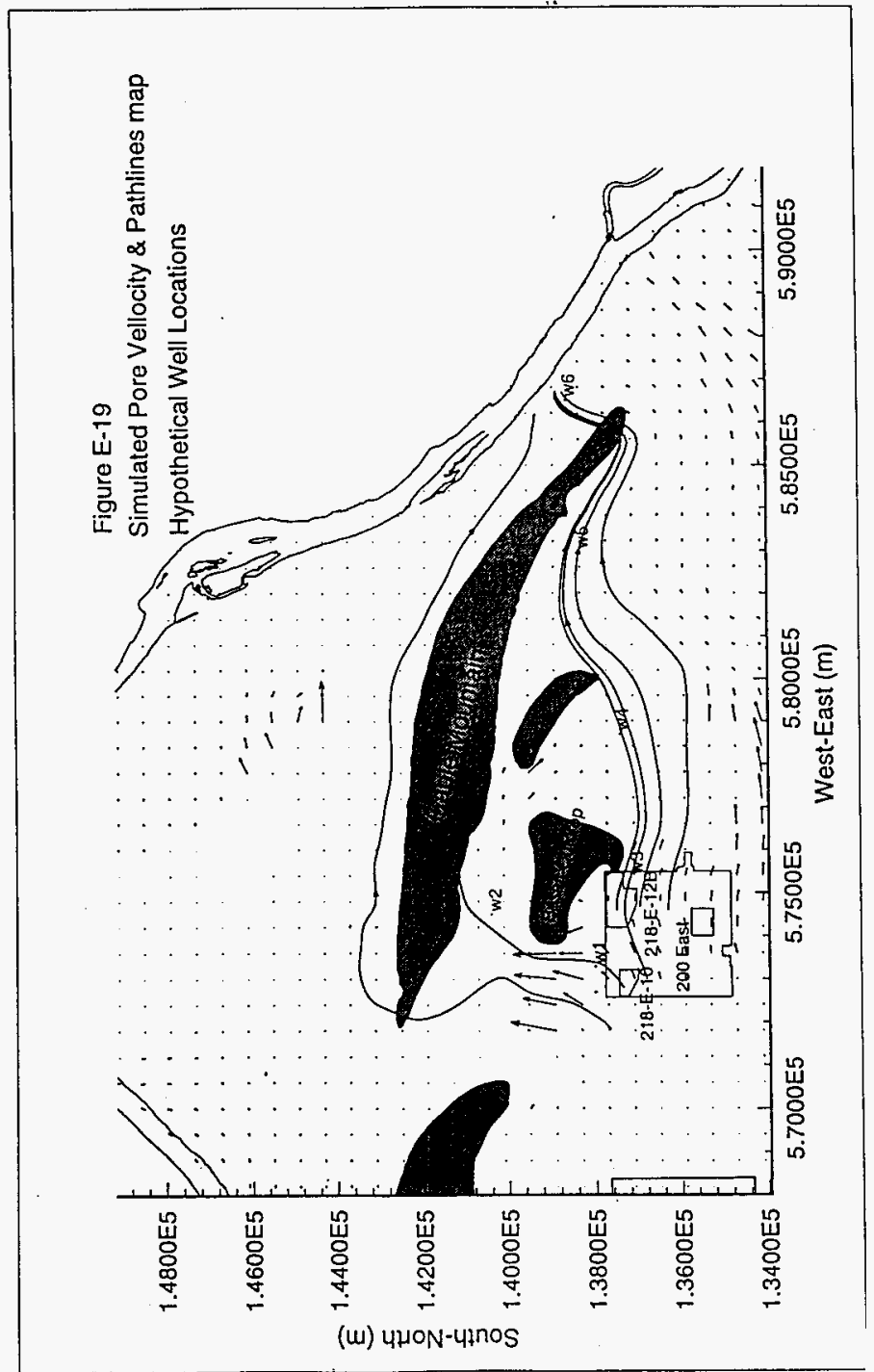


Figure E-20. Simulated Post-Hanford LLBG Plume Concentration Contours at 800 Years.

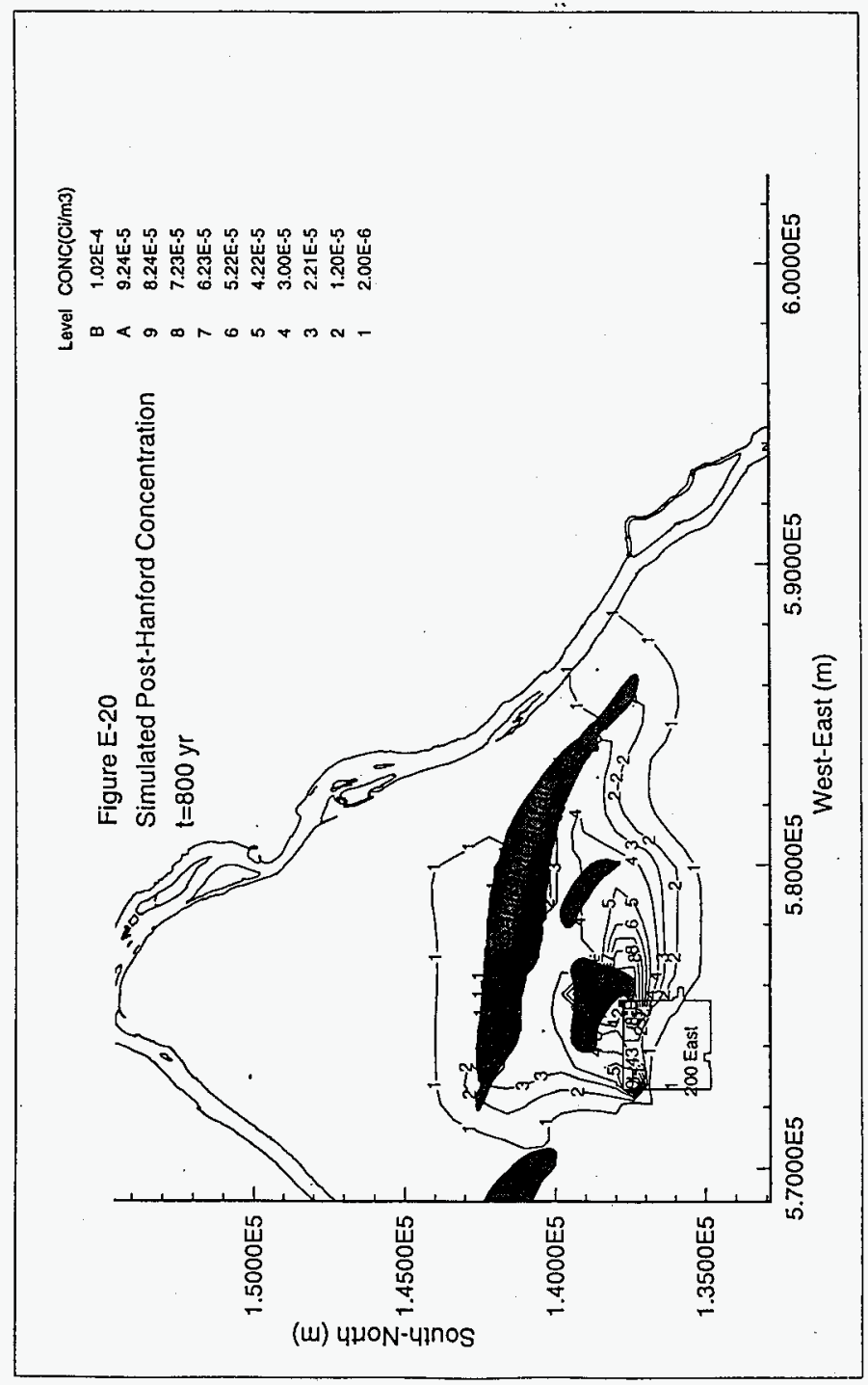


Figure E-21. Radionuclide Concentrations at Hypothetical Downstream Wells W1 and W2 Over Time.

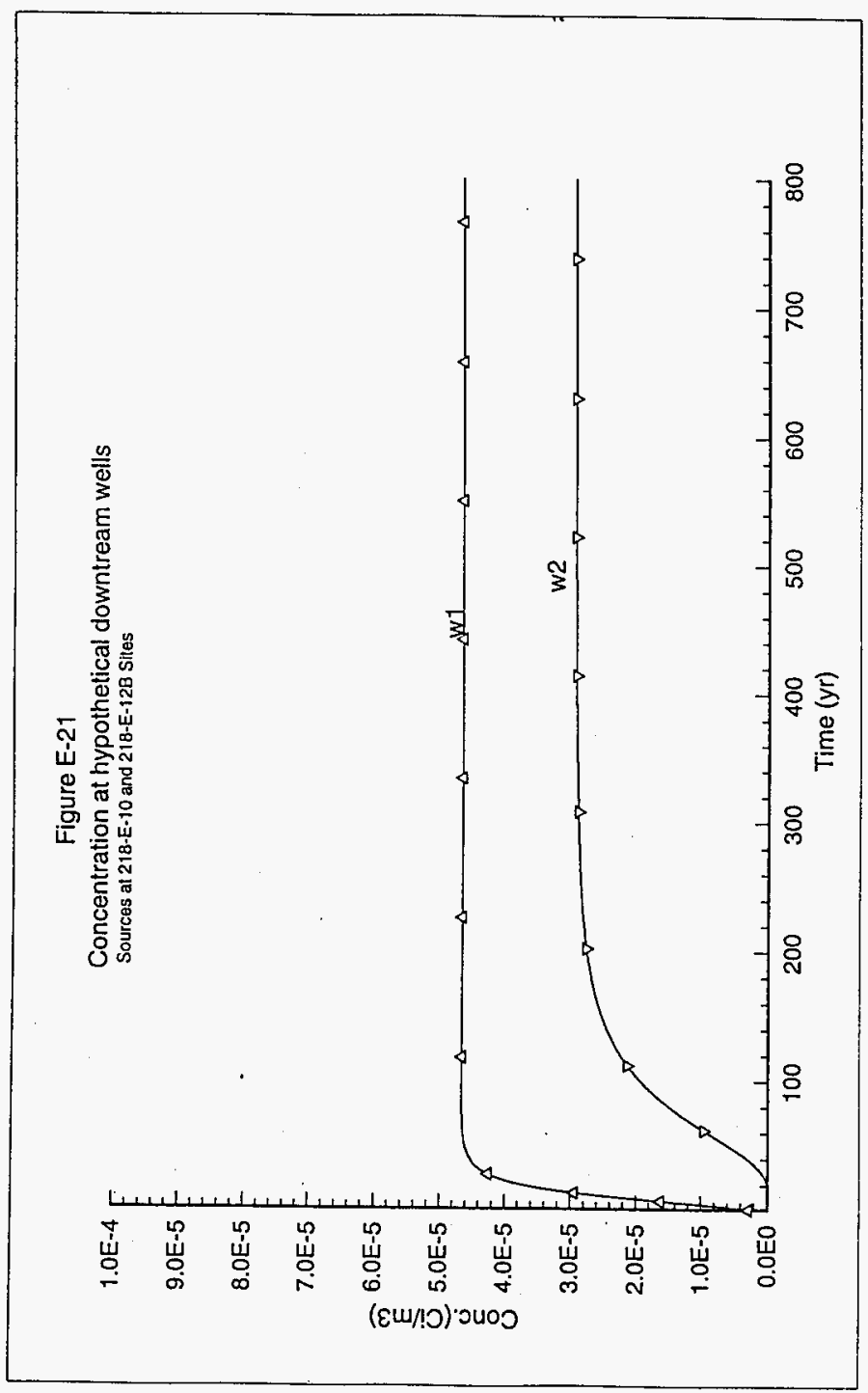


Figure E-22. Radionuclide Concentrations at Hypothetical Downstream Wells W3, W4, W5, and W6 Over Time.

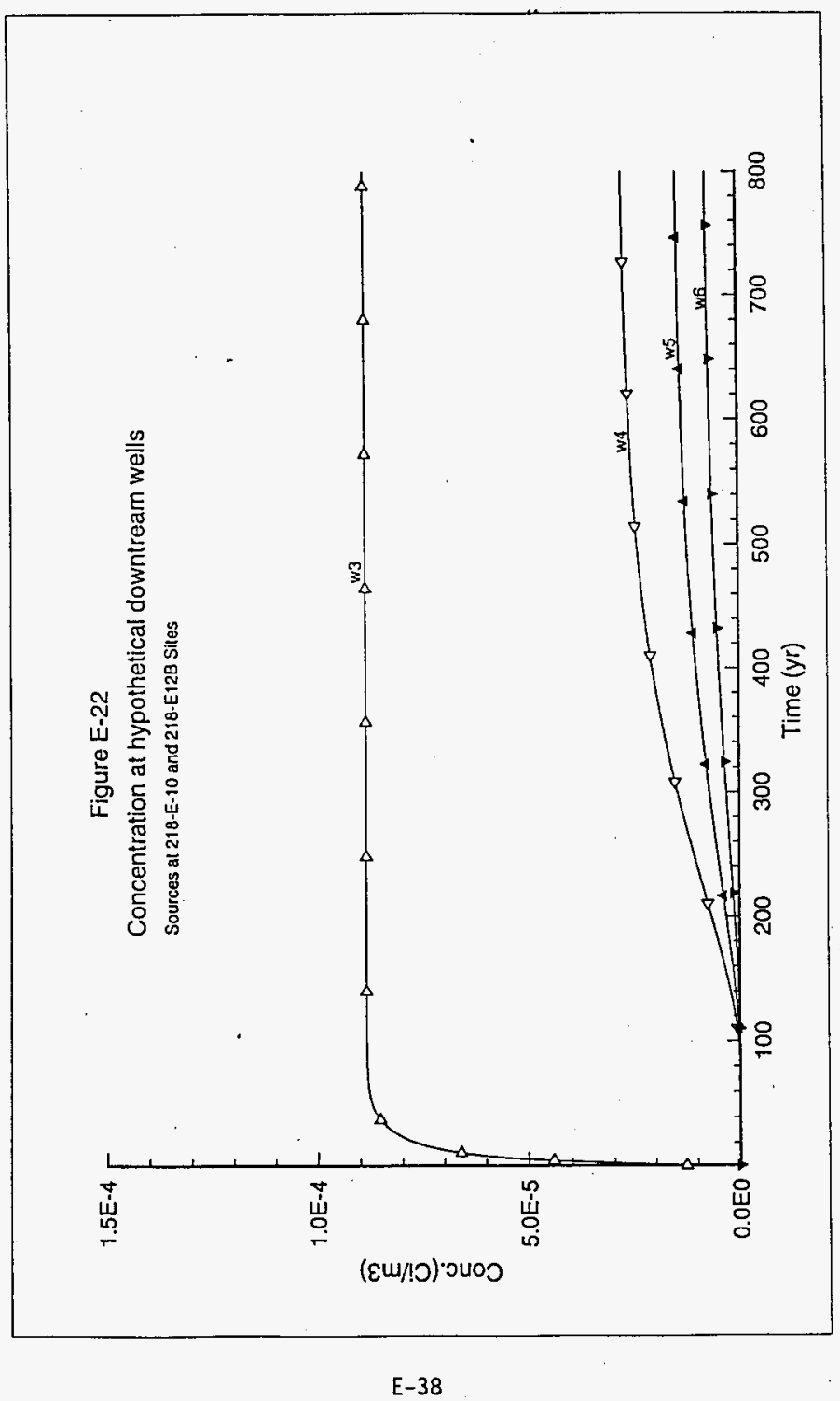


Figure E-23. Simulated Post-Hanford Water Table with Areal Recharge of $0.5 \mathrm{~cm} / \mathrm{yr}$.

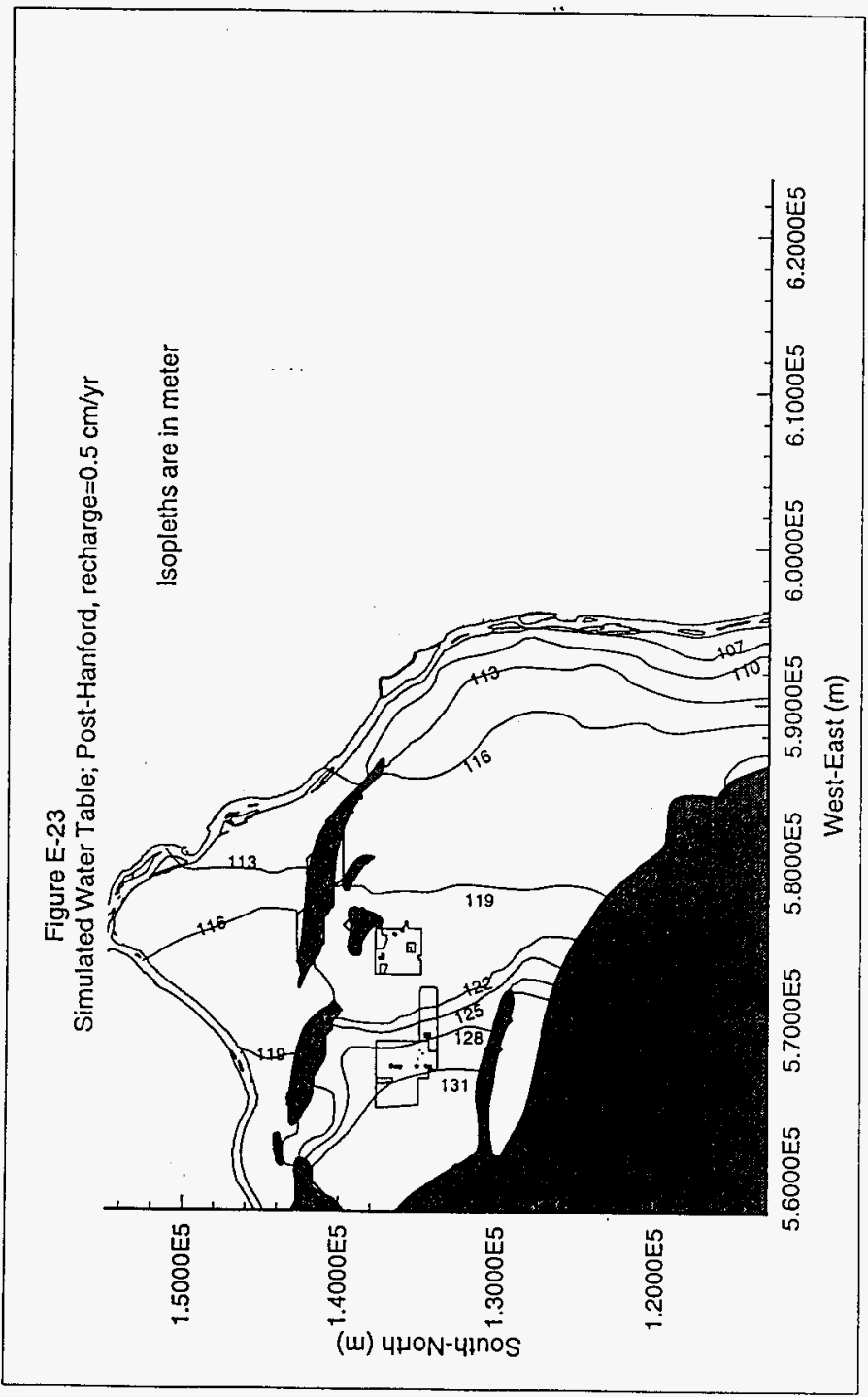




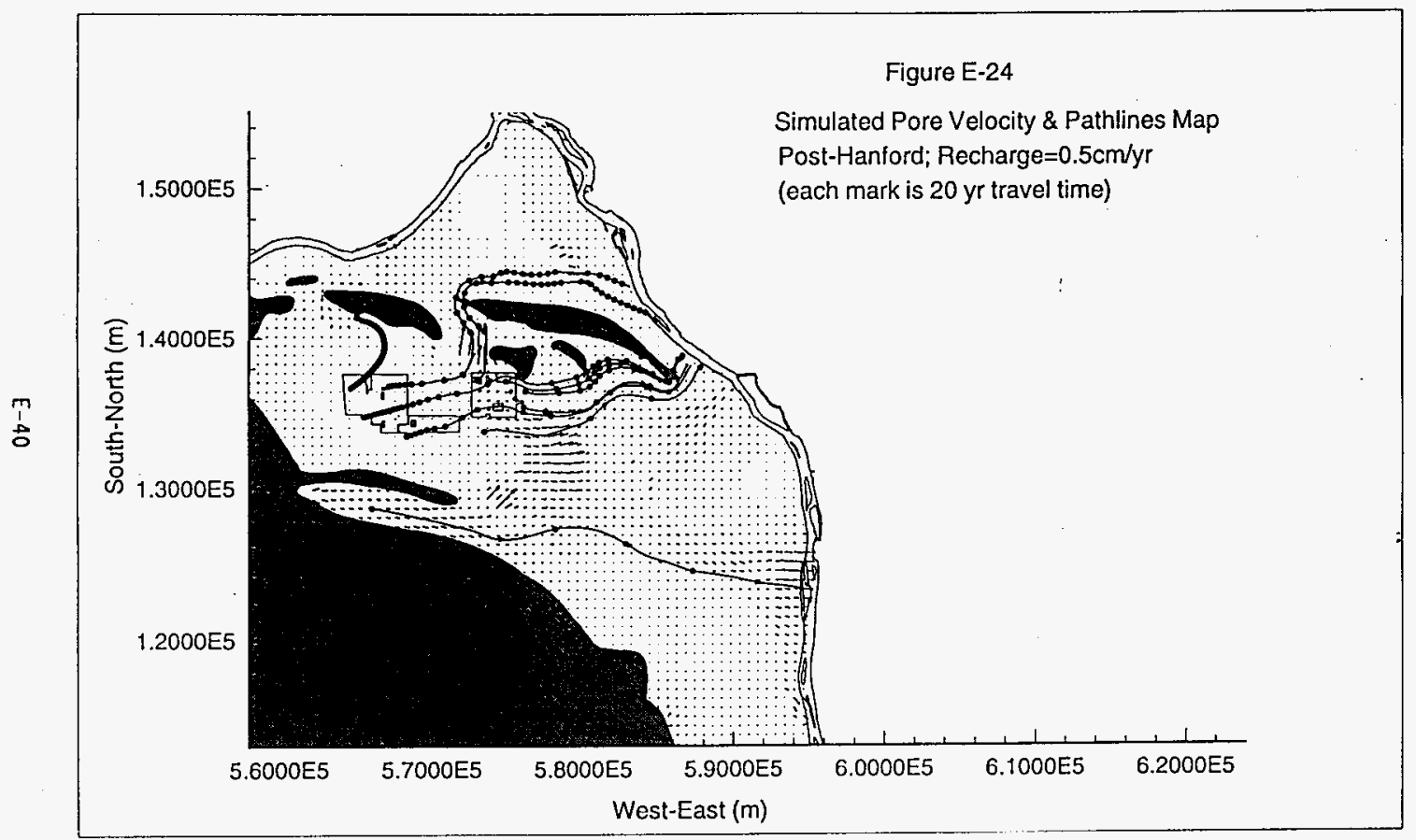


WHC-SD-WM-TI-730, REV 0

Figure E-25. Simulated Post-Hanford Water Table with Areal Recharge of $5 \mathrm{~cm} / \mathrm{yr}$.

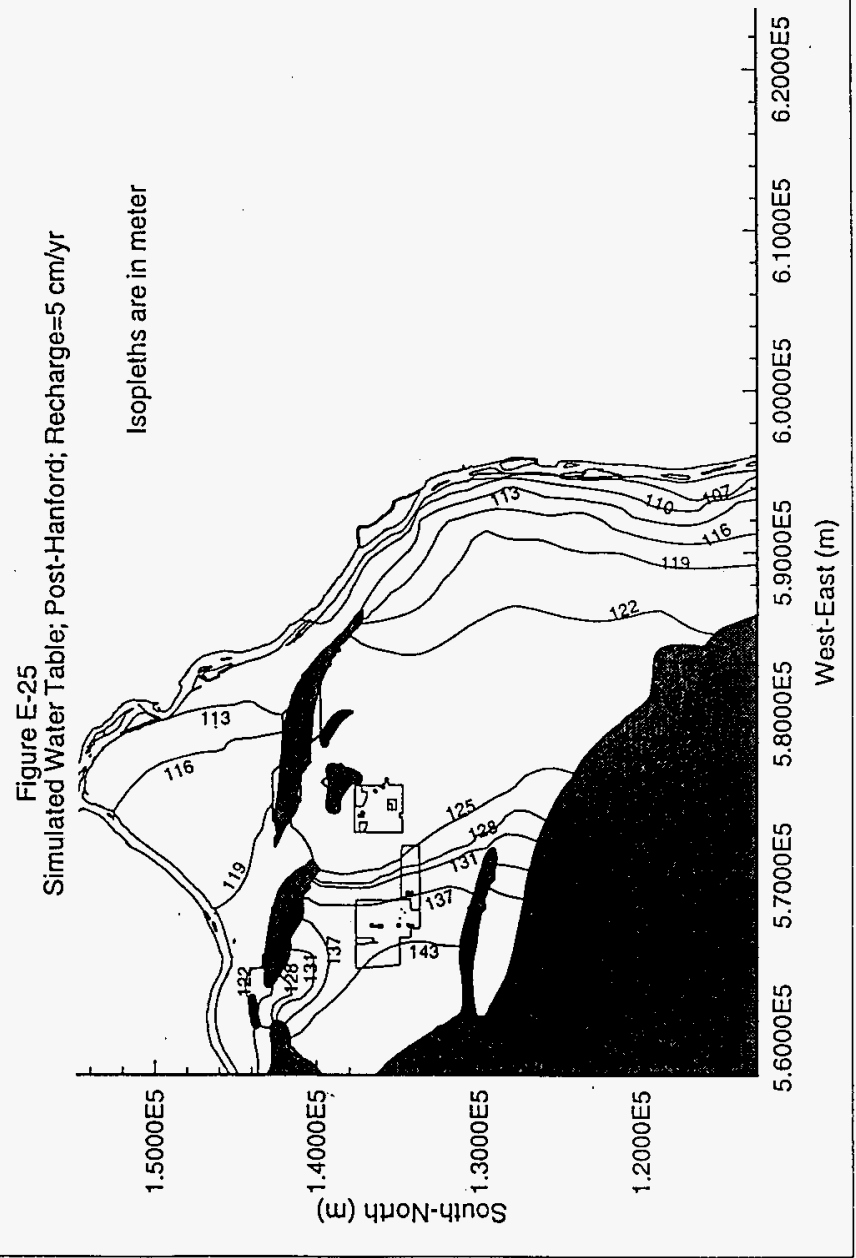


Figure E-26. Simulated Post-Hanford Pore Velocity Stream Lines with Areal Recharge of $5 \mathrm{~cm} / \mathrm{yr}$.

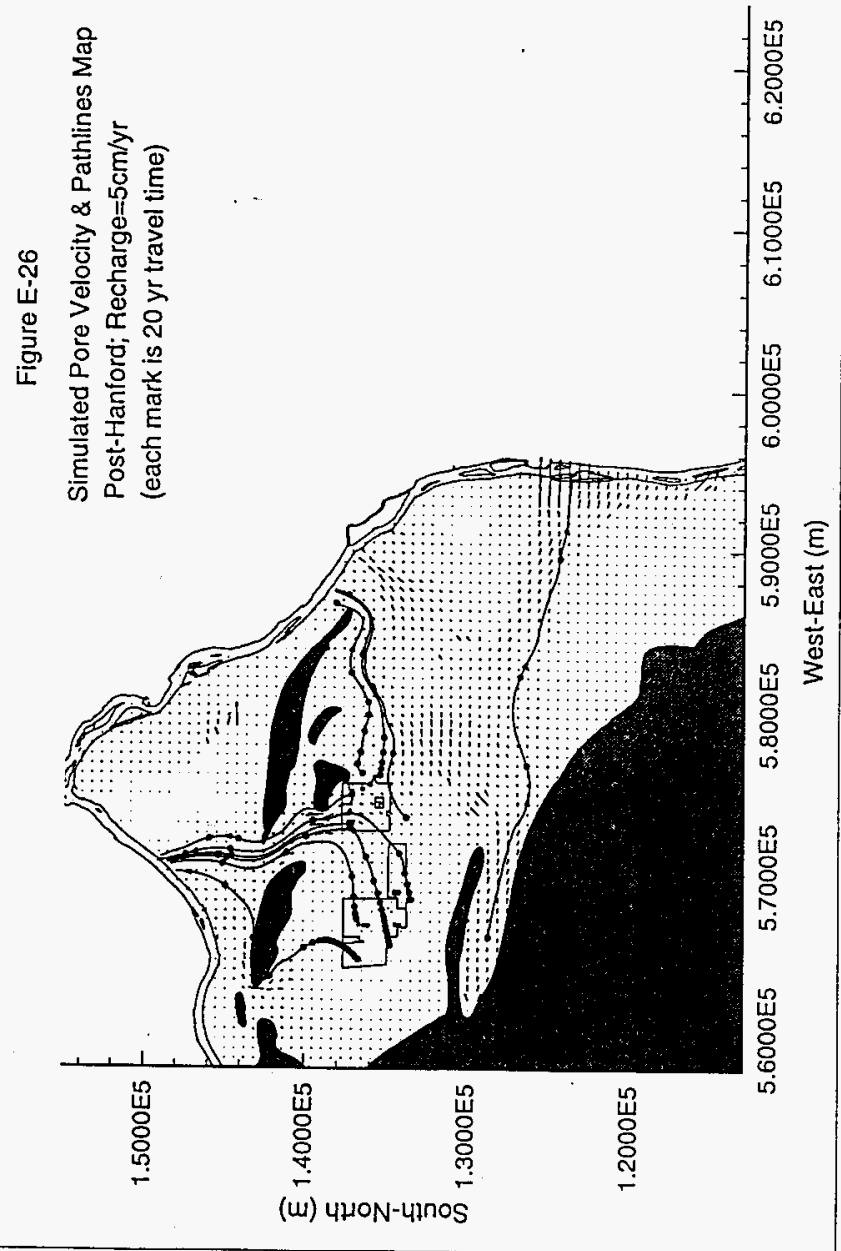


Figure E-27. Simulated Post-Hanford Aquifer Thickness Contours with Areal Recharge of $5 \mathrm{~cm} / \mathrm{yr}$.

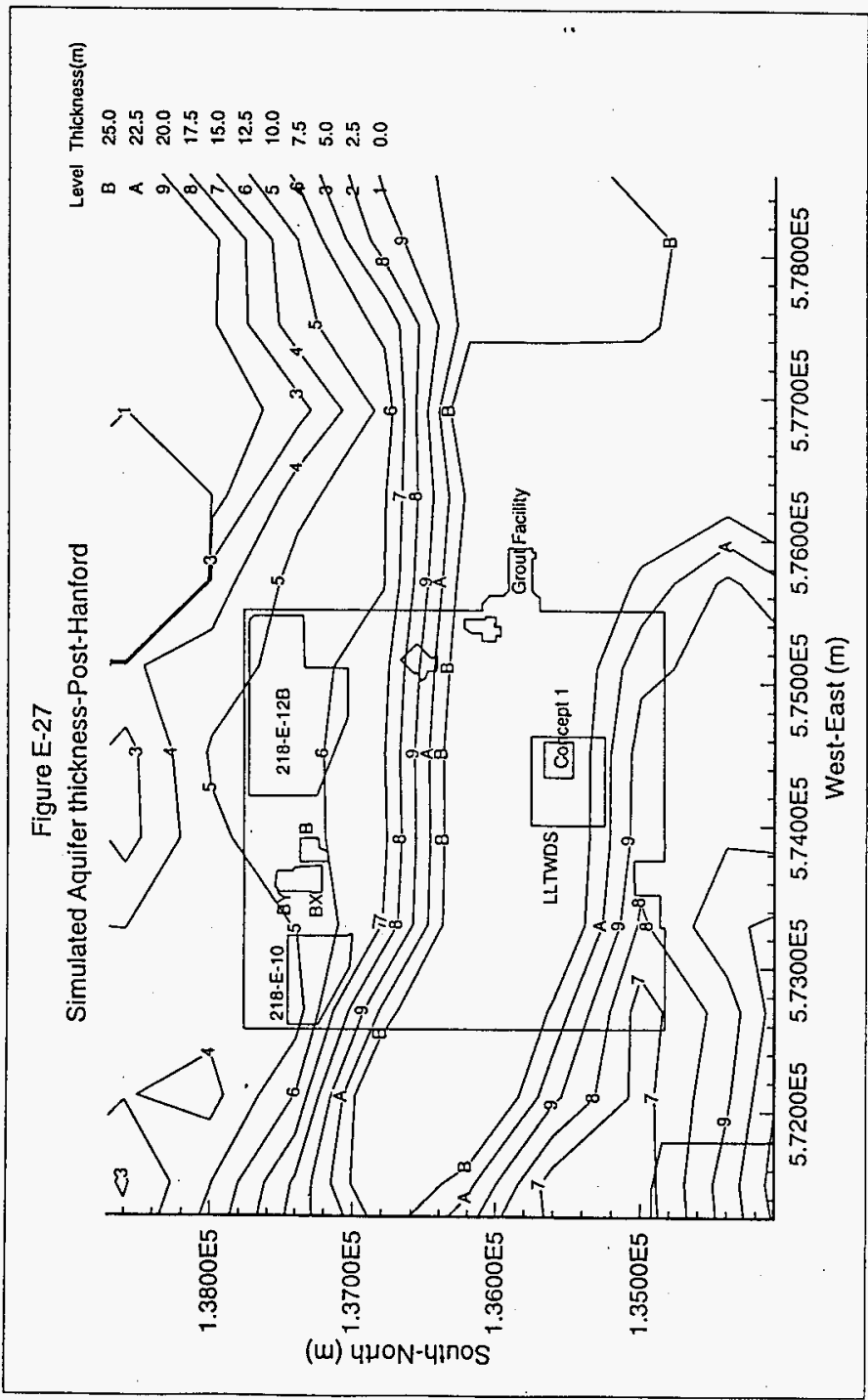


WHC-SD-WM-TI-730, REV 0

This page intentionally left blank. 
WHC-SD-WM-TI-730, REV 0

\section{APPENDIX $\mathbf{F}$}

SUMMARY OF RADIONUCLIDE FIELD OBSERVATIONS AND ANALYSIS

$\mathfrak{F}-\mathfrak{i}$ 
WHC-SD-WM-TI-730, REV 0

This page intentionally left blank.

$F-\mathbf{i} \mathbf{i}$ 


\section{APPENDIX $\mathrm{F}$ \\ SUMMARY OF RADIONUCLIDE FIELD OBSERVATIONS AND ANALYSIS}

\section{F.1 INTRODUCTION}

A wide variety of soil sample and water analysis data is available that provides indications of radionuclide transport and mobility in the soil column. In most cases, the data are insufficient to do a model calibration exercise. The exception is the 241-T-106 Tank leak. The modeling exercise is summarized here. Despite the scarcity of complete data sets, we have sufficient information to verify qualitatively the relative mobility of various radionuclides in the soil column and to confirm that the general assumptions of retardation as expressed by sorption coefficients are adequate to evaluate the likelihood of groundwater contamination by radionuclides present in the solid waste inventory.

We have identified a number of radionuclides in the present PA analysis that are expected to be very mobile in the Hanford Site hydrogeologic system. These radionuclides have been assigned a $\mathrm{Kd}$ value of $0 \mathrm{~mL} / \mathrm{g}$ to indicate that they should be transported with fluxing water with essentially no retardation. The primary radionuclides in this category that are present in solid waste streams include tritium, iodine, technetium, and uranium. All of these radionuclides are currently present as contaminant plumes in the unconfined aquifer. These plumes were generated from extensive discharge of contaminated fluids into cribs, ponds, and ditches at much higher rates than normal groundwater recharge from precipitation.

It is important to note that other radionuclides known to be present in the liquid waste are not generally observed in the unconfined aquifer. These include strontium, cesium, americium, plutonium, and radium. One known exception is the contaminant plume associated with reverse well 216-B-5 (Figures A-11 through A-14 in Appendix A, WHC-SD-WM-TI-730, Rev. 0). These contaminated liquids were discharged directly to the aquifer, bypassing the soil column. When these radionuclides are discharged at the surface, they are expected to be moderately to highly sorbing and should not have reached the unconfined aquifer during the liquid waste disposal period. Unfortunately, the distributions of these radionuclides in the soil column are not known for these waste sites. This information should become available as a result of remediation activities. Some relative transport characteristics for cesium and strontium are available at other sites.

One qualitative indication of plutonium transport in the soil column comes from the excavation of soil beneath the 216-7-9 crib (Ludowise 1978; Reisenauer 1959). The crib is located just east of the 200 West Area LLBG. Aproximately $4 \times 10^{6} \mathrm{~L}$ of plutonium-contaminated liquid was discharged to the crib from 1955 to 1962. Remote sensing equipment showed that the plutonium was highly concentrated in the upper soil layers of the crib. The concentration led to a concern that a criticality event might occur. During excavation in 1978, the top $30 \mathrm{~cm}$ of soil were removed and $58 \mathrm{~kg}$ of plutonium were recovered. No firm evaluation of the remaining plutonium in the soil column was provided, although the remote sensing data suggested that the $30 \mathrm{~cm}$ contained about 60 percent of the plutonium. These data suggest that relatively little movement of plutonium occurred in the soil column.

$$
F-1
$$


WHC-SD-WM-TI-730, REV 0

A number of modeling studies has been conducted at the Hanford Site that provide limited justification the for $K_{d}$ values used in the PA.

\section{F.2 SUMMARY OF INDIVIDUAL WASTE SITE STUDIES}

\section{F.2.1 241-T-106 Tank Leak Study}

The 241-T-106 single-shell tank is located in the 200 West Area, just east of the LLBG. The tank 241-T-106 leak was first documented in 1973 (ARHCO 1973). A report by the U.S. Atomic Energy Commission (AEC 1973) provides a detailed chronology of the leak that began on or about April 20, 1973 . Leakage stopped on June 10,1973, when the pumpable liquid contents of the tank were removed (Routson et al. 1979). The leak lasted approximately 52 days, during which 115,000 gal of supernate were lost from the tank.

Most of the radionuclide inventory of the supernate solution in the tank consists of ${ }^{114} \mathrm{Ce}$ and ${ }^{144} \mathrm{Pr},{ }^{137} \mathrm{Cs},{ }^{87} \mathrm{Sr}$ and ${ }^{90} \mathrm{Sr}$, and ${ }^{106} \mathrm{Ru}$ and ${ }^{106} \mathrm{Rh}$, with lesser amounts of the other radionuclides (Routson et al. 1979). Except for ${ }^{106} \mathrm{Ru}$ and ${ }^{106} \mathrm{Rh}$, the inventory is characterized by long half-lives and high sorption coefficients. The inventory corresponds to $2.67 \times 10^{5}$ total curies of ${ }^{108} \mathrm{Ru}$ and $3.85 \times 10^{4}$ total curies of ${ }^{137} \mathrm{Cs}$ that leaked from the tank. The ${ }^{106} \mathrm{Ru}$ has a half-life of 1 year with sorption coefficients generally considered to be approximately zero; the ${ }^{137} \mathrm{Cs}$ has a half-life of $30.17 \mathrm{yr}$ (Walker et al. 1984) and is considered to be highly sorbed by Hanford Site soils. The movement of ${ }^{106} \mathrm{Ru}$ is of interest because its transport should be essentially concurrent with the fluid front.

The leak apparently occurred on the southeast side of the tank because the contaminant plume is centered around this area. Figure F-l shows a plan view and a vertical cross section of the plume as measured in the summer of 1973, after the leak was detected and the tank pumped out. The concentrations shown in the figure were measured on a per-liter-volume-of-soil basis. The contaminant transport is shown for ${ }^{106} \mathrm{Ru},{ }^{144} \mathrm{Ce}$, and ${ }^{137} \mathrm{Cs}$. The ${ }^{106} \mathrm{Ru}$ is the most mobile of the three radionuclides and traveled the farthest; the ${ }^{137} \mathrm{Cs}$ is the least mobile and was contained in a small zone around the base of the tank. The configuration of the ${ }^{106} \mathrm{Ru}$ plume appears to be approximately circular, with a radius of about 15 to $20 \mathrm{~m}$ in plan view and a maximum depth of about $20 \mathrm{~m}$.

Figure F-2 shows the measured ${ }^{106} \mathrm{Ru} 1-\mu \mathrm{Ci} / \mathrm{L}$ isopleths for 1973 versus 1978; the ${ }^{106} \mathrm{Ru} 1-\mu \mathrm{Ci} / \mathrm{L}$ isppleth appears to have migrated about 5 to $7 \mathrm{~m}$ downward at dry wells 107 and 108 , but shows little movement elsewhere. Because of its relatively short $(1-y r)$ half-life, ${ }^{106} \mathrm{Ru}$ would decay from the estimated $2.7 \times 10^{11} \mu \mathrm{Ci}$ leaked from the tank in 1973 to about $8.4 \times 10^{9} \mu \mathrm{Ci}$ in 1978. However, the decay process alone is not sufficient to explain the relative stationarity of the $1 \mu \mathrm{Ci} / \mathrm{L}$ isopleth of the ${ }^{106} \mathrm{Ru}$ observed in 1978 .

Two modeling studies were reported for the T-106 tank leak (Smoot et al. 1989). The first is a one-dimensional simulation of the infiltration of the meteoric water into surface sediments; the other is a three-dimensional simulation of contaminant plume migration in the vadose zone beneath the tank. The results of both one- and three-dimensional simulations are summarized in the following paragraphs. 
WHC-SD-WM-TI-730, REV 0

Infiltration through the upper $2 \mathrm{~m}$ of soil cover was simulated for the period of 1947 to 2020 using hydraulic properties estimated for the backfill sediments. The one-dimensional infiltration simulations indicate that approximately 77 percent $(13.1 \mathrm{~cm} / \mathrm{yr})$ of annual precipitation infiltrates below a depth of $2 \mathrm{~m}$. The three-dimensional simulation results suggest that the increased flushing of the soil column, resulting from higher infiltration, may increase the potential rate of movement of the ${ }^{\mathrm{P}} \mathrm{Ru}$ plume. The simulated ${ }^{106}$ Ru plume approached, but did not enter, the water table by the early 1980 's; after that time, the simulated ${ }^{108} \mathrm{Ru}$ plume began to recede because of radioactive decay (Figure $\mathrm{F}-3$ ). The simulated plume for ${ }^{106} \mathrm{Ru}$ appears to be consistent with field data. The simulated ${ }^{137} \mathrm{Cs}$ plume is highty sorbed by minerals in the sediments beneath the tank and migrates much less than ${ }^{106} \mathrm{Ru}$; the ${ }^{137} \mathrm{Cs}$ plume becomes essentially stationary after about 50 days

(Figure $\mathrm{F}-4$ ). This result is similar to that observed in the field; the ${ }^{137} \mathrm{Cs}$ sorption appears to be sufficiently high that even the increased infiltration does not significantly increase the mobility of the ${ }^{137} \mathrm{Cs} p$ lume. A $K_{d}$ value of $0.5 \mathrm{~mL} / \mathrm{g}$ was used for ${ }^{106} \mathrm{Ru}$ and $100 \mathrm{~mL} / \mathrm{g}$ for ${ }^{137} \mathrm{Cs}$.

\section{F.2.2 200-BP-1 Operable Unit}

A modeling study using PORFL0-3 was summarized in Phase 1 Remedial Investigation Report for 200-BP-I Operable Unit (DOE 1993). Using $\mathrm{K}_{\mathrm{d}}$ values presented in Table $F-1$, soil concentrations predicted by the model compared favorably to those measured in crib soils and the subsurface infiltration gravel/soil zone (Table 5-11, DOE 1993). Although the model is not calibrated in an exact sense because large uncertainties exist in the recharge estimates and simplifications were used, it did provide a fairly reasonable comparison of model calculation with the field measurements.

\section{F.2.3 N Springs Studies}

Two modeling studies were performed to predict ${ }^{90} \mathrm{Sr}$ transport 30 years into the future. In the first study Lu (1991) used two-dimensional code VAM2DH to simulate the migration of ${ }^{90} \mathrm{Sr}$ from liquid waste disposal facilities in the 100-N Area to the Columbia River. A baseline calibration analysis was made using published concentrations of ${ }^{90} \mathrm{Sr}$ at $N$ Springs on the south bank of the columbia River adjacent to the 100-N Area. Since the measured concentration of ${ }^{90} \mathrm{Sr}$ at $N$ Springs is only a small fraction of the concentration discharged to the disposal facility, Lu (1991) speculated that retardation mechanisms other than sorption were present. Lu suggested that the sludge layer at the battom of the disposal facility consisting of calcium carbonate, iron oxide, and clay acted as a filter for particulate ${ }^{90} \mathrm{Sr}$. Under this conceptual model, an excellent agreement was achieved between the published and simulated concentrations for 1973 through 1990 using a $K_{d}$ value of $10 \mathrm{~mL} / \mathrm{g}$ in both Hanford formation and Ringold Formation sediments.

The results from the two-dimensional modeling were used to help define a three-dimensional model subsequently simulated by the PORFLO-3 code (Connelly et. al. 1991). A modeling process similar to that used for the twodimensional conceptual model was used for PORFLO-3 simulations. Connelly et al. used $K_{d}$ values of $30 \mathrm{~mL} / \mathrm{g}$ for the Hanford formation and $24.5 \mathrm{~mL} / \mathrm{g}$ for the Ringold Formation. The PORFLO-3 simulation estimated an arrival time of ${ }^{90} \mathrm{Sr}$ that was 4 years less than that observed and, hence, overpredicted the 
concentration of ${ }^{90} \mathrm{Sr}$ at $\mathrm{N}$ Spring. Again, although the model was not calibrated, it did approximate the groundwater flow and contaminant transport in the 100-N Area based on field observations. Different $K_{d}$ values used in these two studies may be attributed to the different geometries used in the simulations.

\section{F.3 SUMMARY}

The field data and calibration studies discussed in Section F.2 represent the best available information at the Site. Qualitative examples of mass transport of highly mobile, moderately mobile, and relatively immobile radionuclides that are common to solid waste have been provided. Calibration studies also have been provided that fit the sorption data assumed in the PA analysis fairly well. In addition, the low-level glass performance assessment program plans to conduct model verification for contaminant transport at the injection test site (described in Appendix D, WHC-SD-WM-Ti-730, Rev. 0).

Based on this information, we conclude that the mass transport assumptions in the PA analysis (primarily the Kd assumptions) are supported by the field and modeling data.

\section{F.4 REFERENCES}

AEC, 1973, Report on the Investigation of the 106-T Tank Leak at the Hanford Reservation, Richland, Washington, TID 26431, U.S. Atomic Energy Commission, Richland, Washington.

ARHCO, 1973, Tank 241-T-106 Leak Investigation, ARH-2874, Atlantic Richfield Hanford Company, Richland, Washington.

Cantre11, K. J. and R. J. Serne, 1992, Literature Search For 200-BP-1 sorption, a letter report for WHC from PNL, Pacific Northwest Laboratory, Richland, Washington.

Connelly, M. P., J. D. Davis, and P. D. Rittmann, 1991, Numerical Simulation of $90 \mathrm{Sr}$ Transport from the 100-N Area Liquid Waste Disposal Facilities, WHC-SD-TA-001, Westinghouse Hanford Company, Richland, Washington.

DOE, 1993, Phase 1 Remedial Investigation Report for 200-BP-1 Operable Unit, DOE/RL-92-70, REV. 0, Volume 1, U.S. Department of Energy, Richland, Washington.

Lu, A. H., 1991, Simulations of Strontium-90 Transport from the 100-N Area to the Columbia River Using VAM2DH, WHC-EP-0369, Westinghouse Hanford Company, Richland, Washington.

Ludowise, 1978, Report on Plutonium Mining Activities at 216-Z-9 Enclosed Trench, RHO-ST-21, Rockwell Hanford Operations, Richland, Washington.

Reisenauer, E. A., 1959, 216-Z-9 Core Sampling Data, HW-61787 RD, General Electric Company, Richland, Washington. 
Routson, R. C., W. H. Price, D. J. Brown, and K. R. Fecht, 1979, High-Level Waste Leakage from the 241-T-106 Tank at Hanford, RHO-ST-14, Richland Hanford Operations, Richland, Washington.

Smoot, J. L., J. E. Szecsody, B. Sagar, G. W. Gee, and C. T. Kincaid, 1989, Simulations of Infiltration of Meteoric WAster and Contaminant Plume Movement in the Vadose Zone at Single Shell Tank 241-T-106 at the Hanford site, WHC-E(-0332, Westinghouse Hanford Company, Richland, Washington. 
Table F-1. Summary of $K_{d}$ Data Specific to Hanford under Ambient Conditions

Species

${ }^{3} \mathrm{H}$ (HTO)

Cs-137

Sr-90

Total U

$\mathrm{Pu}-238,239 / 240$

Tc-99 probable

$\mathrm{K}_{\mathrm{d}}(\mathrm{mL} / \mathrm{g})$

0.0

500

20

1

100

0
Range in

$\mathrm{K}_{\mathrm{d}}(\mathrm{mL} / \mathrm{g})$

0.0

500-10,000

$5-100$

$0-3$

100-2000

0-1
Quality of

1

2

2

3

3

2

(a) Quality Rating

(1) Kd values are very well known, little chance for variation because of chemical changes.

(2) Kd values are well known, variability caused by competing salts, $\mathrm{pH}$. Eh and organics generally understood.

(3) Kd values are fairly well known, variability caused by chemical factors (competing salts, redox, organics, etc.) not well documented. 
Figure $\mathrm{F}_{-1}$. . Plan and Vertical Cross Sectional Views of the $1973{ }^{137} \mathrm{Cs},{ }^{144} \mathrm{Ce}$, and ${ }^{105} \mathrm{Ru}(1 \mu \mathrm{Ci} / \mathrm{L})$ Volumetric Isopleths (after Routson et al. 1979).

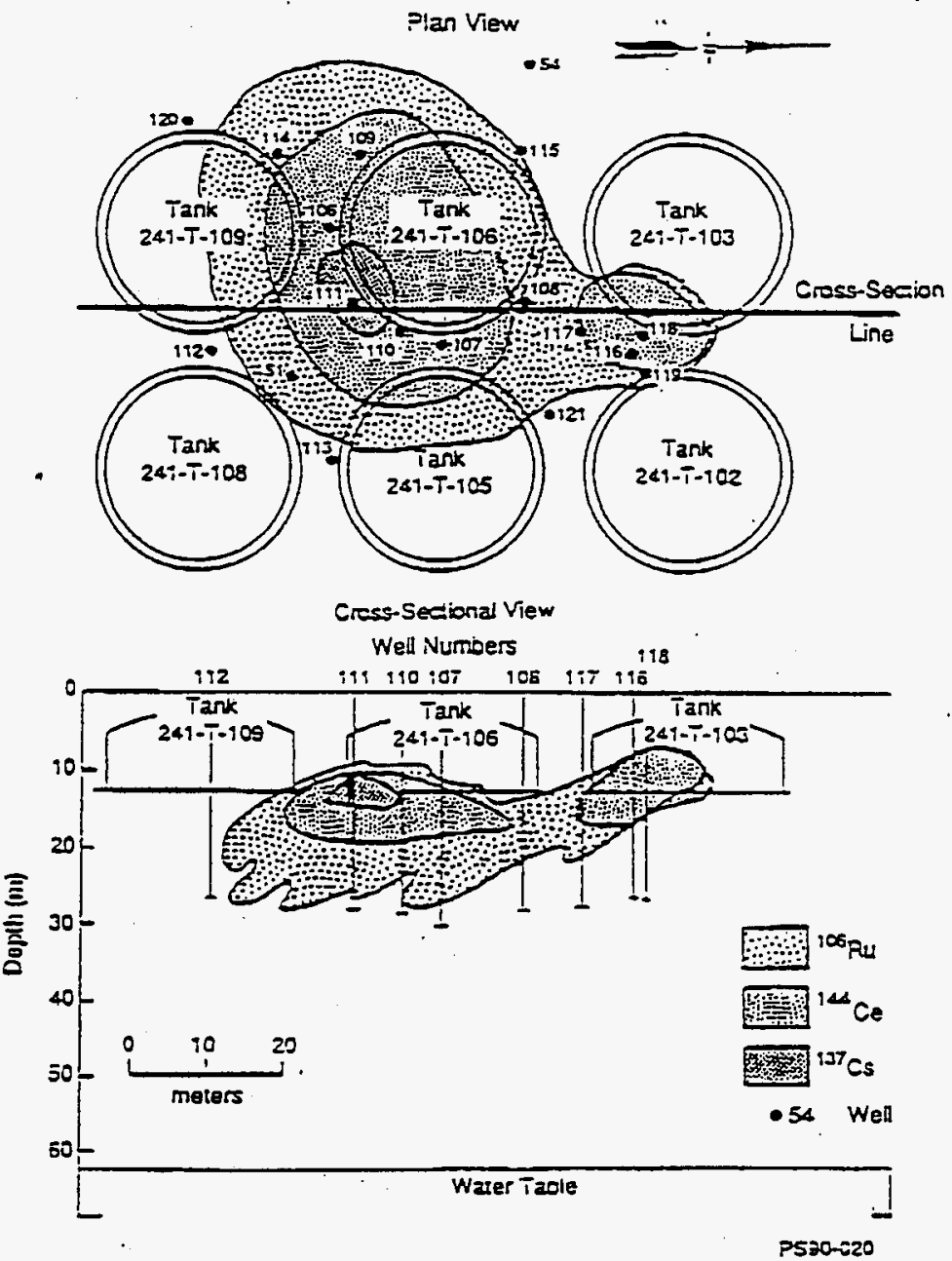


Figure F-2. Plan and Vertical Cross Sectional Views of the 1973 and 1978 ${ }^{106} \mathrm{Ru}(1 \mu \mathrm{Ci} / \mathrm{L}$ ) Volumetric Isopleths (after Routson et al. 1979).
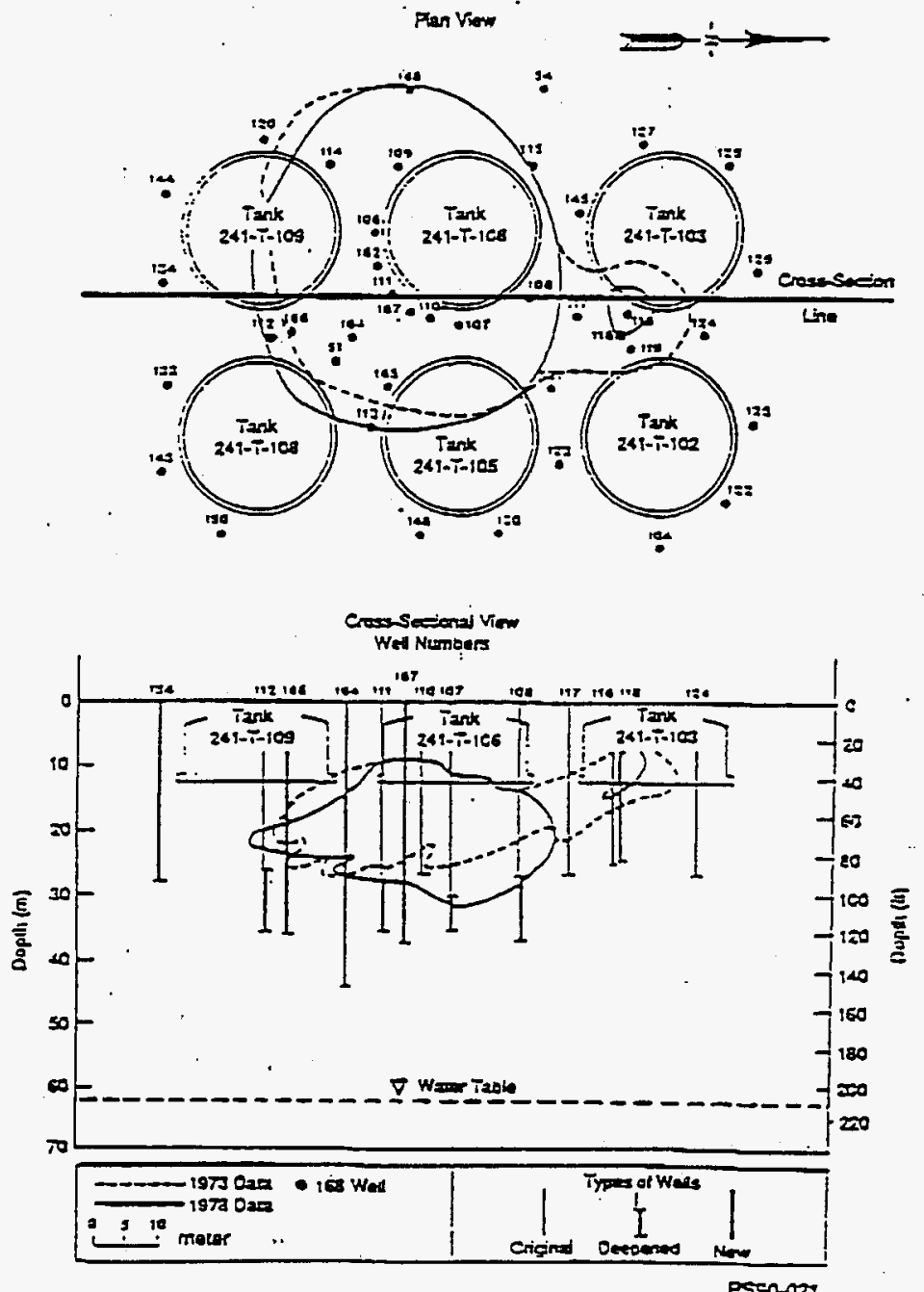
Figure F-3. PORFL0-3 Simulation of the Vertical Extent of the ${ }^{106} \mathrm{Ru}(1 \mu \mathrm{Ci} / \mathrm{L})$ Volumetric Isopleth for Varying Infiltration Rates at Late Simulation Times (Years) (after Smoot et a7. 1989).

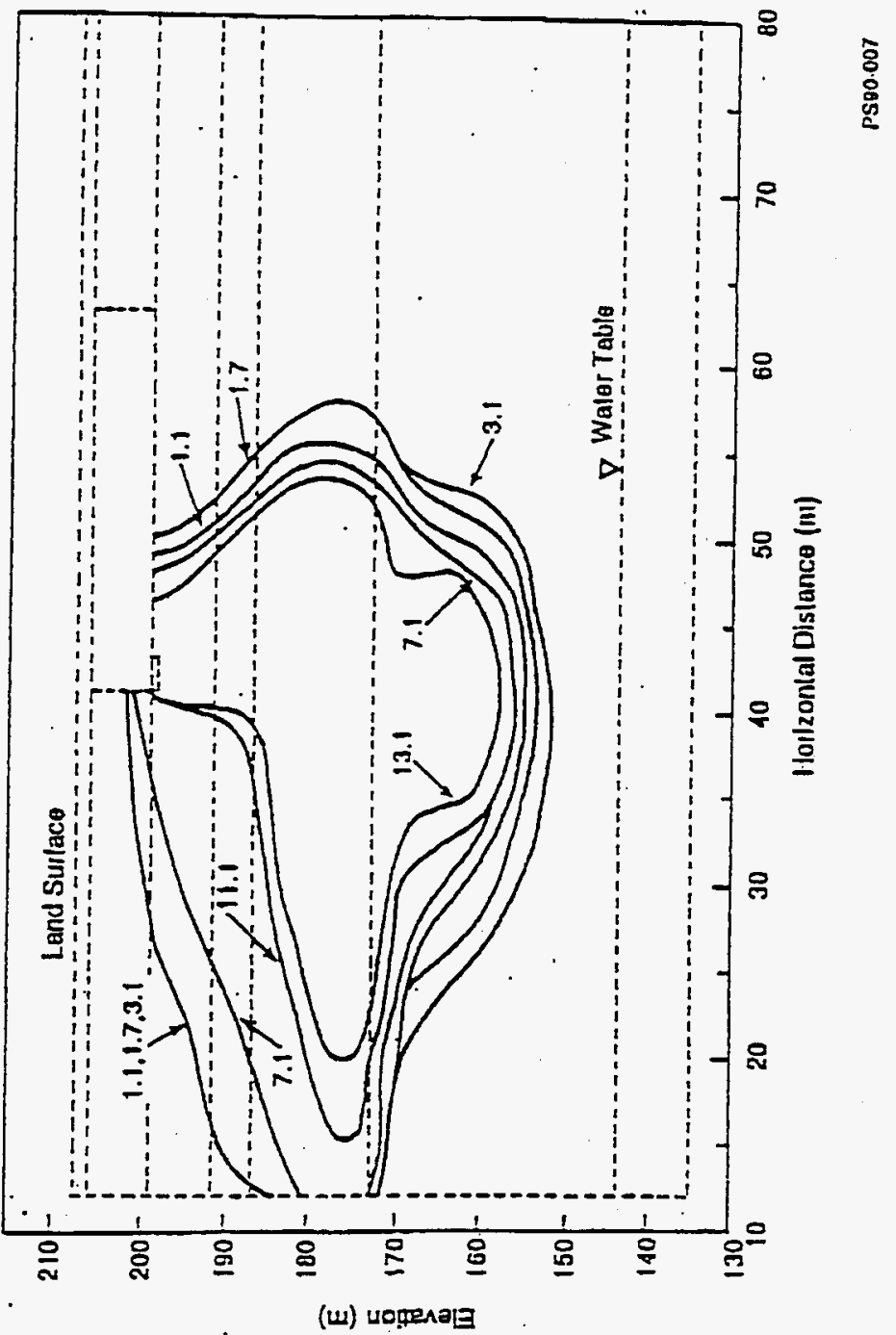


Figure F-4. PORFLO-3 Simulation of the Vertical Extent of the ${ }^{106} \mathrm{Ru}(1 \mu \mathrm{Ci} / \mathrm{L})$ Volumetric Isopleth for Varying Infiltration Rates

(Days) (after Smoot et al. 1989).

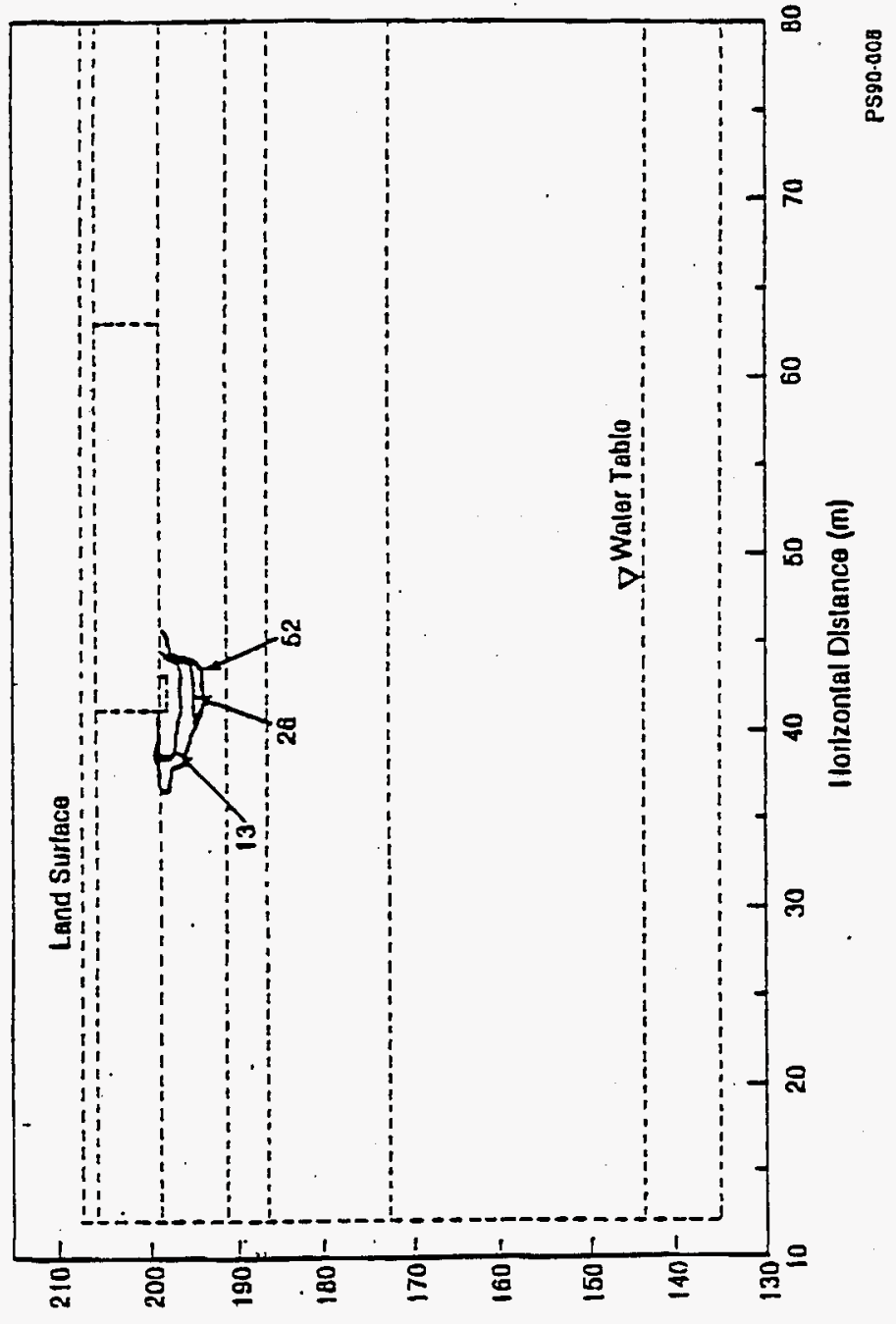

(w) UOMPneE 
WHC-SD-WM-TI-730, REV 0

\author{
APPENDIX G \\ RESPONSE TO PEER REVIEN PANEL COMMENTS
}

G-i 
WHC-SD-WM-TI-730, REV 0

This page intentionally left blank. 
WHC-SD-WM-TI-730, REV 0

\section{APPENDIX G}

\section{RESPONSE TO PEER REVIEW PANEL COMMENTS}

In this appendix, specific responses are given to comments provided by the Peer Review Panel (PRP) in their review of the preliminary draft of this performance assessment (PA) analysis (Letter, Wilhite to Bubar, April 3, 1996). Where appropriate, references are given to sections in the document where the topic is discussed more fully.

Comment: The PRP appreciates the openness of discussion with Dr. Wood.

Response: No response required.

Comment: The draft PA relies too heavily on the 200-W PA. Information from the 200-W PA that is essential to the 200-E PA should be included as the 200-E $P A$ is finalized. The 200-E PA should be a stand-alone document that does not require the 200-W PA to understand it.

Response: Additional information has been added to this document that was provided in the supplemental information to the 200 West Area PA. This includes an appendix (Appendix $F$ ) on observation of radionuclide behavior in the field and modeling analyses completed to simulate those observations. A discussion of the implementation of waste acceptance criteria is provided in Chapter 4, Section 4.4.3. Incorporation of PA requirements into the WAC (WHC 1993) are discussed. (See Section 4.4.3.1 for intruder-based requirements and Section 4.4.3.2 for groundwater-contamination-related requirements.)

Comment: A section on the interpretation of the results of the PA is needed. This section should discuss how the PA results provide reasonable assurance that the performance objectives will not be exceeded, and provide a consolidated representation of the findings of the PA, including the treatment of uncertainties.

Response: More information has been added to the interpretation discussion in Chapter 4, Section 4.4. Sensitivity of dose estimates to various parameters and dose uncertainties generated by the selection of parameter values are summarized (see Section 4.4.1.1 for intruder doses and Section 4.4.2.1 for groundwater contamination dose estimates). A comparison of the dose estimates (assuming a final projected inventory) with the performance objectives is provided in Section 4.4.4. A discussion of PA requirements implementation (Section 4.4.3) and a summary section (4.4.5) have also been added.

Comment: A consolidated overview of the PA methodology, including how Waste Acceptance Criteria (WAC) will be developed from PA results, must be included. In the draft PA, the description of methodology is scattered through Chapters 2,3 , and 4 .

Response: Section 1.3 has been expanded to provide the overview. A larger discussion of the relationship between analysis and associated waste acceptance criteria has been provided. The methodology is described as a five-step process beginning with the definition of performance objectives and ending with a demonstration of compliance with these objectives. 
Comment: The draft PA provides insufficient evidence that the modeling approach represents the disposal site. The final PA should address the effect of heterogeneities in the waste and environment; it should present an interpretation of the existing contaminant plumes, including recent data from the High-Level Waste Tanks, that supports the modeling approach (similar to supplemental information developed during the review of the 200-W PA); it should include a verification of the regional groundwater model; and, it should justify the modeling approach.

Response: Data describing the variability of hydrologic properties have been provided in Table A-1, Appendix A. Table 2-3 provides a breakdown of radionuclide concentration distribution on a per-package basis. A detailed discussion of the sitewide model analyses that has recently been completed is provided in Appendix E. This model has also been exercised to consider potential changes in hydrogeologic conditions in the 200 East Area LLBG and potential contaminant plumes have been projected. The information on tank plume evaluations has been included as Appendix $F$.

Comment: The potential for erosion to compromise the integrity of the closure must be assessed in more detai1. Assurance is needed that design features such as the slopes at the edge of the cap will not erode and compromise performance.

Response: The general erosion characteristics were discussed in the prefiminary PA. In response to this comment, we have discussed the potential for edge effects with the developers of the Hanford Barrier. They are currently testing two designs to minimize or eliminate erosion around the edges in a prototype field model. The first is a gradual slope edge that contains a high percentage of pitrun gravel. The slight slope and gravel component reduce the potential for erosion from turbulence. Also, the gravel promotes growth of vegetation. The second concept is a steeper slope composed of basalt riprap. The riprap is quite coarse and unlikely to be eroded by normal wind and water conditions. Results of ongoing testing will be tracked and evaluated as part of PA maintenance.

Comment: The basis for the inventory presented for the nuclear reactor vessel compartments (Table 2-5) must be presented.

Response: An excerpt from the Environmental Impact Statement completed by the U.S. Navy is provided in Appendix B that addresses in detail the calculation of the reactor compartment inventory.

Comment: In finalizing the PA, the analysis of pre-1988 LLW and other sources of radioactive material (the Composite Analysis) should either be documented in a separate report from the PA, or the Composite Analysis should be clearly distinguished from the $P A$ analyses, if they are documented together.

Response: The pre-1988 LLW evaluation has been dropped from this analysis and will be considered in the Composite Analysis. This decision is stated in the Executive Summary and in the introduction in Chapter 1.

Comment: A more thorough explanation for Tables 4-1 and 4-2 is needed. 
Response: The information is provided in Section 4.1.1. In essence, Table 4-1 lists all the radionuclides considered. Table 4-1 also identifies those isotopes and daughters that are assumed to be in secular equilibrium at the time of disposal and may provide dose. Table 4-2 identifies the subset of parents with daughters that grow in during the time before and during exposure. The daughters that can contribute to dose are listed.

Comment: The inventory for plutonium isotopes and for neptunium-237 is not shown. Care should be taken to present an inventory for every radionuclide considered in the PA.

Response: Generator information indicates that trace quantities of transuranic isotopes may be present in waste. This information and a rough estimate of the inventory is presented in Section 2.3.2.

Comment: More justification is needed for the isotopic composition of BPlant waste.

Response: In the preliminary draft of the PA, a posjtion was stated that because the basic B-Plant function was to separate ${ }^{137} \mathrm{Cs}$ and ${ }^{90} \mathrm{Sr}$ from dissolved fuel waste streams, the generated waste should contain ${ }^{137} \mathrm{Cs}$ and ${ }^{90} \mathrm{Sr}$, primarily. The PRP indicated that because the raw materials should contain a full complement of nuclear fuel isotopes, then waste might be expected to also contain similar isotopes. Currently, we have been unable to find information to resolve this issue. Therefore, we have estimated concentrations of other fission products that may be in B-Plant waste assuming the average fission product yield in Hanford fuel. Fractional quantities of trace isotopes are quantified in Appendix B. It is our expectation that this is a conservative approach because a separation process that concentrates a pair of isotopes should, by the same token, dilute the other isotopes in the waste. In any case, the activities in these wastes are small enough that potential dose estimates are very low relative to the performance objectives.

Comment: Justification should be provided for not considering the contribution of neutron activation in the $\mathrm{C}-14$ inventory.

Response: The only significant source of $\mathrm{C}-14$ by neutron activation comes from activated metal near fuel. Outside of the reactor compartment waste, no generator has had access to these materials. A detailed discussion of inventory estimates has been provided by the Navy in an environmental impact statement (U.S. Department of the Navy 1996). Excerpts from this document on inventory estimates are provided in Appendix $B$.

Comment: Waste volume and curie inventories should be presented so that an indication of radionuclide concentration is given. Presently, inventories and dose results are given by burial ground, but volume is presented by generator. Thus, waste concentrations cannot be estimated.

Response: Waste volume and inventory by generator are presented in Table 22. A breakdown of the distribution of beta gamma concentrations by waste package is provided in Table $2-3$ as a function of the generator and the trench location. The beta gamma concentration is a good indicator because all other fission product concentrations and therefore, distributions are proportional to the beta gamma concentrations. 
Comment: Consideration of the atmospheric pathway to establish a tritium inventory timit for the category-3 facility should be given (see 4-18).

Response: A calculation was done to determine a limit for tritium. This limit turns out to be about $10^{12} \mathrm{Ci} / \mathrm{m}^{3}$, a concentration that exceeds the specific activity of tritium. The large limit is due to the long time until intrusion and significant decay occurs. Also, because only a small fraction of tritium partitions into the vapor phase and limits the fraction of available source for exposure, the projected dose limit is very large.

Comment: On page $\mathrm{C}-9$ the estimation of the amount of resuspended soil on foliage is referred to as "rainsplash". However, the equation for Cpf in Section C.1.3.2 represents the aeolian-driven deposition of resuspended soil onto vegetative surfaces. Rainsplash, in contrast, refers to the physical transfer of soil particles to foliar surfaces by the mechanical ejection of particles by raindrops. How do the estimated doses from soil-derived rainsplash onto leafy vegetables compare with the doses due solely to the redeposition of soil-derived particles for $\mathrm{Cs}-137$ and $\mathrm{Pu}-239$ ?

Response: The data summarized in NUREG/CR-5512 was represented in the airborne deposition model by increasing two parameters, namely, the airborne mass loading and the surface deposition speed. This retains the use of the "translocation factor" representing the transfer from plant surfaces to the edible portions.

The airborne mass loading was increased from $0.225 \mathrm{mg} / \mathrm{m}^{3}$ to $1 \mathrm{mg} / \mathrm{m}^{3}$, and the deposition speed was increased from $0.001 \mathrm{~m} / \mathrm{s}$ to $0.01 \mathrm{~m} / \mathrm{s}$. These changes increase the vegetable contamination due to "rain splash" by a factor of 44 . However, rain splash is a small part of the total for most nuclides. The largest increase occurs for $\mathrm{Pb}-210$, and amounts to 44 percent. The increase for $\mathrm{Cs}-137$ is less than 1 percent, and the increase for Pu-239 is 33 percent.

Comment: Table C-5 includes a comparison of the DOE dose-conversion factors with those of GENII and the US EPA for inhalation and ingestion. For external exposures, the dose-conversion factors also need to be compared with the dose conversion factors for external exposures developed by the US EPA (External Exposure to Radionuclides in Air, Water, and Soil, EPA 402-R-93-081, 1993).

Response: A comparison of dose factors (GENII versus the EPA values) and estimated dose for the postdrilling scenario was completed. The dose factors are very similar with no individual radionuclide factor increasing by more than $90 \%$. For those radionuclides where external exposure is a significant pathway the maximum calculated increase was $33 \%$ for ${ }^{235} U$. The ratios are provided in Table G-1.

Comment: The time-varying concentration of Am-241 in the disposal units after the institutional control period is a function of the decay of Am-241 in the inventory at the time of closure plus the amount of Am-24l derived from the decay of Pu-241 present in the inventory at closure. Did the PA address specifically these two sources of Am-241?

Response: Yes. Am-241 is covered by the A-24l calculation of intruder dose. The ingrowth of Am-24l is incorporated in the Pu-24l calculation of dose (Section 4.1.4 and Table 4-2). 
Comment: A number of minor comments and questions will be documented in the minutes of the meeting and will be forwarded to $\mathrm{Dr}$. Wood for his consideration in the final PA.

Response: Additional comments from the PRP have been incorporated.

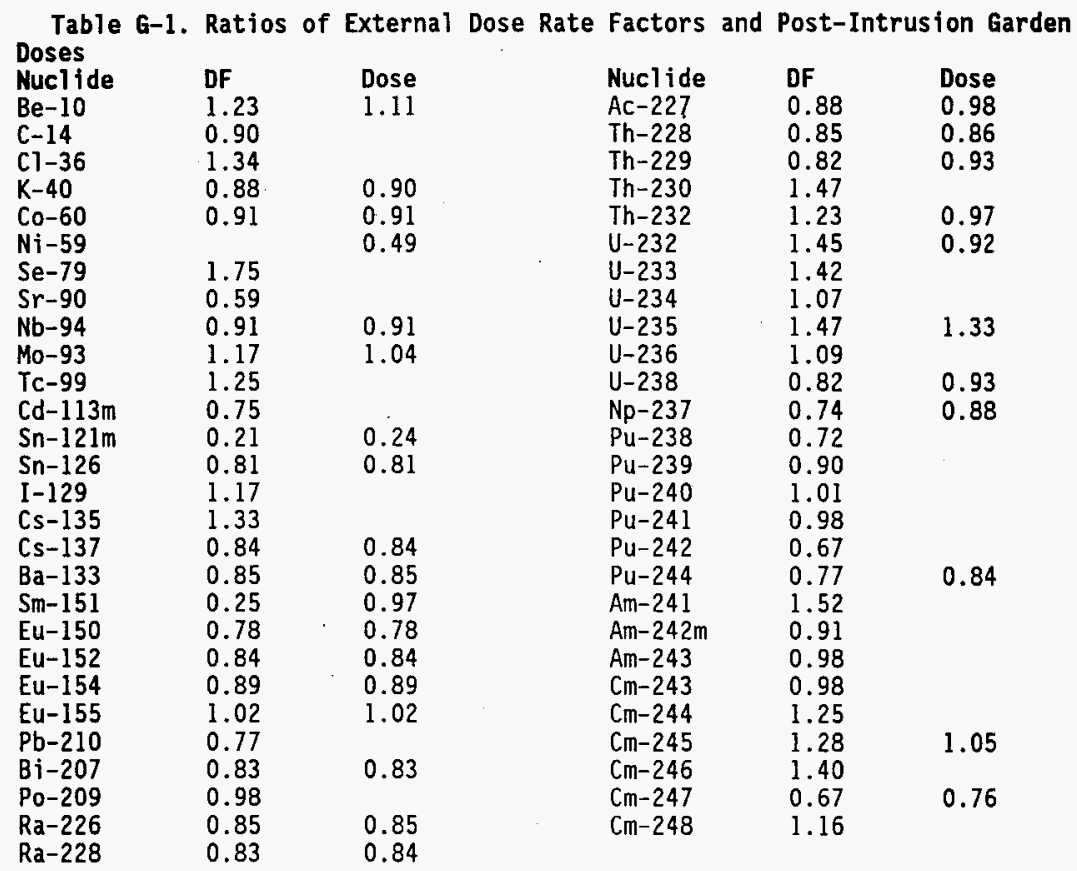

NOTE: Nuclides with differences less than 1 percent are not shown. "DF" means external dose factor ratios, EPA values divided by GENII values. "Dose" means ratio of total doses to the post-intrusion gardener, using EPA versus GENII dose conversion factors.

\section{REFERENCE}

Wilhite, E. L., 1996, Preliminary Review of Hanford 200-E LLW PA (U), memo to P. M. Bubar, U.S. Department of Energy, Headquarters, Apri1 3, 1996, Westinghouse Savannah River Company, Savannah River, South Carolina. 
WHC-SD-WM-TI-730, REV 0

This page intentionally left blank. 